\title{
Michiel CoXCIE
}

\section{Studien zur flämischen Malerei im Zeitalter der Konfessionalisierung}

\author{
Dissertation \\ zur Erlangung des philosophischen Doktorgrades \\ an der Philosophischen Fakultät der \\ Georg-August-Universität Göttingen
}

vorgelegt von

Hanke E. Tammen

Göttingen 2019 
1. Gutachter: Prof. Dr. Thomas Noll

2. Gutachter: Prof. Dr. Manfred Luchterhandt

Tag der mündlichen Prüfung: 23. Januar 2020 


\section{Zum Geleit}

Bei der vorliegenden Untersuchung „Michiel Coxcie. Studien zur flämischen Malerei im Zeitalter der Konfessionalisierung“ handelt es sich um eine überarbeitete Fassung meiner Dissertation, die ich im Oktober 2019 bei der Philosophischen Fakultät der Georgia-Augusta zu Göttingen eingereicht habe.

Mein ergebener Dank gilt an erster Stelle meinem Doktorvater Herrn Prof. Dr. Thomas Noll für die vielen inspirierenden Gespräche und die ausgezeichnete Betreuung während der vergangenen Jahre. Danken möchte ich auch dem Dekan der Fakultät, Herrn Prof. Dr. Manfred Luchterhandt, für die Förderung, die mir durch die mehrjährige Tätigkeit als Hilfskraft am Lehrstuhl zuteilwurde. Für wichtige Impulse, die mich zum Thema dieser Arbeit geführt haben, möchte ich Herrn Priv.-Doz. Dr. Arwed Arnulf danken. Auch der Kustodin der Göttinger Universitätskunstsammlung Frau Dr. Anne-Katrin Sors gilt mein Dank für ihr Interesse am Fortgang meines Promotionsvorhabens. Nicht zuletzt danke ich meiner Kommilitonin Judith Krüger einmal mehr für ihr konstruktives Lektorat.

Widmen möchte ich diese Studie meinen lieben Eltern, die mir mit großer Umsicht den Weg geebnet haben.

Hanke E. Tammen

Göttingen, im Frühjahr 2020 



\section{Inhalt}

I Einleitung: Zur Biographie Michiel Coxcies und dem Stand der Forschung.........................1

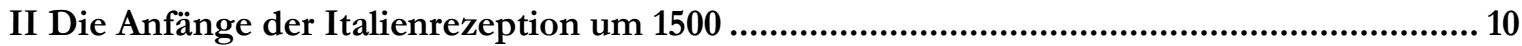

2.1 Jan Gossaert und der Beginn des Romanismus in der niederländischen Malerei..........................10

2.2 Der ,spätgotische Manierismus‘ als stilgeschichtliches Scharnier.................................................18

Exkurs: Zum Begriff der sogenannten ,Antwerpener Manieristen '................................................22

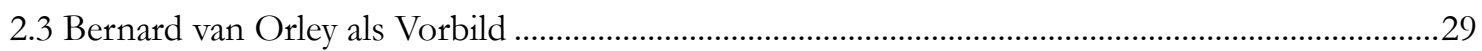

III Michiel Coxcie als Romanist in den Niederlanden ..............................................................50

3.1 Eine Annäherung an die Lehrjahre in den südlichen Niederlanden (vor 1530) .............................50

3.2 Das Studium der italienischen Kunst in Rom (ca. 1528-1539) ....................................................... 51

3.2.1 Die epochalen und biographischen Gründe für die Reise nach Italien ..................................51

3.2.2 Die Ausbildung in der Freskomalerei und das künstlerische Umfeld .....................................55

3.2.3 Zur Rolle der Druckgraphik in Coxcies Frühwerk ................................................................63

3.3 Das italianisierende Erstlingswerk nach Coxcies Rückkehr aus Rom 1539 ....................................71

3.3.1 Die Seitentafeln (um 1540) für Gossaerts Lukas, der die Madonna malt von 1515 .................71

3.3.2 Michiel Coxcies Triptychon mit der Heiligen Sippe (1540) .........................................................78

3.3.3 Die Beziehung zu den Werken Bernard van Orleys nach der Rückkehr aus Rom...............86

3.3.4 Das Triptychon mit Szenen aus dem Leben der heiligen Jungfrau (um 1550) ..................................92

3.4 Michiel Coxcie im Dienst der habsburgischen Höfe in Brüssel und Madrid..................................98

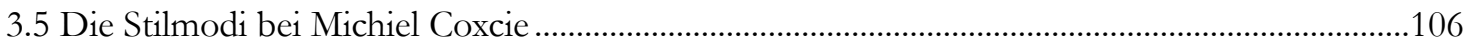

3.6 Die Kopien nach Jan van Eyck und Rogier van der Weyden....................................................113

3.7 Zur Funktion und Bedeutung von Coxcies Kopien altniederländischer Werke ..........................128

IV Michiel Coxcie als Maler der katholischen Reform .............................................................137

4.1 Grundzüge der Bilddebatte: Johannes Molanus (1533-1585) und seine Kritiker.......................137

4.2 Die Rekatholisierung von Mecheln und Brüssel: Die Position Michiel Coxcies ..........................146

4.2.1 Das Triptychon mit dem Letzten Abendmahl von 1567............................................................. 150

4.2.2 Die Heiligendarstellungen von Michiel Coxcie in den 1570er und 1580er Jahren........... 156

4.3 Der geharnischte Maler - Michiel Coxcies Selbstverständnis .......................................................167

V Zur Rezeption und fortuna critica von Michiel Coxcie .......................................................173

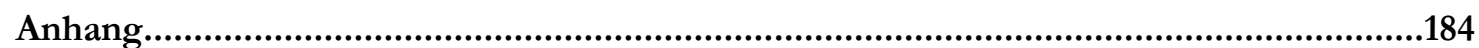

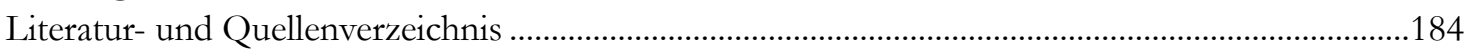

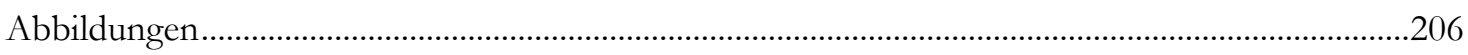

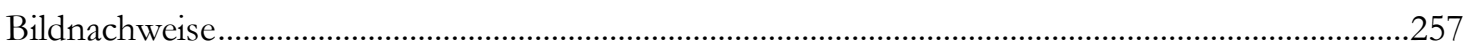





\section{I Zur Biographie Michiel Coxcies und dem Stand der Forschung}

Als einen Freund bezeichnete Giorgio Vasari den jungen und talentierten Maler aus dem weitentfernten Mecheln, dessen Bekanntschaft er 1532 in Rom gemacht haben will, wie er in seiner Sammlung italienischer Künstlerviten von 1568 schreibt. ${ }^{1}$ Michiel Coxcie mag seinerseits als ein ,Freund' dessen gelten, was Vasari als Autor und Maler bereits zu Lebzeiten verkörperte - die italienische Kunst der Renaissance, für die dieser selbst den Epochenbegriff rinascita prägte. Obschon die Werke des Mechelner Malers Michiel Coxcie nicht allgemein zum Kanon der nordalpinen Renaissancemalerei gezählt werden, kommt man nicht umhin, ihm neben Jan Gossaert, Marten van Heemskerck, Jan van Scorel und weiteren weitaus häufiger anzutreffenden $\mathrm{Na}$ men, eine nicht unbedeutende Rolle bei der Etablierung des an Italien orientierten ,Romanismus' in den Niederlanden einzuräumen. Seine Fähigkeit, in der maniera italiana zu malen, die schon im Hinblick auf den Beginn seiner Karriere in Rom von Vasari beschrieben wird,

1 „Conobbi nel 1532 in Roma un Michele Cockisien, il quale attese assai alla maniera italiana e condusse in quella città molte opere a fresco [...]“ (Vasari 1568, Bd. 3, S. 358 / Vasari, ed. Milanesi VII, S. 585)

2 HOOGEWERFF 1912, S. 75.

3 Hendrick Hondius: Pictorum aliquot celebrium praecipue Germaniae inferioris Effigies, Den Haag 1610, S. 47. Für den Stich s. New Hollstein: Simon Frisius, Bd. 1, S. 152, Kat.-Nr. 162.

4 s. van Mander 1604, S. 258 f.; Bedenkt man, dass sein eigener kunsttheoretischer Entwurf die vollständige Aneignung (imitatio) des fremden, d. h. italienischen Stiles bedeutet (vgl. MÜLLER 1993, S. 40-45), hätte er Coxcies Rolle bei der Überführung dieses Stiles in die niederländische bildet den Ausgangspunkt eines umfangreichen Euvres, das neben eindrucksvollen Werken der religiösen Malerei auch Entwürfe für Tapisserien, Glasfenster und Druckgraphik beinhaltet. In der Forschung später als „de eerste volslagen Romanist" bezeichnet und von Zeitgenossen, von denen Karl V. wohl als der prominenteste gelten kann, als ,vlaamse Rafaël“" gefeiert, ${ }^{2}$ hatte er sein Lebenswerk in den Dienst der habsburgischen Herrscher in der spanischen Exklave gestellt. Zu seinen Gönnern zählten neben dem römisch-deutschen Kaiser Karl V., König Philipp II. von Spanien sowie die Generalstatthalterin der Niederlande, Maria von Ungarn. Hendrick Hondius nennt ihn samt einem von Simon Frisius bereits zu Lebzeiten des Malers gestochenen Portrait und den von Dominicus Lampsonius ersonnenen Versen in seinen Effigies von $1610 .^{3}$ Auch Karel van Mander wusste ihn als fähigen Maler zu loben, jedoch nicht ohne sein Lebenswerk gleichzeitig mit dem Verdacht des Epigonalen zu verunglimpfen, indem er einen größeren Teil als Nachahmung Raffaels bezeichnete. ${ }^{4}$ In den Angaben

Malerei eigentlich höher achten müssen. Er beruft sich dabei höchstwahrscheinlich auf die Rhetorik von Quintilian, die davon ausgeht, dass eine imitatio aus sich heraus zur aemulatio führe (vgl. MÜller 2015, S. 131 u. MiEDEMA 1973a, S. 414 f.). Vgl. auch MiCHALSKY 2012, S. 167.

Diese Leistung gesteht er Coxcie jedoch nicht zu. Möglicherweise hat van Mander auch nie eines der Werke Coxcies gesehen und seine Kenntnis den Berichten Dritter entnommen (Vgl. Miedema 1997, Bd. 4, S. 182-191). Bei seiner Negativwertung bezieht er sich auch auf einen konkreten Vorfall, der sich nach der Veröffentlichung von Hieronymus Cocks Druck 
van Manders tritt die Vielschichtigkeit einer von Zeitgenossen kontrovers beurteilten südniederländischen Künstlerpersönlichkeit hervor. Die hierfür nicht unwesentliche Überschneidung beider Biographien, der des Autors und der des Künstlers, schwingt zumindest unterschwellig in van Manders Beschreibung der Vita Michiel Coxcies mit. Karel van Mander, dem Sohn protestantischer Glaubensflüchtlinge, dessen Familie während der spanischen Rückeroberung von Flandern und Brabant ins nordniederländische Haarlem hatte flüchten müssen, mag es an persönlichen Gründen für seine verhaltene Würdigung von Coxcies Lebenswerk nicht gefehlt haben. Obwohl er in Bezug auf die künstlerische Darstellung Gottes und der Heiligen für einen calvinistischen Autor immerhin eher unübliche Ansichten vertrat, ${ }^{5}$ wird er über Coxcies
Beziehungen zur habsburgischen Herrschaft sowie seine Rolle in der Zeit der Bilderstürme und während der Rückeroberung durch die Spanier - unter anderem stand jener in Kontakt zum Herzog von Alba - aus erster Hand unterrichtet gewesen sein, zumal Coxcie erst zwölf Jahre vor dem Erscheinen des SchilderBoeck 1604 verstorben war.

Die Schwierigkeit van Manders, die tatsächliche Leistung Michiel Coxcies über das Mindestmaß hinaus zu würdigen, mag durchaus in einer Missbilligung von dessen Verbindungen zu hohen Mäzenen aus dem Umfeld der spanischen Herrschaft zu suchen sein. ${ }^{6}$ Diese sogar in seinen Bildern propagierte Treue gegenüber den Habsburgern und der alten religiösen Ordnung war für seine Zeitgenossen unübersehbar und verband ihn unweigerlich auch mit der gewaltsamen Besetzung

hauptet hat, sondern zeigt sich in einem größeren Umfang, dem kennerschaftliche Methode zugesprochen werden kann.

5 Die mutwillige Zerstörung von Werken der Kunst, zu der es im Zuge des niederländischen Ikonoklasmus kam, erachtete er als die „sinnlose Tat blinder Barbaren“ (vgl. WESTSTEIJN 2012, S. 109 u. FreEdBerg 1986, S. 77). Hierin dürfte auch begründet sein, weshalb er das fortwährend aktuelle Thema der Idolatrie in seinem Schilder-Boeck nicht weiter erörtert hat.

6 Außerdem waren die Anforderungen des frühen 17. Jhs. an die Malerei inzwischen andere als noch zu Beginn der Karriere Michael Coxcies. Auch für heutige Betrachter mag die eigentliche Entwicklung Coxcies, die von der Aufnahme italienischer Einflüsse geprägt war, als eine eher geringe Leistung erscheinen, während sie dies in der ersten Hälfte des 16. Jhs. nicht war und stattdessen einer Pionierrolle gleichkam, welcher daran gelegen war die Bemühungen der vorherigen Generation auszubauen und zu konkretisieren (vgl. LEUSCHNER 2016, S. 58). Für eine Erörterung der Wahrnehmung von älteren Kunstwerken im 17. Jh. s. COPPER 2005 zur sog. „Domenichino Affair". 
von Teilen der Niederlande durch Fernando Álvarez de Toledo (1507-1582), an die sich eine gnadenlose Verfolgung protestantischer Häretiker anschloss. ${ }^{7}$

In der Zeit nach dem Bildersturm von 1566 gelang es Coxcie, als einem gegenüber den spanischen Herrschern loyalen und bekennenden katholischen Künstler, zahlreiche Aufträge an seine Werkstatt zu binden, die infolgedessen wie kaum eine andere für die erfolgte Wiederaufrichtung der römischen Liturgie in Flandern stand. Als bemerkenswert ist der Charakter dieser Altarbilder zu nennen, die der vorreformatorischen Praxis treu geblieben, in der Regel von laikalen Bruderschaften gestiftet worden waren und nicht zu- letzt auch hierdurch bereits einen Restaurationsprozess markieren, an dem einige linientreue Maler großen Anteil hatten. ${ }^{8} \mathrm{Zu}$ diesem Zeitpunkt war Michiel Coxcie längst auf der Höhe seiner stilistischen Entwicklung angelangt. Seine späten, in gewisser Hinsicht formalisierten Altarbilder mit ihren drastischen Schilderungen aus dem Leben und Sterben der Heiligen können als wegweisender Beitrag zur zunehmend konfessionell aufgeheizten ,Bilderfrage' des späten 16. Jahrhunderts gewertet werden und haben Zeitgenossen wie Ambrosius Francken sowie die Generation von Malern um Peter Paul Rubens mutmaßlich mitbeeinflusst. ${ }^{?}$

7 So verwendet Coxcie für einer überlebensgroße Darstellung des Hl. Georg auf der Außenseite eines Retabel für die Jonge Voetboog, einer von zwei Armbrustschützengilden in Antwerpen, Mitte der 1570er sein eigenes Portrait. Er kleidete den Heiligen, ergo sich selbst, in derselben Montur mit Harnisch und rotem Mantel, in welcher Anthonis Mor van Dashorst den Herzog von Alba, Fernando Álvarez de Toledo, wenig zuvor auf einem Portrait hatte dargestellt. s. hierzu Ausführungen in Abschn. $4.3 \mathrm{u}$. [Abb. 112 u. 123]. Vgl. auch JONCKHEERE 2013b, S. 129.

8 Etwa Ambrosius Francken, der nach der spanischen Rückeroberung ab 1585 (ab 1581 war Antwerpen offiziell für einige Jahre calvinistisch; Bilder wurden aus den Kirchen entfernt) wieder als Katholik auftrat und sich mit der Anfertigung von Altarbildern für die im Zuge der Gegenreformation neugeschaffenen (Hoch-)Altäre einen Namen machen konnte (vgl. FrEEDBERG 1978, S. 128-138).

9 Vgl. WoolletT 2012, S. 75 f. Die Altarbilder Coxcies, die nach dem Bildersturm von 1566 entstanden, waren in der Regel Aufträge der örtlichen Schützengilden (,schuttersgilden'), deren Kapellen unter den Übergriffen der ,beeldenstormers' gelitten hatten. Die Wahl der Motive (i.

d. R. blutige Martyrien) und die emotionale $\mathrm{Zu}$ spitzung, die diese Bilder auszeichnet, stellen einen Kontrast dar zur verunsicherten Wirklichkeit in Zeiten von Bildersturm und der Kritik an der Rolle religiöser Bilder. Für zwei der sechs Schützengilden von Antwerpen schuf Coxcie neue Altarbilder: Das Martyrium des Hl. Sebastian von 1575 (Koninklijk Museum voor Schone Kunsten, Antwerpen) und zwei noch erhaltene Flügel mit Episoden aus dem Leben des $\mathrm{Hl}$. Georg - der Marter mit Salz und die Enthauptung des Hl. Georg (Koninklijk Museum voor Schone Kunsten, Antwerpen) eines monumentalen Retabels für die Jonge Voetboog (Neue Gilde der Armbrustschützen) von 1574-75 (beide bei WoOlLETT 2012, S. 75-94; VAN DE VELDE 1992, S. 195-214 u. GRIETEN - BUNGENEERS 1996, S. 364-65, Nr. 9).

Eine Anekdote berichtet davon, dass $\mathrm{Ru}-$ bens gefragt worden sei, wie er die oft behauptete Nachahmung Raffaels durch Coxcie bewerten würde und worauf er geantwortet haben soll, dass „Rüben dann gut seien, wenn sie wieder und wieder gekocht würden“" (MENSAERT 1763, S. 241 f.: „Raepen syn goet als die wel gekoockt syn'). Vgl. auch JONCKHEERE - SUYKERBUYK 2013, S. 45. 
Die stilgeschichtliche Wende, die zugleich auch als Epoche der niederländischen Kunst dem flämischen Barock und dem Goldenen Zeitalter der Niederlande unmittelbar vorausgeht, vollzog sich allmählich ab den 1520er Jahren und war bis spätestens Mitte des Jahrhunderts soweit gediehen, dass man der altniederländischen Tradition nur noch indirekt in Form einer von verfeinertem Realismus geprägten Malerei begegnet, außer in den Werken einzelner Maler, etwa von Pieter Pourbus, in dessen Bildern sich die Einflüsse aus Italien eigentlich erst relativ spät, nach der Mitte des Jahrhunderts geltend machen, während das frühere Werk vergleichsweise konservativ ist und an der Tradition der Brügger Malerschule der Jahrhundertwende festhält. ${ }^{10}$

Andernorts, vor allem in Antwerpen, sind es in den ersten Jahrzehnten des 16. Jahrhunderts Maler wie Jan Gossaert, Bernard van Orley und zu einem gewissen Grad auch Quentin Massys, die sich als frühe ,Romanisten' mit der italienischen Kunst zu befassen begannen und in ihr zunächst eine Fülle von formal-stilistischen Aspekten - von der Figurenbildung bis hin zur Komposition - für die eigene Malerei fruchtbar machten. Es ist

10 Vgl. HuvenNe 1984, passim u. MARTENS 2010, S. 173 f. Beispielhaft für den Konservatismus des Malers ist das 1559 für die Sakramentsbruderschaft von St. Salvator in Brügge gemalte Kreuzigungstriptychon, das eine typisch altniederländische Landschaft in der Manier Joachim Patinirs sowie Figuren nach altniederländischen Vorbildern zeigt (Öl auf Holz, $51 \times 41 \mathrm{~cm}$ (Mitteltafel), $51 \times 18 \mathrm{~cm}$ (Flügel), Kunsthistorisches Museum, Wien, Gemäldegalerie Inv.-Nr. 878).

11 Vgl. Ainsworth 2010, Mensger 2002 u. BOON 1965, S. 15-31.

12 Guicciardini, Ludovico: De idyllische Nederlanden: Antwerpen en de Nederlanden in de 16e eeuw, Antwerpen 1567, S. 98: „,...] Giovanni di schließlich Gossaert, bei dem eine Synthese beider Idiome zu beobachten ist, während viele seiner Zeitgenossen es bei einer eher zaghaften Übernahme einzelner formaler und motivischer Vorbilder beließen. ${ }^{11}$ Er gilt auch als einer der ersten in den Niederlanden, der die „nackten Figuren“ Italiens präsentierte, wie der gebürtige Florentiner Lodovico Guicciardini in der Beschreibung seiner niederländischen Wahlheimat von 1567 über Gossaert schrieb. ${ }^{12}$ Der in der Entourage des Kardinalbischofs Wilhelm von Enckenvoirt in den 1530er Jahren in Rom die Antike und die italienische Kunst studierende, aus Mecheln stammende Michiel Coxcie gehörte indessen nicht mehr zu den nur nach einer Erweiterung ihres Formenschatzes strebenden Künstlerpersönlichkeiten aus der ersten Phase der flämischen Italienrezeption, zu deren prägenden Meistern neben Gossaert unter anderem Coxcies Lehrer Bernard van Orley zu zählen ist, sondern zu einer neuen Generation, die ihre in Italien gewonnenen Eindrücke stärker von der Tradition ihrer Heimat zu differenzieren und das von ihren Vorgängern eingeleitete ,Experiment' weiterzuentwickeln suchten.

\footnotetext{
Maubeuge, il quale ful il primo che porto d'Italia in questi paesi, l'art del dipingere Historie, \& Poesi con giure nude: fece costui fra alte sue opere quella eccelente tavola, che si vede nella gran' Badia di Middelborgo in Silanda [...]"; sehr ähnlich auch Vasari, ed. Milanesi VII, S. 584: „E Giovanni Mabuse fu quasi il primo che portasse d'Italia in Fiandra il vero modo di fare storie piene di figure ignudi e di poesi $[\ldots]$ ".

MENSGER hat darauf hingewiesen, dass Gossaert als erster, der überhaupt ,rein antikische'Themen in den Niederlanden gemalt habe, im Sinne des Künstlerwettstreites, die Sinne des Betrachters zu erregen versucht habe (vgl. MENSGER 2002, S. 190).
} 
Trotz der in großer Zahl überlieferten, vielfach signierten Werke Michiel Coxcies hat die kunstgeschichtliche Forschung diesem Maler, vermutlich auch wegen der von seinen Zeitgenossen kritisch betrachteten Verbindungen zur habsburgischen Fremdherrschaft und seiner augenscheinlich in extenso an römische Vorbilder anknüpfende Malerei, lange Zeit nur stiefmütterliche Beachtung geschenkt. ${ }^{13}$ Auch van Manders persönliches (Vor-)Urteil mag in dieser Sache maßgebend gewesen sein. Notwendig ist jedoch eine unvoreingenommene Würdigung von Coxcies Rolle bei der Herausbildung einer flämischen Malerschule, die seine Ausbildung in der Tradition der altniederländischen Meister und das knapp zehnjährige intensive Studium der italienischen Malerei der Hochrenaissance, berücksichtigt (ca. 1528 bis 1539). Dies erscheint nicht zuletzt auch deshalb lohnend, weil sein Gesamtwerk die Beherrschung beider ,Seiten', das heißt ein Bewusstsein für die stilistischen Eigenheiten der lokalen und der italienischen Stilform, vollumfänglich belegt, so dass es umso erstaunlicher ist, dass bisher kaum das Verhältnis bzw. die Synthese dieser Faktoren in seinem Werk genauer untersucht wurde, wie es für seinen Lehrer Bernard van Orley und seinen Zeitgenossen Jan Gossaert vielfach in der Forschung geschehen ist. ${ }^{14}$

13 s. hierzu Peter CAPREAUS Aussagen im Internetartikel von MUNDELL 2013: „Leuven exhibition proves artistic merit of Michiel Coxcie“" vom 07. Nov. 2013, http://www.flanderstoday.eu (13.06.2019).

14 Vgl. AinswORTH 2010, S. 6 u. FARMER 1981.

15 Für Antwerpen zu Beginn des 16. Jhs. s. HAND 2004, S. 95 f.; am Bsp. Quentin Massys s. BUINSTERS-SMETS 1995, passim.
Das bei diesen Künstlern des 16. Jahrhunderts zumindest indirekt aufscheinende ,Stilbewusstsein“ ist eng verknüpft mit der bedeutend älteren Praxis des Kopierens, besonders mit der Rezeption einzelner Elemente aus einem oftmals populären Vorbild. ${ }^{15}$ Erst kürzlich hat Christina UNSINN in einem Aufsatz, welcher die zahlreichen (Teil-)Kopien im CEuvre des Joos van Cleve behandelt, eines von dessen Werken besprochen, bei dem es sich um eine Interpretation der Großen Kreuzabnahme von Rogier van der Weyden von 1435 handelt, die Joos van Cleve für die Kapelle der Löwener Armbrustschützen schuf. Das Original wurde später, 1545, von Maria von Ungarn erworben und durch eine detailgenaue Kopie Michiel Coxcies ersetzt. ${ }^{16}$ Joos van Cleve hatte sein Werk ebenfalls nach dem großen Meisterwerk des 15. Jahrhunderts gestaltet, dabei die Komposition und die Anordnung der Figuren übernommen, während er das kastenartige Raumkonzept Rogiers verwarf und die Figuren stattdessen in einen weiten Landschaftsraum in der Art Joachim Patinirs stellte. Die Gesichter gestaltete er in seinem eigenen Stil, um dem Werk eine unverkennbare, vielleicht auch als zeitgemäß empfundene Form zu geben, während man mit der Komposition zugleich aber auf das berühmte Vorbild verwies. ${ }^{17}$ Ganz anders verhält es sich bei Coxcies Kopien für Philipp II. und Maria von Ungarn.

16 Diese Kopie, die zwischen 1540 und 1548 im Auftrag Marias von Ungarn geschaffen wurde und Bestandteil des Vertrags zum Kauf des Originals mit der Armbrustschützengilde von Löwen war, befindet sich heute in der Gemäldegalerie in Berlin. Das Original von 1435 ist im Besitz des Prado in Madrid (vgl. CAMpBell 2015, S. 18-24).

17 Vgl. Unsinn 2018, S. 5. 
Bei seiner maßstabsgetreuen Version des Genter Altares von 1558, die heute größtenteils in der Berliner Gemäldegalerie zu sehen ist, handelt es sich nahezu um eine 1:1 Kopie, die nur durch die Figuren von Auftraggeber und Künstler erweitert und durch den Verzicht auf die Stifter des Originals verändert wurde. Bis auf technische Abweichungen, die in der Regel das weniger feinmalerisch ausgearbeitete Detail betreffen, handelt es sich um die größtmögliche stilistische Annäherung an Jan van Eyck, dem man in dieser Zeit die Würde eines Begründers der niederländischen Malerei zuzusprechen begann. ${ }^{18}$

Neben der Erörterung der auf uns gekommenen biographischen Informationen und der Rekonstruktion seines frühen Werdegangs einschließlich seiner mutmaßlichen Ausbildung in der Werkstatt Bernard van Orleys sowie der stilgeschichtlichen Auseinandersetzung mit dem malerischen Werk Michiel Coxcies von der Frühphase der 1530er bis zum Spätwerk der 1570er und -80er Jahre, beschäftigt sich die vorliegende Studie mit den Veränderungen, die sich seit dem Beginn des 16. Jahrhunderts abzeichnen und ausgehend von der Bilderfrage und den daraus hervorgegangenen Ikonoklasmen von 1566 und dem sogenannten ,stillen Bildersturm` des Jahres

18 Für eine Besprechung dieser Kopie s. Abschn. 3.6 u. 3.7.

19 Die beiden maßgeblich zur Bilderfrage Stellung beziehenden Schriften von Johannes Molanus sind De Picturis et Imaginibus Sacris (Leuven, 1570) und die überarbeitete Fassung Historia Sanctarum Imaginum (Leuven, 1594).
1581 allmählich Fahrt aufnehmen. Hierzu gehören die im Vorfeld der Ereignisse sowie in dessen Nachgang von einzelnen zeitgenössischen Protagonisten referierten Anregungen $\mathrm{zu}$ einer neuen Bildtheologie, die vor allem nach Beendigung des Konzils von Trient (1545-1563), unter anderem von Autoren wie Johannes Molanus vertreten wurden und auf die im Zuge der Reformation aufgeworfene Kritik am Bilderkult Bezug nehmen. ${ }^{19}$ Bis heute stellt David FreEDBERGs Monographie Iconoclasm and Painting in the Revolt of the Netherland $s^{20}$ von 1988 unangefochten das Standardwerk zu diesem Thema dar, während neuere Studien, wie die von Koenraad JONCKHEERE und Ruben SuYKERBUYK aus dem Jahr 2012 mit dem Titel Art after Iconoclasm: Painting in the Netherlands between 1566 and 1585 das Thema fortführen. ${ }^{21}$ Zuletzt hat Thijs WeSTSTEIjN die Begegnung von humanistischer Kunsttheorie und religiösen Texten zum Vorwurf der Idolatrie, vor allem solche calvinistischer Autoren, hinterfragt und die sich hieraus ergebenden Probleme für die niederländische Kunst des späten 16. Jahrhunderts aufgezeigt. $^{22}$

Die Forschung des frühen 20. Jahrhunderts erwähnt Michiel Coxcie verschiedentlich, meist in Form von Katalogtexten zu einzelnen Werken, die sich in vielen Museen Europas und in Übersee befinden, so zum Beispiel im Museo del Prado, im National

20 FreedBerg, David: Iconoclasm and Painting in the Revolt of the Netherlands 1566-1609 (Diss. phil., Oxford 1972), New York 1988.

21 JONCKHEERE, Koenraad u. SUYKERBUYK, Ruben (Hrsg.): Art after Iconoclasm: Painting in the Netherlands between 1566 and 1585, Turnhout 2012.

22 Vgl. Weststeijn 2012, S. 109-130. 
Museum of Art in London, im Pariser Louvre, den Berliner Museen sowie im Metropolitan Museum of Art in New York, um nur einige Häuser zu nennen. ${ }^{23}$ Im Jahr 1860 ließ die Stadt Mecheln ihrem Sohn Michiel Coxcie ein Denkmal von dem ebenfalls von dort stammenden Akademiebildhauer Louis Royer errichten und stellte damit eine von ähnlichen nationalen Ideen getragene Analogie zu der von demselben Künstler geschaffenen Statue am Rembrandtplein in Amsterdam her. ${ }^{24}$ In der Allgemeinen Deutschen Biographie von 1876 ist er unter dem Namen Michael van Coxyen geführt. ${ }^{25}$ Der Artikel beschränkt sich auf die Informationen, die durch Vasari, van Mander und Sandrart überliefert sind, während die eigentliche Forschung zu Michiel Coxcie erst vergleichsweise spät einsetzt. Die erste Sammlung von Einzelstudien zum Leben und Wirken des Mechelner Malers wurde von Raphaël DE SMEDT im Rahmen der Tagung „Michel Coxcie, pictor regis (14991592)“ im Jahr 1993 zusammengetragen. ${ }^{26}$

23 Für eine Auflistung aller Michiel Coxcie zugeschriebenen Werke s. DE SMEDT, Raphaël: Autopsie de Michiel Coxcie. Noveaux horizons bibliographiques 1565-2010, Brüssel 2011, S. 177-237.

24 Man sah in der Figur Michiel Coxcies einen Repräsentanten der künstlerischen Entwicklungen in den ,Lage Landen“ des 16. Jhs. (vgl. VAN AUTENBOER 1992, S. 5 f.).

25 Allgemeine Deutsche Biographie, Bd. 4, Leipzig 1876, s. v. „Coxcyen, Michael van“ [SCHMIDT], S. $537-539$.

26 De Smedt, Raphaël (Hrsg.): „Michel Coxcie, pictor regis (1499-1592). International Colloquium, Mechelen, 5.-6. Juni 1992“, in: Handelingen van de Koninklijke Kring voor Oudheidkunde, Letteren en Kunst van Mechelen, Bd. 96, Mecheln 1993. Darin enthalten eine chronologisch geordnete Bibliographie seit dem späten 16. Jh. bis zum Erscheinen des Tagungsbandes.
Weitere Teilaspekte wurden zuvor, 1954, von Julius HELD hinsichtlich einer Zeichnung des Genter Altares, in Bezug auf die Biographie Coxcies von Leo van Puyvelde 1962, sowie 1968 von Jan Karel STEPPE im Zusammenhang mit flämischen Tapisserien in den habsburgischen Sammlungen erörtert. Etwas jüngeren Datums sind die Publikation von Erik Duverger zur Darstellung der Brüsseler Stadtpatrone in der Teppichproduktion von 1993 sowie zwei Aufsätze von Bob C. van den BOOGERT aus dem Jahr 1992, die sich mit Coxcie als Hofmaler und der Verbreitung des Renaissanceornaments in den Niederlanden unter habsburgischer Herrschaft befassen. ${ }^{27}$ Ein Aufsatz von Natasja PEETERs brachte 2012 weitere Einsichten zur Italienrezeption des Künstlers. ${ }^{28}$ Begleitend zur Löwener Ausstellung (Oktober 2013 - Februar 2014) wurde 2013 von Koenraad JONCKHEERE der Katalogband Michiel Coxcie and the Giants of his Age: 1499-1592 herausgegeben. ${ }^{29}$ Die Ausstellung, in der neben den Stücken aus dem Bestand des

27 Held 1954, S. 58-62; VAN PuYVELDE 1962, S. 410-417; STEPPE 1968, S. 719-765; DUVERGER 1954, S. 55-67 sowie VAN DEN BOOGERT 1992a, S. 118-140 u. VAN DEN BOOGERT 1992b, S. 5780. Die im Buchhandel und im GVK deutscher Universitätsbibliotheken nicht erhältliche Thesis von M. H. Stone: ,Michael Coxcie in Rome, New York 1954‘ war mir nicht zugänglich. Aktuelle Bezüge zu diesem Thema finden sich u. a. bei HARNACK 2018 und LEUSCHNER 2013 sowie in der vorliegenden Studie.

28 PeEters, Natasja: „Michiel Coxcie (1499-1592), the Laocoon, and the Introduction of raccourci in the Southern Netherlands“, in: Relations artistiques entre Italie et anciens Pays-Bas (16e et 18e siècles), Brüssel 2012, S. 27-39.

29 JONCKHEERE, Koenraad (Hrsg.): Michiel Coxcie and the Giants of his Age: 1499-1592, London 2013. 
Museum Leuven eine Reihe weiterer Werke aus verschiedenen Sammlungen zu sehen waren, hat erstmals einen Überblick über das Leben und Schaffen Michiel Coxcies geben können.

An dieser Stelle setzt diese Studie an, deren Ziel es ist an ausgewählten Beispielen Stil und Ikonographie bei Coxcie genauer zu beleuchten. Berücksichtigung finden dabei insbesondere seine Beziehungen zu den habsburgischen Höfen sowie das Verhältnis zu anderen Malern seiner Zeit, die sich wie er alle mehr oder weniger mit denselben Herausforderungen, namentlich mit einer zunächst gemäßigten Bildkritik, dann einer radikalen Bilderfeindlichkeit und mit fehlenden Richtlinien im Hinblick auf Form und Inhalt religiöser Bilder von Seiten der katholischen Kirche in den nachtridentinischen Jahrzehnten, konfrontiert sahen. In den abschließenden Bestimmungen des Konzils hatte die Kirche die Problematik des religiösen Bildes als solche weitestgehend abgewiesen und die Verantwortung dem lokalen Episkopat übertragen, ohne dass damit die theologische Dimension in den Anrainergebieten und der neuentstandenen Diaspora der nunmehr mehrheitlich protestantischen Reichsteile, wie etwa den Niederlanden, befriedigend erörtert worden wäre. ${ }^{30}$

Als gesichert anzunehmen ist, dass durch die sich stark verändernde Marktsituation in Folge des Bildersturms des Jahres 1566

30 Vgl. FreEdBerg 1988, S. 134-166, bes. S. 136 mit Verweis auf die Beschlüsse der 25. Sitzung des Trienter Konzils zum Thema religiöser Bilder (1563), abgedr. bei ebd., Appendix II, S. 264 f. Zu den ,Adressaten der bildertheologischen Traktatliteratur' vgl. НЕСHT 2012, S. 37-39.

31 Vgl. Vermeylen 2012, S. 95-108. für die vielen davon massiv existenziell betroffenen Maler in den Niederlanden die drängende Notwendigkeit bestand, Antworten auf die nachlassende Nachfrage nach sakralen Bildern einerseits und deren religiöser Neubewertung andererseits zu finden. ${ }^{31}$ Das nahezu unkritische Festhalten an der bildtheologischen Tradition, wie es das Tridentinum kennzeichnet und das auch für die Erschließung von Michiel Coxcies Altarbildern von Belang ist, stellt das dem bilderfeindlichen Calvinismus gewissermaßen entgegengesetzte Extrem dar, während es zur gleichen Zeit strenge bildreformerische Autoren auf katholischer Seite gab, deren Einfluss am Beispiel des Löwener Theologen Johannes Molanus noch zu klären ist. Letztlich verwundert es wenig, dass besonders die Darstellung altchristlicher Märtyrer, die in der Zeit unmittelbar nach 1566 in Coxcies Werk auftreten, ihrem Charakter nach auch als Apologeten der kirchlichen Tradition und des sakralen Bildes an sich zu verstehen sein können. Die darin zugleich erkennbaren Verstöße gegen die mit der Synode von Mecheln 1570 einsetzenden Bildreformen sind bemerkenswert und erfordern eine Interpretation im Hinblick auf die Rolle, die Coxcie bei der von den Habsburgern forcierten Rekatholisierung der spanischen Niederlande gespielt hat. ${ }^{32}$ Koenraad JONCKHEERE hat zuletzt auf den regelrechten Mangel an Studien

32 Wie etwa das Verbot Portraits von realexistenten Personen auf die Darstellung von Heiligen zu verwenden, wie es zwar nicht vom Konzil selbst, aber durch die Synode von Mechelen im Jahr 1570 beschlossen worden war. Für den originalen Wortlaut des Beschlusses s. DE RAM 1861, S. 319 u. für eine Übersetzung FrEEDBERG 1988, S. 163, Anm. 87. 
zur Bedeutung der Bilddebatte des 16. Jahrhunderts für die Malerei hingewiesen. ${ }^{33}$

Vor diesem Hintergrund sollen im Folgenden sowohl die Debatte um die Rolle religiöser Bilder, der von Michiel Coxcie geleistete Beitrag bei der Wiederherstellung der im Bildersturm zerstörten Altäre sowie zunächst Coxcies stilistische Entwicklung unter dem Einfluss der italienischen Hochrenaissance an ausgewählten Beispielen zur Sprache kommen. Eine voraufgehende Erörterung der kunstgeschichtlichen Entwicklungen in den Niederlanden in den ersten Jahrzehnten des 16. Jahrhunderts ist zum Verständnis des Folgenden unabdingbar. Dabei soll an ausgewählten Beispielen der Beginn der Italienrezeption in der niederländischen Tafelmalerei und ihre wiederum vielschichtige Gestalt, etwa am Beispiel der sogenannten ,Antwerpener Manieristen', veranschaulicht werden. Danach folgt ein Abriss zum Leben und Werk von Coxcies Lehrer Bernard von Orley und dessen Hinwendung zu dem Phänomen, das in der Forschung bereits im 19. Jahrhundert unter dem Begriff ,Romanismus' lanciert worden ist und zuletzt von Maria HARNACK in ihrer Dissertation Niederländische Maler in Italien: Künstlerreisen und Kunstrezeption im 16. Jahrbundert von 2018 in Form eines Überblicks geordnet und in einem Exkurs zur historischen Definition behandelt wurde. ${ }^{34}$ Dieser erste größere Abschnitt (II) ist weniger als Einleitung zum eigentlichen Thema zu verstehen, denn vielmehr als eine Grundlegung der im Werk Coxcies weiter zu konkretisierenden Gesichtspunkte. Der Fokus dieser Studie ist schließlich auf Michiel Coxcie als Romanist im Verhältnis zur altniederländischen Malereitradition gerichtet (III), gefolgt von einer Erörterung seines Selbstverständnisses als katholischer Maler im Dienst der Habsburger (IV). Zuletzt soll einerseits die Rezeption Coxcies im Spannungsfeld seiner Rolle als Vorläufer der Malerei des flämischen Barocks und andererseits seine typenprägende Persönlichkeit als Maler der Gegenreformation in den Blick genommen werden (IV-V).
34 HARNACK 2018, hier bes. S. 9-11 zur Geschichte des Begriffs und S. 73-80. 


\section{TT Die Anfänge der Italienrezeption um 1500}

\subsection{Jan Gossaert und der Beginn des Romanismus in der niederländischen Malerei}

Im ersten Viertel des 16. Jahrhunderts wurde es für aufstrebende niederländische Maler zunehmend eine Notwendigkeit, nach Italien, vor allem nach Rom, zu reisen, um sich durch das Studium der Antike sowie deren Rezeption durch die bereits von ihren Zeitgenossen gerühmten Künstler der italienischen Frühund Hochrenaissance, darunter Raffaello Sanzio und Michelangelo Buonarroti, weiterzubilden. Nicht zuletzt die monumentale Malerei, etwa im Apostolischen Palast, konnte auf diese Weise direkt und nicht mehr nur über graphische Reproduktionen vermittelt studiert und rezipiert werden. Die Motivation für die Reise war nach Auskunft der Quellen im Einzelnen unterschiedlich, zielte insgesamt jedoch vor allem auf die Aneignung eines Stils

35 Für die individuelle Motivation bzw. die Veranlassung zur Reise, so sie sich aus den überkommen Informationen zu einzelnen Künstlerpersönlichkeiten rekonstruieren lässt, s. HARNACK 2018, S. 13-29.

36 WeIDEMA - KoOpstra 2012, S. 8 f.: Zwei Quellen, eine mit dem Antrag Philipps für die Finanzierung der Romreise, vom 23. Oktober 1508 sowie eine spätere Auszahlung für den Unterhalt während selbiger vom 21. August 1509. Vgl. PAuwELS et al. 1965, S. 373; 375.

Zur Motivation und den Folgen der Romreise Gossaerts wurde in der Forschung umfänglich referiert, sodass an dieser Stelle zunächst ganz allgemein auf Max Friedländers umfangreiches Werk zur niederländischen Malerei und für neure Untersuchungen auf MENSGER 2002, den Aufsatz von SCHRADER 2010 sowie zuletzt auf die ausstellungsbegleitende Publikation von AINSWORTH 2010 verwiesen werden kann. all'antica. ${ }^{35}$ Am Anfang dieser Entwicklung steht sicherlich Jan Gossaerts Italienreise (1508-1509) in der Entourage des Grafen Philipp von Burgund, dem Bastardsohn Herzog Philipps des Guten. ${ }^{36}$ Gossaert nahm als Angehöriger des burgundischen Hofes in diplomatischer Funktion an dieser Reise teil, scheint aber in erster Linie dazu abgestellt gewesen zu sein, Werke der italienischen Kunst und antike Artefakte in Rom festzuhalten, während Philipp seine Kunstkenntnisse in Gesprächen mit Papst Julius II. unter Beweis gestellt haben soll. Im Auftrag seines Mäzens entstanden Zeichnungen von antiken römischen Skulpturen und Architekturfragmenten, welche mehrfach in den Texten des Humanisten und Hofschreibers Geldenhouwer erwähnt und teilweise genauer besprochen werden. ${ }^{37}$ Gossaert konnte sich in diesem Zusammenhang bewähren und gewann die Gunst Philipps, dem er nach der Rückkehr aus Italien

37 Vgl. Ainsworth 2010, S. 53; Geldenhouwer 1529 [PRINSEN 1901], S. 232 f.: ,,[...] nihil magis eum Romae delectabat, quam sacra illa vetustatis monumenta, quae per clarissimum pictorem Joannem Gossardum Malbodium depingenda sibi curavit." Davon sind mutmaßlich vier Blätter erhalten, die Zeichnungen römischer Bauwerke und Skulpturen enthalten: Eine Skizze des Dornausziehers und weiterer Skulpturen (Rijksuniversiteit, Leiden), die Westansicht des Kolosseums (Kupferstichkabinett, Berlin), eine Zeichnung des Apoll Citharoedus (Gallerie dell'Accademia, Venedig) und eine Rückansicht des Herkules vom Forum Boarium (Verbleib unbekannt), vgl. hierzu HARNACK 2018. S. 15, Anm. 16 und SChrader 2010, S. 45-55.

Die Romreise erzeugte in den Niederlanden einen Nachklang. So schrieb Guicciardini 1567 in seinen Beschreibungen seiner Wahlheimat, der Niederlande über Gossaert: „,...] il primo che 
auf dessen Landsitz in Zeeland folgte. Einer der ersten prestigeträchtigen Aufträge, die er für Philipp ausführte, war ein Altarbild für die Kirche des Regierungssitzes in Middelburg, wo er später in Kooperation mit Jacopo de' Barbari die Neuausstattung des Palastes für die niederländische Statthalterin Margarete von Österreich plante und zur Ausführung brachte. ${ }^{38}$ Sein Weggefährte erhielt jedoch im Folgenden den Auftrag für die Ausführung und wurde zu Margaretes neuem Hofmaler berufen, bevor dieses Amt später von einem anderen frühen Romanisten, nämlich Bernard van Orley, bekleidet wurde. In der Forschung, die auf der stilkritischen Erschließung des jeweiligen Maler-CEuvres durch Max FRIEDLÄNDER fußt, werden beide - Gossaert und van Orley - bisweilen als die hauptsächlichen Triebkräfte einer Annäherung an die Kunst Italiens bezeichnet. Tatsächlich ist die Bedeutung Gossaerts für die Entwicklung der niederländischen Malerei im ersten Drittel des 16. Jahrhunderts kaum zu überschätzen. Bereits 1521 notierte Dürer in seinem sogenannten Tagebuch der Reise in die Niederlande, dass er Middelburg eigens zu dem Zweck, ein Altarbild von Gossaert zu besichtigen, welches 1568 einem Brand zum Opfer fallen sollte, bereist habe. ${ }^{39}$

Die Rolle Jan Gossaerts in der ersten Phase der Auseinandersetzung mit der italienischen Kunst durch niederländische Maler wird vor allem in den zahlreichen Altarbildern, von denen eine auffällig große Zahl die Muttergottes zum Thema haben, deutlich. Die Heilige Familie von 1510 [ABB. 1] markiert den Übergang von der altniederländischen Tradition zu seinem frühen, ${ }^{40}$ motivisch durch italianisierende bzw. antikisierende Architekturen gekennzeichneten Stilidiom geradezu paradigmatisch. ${ }^{41}$ Das Bild zeigt Maria mit dem Kind auf einem stufenförmig angelegten Postament und von zwei antikisch gestalteten Säulen flankiert. Im Hintergrund, gleichsam als Durchblick durch einen von den Säulen getragenen Bogen, eröffnet sich eine in die Tiefe ausgebreitete phantastische Architektur, die das antike Ornament spielerisch dem spätgotischen, wie etwa bei dem metallenen Brunnen auf der linken Seite im Mittelgrund, nicht antithetisch, sondern gewissermaßen ergänzend gegenüberstellt. ${ }^{42}$ In der Ferne ist ein verblauendes portò d'Italia in questi paesi, l'arte del pingere Historiae [...]“ (Guicciardini 1567, S. 98), vgl. hierzu auch SCHRADER 2010, S. 45.

38 Vgl. Veratelli 2011, S. 61-73. Für biographischen Überblick s. auch ADB 9 (1879), s. v. „Gossart, Jan“ [Woltmann], S. 404-406.

39 Vgl. UNVERFEHRT 2007, S. 125. Zu beachten gilt es in diesem Zusammenhang, dass Dürer während seines Aufenthaltes bei van Orley Quartier nahm und von diesem mit besonderer Gastfreundschaft aufgenommen wurde. Die landesübergreifende Popularität beider Maler wird anhand dieses Umstandes zumindest indirekt bestätigt (Ebd., S. 38-41). Van Mander be- zeichnet es später als ,sein wichtigstes und bekanntestes Werk (van Mander 1604 [1994-99], Bd. 1, S. 160 u. Bd. 3, S. 147 f.)

40 Öl auf Holz, 45,7 × 33,7 cm, Getty Museum, Los Angeles (s. AinsworTH 2010, S. 122).

41 Um 1510 üben Gossaerts Werke maßgeblichen Einfluss auf die Malerei der sog. Antwerpener Manieristen aus, vgl. hierzu das Kapitel 2.2 Der ,spätgotische Manierismus' als stilgeschichtliches Scharnier.

42 Die Differenzierung der Stile, hier zwischen dem ,gotischen' und dem ,antikischen' zeigt einerseits einen Bezug zur Gegenwart der zeitgenössischen Beschauer - die Städte der Nieder- 
Gebirge zu sehen, das im Vordergrund stark verschattet ist, um eine talartige, zusammen mit den Architekturen gleichsam abgeschlossene Umgebung zu suggerieren. In der Art, wie hier eine ferne Landschaft dargestellt bzw. die Tiefenwirkung des Bildraumes angelegt ist, ist Gossaert in der altniederländischen Tradition verwurzelt.

Beim Malvagna-Triptychon, ${ }^{43}$ das etwa zwischen 1513 und 1515 entstanden sein dürfte, wird die Symbiose der heimischen Tradition und der italienischen Malerei noch deutlicher. ${ }^{44}$ Das Mittelbild zeigt Maria mit dem Kind vor einer Landschaft mit Architektur im Hintergrund [ABВ. 2], auf die der Beschauer wiederum, wie durch eine Art Fenster, durch einen kunstvoll verzierten gotischen Baldachin hindurch, gelenkt wird. Der Kopf Marias und ihre Körperhaltung lassen an Werke von

lande waren im 16. Jh. keine durchgängig im Renaissancestil durchgestalteten Schöpfungen, sondern maßgeblich von gotischen Fassaden und deren charakteristischer Bauplastik geprägt. Die Kombination des Älteren mit dem Neuen spiegelt neben dem intendierten Wechsel der Moden bzw. des Geschmacks auch das Bewusstsein von Historizität, die sich ganz besonders in öffentlichen Architekturen, wie etwa einem das Zentrum eines Platzes dominierenden Brunnens, zeigt. Beispielhaft hierfür ist Albrecht Altdorfers Gemälde Rube auf Flucht (58,2 $\times 39,2 \mathrm{~cm}$; Gemäldegalerie, Staatliche Museen Berlin) von 1510 oder sein Holzschnitt mit der Heiligen Familie am Brunnen von 1512 (Bartsch 59).

43 Öl auf Holz, Mitteltafel: 45,5 × $35 \mathrm{~cm}$, Seitentafeln: $45 \times 17,5 \mathrm{~cm}$, Galleria Regionale della Sicilia, Palazzo Abatellis, Palermo. Informationen zum Auftraggeber haben sich nicht erhalten (vgl. AINSWORTH 2010, S. 131).

44 Neuere Überlegungen, die auf einer jüngeren technischen Untersuchung fußen, verweisen auf die hohe Wahrscheinlichkeit, dass die Figuren und Landschaften der Außentafeln jeweils nicht von derselben Hand angefertigt wurden.
Gerard David denken, während das Christuskind und die als Putti gestalteten Engel, obschon sie mit ihrem Detailnaturalismus ebenfalls ein Charakteristikum der altniederländischen Malerei bezeugen, in ihrer Körperbildung und Plastizität italienische Einflüsse $\mathrm{zu}$ erkennen geben, die in einem gewissen Spannungsverhältnis zu der Figur der Maria stehen. ${ }^{45}$

Auf zweien der vier Seitentafeln sind auf einer Seite Adam und Eva im Paradies gezeigt [ABB. 3]. ${ }^{46}$ Diese Darstellung folgt in der Komposition und Auffassung der nackten anatomisch durchgebildeten Figuren allerdings nicht zunächst italienischen Vorbildern, sondern orientiert sich vor allem an Albrecht Dürers entsprechendem Holzschnitt in dessen Kleiner Passion. Angesichts von Dürers Studium der italienischen Kunst stehen mittelbar

Die der Studie zugrundeliegende Infrarotreflektographie der drei Tafeln stammt aus dem Jahr 2002. Eine Zusammenarbeit zwischen Gossaert und Gerard David wurde von AINSWORTH in die Diskussion eingeführt (vgl. AINSWORTH 2010, S. 131 f.).

45 Vergleiche zwischen dem Kopf der Maria auf der Mitteltafel des Malvagna-Triptychons mit Marienfiguren aus dem Werk Gerard Davids haben eine stilistische Übereinstimmung bei mehreren Beispielen bestätigen könne, darunter die Maria auf der Rube vor der Flucht, ca. 1500-1505 in der National Gallery of Art, Washington sowie die Virgo inter virgines aus dem Morgan Museum, New York (s. AINSWORTH 2010, S. 137).

46 Der Kopf der Figur des Adam auf dem linken Außenflügel konnte durch die bei der ,materialtechnischen' Untersuchung sichtbar gemachten Unterzeichnungen mit einer Studie Gerard Davids (ca. 1505-1510) in Verbindung gebracht werden (Kunsthalle Hamburg), welche auch die Zeichnung eines Baumes mit ausladender Krone und einem vergleichsweise wenig beasteten Stamm enthält, der dem Baum der Erkenntnis auf der Tafel des Malvagna-Triptychons ähnelt (s. AINSWORTH 2010, S. 135). 
nichtsdestoweniger die Vorbilder Italiens hinter einer solchen Figurenauffassung. Die beiden Stammeltern sind dynamisch dargestellt; Adam legt seinen rechten Arm um die Schulter Evas, während diese eine Pose mit Standund Spielbein einnimmt und ihrem Mann den Apfel reicht. Er wiederum ist mit der ausgestreckten rechten Hand im Begriff, sich selbst eine Frucht vom Baum der Erkenntnis zu pflücken. Der Vorder- und Mittelgrund sind ausgesprochen dunkel gehalten, ein Felsen sowie dessen Spiegelung - eine Art Monumentalarchitektur links im Hintergrund - schlieBen das Bild zu beiden Seiten ab, während es von dem dunklen Stamm des Baumes zentriert wird. ${ }^{47}$ Gleichzeitig leugnet die Mitteltafel mit ihrer gotischen Schauarchitektur ihr Herkommen von der altniederländischen Tradition nicht. Vergleichbares ist aus dem Umfeld der Brügger Davidschüler auch 15 Jahre später, noch im ersten Drittel des 16. Jahrhunderts bekannt, so zum Beispiel bei Ambrosius Bensons Anna Selbdritt (um 1525) ${ }^{48}$ und einem anonymen Antwerpener Manieristen, der sich offenbar an Gossaert orientiert hat. ${ }^{49}$ Der Bildtypus der architektonisch gerahmten Maria hatte sich wahrscheinlich nach dem Vorbild Rogier van der Weydens, der eine Maria mit Kind schon um 1430 in einer mit gotischen Filialen und Maßwerk bekrönten Architekturnische dargestellt hat, etabliert. ${ }^{50}$ Nicht grundlos also hat MENSGER Gossaerts Malvagna-Retabel als ein vergleichsweise konservatives und „lokaltypisches Produkt“, mit dem Gossaert mutmaßlich seine vielfältigen Möglichkeiten auf dem wachsenden Kunstmarkt habe demonstrieren wollen, bezeichnet. ${ }^{51}$ Überhaupt seien etwaige Stil-Archaismen im Werk Gossaerts nach seinem Italienaufenthalt 1507-1509 als absichtliche Ausformungen zu betrachten, die bei ihm weniger einen Stand der Entwicklung, als vielmehr die Beherrschung unterschiedlicher Stilmodi bezeugen würden. ${ }^{52}$

Ein weiteres Charakteristikum im stilistischen Spektrum Gossaerts stellen die größtenteils von antiken Vorbildern abgeleiteten, in der Regel jedoch nicht authentischen, sondern phantastisch zusammengesetzten antiken Architekturen dar, wie etwa bei seiner

48 Öl auf Holz, $125 \times 90 \mathrm{~cm}$, Prado, Madrid, Inv.Nr. P001933 (s. MARLIER 1957, S. 135-137 u. FRIEDLÄNDER 1974, S. 94).

49 Öl auf Holz, $38 \times 27,5 \mathrm{~cm}$, Privatbesitz, Deutschland; zuvor Galerie Robert Finck, Brüssel (s. Katalog zur Sammlung 1981, Nr. 3; RKDNr. 258816).

50 So zum Beispiel bei der Maria mit Kind (um 1433), Öl auf Holz, 15,8 × 11,4 cm, Museo Thyssen-Bornemisza, Madrid, Inv.-Nr. 435 (1930.125).

51 Mensger 2002, S. 27.

52 Vgl. MeNsGer 2002, S. 67. 
Danaë von 1527 [ABB. 4]. ${ }^{53}$ Die groß im Vordergrund dargestellte Figur ist von starker Plastizität, was neben der unkonventionellen Sitzposition bereits auf italienische Vorbilder verweist. Nach dem Verständnis der Zeit galt Danaë als Präfiguration der Jungfrau Maria, ${ }^{54}$ sodass das hier gewählte Sitzmotiv auf den Typus der Madonna dell'Umiltà, wie etwa Raffaels Alba Madonna von 1510, verweist. ${ }^{55}$ Das Thema hat keine unmittelbaren niederländischen Vorläufer, sondern stellt eine Innovation Gossaerts dar, die auf seine Kenntnis antiker Skulptur und Architektur verweist und dem Geschmack seines Mäzens Philipp von Burgund entsprach, dem der Hofschreiber Gerard Geldenhouwer ein besonderes Interesse an klassischer Architektur zuschrieb. ${ }^{56}$ Danaë sitzt in einer Art Rundtempel, der durch die dunkle Materialität von rotem Porphyr besonders ausgezeichnet ist. Die auf hohen Postamenten ruhenden Säulen besitzen

53 Öl auf Holz, $13.5 \times 95 \mathrm{~cm}$ Alte Pinakothek, München; Signatur auf dem Sockel unterhalb der Danaë: „IOANNES MALBODIVS PINGEBAT 1527“" (s. AINSWORTH 2010, S. 232).

54 PANOFSKY 1933, S. 206 f.

55 Urspr. Öl auf Holz (auf Leinwand übertragen), $94.5 \mathrm{~cm}$ (Durchmesser); National Gallery, Washington D. C., Inv.-Nr. 1937.1.24 (s. MEYER ZUR CAPELLEN 2001, Bd. II, Kat.-Nr. 50, S. 82).

56 Gossaert hat möglicherweise die Reste der Ausmalungen im Tempel der Vesta auf dem Forum Romanum gesehen, gleiches gilt für die Architekturen. Ebenfalls denkbar ist, dass Gossaert zusätzlich zu seinen eigenen Beobachtungen in Rom, Zugang zu den Texten Geldenhouwers gehabt haben könnte und in einem intellektuellen Austausch mit dem Humanisten stand (s. hierzu Herzog 1968, S. 38; Mensger 2002, S. 181 und AINSWORTH 2010, S. 234).

57 Alberti ordnet die Architektur (,ornamentum) einer Stadt danach, ob sie sakral (Buch VII), profan (Buch VIII) oder privat (Buch IX) ge-
Kompositkapitelle, was gemäß Vitruv bei diesem mythologischen Thema für angemessen gelten konnte. ${ }^{57}$ Im Kontrast hierzu gewähren die fensterartigen Durchblicke zwischen den Wandstücken mit ihren vorgeblendeten Halbsäulen, einen Blick auf monumentale, hoch aufragende Bauten, die, einem gotischen Konstruktionsprinzip folgend, in die Höhe streben und Zierrat aus dem spätgotischen Formenvokabular aufweisen. Es finden sich überkuppelte Türme, die von Halbsäulen und Lisenen gegliedert sind und teilweise von gotischen Strebebögen gestützt werden. Gleichzeitig ist aber auch eine offen gestaltete, rundbogige Loggia zu sehen, die in stilistischer Kohärenz zu dem Innenraum im Vordergrund als antikisch bezeichnet werden kann. Ein ähnlicher Gebrauch von antiker Architektur findet sich bei Bernard van Orleys Löwener Madonna von 1520 [АВB. 5], die lange Zeit ebenfalls Jan Gossaert zugeschrieben wurde. ${ }^{58}$ Die Figur ist

dacht ist. Bei der Frage nach der Angemessenheit folgt er dem Schema Vitruvs und verwendet hierfür die Begrifflichkeiten „,hoch“, ,,mittel“, und „niedrig“", um die Würde eines Bauwerks zu bezeichnen. Zu den „hohen“ sakralen Architekturen zählt er den Tempelbau (vgl. BIERMANN 1997, S. 167 u. 169).

Zum einen steht die Danaë als mythologische Gestalt (Geliebte des Zeus) mit dem Göttlichen in Verbindung, andrerseits ist sie als „,Typus Pudicitia“ und Präfiguration Mariens per se eine Symbolfigur der christlichen Ikonographie. Der blaue Mantel auf Gossaerts Gemälde betont die attributive Nähe zur Gottesmutter, s. auch: PANOFSKY, Erwin: Der gefesselte Eros (zur Genealogie von Rembrandts Danaë), in: Oud Holland, Ausg. Nr. 50, Leiden 1933, S. 203-217.

58 Öl auf Holz, $45 \times 39 \mathrm{~cm}$, Prado, Madrid. Das Bild wurde 1588 vom Löwener Stadtrat aus dem Augustinerkonvent erworben und Philipp II. als Geschenk vermacht. Es wurde ursprünglich für 
hier im Vordergrund vor einer monumentalen Architektur platziert, die jedoch deutlich stärker als bei Gossaert eine rein dekorative Funktion erfüllt und die Figur von Maria und dem Jesuskind mehr zu rahmen scheint als sie tatsächlich in sich aufzunehmen. In dieser Hinsicht ähnelt diese Architektur der des Malvagna-Triptychons, obschon sie im Gegensatz dazu stilistisch ganz der ,neuen' Formensprache folgt. ${ }^{59}$

Während sich Gossaerts Anbetung der Könige [ABB. 6] ${ }^{60}$ die um 1510 entstanden ist, im Hinblick auf Farbigkeit, Komposition und Figurenbildung stark an Vorbildern Gerard Davids, das heißt an dem um 1500 noch aktiven und entschiedensten Vertreter der altniederländischen Malereitradition, zu orientieren scheint, ${ }^{61}$ wirkt die kaum zehn Jahre später gemalte Kreurabnabme von 1521 geradezu revolutionär [ABB. 7]. ${ }^{62}$ Die leichte Untersicht, die plastischen Figuren und die Bewegungsmotive bei der Abnahme des Leichnams sowie die im Vordergrund niedergesunkene Maria, ihrerseits körperhaft aufgefasst und perspektivisch

ein Werk Jan Gossaerts gehalten, wie eine Inschrift auf der Rückseite zu erkennen gibt (s. Kat. Prado 1989, S. 88) Die Zuweisung an Bernard van Orley geht auf Friedländer zurück (s. FRIEDLÄNDER 1972, S. 60 f. u. 108; zuletzt diskutiert bei HerIGUEZ 2013, S. 131-141).

59 Bei den Antwerpener Manieristen sind in dieser Zeit ähnliche „Konstrukte` zu beobachten, die sich an dem Prinzip älterer Vorbilder orientieren und streng achsensymmetrisch gebildete Architekturen als dekoratives Rahmen- oder Hintergrundmotiv wählen; so zum Beispiel beim Meister von 1518 alias Jan Dornicke: Das Triptychon mit Christus im Hause des Pharisäers Simon aus der Abtei von Dillighem bei Brüssel (heute Koninklijke Musea voor Schone Kunsten, Brüssel; Inv.-Nr. 329) zeigt noch viel stärke eine Abwandlung des Architekturmotivs aus der gotischen ,Formensprache ${ }^{\varsigma}$, indem hier die Renais- in den Raum gelenkt, aber auch die auf Christus blickende, plastisch-bewegte und höfisch elegant gekleidete Maria Magdalena sind das Ergebnis einer in Italien aufgenommenen und stetig weiterentwickelten Formensprache und deren Verschmelzung mit der niederländischen Tradition, wie denn die Komposition insgesamt deutlich an das Vorbild von Rogier van der Weydens Kreurabnabme im Prado anschließt. Das Bild bietet überdies Einblick in Gossaerts Werkstatt, da die Gruppe um die zusammengesunkene Maria im Schatten unten links die Mitarbeit Jan van Dornickes, der wahrscheinlich identisch ist mit dem Meister von 1518 bei FRIEDLÄNDER, nahelegt. ${ }^{63}$ Dornicke (um 1475-1527) war in den 1510er Jahren Schüler Gossaerts und gründet im Verlauf dieser Dekade eine eigene Werkstatt in Antwerpen, in welcher er bis zu seinem Lebensende tätig blieb. Zu seinen Mitarbeitern soll ab 1522/23 Pieter Coecke van Aelst gezählt haben, ${ }^{64}$ der seit dieser Zeit als in Antwerpen tätiger Meister bei der Lukasgilde eingeschrieben war und kurze Zeit darauf auch

sanceformen keinem klassischen Konstruktionsprinzip, sondern dem aus älteren Vorbildern abgeleiteten, gewissermaßen spielerisch-dekorativen Prinzip, folgen. Für das Triptychon s. Kat. KMSKB 1984, S. 354. Zum Künstler s. Exkurs nach Abschn. 2.2.

60 National Gallery, London; Inv.-Nr. 2790 (s. CAMPBELL 1997, S. 87-97).

61 Die Komposition geht letzten Endes zurück auf Hugo van der Goes, den David hier rezipiert hat.

62 Ermitage, St. Petersburg, Inv.-Nr. 413 (s. FrIEDLÄNDER 1967-1976, Bd. VIII, S. 120 u. NiKULIN 1989, S. 102).

$63 \mathrm{Zu}$ dem Meister von 1518 und den Antwerpener Manieristen s. FRIEDLÄNDER 1967-1976, Bd. 11, passim. s. auch BORN 2010.

64 Vgl. BORN 2005, S. 225 u. KRÖNIG 1957, S. 161-177. Vgl. auch MARLIER 1966, S. 109-145. 
Dornickes Schwiegersohn geworden sein soll. ${ }^{65}$ Als Schüler des Bernard van Orley muss Pieter Coecke als eines von mehreren Bindegliedern zwischen der mutmaßlich von Gossaert stark inspirierten Kunst der Antwerpener Manieristen und dem späteren Romanismus seines Mitschülers Michiel Coxcie gelten, da sich für letzteren, bis auf die posthum überlieferte Nachricht von einer Lehre bei van Orley, kein Werk oder die Mitarbeit an einer Werkstattarbeit vor 1539 nachweisen lässt. ${ }^{66}$ Denkbar wäre, dass der Stil Coxcies zu dieser Zeit noch stark dem seines Meisters, das heißt dem für diese Werkstatt typischen Idiom, entsprach, sodass Stilvergleiche, die Coxcies späteres Schaffen als Referenz nehmen, nicht zielführend wären. ${ }^{67}$ Die Ausbildung Coxcies ist parallel zu van Orleys Arbeiten der 1520er Jahre anzusetzen, sodass hier schon eher nach Übereinstimmungen zu suchen wäre. ${ }^{68}$

Neben der starken Verbindung der Werkstätten in Antwerpen in dieser Zeit untereinander, die Georges MARLIER als derart „familiär" bezeichnete, ${ }^{69}$ dass es schwer sei, deren Erzeugnisse zu unterscheiden, wird deutlich, dass sich innerhalb der überlieferten Produktion des von mir nur exemplarisch beschriebenen Umfeldes unterschiedliche Entwicklungen durchaus an den Objekten selbst

65 Erste Erwähnung als Freimeister findet Pieter Coecke im Mitgliederverzeichnis der Antwerpener Lukasgilde 1527 (s. ROMBOUTS - LERIUS 1872-1876, Bd. 1, S. 108, 113, 135, 150 182).

66 s. Kap. III dieser Arbeit.

67 Hierzu HaNd 2004, S. 95; ebenfalls in dieser Rolle anzusiedeln ist Joos van Cleve, dessen CEuvre einen vielleicht sogar noch differenzierteren Umgang mit unterschiedlichen Stilelementen aufweist. Verwiesen sei hier auf den jüngst erschienenen Aufsatz von Christina UNSINN: Eine exakte Teilkopie von Joos van Cleve. festmachen lassen. Da die Quellenlage hierzu lückenhaft ist und sich in der Regel auf Einträge in den Liggeren der Antwerpener Lukasgilde beschränkt, muss der stilkritischen Bewertung nach wie vor eine gewisse Interpretationshoheit zugesprochen werden. Die Arbeiten von Max J. FRIEDLÄNDER sind hinsichtlich vieler seiner Beobachtungen und differenzierten Zuweisungen noch immer die Grundlage für weitere Überlegungen zur (süd-)niederländischen Malerei des frühen 16. Jahrhunderts, da in genau diesen Zeitraum die Ausbildung der in der Mitte des Jahrhunderts aktiven Künstler fällt, von denen Michiel Coxcie freilich nur einer von vielen mehr oder weniger namhaften Persönlichkeiten ist. Die in den ersten Jahrzehnten des 16. Jahrhunderts sich etablierende Stilrichtung kann deshalb als der Ausgangspunkt für die gesamte weitere Entwicklung der südniederländischen Kunst gelten, ohne deren Einfluss die flämische Malerei des Barocks kaum denkbar gewesen wäre.

Die Kunstproduktion der alten Handelszentren der südlichen Niederlande in Brügge, Brüssel oder auch Gent war bis weit in das erste Drittel des 16. Jahrhunderts an das Formenvokabular des vorherigen Jahrhunderts geknüpft. Der Brügger Maler Gerard

Zur Funktion von Kopien im frühen 16. Jahrhundert (2018), in: E-Journal für Kunst- und Bildgeschichte kkunsttexte.de» 01/2018.

68 Für eine Erörterung der Beziehung zwischen Michiel Coxcie und seinem mutmaßlichen Lehrer Bernard van Orley s. Kap. III dieser Untersuchung.

69 „Leur air de famille est si marqué qu'aujourd'hui encore nous éprouvons quelque difficulté à distinguer nettement la production de chacun d'eux“ (MARLIER 1957, S. 266). 
David bezog seine Modelle und Kompositionen um 1500 noch immer größtenteils von den Werken Rogier van der Weydens und der nachfolgenden Generation altniederländischer Meister wie Hugo van der Goes, Hans Memling oder Dierik Bouts. ${ }^{70}$ Einer der am längsten diesem Idiom verpflichteten Maler ist Colijn der Coter, der in Brüssel noch bis weit in die 1520er Jahre hinein das konservative Gegenstück zum zeitgleich sich etablierenden ,Romanismus‘ Bernard van Orleys bildete. ${ }^{71}$ In Antwerpen hingegen galten andere Voraussetzungen, da es hier keine übermächtige lokale Tradition gab. Stattdessen zeichneten sich die hier zu Beginn des Jahrhunderts etablierenden Werkstätten, wie etwa die von Pieter Coecke van Aelst und Joos van Cleve, durch eine besondere Verlagerung ihres Schwerpunktes auf die serielle Kunstproduktion aus, die besonders auf die häufige Wiederholung beliebter Kompositionen aus der eigenen Herstellung spezialisiert war. ${ }^{72}$ Das Letrte Abendmabl von Pieter Coecke oder die Madonna mit den Kirschen von Joos van Cleve sind zwei solcher erfolgreich vermarkteten Motive, die in der Folge vielfach reproduziert wurden. ${ }^{73}$ Interessant an diesem Vorgang ist die schrittweise Aneignung italienischer Formen und Modelle, die im Fall von Pieter Coecke etwa konkret durch die Rezeption der Reproduktionsgraphik nach Werken Raffaels gekennzeichnet ist. Demgegenüber weisen die zahlreichen Madonnen Joos

70 Vgl. Martens 1998, S. 43.

71 Eine monographische Abhandlung zum Leben und Wirken Colijn de Coters legte PÉRIER-D'IETEREN 1985 vor.

72 Vgl. JANSEN 2003, S. 165-174 u. LeEFLANG 2007.

73 Vgl. HAND 2004, S. 95 u. JONCKHEERE 2012, S. 9 . van Cleves eine stilistische Verwandtschaft zu denen Leonardos auf. Auch die Bezugnahme auf einzelne Kompositionen Giampetrinos lassen sich in seinem Werk nachweisen. ${ }^{74}$

Der Zusammenhang von Kopie und $a$ emulatio ist in diesem Stadium längst nicht mehr nur auf die Übernahme und Einbettung italienischer Vorbilder in die niederländische Malerei beschränkt, sondern beschreibt ebenso den Versuch, die eigene, das heißt lokale Tradition durch solche Zitate und die daraus hervorgehende Syntheseleistung zu übertreffen. Das vergleichsweise banale finanzielle Motiv bestand höchstwahrscheinlich darin, auf diese Weise den Erwartungen zeitgenössischer Kunstliebhaber entgegenzukommen, indem man die Errungenschaften der italienischen Hochrenaissance mit den geschätzten Werken der flämischen Malereitradition zu verbinden suchte. In der Mitte des 16. Jahrhunderts bedienten sich Frans Floris und Willem Key dabei noch desselben Prinzips der (Teil-)Kopie wie Joos van Cleve und Pieter Coecke zu dessen Beginn, wie das Beispiel von Keys Beweinung Christi nahelegt [ABB. 8]. ${ }^{75}$ Die Komposition an sich geht auf ein Werk von Quentin Massys zurück [ABB. 9], ${ }^{76}$ wobei Keys Anliegen offenbar darin bestand, die Verbindung dieses in der altniederländischen Tradition verwurzelten Vorbildes, das wiederum seinen Ursprung bei van der Weyden hatte und um 1500 von Gerard David aufgegriffen

74 s. hierzu LEEFLANG 2011, S. 132-155.

75 Alte Pinakothek, München (s. SILVER 1984, S. 229, Kat.-Nr. 47).

76 Öl auf Holz, $48 \mathrm{~cm} \times 62 \mathrm{~cm}$, Koninklijk Museum voor Schone Kunsten, Antwerpen, Inv.Nr. 565. 
worden war [ABB. 10] ${ }^{77}$ mit stilistischen Errungenschaften der italienischen Renaissance zu vereinen. ${ }^{78}$ Tatsächlich ist der Zusammenhang mit Massys augenfällig; die Figuren erscheinen lediglich spiegelverkehrt. Zwar sind die Änderungen in der Komposition marginal, doch lässt sich bei Key im Detail eine Zunahme des Naturalismus gegenüber dem Vorbild von Massys beobachten. So ist der Arm Marias, der auf der Brust des toten Christus liegt, während sie mit der Hand zärtlich über seinen Bart streicht, natürlicher gebildet. Auch heben sich die beiden den Vordergrund dominierenden Figuren stärker vom Hintergrund ab, was die Raumtiefe des Bildes und die Beziehung der Figuren zum Raum verdeutlicht. Am stärksten tritt der Unterschied jedoch bei der Gestalt Christi hervor, der bei Massys größtenteils durch den Ärmel Marias verdeckt ist, doch als ausgemergelter Leichnam erkennbar bleibt, dagegen bei Key als anatomisch durchgestalteter muskulöser und idealisierter Körper erscheint, der bis zu den Knien dargestellt ist. An diesem Detail ist die Absicht Keys, die aemulatio, deutlich erkennbar. Statt eine bloße Kopie zu verfertigen, versucht er nach italienischen und antiken Vorbildern, das ältere Werk

77 Öl auf Holz, $63 \times 62,1 \mathrm{~cm}$, National Gallery, London, Inv.-Nr. NG1078. Vgl. SILVER 1984, S. 229.

78 Dieser Prozess vollzog sich vor dem Hintergrund der besonders in Antwerpen entwickelten Praxis des Kopierens und Teilkopierens von Kompositionen und Prototypen. Friedländer hatte diese Vorgehen als innovationslos gewertet und am Beispiel von Keys Beweinung, zu dem Schluss geführt, Key habe ein unfertiges Werk Quentin Massys zur Vollendung gebracht (vgl. FRIEDLÄNDER 1929, S. 254-256). Der Trugschluss war auf der stilistischen Nähe zu der Beweinung Massys (oben im Text) gegründet. durch seinen gesteigerten Naturalismus und die Gestaltung einer idealschönen Aktfigur zu übertreffen. Ein sich stetig entwickelndes ,Stilbewusstsein'spätestens seit dem Beginn des 16. Jahrhunderts, das sich im Zusammenhang mit der Rezeption der italienischen Kunst ausprägte, soll dieser Arbeit daher als Grundthese vorangestellt werden.

\subsection{Der ,spätgotische Manierismus ‘ als stilgeschichtliches Scharnier}

Mit den sogenannten ,Antwerpener Manieristen' ist die vierte und letzte Generation gemeint, die der spätgotischen Kunst in den wirtschaftlichen Zentren der südlichen Niederlande - vorrangig in der noch vergleichsweise jungen Wirtschaftsmetropole an der Schelde, Antwerpen - zu ihrer vermeintlich letzten Blüte verhilft. ${ }^{79}$ Zugleich bricht diese Malerei mit dem Realismus der Darstellung, während sie die feinmalerische Akkuratesse, mit welcher die niederländische Malerei über ein Jahrhundert vorbildhafte Geltung erlangt hatte, beibehält. Einer dieser vielfach unbekannten Maler, der nach seinem einzigen

Die Seitenwunde Christi, die ihm der Legende nach von Longinus zugefügt wurde, ist bei zwei weiteren bekannten Versionen des Themas von Key nicht dargestellt. Überhaupt ist das Weglassen ,apokrypher' Überlieferungen, die Eingang in das ,decorum' gefunden hatten, eine Besonderheit des calvinistischen Malers Adriaen Thomasz Key (s. hierzu JONCKHEERE 2007, passim; FREEDBERG 1971, S. 229-245; FREEDBERG 1982, S. 133-153.

79 Vgl. VAN DEN BRINK - MARTENS 2005, S. 7. 
heute erhaltenen Werk den Notnamen ,Meister der Antwerpener Anbetung' erhielt, mag stellvertretend einen Eindruck vom Stil dieser kurzen Phase der niederländischen Kunst geben [ABB. 11]. ${ }^{80}$

FRIEDLÄNDER hat die Schaffenszeit dieses Malers vergleichsweise spät, nämlich um 1520, angesetzt, als die Hochphase der sogenannten Antwerpener Manieristen bereits zu Ende war. ${ }^{81}$ Die hellen Farben und deren vergleichsweise buntfarbige, in sich wenig abgestufte Palette, die kurz nach 1500 auftritt, ist vor allem durch den Einfluss des in Brügge tätigen Gerard David zu erklären. Die Taufe Christi von 1502-1508 zeigt beispielsweise eine ähnliche Farbigkeit. Die Auffassung des Landschaftsraumes, die durch stufenweises Verblauen erreichte Tiefenwirkung und die Beschaffenheit der Vegetation, vor allem der Bäume, erlauben es, eine vorbildhafte Rolle Davids für den Meister der Antwerpener Anbetung zu konstatieren. Die Gräser im Vordergrund etwa bezeugen die Verwandtschaft beider Bilder, die aus der langen Tradition des altniederländischen Naturalismus erwachsen sind. Ferner kann die ruinenhafte Architektur, die fein ausgearbeitete Stadien des Verfalls erkennen lässt, in dieser ungebrochenen Tradition verstanden werden. Der Bruch, der die

80 Öl auf Holz, 32,2 × 23,8 cm, zwischen 1500 und 1520 entstanden (s. FRIEDLÄNDER 1915, S. 65-91); Koninklijk Museum voor Schone Kunsten Antwerpen, Inv./Kat.-Nr. 208, 209 u. 210 (s. VAN DEN BRINK - MARTENS 2005, Nr. 68, S. 162-165). Interessant ist auch eine Tafel mit der Darstellung des Letzten Abendmahles, das diesem Maler zugewiesen wird. Die Komposition steht in der Tradition italienischer Vorbilder, etwa dem Letzten Abendmabl Leonardos, was die drei Fenster mit Landschaftsausblick betrifft, besondere Zuordnung zu den Antwerpener Manieristen begründet, ist in der Auffassung der Figuren, ihrer Anordnung im Bildraum sowie der Körperauffassung zu sehen. Anders als die Figuren Davids, die, dem Vorbild Rogier van der Weydens folgend, in ruhiger Haltung und mit gemessenen Bewegungsmotiven dargestellt sind, weisen die Figuren auf der Antwerpener Anbetung einen hohen Grad von Exaltation auf, der nicht allein inhaltlich, durch die Begegnung mit dem Heiland, zu erklären ist. Das Gebaren der Könige, etwa die Handgeste des vor Maria und dem Christusknaben knieenden oder aber der tänzelnde Kontrapost des in einen grünen Mantel gehüllten Königs zur Rechten Marias, sind Beispiele für eine überbetonte Affektation, die im Gegensatz zu dem Habitus der Figuren Davids und der Maler des 15. Jahrhunderts steht. Ein weiteres Merkmal mit hohem Wiedererkennungswert stellen die im Wind wehenden Stoffe dar, wie etwa das weiße Tuch am Hals Marias und eine am Kleid der höfisch reich gekleideten Nothelferin Margaretha, die auf dem rechten Flügel beschirmend ihre Hand in Richtung des vor ihr knieenden Stifters ausstreckt. Abstehende Stoffe finden sich auch zuvor schon vielfacht dargestellt, näm-

andrerseits greift es durch die Verwendung antikischer Pfeiler, die den Hintergrund gliedern, entsprechende Darstellungen dieses Sujets von Pieter und Frans d. J. Pourbus vorweg (Privatbesitz, Deutschland; von FrIEDLÄNDER nicht aufgenommen, aber durch eine Fotonotiz zunächst Bernard van Orley zugewiesen, s. RKD (https://rkd.nl/nl/explore/images/36049) [28.05.2019]). Trotz der stilistischen Zuweisung deutet das Bild auf eine vergleichsweise komplexe Rezeption hin.

81 Vgl. hierzu FrIEDLÄNDER 1915, S. 65. 
lich beim Lendentuch Christi am Kreuz; dieses traditionelle Motiv wird nun aber in noch gesteigerter Form verwendet. Die Figur selbst wirkt mit ihrem langen Hals und den abfallenden Schultern anatomisch deformiert. Die um den Brustharnisch gebundene Schärpe des Hl. Georg auf der linken Seitentafel wird bei dessen Angriff auf den Drachen ähnlich wie Marias Tuch stark durch die Luft gewirbelt. Die Kleidung der Figuren wirkt teilweise exotisch und ähnelt darin frühen Werken Bernard van Orleys, wie unter anderem an die Tafel mit Stationen aus den Viten der Hll. Thomas und Matthias. $^{82}$

In seinem Schilder-Boeck von 1604 bezeichnet Karel van Mander knapp ein Jahrhundert später die Werke Quentin Massys als Ausgangspunkt der Antwerpener Malerschule. Der von van Mander hauptsächlich mit deren Anfängen assoziierte Massys wird hier, obschon er tatsächlich nur einer von mehreren ,antikisch" und von der italienischen Renaissance beeinflussten Malern war, bei wenigen biographischen Informationen, die van Mander vorgelegen haben mögen, literarisch stark stilisiert und überhöht; ursprünglich im Goldschmiedehandwerk tätig, soll er aus Liebe zu seiner Geliebten den Hammer zur Seite gelegt haben, um den Pinsel zu nehmen, mit welchem er sie fortan zu erfreuen suchte. ${ }^{83}$ Tatsächlich gab es zu Beginn des 16. Jahrhunderts

82 s. hierfür Abschn. 2.3. in dieser Arbeit.

83 Massys wird mit Vulkan verglichen, der auf die Bitte seiner Geliebten eingeht, um vom Schmiedehandwerk zu Malerei zu wechseln. Der Text der Panegyrik folgt dem lateinischen Text von Lampsonius (vgl. van Mander 1604, fol. 215v). Vgl. auch Miedema 1994, Bd. 3, S. 41 f. Für die lateinische Fassung s. ebd., S. 42, Anm. 41. nichts, was dem Namen ,Antwerpener Malerschule entsprechen würde, ganz anders als in Brügge oder Brüssel, wo die lokale Tradition der Primitifs flamands den Stil junger Maler in dieser Zeit noch weitaus stärker geprägt zu haben scheint. ${ }^{84}$ Diese Prägung gilt letztlich aber auch für den Antwerpener Maler Quentin Massys. Dieser stammte aus Löwen, wo er in der lokalen Tradition von Dierik Bouts ausgebildet wurde. Anders als bei Gossaert fällt der Einfluss der italienischen Form bei Massys eher gering aus. Stattdessen zeichnet sich seine Malerei durch einen hohen Grad von Naturalismus aus und steht damit der lokalen Tradition näher. Ähnlich wie Gerard David in Brügge rezipierte er um 1510 hauptsächlich altniederländsche Vorbilder, wie im Falle des Altarretabels für die Gilde der Zimmerleute mit einer zentralen Beweinung Christi [ABB. 12], ${ }^{85}$ die sich motivisch und auch stilistisch an dem berühmten Vorbild der Kreuzabnahme Christi von Rogier van der Weyden orientiert. Deutlich wird dies an dem wagerecht und frontal präsentierten Leichnam, während die klagende Maria und die übrigen Figuren hinter dem auf ein Leichentuch gelegten Christus stehen. Der bühnenartige Aufbau und die szenische Gestaltung folgen diesem Vorbild, wie auch der Figurenstil hier seinen Ursprung hat. Allgemein zeichnet dieses und andere Werke ein hohes Maß an Detailliertheit aus. Auch wirken die Farben, die Oberfläche der Stoffe

84 Vgl. MARTENs 1998, S. 43.

85 Öl auf Holz, $260 \times 503 \mathrm{~cm}$, Koninklijk Museum voor Schone Kunsten, Antwerpen; Inv.Nr. 245-249 (s. Kat. KMSKA 1988, S. 248 f.; FRIEDLÄNDER 1967-1976, Bd. VII, Nr. 1; SILVER 1984, S. 204 f., Nr. 11). 
oder auch das Feuer unter dem Kessel auf dem rechten Seitenflügel vergleichsweise wirklichkeitsgetreu. Gegenüber der tendenziell idealisierten Darstellung in der italienischen Hochrenaissance ist es eine Eigenart Massys, die altniederländische Tradition durch eine weitere Steigerung des Naturalismus, namentlich der Stofflichkeitsillusion, und des Realismus fortzuführen. Es zeigen sich stilistisch $\mathrm{Pa}$ rallelen zu Hugo van der Goes, nicht zuletzt im Hinblick auf die feinmalerische Qualität der Oberflächen, vor allem aber beim ähnlich plastisch ausgearbeiteten Figurenstil und der ,Schwere' der Figuren. Die ausgesprochene Individualität seiner Figuren steht in gewisser Hinsicht im Gegensatz zur weiteren Entwicklung der Antwerpener Malerei. Anstatt als Stammvater für die Antwerpener Malerschule mag Massys in seinem unmittelbaren lokalen Kontext eher als letzter Vertreter der älteren Tradition gelten. Der Ausgangspunkt für die weitere Entwicklung waren Romanisten wie Jan Gossaert, Bernard van Orley oder Joos van Cleve, sodass das Künstlerlob Karel van Manders besser auf Massys Stellenwert in der Gesamtentwicklung des 16. Jahrhunderts bezogen wird als auf die unmittelbar auf ihn folgende Malergeneration der sogenannten Antwerpener Manieristen.

Das Phänomen einer angeblich allmählich einsetzenden ,Abstumpfung ‘ durch generationsübergreifende Nachahmung, wie sie Jan ROMEIN für die älteren Kunstzentren

86 Vgl. Romein 1935, S. 752-777.

87 Vgl. JONCKHEERE 2012, S. 9.

88 Vgl. VAN DEN BRINK - MARTENS 2005, S. 6 f.
Flanderns beschrieben hat, kann auf Antwerpen kaum angewendet werden, wie insbesondere das Beispiel Quentin Massys zeigt. ${ }^{86}$ Stattdessen mag gerade die angebliche Abwesenheit einer lokalen Tradition - vorsichtiger formuliert, das Fehlen einer besonders stark prononcierten Tradition im direkten Vergleich etwa mit Brügge - die Herausbildung des Antwerpener Manierismus begünstigt haben; gewissermaßen als Zeugnis einer Spezialisierung, die versucht, mit ihren gestalterischen Mitteln Aufsehen zu erregen. ${ }^{87}$ Nicht ohne Grund entwickelte sich der Antwerpener Kunstmarkt zu Beginn des 16. Jahrhunderts zum größten nördlich der Alpen, für den erstmals in erheblichem Umfang Kunstwerke, sowohl aus dem Bereich der Malerei wie auch dem der Bildschnitzerei, seriell und ohne Auftrag geschaffen wurden. ${ }^{88}$

An eine Beeinflussung der Antwerpener Manieristen durch Quentin Massys ist folgerichtig nur bedingt zu denken, während sie für Jan Gossaert oder Bernard van Orley anzunehmen ist, wie bereits die Untersuchungen FRIEDLÄNDERS zu Beginn des 20. Jahrhunderts aufzeigen konnten. ${ }^{89}$ Auch die Werkstätten Pieter Coecke van Aelst und Joos van Cleve haben zu Beginn des Jahrhunderts maßgeblichen Einfluss auf die Manieristen. ${ }^{90}$ Diese kurze und so plötzlich, wie sie aufzukommen scheint, bereits wieder verschwindende Erscheinung in der niederländischen Malerei kann schon allein deshalb keine Sackgasse gewesen sein, weil diese zahlenmäßig

89 Vgl. Silver 1984, S. 1-6. Für Jan Gossaert s. im Einzelnen FRIEDLÄNDER 1930 [Bd. 8], S. 9-68 und für Bernard van Orley ebd., S. 78-136.

90 s. hierzu JONCKHEERE 2012, S. 9. 
große Gruppe von namentlich größtenteils nicht mehr fassbaren Malern nicht vom Erdboden verschwunden ist, als die ,Manier' selbst bereits abgeebbt war. Stattdessen ist von einer Weiterentwicklung dieser Künstler auszugehen, deren Stil für ihre Zeitgenossen avantgardistische Züge aufgewiesen haben dürfte und dem deshalb in der künstlerisch und ökonomisch aufblühenden Metropole zu Beginn eines von Innovation und Aufbruch geprägten Zeitalters eine Scharnierfunktion zugesprochen werden kann. ${ }^{91}$

Noch bis in die 1490er Jahre, also nur eineinhalb Jahrzehnte vor dem Erscheinen von Gossaert und Massys in Antwerpen, war es hingegen üblich, für anspruchsvolle Aufträge Maler aus den traditionsreichen Zentren der flämischen Malerei, wie etwa Brüssel oder Brügge, zu beauftragen. 1493 wurde beispielsweise noch der Brüsseler Meister Colijn de Coter, dessen Stil stark an das Vorbild von Jan van Eyck und Rogier van der Weyden anknüpft, ${ }^{92}$ von der Antwerpener Lukasgilde angeworben, um das Gewölbe ihrer Kapelle auszumalen. ${ }^{93}$ Im 15. Jahrhundert hatten sich durch wirtschaftlich günstige Bedingungen in

91 Vgl. BORN 2005, S. 17.

92 Vgl. PÉRIER-D'IETEREN 1985.

93 Vgl. HuVENNE - GREVENSTEIN 2005, S. 5.

94 Brügge galt noch bis weit in das 16. Jh. als humanistische Idealstadt, die mitunter als „Athen des Nordens" verklärt wurde (s. HuvEnNE 1998, S. 22). Noch 1527 verfasste Adrianus Barlandus ein Lobgedicht auf die Stadt: „Pulchra sunt oppida Gandavum, Antverpia, Bruxella, Lovanum, Mechlina, sed nihil ad Bruges“ (BONNEURE 1984, S. 29). Und selbst 1583 drückt die Beischrift eines von Frans Pourbus geschaffenen Gemäldes des Brügger Bürgers Jacob van der Gheenste, das Selbstverständnis der Stadt aus: „Hoe schoone bepeerelt / Gheen ste[de] te weerelt" (So schön bestellt / Keine den niederländischen Städten mit Hafenanbindung enge Handelsbeziehungen entwickelt. Hervorzuheben sind hier Städte wie Brügge, Gent, Brüssel und Löwen, welche zunächst die wesentlichen Triebkräfte dieser beschleunigten Entwicklung waren. Das Zentrum der altniederländischen Malerei war bis dahin Brügge. ${ }^{94}$ Im Jahr 1488 begann der allmähliche Niedergang, als Kaiser Maximilian I. der Stadt ihre Handelsprivilegien entzog. Dieser Umstand gilt als Antwort des habsburgischen Souveräns auf einen Aufstand des sich proportional zu seinem stetigen pekuniären Aufstieg auch politisch emanzipierenden Stadtbürgertums. Hinzu kam der wahrscheinlich noch wichtigere Punkt, dass Brügge seit dem späten 16. Jahrhundert zunehmend unter einer wirtschaftlichen Depression zu leiden hatte, die vor allem mit der fortschreitenden Versandung des Hafens zusammenhing. ${ }^{95}$ Der Stadtrat versuchte, diesem Problem unter anderem durch die Anlage eines neuen Hafens, dem Nieuw Ghedelf, entgegenzuwirken. ${ }^{96}$

Der unaufhaltsame Niedergang der alten Metropole war eine der wesentlichen Voraussetzungen für den Aufstieg eines neuen

Stadt der Welt) heißt es in diesem Vers, der aus der Feder eines unbekannten Rederijkers stammt. Das Ideal dieser Stadt sei durch Kunst und Arbeit (,met konste en arbeydt") durch den Einsatz ihrer Bewohner geschaffen worden (s. HuvenNe 1998, S. 22 u. für kompletten Wortlaut MARTENS-KAT. 1998, Kat. 112). Guicciardini erwähnt ähnliches in seiner Beschreibung von 1567 (s. hierzu Huvenne 1998, Anm. 5, nach Guicciardini 1567, übers. von Kilianus (1612). Zur kulturellen Blüte Brügges im 15. Jh. und zur Entwicklung bis zum Ende des 16. Jhs. s. GEIRNAERT - VANDAMME 1998, S. 33-42.

95 Vgl. BLOCKMANS 1998, S. 27 f.

96 Für die wirtschaftliche Entwicklung bis zur Mitte des 16. Jhs. s. BloCKMANs 1998, S. 28-30. 
Zentrums für den Überseehandel, Antwerpens. Seit 1500 erlebte diese Stadt einen groBen ökonomischen Aufschwung und lief den anderen Zentren in der Folge allmählich ihren wirtschaftlichen Rang ab. ${ }^{97}$ Auch Maler, die zuvor nur vorübergehend für Auftragsarbeiten in die Stadt gekommen waren, zog es nun dauerhaft dorthin. Sie siedelten sich in der aufstrebenden Stadt an und gründeten dort neue Werkstätten. ${ }^{98}$ Mit den Vorzügen des freien Handels und des wirtschaftlichen Wachstums ging auch das einher, was die ältere Forschung oftmals abwertend mit den Begriffen des ,Merkantilen` oder ,Frühkapitalistischen` bezeichnet hat. Die Antwerpener Kunstproduktion zeichnete sich, im Gegensatz zu den älteren Standorten, tatsächlich dadurch aus, dass sie von Anfang an ihren Schwerpunkt von Auftragsarbeiten auf eine gleichsam serielle Produktion verlagerte. Die aus dieser auf eigenes wirtschaftliches Risiko hin betriebenen Vorratsproduktion hervorgegangenen Kunstwerke wurden auf dem städtischen Markt als

97 s. WATERSHOOT 1995, S. 15-21 u. Kat. Antwerpen 1973-1975, S. $11 \mathrm{f}$.

98 Vgl. MARTENS 1998, S. $54 \mathrm{f}$.

99 Vgl. VAN DEN BRINK - MARTENs 2005, S. 6 f.

100 Vgl. Huvenne - Grevenstein 2005, S. 5. Antwerpener Retabel sind in ganz Westeuropa verbreitet und auch die Anzahl von erhaltenen Werken, die sich insbesondere dem Umfeld der Antwerpener Manieristen zuordnen lassen, ist beträchtlich. Dennoch gilt es zu bedenken, dass in Folge der Bilderstürme in der zweiten Hälfte des 16. Jhs. ganze Landstriche ihrer Kirchenausstattungen beraubt und auch noch bis ins 19. Jh., in Folge der aufklärerischen ,Purifikation“ protestantischer Kirchen, mittelalterliche Objekte entfernt wurden. Dabei wurden mutmaßlich auch unzählige Werke aus Antwerpen zerstört, sodass sich heute große Lücken ergeben, besonders in den vornehmlich calvinistisch und damit traditionell dem religiösen Bild gegenüber eher
Schauware angeboten und oftmals an ausländische bzw. kurzfristig in der Stadt weilende Händler verkauft. ${ }^{99}$ Bei vielen der heute in ganz Europa anzutreffenden Antwerpener Retabel handelt es sich um solche nach Mustern geschaffene Objekte aus Vorratsproduktion, an denen gelegentlich noch Änderungen entsprechend den Wünschen der Käufer vorgenommen wurden. ${ }^{100}$ Hier ist der eigentliche Beginn der Antwerpener Malerei zu sehen, die sich in der Folge stilistisch augenfällig von den Charakteristika der altniederländischen Malerei unterscheiden sollte.

\section{Exkurs: Zum Begriff der sogenannten ,Antwerpener Manieristen`}

Der Begriff des ,Antwerpener Manierismus' stammt von FRIEDLÄNDER, der ihn wesentlich in einer qualitativen Weise verwendete, was eine Revision dieses Begriffs meines Erachtens notwendig macht. ${ }^{101}$ FRIEDLÄNDER

feindlich beeinflussten nördlichen Niederlanden (s. hierzu HOFFMANN 1998, S. 120).

101 Für die Begriffswahl FrIEDLÄNDERS ist dessen eigenes Selbstverständnis als Connaisseur wichtig. Darin spiegelt sich möglicherweise eine Reaktion auf die Kunsttheorien seiner Zeit, die durch Riegl und Wölfflin geprägt waren. FRIEDLÄNDER sah in seiner kennerschaftlichen Stilkritik eine Sichtbarmachung des kreativen Aktes mit ,rein ästhetischen Begriffen“, „,welcher dem Objekt seine physische Form gegeben habe“. Stil und Manier beschrieb er in einem antithetischen Verhältnis zueinander; während er den Stil dem schöpferischen Genius zuschrieb, beschrieb er die Manier hinsichtlich ihrer Schwächen mit dogmatischen Äußerungen wie „Manner is style put in cold storage, the style of a tired, senile creator" (FRIEDLÄNDER 1974, S. 11) oder ,the relation of virtuoso to artist is that of manner to style“" (FRIEDLÄNDER 1944, S. 138). 
subsumierte unter den Antwerpener Manieristen solche Künstler, deren Namen größtenteils nicht bekannt waren und deren Werke in dem Zeitraum von etwa 1505 bis 1530 entstanden. Kennzeichnend für diese Künstler sind die teilweise unnatürlich gebildeten Figuren, deren affektbetontes Gebaren, helle wenig abgestufte Farben, phantastische Architekturen mit eigentümlich dekorativ gebrauchten Zitaten aus dem Bereich antikisierender Bauformen und italienischer Renaissanceornamentik. ${ }^{102}$ Die relativ geringe Bedeutung, die er dieser Gruppe von Malern beimaß, führte dazu, dass diese Epoche südniederländischer Malerei nur stiefmütterlich behandelt wurde. Erst die Archivstudien von Dan Ewing, Stephen Goddard, Maximilian P. J. Martens sowie Godehard Hoffmann und anderen haben Licht in das Dunkel gebracht, indem nunmehr Namen mit bestimmten Werken in Verbindung gebracht werden können. ${ }^{103}$

Den Ausgangspunkt für FRIEDLÄNDER bildeten die fälschlich einem Henricus Blesius (Pseudo-Bles) zugeordneten Gemälde, die hauptsächlich die Anbetung der Könige zeigen. Hierfür verantwortlich war eine Signatur auf einem Münchner Gemälde, die sich erst sehr viel später bei einer technischen Untersuchung als Fälschung erwies. ${ }^{104}$ FrIEDLÄNDER unterschied deshalb zwischen zwei Gruppen, der des Pseudo-Bles und der seiner Nachfolger. Um die jeweiligen Hauptwerke wurden

102 s. ,Meister der Antwerpener Anbetung ${ }^{6}$ und ,Meister von 1518' unter Abschn. 2.2.

103 Vgl. HUVENNE - GREVENSTEIN 2005, S. 5.

104 Vgl. BORN 2005, S. 10.

105 Vgl. ebd., S. 14.

106 s. hierzu BORN 2005, S. 11. fünf weitere Gruppen gebildet, denen FRIEDLÄNDER jeweils einen Künstler als prägende Persönlichkeit zuwies. ${ }^{105}$ Bemerkenswert ist immerhin, dass er die Malerei des Antwerpener Manierismus als eigenständige Phase zwischen der ,Internationalen Gotik' und der ,Renaissance' des späteren 16. Jahrhunderts ansah. Dabei verwies er auch auf Parallelen zwischen der Entwicklung in den Niederlanden und in Deutschland; so sah er vergleichbare Tendenzen bei dem in dieser Zeit noch jungen Lucas Cranach d. Ä. und Albrecht Altdorfer, aber auch bei Dürer. Hierauf gründet sich im Wesentlichen seine Prägung eines eigenständigen stilgeschichtlichen Terminus. Auch mag es sich dabei um eine Reflektion der in der zeitgenössischen Forschung spürbaren Tendenz handeln, den italienischen Manierismus von der Renaissancekunst und dem gegenreformatorischen Barock abzugrenzen. ${ }^{106}$ Heute erscheint es sinnvoll, den bei FRIEDLÄNDER vor allem im Hinblick auf die Händescheidung stilkritisch gebrauchten Begriff des Antwerpener Manierismus viel allgemeiner denn nur als ein um 1500 auftretendes, ästhetisches Phänomen` zu beurteilen. ${ }^{107}$ Es müsste stärker noch als bisher aufgezeigt werden, dass die Tendenz zu einer gesteigerten Dynamik, insbesondere zu stark affektierten Gesten, einer größeren Detailfülle, reinen Farben und der Aufnahme reicherer Renaissanceformen und -architekturen, ein übergreifendes, unterschiedlich stark hervortretendes Merkmal der Malerei nach

107 Dem gegenüber ist der Begriff der ,Manier` bei Friedländer kunsttheoretisch begründet und deshalb als Bezeichnung für eine lose zusammenhängende Gruppe von mehr oder weniger ähnlichen Malern kritisch zu bewerten (vgl. FRIEDLÄNDER 1944, S. 138). 
1500 in Flandern darstellt. ${ }^{108}$ Vergleichbare Tendenzen lassen sich so etwa auch für den in Brügge tätigen Lehrer von Pieter Pourbus, Lancelot Blondeel beobachten [ABB. 13], so etwa auf dessen Bild des Hl. Georg, das vergleichsweise spät, zwischen 1535 und 1540, datiert wird. ${ }^{109}$ Die wehenden Stoffe und die anatomisch nicht korrekt, sondern effektvoll gebildeten Körper ergeben deutliche Übereinstimmungen mit der Kunst der Antwerpener Manieristen.

Den Begriff der ,Manier' verwendet FRIEDLÄNDER antithetisch zu ,Stil', um damit das Fehlen von Originalität zum Ausdruck zu bringen. ${ }^{110}$ Für ihn war das Kunstwerk die „Frucht einer spontanen Schöpfung, die aus einer bewussten Anstrengung“ hervorgegangen sei. ${ }^{111}$ Die geringe Vielfalt der Themen und Bildmotive bei den sogenannten Antwer-

108 Wesentliche Inspiration erhielten die Manieristen aus dem Frühwerk Jan Gossaerts, der um 1510 mit seinen Architekturen Aufsehen erregte. Eine Inschrift in einer der Miniaturen des Breviarum Grimani (Biblioteca Nazionale Marciana, Venedig) zeigt den Namen des Künstlers: „COSART“. Dieses sonderbar anmutende Detail ist nicht als Kennzeichnung der Autorenschaft misszuverstehen, sondern vielmehr als Ehrenbekundung gegenüber Gossaert, dessen Werke dem Miniaturisten augenscheinlich als Vorbild gedient haben. Die Miniatur mit der Heiligen Katharina, die mit den Philosophen disputiert, zeigt in Vorder- und Mittelgrund phantastische Renaissancearchitekturen (vgl. AINSWORTH 2010, S. 14 f.). Vergleichbare Bauwerke sind u. a. auch in Gossaerts Heiliger Familie von 15071508 (Getty Museum, Los Angeles) zu sehen.

109 Öl auf Holz, $127 \times 197$ cm, Groeningemuseum, Brügge, Inv.-Nr. 0000.GRO0215.I. Vgl. DUVERGER - ROOBAERT 1960, S. 95-105. Für Lancelot Blondeel s. MARTENS 1998, S. 45.

110 s. Anm. 100. pener Manieristen ist womöglich die Hauptursache für den pejorativen Begriff der Manier bei FRIEDLÄNDER. Er sollte den Mangel an Originalität beschreiben, ließ aber die vielfach nur lückenhafte materielle Überlieferung dabei fast vollständig außer Acht. FRIEDLÄNDER konstatierte stattdessen eine gleichsam inzestuöse Verflechtung unter den Malern, die eine Verwendung des Terminus, Stil' für ihn unmöglich machte. Einige Jahrzehnte nach FRIEDLÄNDER beschrieb VAN PUYVELDE die Antwerpener Manieristen, als ,able painters but without stature“, welche zu einer „bombastic rhetoric" neigen, dabei aber das gewisse Etwas, mit seinen Worten das „,restaint vital to an authentic work of art", fehlen würde. ${ }^{112}$ Die Meinung FrIEDLÄNDERS, es habe den Antwerpener Manieristen vor allem an Origi-

111 „Genuine creation is a blend of visual experience and emotion that is materialised in the work" (zit. bei BORN 2005, S. 11). Kunst, die keine Erneuerung in ihrer Entwicklung aufweise, sondern stattdessen eine Rückkehr zu eigenen Wurzeln oder nur noch durch die Werke anderer Künstler inspiriert ist, sei als Manier anzusehen. BORN weist darauf hin, dass FRIEDLÄNDERS Definition den Kunsttheorien der Renaissance, namentlich denen von Cennini, Alberti und Leonardo da Vinci ähneln würde (s. BORN 2005, Anm. 26). Für FRIEDLÄNDER ist in Kunstwerk die Frucht einer spontanen Schöpfung, andernfalls, wenn es sich stattdessen nur um eine vorsätzliche Anstrengung handle, sei es nur eine Art Replik. Er folgt auch hier einer älteren Theorie, nämlich einer Betrachtung Goethes zur Kunst (Goethe, J. W. von: „Einfache Nachahmung der Natur, Manier, Stil“", in: „Der Teutsche Merkur (Feb. 1789), A. G. XIIII, S. 66-71).

112 VAN PuYvelde 1960, S. 63. Auch hier ist die theoretische Definition Friedländers maßgebend. 
nalität gefehlt, wird damit nochmals bekräftigt. $^{113}$

FRIEDLÄNDER verband den Beginn des Antwerpener Manierismus mit dem Erscheinen von Jan Gossaert als dessen mutmaßlichem Begründer und Jan van Leyen, der von FrIEDLÄNDER mit Jan Wellens de Cock identifiziert wurde, in Antwerpen. ${ }^{114} 1504$ trat schließlich Jan de Beer in Antwerpen auf und wurde als Freimeister in den Liggeren der St. Lukas-Gilde geführt. Laut FRIEDLÄNDER war auch er eine Art Vorbild innerhalb der Gruppe. 1508 folgte Adriaen van Overbeck als ,manieristisch' malender Freimeister in Antwerpen. Zur selben Zeit sind dort auch andere Künstler nachweisbar: Seit 1483 Hendrick van Wueluwe (mutmaßlicher Meister von Frankfurt), der schon bei van Mander hervorgehobene Quentin Massys seit 1491 und Joos van Cleve, der wiederum 1511 erstmals quellenmäßig belegt ist. FRIEDLÄNDER erkannte, dass das Frühwerk Jan Gossaerts stilistisch dem nahestand, was er als den ,Antwerpener Manierismus ${ }^{6}$ bezeichnete. ${ }^{115}$ Das Tafelbild Christus

$113 \mathrm{Zu}$ einem ähnlichen Schluss kommt auch Paul VANDENBROECK: „Late Gothic Mannerism in Antwerp. On the Significance of a ,Contrived' Style", in: Jaarboek Koninklijk Museum voor Schoone Kunsten Antwerpen (2004-2005), S. 301-329.

114 Vgl. FRIEDLÄNDER 1918, S. 67-74, für Gossaerts Erscheinen in Antwerpen s. ROMBOUTS - LERIUS 1872-1876, BD. 1, S. 58.

115 Genannt seien hier vor allem die Zeichnung Kaiser Augustus und die Tiburtinische Sibylle aus Berlin (FRIEDLÄNDER 1937 [14], S. 111; BORN 2005, Kat. Nr. 10 [Konowitz], S. 41 f.), die Mystische Hochzeit der Hl. Katharina (BORN 2005, Kat. 10, S. 42, Abb. I) und das Lissaboner Triptychon mit der Heiligen Familie mit musizierenden Engeln im Haus des Pharisäers Simon [ABB. 14], das seit FRIEDLÄNDER dem sogenannten Meister von 1518 zugerechnet wird, zeigt auf der Mitteltafel Architekturen, wie sie tatsächlich ohne das Vorbild Gossaerts oder Bernard van Orleys nichts zu denken sind. Vergleicht man die den Hintergrund dominierende Treppenarchitektur mit den Tempelbauten bei van Orleys Löwener Madonna von 1517, ${ }^{116}$ ist eine ähnliche Funktion der Architektur zu beobachten [ABB. 5]. In beiden Fällen hinterfangen die aus verschiedenen Teilen zusammengesetzten, stark symmetrischen Bauten die Szenerie im Vordergrund und haben hierdurch einen ähnlichen Effekt wie architektonische Baldachine aus der Bildschnitzerei, ähneln in funktionaler Hinsicht zugleich aber auch Ehrentüchern eine Wirkung, die durch das Ehrentuch aus tiefblauem Brokatstoff hinter der Figur des Christus beim Meister von 1518 nochmals verstärkt wirkt.

und den Hll. Katharina und Barbara (FRIEDLÄNDER 1930 [8], S. 29-31; BORN 2005, Kat. 14 [Hendrikman], S.48-50); vgl. ebd., S. 12.

Auch Boon 1965 kommt zu dem Schluss, dass Gossaert selbst in der Manier des ersten Viertels des 16. Jhs. ,großgeworden' sei, bevor er sich von der großen Anzahl der Nachahmer ab- und einer neuen Stufe der Entwicklung seines romanistischen Stils zuwandte (Vgl. BOON 1965, S. 17 f.)

116 Öl auf Holz, $45 \times 39 \mathrm{~cm}$, Prado, Madrid, Inv.Nr. P001536. Die stilistische Zuweisung zum Cuvre Bernard van Orley stammt von Friedländer (FRIEDLÄNDER 1972, S. 60 f.), während es im 16. Jh. als Werk Jan Gossaerts in den Besitz Philipps II. gelangt ist. Für einen jüngeren Beitrag zur Diskussion um die Zuweisung s. HERIGUEZ 2013, S. 131-141. 
So lässt sich konstatieren, dass FRIEDLÄNDER den Begriff des ,Antwerpener Manierismus' im Wesentlichen stilkritisch verwendete, indem er damit vor allem Eigentümlichkeiten in der Beschaffenheit der länglichen und gedrehten Figuren bezeichnet, um damit deren Andersartigkeit gegenüber denen der altniederländischen Tradition, wie sie etwa zeitgleich zu den Entwicklungen in Antwerpen kurz nach 1500 noch von Gerard David fortgesetzt wurde, herauszustellen. Größter Kritiker an FRIEDLÄNDERS Begriffsfindung war Ludwig BALDASS, der 1937 erklärte: „Die niederländischen Maler, von denen hier die Rede ist, sind nicht Manieristen, sondern ihrem Wesen nach Spätgotiker ${ }^{\text {“c }}{ }^{117}$ Für ihn stand der Begriff für die Entwicklung der Kunst in Italien nach dem Tod Raffaels, die eine Reaktion auf die Ideale der Hochrenaissance darstellt und für die beispielsweise in Florenz Jacopo da Pontormo und Rosso Fiorentino zu nennen sind, während sich in den Niederlanden um 1515 die letzte Stufe der Entwicklung der ,spätgotischen' Kunst abzeichnen würde. BALDASs begründet dies damit, dass ,,alle Elemente ihres Stiles [...] noch auf die große Kunst des 15. Jahrhunderts zurück“" gehen würden. Weiter: „Die Strömung läßt sich weit über das Jahr 1500 zurückverfolgen, und wir sehen, wie sie hier und dort im letzten Drittel des 15. Jahrhunderts auftaucht und sich vor allem überall in einen bewussten Gegensatz stellt zur klassisch ausgeglichenen Kunst des Roger van der Weyden. “118 Für BALDASS war der in dieser Malerei der Manieristen zu beobachtende ,spätgotische Stil' eine eigenständige Ausprägung innerhalb des Idioms der gotischen Kunst, welcher die Fortführung der Tradition mit einer Suche nach zeitgenössischer Modifikation vereint, was sich mitunter in überschwänglichem Formenreichtum zeige, welcher zur Spätgotik hin weiter gesteigert worden sei, bis er die gotische Form hinter sich zurück gelassen habe, um sich dem Renaissanceornament zu öffnen - ohne dabei jedoch seine formale und inhaltliche Herkunft aus dem 15. Jahrhundert zu verleugnen. Die Kunst der ersten Hälfte des 16. Jahrhunderts stelle, so BALDASS, die letzte Phase dieser Entwicklung dar. Es zeige sich nämlich ein letztes Aufbäumen, das darin gipfele, dass der bis dahin für die altniederländische Malerei so charakteristische Realismus zum Teil verworfen worden sei. Die frühen Werke der Flamen Jan Gossaert, Bernard van Orley, Jan de Beer, Jan de Cock sowie Jacob Cornelisz. van Oostsanen aus Amsterdam und Cornelis Engebrechtsen aus Leiden bezeichnen diese Entwicklung seiner Meinung nach. ${ }^{119}$

Kritik an der auf Antwerpen konzentrierten Lokalisierung des ,Manierismus‘ bei FRIEDLÄNDER äußerte auch Godefridus J. HOOGEWERFF, der noch nachdrücklicher darauf hinwies, dass sich die stilistischen Eigenheiten der ,Antwerpener ' Manieristen keineswegs auf die Erzeugnisse der Stadt an der Schelde beschränkten, sondern ebenso bei

$\mathrm{Zu}$ Schwierigkeiten bei der chronologischen und geographischen Verortung eines Stilbegriffs vgl. BIALOSTOCKI 1968, S. 125-128.

118 BALDASS 1937, S. 117.

119 Vgl. BORN 2005, S. 14. 
Bernard van Orley in Brüssel, Adriaen Isenbrandt und vor allem Lancelot Blondeel in Brügge, aber auch beim nordfranzösischen Meister von Amiens zu beobachten seien, wie weiter oben am Beispiel Blondeels aufgezeigt worden ist. ${ }^{120}$ Auch suchte er die Ursprünge des Manierismus in der Spätgotik selbst und betrachtete sie weniger als Reaktion darauf. Ähnlich wie BALDASs ging er von einer, Manifestation' des spätgotischen Stils aus, die sich vor allem in der Wahrung und Fortführung der technischen Qualität - zumindest der herausragenden Arbeiten - zeige. Als Ausgangspunkte der Manier, die angesichts kaum zu bestimmender Chronologie und weitestgehend anonymer Künstlerpersönlichkeiten kritisch betrachtet werden müsse, nennt er Utrecht, dann Amsterdam mit Jacob Cornelisz. van Oostsanen, weiter Leiden mit Cornelis Engebrechtsen und erst zuletzt Antwerpen, wo der Stil mannigfach von den dort ansässigen Werkstätten rezipiert und verbreitet worden sei. $^{121}$

MARLIER hatte in seiner Studie zu Pieter Coecke von 1966, einem Schüler des Antwerpener Malers Jan van Dornicke, der mit der Werkstatt Gossaerts assoziiert wird, die Gruppe der Manieristen als „Pre-Renaissance Mannerists in the Netherlands" bezeichnet. ${ }^{122}$ Gert VON DER OSTEN und Horst VEY wiederum bezeichneten sie als die „ersten Antwerpener Manieristen“, um damit das stärker noch mit der Malerei des 15. Jahrhunderts verbundene Werk eines Adriaen van Overbeck, eines Goswin van der Weyden und das Frühwerk Joos van Cleves von den späteren Entwicklungen der ,niederländischen Renaissance ${ }^{6}$ abzugrenzen. ${ }^{123}$ Diese der italienischen Renaissancemalerei offenbar nur sehr begrenzt sich öffnende Malerei bezeichneten sie als „Spätgotisch-manieristischen Stil““ ${ }^{124}$ Von $\mathrm{da}$ aus ist es nicht mehr weit zu dem von Paul PHILIPPOT vorgestellten Begriff des „Gotischen Manierismus“ " ${ }^{125}$, den auch Annick BORN favorisiert. Sie spricht sich ebenfalls dafür aus, das Phänomen stärker noch als Max FRIEDLÄNDER in den Anfängen der Forschung - auch er gibt diese Tendenz stellenweise bereits andeutungsweise zu erkennen nicht als nur auf Antwerpen beschränkt anzusehen, obschon sich die kurze Blüte dieses Stils sicherlich wesentlich in dieser Stadt vollzog. Meines Erachtens trifft dieser Begriff am ehesten das Verhältnis der Antwerpener Manieristen zu der malerischen Tradition der alten Niederlande und dem Aufbruch des frühen 16. Jahrhunderts. Auch die von BALDASS monierte begriffliche Vermengung mit dem zeitlich späteren, aus gänzlich anderen Motiven herzuleitenden italienischen (und niederländischen) Manierismus wird auf diese Weise vermieden. Auch wird die problematische Definition des Begriffs der Manier bei FrIEDLÄNDER und dessen negative Konnotation umgangen. Auf das Beispiel des Meisters von 1518 etwa lässt sich die alternative Begrifflichkeit eines ,spätgotischen Manierismus' sinnfällig anwenden, weil hier die eklektizistische

123 Vgl. VON DER OSTEN - VeY 1969.

124 Vgl. BORN 2005, S. 15.

125 Pнilippot 1994, S. 109 f. Für den Begriff „Renaissance Gothic" s. KAVALER 2000, S. 226-151. 
Kombination des affektvoll gesteigerten altniederländischen Figurenstils, mit gotisch' konstruierter Phantasiearchitektur, die hier und da Elemente des Renaissanceornaments aufweist, als Haupteigenschaft deutlich erkennbar ist. ${ }^{126}$

Mit dem Abebben und Versiegen der spätgotischen Tradition, die im Antwerpener Manierismus ein letztes Mal bestimmend zu Tage getreten waren, endete die Antwerpener Malerschule nicht; vielmehr waren die ersten Jahrzehnte nach 1500 der Beginn für die Herausbildung einer sich zunehmend gegenüber den mittelalterlichen Zentren behauptenden Malerschule, die im weiteren 16. Jahrhundert - durch die bereits angefachte Auseinandersetzung mit der Kunst Italiens - zu ihrer vollen Blüte gelangen sollte. Zusammenfassend ließe sich der ,Antwerpener Manierismus', der, wie sich gezeigt hat, vor allem als Phänomen der Form zu verstehen ist, während er inhaltlich und ikonographisch in der altniederländischen Tradition verwurzelt ist, innerhalb einer größeren Entwicklung betrachten.

Die Paradoxie dieser Malerei besteht darin, dass bei der Rezeption zeitgenössischer Werke von Künstlern, die in Italien waren, der Reproduktionsgraphik nach italienischen Kunstwerken und des darin vermittelten Formengutes dieses einerseits nicht in der ursprünglichen Weise, sondern spielerisch verwendet und phantastisch überformt wurde, andererseits aber half - und das trotz der teilweise ad absurdum geführten Interpretation der Manieristen, die italienische Kunstentwick-

126 Dies ist etwa in dem bereits angeführten Gemälde Christus im Hause Simons des Meisters von lung zum neuen Maßstab in der niederländischen Kunst zu machen. Die wenigsten unter diesen Malern werden sich zu dieser Zeit ein eigenes Bild von der italienischen Kunst gemacht haben, stattdessen schlossen sie sich einer Art künstlerischer Mode an, die Elemente dieser Kunst betraf und frei verarbeitete. Das Phänomen des Antwerpener Manierismus stellt zugleich die letzte Stufe der spätgotischen Vorliebe für reine Ornamentik dar, die sich jedoch in der beschriebenen Weise nunmehr einer gleichsam freien Interpretation von antikischen Bauformen und Ornamenten zuwendete, um den am Markt orientierten Forderungen nach neuen Bildfindungen gerecht zu werden.

\subsection{Bernard van Orley als Vorbild}

Als Lehrer des späteren Romreisenden Michiel Coxcie bildet der in der Forschung ungleich umfassender erforschte, zu den frühen Romanisten in den südlichen Niederlanden in der ersten Hälfte des 16. Jahrhunderts zählende Bernard van Orley den frühesten Bezugspunkt, von dem aus sich die Entwicklung des Schülers erörtern lässt. Durch seinen Umfang und den Grad der Innovation, respektive sein Verhältnis zur lokalen Tradition, steht Bernard van Orleys CEuvre (1492-1542) nicht nur quantitativ und zeitlich, sondern vor allem stilistisch mit dem von Jan Gossaert, Joos van Cleve oder Quentin Massys in wechselseitiger Beziehung. Wie alle diese Maler, zeigen auch van Orleys Werke italienische Einflüsse, die

1518 (Jan van Dornicke) zu beobachten, s. o. Abschn. 2.2. 
am ehesten noch mit denen Gossaerts verglichen werden können. Bereits FRIEDLÄNDER wies auf diese entwicklungsgeschichtliche Kohärenz hin, indem er die beiden Maler nacheinander im achten Band seines Werks zur altniederländischen Malerei behandelte. ${ }^{127} \mathrm{Als}$ einander vergleichbar identifizierte er sie vor allem wegen ihres stilistisch ähnlichen Frühwerks und den darin vielfach fassbaren Architekturzitaten pseudoantikischen Zuschnitts. ${ }^{128}$ In der Frühphase van Orleys lässt sich eine noch deutlich ausgeprägte Bindung an die lokale Tradition beobachten, die sich jedoch allmählich durch die Aufnahme neuer Modelle zu lösen beginnt, was die ältere Forschung mit einem postulierten Aufenthalt van Orleys in Italien zwischen 1509 und 1515 zu erklären versucht hat. Unter anderem schrieb etwa J. E. Wessely hierzu: „Im Ausdruck, in der Gruppirung [sic] und Farbe beweist er, daß er nicht vergebens in Rom gewesen ist. ${ }^{\text {“129 }}$ Konkrete, als „italienisch“ zu bezeichnende Einflüsse auf seinen Stil, die in den 1520ern, das heißt in etwa in der mittleren Schaffensphase, zugenommen haben, sind viel wahrscheinlicher jedoch auf die Werke Gossaerts, die nach dessen Italienaufenthalt 1507-1509 entstanden sind, oder aber auf die Entwürfe italienischer

127 Für Jan Gossaert s. FrIEDLÄNDER 1930 [Bd. 8], S. 9-68 und für Bernard van Orley ebd., S. 78136. Vgl. auch GALAND 2019, S. 16-19.

128 Mit dieser Gemeinsamkeit ist auch begründet, weshalb Friedländer zumindest Jan Gossaert als ,Begründer und hauptsächlichen Einflussgeber der Antwerpener Manieristen bezeichnete, da er deren Stilistik zuerst im Frühwerk des zu diesem Zeitpunkt bereits in Antwerpen nachweisbaren Jan Gossaert herausgestellt hat (FRIEDLÄNDER 1933 [Bd. 11], S. 73-78).

129 ADB, Bd. 24 (1887), s. v. „Orley, Barend van” [Wessely, J. E], Sp. 422 f.
Künstler für in Brüssel verfertigte Tapisserien zurückzuführen, wie MIEDEMA im Zusammenhang mit den Angaben in Karel van Manders Schilder-Boeck angemerkt hat. ${ }^{130}$ Diese Überlegung ist insofern stichhaltig, als dass sich beobachten lässt, dass van Orley in seinem ,fortgeschrittenen Schaffen', wie FRIEDLÄNDER es auszudifferenzieren versucht hat, die monumentalen Architekturen Gossaerts aufgreift und sie beispielsweise in seinem Triptychon mit den Leiden Hiobs verwendet, ${ }^{131}$ während die früher entstandene Tafel mit Szenen aus den Viten der Hll. Thomas und Matthias eine andere Auffassung von antikisierender Architektur zu erkennen gibt [ABB. 15], welche stilistisch noch den Antwerpener Manieristen nahe steht und mehr eine im besten Sinne, dekorative' Ergänzung oder Aktualisierung der zuvor geläufigen gotischen Architekturformen denn eine Stilentwicklung, bedeutet. ${ }^{132}$

Während der frühe Romanismus bei van Orley also zunächst vornehmlich die Wiedergabe phantastischer Renaissancearchitekturen meint, wie es sie in Flandern bzw. Brabant zu diesem Zeitpunkt realiter nicht gab, lässt sich spätestens in den 1520er Jahren, parallel zu seiner Anstellung als Hofmaler bei der Statthalterin Margarete von Österreich von

130 Vgl. Miedema 1995, Bd. 2, S. 326 u. CAMPBELL 2002, passim.

131 Koninklijke Musea voor Schone Kunsten van België, Brussels, Inv.-Nr. 1822 (s. LOOTSMA 2017, Nr. 1367, S. 88-98 u. FARMER 1981, 123144).

132 Öl auf Holz, $140 \times 180 \mathrm{~cm}$; Kunsthistorisches Museum, Wien, Inv.-Nr. 992. Inschrift auf Mittelpfeiler: „BERNART VAN ORLEI“ (vgl. Kat. KHM 1991, S. 90 u. Abb. 297). Zur Datierung s. FARMER 1981, S. 49-66 u. 337, Nr. 82. 
1518 bis 1527, ${ }^{133}$ eine ähnliche Entwicklung seines Stils beobachten wie bei Jan Gossaert. Die bereits genannte Matthias und Thomas-Tafel aus Wien von 1512 - ehemals die Mitteltafel eines Triptychons - zeigt in der linken Bildhälfte die Marter des Hl. Thomas, der im Hintergrund über glühende Stangen geht, daraufhin in einen Ofen geschoben und im Vordergrund mit dem Schwert getötet wird [ABB. 15]. In der rechten Bildhälfte sieht man im Vordergrund die Wahl des Apostels Matthias, im Hintergrund rechts ist eine Predigt desselben dargestellt, und im Hintergrund links empfängt er den Giftbecher, der ihm jedoch im Gegensatz zu seinen Widersachern nicht schadet. ${ }^{134}$ Beide Viten werden parallel und in chronologischer Abfolge links von hinten nach vorne, rechts von vorne nach hinten in einem einheitlichen Bildraum visualisiert. Dieser ist durch eine zentrale Pfeilerarchitektur geteilt. Zwei pavillonartige Bauten ohne Sei- ten- und Rückwand, die mit reicher Ornamentik versehen sind, gewähren einen Ausblick in die dahinterliegende Landschaft. Die Tiefenwirkung wird, wie für die Zeit um 1500 typisch, durch ein Verblauen im Hintergrund erreicht, wobei die scharfe Zeichnung der Konturen und der Detailreichtum der Darstellung gleich bleiben; es findet sich somit keine Luftperspektive. Eine halbhohe Mauer trennt den Vorder- vom Mittelgrund und damit die Hauptszene von den übrigen Szenen. Weiter wird das Bild und der einheitliche Bildraum durch ein pfeilerartiges Architekturmotiv in der vordersten Bildebene in zwei Hälften geteilt. Diese trumeau-artige Architektur ist eklektizistisch aus einem antikischen Pfeiler als Fundament und einer darauf aufgesetzten, metallene Materialität evozierenden gotischen Filiale, die sich am oberen Rand zu beiden Seite zu einer Art floral gestaltetem Gesprenge erweitert, gebildet. ${ }^{135}$ Auch die beiden Pavil-
133 s. hierzu DUVERGER 1980, S. 127-142 u. BOOM 1933, S. 138 f. Für die Wiederanstellung bei Margarethes Nachfolgerin Maria von Ungarn s. die erneute vertragliche Bindung vom 13. Oktober 1532 (s. hierzu Miedema 1995, Bd. 2, S. 325, Anm. 15 u. WAUTERS 1893, S. 13 f.).

134 Die Seitentafeln zeigen innen Szenen mit dem ungläubigem Thomas (links), die Enthauptung des Hl. Matthias (rechts) sowie außen die Darstellungen des Hl. Thomas (links) und die des Hl. Matthias (rechts). Beide Flügel befinden sich in den Koninklijke Musea voor Schone Kunsten van België, Brüssel, Inv.-Nr. 1435 / 1436 (für Näheres s. Kat. KMSKB 1984, S. 217 u. FARMER 1981, S. 49-66, 337, Nr. 82).

135 Lancelot Blondeel kreiert zur selben Zeit noch bis in die 40er Jahre hinein bei den meisten seiner Tafelbilder ähnliche Architekturrahmungen, öffnet sich jedoch vollständig dem Renaissanceornament, obschon der Gestaltungstrieb bei ihm weiterhin gotisch anmutet, weshalb er bei Friedländer mit den Antwerpener Manieristen in Verbindung gebracht wurde; hier allerdings als der einzige der noch über 1520 hinaus an deren Gestaltungsprinzipien festhält. Interessant ist in diesem Zusammenhang, dass Blondeel Entwürfe für die Umgestaltung der Fassaden mehrerer öffentlicher Bauten in Brügge lieferte (vgl. MARTENS 1998, S. 45 f. u. MARLIER 1957, S. 50).

Einflüsse auf Lancelot Blondeel gingen womöglich hauptsächlich von der Druckgraphik von Agostino Veneziano und Giovanni Antonio da Brescia aus (vgl. MARTENS 1998, S. 50. Für entsprechende Untersuchung s. KAT. MARTENS 1998, Nr. 78 [L. Jansen].

Beispielhaft für die Rahmendekoration Blondeels ist die Tafel mit der Legende des Hl. Georg (Öl auf Holz, 125,8 × 198,5 cm, Groeningemuseum, Brügge; Inv.-Nr. 0.215), die auf ca. 1535 
lons sollen augenscheinlich antike Architekturen darstellen, verbinden jedoch eine überbordende Fülle von antikisierenden und spätgotischen Baugliedern und Zierformen.

Ein solches Pasticcio ist in dieser Zeit mehrfach im Werk van Orleys zu beobachten. Die beiden erhaltenen Flügel eines Retabels mit Szenen aus dem Leben der Hl. Helena zeigen ähnliche Motive. ${ }^{136}$ Auf der Innenseite des ehemals linken Flügels ist die Begegnung von Kaiserin Helena und Kaiser Konstantin mit Papst Silvester in einer offenen Halle zu sehen [ABB. 16], die der Architektur in der Wiener Tafel mit Matthias und Thomas ähnelt. Die Figuren hier sind wiederum stärker dem Figurenstil der altniederländischen Malerei verpflichtet, mit Ausnahme der beiden Soldaten links im Vordergrund, die sich durch ihre Haltung, ihre Bewegungsmotive und ihre landsknechtartige Tracht von den übrigen Figuren abheben. ${ }^{137}$ Möglicherweise dient diese stilistische Differenz der Akzentuierung des Geschehens, indem die Figuren rings um die
H1. Helena durch ihre altertümliche Erscheinung an das hohe Alter der Erzählung selbst erinnern sollen. Die antikisierende Architektur, obschon sie wiederum in einem Spannungsverhältnis zu den Figuren steht, bildet einen Verweis auf die römische Antike. Auf der Innenseite des rechten Flügels wird wiederum ein gotischer Kirchenraum gezeigt, in welchem zu sehen ist, wie Karl der Große mit Bischöfen und anderen Klerikern die Passionsreliquien, die Helena im Heiligen Land gesammelt hat, in einem Schrein birgt [ABB. 17].

Das augenfälligste Merkmal der Matthias- und Thomastafel sind die zahlreichen Figuren im Vordergrund, die mit einer großen Variation der Gesten und der Körperhaltung die beiden Hauptpersonen umgeben. Der Habitus dieser Figuren ist grundsätzlich noch als altniederländisch zu bezeichnen; einige Figuren wirken wie von Dieric Bouts oder Rogier van der Weyden entlehnt, hier besonders die Frauenfigur links im Vordergrund. Demgegenüber geht die mit einem ausgeprägten bis 1540 datiert wird (vgl. MARTENS - HUVENNE - AINSWORTH 1998, Kat.-Nr. 82; DE Vos 1979 [Kat. Groeningemuseum], S. 85-86) sowie eine Tafel mit dem Hl. Petrus als Papst, die um 1550 entstanden sein soll und möglicherweise ebenfalls Blondeel zugeschrieben werden kann (s. Kat. KMSKB 1984, S. 385). Alle drei Werke zeigen gemalte Rahmen, die ihrer Grundstruktur nach an gotisches Maßwerk erinnern, allerdings Renaissanceornamente und Akanthus- bzw. Weinlaubranken sowie antikische Architekturelemente aufweisen. Für Blondeels Lukas, der die Madonna malt von ca. 1545 (Groeningemuseum, Brügge; Inv.-Nr. 0.18) s. AINSWORTH 1998, S. 111 f., Nr. 82. Das eigentliche Bildthema wird hier als Reflexion in einem mit reicher Renaissanceornamentik ausgestattetem Spiegel gezeigt. Das Bild nimmt hier Entwürfe für Innenausstattungen auf, wie sie u. a. aus dem Umkreis von Frans Floris überliefert sind.

136 Öl auf Holz $94 \times 102 \mathrm{~cm}$, Koninklijke Musea voor Schone Kunsten van België, Brüssel, Inv.Nr. 4999 [innen rechts] (s. VAN DEN BRINK 1995, S. 177-184; FARMER 1981, S. 217; BALDASS 1944, S. 156-159); $94.5 \times 106 \mathrm{~cm}$, Galleria Sabauda, Turin, Inv.-Nr. 317 [innen links] (s. FARMER 1981, S. 90-99, 339, Nr. 99, Abb. 34 u. BALDASS 1944, S. 141-191, bes. 156159).

137 Die Geistlichen in ihren prächtigen Pontifikalgewändern erinnern an die Darstellung der Hll. Martinus, Bernardin von Siena und Donatian auf dem Stifterbild des von Bernardijn Salviati um 1506 gestifteten Retabels von Gerard David, National Gallery, London, Inv.-Nr. 1045 (s. CAMPBEll 1998, S., 122-133 u. AinswORTH 1998, S. 3, 156 u. 184). 
Helldunkel verbundene Plastizität und körperliche Präsenz der Gestalten um einiges über diese älteren Vorbilder hinaus - abgesehen nur von dem in mancher Hinsicht exzeptionellen Werk des Hugo van der Goes. Die anbetenden Gestalten im rechten Flügel sind wohl dem Vorbild des Portinari-Retabels entlehnt. ${ }^{138}$

Der alttestamentliche Priester in der linken Bildhälfte mit seiner exotischen an eine Mitra erinnernden Kopfbedeckung, aber auch die Frauenfigur mit dem überlangen und weit ausgebreiteten Kleid sowie nicht zuletzt die mit antikisierendem Zierrat geschmückten Architekturen, rücken die Tafel stilistisch auch in die Nähe der Antwerpener Manieristen. Einzelne Charakteristika, wie etwa die Tendenz zum horror vacui und Figuren mit besonders betonten Bewegungsmotiven, die vor allem mit den Antwerpener Manieristen assoziiert werden können, erweisen sich als übergreifende Stilelemente der niederländischen Malerei im ersten Viertel des 16. Jahrhunderts.

Die eingangs angeführte These, dass in der niederländischen Malerei zunächst weniger das Bemühen um eine Synthese, als vielmehr eine additive Bereicherung durch die

138 Für diesen Hinweis danke ich Thomas Noll.

139 Koninklijk Museum voor Schone Kunsten, Antwerpen, Inv.-Nr 741, 743 u. 745 (s. AINSWORTH 2006, S. 109-112 u. FARMER 1981, S. 148-149, 150-155 u. 337, Nr. 87).

140 Öl auf Holz (Eiche), $176 \times 184 \mathrm{~cm}$ (Mitteltafel), $174 \times 80$ (Seitenflügel), Koninklijke Musea voor Schone Kunsten, Brüssel, Inv.-Nr. 1822 (s. FRIEDLÄNDER VIII, Taf. 87-81. Hierzu auch MiEDEMA 1995, Bd. 2, S. 326 u. FARMER 1981, S. 123-162; zuvor u. a. VAN PUYVELDE 1962, S. 453, Anm. 476 f.).

141 Nicole DACOS sah in diesem Leitspruch eine Anspielung auf das künstlerische Prinzip Bernard van Orleys, nach dem ein Künstler ein vollständig in seine Zeit integrierter Mann sein solle
Einbeziehung von italienischen Vorbildern zu beobachten ist, wird durch dieses Beispiel bestätigt. Zwei vollständig erhaltene Triptychen aus der Werkstatt Bernard van Orleys, die um 1525 entstanden und im Museum voor Schone Kunsten in Antwerpen bzw. in den Musées Royaux des Beaux-Arts in Brüssel zu sehen sind, verdeutlichen die weitere Entwicklung van Orleys sehr eindrücklich. Dabei handelt es sich zum einen um das Weltgerichts-Triptychon, ${ }^{139}$ das um 1525 datiert wird, zum anderen um das schon erwähnte Hiob-Retabel von 1521 [ABB. 18]. ${ }^{140}$ Letzteres enthält gleich zweifach die Signatur des Malers sowie dessen Wappen und sein Motto „ELX SYNE TYT $^{\text {“‘ (= jedem seine Zeit). }}{ }^{141}$

(s. DACOS 1987, S. 17-28). Ein daraus abzuleitender Modernitätsanspruch wäre noch zu diskutieren. Weder das Gedicht des Lampsonius noch van Manders Biographie über Bernard van Orley ist besonders rühmlich ausgefallen. Wie auch für Michiel Coxcies Lebensbeschreibung mehrfach angenommen wurde, hat Miedema auch hier lediglich eine möglicherweise unzureichende Informationslage angeführt (s. MIEDEMA 1995, Bd. 2, S. 324 u. 328-331). Während diese Annahme in Coxcies Fall wenig plausibel ist, mag sie auch in Bezug auf dessen Lehrer, der immerhin Hofmaler unter zwei niederländischen Generalstatthalterinnen war, nicht vollends befriedigen. 
Der geöffnete Zustand zeigt die Prüfungen des Hiob, während auf den Außenseiten der Flügel das Gleichnis von dem reichen Mann und dem armen Lazarus dargestellt ist. Diese Ikonographie brachte dem Retabel auch den gelegentlich gebrauchten und aus einer zeitgenössischen Quelle abgeleiteten Namen Tableau sur la vertu de Patience ein. ${ }^{142}$

Die Mitteltafel und die Innenseiten der Flügel schildern die Geschichte Hiobs von links nach rechts. Dementsprechend ist auf der linken Tafel das erste Unheil zu sehen, mit dem Hiob von Satan geschlagen wird, nachdem dieser vor Gott getreten war und Hiob der frömmlerischen Heuchelei bezichtigt hatte. Gott überträgt Satan daraufhin die Macht, ungehindert über Hiobs irdischen Besitz zu verfügen, jedoch mit der Auflage sein Leben zu schonen. Gott prüft auf diese Weise den Glauben Hiobs, indem er ihn dem Bösen aussetzt (Hiob 1,6-19). Das Unglück äußert sich zunächst durch drei zeitnahe Ereignisse, über die er jeweils unterrichtet wird: Der Verlust seiner Herden und der Hirten durch einen militärischen Übergriff der Chaldäer. Der ungleich schlimmere zweite Schlag ist indessen auf der Mitteltafel dargestellt: Der Verlust seiner zehn Kinder, die während einer Feier von einem starken Sturm heimgesucht und durch den Einsturz des Gebäudes, in welchem sie sich versammelt hatten, getötet werden. Die rechte Tafel zeigt den Ausgang der Geschichte;
Gott beendet seine Prüfung und schenkt Hiob weitere Nachkommen sowie das Doppelte seines vormaligen Besitzes.

Die Darstellungen auf dem Retabel erweisen sich als textgetreu, auch wenn sie nur die zentralen Ereignisse der Geschichte zeigen. Der für die Auslegung des Geschehens zentrale Aspekt, dass das Leid, welches Hiob widerfährt, nicht unmittelbar von Gott selbst ausgeht, sondern ihm durch Satan zugefügt wird, ist dadurch kenntlich gemacht, dass dieser auf der linken Tafel in Form eines Drachen am Himmel vor der goldenen Gloriole Gottes erscheint, während unten auf der Erde die chaldäischen Soldaten Hiobs Vieh rauben. Die Mitteltafel ist geprägt von der zugespitzten Dynamik einer plötzlich hereinbrechenden Katastrophe, die durch die Darstellung dämonischer Wesen gekennzeichnet wird. Die erschrockenen Festgäste, von denen einige bereits von herabfallenden Bauteilen erschlagen wurden oder gerade in diesem Moment zu Boden stürzen, versuchen in großer Panik aus dem Gebäude zu entfliehen.

Auf dem rechten Flügel erscheint im Mittelgrund in steiler Tiefenflucht das Haus Hiobs. Dieser ist als vornehm gekleideter älterer Mann mit grauem Haar dargestellt (Hiob 42,17), während vor ihm in einem Halbkreis vier weitere Männer niederknien, um mit ihm zusammen in den Lobpreis Gottes einzustim-

a mons le comte Dhoocstraete, pour icelluy mectre et poser devant la cherninee de la chambre ou elle se lougeait au chasteaul Dhoscstraete quand elle y allait" (Lille, Archives départementales du Nord, Chambre des compres, reg. 1832, fol. 203, zit. nach HeNNE 1855, S. 100). 
men, während er die Hände ausbreitet und seinen Blick gen Himmel richtet. Rechts sind zwei wohlgenährte Schafe zu sehen, auf der linken Seite zwei Rinder und zwei Kamele, mit denen die dem Hiob neuerlich geschenkten Besitztümer angedeutet sind (Hiob 1,3; 42,12). Auf der Mitteltafel ist im Vordergrund vorne rechts ein figürlich und ornamental verzierter Pfeiler zu sehen [ABB. 18: Detail]. Dieser zeigt das Medaillon eines geharnischten Mannes im Profil, das aus einem weißen stuckartigem Material gearbeitet ist und von geflügelten Puttenköpfen getragen wird, darüber einen Putto, der sich an der mit einem Renaissanceornament verzierten Außenseite des Pfeilers abstützt. ${ }^{143}$ Der im Profil gezeigte Mann trägt einen Helm, der ähnlich phantastisch anmutet wie der des Chaldäers auf der linken Tafel. Der Nasenschutz ist wie ein krummer Vogelschnabel gearbeitet, was eine Groteske als Vorlage nahelegt. Der Pfeiler wiederum zeigt an seinen Ecken Rundvorlagen, die oben in bekränzten Phantasiekapitellen münden. Zwischen den Kapitellen ist jeweils ein marmornes Feld mit einem Bukranion zu sehen. Es folgt eine reicht profilierte Deckplatte mit

143 Medaillons nach dem Vorbild der Kaiserbüsten auf römischen Münzen könnten van Orley über die Kenntnis von Marcanton Raimondis Serie mit Imperatorenbildnissen nach Vorlagen aus der Raffael-Werkstatt vermittelt worden sein. Für diese Portraitserie s. BLOEMACHER 2016, S. 62-65. Eine inhaltliche Deutung des Medaillons in Bezug auf das Bildthema lässt sich schwerlich herleiten; allerdings könnte der Gebrauch des Medaillons als architektonisches Zierelement zumindest indirekt auf antike Vorbilder verweisen. Auf welchem Weg dieses Motiv rezipiert wurde, d. h. ob dem eine theoretische Grundlegung über zeitgenössischer Kunsttraktate zu Grunde liegt oder van Orley lediglich konkrete
Zahnschnitt, über der sich eine zweite Art von Kapitell mit einer volutenförmigen Groteske und Puttenkopf anschließt. Ein vergleichbares Motiv verwendet van Orley auch bei der Hintergrundarchitektur seiner Löwener Madonna, nämlich bei den Kapitellen der beiden Hauptpfeiler. Auch der gegenüberliegende Pfeiler auf der Mitteltafel des Hiob-Retabels zeigt Relieffelder mit antikisierenden Ornamenten. ${ }^{144}$ Darüber hinaus sind die Harnische und die Beinschienen der chaldäischen Soldaten sowie ganz besonders der groteskenhaft geformte Helm des zuvorderst dargestellten Mannes mit ähnlichen Ornamenten verziert. Besonders augenfällig ist jedoch die voll ausgebildete italienische Groteske mit den beiden fischartigen Chimären mit Vogelköpfen auf dem erstgenannten Pfeiler. Dabei handelt es sich um die Variation eines Motivs, wie es ganz ähnlich auf einem Ornamentstich von Lucas van Leyden zu sehen ist [ABВ. 19], der allerdings auf 1528 datiert ist, was nahelegt, dass Lucas van Leyden und Bernard van Orley zumindest auf zwei eng verwandte Darstellungen zugegriffen haben. ${ }^{145}$ Die Groteske spiegelt den Einfluss der italienischen Graphik, vor allem der des

Vorbilder kopiert, lässt sich nicht genau bestimmten. Architekturelemente, die auf Grund ihres Alters (etwa ausgedrückt durch ihren baufälligen Zustand) auf das (biblische) Altertum verweisen sollen, sind indessen schon seit dem 15. Jh. bekannt (vgl. KROHM 2001, S. 77-90).

144 Das des Pfeilers ist in der Art der sog. Kandelabergrotesken, ähnlich denen Lambrecht Hopfers gestaltet (s. Berliner Ornamentale, Nr. 68 u. 69; beide um 1530 datiert und verweisen möglicherweise auf ein älteres Vorbild. Ähnlich verhält es sich bei dem unteren Relieffeld des linken Pfeilers.

145 Kupferstich, 7,8 $\times 11,9 \mathrm{~cm}$, Victoria and Albert Museum, Prints and Drawings, Inv.-Nr. 28611A. 
Marcanton Raimondi, ${ }^{146}$ auf das Werk des Lucas van Leyden wider, dessen frühe Ornamentstiche aus den 1510er Jahren noch deutlich stärker von lokalen Vorbildern geprägt waren.

Stilistisch vergleichbar mit dem HiobRetabel ist ein nurmehr als Fragment erhaltenes Marienretabel Bernard van Orleys, das ungefähr zur gleichen Zeit entstanden sein könnte. Dafür sprechen augenfällige Parallelen, etwa in der Tafel mit der Darstellung Christi im Tempel (Lk 2:22-39) [ABB. 20], die eine ähnliche von Pfeilern getragene antikisierende Architektur wie die Mitteltafel des Hiob-Retabels zeigt. Unter anderem finden sich dort auch zwei vergleichbare Phantasiekapitelle mit Grotesken. Auch in der Figurenauffassung lassen sich Übereinstimmungen entdecken, etwa bei der Frauenfigur vorne rechts auf in dem Bild mit der praesentatio, die im Kontrapost dargestellt ist und hierin der Schrittbewegung des Hiob von der rechten Tafel des Hiob-Retabels ähnelt. Auch die knieende in Rückenansicht gezeigte Frauenfigur mit dem vorgestreckten Hals erinnert in Bezug auf die Körperhaltung an einen der Freunde Hiobs. ${ }^{147}$

Eine antikisierende Phantasiearchitektur hatte Bernard van Orley bereits zehn Jahre

Vgl. Berliner Ornamentale, Nr. $334=$ B. VII 427, 161.

146 Ein Beispiel hierfür stellt eine Groteske mit zwei zwischen Akantshusranken sitzenden Phantasiewesen, einem Meerjungmann und einer Meerjungfrau, dar (Berliner Ornamentale, Nr. $331=$ B. VII 430, 169). Für Beeinflussung durch Marcanton Raimondi s. LEEFLANG 2011, S. 145-148 u. IRMSCHER 1984, S. 174.

147 Zuletzt 2005 auf der TEFAF in Maastricht von Cesare Lampronti, Rom / London angeboten. Gegenwärtiger Verbleib unklar. Wird bei FARMER 1981, S. 259 f. und bei DACOS 1987, S. 17 zuvor bei der Matthias- und Thomastafel eingesetzt. Während eine der Tafeln dieses Retabels jedoch auch ein rein gotisches Bauwerk aufweist, hat es den Anschein, dass er sich in den 1520er Jahren weitestgehend auf die Wiedergabe einer aus Einzelmotiven frei zusammengefügten Renaissancearchitektur konzentriert, die zum Teil noch an die Architekturphantasien der Antwerpener Manieristen erinnert. Zugleich aber deutet die Art und Weise, wie hier die Architektur aufgefasst wird, auf die möglichen Quellen, die über diejenigen der Antwerpener Manieristen hinausgehen. Die These, dass van Orley selbst nie in Italien war und sich hauptsächlich an den Werken Gossaerts und denen italienischer Meister schulte, die er möglicherweise am Hof Margaretes oder in Graphiken von oder nach italienischen Stechern fand, wird durch die stilistische Analyse unterstützt. Vor allem die reiche Ornamentik legt den Verdacht nahe, dass ihm italienische Ornamentstiche oder entsprechende Blätter von Lucas van Leyden oder auch Daniel und Lamprecht Hopfer bekannt waren, die in Flandern zu dieser Zeit möglicherweise bereits verkauft wurden. ${ }^{148}$ Auch Kartons für Tapisserien, die nach Flandern gelangten und die für ihn, der selbst Entwürfe

28 behandelt. Bei DACOS jedoch Pieter der Kempener zugewiesen. Dem muss jedoch widersprochen werden, da die stilistische Nähe zum Hiob-Retabel meines Erachtens überzeugt; wie bereits FARMER anmerkte handelt es sich daher möglicherweise um eine Werkstattarbeit bzw. ein im Umfeld von Bernard van Orley entstandenes Werk.

148 Vgl. AinsworTH 2019, S. 39-48. Der Umfang, in welchem italienische Graphik in den ersten zwei Jahrzehnten in den Niederlanden verbreitet war, lässt sich schwerlich genau bestimmten. 
für Tapisserien geliefert haben soll, zugänglich gewesen sein könnten, kommen als Inspirationsquelle in Betracht. Vergleichbare Architekturelemente, hier besonders die mit Relieffeldern verzierten Pfeiler, sind bei Jan Gossaert seit 1510, also unmittelbar nach seinem Italienaufenthalt, nachweisbar. ${ }^{149}$ Darüber hinaus attestiert Günter IRMSCHER den niederländischen Grotesken des frühen 16. Jahrhunderts, ähnlich wie dies in der Malerei zu beobachten ist, eine plötzlich einsetzende Hinwendung zu italienischen bzw. antikisierenden Vorbildern. Die Rezeption solcher Ornamentstiche in den Niederlanden, wie sie bei Bernard van Orley zu sehen ist, belegt eine „Affinität [...] für akanthisierte Mischwesen“. ${ }^{150}$ Während das Bild selbst eine biblische Geschichte schildert, besteht die eigentliche Auszeichnung der Darstellung in der Verwendung von antiker Architektur und entsprechender Ornamentik. Vor allem der Pfeiler vorne rechts in der Mitteltafel des Hiob-Retabels, wirkt wie eine ,Litfaßsäule‘,

Das graphische Adaptionen italienischer Kunstwerke im Umlauf waren, ist indessen anzunehmen, wie auch die Verwendung solcher durch Jacob Cornelisz. von Oostsanen aus Antwerpen für seine Maria Magdalena von 1519 (Öl auf Holz, $57.8 \times 40.6$ cm; Saint Louis Art Museum, Saint Louis), der sich an dem frühen italienischen Stich Pollaiuolos mit den Kämpfenden Männern orientiert (vgl. HARNACK 2018, S. 131; ebd., Anm. 1 u. Meuwissen 2014, S. 235). Dass es sich bei Jacob Cornelisz. van Oostsanen um Jan van Scorels zweiten Lehrer handelt, mag ein Indiz dafür sein, dessen späteres Italienstudium seinen Ursprung in der Ausbildung bei Cornelis hat (vgl. MEuWISSEN 2014, S. 93).

149 Ein frühes Beispiel ist die um 1510 entstandene Hl. Familie; Öl auf Holz, $46 \times 33.7 \mathrm{~cm}$; Getty Museum, Los Angeles, Inv.-Nr. 71.PB.45 (s. AINSWORTH 2010, S. $122 \times 125$, Nr. 4). Für die konkrete Auseinandersetzung mit antiker Architektur steht aber vor allem Gossaerts Neptun und Amphitrite von 1516; Öl auf Holz, $188 \times 124 \mathrm{~cm}$; die mittels Ornamentreliefs, Grotesken und der Medaillons im Renaissancestil, die Kenntnisse und ,Modernität' des Malers zur Schau stellt. Die von Nicole Dacos vorgeschlagene Auslegung des Wahlspruchs Bernard van Orleys als Ausdruck einer Hinwendung zu den Erfordernissen der Zeit stimmt mit den an diesem Retabel gemachten Beobachtungen ebenfalls überein. ${ }^{151}$

Die Entwicklung des Künstlers in den 1520er Jahren bezeugt neben dem Hiob-Retabel, vor allem der Altaraufsatz mit dem Jüngsten Gericht und den Sieben Werken der Barmberzigkeit, der um 1525 entstanden ist [ABB. 21]. ${ }^{152}$ Dieses Triptychon zeigt eine noch weiter gesteigerte Tiefenwirkung. Das Mittelbild und die beiden Seitentafeln sind als einheitlicher Raum gestaltet, wobei der in starker Bewegung gezeigte Erzengel Michael mit dem für van Orley charakteristisch wehenden Mantel den Fluchtpunkt markiert. ${ }^{153}$ Kompositorisch und motivisch steht es dem Jüngsten Gericht des Lucas

Gemäldegalerie, Staatliche Museen Berlin, Inv.Nr. 648 (vgl. MENSGER 2002, S. 73-90). MENSGER konstatierte hierzu, dass es sich um die „die erste große mythologische Komposition mit Aktfiguren und rein antikischer Architektur nördlich der Alpen“ überhaupt handle (MENSGER 2002, S. 73).

150 IRMSCHER 1984, S. 174.

151 Vgl. DACOS 1987, S. 17-28.

152 Öl auf Holz, $248 \times 218 \mathrm{~cm}$; Koninklijk Museum voor Schone Kunsten, Antwerpen, Inv.Nr. 741-745.

153 Ein Detail, dass bei van Orley häufiger zu sehen ist. So etwa auch im selben Bild bei der Figur des Weltenrichters oben unterhalb des Bogensegments des Rahmen. Vergleichbares ist deutlich früher bereits beim wehenden Lendenschutz auf Dürers Christus am Kreu₹, von 1506 zu sehen, was bereits zu diesem frühen Datum auf eine mögliche Auseinandersetzung mit Italien hindeutet. 
van Leyden von 1526-1527 nahe [ABB. 22]. ${ }^{154}$ Vergleichbar ist hier insbesondere das Verhältnis der Figuren zum Raum, das heißt der zum Hintergrund abnehmende Figurenmaßstab, der etwa den Weltenrichter kleiner als die Auferstandenen im Vordergrund vor Augen bringt. Auffällig sind - wie bei Lucas van Leyden - die zahlreichen Aktfiguren und die Darstellung ausschließlich antikisierender Architektur. ${ }^{155}$ Die Datierung beider Werke etwa in die gleiche Zeit wirft die Frage auf, welches der beiden Werke früher entstanden ist. Während das Retabel des Lucas van Leyden zum Gedächtnis eines 1525 verstorbenen Claes Dircksz. van Swieten, kurz darauf, um 15261527 geschaffen und in der Pieterskerk in Leiden aufgestellt wurde, weiß man über das Werk von Bernard van Orley, dass es 15181519 von der Antwerpener Armenkammer in Auftrag gegeben worden ist und um 1525 in der Onze-Lieve-Vrouwekerk über dem Altar der Kammer platziert wurde. ${ }^{156}$ Die uns überkommenen Informationen legen nahe, dass das Retabel van Orleys wenige Jahre älter ist. Grundsätzlich lässt sich konstatieren, dass beide Werke in der Tradition von Hans Memlings Danziger Weltgerichts-Triptychon aus der Zeit zwischen 1466 und 1473 stehen [ABB. 23], während sie die für ihre Zeit typische stilistische ,Aktualisierung' aufweisen. Vor allem für die jeweilige Mitteltafel der beiden Retabel orientierten sich beide Maler an Memling. Im oberen Bildbereich sitzt jeweils Christus als Weltenrichter auf einem Regenbogen, während seine Füße auf einem Globus stehen. Bernard van Orley übernimmt letzteren, zeigt jedoch an Stelle des Segensgestus bei Memling Christus mit ausgestreckten Armen. Lucas van Leyden gestaltet die Figur des Weltenrichters stärker nach Memling, indem er den Segensgestus beibehält und darüber hinaus auch Schwert und Lilie neben dessen Haupt zeigt, worauf Bernard van Orley verzichtet. Den Globus deutet Lucas jedoch nur mit einer ,Wolkenkugel' an - die rundliche Form nimmt aber dennoch unverkennbaren Bezug darauf. Christus selbst sitzt vor einer goldenen Gloriole, die nur bei Lucas van Leyden etwas weiter oben, zusammen mit der Darstellung Gottvaters, angesiedelt ist. Umgeben ist Christus von Engeln, darunter einem, der bei van Orley das Kreuz in der Mitte der oberen Bildhälfte präsentiert. Ein solcher Engel ist auch bei Memling links oben im Hintergrund zu sehen, während Lucas van Leyden wiederum auf das Motiv verzichtet. Johannes und Maria nebst jeweils sechs Aposteln sitzen bei van Orley zu beiden Seiten Christi auf einem Wolkenband, sind jedoch im Gegensatz zur Darstellung Memlings nicht auf der Mitteltafel, sondern in

Retabel von Hans Memling in Danzig, welches auf 1467-1471 datiert ist (Öl auf Holz, $242 \times$ $180 \mathrm{~cm}$ (Mitteltafel), $242 \times 90 \mathrm{~cm}$ (Seitenflügel); Muzeum Narodowe, Danzig).

156 Für Bernard van Orley s. AInswOrTh 2006, S. 109-112; FARMER 1981, S. 148 f. u. FRIEDLÄNDER 1967-1976, Bd. VIII, Kat.-Nr. 87. Für Lucas van Leyden s. DEN HARTOG - VEERMAN 2011, S. 218-234 u. FRIEDLÄNDER 1967-1976, Bd. X, Kat.-Nr. 113. 
der oberen Hälfte der beiden Seitenflügel dargestellt. Lucas von Leyden gruppiert die Apostel, jedoch ohne Maria, jeweils zu sechst auf vorgelagerten Wolken beiderseits unterhalb von Christus. Darunter sind zu beiden Seiten jeweils ein Engel, der die Posaune bläst, zu sehen. Auch Bernard van Orley zeigt an entsprechender Stelle vergleichbare Figuren. Zusätzlich sind bei ihm gemäß Offb 15,1 im Hintergrund sieben weitere Engel mit gleichem Abstand auf einem konvex umlaufenden Wolkenband zu sehen.

In der unteren Bildhälfte zeigen alle drei Gerichtsdarstellungen die Auferstehung der Toten. Die Auferstandenen werden vom Erzengel Michael in einer Waagschale gewogen und daraufhin links zum Paradies geleitet, das bei Memling durch die Paradiespforte auf dem linken Seitenflügel angezeigt ist oder rechts in die Hölle geworfen, welche Memling in Form eines brennenden Abgrundes darstellt. Letzteres Motiv wird von Lucas van Leyden aufgegriffen und in seine Darstellung eines fischköpfigen Höllenschlundes übertragen, während links Engel die Gerechten wegführen. Die Scheidung der Seligen und der Verdammten beginnt bei allen drei Beispielen bereits im Mittelbild. Einzig Bernard van Orley zeigt auf den beiden Flügeln weder Himmel noch Hölle, sondern verweist auf die Guten Werke, die als ein Mittel verstanden wurden, mit dem man sich das Himmelreich erwerben konnte. Links sind Wohltäter zu sehen, darunter zwei Geistliche, die Bettlern zu trinken und zu essen geben. Rechts wiederum wird ein Kleriker gezeigt, der Kleidung an Bettler verteilt, während dahinter ein Krankenbesuch in einer offen gestalteten Halle zu sehen ist. Diese Abweichung vom Vorbild Memlings ist sicherlich den Wünschen des Auftraggebers, namentlich der Antwerpener Armenkammer, geschuldet.

Während sich motivisch vor allem für die Mitteltafeln größere Übereinstimmungen unter den drei Beispielen ergeben, so ist auch in stilistischer Hinsicht einiges über den Umgang der beiden jüngeren Werke mit dem Vorbild des 15. Jahrhunderts auszusagen. Am augenfälligsten ist sicherlich der Verzicht des bei Memling ausgeprägten Bedeutungsmaßstabs. Der Weltenrichter, die ihn umgebenden Apostel sowie der Erzengel Michael sind nahsichtig gezeigt, um damit das Problem des Maßstabs $\mathrm{zu}$ verringern. Durch den weitestgehenden Verzicht auf einen gestalteten Mittelgrund wird das grundsätzliche Problem der Bedeutungsperspektive noch deutlicher. Das auf die ganze Welt bezogene Gericht erscheint in der Darstellung auf einen relativ kleinen Raum im Vordergrund reduziert. Durch die angeschnittenen Figurengruppen zu beiden Seiten der Mitteltafel und deren Fortsetzung in den Seitenbildern, wird dieser Bildraum zumindest im Vordergrund erweitert. Dennoch wirken alle drei Bilder für sich genommen als Einzelszenen, die sich nicht wirklich einen einheitlichen Bildraum teilen. Wie weiter oben bereits angesprochen, ähneln die Gerichtsbilder von Lucas van Leyden und Bernard van Orley sich darin, dass sie einen einheitlichen Bildraum zeigen, der alle drei Tafeln umspannt. Auch motivisch haben sich Übereinstimmungen ergeben, die dem gemeinsamen Vorbild, dem Retabel von Hans Memling, entsprechen. Anders jedoch als bei diesem werden die Figuren nicht in ei- 
nem Bedeutungsmaßstab dargestellt. Der Weltenrichter und der Erzengel Michael, auf den Lucas van Leyden verzichtet, werden in großer Distanz dargestellt. Dies fällt besonders bei Bernard van Orley ins Gewicht, welcher zu beiden Seiten der Waagschale eine große Menschenmenge darstellt, deren Reihen sich wie die zweier gewaltiger Heere bis zum Horizont fortsetzen. Damit wird die weltumspannende Bedeutung des Jüngsten Gerichtes sehr eindrücklich veranschaulicht. Die Bewegungsmotive der menschlichen Figuren auf beiden Seite sind der Situation geschuldet - während rechts flehende Menschen und schmerzvoll verzerrte Leiber zu sehen sind, die überdies von Engeln gescheucht werden, sind links aufrechte Menschen zu sehen, die ihre Arme zum Jubel und zur Akklamation angesichts des Erlösers emporheben. Nur im Vordergrund links ist eine Frau zu sehen, die ihre Hände anbetend erhebt, während sie hinauf zu Christus blickt. Statt der mit zusammengelegten Händen dargestellten Seligen bei Memling, dominiert bei van Orley das Motiv der lebhaften Freude über die Wiederkunft Christi. Es handelt sich um eine andere Auffassung des Menschen, die in der Darstellung der menschlichen Figuren zum Ausdruck kommt. Statt der dürren langgliedrigen und relativ wenig bewegten gotischen' Figuren, handelt es sich hier um anatomisch durchgebildete, muskulöse Figuren mit vielfältigen Bewegungsmotiven.

Während die unzählbare Menge derer, die auferstehen, bei Bernard van Orley evoziert werden soll, liegt bei Lucas van Leyden das Hauptaugenmerk bei der Mitteltafel auf einzelnen Figuren und kleineren Gruppen.
Auch hier handelt es sich um idealisierte, anatomisch durchgebildete Körper, die eine Reihe von Bewegungs- und Standmotiven zeigen sowie liegend erscheinen. Vorder-, Mittel- und Hintergrund sind klar gegliedert, während die Schwierigkeit, ein globales Geschehen darzustellen, durch eine Art Krümmung der Horizontlinie, die die Erdkrümmung meint, bewältigt wird. Statt einer schier unermesslichen Tiefe des Raumes wie bei van Orley wird damit eine ,globale Weiträumigkeit` suggeriert.

Grundsätzlich bilden die zeitliche Nähe der Entstehung und die motivische Orientierung an einem Vorbild aus der altniederländischen Tradition bei beiden Werken einen deutlichen Hinweis darauf, dass sie einander beeinflusst haben. Bis auf die Datierung, die van Orleys Werk als das ältere kennzeichnet, lässt sich nicht bestimmen, inwieweit von einer konkreten Beeinflussung seitens Lucas van Leyden - oder umgekehrt - ausgegangen werden kann. Tatsache ist allerdings, dass beide Werke bestimmte Parameter teilen, sie greifen beide auf italienische Vorstellungen der idealisierten menschlichen Figur zurück und versuchen gegenüber dem Vorbild aus dem 16. Jahrhundert die oben genannten Probleme bei der Perspektive und dem Figurenmaßstab zu lösen. Bernard van Orley versucht dies, indem er die Raumtiefe zum ÄuBersten zu steigern versucht, was sich unter anderem auch in der mehrschichtigen Gestaltung des Himmels bemerkbar macht. Zwischen dem Weltrichter, den Engeln um das Kreuz, den sieben Engeln der Offenbarung und einer weiteren nur schemenhaft angezeigten Engelsschar, sind deutliche Entfernungen auszumachen, die in der maßstabsgerechten 
Verkleinerung der Figuren erkennbar werden. Lucas van Leyden scheint diese gleichsam stufenweise Hintereinander Reihung aufzugreifen, indem auch er hinter seinem Weltenrichter eine weitere Wolke mit der Darstellung der Seligen zeigt, auf welche wiederum eine noch weiter entfernte Gruppe von Engeln folgt, die bereits oberhalb der Wolken im Bereich des goldenen Empyreums angesiedelt ist. Die Darstellungen von Gottvater und Heiligem Geist in jeweils einer Gloriole wirken dagegen räumlich vom Rest des Bildes abgerückt. Bei einer stärkeren Aufsicht auf die Erde wird auch hier durch eine sukzessive Verkleinerung der Figuren eine - wenn auch weniger große Raumtiefe suggeriert. Bei der Frage nach der gegenseitigen Beeinflussung kann letztlich nur spekuliert werden, dass Lucas van Leyden das zwei Jahre ältere Retabel von Bernard van Orley zu übertreffen versucht, sich dabei aber nach anderen formalen Vorgaben zu richten hatte. So konnte er das Weltgericht wie üblich über die gesamte Fläche ausbreiten, während van Orley - höchstwahrscheinlich auf einen entsprechenden Auftraggeberwunsch hin die Werke der Barmherzigkeit ins Bild einbringen musste.

Im Vergleich zum Hiob-Retabel lassen sich ähnliche Bewegungsmotive wiederfinden, die vor allem die im Vordergrund frontal zum Betrachter heranstürmenden Figuren betreffen. Das Mittelbild des Jüngsten Gerichtes von Bernard van Orley zeigt Figuren, die obschon diese nackt sind, ähnlich verrenkte Körperhaltungen aufweisen und dem Betrachter frontal zugewandt sind. Auch das hier angedeutete Helldunkel, mit dem die Hautpartien der Fi- guren modelliert sind, findet sich in gesteigerter Weise bei den nackten Auferstandenen wieder. Beiden Werken ist auch die Aufsicht gemein, die sich besonders in der Art, wie die Architekturen in den Raum gestellt sind, bemerkbar macht. Es ergeben sich aber auch stilistische Unterschiede, etwa bei den Farben, die bei dem Hiob-Retabel heller ausfallen. Auch weisen die Architekturen beim Jüngsten Gericht gegenüber dem Hiob-Retabel eine Entwicklung auf, die sich darin ausdrückt, dass die hier gezeigten Formen authentischer wirken; zu sehen sind etwa ionische Kapitelle und Architrave mit mehrfach profiliertem Gesims sowie vor Pfeiler vorgeblendete Halbsäulen, die wiederum eine rundbogige Maueröffnung flankieren. Auch verzichtet er auf den Gebrauch von Grotesken und Ornamentreliefs, die die Gestalt der Bauwerke auf dem Hiob-Retabel maßgeblich prägen. Zuletzt verzichtet er auch auf die Dämonen, die bei der Darstellung des Weltgerichts durchaus denkbar und inhaltlich angemessener gewesen wären als bei der symbolhaften Darstellung des Sturmes, der das Haus Hiobs zum Einsturz bringt. Stilistisch bezeichnen diese letztgenannten Triptychen allerdings dennoch allesamt eine Zäsur: Als ,italienisch geprägte' Werke setzen sie sich vom Frühwerk van Orleys, aber auch von den phantastischen Schöpfungen der Antwerpener Manieristen ab. Das später entstandene Jüngste Gericht beschreibt diesen Schritt im Vergleich zum Hiob-Retabel sogar noch stärker.

Der Name Bernard (oder auch Barend) van Orley fällt verschiedentlich auch im $\mathrm{Zu}$ sammenhang mit Tapisserien aus Brüsseler 
Produktion in der ersten Hälfte des 16. Jahrhunderts. ${ }^{157}$ Die Tatsache, dass es als gesichert gilt, dass sein Schüler Coxcie später als Gestalter von Teppichen, wie etwa für die Ausstattung des Palastes von Binche, sowie für Glasfenster in mehreren Kapellen in den Quellen in Erscheinung tritt, ${ }^{158}$ lässt es zunächst nicht abwegig erscheinen, dass er in derlei Gestaltungsarbeiten in der Werkstatt seines Lehrers eingebunden gewesen sein könnte. Auch für den besser erforschten Orley-Schüler Pieter Coecke van Aelst ist eine Reihe von Tapisserie-Entwürfen überliefert. ${ }^{159}$ Stichhaltige Beweise für die unter anderem bei Wessely geäuBerte Behauptung, van Orley sei maßgeblich für die Einführung des Renaissance-Ornaments in die flämische Tapisserie verantwortlich gewesen, gibt es indes nur wenige; allerdings bestärken stilistische Übereinstimmungen zwischen Gemälden und einigen Tapisserien aus demselben Zeitraum diese Annahme. Es sei hier nur angemerkt, dass bis heute eine ganze Reihe von erhaltenen Entwürfen und solche, auf die durch die ausgeführten Tapisserien geschlossen werden kann, seiner Hand zugeordnet werden. ${ }^{160}$

157 Ausführlich wird dieses Thema u. a von AINSWORTH 1982 u. CAMPBELL 2002 behandelt; vgl. auch PAREDES-DEMETER 2019, S. 19-28.

158 Vgl. LECOQ 2019, S. 76-78. In Bezug auf die Glasfenster in der Sakramentskapelle von St. Gudula in Brüssel ist überliefert, dass Coxcie die noch nicht umgesetzten Kartons seines Lehrers Bernard van Orley zur Verfügung standen. Unter Berücksichtigung des einzigen bereits unter van Orley ausgeführten Fensters in der Sakramentskapelle, konnte er sich bei bei seinen Entwürfen für die Fenster im nördlichen und südlichen Transept auf die Vorarbeit seines Lehrers stützen. Der Klerus von St. Gudula hatte diese Entwürfe van Orleys im Oktober 1541 sowie im
Von Bedeutung ist in diesem Zusammenhang die Übersetzung eines Verses aus dem Lobgedicht, das Domenicus Lampsonius in seiner Sammlung von Künstlerportraits, den Pictorum aliquot celebrium Germaniae inferioris effigies, zusammen mit einem Kupferstich 1572 veröffentlichte. Bereits der zweite Vers weist van Orley eine spezifische Fertigkeit zu: „[...] doctissima pingere vestes“. ${ }^{161}$ Es hat den Anschein, dass schon van Mander, für den dieses kurze Gedicht als die maßgebliche Quelle für seine Biographie gedient haben könnte, den Begriff ,vestes“ mit Tapisserien in Verbindung gebracht hat, obwohl nicht sicher ist, was Lampsonius damit meint. ${ }^{162}$ Van Mander lobt van Orleys Verdienste als Gestalter von Tapisserien. Darunter seien prestigeträchtige Aufträge aus dem Umfeld des Hauses Habsburg gewesen, die ihn für die teilweise monumentalen Projekte gut bezahlt hätten. ${ }^{163}$ Es ist zu überlegen, ob der Vers vielleicht nur zu verstehen gibt, dass van Orley vor allem für seine figürliche Malerei, und hier besonders für seine Darstellung der Kleidung (,,vestes“), von seinen Zeitgenossen geschätzt wurde. Ein wirkliches Lob enthält das Gedicht nicht, wie

Januar 1542 erwerben können (s. hierzu MIEDEMA 1995, Bd. 2, S. 327 f.). Für die Quellen s. LEFÈVRE 1945, S. 117-162. Zur stilistischen Unterscheidung zwischen van Orleys Fenster und denen seines Schülers s. VAN DEN BOOGERT 1992b, S. 57-80.

159 Vgl. CAMPBell 2002, S. 302. Zum Werk Coecke van Aelst s. u. a. ROOBAERT 2004, passim.

160 Vgl. CAMPBELl 2002, 287 f. u. Miedema 1995, Bd. 2, S. 327; s. auch SNYDER 1985, S. 429.

161 Zit. nach Miedema 1995, Bd. 2, S. 324 u. 328 für Originalwortlaut, s. Ebd., Anm. 3.

162 Hierzu Miedema 1995, Bd. 2, S. 324.

163 ,Waer in hy hadde een sonderlinge vast en veerdige handelinge en wierdter seer heerlrijk van betaelt [...]“ (van Mander 1604, S. 211). 
Miedema bemerkt, was auch der Bewertung des Künstlers bei van Mander entspräche. ${ }^{164}$

Tatsächlich hält diese Alternative der stilistischen Untersuchung meines Erachtens durchaus Stand. Betrachtet man den reichen Faltenwurf der dynamisch agierenden Figuren auf der Mitteltafel des Hiob-Retabels von 1521 mit den für van Orley charakteristischen wehenden Stoffen, die schon die Antwerpener Manieristen zeigen, findet man eine starke Akzentuierung der plastischen und stofflichen Wiedergabe von Kleidungsstücken [ABB. 18]. Auch zeigt uns diese Tafel ein eindrückliches Beispiel für eine den Figuren in gewisser Hinsicht untergeordnete Architektur. Diese sich weit in die Tiefe erstreckende Architektur, bildet ein allseits geöffnetes Gehäuse, in das die monumentalen Figuren gestellt sind. Die auffällige Überschneidung der Architektur durch die Figuren, deutet ebenfalls darauf hin, dass van Orley den Figuren den Vorrang zuweist. Eine Auszeichnung des Meisters als ,guten Figurenmaler ${ }^{6}$ mit einem besonderen Augenmerk auf deren Bekleidung könnte darauf Bezug nehmen. Bei den Figuren und den komplizierten Bewegungsmotiven vor allem auf der Mitteltafel sieht man reiche und vielfältige Gewänder, die ihrerseits teils in starker Bewegung gezeigt werden. Denkbar wäre, dass sich das Lob der von Lampsonius herausgestrichenen „vestes“ auf van Orleys Gewandstil und die überragende naturalistische Wiedergabe dieser Stoffe und Materialien bezieht.

Trotz des zurückhaltenden Echos bei Lampsonius und Karel van Mander gilt van Orley heute als einer der erfolgreichsten Maler in den 1520er und 1530er Jahren, dem bereits früh attestiert wurde, mit dazu beigetragen zu haben, die Formen der italienischen Hochrenaissance in die flämischen Tapisserie-Produktion eingeführt zu haben. ${ }^{165}$ Sicher ist, dass er seit 1515 Meister in Brüssel war und wenige Jahre später, 1518 oder 1520, in der Nachfolge Jacopo de' Barbaris, Hofmaler bei der Generalstatthalterin der Spanischen Niederlande, Margarete von Österreich, wurde. Noch vor seiner Ernennung begann er 1515, die Angehörigen der Familie seiner Herrin zu porträtieren, darunter sieben Bilder, die Margarete ihrem Neffen, dem späteren Karl V., schenkte. Ein Jahr vor seiner Ernennung wurde van Orley in die Antwerpener Lukasgilde aufgenommen. ${ }^{166}$ Nach dem Tod der Generalstatthalterin erhielt er nach fünfjähriger Unterbrechung 1532 erneut das Amt des Hofmalers bei Margaretes Nachfolgerin Maria von Ungarn. Etwa seit den späten 1520er Jahren lässt sich die oben exemplarisch beschriebene Veränderung seines Stilidioms beobachten, die differenzierter ausfällt als bei Jan Gossaert, der in dieser Zeit bereits auf der Höhe seines auf einer Synthese beruhenden (früh)-romanistischen Idioms angelangt war. ${ }^{167}$ Es lässt sich nicht sicher sagen, ob diese bei van Orley zu beobachtende, plötzliche Hinwendung zu italienischen Vorbildern seiner Funktion als Hofmaler geschuldet ist und ob er damit gewissermaßen den Ansprüchen seiner Patronin gerecht zu werden versuchte. Angesichts der Tatsache, dass sein Schüler Michiel Coxcie, den man später den ,flämischen Raffael' nen- 
nen wird, unmittelbar nach einem fast zehnjährigen Aufenthalt in Italien seinen Meister in der Funktion des Hofmalers bei Maria beerbt, ist es höchstwahrscheinlich kein Zufall, dass ein in Italien geschulter Künstler, der eigens zu dem Zweck, die italienische Renaissancemalerei zu studieren, dorthin gereist war, zum Hofmaler berufen wurde. Möglicherweise war er sogar entsendet worden, um sich für den Dienst am Brüsseler Hof fortzubilden. ${ }^{168} \mathrm{Im}$ Übrigen wurden in den Jahren von 1516 bis 1530 in Brüssel eine Reihe von Tapisserien nach Kartons von Raffael gewebt, die van Orley möglicherweise hatte studieren können. ${ }^{169}$ Neben der Tradition des altniederländischen Detailnaturalismus steht bei ihm erkennbar das Vorbild der figürlichen Malerei in Italien im Fokus, was seinen Schüler Coxcie zu seinem Studium der Werke Raffaels in Rom inspiriert haben könnte.

In den 1520er Jahren muss die Werkstatt van Orleys eine Reihe von Mitarbeitern umfasst haben, die nötig waren, um die nicht

168 Für weitere Ausführungen hierzu s. Abschn. 3.2.1.

169 Vgl. BÜCKEN 2019, S. 29-38. Es ist bekannt, dass die Teppiche nach Entwürfe für Raffaels Serie mit den Taten der Apostel von 1517 bis 1520/21 in der Werkstatt von Pieter van Edingen van Aelst in Brüssel gewebt wurden (vgl. SHEARMAN 1972, S. 138). Für den Gebrauch in der Weberei wurden die Kartons in Streifen geschnitten, die noch vor 1528 in die Weberwerkstatt des Jan van Tiegen in Brüssel gelangten, wo sie bis 1540 verblieben und vielfach für Produktionen der Werkstatt aufgegriffen wurden (vgl. SHEARMAN 1972, S. 143-145). Das bedeutet, dass sie nicht nur für die Ausführung des originären Auftrags verwendet wurden, sondern auch durch Weber wie besagten Jan van Tiegen aufgegriffen und variiert wurden - in ähnlicher geringe Zahl von Bildern in dieser Zeit fertigzustellen. ${ }^{170}$ Darunter finden sich zahlreiche Kopien eines Portraits von Margarete von Österreich, die nicht unbedingt die Beteiligung des Meisters voraussetzen, ${ }^{171}$ aber die serielle Produktion der Werkstatt veranschaulichen. In diese Phase könnte auch die Herstellung von großformatigen Tapisserie-Entwürfen fallen, wie CAMPBELL vermutet. ${ }^{172}$ Eine Tätigkeit, für die Bernard van Orley bei van Mander hauptsächlich gelobt wird. Der Teppich sei sein ,Medium“ gewesen und er habe eine Reihe von großen, nicht näher genannten Aufträgen bekommen. ${ }^{173}$ Viele dieser umfangreichen Aufträge gingen vom habsburgischen Hof selbst aus. ${ }^{174}$ So gestaltete van Orley beispielsweise neun großformatige Tapisserien mit Allegorien der Tugenden, die sich auf den Kaiser bezogen. ${ }^{175}$ Weiteres ist zu diesem Werk nicht überliefert.

Anders sieht es bei der Passionsserie aus, deren Umsetzung in einem Vertrag mit Pieter de Pannemaker, dem Teppichweber von Margarete von Österreich, bei dessen Festsetzung

Weise können solche Kartons, etwa in Form von Abzeichnungen einzelner Modelle auch in die Hände von Malern gelangt sein. Eine graphische Reproduktion durch den niederländischen Stecher Cornelis Massys, den Sohn des Maler Quinten, lässt sich etwa für dessen Stich des Wunderbaren Fischfangs nach Raffael annehmen, da das Motiv Teil der Apostelserie war (vgl. HARNACK 2018, S. 129).

170 s. hierzu die umfangreichen Ergebnisse von FARMER 1994, passim.

171 Vgl. FARMER 1994, S. 27.

172 Vgl. CAMpBell 2002, S. 288.

173 Van Mander 1604, S. 211.

174 Vgl. CAMPBELl 2002, S. 288.

175 Abbildungen bei CAMPBELL 2002, Kat.-Nr. 17 u. Abb. 128-130. 
van Orley als Zeuge diente, festgesetzt ist. Die Serie sollte aus vier Teppichen bestehen, die Christus in Gethsemane, die Kreuztragung, die Kreuzigung und die Grablegung darstellen. ${ }^{176}$ Unklar ist dabei, ob van Orley auch der Gestalter der Entwürfe war oder in seiner Funktion als Hofmaler lediglich als Berater hinzugezogen wurde. ${ }^{177}$ Angesichts der groBen stilistischen Unterschiede zwischen den beiden ersten Szenen und den beiden letzteren ist in der Forschung die These geäußert worden, dass zwei Künstler sich den Auftrag geteilt haben könnten. DELMARCEL hält für die beiden ersten Teppiche die sich durch eine starke Anlehnung an ikonographische und stilistische Vorbilder aus der Zeit um 1500 auszeichnen, den Brüsseler Maler Colijn de Coter für den Urheber, während die anderen beiden stilistisch eher van Orley zugeordnet werden können. ${ }^{178}$ Auch zeitlich liegen die beiden Paare um einige Jahre auseinander. Während die ersten um 1518 gewebt wurden, werden die anderen beiden später, in die Zeit etwa zwischen 1520 und 1522 datiert. Die wichtigste Stütze für ihre Zuschreibung an van Orley bilden die Vorlagen der beiden Bilder. Die Figuren sowohl von der Kreuztragung wie der Gethsemane-Szene zeigen deutlich den Ein-

176 Vgl. DelmarCel 1992. Abbildungen bei CAMPBELL 2002, Abb. 131-134 u. Kat. Brüssel 2019, S. $160-167$.

177 Vgl. CAMPBELl 2002, S. 287-289.

178 Vgl. Delmarcel 1992, S. 138-140.

179 Vgl. UNVERFEHRT 2007, S. 38

180 Vgl. Delmarcel 1992, S. 134. CAMPBell vergleicht außerdem die die ferne Landschaft des Hintergrundes mit dem dort erkennbaren Kalvarienberg mit Raffaels Gemälde Spasimo di Sicilia, welches kurz vor 1520 als Teppichadaption fluss der Dürergraphik. Aus Dürers Niederlande-Tagebuch wissen wir, dass der Nürnberger sich 1520 in den Niederlanden aufgehalten hat und von Bernard van Orley beherbergt wurde. ${ }^{179}$ Zudem hat sich eine Zeichnung mit Dürers Monogramm erhalten, die eine sehr ähnliche Gethsemane-Szene zeigt und auf 1520 datiert wird. Vor allem die Landschaft und die Figur des schlafenden Petrus weisen eine starke Nähe zum entsprechenden Teppich auf. ${ }^{180}$

$\mathrm{Zu}$ den Spezialisten in van Orleys Werkstatt zählte in den 1520er Jahren auch der Italiener Tommaso Vincidor, der sich in dieser Zeit bei der Anfertigung von Tapisserien nach eigenen Entwürfen in Brüssel befand und von dem er möglicherweise Eindrücke von der römischen Renaissancemalerei aus erster Hand vermittelt bekam. Ihre Bekanntschaft hatten beide bereits im Sommer 1520 gemacht. CAMPBELL sieht darin eine Möglichkeit, wie konkrete Vorbilder Raffaels zu van Orley gelangt sein könnten, für die eine Herleitung von den Kartons der Apostelserie nicht ausreichen. ${ }^{181}$ Für die Darstellung seiner Beweinung Christi, die als einzelne Tapisserie zwischen 1520 und 1525 entstand, könnte er sich beispielsweise an Vincidors ornamentale Giochi di

in Brüssel für den Kardinal Bernardo Dovizi da Bibbiena verfertigt worden war (vgl. CAMPBELL 2002, S. 292 u. Kat.-Nr. 25).

181 Zur Bekanntschaft zwischen Bernard van Orley und Tommaso Vincidor s. AINSWORTH 1982, S. 100 f. u. AINSWORTH 1990, S. 60 f. Für die möglichen Einflüsse aus Raffaels Werk sowie hierfür in Frage kommenden Werke s. CAMPBELL 2002, S. 293 f. u. DE MEÛTER 2019, S. 54 f. 
putti-Serie für die Rahmung des Teppichs orientiert haben. ${ }^{182}$ Der Hinweis im Zusammenhang mit dem Hiob-Retabel auf italienische Ornamentstiche könnte durch die Bekanntschaft mit Vincidor gestützt werden. Eine Darstellung der Beweinung Christi bildet das Mittelbild des um 1525 entstanden Haneton-Triptychons, dessen Seitentafeln jeweils den Stifter und seine Frau zeigen. Es ist unklar, welches der beiden Werke zuerst entstanden ist, oder ob für beide eine Zeichnung van Orleys angenommen werden muss, die dann sowohl von seinen Mitarbeitern für das Retabel als auch von der Weberei aufgegriffen wurde. ${ }^{183}$ Allerdings bezeugt dieses Beispiel das Kopieren von Motiven als einen dem Werkstattbetrieb immanenten Prozess. Ähnlich wie beim Besuch Albrecht Dürers besteht die Möglichkeit, dass van Orley von Vincidor Zeichnungen und Drucke, die dieser aus Rom nach Brüssel mitgebracht haben könnte, kaufte. Vor diesem Hintergrund ist möglicherweise auch eines der größten Projekte, dessen Entwurf der Werkstatt van Orleys zugeschrieben worden ist, zu

182 Eine Abbildung findet sich bei CAMPBELL 2002, S. 295, Abb. 136.

183 Vgl. CAMpBell 2002, S. 295 mit Verweis auf AINSWORTH 1990, S. 43-45 u. FARMER 1994, S. $30 \mathrm{f}$.

184 Kat. Brüssel 2019, S. 180. Die Tapisserien befinden sich heute im Museo di Capodimonte in Neapel, während die sieben Kartons sich in der Sammlung des Pariser Louvre befinden. Abbildung finden sich bei CAMPBELL 2002, S. 296, Abb. 140 u. Kat. Brüssel 2019, S. 181-183, Abb. 1-6.

185 Laut der aus dem 19. Jh. tradierten Dokumentation ist das Retabel erst nach dem Tod der Regentin 1531 von deren Hofbeamten in Auftrag gegeben und nicht vollendet worden. Das unfertige Triptychon sei dann von den Nachkommen Bernard van Orleys an Marcus Geraerts d. verstehen: Der monumentale Teppich mit der Schlacht von Pavia, ${ }^{184}$ der nicht ohne Kenntnis der von Raffael geprägten Historienmalerei, etwa dem Fresko der Schlacht an der Milvischen Brücke, das nach Raffaels Entwürfen posthum 1520-1524 in der Sala di Costantino in Rom von Giulio Romano umgesetzt wurde, hätte entstehen können.

Das späte Werk van Orleys wird durch das auf 1534 datierte Passionstriptychon in der Onze-Lieve-Vrouwekerk in Brügge repräsentiert [ABB. 24]. Ursprünglich soll es sich um einen Auftrag Margaretes gehandelt haben, die dieses Retabel für die Aufstellung in ihrer Grabkapelle in der Klosterkirche von Brou im französischen Bourg-en-Bresse vorgesehen hatte. ${ }^{185}$ Das Retabel umfasst eine Kreuzigungsdarstellung auf der Mitteltafel und je zwei Passionsszenen auf den Innenseiten der Flügel. Die Darstellungen von Margarete von Österreich und der ihr gegenübergestellten Nichte Isabella von Österreich in der Personifikation der Justitia, die zu beiden Seiten des Kreuzesstammes zu sehen sind, deuten auf

Ä. verkauft worden. Dieser habe die unfertigen Seitenflügel vervollständigt. Erst Margarethe von Parma, die 1559 von Philipp II. als Generalstatthalterin in den Niederlanden eingesetzt worden war und damit Maria von Ungarn, die wiederum Nachfolgerin Margarethes von Österreich gewesen war, beerbte, habe das Retabel an seinen heutigen Standort in Brügge verbringen lassen. Dort wurde es in der unmittelbaren Nähe der Gräber von Maria von Burgund und Karls dem Kühnen, zwei burgundischen Regenten des späten 15. Jhs. aufgestellt. Im Jahr 1589 soll das Retabel von Frans Pourbus restauriert worden sein (für die Quellen hierzu s. WAUTERS 1893, S. 21 u. Lavallaye 1943, S. 47. Vgl. MieDEMA 1995, Bd. 2, S. 327 sowie Kat. Brüssel 2019, S. 150. 
Margarete als Auftraggeberin hin. ${ }^{186}$ Gezeigt werden Christus am Kreuz, Gottvater und die Taube des Heiligen Geistes, die beiden Schächer (Lk 23,39-43), die trauernde Maria, Johannes und Maria Magdalena, die den Kreuzesstamm umfängt und die Füße des Heilands küsst. Rechts sind der gute Hauptmann, die Soldaten, die um das Gewand Christi würfeln, sowie zwei weitere namentlich nicht fassbare Reiter zu sehen. Auf der Innenseite des linken Außen-flügels ist zuoberst die Geißelung Christi dargestellt, darunter folgt die Kreuztragung. Dem gegenüber auf der rechten Seite werden die Höllenfahrt Christi und die Kreuzabnahme gezeigt.

Bei der Darstellung der trauernden, zu Boden gesunkenen Maria, die von zwei weiteren Frauen getröstet wird, der verzweifelt am Kreuzesstamm stehenden Maria Magdalena und dem erschrocken gestikulierenden Johannes handelt es sich um dynamisch gebildete und zu einer Gruppe zusammengefasste Figuren, die auf das Kreuzigungsgeschehen, genauer auf den Tod Christi am Kreuz, mit starken Affekten reagieren und durch den seitlich heranreitenden guten Hauptmann samt zweier begleitender Reiter und der im Hintergrund zu erkennenden Soldaten, die über das Gewand Christi würfeln, szenisch noch ergänzt werden. Die Gruppe von Christus am

186 Museum Boijmans Van Beuningen, Rotterdam, Inv.-Nr 1629 (vgl. FriEDLÄNDER 1967-1976, Bd. VIII, Nr. 11; AINSWORTH 2006, S. 113 u. zuletzt Kat. Brüssel 2019, S. 178, Kat.-Nr. 38).

187 Öl auf Holz, $140 \times 96,5 \mathrm{~cm}$, Museum Boijmans Van Beuningen, Rotterdam, Inv.-Nr. 1629 (RKD-Nr. 28267. Vgl. FRIEDLÄNDER 19671976, Bd. VIII, Kat.-Nr. 11 u. AINswORTH 2006, S. 113).
Kreuz, Maria und Johannes sowie der oberhalb des Kreuzes aus dem Himmel herniederfahrende Gottvater stehen in einer engen motivischen und stilistischen Verwandtschaft mit einem möglicherweise einige Jahre früher, etwa um 1525, in der Werkstatt van Orleys entstandenen Tafelbild, von dem sich weitere Versionen erhalten haben. ${ }^{187}$ Der unbußfertige Schächer mit seinem emporgehobenen rechten Arm und der komplizierten Verschränkung des an den Kreuzesbalken gebundenen linken Armes sowie dem schräg nach hinten gelegten Haupt erinnert an die Figur des Laokoon.

Die Schädelstätte, Golgotha, ist durch Gebein am unteren Bildrand gekennzeichnet. Bemerkenswert ist neben einem stark ausgeprägten chiaroscuro, welches an den späten Raffael und Giulio Romano denken lässt, ${ }^{188}$ der in ein Halbrund eingefasste Gottvater in leuchtend rotem Gewand, der sich mit offenen Armen zu seinem toten Sohn herabbeugt, während die Taube des Hl. Geistes über seinem linken Arm erscheint - ein Motiv, dass aus der dritten Genesis-Szene Michelangelos in der Sixtinischen Kapelle stammt. Am ehesten ist die Kenntnis dieses und anderer italienischer Kunstwerke noch mit der Druckgraphik zu erklären, ${ }^{189}$ mit der van Orley durch Vincidor in Berührung gekommen sein könnte, darunter möglicherweise Werke Marcanton Raimondis,

188 Das Martyrium des Hl. Stephanus von 1521 (Chiesa di Santo Stefano, Genua) Giulio Romanos sei hier neben Werken seines Meisters, wie etwa der Himmelfahrt von 1518 (Tempera auf Holz, 410 $\times 279 \mathrm{~cm}$, Vatikanische Museen, Rom), genannt.

189 Für Überlegungen hierzu s. SNYDER 1985, S. $426 \mathrm{f}$. 
der neben Antonio Pollaiuolo zu den ersten Vertretern der frühen italienischen Reproduktionsgraphik um 1520 zu zählen ist. ${ }^{190}$ Die beiden unteren Szenen auf den Flügeln, die Kreuztragung und die Beweinung, erinnern dagegen an entsprechende Blätter aus Dürers Großer bzw. Kleiner Passion; ${ }^{191}$ die stark in den Vordergrund gerückten monumentalen Figuren der graphischen Vorlage sind bei van Orley allerdings teilweise umgeformt. So hat der Scherge rechts in der Szene der Kreuztragung eine geradezu herkulische Statur und überragt deutlich und einschüchternd den gebeugten, zu Boden gestürzten Christus.

Aus Dürers Reisetagebuch wissen wir, dass er 1521 bei van Orley zu Gast war und diesen möglicherweise porträtierte, was ein erhaltenes Portrait des Malers aus dieser Zeit nahelegt. ${ }^{192}$ Er sei dort mit einem äußerst üppigen Festmahl empfangen worden, heißt es in seinem knappen Bericht, was als Ausdruck der Wertschätzung, die Dürer bei den niederländischen Künstlern seiner Zeit genoss, zu deuten ist. Es ist nicht unwahrscheinlich, dass van Orley bei dieser Gelegenheit Drucke von Dürer erwarb, von denen er ohnehin bereits

190 Vgl. GramaccinI - MeIER 2003, S. 10 u. 2732.

191 Ab 1510 gedruckt; erst 1511 offiziell in Nürnberg herausgegeben. Enthält 12 Holzschnitte, jeweils ca. $28 \times 39$ cm, darunter: „Kap. 6: Christus wird zur Kreuzigung geführt (Kreuztragung)“ u. „Kap. 9: Christus wird vor seine Mutter gelegt (Beweinung)“. Der beigegebene lateinische Text stammt von dem Nürnberger Ordensgeistlichen und Humanisten Benedictus Chelidonius. Sieben der Holzschnitte sind mutmaßlich bereits zwischen 1496 bis 1498 entstanden, die restlichen fünf erst 1510 . manches besessen haben wird. Die Kreuzabnahme wiederum weist gewisse Übereinstimmungen mit Dürers Beweinung Christi aus der Kleinen Passion auf. ${ }^{193}$ Die Figuren sind ähnlich wie auf dem Blatt größtenteils im Dreiviertelprofil gezeigt, während einzig der auf dem Boden liegende, von Maria gestützte Leichnam Christi frontal zum Betrachter gewendet ist. Die Dornenkrönung auf der linken Seite - wo auch im Hintergrund die Geißelung zu erkennen ist - lässt sich nicht unmittelbar mit einem graphischen Vorbild verbinden, man gewinnt jedoch den Eindruck, dass hier ein ganz ähnlicher Schergen-Typus wie bei der Kreuztragung aufgegriffen wird und wie ihn Raffael etwa in seinem Gemälde der Kreuฉtragung Christi von 1516 verwendet hat. ${ }^{194}$ Der den Oberkörper betonende eng anliegende gelbliche Lederharnisch mit den herausragenden weißen Hemdsärmeln ist wiederum ein Motiv, das van Orley wenn nicht diesem konkreten Vorbild, so doch einem anderen mit italienischer Provenienz bzw. dessen graphischer Adaption entnommen haben könnte. Die dem gegenüberliegend dargestellte Höllenfahrt versucht, stilistisch zu den anderen Darstellungen des Retabels aufzuschließen, enthält

192 Zum Aufenthalt Dürers bei Massys vgl. UNVERFEHRT 2007, S. 38-41. Unter den Portraits, die Dürer in seinem Tagebuch nennt, ist das von Massys nicht explizit genannt (vgl. UNVERFEHRT 2007, S. 44-46).

193 Um 1509-1510; Holzschnitt, ca. $127 \times 98$ mm (Bartsch VII, Nr. 43).

194 Öl auf Leinwand (urspr. auf Holz), 318 $\times 229 \mathrm{~cm}$, Prado, Madrid, Inv.-Nr. P000298. Auch unter dem Titel Il Spasimo di Sicilia bekannt (erstmals erwähnt im Inventario Palacio Real de Madrid, III, Madrid, 1686, S. 12; Kat. Prado 1985, S. 526 f. u. zuletzt DAL BELLO 2012, S. 84 f. 
aber einige Besonderheiten, deren Ursprung nicht eindeutig zu klären sind. Zum einen entbehrt die geduckte Figur Christi, die zugleich durch einen großen Ausfallschritt höchste Eile suggeriert, jeder Bodenhaftung, zum anderen sind die räumlichen Verhältnisse nicht klar. ${ }^{195}$ Christus scheint seinen rechten Arm den Seelen im Limbus, der als schwarzer Abgrund mit einer Art Höllenofen in der Ferne dargestellt ist, entgegenzustrecken, während er gleichzeitig mit einem Satz über diese hinwegspringt. Diese merkwürdige Darstellungsweise drückt eine starke Dynamik aus. Im Übrigen hält Christus die Siegesfahne, die traditionell bei der Auferstehung als Zeichen des Sieges über Tod und Teufel dargestellt ist. Im Schwarz des Hintergrundes verweist sein Nimbus in Form und Farbe auf das Empyreum in der Mitteltafel, vielleicht als Andeutung, dass den befreiten Seelen durch das Erlösungsopfer Christi das Himmelreich geöffnet ist. Am ehesten lässt sich die Figur des Christus noch mit dem entsprechenden Blatt aus Dürers Kupferstichpassion von 1512 vergleichen. ${ }^{196}$ Auch hier tritt Christus frontal zum Betrachter gerichtet von links heran und ergreift mit der rechten Hand eine der sich im Limbus befindenden Personen, während er mit der linken die Siegesfahne hält.

Der Einblick in die stilistische Entwicklung Bernard van Orleys in der Zeitspanne von etwa 1510 bis 1535 , in die Charakteristika seiner Kunst und in die für ihn maßgeblichen Bezugspunkte und Vorbilder zeigt,

195 Eine vergleichbare Darstellung ist auf dem Passionsretabel von Oplinter (um 1530) zu sehen (Koninklijke Musea voor Kunst en Ge- welche Impulse Michiel Coxcie von seinem Lehrer empfangen konnte und unter welchen Aspekten Coxcies Beziehung zu seinem Lehrer van Orley im Folgenden zu erörtern sein wird. Der ,Romanismus', wie er unter anderem von Jan Gossaert und Bernard van Orley in den 1520er und 1530er Jahren vorbereitet worden war, bildet den unmittelbaren Anknüpfungspunkt und die Grundlage für Michiel Coxcie und eine neue Generation von Malern, die in den 1540er Jahren aktiv werden und die weitere Entwicklung bis zum Ende des Jahrhunderts prägen werden. Die Rückkehr seines Schülers aus Rom erlebte Bernard noch, bevor er am 6. Januar 1542 in Brüssel verstarb.

schiedenis, Brüssel; Inv.-Nr. 3196). Zuletzt behandelt bei BEHLING-VAN-PUYVELDE 2000, S. 72-79.

196 Christus in der Vorbölle, Kupferstich, ca. $117 \times 75$ $\mathrm{mm}$ (Bartsch VII, Nr. 16). 


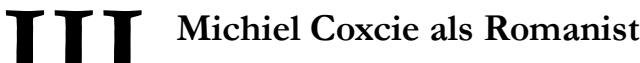 in den Niederlanden}

\subsection{Eine Annäherung an die Lehrjahre in den südlichen Niederlanden (vor 1530)}

Trotz der großen Schwierigkeiten bei der Bestimmung eines Frühwerks kann angenommen werden, dass Coxcie, wie van Mander schreibt, tatsächlich beim Brüsseler Maler Bernard van Orley ausgebildet worden ist. ${ }^{197}$ Die zeitliche Nähe des Erscheinens des SchilderBoeck (1604) zu Coxcies Sterbejahr 1592 lässt die Vermutung zu, dass van Mander die Informationen über das Leben des Malers noch mehr oder weniger aus erster Hand hatte erfahren können. Auch das weitgefasste Betätigungsfeld Coxcies als peintre-inventeur, etwa als Gestalter von Tapisserien und farbigen Glasfenstern, rückt ihn in die Nähe der Werkstatt van Orleys, welcher sich besonders in seinen späten Jahren auf solche Entwürfe spezialisiert haben soll. ${ }^{198}$ Ein weiterer Schüler van Orleys, Pieter Coecke van Aelst, hinterließ ein ähnlich vielgestaltiges Lebenswerk wie sein Meister. Außerdem spricht der Auftrag, die bei Bernard van Orleys Tod unvollendet gebliebene Serie von Glasfenstern für die Sakramentskapelle von St. Michael und St. Gudula in Brüssel zu vervollständigen, ebenfalls für

197 Vgl. van Mander 1604, fol. 258v.

198 Vgl. AINSWORTH 1990, S. 41-64.

199 Neben den erhaltenen Glasfenstern in St. Gudula in Brüssel hat sich eine Zeichnung Coxcies für ein heute verlorenes Fenster für St. Bavo in Gent erhalten, das er im Auftrag Karls V. entworfen haben soll (Staatsarchiv Brüssel, $910 \mathrm{x}$ $315 \mathrm{~mm}$, Zeichnung auf Papier mit brauner Tinte und brauner Wasserfarbe, für Abb. s. JONCKHEERE - SUYKERBUYK 2013, S. 187, Kat.-Nr. eine Verbindung beider Künstler. Es gibt Hinweise, die darauf hindeuten, dass Coxcie die Entwurfszeichnungen van Orleys aufgriff bzw. sich daran orientierte, was eine sichere Zuweisung der erhaltenen Buntglasfenster bis heute erschwert. ${ }^{199}$

Auch ist unklar, ob er bereits Meister war, bevor er mit potenziellen Empfehlungen des Brüsseler Hofes nach Rom ging, da sich hierzu bisher keinerlei Archivalien haben auffinden lassen. Eine Möglichkeit wäre auch, dass Coxcie in van Orleys Werkstatt als Geselle bis zu dessen Inhaftierung 1527 angestellt blieb, während der Abschluss seiner Ausbildung erst in Italien erfolgte, bevor er sich 1539 als Freimeister in Mecheln niederließ, wie ein entsprechender Eintrag im Verzeichnis der Lukasgilde bezeugt. ${ }^{200}$ So wie die späten Werke Gerard Davids die Mitarbeit seines Schülers Adriaen Isenbrandt nahelegen und stilistisch nur schwer von dessen eigenen unterschieden werden können, ${ }^{201}$ bestand vielleicht auch zwischen Bernard van Orley und Michiel Coxcie eine ähnlich stark ausgeprägte stilistische Übereinstimmung. Möglicherweise hatte auch er den Stil seines Meisters nachgeahmt, was zusätzlich, aber nicht zwingend, auch auf seine spätere Tätigkeit als Kopist vorausweisen würde. Erschwert wird die Bestimmung eines Frühwerks vor allem dadurch,

12). Zu den Glasfenstern von St. Gudula s. REINTJENS 2013, S. 138-155.

200 Längst nicht jeder Maler wurde nach dem Abschluss einer mehrjährigen Ausbildung auch Meister und erlangte damit die Voraussetzung für die Gründung einer eigenen Werkstatt (vgl. CAMPBELL 1981, S. 48 f. und MARTENS 2004/05, S. 51.

201 Vgl. BORCHERT 1998, S. 18. 
dass sich Coxcies eigener Stil erst anhand der ab etwa 1530 entstandenen Werke überhaupt charakterisieren lässt, diese aber zugleich bereits den vollen Umfang von Coxcies Italienrezeption zeigen, welche weit über die seines Lehrers hinausgeht. Zu diesem Zeitpunkt war Coxcie bereits um die 30 Jahre alt - umso verwunderlicher also, dass sich keine Nachricht über ein Werk vor dieser Zeit erhalten hat. Zur weiteren Klärung des Sachverhalts wird es daher nötig sein, den Stil Coxcies in beide Richtungen zu untersuchen, also inwieweit sich Hinweise auf van Orley finden lassen und in welchem Verhältnis diese zur Rezeption italienischer Vorbilder stehen.

Weiterhin erhärtet das unmittelbare Nachrücken Michiel Coxcies in die bis zu seinem Tod von Bernard van Orley bekleidete Stellung des Hofmalers bei der Generalstatthalterin Maria von Ungarn die These einer möglichen Entsendung Coxcies nach Rom, ${ }^{202}$ um dort seine Ausbildung mit dem Studium der italienischen Hochrenaissance fortzusetzen und über den von van Orley erreichten Grad der Italienrezeption hinauszuwachsen. Möglicherweise geschah dies sogar auf ausdrücklichen Wunsch der habsburgischen Statthalterin. Tatsache ist, dass Coxcie bereits unmittelbar nach seiner Rückkehr aus Italien im Jahr 1539 damit begann, für Maria von Ungarn, die einflussreichen Gilden von Mecheln, Antwerpen und Brüssel sowie bald darauf

202 Die erste Erwähnung Coxcies als Hofmaler stammt aus dem Jahr 1546: „Meester Michiel, schildere der Coninclycke Majesteyt [...] afgequeten anno XVXLVI [vollständig bezahlt im Jahr 1546]“ (zit. nach BONENFANT - FRANKIGNOUELLE 1535, S.111. Vgl. auch AINSWORTH 2010, S. 77 u. JONKHEERE-SUYKERBUYK 2013, S. $24 \mathrm{f}$. auch für Philipp II. und Karl V. zumeist großformatige Werke in der maniera italiana zu malen, was eine umfangreiche Kenntnis der italienischen Kunst in der ersten Hälfte des 16. Jahrhunderts voraussetzt.

\subsection{Das Studium der italienischen Kunst in Rom (ca. 1528-1539)}

\subsubsection{Die epochalen und biographischen Gründe für die Reise nach Italien}

Den meisten Malern der südlichen Niederlande waren die Kunstwerke Italiens zu Beginn des 16. Jahrhunderts weitestgehend unbekannt. Lediglich über den indirekten Weg der Druckgraphik ergaben sich Möglichkeiten für ein Studium dieser Werke. ${ }^{203}$ Erst als vermehrt Entwürfe für Tapisserien aus Italien nach Flandern gelangten, um von einer der Teppichwebereien in Brüssel verfertigt zu werden, begann sich dies zu ändern. ${ }^{204}$ In den letzten Jahren ist vielfach darüber diskutiert worden, dass es einigen Künstlern möglich gewesen sein muss Zeichnungen nach den Kartons mit Szenen aus dem Leben von Petrus und Paulus von Raffael anzufertigen. ${ }^{205} \mathrm{Als}$ gesichert gilt etwa, dass Quentin Massys' Sohn Cornelis, der sich etwa ab 1537 mit dem Medium der Druckgraphik befasste, die Kartons als Vorlage für eine Reihe von italianisierenden Stichen aufgriff; unter anderem für seinen

203 Vgl. hierzu BARTSCH 2013, S. 13-26 u. RUBACH 2013, S. 61-74.

204 Dies betrifft u. a. die von Raffael entworfenen Behänge im unteren Wandabschnitt der Sixtinischen Kapelle. Eine umfangreiche Studie hierzu liefern EVANS - WOODTHORPE et al. 2010.

205 Vgl. HARNACK 2018, S. 129 f; s. auch Abschn. 2.3 . 
Druck mit dem Wunderbaren Fischzug, der sich vergleichsweise genau an Raffaels Entwurf für die Sixtinische Kapelle orientiert. ${ }^{206}$ Wenige Jahre später nach der Ausführung wurden weitere Wandteppiche nach den Entwürfen von Giulio Romano in Brüssel gewebt, die mit in die Überlegung einzubeziehen sind. ${ }^{207}$

Die aus diesen Vorlagen gewonnenen Eindrücke sollen auch auf Bernard van Orley prägenden Einfluss ausgeübt haben. Demnach habe der in Brüssel ansässige Maler seinen Stil unmittelbar nach dieser ,Italienerfahrung', die in der älteren Literatur noch mit einer heute eher als unwahrscheinlich geltenden Reise nach Italien verknüpft wurde, maßgeblich verändert. Grundsätzlich kann konstatiert werden, dass seine Figuren größer, das heißt raumfüllender wurden und sie eine stärkere anatomische Durchbildung aufweisen. Außerdem war er sichtlich bemüht, die antikisierende Renaissancearchitektur, wie er sie auf Raffaels und Giulios Entwürfen gesehen haben mag, in seine Altarbilder einzubinden. ${ }^{208}$ Dieser, wenn auch begrenzte Eindruck von der Kunst der italienischen Hochrenaissance könnte eines der Bindeglieder zur Ausbildung Coxcies darstellen. Sein Aufbruch nach Italien fand demnach parallel zu der ab den späten 1520er Jahren einsetzenden Rezeption italienischer Druckgraphik in den Niederlanden statt, wie sie etwa bei Lucas van Leydens Serie mit den Sieben christlichen Tugenden von 1530 zu beobachten ist. ${ }^{209} \mathrm{Da}$ dieses Medium auf Grund seiner verhältnismäßig einfachen Vervielfältigung als Hauptvermittler von neuen Bildideen gelten kann, steht diese Technik in einem unmittelbaren Zusammenhang mit der Aneignung der italienischen Kunst. Entsprechend stehen auch Coxcies Entwürfe sowie deren Ausführung im Druck, die noch in die Zeit seines Romaufenthaltes datiert werden können, stellvertretend für den Aneignungsprozess, der sich in dieser Zeit bei ihm vollzog. ${ }^{210}$

Den konkreten Anlass für die Reise könnte Bernard van Orley gegeben haben, indem er seinen Schüler zu der Reise nach Italien, wie sie nun allmählich üblich wurde, motivierte - sie womöglich sogar durch seine Kontakte bei Hof, vermutlich noch vor seiner Anklage wegen Häresie 1527, zu fördern vermochte. Die Anklage seines Meisters könnte Michiel Coxcie in seinem Entschluss, nach Rom zu reisen, noch zusätzlich bestärkt haben. Van Orley hatte protestantische Predigten in seinen Räumlichkeiten halten lassen, sodass Werk- und Heimstätte des Malers und seiner Familie konfisziert wurden. Dokumentiert ist, dass er den lutherischen Prediger Nicolaas van der Elst zum Abendessen am Gründonnerstag,

sei (vgl. HARNACK 2018, S. 126; HOOGEWERFF 1928, S. 52 u. MARROW - STRAUSS 1981, S. $261-$ 267. Ähnlich wie van Manders Aussage, dass es sich bei Coxcies Gemälden hauptsächlich um Nachahmungen Raffaels handle, sah vermutlich auch Buchelius die Errungenschaften der romanistischen Malerei der ersten Hälfte des 16. Jhs. im Hinblick auf die Ansprüche seiner eigenen Zeit, nur als bedingt fortschrittlich an.

210 s. hierzu Abschn. 3.2.3. 
den 18. April 1527 eingeladen hatte. Der Maler wurde daraufhin denunziert und verbrachte mehrere Monate im Gefängnis. ${ }^{211}$ Laut der von Koenraad JONCKHEERE geäuBerten und von Maria HARNACK aufgegriffenen These war Coxcie in Folge der Festnahme seines Lehrers arbeitslos geworden und hatte deshalb den Beschluss gefasst, sich alsbald auf die Reise nach Rom zu begeben. ${ }^{212}$ Die von der älteren Forschung aufgestellte These, dass Raffaels Werkstatt für seine weitere Ausbildung in Italien in Frage komme, wird hingegen aus dem einfachen Grund hinfällig, dass dieser bereits lange verstorben war, als Coxcie die Ewige Stadt erreichte. ${ }^{213}$

Jüngst hat JONCKHEERE die Ursachen für die Rezeption der antiken Kunst in ihrem geistesgeschichtlichen Kontext, wie er auch für die Kunstgeschichte seit langem definiert ist, dabei auf HoOGEWERFFs Erkenntnisse verweisend, ${ }^{214}$ als eine „logical consequence of growing intellectual fascination with classical antiquity “ ${ }^{215}$ beschrieben. Der Humanismus des 15. Jahrhunderts hatte mit seinem Interesse an der lateinischen und griechischen Literatur, die unter anderem in Erasmus kritischer Ausgabe des griechischen Textes des Neuen Testaments gipfelte, seinen vorläufigen

211 Die Denunziation durch Grietkin van der Bossche ereignete sich am 25. April 1527. Die Quellen legen nahe, dass Bernard van Orley am 4. Mai verhört und daraufhin mindestens bis Ende des Jahres festgehalten wurde (vgl. GALAND 2013, S. 69).

212 Vgl. HARNACK 2018, S. 25 mit Verweis auf JONCKHEERE - SUYKERBUYK 2013, S. 26.

213 Vgl. NeEFs 1876, Bd. 1, S. 147 f.

214 Ebenfalls beziehen sich KOLDEWEIJ - HERMESDORF - HUVENNE 2006/07 (Bd. 1); SNYDER 2005 sowie CHIPSS - SMITH 2004 auf HOOGEWERFF.
Höhepunkt erreicht. ${ }^{216}$ Unter diesen Umständen ist es verwunderlich, dass es in Humanistenkreisen im Umfeld des habsburgischen Hofes dem Anschein nach erst vergleichsweise spät zu einem Interesse an der die Antike rezipierenden italienischen Kunst kam. Die Sammlungen der Habsburger zeigen hingegen kurz nach 1500 bereits eine ausgeprägte Vorliebe für diese Kunst, sodass es denkbar ist, dass sowohl gelehrte Auftraggeber wie auch die traditions- und zunftgebundenen Maler zunächst einer ,Nachhilfe ${ }^{6}$ bedurften, bevor sich daraus zunächst eine Art Italienmode entwickelte. Die ersten Tendenzen hin zu diesem ,Italianismus', die sich bei Bernard van Orley, dem Hofmaler Margaretes von Österreich, zeigen, könnten eine Reaktion auf den Geschmack seiner Mäzenin und die zunehmende Nachfrage solcher Werke darstellen. Jedenfalls muss parallel zum humanistischen Interesse an antiken Artefakten, das in der zeitgenössischen Literatur als Topos des Herrscherlobs begegnet, etwa in dem Bericht über die Romreise von Jan Gossaerts Förderer Philipp, auch von einer gezielten Förderung der an Italien orientierten Kunst durch fürstliche Auftraggeber ausgegangen werden. ${ }^{217}$

215 JONCKHEERE 2013a, S. 72.

216 Erasmus: Novum Instrumentum omne (1. Auflage), Basel 1516.

217 Deutlich wird dies am Beispiel des Historiographen Geldenhouwer, der von den ,gelehrsamen" Gesprächen seines Herren Philip von Burgund und der Beauftragung Gossaerts, die antiken Monumente zu zeichnen, um damit die humanistische Bildung seines Dienstherrn topisch zu verewigen, berichtet (vgl. hierzu HARNACK 2018, S. 14 f.). 
Die Anstellung derart bewanderter Maler, wie etwa Jacopo de' Barbari und später Bernard van Orley, am Hof der Generalstatthalterin sowie schließlich das Erscheinen Michiel Coxcies in einer Zeit, in der Tizian zum kaiserlichen Hofmaler ernannt wurde, unter-streicht die These, dass auch der Hof in Brüssel nach Malern verlangte, die etwas von der italienischen Kunst verstanden. Deutlich wird dies schon früher bei den ephemeren Aufbauten und tableaux vivants beim Einzug Karls V. in Brügge 1515, mit denen die Stadtregierung unter Beteiligung der Rederijkers und der ansässigen Künstlerschaft den Geschmack des Habsburgers zu treffen versuchte, um ihn wohlgesonnen zu stimmen. Obwohl man zu dieser Zeit noch fast ausschließlich und besonders in Brügge das altniederländische Stilideal des späten 15. Jahrhunderts bevorzugte, wie unter anderem die Werke Gerard Davids und seiner Schüler zeigen, sollen die für den Einzug geschaffenen Bilderzählungen gezielt antikisierend gestaltet gewesen sein und den

So scheint der Brüsseler Stadtrat in der Lage gewesen zu sein diese Neigung des Fürstenhauses für ihre politische Werbung zweckdienlich zu machen, etwa in Form von tableux vivants, von denen der Historiograph Remy de Puys im Zusammenhang mit der Trauerprozession für Ferdinand II. von Aragon in Brüssel berichtet. So seien dort Figuren mit Lorbeerkränzen ,in more Romanoru triumphantio, ut videre est in vetustatis monumetis" zu sehen gewesen (s. Geldenhouwer 1516, fol. 3r, zit. nach HARNACK 2018, S. 15). Einige dieser Dekorationen habe Jan Gossaert gefertigt, heißt es weiter (s. ebd., mit Verweis auf eine Zahlungsanweisung an Gossaert, publ. bei WEIDEMA - KOOPSTRA 2012, S. 14).

218 Nachzeichnungen dieser Bauwerke im Renaissancestil sind durch den Hofgeschichtsschreiber Remy de Puys De Puys überliefert in dessen Werk La triomphante et solennelle entrée de Charles-
Herrscher auch inhaltlich mit den römischen Herrschern Caesar und Augustus in Beziehung gesetzt haben. ${ }^{218}$

Im Fall Michiel Coxcies spricht daher einiges dafür, dass der Statthalterin Margarete (†1530) bzw. ihrer Nachfolgerin Maria (ab 1531) daran gelegen war, eine Ausbildung des zukünftigen Hofmalers im italienischen Stil zu besorgen, um entweder Ersatz für den 1527 inhaftierten Bernard van Orley zu schaffen oder aber um einen fähigen Maler für die $\mathrm{Zu}$ kunft bereitzuhalten. Stilistisch gesehen handelt es sich dabei um die Fortführung dessen, was bereits in van Orleys Annäherung an Raffael vorgebildet war. ${ }^{219}$ Dafür spricht auch, dass Coxcie in einem Dokument von 1587 angibt, dass er seit 1540 Hofmaler der Statthalterin Maria und Kaiser Karls V. gewesen sei. Selbst wenn in dieser Rückschau der Ruhm späterer Jahrzehnte mitschwingt, so ist die Nennung des Jahres 1540 doch insofern von Bedeutung, als dass er zu diesem Zeitpunkt

Quint en sa ville de Bruges [...] [Der Einzug Karls $\mathrm{V}$. in Brügge] überliefert. Das Original befindet sich unter der Signatur Cod. 2591 in der Österreichischen Nationalbibliothek und enthält farbig gefasste und in Tempera ausgeführte Nachzeichnungen des Einzuges und seiner ephemeren Bauten; darunter bspw. solche mit verschiedenen Triumphbögen (vgl. fol. 35v; fol. $42 \mathrm{v} \mathrm{u}$. fol. 46v) und dem ,adventus' vor der Stadt (foll. $7 \mathrm{v}-8 \mathrm{r})$.

219 Vergleichbare Beispiele eines gezielten Kulturerwerbs, der schließlich in die ,æmulatio', d. h. die Aneignung und Einbettung in die eigene künstlerische Tradition mündet, beschreibt die Kunstliteratur des 16. und 17. Jhs. Van Mander stellt die Synthese (und das Übertrumpfen) des Italienischen mit dem Flämischen als das vorrangige Ziel der Kunst der zeitgenössischen Kunst vor (vgl. MiedEMA 1973, S. 653-668). 
gerade erst aus Italien zurückgekehrt war. ${ }^{220}$ Die Nennung Karls wiederum impliziert, dass er zu diesem Zeitpunkt bereits in den Diensten des Kaisers gestanden habe, was sich jedoch erst ab sehr viel späterer Zeit tatsächlich belegen lässt. Möglicherweise ist die Verbindung zum habsburgischen Hof jedoch tatsächlich älter, als die bislang bekannten Quellen zu erkennen geben.

Die Tatsache, dass der Name Michiel Coxcie vor der Zeit in Italien in keiner einzigen erhaltenen Quelle auftaucht, hilft immerhin den Romaufenthalt zeitlich einzugrenzen. Erst nach seiner Rückkehr ist der Künstler ab 1539 mit Werken und in schriftlichen Quellen fassbar: Fünf signierte Altarbilder, ${ }^{221}$ ein Brief von seinem Mäzen König Philipp II. sowie eine Reihe notarieller Dokumente belegen den Umfang seiner Tätigkeit. ${ }^{222}$

220 VAN DEN BOOGERT 1992a , S. 124 u. 126 (Nachdr. einer bis dahin unveröffent. Anfrage Coxcies).

221 Triptychon mit dem Martyrium des Hl. Sebastian (Koninklijk Museum voor Schoone Kunstne, Antwerpen): „Michel D. Coxscin Aetatis suae 76 Fe. 1575“; Triptychon mit dem Martyrium des Hl. Sebastian (Sint-Rombouts, Mecheln): „MICHAEL D. COXCIEN PICTOR REG. FECIT ANNO 1587. AETAT. SUAE 88"; Triptychon mit dem Martyrium des Hl. Georg (Sint-Rombouts, Mecheln): „MICHAEL VAN COXCIEN PICTOR REGIUS ME FECIT. ANN. 1588 AETATIS SUAE 89“; Bild mit der Beschneidung Christi (Sint-Rombouts, Mecheln): „MICHIEL D. COXCIEN FECIT 1589. AETATIS SUAE 90“ und ein weiteres Triptychon aus St. Gudula (St. Gudula, Brüssel): „ME MICHAEL VAN COXIE PICTOR REGIUS ME FECIT ANNO SALUTIS 1592. AETATIS VERO SUAE 92”.

222 Vgl. Pinchart, Vol. 2, S. 320-321, darunter ein Brief vom 1. April 1590 von Philipp II. an den

\subsubsection{Die Ausbildung in der Freskomalerei und das künstlerische Umfeld in Rom}

In die Reihe der frühen deutschen und niederländischen Italienreisenden ist auch Michiel Coxcie einzuordnen, der sich im 16. Jahrhundert dem Studium der antiken Skulptur und der zeitgenössischen Kunstwerke italienischer Meister des Quattro- und Cinquecento widmete. ${ }^{223}$ Während sein Lehrer Bernard van Orley, anders als früher angenommen, wahrscheinlich nie in Italien war, hielt sich Coxcie ein knappes Jahrzehnt nach Pieter Coecke van Aelst, nachweislich in den 1530er Jahren, etwa ab 1528 bis zu seiner Rückkehr nach Mecheln im Jahr 1539, in Rom auf. ${ }^{224}$ Es gibt Grund zu der Annahme, dass er Protegé des aus Brabant stammenden Kardinalbischofs Willem von Enckenvoirt war, eines Weggefährten des niederländischen Papstes Hadrian VI. ${ }^{225}$ In ähnlicher Beziehung zum Kardinal wie möglicherweise Coxcie stand Marten van Heemskerck,

Feldherren Alexander Farnese mit der Anordnung, dem betagten („le grand eaige de quatrevingts et dix ans, qu'il a dejà attainct") regelmäBige Unterhaltszahlungen zu leisten. JONCKHEERE weist darauf hin, dass sich vermittels des Briefdatums sowie des genannten Alters das Geburtsjahr Coxcies für 1499/1500 bestimmten lässt (JONKCHEERE - SUYKERBUYK 2013, Anm. 4).

Zwei Dokumente von jeweils 1583 (s. SCHNEEBALG-PERELMAN 1973，S. 219-221) und 1585 (s. DUVERGER 1993, S. 192) mit Erwähnung des Alters des Künstlers von 82 bzw. 85 Jahren.

223 Vgl. LEUSCHNER 2013, S. 52 f.

224 Das Verzeichnis der römischen Lukasgilde verzeichnet für 1534: „Michele Tedesco pittore, qual fece la capella del cardinale Inckevorte in Santa Maria de Anima [...]", zit. nach HoOGEWERFF 1923, S. 21 f. Vgl. auch VAN AUTENBOER 1992, S. 7 u. LEUSCHNER 2013, S. 52.

225 s. hierzu LEUSCHNER 2013, S. 53. 
der zur selben Zeit in Rom arbeitete, aber in seinem weiteren Schaffen andere Schlüsse aus seinem Studium der italienischen Kunst zog, die keine unmittelbare Verwandtschaft mit den Werken Coxcies aufweisen. ${ }^{226}$ Die gegebene Verbindung zur römischen Kurie verschaffte Coxcie die einerseits prestigeträchtige, andrerseits aber auch ökonomisch vorteilhafte Situation, Aufträge für den hohen Klerus ausführen und dabei seine Beherrschung des, italienischen Stils', für die ihn Vasari später loben wird, unter Beweis stellen zu können. ${ }^{227}$

Einer dieser Aufträge war die Ausmalung der Kapelle Enckenvoirts in Santa Maria dell'Anima. ${ }^{228}$ Die mehrjährige Arbeit an diesem Werk gilt als das Debut Coxcies in der traditionsreichen, der nordalpinen Malerei nahezu fremden Technik der Freskomalerei, die ihm 1534 die Ehre der Aufnahme in die römische Lukasgilde bescherte. Zuvor hatte er sich, wie Vasari schreibt, gegen den Venezianer Sebastiano del Piombo durchsetzen müssen. ${ }^{229}$ In der Folge wurden ihm die Ausmalung weiterer Kapellen in derselben Kirche sowie in Alt-St. Peter aufgetragen. ${ }^{230}$ Karel van Mander erwähnt diese bedeutenden Arbeiten in der italienischen Technik in seinem Schilder-Boeck von 1604: „Hy heeft gheweest een Discipel van Bernaert van Brussel [= Bernard van Orley], en heeft grooten vlijt om leeren ghedaen, en is ghereyst buyten s'Landts: was langen tijt in Italien, daer hy vlijtigh was te teyckenen nae

226 Vgl. JONCKHEERE - SUYKERBUK 2013, S. 30.

$227, \ldots[. . .[$ il quale attese assai alla maniera italiana, e condusse in quella città molte opere a fresco, e particolamente in Santa Maria de anima due capelle“ (s. Vasari 1568, ed. Milanesi, Bd. VII, S. 585).

228 Hierzu Vasari 1568, Bd. III, S. 858 u. Eintrag im Register der röm. Campagnia di San Luca (s. o).
Raphaels en ander dinghen, heeft op t'nat geschildert, tot S. Pieters te Room in d'oude Kerck, een Verrijsnis, oock in de Duytsche Kerck S. Maria de la pace, en meer wercken die hy daer dede. ${ }^{\text {‘231 }}$ Von den Fresken in der alten Petersbasilika hat sich nichts, auch keine Vorstudie oder Nachzeichnung, erhalten.

Die erhaltenen Fresken der Barbarakapelle von Santa Maria dell'Anima hingegen zeigen eindrucksvoll den frühen italianisierenden Stil Michiel Coxcies [ABB. 25-27]. Der Zyklus besteht aus den Darstellungen von „Barbara vor den Richtern', dem ,Martyrium der Hl. Barbara', der ,Himmelfahrt Christi“ in der Apsiskalotte der Kapelle sowie einem Altarbild mit der Hl. Barbara, die als Interzessorin für den Stifter Kardinal Enckenvoirt in Erscheinung tritt [ABB. 28]. Als einzige Michiel Coxcie sicher zuzuweisende Bilder aus der Zeit in Rom stellen die Fresken und das Altarbild der Kapelle den Ausgangspunkt der stilistischen Bestimmung des Künstlers dar. In diesem Zusammenhang ist die für das spätere Schaffen so bedeutsame Auseinandersetzung mit dem Werk Raffaels, die auch van Mander erwähnt, zu diesem Zeitpunkt bereits eindrücklich ausgebildet, sodass man von einer regelrechten Faszination durch die Kunst Raffaels, der knapp ein Jahrzehnt zuvor verstorben war, sprechen kann, wie jüngst LEUSCHNER resümiert hat. ${ }^{232}$ Die konkrete Bezugnahme auf die Werke des in Florenz

s. auch JONCKHEERE - SUYKBERBUYK 2013, S. 26. Erhalten haben sich nur Coxcies Ausmalungen der Barbarakapelle von Santa Maria dell'Anima.

229 Vasari 1568, ed. Milanesi, Bd. VII, pag. 581.

230 Vgl. LEUSCHNER 2013, S. 50-63.

231 Zit. nach van Mander 1604, S. 258.

232 Vgl. LEUSCHNER 2013, S. 53. 
und Rom tätigen Malers lässt sich besonders gut anhand des Altarbildes in der Barbarakapelle beschreiben, das von Raffaels Madonna di Foligno von 1511 beeinflusst ist. ${ }^{233}$ Vergleichbar ist die Komposition. Das hochrechteckige Bild zeigt vier Figuren, nämlich die der Hl. Barbara auf der linken Seite, die den auf der rechten Seite gezeigten Kardinal, der Trinität empfiehlt. Gottvater und Christus mitsamt der Heilig-Geist-Taube kommen auf Wolken und in der Gloriole erscheinungshaft vor Augen. Während die Hl. Barbara, die Märtyrerpalme in der rechten Hand, mit dem weisenden Gestus ihrer Linken den Kardinal der Trinität empfiehlt, blickt Enckenvoirt kniend im Gebet empor, wo Christus seine Rechte segnend gegen ihn ausstreckt. Zwischen der Hl. Barbara und dem Kardinal ist ein Ausblick in eine Landschaft gegeben, die ein paar Bäume am Rand eines Hügels zeigt. Das Kolorit fällt deutlich blasser aus als bei dem berühmten Vorbild Raffaels. Coxcie verzichtet zwar auf den blau-ätherischen Bogen und die darin eingegebene Schar der Puttenköpfe, welche die Figur der Madonna umgeben; dennoch ist das Motiv einer ,himmlischen Erscheinung' mit dem Wolkenring beibehalten. Große Ähnlichkeit weist auch die Figur des knienden und anbetenden Stifters auf. In beiden Fällen handelt es sich um einen Kardinal. Anders als bei Raffaels Bild, auf dem gleich drei Heilige die Fürsprache für den Stifter übernehmen, ist bei Coxcies Altarbild aus Santa Maria dell'Anima

233 Öl auf Holz, $308 \times 198 \mathrm{~cm}$, Musei Vaticani, Rom, Inv.-Nr. 329 (Meyer zur Capellen 2001, Bd. 2, Kat.-Nr. 52, S. 98-106. Vgl. hierzu auch LEUSCHNER 2013, S. 58. lediglich die Hl. Barbara, welcher die Kapelle geweiht ist, zu sehen. Thre Linke weist auf den Kardinal, während ganz anders bei Raffael der Fingerzeig des Hl. Johannes auf die im Himmel thronende Gottesmutter deutet. Auch blickt die Hl. Barbara nicht wie der Täufer Raffaels zum Betrachter, sondern empor zur Trinität, was ihre Rolle als Interzessorin verdeutlicht.

Auch die Fresken in der Apsiskalotte, über einem profilierten Sockel und einer bräunlichen Marmorinkrustation der Kapellenwand, weisen Zitate aus dem Werk Raffaels auf, etwa aus den Fresken der Schule von Athen und der Vertreibung des Heliodor im Apostolischen Palast. Der Innenraum in der Szene mit der Hl. Barbara vor den Richtern ähnelt einem Ausschnitt aus Raffaels Schule von Athen in der Stanza della Segnatura. Der architektonische Ausschnitt zeigt eine antikische Pfeilerhalle, die nach links in die Tiefe führt, wo sie in einen überkuppelten Raum mündet. Der nur ausschnitthaft gegebene vordere Raum ist von einem Kreuzgratgewölbe überfangen, das auf Pfeilern aufsitzt, zwischen denen sich offenbar allseits Rundbogenarkaden öffnen. Die Wände sind nicht farbig gefasst, sondern zeigen eine ungleichmäßige graue Tönung, die an römische Ruinen, vor allem aus dem Bereich der Thermenarchitektur erinnert, wie sie seit den 1530ern Jahren vielfach in Rom dargestellt wurden. ${ }^{234}$ Die Farbenpracht einer Domus Aurea oder das mit Marmorinkrustationen

234 Kardinal Granvelle beauftragte den Architekten Sebastian van Noyen 1551, die Ruinen der Diokletians-thermen in Rom aufzunehmen (hierzu HARNACK 2018, S. 19) und auch in den römischen und nachrömischen Bildern von Jan 
verschalte Interieur der Barbarakapelle selbst, spiegelt sich darin nicht wider, auch nicht die goldenen Kuppeln im Fresko der Stanza d'Eliodoro, das für die Gestalt der restlichen Architektur hingegen durchaus vorbildhaft gewesen sein könnte. Im Vordergrund sind zwei Stufen zu sehen, auf denen sich mehrere in Bewegung gezeigte Personen befinden, die in einen Disput vertieft zu sein scheinen. Die Konstellation dieser Figuren, die teilweise Codices in den Händen halten, erinnert ohne dass bestimmte Gestalten übernommen wären - an Raffaels Schule von Athen. Die Hl. Barbara wird mit gebundenen Händen dem Richter vorgeführt. Dieser, auf einem Podest erhöht sitzend, stellt die Gefangene mit einer herrischen Handbewegung zur Rede. Insgesamt zeigen die Figuren eine starke Interaktion. Als stumme Zeugen des Verhörs sieht man zwei ältere Männer unter einem die Wand zur Seite hin öffnenden Rundbogen.

Das Fresko mit dem Martyrium der Hl. Barbara zeigt die Heilige an ein hölzernes Gerüst gebunden und umringt von Soldaten, die ihr mit heißen Stangen, die zuvor in einer Feuerstelle zu ihren Füßen zum Glühen gebracht wurden, zusetzen. Die bewegten muskulösen Körper der Soldaten erinnern an Figuren Raffaels, wie sie etwa in der Vertreibung des Heliodor begegnen. Eine Gestalt, wie der Soldat links

van Scorel und Marten van Heemskerck sind Ruinen zu sehen, die auf die Eindrücke in Italien zurückzuführen sind, wie Zeichnungen aus dieser Zeit belegen und erst jüngst umfangreich dargelegt wurde (vgl. DiFuRIA 2019, S. 79-156). 235 s. Abschn. 4.2.2.

236 Öltempera auf Holz, Vatikanische Museen, Inv.-Nr. 333. Im Depot der Alten Pinakothek in München befindet sich eine Coxcie zugeschriebene Tafel mit dem Titel Die Verklärung Christi im Vordergrund, mit weit auseinandergestellten Beinen und verzerrtem Gesichtsausdruck, findet sich auch in der Figurengruppe rechts auf dem Fresko Raffaels. Das Bild steht in motivischer, wie auch stilistischer Hinsicht in der Nähe der erst ab den 1570 er Jahren in gröBerer Zahl in Coxcies Werkstatt geschaffenen Heiligenmartyrien, was in einem entsprechenden Kapitel noch aufzugreifen sein wird. ${ }^{235}$

Das Wandbild mit der Himmelfahrt Christi in der Apsiskalotte bzw. der Halbkuppel des Kapellenraumes zeigt den in den Himmel aufsteigenden Christus mit ausgebreiteten Armen und nach unten gerichtetem Blick umgeben von zahlreichen Putten, die mit ihm in den goldenen von Lichtstrahlen durchfluteten Äther aufsteigen. Das Gebälk am Ansatz der Kalotte begrenzt das Fresko und wird von Coxcie als eine Art Balustrade aufgefasst, hinter der die Apostel als erregte Zeugen der Himmelfahrt stehen (Lk 24,50-53). Die Figur Christi sowie die ihn umgebenden Wolken stellen erneut eine Reminiszenz an Raffael dar. Dessen letztes Werk von 1520, die Transfiguration Christi, zeigt, obgleich aus einer anderen Perspektive, eine vergleichbare Situation [ABB. 29]. ${ }^{236}$ Raffael zeigt in der unteren Bildhälfte die Jünger, die von den Eltern und Angehörigen eines mondsüchtigen Jungen gebeten werden, ein Heilungswunder zu vollbringen, das

(Öl auf Holz, 112,3 × 81 cm, Inv.-Nr. 9788), bei welcher es sich um eine Nachahmung von Raffaels Transfiguration handelt. Die Existenz dieses Werkes legt nahe, dass Coxcie sich mit dem Original sehr eindringlich befasst haben könnte. Ein weiteres Beispiel für eine Kopie nach Raffael stellt Coxcies jugendlicher Johannes der Täufer dar (Privatbesitz, Antwerpen; hierzu u. für Abb. s. JONCKHEERE 2013, S. 185, Kat.-Nr. 4). 
der Schrift nach erst durch Christus gewirkt wird. In der oberen Bildhälfte ist dagegen die Verklärung Christi zu sehen, der zwischen Mose und Elija erscheint, während Jakobus d. Ä., Petrus und Johannes zu ihren Füßen dargestellt sind. Das Motiv der ausgestreckten Arme Christi sowie das stoffreiche und im Wind bewegte Gewand sind von Raffael übernommen. Die kleinen Engelsfiguren rings um Christus fehlen bei Raffaels Transfiguration, sind aber bei dessen Madonna di Foligno zu sehen [ABB. 30]. ${ }^{237}$ Coxcie greift dieses Detail für seine Himmelfahrt auf, indem er die teilweise nur schemenhaften Engelchen aus der Maria hinterfangenden Aureole herauslöst, und als eigenständig agierende Figuren uminterpretiert, sie aber in ähnlicher Weise in den höherliegenden Wolkenschichten miteinander, verschmelzen' lässt. Doch auch andere Vorbilder kommen dafür in Betracht; etwa für die Gestalt Christi, welche der aus der Apsiskalotte der Cappella Borgherini in der römischen Kirche San Pietro in Montorio ähnelt [ABB. 31] dieselbe Kirche, in der auch Raffaels Transfiguration kurz zuvor Aufstellung fand. Diese zeigt ihrerseits einen vergleichbar gestalteten Christus sowie beidseitig unterhalb des Heilandes angeordnete Jünger mit exaltierter Gestik, von denen Coxcie Anregungen gewinnen konnte. Christus hält hier ähnlich wie bei Coxcies Kalottenbild seine Arme empor, während er seinen Blick gen Himmel richtet und sein Gewand vom Wind bewegt wird. Sebastiano del Piombo, der dieses Wandbild geschaffen hat, wird die Figur des Christus ebenfalls von dem Altarbild Raffaels entlehnt haben, da es sich in unmittelbarer Nähe zu ,seiner' Kapelle befand und sich eine motivische sowie stilistische Bezugnahme auf den Hauptaltar der Kirche, das heißt auf Raffaels Transfiguration, anbot.

Die Nachricht, dass Coxcie mit seinen Wandbildern für den Kardinal Enckenvoirt in der Freskomalerei brillierte, zeigt, dass er auf die Höhe der italienischen Kunst gelangte. ${ }^{238}$ Auch deutet dies darauf hin, dass vor der Beauftragung durch den Kardinal ein Studium dieser Maltechnik erfolgt sein muss. ${ }^{239}$ Bemerkenswert ist, dass laut Vasari auch der zu dieser Zeit bereits deutlich bekanntere und in Venedig ausgebildete Sebastiano del Piombo in der engeren Auswahl gestanden haben soll, die Kapelle des niederländischen Kardinals auszumalen. Sollten die Fresken zu Beginn der 1530er Jahre ausgeführt worden sein, muss davon ausgegangen werden, dass Coxcie zwischen 1527 und 1530 in Italien angelangt war, um sich einer entsprechenden Ausbildung zu widmen. Mehr oder weniger sicher ist, dass Coxcie erst nach dem Jahr des Sacco di Roma von 1527, in die Ewige Stadt gekommen war. Die Truppen Karls V. hatten die Paläste der Stadt und deren Kunstschätze geplündert, was zur Flucht vieler dort ansässiger Künstler geführt hatte. Nur wenige Maler werden sich zu dem Zeitpunkt von Coxcies Erscheinen noch oder bereits wieder in der Stadt befunden haben, was die Benennung eines potenziellen Lehrers jedoch keineswegs vereinfacht. Potenzielle Künstler aus dem Umfeld Raffaels, darunter der Florentiner Perino del Vaga (15011547), der Sienese Baldessare Peruzzi (1481- 
1536) sowie Battista Franco (ca. 1498-1561) aus Venedig, kehrten erst in den frühen 1530er Jahren nach Rom zurück. ${ }^{240}$ Einer der wenigen Maler, die sich bereits wieder in der Stadt befanden, als Coxcie sie um 1528 erreichte, war wiederum Sebastiano del Piombo (ca. 14851574), ${ }^{241}$ zu dem Coxcie später in einem Konkurrenzverhältnis gestanden haben soll, wie Vasari berichtet. Eine Ausbildung und Mitarbeit in Sebastianos Werkstatt ist dennoch nicht gänzlich von der Hand zu weisen und könnte sogar erklären, wieso beide Namen im Zusammenhang mit den Fresken überliefert sind und stilistische Beziehungen zu Werken Sebastianos bestehen. Möglicherweise wurde der Auftrag auch zunächst an diesen und erst im nächsten Schritt an Michiel Coxcie übertragen - möglicherweise durch den potenziellen Lehrer selbst.

Auch der Mangel an einheimischen Künstlern könnte ein Grund dafür gewesen sein, dass der noch junge flämische Maler namhafte Auftraggeber wie den Kardinal Enckenvoirt für sich gewinnen konnte, obwohl er sich erst wenige Jahre in der Stadt aufhielt. ${ }^{242}$ Auch eine mögliche Bekanntschaft mit dem zeitgleich in Rom tätigen Flamen Marten van Heemskerck könnte ihm Zutritt in das Umfeld des Kardinals ermöglicht haben. An-

240 Vgl. ebd.

241 Diese Information geht aus einem Vertragsschluss des Jahres 1530 hervor, nach welchem Sebastiano eine Geburt der Jungfrau für die Kapelle der Chigi in der Kirche Santa Maria del Popolo zu malen habe. Das Altarbild bleibt unvollendet. Erst Francesco Salviati führt ab 1554 das Bild und die Gestaltung der Kapelle zu ihrem Abschluss (zu Salvatis Zeit in Rom s. MONBEIG-GOGUEL 1998, S. 116 f.). ders war es den niederländischen Malern ergangen, die bereits vor der Plünderung, etwa unter dem kurzen Pontifikat des Niederländers Hadrian VI. (1522-23), in die Ewige Stadt gereist waren, darunter Jan van Scorel, der von 1522-1524 Leiter der päpstlichen Antikensammlung im Belvedere war, gefolgt von Pieter Coecke van Aelst 1521-1525 (?). ${ }^{243}$ Hier mag die ausdrückliche Förderung durch einen Landsmann auf dem Heiligen Stuhl eine Begünstigung der niederländischen Künstler gegenüber den etablierten italienischen der ausschlaggebende Grund dafür gewesen sein, dass sie überhaupt Fuß fassen konnten. ${ }^{244}$ Marten van Heemskerck, der nachweislich von 1532 bis 1535/36 in der Stadt lebte, ${ }^{245}$ sowie Lambert Lombard, der nach schriftlicher Überlieferung um 1537/38 in Italien gewesen sein soll, haben Rom erst in einer späteren Zeit besucht. ${ }^{246}$ Noch vor all diesen war es Jan Gossaert gewesen, der im Gefolge Philipps von Burgund von 1508-1509 nach Italien reiste, dort im Auftrag seines Herrn umfangreiche Antikenstudien betrieb und damit nachfolgende Generationen von Italienreisenden maßgeblich inspirierte. ${ }^{247}$

Es können nur Mutmaßungen darüber angestellt werden, in welchen Kreisen Coxcie sich während dieser Zeit in Rom bewegte. Ähnlich wie Jan van Scorel besaß er über

242 Vgl. LEUSCHNER 2013, S. 53-56.

243 Für Jan van Scorel s. BARTSCH 2019, S. 19-32. u. Pieter Coecke van Aelst s. van Mander 1604, fol. $218 \mathrm{v}$.

244 Vgl. LEUSCHNER 2013, S. 52 u. HARNACK 2018, S. 21-23.

245 Vgl. hierzu Grosshans 1980, S. 20-21.

246 LEUSCHNER 2013, S. 52 f.

247 Vgl. JONCKHEERE - SUYKERBUYK 2013, S. 29. 
Enckenvoirt eine Verbindung zur römischen Kurie, die ihm die Möglichkeit eröffnet haben könnte, die Kunstwerke im Vatikan und die Antiken in der päpstlichen Sammlung zu studieren. Es erscheint undenkbar, dass er dabei nicht auch mit den humanistischen Ideen seiner Zeit in Kontakt gekommen ist. Ein Zeugnis seiner Aneignung antiker Gelehrsamkeit ist die bildliche Umsetzung des Höhlengleichnisses von Platon [ABB. 32], das traditionell in die Zeit seiner Anwesenheit in Rom datiert wird. ${ }^{248}$ Der zu Grunde liegende Text beschreibt die Wahrnehmung von in einer Höhle angeketteten Sklaven, deren ganze Wirklichkeit in den von anderen Menschen absichtlich erzeugten Schatten an der Höhlenwand besteht. Die Wahl des Themas und die Umsetzung sind bezogen auf das Gesamtwerk Michiel Coxcies als exzeptionell zu bezeichnen. Einzig seine Bearbeitungen mythologischer Themen für die Reproduktionsgraphik ließen sich als Referenz für vergleichbare Motive heranziehen. ${ }^{249}$ Das Bild ist gerahmt von einer stark verschatteten und bewachsenen Gesteinsformation, die gleichsam wie bei einem Guckkasten Einblick in den Höhlenraum gewährt. Zu sehen sind acht mit Stricken in der Höhle festgebundene männliche Figuren, die stehend, liegend oder sitzend dargestellt sind und dabei den Blick seitlich an die Wände oder frontal zum Betrachter richten. Zu beachten gilt hier, dass im Bereich der Öffnung, durch die man in das Innere der Höhle blickt, eigentlich eine Höhlenwand zu denken ist, auf welche nach der Beschreibung Platons jene Schatten fallen müssten, die von Coxcie stattdessen an den Seiten dargestellt sind, während eine stehende Fackel hinter einer Mauer dem Text getreu als Lichtquelle fungiert. Die Objekte, deren Schatten mit Hilfe des Lichtscheins an die Wände geworfen werden, sind hinter eine Mauer zu sehen, die sich wieder hinter den Gefangenen befindet und die Sicht auf den rückwärtigen Raum - und den dort zu denkenden Ausgang, sowie die Personen, welche die Objekte in den Fackelschein halten - verdeckt. Bei den Objekten handelt es sich um eine menschliche Statuette, ein Schaf, einen Stier sowie unterschiedlich gearbeitete Kratere.

Dabei vereint das Bild eine ganze Reihe von Zitaten aus der wiederentdeckten antiken Skulptur sowie Werken Michelangelos. Neben der Figur links, die ihren rechten Arm über dem Kopf hält und sich in ihrer Gestalt offenbar an dem Apoll Kitharoidos orientiert [ABB. 33], der sich im 16. Jahrhundert in der Sammlung des Palazzo Valle-Capranica befunden hat, ist die ihr gegenüberliegende Figur mit dem erhobenen linken Arm dem Satyr mit dem Fruchtbouquet [ABB. 34] nachempfunden.

ihre Körperhaltungen beziehen sich laut JONCKHEERE auf dieselben antiken Statuen (z. B. der ,Apollo Kitharoidos' aus der Sammlung der Villa Valle-Capranica und der ,Satyr mit dem Fruchtbouquet ${ }^{\natural}$ aus den Uffizien in Florenz), die er auch in anderen Werken zitiert (vgl. hierzu JONCKHEERE 2013a, S. 73). Für die Einordnung in die Zeit in Rom s. MCGRATH 2009.

249 Diese Sujets sollen im Verlauf dieses Kapitels noch besprochen werden. 
Auch könnte Coxcie mit dieser Figur auf Michelangelos Skulptur eines Sterbenden Sklaven Bezug genommen haben [ABB. 35]. Der leicht nach rechts geneigte Oberkörper und das Standmotiv ähneln einander. JONCKHEERE sieht darüber hinaus bei der liegenden Figur vorne rechts noch eine weitere Übereinstimmung mit einem Soldaten aus der Schlacht von Cascina, einem nie ausgeführten Fresko für den Palazzo Vecchio in Florenz [ABB. 36]. ${ }^{250}$ Die im Vordergrund der Höhle, angebunden und am Boden liegende, größtenteils entblößte Männerfigur scheint einen Gefangenen von einem der Reliefs der Trajanssäule wiederzugeben [ABB. 37], ${ }^{251}$ während der erhobene ebenfalls gebundene Mann in der Mitte des Bildes, der die rechte Hand im Zeigegestus erhoben hat und mit der linken Hand sich abstützt, eine gewisse Ähnlichkeit mit dem Laokoon in den Kapitolinischen Museen aufweist.

Die umfangreiche Auswahl an ,Modellen' aus dem Bereich der antiken römischen Skulptur und den Werken italienischer Meister bei gleichzeitiger disproportionaler Wiedergabe ist auffällig. So ist die sitzende Figur links im Verhältnis zu den Dreien im Vordergrund viel zu groß. Der Kopf der mittleren Figur wiederum ist im Verhältnis zu dem massigen Oberkörper zu klein, ein Hals ist kaum vorhanden und auch Beine und Arme wirken leicht verkürzt. Der Mann rechts wiederum zeigt eine höchst sonderbare, halb liegende und mit den Armen sich an einem Vorsprung abstützende Körperhaltung. Zusammen mit

250 Zeichnung, $42 \times 28,5 \mathrm{~cm}$, British Museum, London; Inv.-Nr. 1887,0502.116. Vgl. hierzu auch JONCKHEERE 2013a, S. 73.

251 Vgl. BOBER - RUBINSTEIN - WOODFORD 1986, Nr. 158 und 159. dem sorgsam unter dem Körper drapierten roten Stoff erscheint das unnatürlich zur Seite gespreizte rechte Bein mit dem leicht nach oben verdrehten $\mathrm{Fu}$ anatomisch zumindest fragwürdig. Auch sind die vier weiter in den Hintergrund gerückten Figuren zu groß wiedergegeben, besonders im Verhältnis zu der mittleren Figur mit den gestauchten GliedmaBen und dem zu kleinen Kopf.

Zur inhaltlichen Bedeutung des Bildes konnten bisher nur Mutmaßungen angestellt werden, da keinerlei Zeugnisse des Künstlers oder von Zeitgenossen über dieses Werk bekannt sind. Ganz allgemein lässt sich sagen, dass das Höhlengleichnis aus Platons Politeia eines der zentralen Motive in den theoretischen Abhandlungen zur Bildenden Kunst im 16. Jahrhundert war. ${ }^{252}$ Es liegt daher nahe, dass die Wahl dieses Themas Bezug auf zeitgenössische Diskussionen nahm oder zumindest Aspekte verarbeitet, die Coxcie in Rom kennengelernt haben könnte. Das Gleichnis ist als eine der platonischen rationes didaktisch ausgerichtet, was den Gedanken zulässt, dass Coxcie, wie viele Maler der Frühen Neuzeit von den allegorischen Auslegungen Platons beeinflusst wurde, wie PANOFSKY dargelegt hat. ${ }^{253}$ So könnte das Gemälde auch in seiner Gestalt Bezug auf das Gleichnis nehmen, etwa durch die unproportionale Dimensionierung der Figuren. Die Fehler in der Anatomie der Figuren könnten sinnbildhaft für eine andere, durch den Künstler geschaffene Realität stehen, die bewusst vom Naturvorbild abrückt.

252 Zur Verwendung allegorischer Motive aus den Werken Platons s. PARTENIE 2009.

253 Vgl. PANOFSKY 1938, S. 261. 
Eine solche Deutung würde etwa die Kenntnis von Marsilio Ficinos neuplatonischer Kunsttheorie voraussetzen. ${ }^{254}$ Diesem zu Folge ist der Künstler nicht auf die Wiedergabe der $\mathrm{Na}$ tur beschränkt, sondern kann in seinen Werken Gott selbst nachahmen und schöpferisch tätig werden, indem er die Natur verbessert oder sie für seine Zwecke verändert. ${ }^{255}$ Interessant ist das Bild auch deshalb, weil die hier absichtlich verstellten Proportionen bei den Figuren, auf eine Auseinandersetzung mit dem Manierismus in Italien schließen lassen.

\subsubsection{Zur Rolle der Druckgraphik in Coxcies Frühwerk}

Eine weitere konkrete Auseinandersetzung mit antiken Stoffen, die die äußere Form mit dem Inhalt verbindet, lässt sich am ehesten noch bei Coxcies frühen Entwürfen für die Reproduktionsgraphik beobachten. Die Arbeiten, die Michiel Coxcie in diesem Bereich geschaffen hat sind anders als bei seinen Zeitgenossen Lucas van Leyden oder Cornelis Massys nicht autonom, ${ }^{256}$ sondern in Kooperation mit mehreren Kupferstechern in unterschiedlichen Schaffensphasen entstanden. Rein quantitativ gesehen bildet das graphische Werk eine eher untergeordnete Rolle, während es in Bezug auf die Italienrezeption in Coxcies Werk aussagekräftige Hinweise liefert. So kann mit Hilfe der Entwürfe möglicherweise auf die bei van Mander beschriebene rege Zeichentätigkeit Coxcies in Rom geschlossen werden. ${ }^{257}$

Die Vorlagen für die 32, nur teilweise nummerierten Blätter zur Geschichte von Amor und Psyche nach dem Roman des antiken Schriftstellers Apuleius stellen ein frühes Beispiel für Michiel Coxcies Auseinandersetzung mit diesem Medium dar. ${ }^{258}$ Vasari schreibt, dass die Serie von einem Maler namens „Michele“ stamme, der für viele Jahre in zwei Kapellen von Santa Maria dell'Anima für die „Deutschen“ gearbeitet habe. ${ }^{259} \mathrm{Da}$ er die Ausmalungen der Kapelle des Kardinal Enckenvoirt kannte und Coxcie an anderer Stelle als den Urheber benennt, liegt es nahe, dass dieser gemeint ist. DACOS und zuletzt LEUSCHNER SOwie VAN GRIEKEN haben sich für die Zuschreibung dieser Serie an Coxcie ausgesprochen, ${ }^{260}$ was jedoch nach stilistischen Gesichtspunkten bisher kaum untersucht worden ist. Gestochen und herausgegebenen wurden die Blätter von Agostino Veneziano (die Blätter 4, 7 und 13 sind mit seinem Monogramm gemarkt), einem Schüler

257 s. hierzu van Mander 1604, S. 258.

258 In den Beischriften der Stiche,Cupido' statt Amor. Vgl. VAN GRIEKEN 2013, S. 159.

259, ,...] sono molto belle alcune disegnate da un Michele pittore, il quale lavorò molti anni in Roma in due cappelle, che sono nella chiesa de'Tedeschi, [...] e trentadue storie die Psiche e d'Amore; che sono tenute bellissime" (Vasari 1568, Bd. 3.1, S. 309).

260 Vgl. LeusChNer 2013, S. 61; DACOS 1993b, S. $57 \mathrm{f}$. 
und Nachfolger Marcanton Raimondis, ${ }^{261}$ dessen Betrieb beim Sacco di Roma von 1527 als einziger nicht von den Soldaten Karls V. beschlagnahmt worden sein soll, ${ }^{262}$ sowie von dem sogenannten ,Meister mit dem Würfel $^{6}$ (betrifft Blatt 6 und 9). ${ }^{263}$ Eine zweite, inhaltlich wie stilistisch unveränderte Auflage wurde von Antonio Salamanca herausgegeben und mit Beischriften versehen. ${ }^{264}$

Die Blätter enthalten die Darstellungen von dem verwandelten Apuleius, der der Geschichte einer Alten lauscht (1), von der Verehrung Psyches durch das Volk (2), der Verheiratung ihrer Schwestern mit zwei Königen (3), Psyches Vater, der das Orakel befragt (4), davon wie Psyche auf einen Berg getragen wird (5) und dann von Zephyr zu einem verzauberten Palast verschleppt wird (6). Weiterhin dargestellt sind Psyche im Bad (7), der Besuch der unsichtbaren Diener (8), Cupido und Psyche gemeinsam auf dem Lager (9), die Nymphen, wie sie Psyches Haar kämmen (10), Psyche, die ihren Schwestern Geschenke offeriert (11), Psyches Schwestern, die sie davon überzeugen, mit einer Schlange geschlafen zu haben (12) und wie Psyche den schlafenden Cupido beobachtet (13) sowie Psyche, die vor dem fliehenden Cupido auf die Knie fällt (14). Außerdem Szenen, wie sie ihren Schwestern von ihrem Unglück erzählt (15), wie ein weißer Vogel ihr von Cupidos Erkrankung berichtet

261 Vgl. LANDAU 1996, S. 143.

262 Ebd., S. 122.

263 In der Forschung entweder mit Tommaso Vincidor oder mit dem Sohn von Marcanton Raimondi, Dado, identifiziert. Stilistisch knüpft er an Raffael und Marcantonio Raimondi an (vgl. ZENTAI 1983, S. 16-18).

264 Neben der Beischrift enthalten diese Blätter die Abkürzung „Ant. Sal. exc.“, während der Name
(16), wie Venus Cupido züchtigt (17), wie Venus in ihrem von Tauben gezogenen Wagen vor Jupiter erscheint (18), wie Ceres Psyche ihre Hilfe verweigert (19), wie Juno Psyche fortschickt (20) sowie die Darstellung ihrer Peinigung durch die Personifikationen von Sorge und Schmerz (21). Weitere Blätter zeigen, wie Venus Psyche befiehlt, einen Haufen Getreide zu sortieren (22), wie sie im Auftrag der Venus das Goldene Vlies sucht (23), die Unterwelt erreicht (24), mit Charons Boot übersetzt (25) und dem Cerberus beim Betreten der Unterwelt opfert (26). Weiterhin, wie Proserpina Psyche das Gefäß der Schönheit überreicht (27) und sie dieses öffnet (28). Die letzten fünf Blätter zeigen Cupido, der Jupiter um Gnade für Psyche bittet (29), wie Cupido und Psyche ihre Lage den Göttern vortragen (30) und diese schließlich die Hochzeit der beiden begehen (31). Das letzte Blatt zeigt $\mathrm{Cu}-$ pido und Psyche im Ehebett (32). ${ }^{265}$

Stilistisch bleibt die Zuweisung an Michiel Coxcie wie bei den meisten Druckgraphiken, die heute auf seinen Entwurf zurückgeführt werden, schwierig, wie VAN GRIEKEN konstatiert. ${ }^{206}$ Die früher behauptete Nähe zu den Fresken Raffaels und Giulio Romanos in der Villa Farnesina haben dazu geführt, dass

Michiel Coxcies erneut unerwähnt bleibt. Bei den hier verwendeten Abbildungen handelt es sich um die spätere Ausgabe, von der sich ein komplettes Exemplar im Metropolitan Museum of Art in New York befindet (jeweils 19,7 $\times$ 23,5 cm (Kupferstich), Inv.-Nr. 41.71 .3 (1-32).

265 Abb. bei The illustrated Bartsch, Bd. 29, S. 226 $\mathrm{f}$.

266 Vgl. VAN GrieKEN 2013, S. 159-162. 
die Serie eine Zeit lang sogar für ein Werk Raffaels gehalten wurde, ${ }^{267}$ bzw. für Entwürfe, die bei der Ausmalung der Galleria di Psiche keine Verwendung fanden. ${ }^{268}$ Die Beliebtheit des Themas in dieser Zeit wird übrigens auch durch die Fresken von Giulio Romano im Palazzo del Te von 1527/28 unterstrichen, die ihrerseits dem Vorbild Raffaels verpflichtet sind.

Mit den zwölf Fresken aus der Galleria di Psiche ergeben sich stilistische, wie motivische Übereinstimmungen. Hier sind es vor allem die beiden vielfigurigen Szenen mit der Versammlung der Götter [ABB. 38] und dem Hochzeitsmahl [ABB. 39], die ihrerseits große Ähnlichkeit untereinander aufweisen und von Coxcie für zwei thematisch entsprechende Kupferstiche adaptiert wurden. Beide Szenen sind sowohl in der Deckenmalerei wie auch in der Graphikserie im Olymp angesiedelt, was durch Wolken angegeben wird, auf denen die Götter um die beiden Hauptfiguren gruppiert sind. Die Blätter Cupido und Psyche vor den Göttern (30) [ABB. 40] und das Hochzeitsmahl (31) [ABB. 41] übernehmen überdies auch die friesartige Reihung der Figuren, die bei den Fresken ihrer Platzierung an der Decke eines längsrechteckigen Saales geschuldet ist. Bei der Versammlung der Götter im Olymp in der Serie (30) sind dieselben Personen wie bei Raffael wiedergegeben [АВВ. 38], einige sind nahezu identisch dargestellt, während andere abgewandelt sind. Dennoch lässt sich die Beziehung zum Vorbild deutlich erkennen, da auch die ungefähre Position der einzelnen Gottheiten dem Fresko entspricht. Lediglich das schmälere Format des Kupferstichs hat dazu geführt, dass die Gruppe insgesamt stärker zusammengerückt wird und die Figuren von Merkur und Hebe am linken Bildrand nicht wie im Fresko in gleicher Höhe mit den anderen Göttern dargestellt sind, sondern aus Platzgründen weiter in den Hintergrund gerückt und im Maßstab entsprechend verkleinert sind. Auch die Wolkenformation wirkt gestauchter und ergibt anders als bei Raffael keine ebene Grundfläche. Dies führt dazu, dass die Haftung der einzelnen Figuren am „Boden' teilweise nicht richtig nachvollzogen werden kann und sie in der Luft zu schweben scheinen. Besonders deutlich wird dies bei Darstellung des Herkules links, der, auf einem Löwen sitzend, sein linkes Bein anhebt und es zugleich mit dem rechten Arm am Schienbein packt. Durch diese ungewöhnliche Verknüpfung aus sitzender und zugleich bewegter Figur wirkt Herkules als könne er jeden Moment von seinem ,Sitz ' herunterrutschen. Die Verrenkung der Gliedmaßen resultiert offenbar aus der Übersetzung des bei Raffael liegend und mit angewinkelten Beinen wiedergegebenen Herkules in eine sitzende Figur. Ähnlich verhält es sich mit dem Globus auf welchem Jupiter seinen linken Fuß stützt. Die Kugel scheint zu schweben, während sie auf dem Deckengemälde auf der Wolkenformation aufliegt.

Die Figuren sind anatomisch korrekt und im Falle der männlichen Gottheiten betont muskulös gestaltet, insbesondere die Gestalt des Herkules und der nackte Oberkörper Jupiters. Die Figur der Psyche ist auf dem 
Stich im Profil dargestellt, während sie eine Schrittbewegung auf den vor ihr thronenden Jupiter zu macht. Sie trägt einen unter der Brust gegürteten Chiton. Cupido in seiner knabenhaften geflügelten Gestalt schmiegt sich gegen Psyche und umfasst ihren Leib, als wolle er zeigen, dass er sich nicht mehr von ihr trennen werde. Während die Frauengestalt, in Bezug auf ihre Statur, die Haltung und das Haupt samt Haartracht, der in dem Fresko grundsätzlich ähnelt, können zugleich ein paar Unterschiede ausgemacht werden. Zunächst ist der Oberkörper der Figur bei Raffael unbekleidet, was zusammen mit dem leicht nach links geneigten Haupt und dem auf Cupido weisenden linken Arm, einen anderen Ausdruck erzeugt, als die bedeckte, anmutig schüchtern ihren Kopf neigende Frauengestalt auf dem Kupferstich. Auch hat Cupido in dem Fresko mehr das Aussehen eines Jünglings denn das eines Knaben, was gegenüber der barbusigen selbstbewussten Psyche im Ausdruck passend erscheint. Statt die sterbliche Königstochter zu umfassen, steht er frontal zu Jupiter gewendet und ist in ein Gespräch mit dem Göttervater verwickelt, was durch den Redegestus der rechten Hand und den Blickkontakt der beiden Figuren hervorgehoben ist.

Weitere Beispiele für die Rezeption von Raffaels Figuren betreffen Pallas Athene am rechten Bildrand, welche bei Raffael im Dreiviertelprofil dargestellt ist und deren Haupt im Profil und geneigt wiedergegeben wird. Die Figur schließt die Gruppe zum Bildrand hin ab, ähnlich wie der im Profil dargestellte Herkules auf der gegenüberliegenden Seite bzw. Hebe auf dem Deckengemälde.
Links neben der stehend dargestellten Athene sitzen vorne Juno und hinten Diana, welche zusammen mit Mars und Janus den Raum zwischen Jupiter und seiner Gemahlin ausfüllen, während dieser Abstand bei Raffael nicht existiert. Die Figur des Janus ist als einzige nicht aus dem Deckengemälde der Galleria di Psiche entlehnt. Mars hingegen ist bei Raffael mit einem aufwendigeren Helmschmuck verziert und anders als sein Pendant auf dem Stich nicht bärtig. Außerdem ist er hinter Psyche dargestellt, während er in der Druckgraphik hinter Jupiter steht und nur sein Kopf und Oberkörper zu sehen sind. Links neben Jupiter ist Neptun dargestellt, bei dem der Kopf wiederum dem Vorbild verpflichtet ist, während er den Dreizack im Unterschied zum Vorbild nur mit einer Hand hält, um mit der anderen auf Psyche zu weisen, während sein leicht geneigter Kopf andeutet, dass die Geste an den zu seiner Linken sitzenden Jupiter gerichtet ist. Dieser Fingerzeig ist bei Raffael nicht dargestellt - scheint aber die vergleichbare Geste von Psyche aufzugreifen und umzukehren. Dieser Umstand verändert die bildimmanente Erzählweise gegenüber dem Vorbild so, dass nun nicht Psyche auf ihren Geliebten weist, als würde sie ihn vor den versammelten Göttern als hauptsächlichen Urheber ihrer Liebesgeschichte benennen, sondern auf sie - die sterbliche Geliebte - gezeigt wird. Trotz der Ähnlichkeit des Aufbaus und der zahlreichen Übereinstimmungen bei den einzelnen Figuren, kann konstatiert werden, dass die beiden zentralen Gestalten gänzlich anders charakterisiert sind, als es bei Raffael der Fall ist. An die Stelle der heroischen Frauenfigur 
und des selbstbewussten Liebesgottes bei Raffael treten eine mädchenhaft schüchterne Psyche und ein eher trotziger Cupido in der graphischen Adaption.

Das Blatt mit dem Hochzeitsmahl (31) stellt indessen eine in Bezug auf den Bildraum und die Anzahl der Figuren reduzierte Wiedergabe dar [ABB. 41]. Auch wirkt die Darstellung insgesamt nüchterner, was durch den einfachen rechteckigen Tisch mit glattem unverzierten Tischtuch im direkten Vergleich mit der von vergoldeten Löwen getragenen metallbeschlagenen Tafel bei Raffael deutlich in Erscheinung tritt. Am augenfälligsten sind die drei Horen, die Blumen in den Händen halten und hinter der Tafel über den Köpfen der Tischgesellschaft schweben. Coxcie gibt diese Szenerie variiert wieder, indem er die Figur rechts nahezu identisch gestaltet, sie dupliziert und danach die zweite Hore links als gespiegeltes Gegenstück zu der rechten hinzufügt. Die mittlere mit den ausgebreiten Armen stellt indessen eine etwas freiere, zugleich aber vereinfachende Interpretation der Hore mit den nach vorn ausgestreckten Armen bei Raffael dar. Weiterhin erscheint die weibliche Figur vorne rechts vor der Tafel bekleidet. Auch Cupido und Psyche sind entsprechend den voraufgehenden Blättern der Serie einheitlich gestaltet und im Unterschied zu Raffael komplett bekleidet. Dieser hat die beiden als junges Paar weitestgehend nackt am rechten Ende des Banketts dargestellt, was als Vorausdeutung auf die Hochzeitsnacht zu verstehen sein könnte - ein Motiv das in der Kupferstichserie auf dem letzten Blatt mit der Nummer $32 \mathrm{zu}$ sehen ist. Sowohl dort, wie auch auf dem Blatt mit dem Hochzeitsmahl (31) tritt Cupido als kleiner Knabe in Erscheinung, der sich der Psyche, wie einer Mutter schutzsuchend zuwendet. Das erotische Moment ist somit in beiden Fällen nahezu vollständig getilgt, während diesem in der Galleria di Psiche ein ungleich höherer Stellenwert zukommt.

Von besonderer Bedeutung ist die Tatsache, dass viele der in der Stichserie gezeigten figürlichen Motive im späteren malerischen Werk Coxcies wiederkehren, sodass eine stilistische Zuweisung weniger schwierig scheint als früher angenommen. Aus den beiden hier besprochenen Blättern ist es unter anderen die Figur des Herkules (30), die beispielsweise in Coxcies Sakramentstriptychon von 1567 als Vorbild fungiert haben könnte, nämlich bei dem Jünger links im Vordergrund in der Szene der Fußwaschung auf der Innenseite des linken Seitenflügels [ABB. 42]. Die Art wie hier das linke Bein angewinkelt und mit beiden Armen festgehalten wird, während das rechte Bein leicht angewinkelt auf dem Boden der Waschschüssel aufsetzt, sowie der leicht vorgebeugte Oberkörper erinnern an den Herkules. Ähnlich verhält es sich mit der Frauenfigur vorne links an der Tafel auf dem Blatt mit dem Hochzeitsmahl (31). Die Sitzhaltung mit dem angewinkelten rechten Bein und dem zum Zeigen ausgestreckten Arm erinnert an die Figur des Judas Iskariot auf der Mitteltafel des Retabels [ABB. 43]. Auch der im Profil gezeigte, am rechten Ende des Tisches sitzende Jünger stellt einen Verweis auf die Figur der Psyche auf demselben Blatt dar. Beide Figuren berühren den Boden nur mit den Zehen, während der Oberkörper leicht nach vorn geneigt und zum Tisch gewendet ist, wodurch die Partie des oberen Rückens sichtbar wird. Auch die 
dem entgegengesetzte Drehung des Kopfes nach links ins Profil ist bei beiden Figuren zu beobachten, wobei der Kopf des Jüngers zusätzlich leicht zur linken Schulter geneigt ist. An Stelle des Cupido auf Höhe des Knies von Psyche ist bei dem Jünger in der Abendmahlsdarstellung dessen nacktes rechtes Bein zu sehen, welches die durch den Körper des Liebesgottes verlaufende Diagonale reproduziert und dem linken Arm der Psyche entsprechend im Oberarm des Jüngers fortläuft.

Diese Beobachtungen, die im Folgenden noch ergänzt werden können, ${ }^{269}$ legen die Vermutung nahe, dass die Entwürfe für die Serie aus demselben umfangreichen Studienmaterial, das Coxcie mutmaßlich während seines Aufenthaltes in Rom angefertigt hat, hervorgegangen sind, wie seine späteren Kompositionen. Zugleich lässt sich damit die Richtigkeit der bei Vasari überlieferten Nachricht einer Urheberschaft Coxcies untermauern. Ob tatsächlich und in welchem Ausmaß die bekannten Werke aus dem Bereich der Reproduktionsgraphik sowie die hierzu vereinzelt vorliegenden Entwürfe, als vorbereitende Studien und wiederkehrende Muster für Coxcies späteres malerisches Werk gewertet werden können, wird dabei noch zu klären sein.

Neben mehreren gedruckten Auflagen haben sich zehn Zeichnungen der sogenannten Liebschaften Jupiters erhalten, die heute im British Museum aufbewahrt werden. ${ }^{270}$ Die

269 s. hierzu Abschn. 4.2.1.

270 Vgl. Leuschner 2013, S., 62 u. Anm. 32; DACOS 1995a, S. 172, Nr. 79.

271 Die Abbildungen beziehen sich im Folgenden auf die zehn erhaltenen Zeichnungen aus dem British Museum (Inv.-Nr. 1861,0112.1-10).

272 „Jupiters liefdesavonturen“, als Werk von Cornelis Bos aufgeführt bei SCHÉLE 1965, Nr. 224
Serie zeigt den Göttervater Jupiter und seine erotischen Beziehungen und orientiert sich dabei an den Beschreibungen in den Metamorphosen des Ovid. Die zehn Blätter zeigen den Raub des Ganymed (1), Jupiter und Antiope (2), Jupiter in der Gestalt von Amphytrion bei Alkmene (3), Jupiter und Semele (4), den Raub der Europa (5), Jupiter und Aegina (6), Proserpina und Jupiter in Schlangengestalt (7), Leda und den Schwan (8), den von Juno überraschten Jupiter, der Io in eine Kuh verwandelt (9) und zuletzt Callisto mit Jupiter in der Gestalt der Diana (10). ${ }^{271}$ Die druckgraphische Vervielfältigung übernahm höchstwahrscheinlich Cornelis Bos, wie der Inventareintrag zu einer Graphikserie nach den Zeichnungen Coxcies aus dem Rijksmuseum zu verstehen gibt. ${ }^{272}$ Diese Zuweisung nach Sune SCHÉLE bleibt allerdings fraglich, da sie nicht weiter begründet wird. ${ }^{273}$ Eine Druckausgabe befindet sich heute neben den Zeichnungen im British Museum. ${ }^{274}$

Die Autorschaft Michiel Coxcies lässt sich im stilistischen Vergleich der Zeichnungen mit der Folge von Cupido und Psyche erhärten. Obwohl das hochrechteckige Format der Bilder gegenüber den querformatigen Stichen der zuletzt genannten Serie weniger Platz zur Verfügung stellt, sind die Bildausschnitte recht ähnlich gewählt. Meist ist im Hintergrund auf einer Seite eine Art Architekturfond hinter

234. Vgl. auch LeusChNER 2013, S. 62 u. VAN GRIEKEN 2013, S. 164-170. Für Abbildungen s. ebd. S. 166 f., Nr. 160-169.

273 Vgl. SCHÉLE 1965, S. 203-205, Nr. 225-234.

274 Unter der Inv-Nr. 1925,1117.19 sind die zehn Blätter der Druckserie fälschlicherweise einer Mappe mit Blättern von Lambert Suavius zugeordnet. 
den Figuren gezeigt, neben dem sich ein Ausblick in eine Landschaft anschließt; so etwa auf den Blättern 2, 3 und 4. Vergleichbar ist dies unter anderem mit den Architekturen auf den Stichen der Blätter 4, 12 und 21 aus der Folge mit Cupido und Psyche. Die Figuren sind in allen Fällen nahsichtig gestaltet, wobei ein besonderes Augenmerk auf der anatomischen Durchgestaltung der Körper liegt. Die Figur der Proserpina (7) [ABB. 44] ist nahezu identisch mit der der Venus auf Blatt 21 aus der zuvor behandelten Serie [ABB. 45]. Die Wendung ins Dreiviertelprofil, die angewinkelten Beine, die Haartracht sowie der unter und hinter ihrem Rücken ausgebreitete Stoff sind sehr ähnlich wiedergegeben. Auch sind beide Figuren nackt, was den Blick auf den idealschön durchgearbeiteten Körper freigibt. Auch die Leda (8) ist, was die Körperhaltung betrifft [ABB. 46], offenbar nach der Psyche auf Blatt 6 von Cupido und Psyche gestaltet [ABB. 47] und verweist auf das Vorbild Michelangelos. Beide Frauenfiguren sind sitzend mit leicht nach unten geneigtem Gesicht und mit angewinkeltem rechtem Bein dargestellt. Das linke Bein ist bei beiden angehoben, was bei der Leda noch etwas gesteigert ist. Der linke Arm liegt auf dem Knie des linken Beins bei Psyche, bei der Leda auf dem Hals des Schwans. Auch in der Figur des Ganymed (1) spiegelt sich die der Psyche von Blatt (9). Der geraubte Jüngling legt seinen rechten Arm hinter seinen Kopf, während er sich mit der linken Hand an den Flügeln des Adlers festhält. Auch Psyche hat einen Arm hinter ihren Kopf gelegt, während sie mit $\mathrm{Cu}$ - pido auf einem Bett liegt und mit dem anderen ihren Geliebten umarmt. Diese und weitere Übereinstimmungen im Detail untermauen den weiter oben gefassten Gedanken, dass die frühen Arbeiten im Bereich der Druckgraphik von Michiel Coxcie aus einem gemeinsamen ,Vorrat' an Motiven schöpfen, deren Grundstock er während seines Studiums in Rom anlegte. Auch in diesem Fall wird im Weiteren zu prüfen sein, ob Coxcie die Modelle, die er hier verwendet hat, in seinem späteren Werk, das heißt nach seiner Rückkehr nach Flandern, wieder aufnimmt und welche Rolle sie innerhalb seiner Bilder spielen.

Thematisch orientieren sich diese Zeichnungen höchstwahrscheinlich an Giulio Romanos 16 „I Modi“-Bildern, die dieser für Federico II. Gonzaga gezeichnet hatte und von Marcantonio Raimondi in Kupfer stechen ließ. Wegen der deutlichen Darstellung von Sexualität wurden die erste Auflage sowie ein weiterer Druck mit Beischriften von Petro Aretino auf Anordnung der katholischen Kirche fast vollständig vernichtet. Nur ein paar Fragmente haben sich erhalten und befinden sich heute im British Museum [ABB. 48]. ${ }^{275}$ Angesichts der geringen Anzahl und Größe dieser Überreste ist ein stilistischer Vergleich nur bedingt möglich. Grundsätzlich kann aber ausgesagt werden, dass auch Coxcies Stichfolge ein vergleichbares erotisches Thema behandelt, obschon deutlich weniger explizit. In Bezug auf die verglichen mit Raimondi weniger drastischen Motive ergeben sich weitere Überschneidungen von Coxcies Stichfolge mit

275 British Museum, London, Inv.-Nr. 1972,U.1306-1314. 
Gian Giacomo Caraglios sogenannten Götterliebschaften nach Entwürfen von Perino del Vaga für die Tapisserien des Salone de Giove im Palazzo Doria in Genua von 1532-1535. Diese behandeln ebenfalls die Liebesabenteuer des Jupiter, jedoch ungleich expliziter als es bei Coxcie der Fall ist. ${ }^{276}$

Weitaus konkreter verhält es sich mit einem einzelnen Blatt aus der Serie, dem Raub des Ganymed (1) [ABB. 49], ${ }^{277}$ für den Coxcie auf eine Zeichnung von Michelangelo zurückgegriffen hat, die dieser 1532 für Tommaso de'Cavalieri angefertigt hatte [ABB. 50]. ${ }^{278}$ Erkennbar wird dies in der sehr ähnlich gestalteten zentralen Figuration von Ganymed und dem Adler. In beiden Fällen ist der nackte Jüngling in den Fängen des Adlers zu sehen, die diesen an den Unterschenkeln packen. Gemeinsam steigen sie in den Himmel auf, während keine Gegenwehr des Ganymed zu beobachten ist. Stattdessen haftet der Figur jeweils der Ausdruck der Bereitwilligkeit an, die bei Coxcie etwas stärker noch als bei Michelangelo in der lasziven Pose des über den Kopf gelegten Arms überhöht wird. Der Körper wirkt durch die leichte Schrägstellung, als würde er auf dem Adler ,lagern', während er sich doch eigentlich in dessen Fängen befindet. Der Kopf des Greifvogels ist jeweils von links vor den Oberkörper des Jünglings gewendet, während die Flügel weit ausgebreitet sind. Auch der Umhang, der durch den Auftrieb in Bewegung geraten ist, wird bei Coxcie aufgegriffen. Coxcies Zeichnung wäre damit eines der frühesten Beispiele für die Rezeption dieses Werkes. ${ }^{279}$ Die Tatsache, dass die Zeichnung nicht signiert ist, könnte möglicherweise dem delikaten Thema geschuldet sein, wie LEUSCHNER vorgeschlagen hat. ${ }^{280}$ Nach heutiger Kenntnis entstand ein weiteres graphisches Werk erst Jahrzehnte später. Als inventor wird Coxcie in einer 1576 von Jan Sadeler gedruckten Serie von Kupferstichen zur Geschichte von Kain und Abelgenannt. ${ }^{281}$ Zeitlich, aber auch stilistisch weicht dieses Werk von den älteren beiden Stichfolgen ab, sodass es eher nicht als Indiz gelten kann für die vorgeschlagene Existenz einer ,Skizzen- und Mustersammlung', welche besonders in diesen frühen druckgraphischen Entwürfen zum Vorschein kommt. ${ }^{282}$

Für diese Studie ist die stilistische Beziehung zwischen Coxcies graphischem und malerischem Werk von größerer Bedeutung. Viele der Motive aus den Zeichnungen und den danach angefertigten druckgraphischen Blättern bezeugen die in der Literatur oft genannte, aber kaum konkretisierte stilistische

\section{LEUSCHNER 2013, S. 62.}

280 Ebd.

281 Blätter enthalten den Vermerk: ,JSadelaer fecit / CIV ex. / Michael de coxcij / inventor". Im British Museum haben sich zwei mal drei der Blätter erhalten (s. Inv.-Nr. 1910,0208.15 im Online-Katalog des British Museum uhttps://www.britishmuseum.org/research/collection_onlines).

282 Für eine Besprechung dieser Serie s. auch VAN GRIEKEN 2013, S. 156-183. 
Prägung Coxcies durch bestimmte Maler der italienischen Hochrenaissance.

\subsection{Das italianisierende Erstlingswerk nach Coxcies Rückkehr aus Rom 1539}

\subsubsection{Die Seitentafeln (um 1540) für Gossaerts Lukas, der die Madonna malt von 1515}

Bald nach seiner Rückkehr in die Niederlande soll Coxcie bereits am 11. November 1539 als Mitglied der Lukasgilde in seiner Heimatstadt Mecheln eingeschrieben worden sein. ${ }^{283}$ Diese verschaffte ihm den Auftrag für die Ausführung zweier Außenflügel für ein von Jan Gossaert um 1520 geschaffenes Retabel mit dem Hl. Lukas, der die Madonna zeichnet. ${ }^{284}$ Die Tafeln zeigen das Martyrium des Evangelisten Johannes an der Porta Latina auf der einen und Johannes auf Patmos auf der anderen Seite [ABB. 51-55]. Der linke Flügel enthält die Aufschrift: „MIGHEL DE MALINO FACIEBAT“، 285 was die Richtigkeit der nur mittelbar überlieferten Information des Gildenbeitritts in Mecheln unterstreicht. Sowohl Jan Gossaerts Tafel mit Lukas, der die

283 JONCKHEERE und SUYKERBUYK haben hierzu angemerkt, dass das originale Dokument dem Anschein nach verloren gegangen ist, die Information über Coxcies Beitritt in die Gilde jedoch im 18. Jh. von dem Spanier Azevedo Coutinho y Bernal (ebd. 1775, S. 192) sowie darauf fußend von NEEFs 1876 (Bd. I, S. 148) ohne Nennung der ursprünglichen Quelle tradiert worden ist (s. JONCKHEERE - SUYKERBUYK 2013, S. 46, Anm. 31).

284 Öl auf Holz, $230 \times 205$ cm, Národní Galerie, Prag, Inv.-Nr. O-8765 (s. KOTKOVA - POTKORNY 2008, S. 31-41 u. SILVER 1986, S. 21).

Die Zuweisung der Mitteltafel an Gossaert und die Ergänzung zweier Flügel durch Coxcie
Madonna malt, als auch die von Coxcie ergänzten Seitenflügel befinden sich heute in der Prager Národni-Galerie. Die vier Darstellungen gelten, neben dem Retabel mit der Heiligen Sippe um 1540, ${ }^{286}$ als der erste größere Auftrag nach Coxcies Rückkehr aus Rom, mit denen er seine in Italien geschulten Fähigkeiten erstmals dem heimischen Publikum vorführen konnte. Als Erstlingswerk zeigt es weitaus weniger eine Adaption des Stils von Gossaert, als vielmehr die Entwicklung, die sich in den knapp 20 Jahren zwischen den Tafeln vollzogen hat. ${ }^{287}$

Auf dem von Jan Gossaert geschaffenen Mittelbild sind zunächst Maria mit dem Jesuskind, die mit der entblößten Brust in der Tradition des Typus der Maria lactans steht, und Evangelist Lukas zu sehen [ABВ. 55]. Maria, die das Kind auf ihrem Schoß hält, erscheint links im Vordergrund und ist dem Betrachter zugewandt, während Lukas mit etwas Abstand rechts davon, auf einem Postament sitzend, sie mit dem Silberstift zeichnet. Dass Maria zum Betrachter gewendet ist, hat zur Folge, dass sie für Lukas nur von der Seite ansichtig ist. Eine in sich schlüssigere Lösung hat Gossaert bei seinem ungleich bekannteren

erfahren wir u. a. durch Sandrart: „Zu Mechlen hat er gemacht die Altar-Tafel der Mahler / da S. Lucas unser Frau mahlet / so ein sehr künstlich Stuck von OelFarbe / und von Michaël Coxice nachgehends mit gemahlten Thüren gezieret worden ist." (Sandrart, TA 1675, II, Buch 3, S. 238).

285 Vgl. Miedema 1997, Bd. 4, S. 189.

286 Dieses Werk wird im Verlauf dieses Kapitels ebenfalls behandelt.

287 MiEDEMA verweist darauf, dass van Mander solche ,Ergänzungen' zu den Werken anderer Maler in mehreren seiner Künstlerbiographien überliefert (vgl. MiEDEMA 1997, Bd. 4, S. 189, Anm. 64). 
Bild desselben Themas von 1520-1525 gewählt, ${ }^{288}$ indem er den Evangelisten im Profil zeigt, während das visionäre Bild der Madonna ihm gegenüber frontal in einer Wolke erscheint, dem Betrachter dagegen sich im Dreiviertelprofil präsentiert. Der Fluchtpunkt dieses Bildes liegt in einer rundbogigen Architekturnische mit einer Skulptur von Mose, der eine Gesetzesstafel in der Hand hält und auf einer Art säulengestütztem Rundtempel positioniert ist. Die Gottesmutter samt Christuskind und der Evangelist Lukas auf dem Tafelbild von 1515 sind dagegen in einer offen gestalteten Architektur ohne weitere Personen dargestellt. Der zunächst ein gutes Stück weit nach hinten sich erweiternde Innenraum, der in einem Rundbogen mündet, gewährt einen Blick nach außen auf einen befestigten Platz, auf welchem ein mit gotischen Filialen verzierter Brunnen sowie ein ebenfalls mit Filialen geschmücktes gotisches Bauwerk mit auBenliegenden Strebebögen zu sehen ist. Vergleichbare Details sind auch auf dem Malvagna-Triptychon zu sehen. ${ }^{289}$ Beide Motive stellen einen Kontrast zur antikisierend gestalteten Architektur des Mittel- und Vordergrundes dar. Letztere ist geprägt durch reich profilierte und mit Reliefs verzierte hohe Postamente, auf denen Pfeiler, Säulen und Skulpturen stehen. Die Relieffelder zeigen Kleinplastiken und antikisierende Ornamente. Die Säulen und Pfeiler tragen ein Gebälk, über dem

288 Öl auf Holz, 110,5 × 83,5 cm, Kunsthistorisches Museum, Wien, Inv.-Nr. 894 (Gemäldegalerie).

289 s. Abschn. 2.1.

290 s. Abschn. 2.2.

291 Öl auf Holz, $188 \times 124$ cm, Gemäldegalerie der Staatlichen Museen, Berlin, Inv.-Nr. 648. Signiert: „IOANNES MALBODIVS PINGEBAT ein Tonnengewölbe ansetzt, das weiter hinten in einer muschelförmig gestalteten Kalotte mündet, während der dahinterliegende Raum mit einer Kassettendecke ausgestattet ist. Insgesamt mutet die Architektur phantastisch an und weist gewisse Parallelen zu den Architekturmotiven der Antwerpener Manieristen auf. Diese hatten Anregungen von Jan Gossaert und Bernard van Orley bezogen, sodass wir hier von einem der potenziellen Vorbilder beispielsweise für die Architekturen des Meisters von 1518 sprechen können.

Statt einer genauen Wiedergabe antiker Architektur findet man auch in diesem Bild noch eine freie Verwendung antikisierender Bauformen, die vor allem auf Vielgestaltigkeit und Abwechslungsreichtum hin angelegt zu sein scheint und damit ein Charakteristikum zeigt, dass in dieser Zeit durch die Antwerpener Manieristen noch weiter getrieben wurde. ${ }^{290}$ Auch steht es im Hinblick auf die Authentizität der architektonischen Gebilde hinter anderen, zum Teil späteren Werken zurück, wie etwa Gossaerts Bild mit Neptun von Amphitrite von 1516. ${ }^{291}$ Die zentralperspektivische Darstellung des Raumes wird hier durch den schachbrettartigen Fliesenboden unterstrichen. Der Fluchtpunkt liegt im Bereich der Rundbogenöffnung.

Die Innenseite des linken Flügels, der von Michiel Coxcie geschaffen wurde, zeigt das Martyrium des Hl. Johannes an der Porta

1516" mit dem Verweis auf den Auftraggeber Philipp von Burgund: „PLVS SERA / phe bourg ne ['ne' r.b. 'bourg']“" (vgl. Kat. Berlin 1996, S. 55 u. SILVER 1986, S. 11 f.; RKD-Nr. 51022). 
Latina in Rom [ABB. 51]. Johannes, den Blick gen Himmel gewandt und die Hände zum Gebet zusammengelegt, erscheint der legendarischen Überlieferung entsprechend in einem metallenen Kessel mit siedendem Öl, während vier Schergen mit entblößtem Oberkörper das Feuer darunter schüren und mit herangeschafftem Reisig nähren. ${ }^{292}$ Schräg hinter Johannes ist der römische Befehlshaber zu erkennen, wenn mit der Gestalt nicht sogar Kaiser Domitian gemeint ist, der den Richterstab über den Evangelisten hält. Im Mittelgrund zeigt sich der Ausschnitt einer Portikus mit korinthischen Säulen. Im Hintergrund rechts angeschnitten ist ein hoch aufragendes Bauwerk mit vorgestellten Säulen auf Postamenten und mit Relieffeldern zu sehen, welches an antike Triumphbögen, wie den Konstantinsbogen in Rom, erinnert. In der Mitte des Hintergrundes ist ein Obelisk aufgerichtet, hinter dem wiederum die teilweise mit Gesträuch bewachsenen Fragmente eines weiteren antiken Bauwerks zu sehen sind. Über der Szene spannt sich ein

292 In der Dokumentation zu diesem Bild ist mehrfach behauptet worden, dass es sich um das Martyrium des Hl. Lukas handle (s. RKD-Nr. 272152, zuletzt JONCKHEERE 2013b, S. 132 f.). Traditionell wird der Evangelist und Verfasser der Apostelgeschichte mit dem Apostel Lukas identifiziert, welcher Paulus nach Rom gefolgt sei (Apg 28:16) und der Überlieferung nach kurze Zeit nach diesem sein Martyrium während der Christenverfolgung durch Kaiser Nero erlitten haben soll (s. hierzu WALSH 1991, S. 342).

Die Art des Martertodes in einem mit siedendem Öl gefüllten Kessel entspricht allerdings eindeutig der ikonographischen Tradition des Martyriums, das Johannes der Evangelist um $96 \mathrm{n}$. Chr. an der Porta Latina in Rom in Folge der Christenverfolgungen unter Domitian blauer Himmel, der mit weißen Streifenwolken durchzogen ist. Der Horizont liegt auf Augenhöhe des Johannes, der Fluchtpunkt am rechten Bildrand. Während Johannes und die um ihn versammelten Schergen groß im Vordergrund erscheinen, ist eine dicht gedrängte Menschenmenge, die das Geschehen beobachtet, im Mittelgrund hinter einer gemauerten steinernen Balustrade dargestellt. Der geschwungene obere Abschluss des Bildfeldes entspricht der Vorgabe Gossaerts bei der Mitteltafel. Auch das goldene Akanthusmuster auf schwarzem Grund findet sich hier.

Der unmittelbare Vergleich der Architektur auf der Mitteltafel von Gossaert mit Coxcies Darstellung des Martyriums des Hl. Johannes zeigt eine andere Gewichtung der Figuren und der Architektur; er gibt einen andersartigen Gebrauch der antiken Architekturelemente und den Verzicht auf eine ausgeprägte zentralperspektivische Bildführung zu erkennen. Während Jan Gossaert offenbar noch das Ziel verfolgt, eine vielgestaltige, bis dahin in der flämischen Malerei weitestgehend

erlitten haben soll (vgl. LCI, VII [1974], s. v. ,Johannes der Evangelist“, Sp. 121). Die Legenda Aurea schildert weiter, dass sich das Öl sich in ein erfrischendes Bad verwandelt habe, welchem er unversehrt entsteigen konnte. Daraufhin sei er auf die Insel Patmos verbannt worden, wo er das Buch der Offenbarung schrieb. Nach dem Tod Domitians sei Johannes nach Ephesus zurückgekehrt, wo er sich dem Verfassen des Evangeliums gewidmet habe. Als stilistisches Indiz kommt noch hinzu, dass es sich bei dem jugendlichen Gesicht der im Kessel sitzenden Figur eindeutig um das des Hl. Johannes auf der Außenseite und der auf Patmos angesiedelten Szene handelt und nicht etwa um Lukas, wie es in der Literatur falsch fortgeschrieben wurde (vgl. HÄUPTLI 2014, Legenda Aurea, S. 225). 
unbekannte Architektur vor Augen zu bringen, die im hohen Grade die Aufmerksamkeit auf sich zieht und ziehen soll, dienten Coxcie die antiken Bauten, die im Übrigen sehr viel genauer der Wirklichkeit entsprechen, vor allem zur Kennzeichnung der Örtlichkeit; das Hauptgewicht liegt auf den Figuren. Neben einer gegenüber Gossaert genaueren Wiedergabe der antiken Architektur, ist bei Coxcie ein entsprechend verändertes Verständnis des Bildraumes $\mathrm{zu}$ beobachten. Wenn bei Gossaert die Größenverhältnisse zwischen den Figuren und der Architektur durchaus korrekt sind, so ist doch noch immer die Auffassung des architektonischen Raumes als Gehäuse zu erkennen, wie sie die altniederländische Malerei kennzeichnet. Allerdings zeigt Coxcie kein Interieur, so dass ein genauer Vergleich mit Gossaerts Darstellung nicht möglich ist. Erkennbar bleibt jedoch, dass bei Coxcie die Bauwerke die Figuren eher wie ein Bühnenbild hinterfangen. Dies entspricht den Vorbildern, die Coxcie in Italien fand. So zeigt etwa Raffaels Brand des Borgo aus der Stanza dell'Incendio im Apostolischen Palast ein vergleichbares Verhältnis zwischen den Figuren und der Architektur [ABB. 56]. ${ }^{293}$ Letztere erscheint auf dem Wandbild Raffaels ebenfalls wie ein Bühnenbild, vor dem sich die Handlung abspielt. Hinzu kommt, dass es sich um eine Wiedergabe von realen Bauten handelt, die Ostfassade von Alt-St. Peter und die Benediktionsloggia an der Ostfassade des Atriums. Coxcie mag davon in der Wese inspiriert gewesen sein, dass er das Martyrium des Hl. Jo- hannes vor einer nach seiner Vorstellung authentischen antiken Stadtsilhouette darstellt.

Zusätzlich lassen sich gewisse kompositorische Übereinstimmungen mit dem Fresko Raffaels ausmachen, obschon es sich hier um ein Querformat handelt, während bei Coxcies Altartafel ein Hochformart erforderlich war. Die Verteilung der Architekturelemente in Mittel- und Hintergrund weist Entsprechungen auf. Während bei Coxcie im Hintergrund die antikische Triumphbogenarchitektur angeschnitten dargestellt ist, ist bei Raffaels Fresko rechts ebenfalls eine Säulenarchitektur zu sehen. Statt am rechten Bildrand wie bei Coxcie liegt der Fluchtpunkt bei Raffael im Bereich der Fassade von Alt-St. Peter, auf den die am Raster der leicht diagonal verlaufenden Fluchtlinien ausgerichtete Säulenreihe mit Kompositkapitellen zuläuft. Die kompositorisch äquivalente Stelle bei Coxcie zeigt ebenfalls eine Säule, hier mit korinthischem Kapitell, nämlich die der Portikus links im Mittelgrund, an der Stelle also, an der sich bei Raffael die antike Kolonnade befindet.

Wie die Architekturdarstellung und Gestaltung des Bildraums, so unterscheidet sich auch Coxcies Figurenstil von Gossaert, etwa durch eine malerischere Auffassung, während Gossaerts Figuren fein gezeichnete Konturen aufweisen, die sich unter anderem in dem reichen Faltenwurf der auf dem Boden drapierten Gewandstoffe bemerkbar machen, von welchen die Figuren stark aus der Bildfläche herausgehoben erscheinen. Auch tritt die Anatomie der Figuren vor der Gestal- 
tung reicher Gewänder zurück, ist aber dennoch als naturalistisch zu bezeichnen, da sich an den Stellen, an denen der Stoff der größten Zugkraft ausgesetzt ist, Knie und Oberschenkel abzeichnen, wodurch die sitzende Haltung Marias trotz des nur scheinbar verunklärenden Gewandes, gut nachvollzogen werden kann. Neben der feinmalerischen Darstellung führen auch die angemessenen Farben von Kleidung und Inkarnat zu einem hohen Grad von Stofflichkeitsillusion, die auch in der Oberflächengestaltung von Architekturbestandteilen, wie dem Fliesenboden und den Marmorsäulen zu beobachten ist. Die Gesichter wiederum sind detailliert wiedergegeben. Der gesenkte Blick der Maria, der durch die fast geschlossenen Augen bezeichnet ist, erzeugt einen verinnerlichten Ausdruck, während sich an den Augen des Lukas erkennen lässt, dass er Maria mit dem Blick fixiert, um ihre Gestalt auf dem Blatt wiederzugeben.

Die Figuren in Coxcies Johannes-Martyrium sind dagegen deutlich weniger stark konturiert [ABB. 51], was zusammen mit den bräunlichen Farbtönen des Inkarnats, die nur wenig heller sind als die der Architektur, dazu führt, dass die Figuren deutlich weniger von dem sie umgebenden Raum abgehoben sind. Dem scheint Coxcie durch die Modellierung der nackten Körperpartien mit einem ausgeprägten Helldunkel entgegenzuwirken. Hierdurch wird die anatomische Bildung der muskulösen Figuren betont. Der im Vordergrund gezeigte Johannes und die Schergen mit nackten Oberkörpern repräsentieren ein Körperideal, das sich an der Antike und der italienischen Malerei der Zeit orientiert. Mit komplizierten Bewegungsmotiven wie der mit dem
Körper frontal zum Betrachter gewendeten knieenden Gestalt vorne links, die einen Holzscheit vom Boden aufhebt, während sie im selben Moment den Kopf fast unnatürlich weit in den Nacken legt, belegt einerseits Coxcies Kenntnisse und Fähigkeiten in diesem Bereich und deutet andrerseits auf eine Übersteigerung des Naturalismus hin. Noch deutlicher aber zeigt die rasche Reduktion der Figurengröße zwischen den Figuren des Vordergrunds und denen hinter der Mauerbalustrade eine manieristische Tendenz. Die Figur des römischen Befehlshabers steht auf einer Art steinerner Platte, die der Tempelarchitektur links dahinter zugeordnet werden kann. Die Figuren hinter der sich unmittelbar anschlieBenden Balustrade erscheinen deutlich zu klein, da die für die Maßstabsverkleinerung nötige Distanz nicht gegeben ist. Ob hierin eine Absicht zu erkennen ist, die mit einer Auseinandersetzung mit der Kunst italienischer Manieristen zusammenhängen könnte, oder ob es sich vielleicht um Schwierigkeiten bei der Gestaltung des Bildraums handelt, die dem schmalen Format der Tafel geschuldet sein könnten, lässt sich nicht mit Sicherheit sagen, da sich Vergleichbares bei keinem der nachfolgenden Werke beobachten lässt, während eindeutig manieristische Tendenzen, etwa in der Körperauffassung der Figuren, deutlicher erst in seinem Spätwerk hervortreten.

Auf der Innenseite des rechten Flügels ist die Vision des Johannes auf Patmos dargestellt [ABB. 52], wovon in der Vita des Heiligen 
berichtet wird. ${ }^{294}$ Johannes erscheint im Vordergrund auf einem grünen Hügel, auf dem, am rechten Bildrand gelegen, ein Baum mit reichem Laubwerk emporwächst. Neben ihm sieht man den Adler, das Symbol des Evangelisten. Unterhalb des Stammes liegt ein aufgeschlagenes Buch, das als Hinweis auf die Offenbarung zu deuten ist. Im Mittelgrund ist eine Bucht zu sehen, die sich ein gutes Stück weit in die Landmasse eingräbt. Am Himmel sieht man schwere und bedrohliche Gewitterwolken, aus denen Blitze niedergehen. Inmitten der Wolken tritt jene Vision, die Johannes im 12. Kapitel der Offenbarung beschreibt, vor Augen. Zu sehen ist das Apokalyptische Weib, von dem es heißt: „Und es erschien ein großes Zeichen im Himmel; ein Weib, mit der Sonne bekleidet, und der Mond unter ihren Füßen und auf ihrem Haupt eine Krone mit zwölf goldenen Sternen. Und sie war schwanger und schrie in Kindesnöten und hatte große Qual zur Geburt. Und es erschien ein anderes Zeichen im Himmel, und siehe, ein großer, roter Drache, der hatte sieben Häupter und zehn Hörner und auf seinen Häuptern sieben Kronen; und sein Schwanz zog den dritten Teil der Sterne des Himmels hinweg und warf sie auf die Erde. Und der Drache trat vor das Weib, die gebären sollte, auf dass, wenn sie geboren hätte, er ihr Kind fräße“ (Offb 12,1-4). Etwas unterhalb der Frau ist der Kampf der Engel mit jenem Drachen zu sehen, über welchen es im Text heißt: „Und es erhob sich ein Streit im Himmel; Michael und seine Engel stritten mit dem Drachen; [...] und siegten nicht, auch ward ihre Stätte nicht mehr gefunden im Himmel“" (Offb 12,7-9). Die beiden Textstellen aus dem Buch der Offenbarung sind getreu dem Wortlaut dargestellt. Die Tatsache, dass es sich um eine Vision handelt, ist durch die Wolkenformationen und die dramatischen Lichtphänomene zum Ausdruck gebracht. Eine sehr ähnliche Schilderung der Vision findet sich auf einem Gemälde von Jan Massys [ABB. 57], einem der Söhne von Quentin Massys, von 1563, dessen lichtdurchflutete Gestalten am Himmel denen von Coxcie nahestehen. ${ }^{295}$ Die Art der Darstellung im Zusammenhang mit dramatischen Licht- und Wettererscheinungen scheint allerdings eine Invention Michiel Coxcies zu sein. Eine frühere Umsetzung des Themas durch Joos van Cleve um 1525 orientiert sich bei der Darstellung des Apokalyptischen Weibes an dem noch älteren Beispiel von Hieronymus Bosch [ABB. 58-59], ${ }^{296}$ das um 1500 entstand. ${ }^{297}$ Diesen beiden Bildern ist die deutlichere Kennzeichnung der Frau als Muttergottes gemein, auf die sowohl Coxcie als auch Jan Massys verzichten, obgleich die mariologische Deutung des Apokalyptischen Weibes auch hier selbstverständlich vorauszusetzen ist. Die dunkelblauen Wolken und die zu ihrem Zentrum hin immer heller werdenden Lichter, erinnern erneut an Raffaels spätes Werk, die Transfiguration Christi von 1520 [АВB. 29], auf welcher der verklärte Christus von einer ähnlichen, Lichtemanation' umgeben ist, die die blauen Wolken des

296 Öl auf Holz, $71,8 \times 74 \mathrm{~cm}$, University of Michigan Museum of Art, Inv.-Nr. 1958/2.77.

295 Öl auf Holz, 117,2 × $147 \mathrm{~cm}$, ,1563 / JOANNES MASSiiS. PINGEBAT“" (s. BUIJNSTERSSMETS 1995, S. 207).
297 Öl auf Holz, $63 \times 43,3$ cm, Gemäldegalerie, Staatliche Museen Berlin, Inv.-Nr. 1647A. 
Abendhimmels zu ihrem Zentrum hin, das heißt näher an Christus und den sich öffnenden Himmel, sukzessive heller erscheinen lassen.

Die Außenseiten bei den Flügeln zeigen die Evangelisten Lukas auf der linken und Johannes auf der rechten Seite. Bei der gemeinsamen Architektur im Hintergrund beider Tafeln handelt es sich um eine massive steinerne Mauer, vor die jeweils ein Pilaster geblendet ist. Auf der rechten Tafel, mit dem Evangelisten Johannes, öffnet sich rechts neben der Mauer ein Blick in den blauen Himmel. Beide Bilder sind wie die der Innenseiten in Untersicht angelegt. Wie schon auf dem Bild auf der Innenseite ist Johannes auch hier durch den Adler, der angeschnitten im Vordergrund dargestellt ist, gekennzeichnet. Johannes hält ein Buch in der Hand und sitzt auf einer Art Mauer, die von vorne mit Marmor verkleidet zu sein scheint. Ähnlich verhält es sich auf dem linken Bild, auf dem der Evangelist Lukas ebenso auf einer Mauer sitzt, während er eine Holztafel in der Hand hält, auf der rückseitig ein mit griechischen Buchstaben beschriebenes Pergament oder Papier befestigt ist. Es ist davon auszugehen, dass ein weiteres Blatt auf der anderen Seite festgemacht ist, da Lukas schreibend dargestellt ist. Auf der Mauer liegen weitere Codices sowie ein aufgeschlagenes Buch, ebenfalls mit griechischer Schrift, das möglicherweise auf das

298 Der Verweis auf den griechischen Originaltext des Neuen Testaments ist insofern interessant, als dass dieser erst mit der Übersetzung des Erasmus von Rotterdam von 1516 einem gröBeren humanistischen Gelehrtenkreis zugänglich wurde. Die Ausgabe samt eines kritischen Kommentars wurde 1559 vom Trienter Konzil indiziert (Index Librorum Prohibitorum 1559; von ihm verfasste Evangelium bzw. die ihm nach der kanonischen Schrifttradition ebenfalls zugeschriebene Apostelgeschichte verweist. ${ }^{298}$ Durch den Stier im Vordergrund ist auch er unzweifelhaft als der Evangelist Lukas gekennzeichnet. Im Gegensatz zu Lukas, der als Mann mittleren Alters schreibend dargestellt wird, ist Johannes wie üblich als Jüngling gezeigt, der den Kopf zur Seite gewendet hat und mit weit geöffneten großen Augen in die Ferne blickt; der Evangelist ist damit als Visionär charakterisiert als den ihn nicht nur die Offenbarung, sondern auch der Anfang seines Evangeliums ausweist. Seine rechte Hand liegt auf der Brust, was den verinnerlichten Ausdruck der Figur, aber auch seine seelische Ergriffenheit nochmals betont.

Die Art, wie die beiden Einzelfiguren vor einem architektonischen Fond mit ihren jeweiligen Attributen sitzend gezeigt werden, erinnert an die Propheten und Sibyllen auf dem Deckenfresko der Sixtinischen Kapelle. Die auf die Brust gelegte Hand mit dem gespreizten Zeigefinger sowie die Art wie er mit der anderen einen aufgeschlagenen Codex hält, erinnern an Michelangelos Jesaja [ABB. 60]. Auch hier ergeben sich in Bezug auf den sinnenden Ausdruck und die Wendung ins Halbprofil Ähnlichkeiten. Vergleichbare Anleihen finden sich in der Figur des Lukas, die wiederum dem Propheten Sacharja oder der Persischen Sibylle ähnelt. Obwohl es sich um keine

Digitalisat bei der Bayerischen Staatsbibliothek 〈http://daten.digitale-sammlungen.de)). Die Verwendung griechischer Buchstaben oder zumindest einer danach anmutenden Schrift gibt zumindest den Hinweis, dass hier neben der antikisierenden Gestaltung des Architekturhintergrundes auch das das geschriebene Wort in historisch angemessenen Weise zu gestalten. 
unmittelbaren Übernahmen handelt, muss doch davon ausgegangen werden, dass die Figuren aus Michelangelos Deckenfresko vorbildhaft für Coxcies Evangelisten waren.

\subsubsection{Michiel Coxcies Triptychon mit der Heiligen Sippe (1540)}

Im Triptychon mit der Heiligen Sippe begegnet nach einhelliger Meinung der Forschung die Summe von Michiel Coxcies Italienerfahrungen. ${ }^{299}$ Das Werk ist mehrfach als Referenz für den Stil Coxcies behandelt worden, mit dem er sich zu Beginn der 1540er Jahre dem Publikum seiner Heimat vorstellt [ABB. 61]. Es ist inschriftlich datiert: „MICHALE. COXCI $\mathrm{M}[\mathrm{E}] \mathrm{FE}[\mathrm{CIT}] \mathrm{A}[\mathrm{NNO}]$ M.D.XL“ und kann deshalb sicher Coxcie zugewiesen werden. ${ }^{300}$ Bekannt ist außerdem, dass er dieses Werk im Auftrag der Antwerpener Gilde der Strumpfweber (kousenwevers) schuf und in deren Kapelle in der Liebfrauenkirche Aufstellung fand. ${ }^{301}$ Ähnlich wie die Flügel des Lukas-Retabels markiert es den ,Bruch' mit der altniederländischen Tradition, indem Coxcie das aus

299 Öl auf Holz, $245 \times 191$ (Mitteltafel), $245 \times 190$ $\mathrm{cm}$ (Seitentafeln, zusammengefügt), Bildergalerie des Benediktinerstiftes von Kremsmünster, Österreich (s. RKD-Nr. 271841 u. 272135; JONCKHEERE 2013a, S. 67 f.u. S. 186, Kat.-Nr. 10).

300 Vgl. LOINIG 1995, S. 113-127 zum Werk an sich und DeLIEUVIN 2012, Nr. 118 für die Inschrift.

301 Vgl. VAN DE VELDE 1992, S. S. 206.

302 Vgl. JONCKHEERE 2013a, S. 67-72. Zuvor hatte der Aufsatz von Hans LoINING zur sog. Sippen- und Johannestafel von 1540 die augenfälligen Zitate aus den Werken namhafter italienischer Meister bereits erwähnt, jedoch noch nicht konkretisiert (s. LOINING 1995, passim).

303 Vgl. JONCKHEERE 2013a, S. 66.
Italien mitgebrachte Stilidiom Raffaels und Michelangelos, wie er es in Rom hatte studieren können, für die nun entstehenden Altarbilder aufgriff und damit das zu übertreffen suchte, was stilistisch und motivisch von van Orley und dessen Generation geleistet worden war. Zuletzt hat sich JONCKHEERE der Frage nach Coxcies Vorbildern, seinen Quellen und der rezeptionsgeschichtlichen Bedeutung des Werkes gewidmet, um eine Revision der Beurteilung von dessen kunstgeschichtlicher Stellung einzuleiten. ${ }^{302}$

Im späten 16. Jahrhundert wurde das Retabel veräußert - mutmaßlich unter der kurzen protestantischen Stadtregierung der Jahre 1577-1585 - und gelangte in der Folge in den Besitz Kaiser Rudolfs II., ${ }^{303}$ der es zunächst in seiner Prager Sammlung bewahrte und schließlich der Abtei von Kremsmünster stiftete, wo es sich bis heute befindet. ${ }^{304}$ Das Inventar der Prager und Wiener Kunstkammern von Theodor Byhers aus dem Jahr 1728, zu deren Bestand Coxcies Retabel gehörte, nennt das Werk unter dem Titel „familia Christi““. ${ }^{305}$

304 Diese überlieferte Haustradition ließ sich bisher nicht belegen. Die beiden Seitentafeln wurden darüber hinaus zu einer einzigen verbunden und die entstehende ,Naht' übermalt.

305 Genauer heißt es: „,[...] ein grosses Kunstgemähl von Michael D. Coxycum anno 1540 auf Holz, Familia Christi aus der Kunst-Cammer Kaiser Ferdinand II. Sub Antonio Principe." Die zugehörige zweite Tafel benennt Byhers fälschlich als „Assumptio B.M.V“ (Theoderich Byhers: Inventar der Schatzkammer Kremsmünster, Stiftsbibliothek, MS 1728, zit. nach LOINING 1995, S. 115). Erst das Inventar von Laurenz Doberschierz aus dem Jahr 1763, das eine Auflistung der Werke, die nunmehr im 
Die beiden Seitenflügel werden hier nicht genannt. Da sie heute eine einzige Tafel bilden, besteht die Möglichkeit, dass sie zum Zeitpunkt der Entstehung des Inventars bereits zusammengefügt und im Übergang entsprechend ergänzt worden waren, sodass der Zusammenhang mit der Sippentafel nicht mehr nachvollzogen werden konnte.

Trotz der stilistischen Orientierung an italienischen Vorbildern, ist das Thema sehr eng mit der lokalen Tradition verknüpft und stellt ein in der altniederländischen Malerei vergleichsweise häufig ins Bild gesetztes Motiv. ${ }^{306}$ Die mit dem Thema der Heiligen Sippe verbundenen Vorstellungen einer dreimaligen Eheschließung Annas und von den zwei Halbschwestern der Muttergottes, Maria Cleophas und Maria Salome, deren Söhne entsprechend als Vettern Jesu zu gelten haben, reichen bis auf Hieronymus zurück, und wurden in den folgenden Jahrhunderten weiter entwickelt. ${ }^{307}$ Die ikonographische Tradition der Heiligen Sippe beginnt jedoch erst im späten Mittelalter und geht auch nicht über das 16. Jahrhundert hinaus. Eine ganze Reihe altniederländischer Gemälde dieser Zeit behandeln den Stoff, so

sog. ,Mathematischen Turm` verwahrt würden. - gemeint ist die Sternwarte des Klosters, die als Universalmuseum nach frühneuzeitlichen Vorstellungen fungiert hat - enthält den Hinweis auf ein zugehöriges ,großes Stück S. Joannes" (Laurenz Doberschierz: Specula Cremifanensis 1764, Stiftsbibliothek Kremsmünster, Cod. Nov. 1048, S. 406 f., zit. nach LONING 1995, S. 116). Die Deutung gelang Pater Doberschierz nach eigener Aussage nur vermittels der Aufschrift auf dem ,Sarg', die da lautet: „Hic est Discipulus ille qui testimonium perhibuit veritati“", aus Joh 21,24 (Vulgata), auch Antiphon zum Fest des Hl. Johannes Evangelist.

306 Öl auf Holz, $138 \times 111 \mathrm{~cm}$, Museum of Fine Arts, Boston; Inv.-Nr. 93.153 (s. BORCHERT etwa der 1509 geschaffene Annenaltar von Quentin Massys oder das zuvor bereits besprochene Bild Jan Gossaerts von 1510, welches Anregungen möglicherweise von Dürers Stich der Maria mit der Libelle bezieht. ${ }^{308}$

Die ursprüngliche Mitteltafel enthält die Darstellung der Heiligen Sippe, welche ehemals von, Johannes mit dem vergifteten Kelch` und der ,Entrückung des Evangelisten Johannes" flankiert wurde. Stilistisch und kompositorisch setzt das Retabel dort an, wo Coxcie mit den Seitenflügeln für Gossaerts Lukasaltar zuvor aufgehört hatte und überzeugt erneut vor allem mit seiner Darstellung von Architektur und den ausgeglichenen Proportionen der Bildkompartimente. Es zeigt ebenfalls Bildräume mit angeschnittenen antiken Architekturen, welche die Figuren als Fond hinterfangen.

Auch für dieses Werk hat Coxcie eine leichte Untersicht gewählt, die mit dem ursprünglichen leicht erhöhten Aufstellungsort auf einem Altar und dem daraus resultierenden Betrachterstandpunkt korrespondiert. Das Zentrum der Mitteltafel bildet die Muttergottes, die ihren Sohn, den Christusknaben an

1997, S. 61-87). Gossaert selbst wiederholt das Thema später mindestens ein weiteres Mal, wie das Bild von 1521 aus dem Kunsthistorischen Museum in Wien nahelegt (Öl auf Holz, $128 \times$ 100,5 cm, Gemäldegalerie, Inv.-Nr. 894 (RKDNr. 218771).

307 SCHREINER 1994, S. 24 f.

308 Annenaltar (Massys): Öl auf Holz, 224,5 × 219 $\mathrm{cm}$ (Mitteltafel), $220 \times 92 \mathrm{~cm}$ (Flügel einzeln), Koninklijke Musea voor Schone Kunsten, Brüssel, Inv.-Nr. 2784 (vgl. SILVER 1984, S. 141 u. SCHNEIDER 2015, S. 75-83). Für Gossaerts Heilige Familie s. Abschn. 2.1. Zu Dürers Kupferstich s. Bartsch VII.62.44, 1a u. Hollstein (German) VII.36.42. 
Elisabeth übergibt, während der etwas ältere Johannes sich halb knieend und anbetend Jesus zuwendet. Weitere Kleinkinder und deren Mütter stellen die Halbschwestern der Gottesmutter, Maria Cleophas und Maria Salome, sowie deren Söhne und Ehemänner dar. Letztere stehen im Hintergrund, wobei einige das Jesuskind betrachten. Als einen sich auf einen Hirtenstab stützenden Mann mittleren Alters links neben einer das Bild zur Seite begrenzenden grünen Porphyrsäule, der das innigliche Spiel zwischen den Müttern und Kindern beobachtet, bringt sich Coxcie selbst ins Bild ein. ${ }^{309}$ Den Hintergrund bildet eine durch Pilaster gegliederte Wand mit einer Nische und darin aufgestellter Skulptur, links öffnet sich ein rundbogiger Durchgang, welcher einen Ausblick nach draußen sowie auf weitere Bauwerke freigibt.

Die Pfeiler der Wand sowie die beiden auf Basen stehenden grünen Säulen auf der linken Seite des Mittelbildes geben der Komposition eine stark vertikale Ausrichtung, die als Gegengewicht zu der horizontalen Gruppierung der Frauen und Kinder fungiert. Erneut lässt sich Coxcies Bemühen erkennen, einen möglichst authentischen Architekturfond wiederzugeben, der deutliche Übereinstimmungen mit der bühnenbildartigen Konstruktion seines Johannes-Martyriums aufweist, bei der Vorder- und Mittelgrund zusammengezogen sind und eine eng gefügte Figuration in das Zentrum dieses erweiterten Vordergrundes gestellt ist. Ganz ähnlich verhält es sich bei der Heilige Sippe, bei der die Figuren zwischen der am linken Bildrand gezeigten Säule und dem gegenüberliegenden Pfeiler positioniert sind.

Die Figur der Maria, die sich - den Christusknaben vor sich in den Händen haltend - nach vorne beugt, um ihn an Elisabeth zu übergeben, stellt überdies ein Zitat aus Leonardo da Vincis Anna Selbdritt von 1513 dar [ABB. 62]. ${ }^{310}$ Vergleichbare Übernahmen finden sich in den 1520er Jahren im Werk des eine Generation früher aktiven Joos van Cleve. ${ }^{311}$ Auch die von Raffael entworfene und von Giulio Romano teilausgeführte Heilige Familie (um 1518) weist im Hinblick auf den Kopf der Maria eine gewisse stilistische Ähnlichkeit auf. ${ }^{312}$ Eine vergleichbar gestaltete Maria zeigt auch die zweite Version der Heiligen Sippe, die 1586 von Philipp II. zusammen mit weiteren Werken Coxcies für sein Kloster El Escorial angekauft wurde [ABB. 63]. ${ }^{313}$ Überhaupt ähnelt diese Komposition der früheren in der grundsätzlichen Anlage, dem Figurenstil und der sie hinterfangenden antiken Architektur. Die Figuren stellen eine Verbindung

313 Öl auf Holz, Real Monasterio de El Escorial (RKD-Nr. 272142; vgl. Pérez de Tudela 2013, S. 107-109, bes. 109). Das Werk wurde von Philipp zusammen mit einem Retabel mit dem Leben Mariens (heute im Prado, Madrid) gekauft, das zuvor in der Kirche von St. Michael und St. Gudula in Brüssel aufgestellt gewesen sein soll, wie die erhaltene Dokumentation des Kaufs zu erkennen gibt (s. hierzu ZARCO 1930, S. 23, Nr. 883). Ferner s. Abschn. 3.3.4 dieser Arbeit. 
aus niederländischen und italienischen Vorbildern dar. Hier sind es besonders die Gesichter, die Züge der niederländischen Tradition aufnehmen, während Körper und Gewandungen eher italienisch anmuten. Der Typus des bartlosen Jünglings bei der Figur des Hl. Johannes auf der linken Seitentafel entspricht dem auf den Seitentafeln des weiter oben besprochenen Lukas-Retabels. In der Mittelachse des schmalen Hochformats steht Johannes, den eine Säule hoheitsvoll hinterfängt und der in leichter Untersicht vor Augen kommt. Im Vordergrund ist ein eben zu Boden stürzender älterer Mann dargestellt. Rücken und rechte Schulter sind nackt und werden durch ein kräftiges Helldunkel plastisch modelliert. Als Vorbild ist hier erneut der Laokoon zu erkennen, während von dem dargestellten Thema die Legenda Aurea berichtet. Zu sehen sind die Geschichte mit dem Wunder des vergifteten Kelches und der Tempel der Göttin Diana, die der Text als den Ort des Geschehens ausweist. Die Verweigerung des Johannes der heidnischen Göttin zu opfern, führt dazu, dass der Oberpriester, der links neben Johannes zu sehen ist, diesen dazu zwingt, aus einem vergifteten Kelch zu trinken. ${ }^{314}$ Johannes, der wie üblich mit zum Segensgestus erhobener Hand dargestellt ist, schlägt der Legende nach das Kreuzzeichen über den mit Gift gefüllten Kelch und trinkt anschließend daraus, jedoch ohne dass dies ihm etwas anhaben kann. Dass die Wirksamkeit des Giftes zuvor geprüft worden war, wird im Bild dadurch veranschaulicht, indem eine weitere Person im Vordergrund, die dem Text zu Folge als, Gesetzesbrecher' zu identifizieren ist, davon trinkt und daraufhin stirbt. In unterschiedlicher Weise reagieren die umstehenden Personen auf das Geschehen; erschrocken erscheint der eine, verehrungsvoll Johannes zugewandt ein anderer, als ruhiger Zuschauer ein dritter. Der heidnische Priester links neben Johannes ist auf die Knie gefallen, um das Wunder, dessen er teilhaftig geworden ist, zu preisen. Es kann daher konstatiert werden, dass es sich nur scheinbar um eine Momentaufnahme handelt, vielmehr jedoch um eine erzählerische Konfiguration mehrerer chronologisch aufeinander folgender Handlungsmotive.

Der ehemals rechte Seitenflügel zeigt im unteren Bildbereich das leere Grab des Johannes, das gerade von einem der Jünger untersucht wird, der auf die Gestalt des Euklid in Raffaels Schule von Athen zurückgeht. ${ }^{315} \mathrm{Im}$ oberen Bereich des Bildes ist Johannes umgeben von Wolken zu sehen, was seine Entrückung veranschaulicht. Die Art dieser Darstellung ist originell und erinnert an die Himmelfahrt Christi in Santa Maria dell'Anima, bei welcher Coxcie eine ähnliche von Licht durchschienene Wolkenöffnung gewählt hat. Coxcies Komposition greift offenbar auf die Ikonographie der Himmelsaufnahme Marias

314 Vgl. HÄUPTLI 2014, Legenda Aurea, S. 231; LCI VII [1974], s. v. „Johannes der Evangelist“, Sp. 119.

315 Ein Modell, das von Raffael selbst mindestens ein weiteres Mal, nämlich für seinen Karton für den Bildteppich mit dem Wunderbaren Fischzug für die Sixtinische Kapelle, wiederholt (hierzu

LOINING 1995, S. 122). Diese wie auch die anderen Vorlagen für die Tapisserie-Srie mit den Aposteltaten befand sich im ersten Drittel des 16. Jhs. in Brüssel und ist höchstwahrscheinlich von mehreren zeitgenössischen Künstlern rezipiert worden, s. hierzu Abschn. 2.3. Vgl. auch HARNACK 2018, S. 129 f. 
zurück, wie sie etwa Tizians Himmelfahrt Mariens von 1518, veranschaulicht. ${ }^{316}$ Johannes ist dagegen ins Profil gedreht, zeigt aber eine sehr ähnliche Geste. Darüber hinaus sind die Farben desblauen und roten Gewandes nahezu identisch, lediglich vertauscht. Die Art, wie hier das ,himmlische Licht' evoziert wird, schließt an die Beschaffenheit der Johannesvision auf dem Seitenflügel für Gossaerts Lukasaltar an und weist ebenfalls auf Coxcies Himmelfahrtsdarstellung in der Barbarakapelle in Rom zurück. ${ }^{317}$

Der im Vordergrund geöffnete Bildraum ist von einer Vielzahl anatomisch korrekt gebildeter menschlicher Figuren bevölkert, von denen viele mehr oder weniger direkte Übertragungen aus dem Umfeld Raffaels darstellen, die er neu zu arrangieren wusste. ${ }^{318}$ So weisen der Kopf und die Körperhaltung der Maria eine große Ähnlichkeit $\mathrm{zu}$ den Madonnen Leonardos auf. Weitere Bildelemente, wie die Architektur, die marmorne Säule und die rote Draperie sind ebenfalls italienischen Ursprungs und verweisen auf die besondere Rolle der Werke Raffaels für die Stilgenese bei Michiel Coxcie. ${ }^{319}$ Es ist nicht von der Hand zu weisen, dass Coxcie in Raffael sein größtes Vorbild gefunden hat. ${ }^{320}$ Die Bestätigung hierfür liefern die zahlreichen Zitate aus dem Werk des Italieners auf den drei Tafelbildern Coxcies. So gehen die drei Ehemänner Annas auf Gestalten in der Schule von Athen zurück. Auch der in den Bildraum blickende Knabe scheint sich auf eine Figur aus der Pythagoras-Averoes-Konstellation des Wandbildes zu beziehen. Die von van Mander überlieferte Anekdote, dass Coxcie in einem schlechten Verhältnis zu dem Kupferstecher Hieronymus Cock gestanden habe, nach dem dieser durch die Publikation eines Stichs nach Raffaels Wandbild in der Stanza della Segnatura offengelegt hatte, wie stark Coxcie sich an diesem Vorbild orientiert habe, erscheint in diesem Kontext plausibel und bekräftigt die große Bedeutung, die Coxcie dem Werk Raffaels eingeräumt hat. ${ }^{321}$ Die Anekdote scheint mit van Manders negativer Bewertung der künstlerischen Originalität Coxcies Hand in Hand zu gehen. Sehr deutlich

\footnotetext{
Werk dritter herauszuarbeiten und zu kopieren verstand: „Dieser Künstler war wunder-süß und fließend in seinem Mahlen / auch nett und sauber in seinen Zierrahten / und gab seinen Frauenbildern einen herrlichen Wolstand / doch von Ordinanzien erwieß er keinen Uberfluß / sondern bediente sich vieler Italienischen Stuck / weßwegen er nicht wol mit Hieronymo Kock zufrieden gewesen / weil derselbe folget dem Raphaël d' Urbino nach. die Schul Raphaels in Kupfer gebracht / als woraus er seine studien genommen / und viel darvon in die Altar-Tafel von dem Ableiben Mariae zu S. Goelen in BrüBel gebracht / so hernach bey jedermann offenbar und bekannt worden." (zit. nach TA 1675, II, Buch 3 (niederl. u. dt. Künstler), S. 271).

321 Van Mander 1604, fol. 258v.
} 
hat Coxcie sich wiederum bei der im Profil gezeigten Figur am äußeren rechten Rand der Mitteltafel an der Tiburtinischen Sybille auf Raffaels Fresko in der Chigi-Kapelle von Santa Maria della Pace orientiert. Es handelt sich um eine nahezu identisch übertragene Figur. ${ }^{322}$

Neben Raffael war aber auch die Malerei Leonardos für die Figurationen Coxcies anregend. Die zentrale Konfiguration der Heiligen Sippe ähnelt in vielerlei Hinsicht der Anna Selbdritt Leonardos, wie KLAUNER zeigen konnte. ${ }^{323}$ Höchstwahrscheinlich habe es die Grundlage für Coxcies Komposition geliefert. Dem muss zugestimmt werden, weil die zu diesem Zeitpunkt für die niederländische Malerei eher unkonventionelle Darstellung der Maria in einer aufgelockerten Pose mit ausgestreckten Armen und dem ihrem Kind entgegengeneigten Haupt unmittelbare Übereinstimmung mit dem Bild Leonardos aufweist und darüber hinaus auch keine vergleichbare Entsprechung in der lokalen Tradition hat. Der Kopf des Christusknaben in Leonardos Anna Selbdritt wird bei Coxcie wiederum in modifizierter Form aufgegriffen. LOINING hatte hierzu allerdings auch herausstellen können, dass sich diese Übernahmen auf die Form beschränken und gegenüber Leonardos

322 Vgl. LOINING 1996, S. 122.

323 Vgl. KLAUner 1977, S. 134.

324 Vgl. LOINING 1995, S. 121.

325 Vgl. LOINING 1995, S. 121.

326 Vgl. ebd., S. 122 mit Verweis auf HÜBNER, P. G.: Le Statue di Roma. Grundlage für eine Geschichte der antiken Monumente in der Renaissance, Bd. I., Leipzig 1812, S. 54. Bemerkenswert ist die historische Korrektheit der Darstellung - Heemskerck hat den Hof noch unvollendet erlebt, wie der reproduzierende Stich von Hieronymus Cock zeigt. Tatsächlich wurde der sfumato eine Betonung des Zeichnerischen zu beobachten sei. ${ }^{324}$ Insgesamt sind Coxcies Figuren deutlich, glatter ${ }^{6}$ und stärker von der Linie her entwickelt, was keine unmittelbare stilistische Beeinflussung durch Leonardo nahelegt, auch wenn die Motivik so hergeleitet werden kann.

Ein weiteres Vorbild stellt auch hier Michelangelo dar. Die Figurengruppe mit Mutter und Kind am rechten Bildrand sowie Maria Salome (?) vorne links verweisen auf die Kenntnis einer ähnlichen Anordnung im Stichkappenfresko mit Zorobabel und seinen Eltern in der Sixtinischen Kapelle. ${ }^{325}$ Auch aus antiken Vorbildern wusste Coxcie zu schöpfen. Die im Sippenbild gezeigte Nischenfigur zeigt eine der zu seiner Zeit in Rom im Innenhof des Palazzo Valle-Capranica aufgestellten Antiken. Über die Aufstellung an diesem Platz sind wir durch einen 1553 erschienenen Stich von Hieronymus Cock [ABB. 64], der einer verlorenen Handzeichnung Heemskercks aus der Zeit von 1532 bis 1536 folgt, informiert. ${ }^{326} \mathrm{Da}$ der Stich später erschienen ist, hat Coxcie die Skulptur aus eigener Anschauung oder aber von der Zeichnung des zeitgleich mit ihm in Rom arbeitenden Marten van Heemskerck gekannt.

Der Stil der Heiligen Sippe ähnelt stark

Hof erst nach 1536 fertiggestellt. Die Figur muss jedoch bereits während der Bautätigkeiten in der Nische ihren Platz gefunden haben. HÜBNER verweist auf eine Zeichnung von Francisco de Holland von 1538/39, die den Hof in seiner vollendeten Form zeigt. Darüber hinaus habe sich eine Beschreibung der endgültigen Disposition des Hofes und der darin aufgestellten Plastik von Ulisse Aldrovondi (1522-1605) erhalten (vgl. HÜBNER 1912, S. 118). Vgl. auch KuHN-FORTE 2013, S. 77, Kat.-Nr. II.16. 
dem der Tafeln mit Johannes auf Patmos und dem Johannes-Martyrium. Deutlich wird dies in einer ähnlichen Gestaltung des Bildraumes, dessen Gewicht auf dem Vordergrund liegt. Durch die hintereinander gestaffelten Figuren gewinnt der Raum an Tiefe, und die gezeigten Architekturen wirken begehbar und maßstabsgerecht, besonders der im Mittelbild angedeutete Innenraum. Ähnlich wie zuvor sind die Figuren durch ein ausgeprägtes Helldunkel plastisch modelliert und weisen eine Vielzahl von Bewegungsmotiven auf, die den Darstellungen szenischen Charakter verleihen. Die satten Farben und die ausbalancierte Komposition sollen einer weiteren Anekdote nach später von Peter-Paul Rubens bewundert und adaptiert worden sein. ${ }^{327}$

Die Neuerungen von Coxcie in seinen sogenannten Sippen- und Johannestafeln und den kurz zuvor geschaffenen Seitenflügeln zu Gossaerts Lukasaltar werden deutlich, wenn man die Werke von Quentin Massys zum Vergleich heranzieht. ${ }^{328}$ Der dreiflügelige Annenaltar [AВB. 65], der um 1509 für St. Peter in Löwen entstand, zeigt die Heilige Sippe auf der Mitteltafel in einem offen gestalteten Gewölbebau mit einer Art überkuppelter Vierung. ${ }^{329}$

327 Vgl. JONCKHEERE - SUYKERBUYK 2013, S. 45.

328 Das künstlerische Werks Quentins Massys steht im ersten Drittel des 16. Jhs. für das letzte Aufleben der altniederländischen Tradition. Sein Stil ist weniger als der Jan Gossaerts zu dieser Zeit von der forcierten Italienrezeption geprägt, sondern beweist einen vergleichsweise distinguierten Umgang mit den Leistungen der italienischen Malerei des Quattrocento, hier v. a. der Physiognomie der Figuren Leonardos (vgl. PANOFSKY 1977, S. 281).

329 Öl auf Holz, 224,5 × $219 \mathrm{~cm}$ (Mitteltafel), 220 $\times 92 \mathrm{~cm}$ (Flügel einzeln), Koninklijke Musea voor Schone Kunsten, Brüssel, Inv.-Nr. 2784 (s.
Die Architektur mit ihrer Kuppel und den Rundbögen, die Ausblick in eine ferne Berglandschaft gewähren, weist Formen der italienischen Renaissancearchitektur auf. Die Pfeiler sind jedoch nur andeutungsweise danach gebildet und als rechteckige Träger zweier übereinandergestellter Versatzstücke eines Gebälks gestaltet und nicht nach einer überkommenen antiken Säulenordnung. Stattdessen erinnert die Konstruktion an entsprechende Darstellungen aus der zeitgenössischen Druckgraphik, etwa denen aus Albrecht Dürers Marienleben, nicht aber an tatsächliche Bauwerke. $^{330}$

Die Figuren, allen voran die zentralen Gestalten von Maria und ihrer Mutter Anna, orientieren sich an Beispielen der altniederländischen Malerei und sind vergleichbar mit der Marienfigur, die Jan Gossaert in dieser Zeit auf seinem Malvagna-Triptychon darstellt. Dort wie auch hier handelt es sich um denselben Typus der sitzenden Maria, der um 1500, etwa im Umkreis des Gerard David, oft gewählt wurde und bei dem das Jesuskind auf dem einen Bein Marias sitzend oder liegend dargestellt ist. ${ }^{331}$ Die recht ähnlich gestalteten Männerköpfe zeigen einen Grad der Typisierung, wie sie

SILVER 1984, S. 141 u. SCHNEIDER 2015, S. $75-$ 83).

330 Hier besonders das Blatt Christus und den Schriftgelehrten (1503, Holzschnitt, 29,5 × $21 \mathrm{~cm}$ ), welches ein ähnliches Tonnengewölbe und in die Tiefe des Bildraumes ,gestaffelte‘ Rundbögen zeigt. Die beiden Stangen, die bei Massys den Bereich zwischen den Pfeilerkapitellen überspannen, verweisen auf die Holzdecke bei Dürer, die den Raum im hinteren Bereich ein stückweit überdeckt.

331 Wie etwa die Maria auf dem Columba-Altar aus Köln (Alte Pinakothek, München, Inv.-Nr. WAF 
ebenfalls von der Druckgraphik Dürers beeinflusst sein könnte. Das, was als Neuerung gegenüber der Malerei des 15. Jahrhunderts zu bewerten ist, stellt im Vergleich zu Coxcies Werk, eine vergleichsweise zaghafte Entwicklung dar, die noch sehr viel stärker von den lokalen Vorbildern geprägt ist. ${ }^{332}$ Die Architektur ist bei Massys bereits ,belebter', aber noch nicht als Bühnenbild angelegt und ähnelt darin den Kompositionen Jan Gossaerts oder Bernard van Orleys, die Architektur auch vornehmlich als streng bildparallele ,Rahmung' auffassen, aber noch stärker in der Tradition der ,Gehäuse` des 15. Jahrhunderts stehen. ${ }^{333}$ Ganz anders verhält es sich mit Coxcies Heilige Sippe und ihren monumentalen Figuren, die jene Barriere zu überwinden suchen, indem Architektur nicht als starre räumliche Begrenzung aufgefasst wird, sondern begehbar

1189, WAF 1190 u. WAF 1191) oder Hans Memlings Thronende Maria aus den frühen 1480er Jahren (Öl auf Holz, 68,3 × 73,3 cm, Metropolitan Museum, New York, Inv.-Nr. 14.40.634). Das offen getragene Haar Marias verweist wiederum auf Dieric Bouts, dessen Maria mit Kind von 1470 (Öl auf Holz, $40 \times 29$ cm Rijksmuseum, Twenthe, Inv.-Nr. 0046; RKD-Nr. 27571) ebenfalls ihr langes rotes Haar unbedeckt trägt. Massys hatte seine Ausbildung in Löwen in der Tradition von Bouts erhalten, sodass hier von einer motivischen Beeinflussung ausgegangen werden kann. Möglich ist, dass er sogar in dessen Werkstatt ausgebildet worden ist (vgl. MARTENS 2003, S. 253-284).

332 Vgl. JONCKHEERE 2013, S. 66 u. den Exkurs zu den Antwerpener Manieristen am Beginn in dieser Studie.

333 Ähnliches habe ich zuvor im Zusammenhang mit dem Einsatz von Architektur in Jan Gossaerts Bildern besprochen, s. Abschn. 2.1.

334 Die Darstellung von vordergründig dargestellten Architekturausschnitten, in die hinein Figuren gestellt sind, die mit der Raumtiefe korrespondieren ist an sich keine Neuerung. Gossaerts Hl. Lukas, der die Madonna malt von 1520 (110,5 und mit Leben gefüllt erscheint. ${ }^{334}$

Das Ergebnis von LOININGs Untersuchung hat zunächst ein eher ernüchterndes, in gewisser Hinsicht von van Manders negativem Urteil mitbestimmtes Bild von diesem zentralen Werk Michael Coxcies gezeichnet. Die „mangelnde Originalität in Motivfindung und Verquickung des Formenschatzes zu einheitlicher, stringenter Komposition “ ${ }^{\text {335 }}$ sei zwar als eindeutige Schwäche des Malers zu identifizieren, könne aber auch bei anderen Künstlern auf derselben Stufe, wie etwa bei Frans Floris, Marten de Vos und Lambert Lombard beobachtet werden. Nur wenige Künstler in der frühen romanistischen flämischen Malerei wie Jan van Scorel oder Marten van Heemskerck seien in dieser Hinsicht einen Schritt weiter gewesen. ${ }^{336}$ Gegenüber dieser Negativwertung

$\mathrm{cm} \times 83,5 \mathrm{~cm}$ ) und seine Danä̈ von 1527 zeigen Figuren, die in größere, nur als Ausschnitt gezeigte Architekturen hineingestellt sind (s. hierzu AINsworTh 2010, S. 232). Erste Beispiele finden sich bereits in Gossaerts spätem Frühwerk, so zeigt etwa ein Gemälde von 1515, ebenfalls mit dem Hl. Lukas, der die Madonna malt, eine Architektur, deren Ausschnitt noch bedeutend größer angelegt ist und den Bildraum weitestgehend als eine Innenansicht wiedergibt. Die Figuren von Lukas und der Madonna treten in diesem Beispiel noch bedeutend vor der Monumentalität der Architektur zurück. Als vergleichbar anzusehen sind hier einzelne Beispiele der Antwerpener Manieristen aus derselben Phase oder aber Bernard van Orleys Hiobaltar von 1521 (Koninklijke Musea voor Schone Kunsten, Brüssel).

335 LOINING 1995, S. 138.

336 Der „grobschlächtige Eklektizist“ Coxcie (LOINING 1995, S. 123), wie ihn die stilgeschichtliche Forschung abgestempelt hat, muss hinsichtlich seiner Befähigung die in Italien aufgenommenen Motive zu variieren und sinnvoll $\mathrm{zu}$ interpretieren rehabilitiert werden. Wie 
kann man Michiel Cocxie durchaus zugestehen, dass er nicht zuletzt durch seine lange Lebenszeit eine wesentliche Mittlerrolle bei der Synthese zwischen italienischer und flämischer Malereitradition gespielt hat. Gerade bei der frühen Annäherungen an die italienische Malerei geht Coxcie nicht nur im Hinblick auf die konsequente Orientierung an italienischen Vorbildern auch kompositorisch über die Leistungen der vorherigen Generation hinaus. Coxcies maniera italiana, für dessen Beherrschung ihn Vasari gerühmt hatte, ${ }^{337}$ ist für die nachfolgende Kunstentwicklung Flanderns und noch für Peter Paul Rubens von entscheidender Bedeutung, worauf zuletzt Peter CAPREAU hingewiesen hat. Dieser betont die Notwendigkeit einer kritischen Überprüfung der in der Frühen Neuzeit bei Autoren wie van Mander begonnenen Negativrezeption auf ihre tatsächlichen Ursachen. So hält er zuletzt nationalistische Diskurse in der Kunstgeschichte des 19. Jahrhunderts, nach denen Coxcie die ,Reinheit ${ }^{\star}$ der altniederländischen Malerei durch die aus Italien mitgebrachten Ideen preisgegeben habe, für ausschlaggebende Maximen, die zuletzt auch Autoren der letzten dreißig Jahre noch in gewisser Hinsicht mitbeeinflusst hätten. ${ }^{338}$

Dem ist zu entgegnen, dass gerade weil es die differenzierte Auseinandersetzung mit der italienischen Kunst aufweist, Michiel Coxcies Triptychon mit der Heiligen Sippe einen

LOINING schreibt, sei es ihm durchaus gelungen die geliehenen Motive zumindest auf dem Sippenbild „zu planvoller, gefälliger Komposition zusammenzuführen“ (LOINING 1995, S. 123).

337 Vgl. Vasari, ed. Milanesi VII, S. 585: „Michel Coxcie, del quale ho favellato di sopra, e detto che portò in Fiandra la maniera italiana $[. . .]^{\text {“. }}$.
Fortschritt in der Entwicklung der südniederländischen Malerei beschreibt, der die Bestrebungen der vorangehenden Generation, eine Neuausrichtung an der italienischen Kunst zu erreichen, fortsetzt und sich dabei, nicht anders wie seine Zeitgenossen auch, an konkreten Vorbildern orientiert. Dieser Zwischenschritt der Aneignung wiederum stellt die notwendige Grundlage für die spätere Entwicklung dar.

\subsubsection{Die Beziehung zu den Werken Bernard van Orleys nach der Rückkehr aus Rom}

Gegenüber dem immer wiederkehrenden Verweis auf die Rezeption Raffaels ist die stilistische Beziehung Coxcies zu seinem Lehrer Bernard van Orley in der Literatur zwar erwähnt, selten aber an Bespielen konkretisiert worden. Ähnlich wie bei der Prägung durch die italienische Kunst, ist auch das Verhältnis zum Umfeld seines Lehrers nicht als eine bloße Gegebenheit anzuerkennen, zumal konkrete historische Belege wie auch entsprechend sicher zugewiesene Werke, eine Ausbildung Coxcies in der Werkstatt van Orleys als gesichert erscheinen lassen, immer noch fehlen. Die euphorische Bezeichnung Coxcies als den ersten echten flämischen Romanisten durch HoOGEWERFF, ${ }^{339}$ hat in den Hinter-

338 Dieser Sachverhalt sowie die Rezeption Michiel Coxcies wird ausführlich in Kap. V behandelt. Für CAPREAU s. den Internetartikel von MUNDELL 2013 „Leuven exhibition proves artistic merit of Michiel Coxcie“ vom 07. Nov. 2013, 〈http://www.flanderstoday.eu〉 (13.06.2019).

339, „[...] de eerste volslagen Romanist“ (HoOGEWERFF 1912, S. 75). 
grund treten lassen, dass Coxcies seinen Ausgang von der südniederländischen Malerei genommen hat. Die zahlreich erhaltenen Werke des Bernard van Orley können als Hinweise dafür dienen, wie Coxcies künstlerische Anfänge zu denken sind.

Eine der augenscheinlich modernsten Kompositionen aus dem späten Werk Bernard van Orleys, ${ }^{340}$ stellt das heute im Louvre befindliche Bild mit der Heiligen Familie von 1521 dar, welches der Maler signiert und datiert hat [ABB. 66]. ${ }^{341} \mathrm{Zu}$ sehen ist Maria, die hinter einer steinernen Brüstung sitzt und den Jesusknaben mit beiden Händen stützt, während das Kind sich auf der Brüstung stehend gegen seine Mutter lehnt, den linken Arm um Marias Hals geschlungen und mit der rechten Hand ihren Schleier ergriffen hat. Hinter den beiden sieht man Josef, der nachdenklich auf Mutter und Kind blickt, die auch ihrerseits zu einem Engel hinsehen, der ihnen frontal gegenübersteht. Dieser trägt ein weißes Gewand mit schwarzem Überrock und hält Blumen in einer Art Gewandtasche bereit, die er vor die Füße des Kindes streut. Diese beziehen sich höchstwahrscheinlich auf die Passion Christi, was wiederum in einem Zusammenhang mit

340 Modernität im Sinne des ausgeprägten Grades einer italienischen bzw. ,romanistischen' Beeinflussung.

341 Der Vermerk im Inventar des Louvre zu diesem Werk: „Un des premiers grands tableaux italianisants de l'artiste. Evident hommage à Raphaël dans une habile flexibilité de lignes encore gothicisantes“. Die Inschrift gilt als authentisch: „BERN · ORLEYN PINGEBAT ANNO VERBI 1521“ (s. FARMER 1981, S. 144-145 u. Kat-Nr. 139, Abb. 86. Vgl. auch Kat. Brüssel 2019, S. 118, Kat.-Nr. 14).

342 Immergrün deutet häufig auf die Jungfrau Maria hin. Es ist u. a. auch im Paradiesgärtlein des Oberrheinischen Meisters von 1410 dargestellt der Haltung des Jesusknaben, der sich an seine Mutter schmiegt, zu sehen ist. Dargestellt sind unterschiedliche Blumen, darunter rötliche Feder- bzw. Gartennelken, die auf Grund ihrer Größe vor den anderen Blüten hervortreten. Daneben lassen sich vereinzelt blauer Borretsch oder aber die sehr ähnlich blühende Jungfer im Grünen (Nigella damascena) erkennen, die beide wegen ihrer Blütenfarbe als Mariensymbole zu interpretieren sind. Auf die Brüstung gestreut sieht man kleine weiße Blüten, bei denen es sich um Immergrün (Vinca) oder aber Windröschen (Anemonen) handeln könnte, sowie um Wacholder. ${ }^{342}$ Die roten Nelken stehen einerseits für Maria und ihre Mutterschaft, die sich auch im inniglichen Verhalten von Mutter und Kind ausdrückt. Andrerseits steht die Nelke auch für die Passion Christi, was oft auf die Dreizahl der Blütenblätter, aber auch das nagelartige Aussehen der getrockneten Samen bezogen wird. Der volkstümliche Name „Nägelein“ deutet ebenfalls auf diese Symbolik hin. ${ }^{343}$ Anemonen stehen in der symbolischen Tradition ebenfalls für die

(vgl. ZERLING 2007, Sp. 124); Wachholder, sofern es sich hier um diesen handelt kann allgemein ein Symbol für Entsühnung darstellen (vgl. ZERLING 2007, Sp. 277). In dieser Darstellung könnte er also auch auf den Opfertod und die damit verbundene Erlösungslehre hindeuten.

343 In der Bildenden Kunst taucht die Nelke meist als ,Offerte' auf, die wie in dieser Darstellung, dem Christusknaben und seiner Mutter übergeben wird. Gelegentlich wird sie aber auch von Maria an ihren Sohn überreicht oder umgekehrt, was die Annahme des bevorstehenden Leidens (Passion u. Kreuzigung) von Mutter und Sohn ausdrückt (vgl. SCHMIDT 2000, S. 132 u. ZERLING 2007, Sp. 191-193). 
Passion Christi und Maria als Schmerzensmutter. ${ }^{344}$ Insgesamt deuten die verschiedenen Blüten, die der Engel dem Christusknaben vor die Füße streut, auf verschiedene Aspekte der Heilsgeschichte und die Rolle hin, die Christus, aber auch seine Mutter darin zu erfüllen haben. Neben dieser symbolischen Ebene, kann die Darstellung gesammelter Pflanzen aber möglicherweise auch auf den Brauch der Kräuterweihe hindeuten, die am Fest von Mariä Himmelfahrt vor dem Hochamt stattfindet und die auf den Bericht des Johannes von Damaskus Bezug nimmt, nach welchem das Grab Marias ohne Leichnam und stattdessen mit duftenden Blumen und Kräutern gefüllt, vorgefunden worden sei. ${ }^{345}$

Über die Brüstung ist eine Art Webteppich gebreitet, auf welchen das Jesuskind steht. Rechts erhebt sich über einer reich profilierten Basis ein Pfeiler, der vom rechten Bildrand überschnitten wird. Im Hintergrund ist ein reich gestaltetes antikes Gebälk zu sehen, während links oben ein angeschnittener Rundbogen den Eindruck vermittelt, dass sich die Gruppe in einer offenen Halle befindet. Der Bogen gewährt einen Ausblick auf einen weiteren antikisch gestalteten Bau, der von einer hoch aufgestellten Skulptur bekrönt ist, die von der auf Raffaels Karton mit dem Opfer von Lystra (Apg 14,8-18) inspiriert worden sein könnte. ${ }^{346}$ Nicht zuletzt deshalb lässt sich der Stil dieses Werkes als ,romanistisch` bezeichnen, da es durch die gerade auch

344 Die roten Flecken, die auf den Blüten der Pflanze gelegentlich auftreten wurden mit dem Blut Christi und seinen Wundmalen assoziiert (vgl. ZERLING 2007, Sp. 14).

345 LThk (1935), Bd. 7, s. v. „Kräuterweihe“, Sp. 235. im Vergleich zu anderen Werken dieser Phase, wie etwa das Hiob-Retabel, eine vergleichsweise authentische Auseinandersetzung mit antikisierender Architektur zeigt. Auch die nahsichtig gezeigte Heilige Familie ist nicht unmittelbar über die niederländische Tradition zu erklären, sondern setzen weitere Vorbilder voraus.

Eine weitere, auf einem cartellino im Bild signierte und auf 1522 datierte Darstellung der Heiligen Familie, die sich heute im Prado befindet [ABB. 67], stellt eine Variation des kurz zuvor entstandenen Bildes im Louvre dar. ${ }^{347}$ Es handelt sich erneut um eine in einem Innenraum angelegte Szene, welche dieselben vier Figuren zeigt, wie dem anderen Bild; ergänzt um einen zweiten Engel, der von links herangeflogen ist und der eine Krone über dem Haupt der zentral dargestellten Maria hält. Der Raum ist angesichts des profilierten Gesimses in dem Pariser Bild weniger reich ausgestaltet, teilt allerdings dessen Anlage. Rechts sieht man eine in dunkleren Farben gehaltene Wand, während sich links ein rechteckiger fensterartiger Ausschnitt öffnet, der einen Ausblick in eine weithin ausgedehnte Küstenlandschaft gewährt. Vergleichbares findet sich rechts auf Raffaels Entwurfszeichnung für ,den Tod des Ananias‘ (Apg 5,1-5), die einen

346 Kartonzeichnung, Victoria and Albert Museum, Königl. Leihgabe (No. 6).

347 Öl auf Holz, $90 \times 74 \mathrm{~cm}$, Prado, Madrid, Inv.Nr. P002692 (vgl. GALAND 2013, S. 34, 91, 99, 114-116, 125 u. Kat. Prado 2001, S. 123. Vgl. auch Kat. Brüssel 2019, S. 120, Kat.-Nr. 15). 
sehr ähnlichen Ausblick zeigt. ${ }^{348}$ Das Jesuskind steht wieder auf einer Brüstung, auf der rechts auch hier ein reich profilierter Sockel ruht, jedoch ohne aufgesetzten Pfeiler, sondern mit einem darauf liegenden aufgeschlagenen Buch. Das Kind wird wiederum von Maria gestützt, wendet sich allerdings auf wackeligen Beinen stehend seiner Mutter zu, nach der es in kindlicher Weise seine Arme ausstreckt. Der Engel, der sich von links mit einem Blumenkorb nähert, ist anders als bei dem früheren Bild durch seine Flügel als Engel ausgewiesen. Auch hier steht das Jesuskind auf einem reich gemusterten Webteppich, der auf der Brüstung liegt. Josef ist hinter Maria und dem Kind dargestellt und hält einen gelben Apfel in der Hand, der sich auf die Frucht vom Baum der Erkenntnis bezieht und Christus als neuen Adam kennzeichnet. Die Figuren weisen eine große Ähnlichkeit mit denen des Bildes von 1521 auf. Dies gilt auch für Details, wie Marias Frisur mit den über den Kopf geführten, mutmaßlich in einer Art Dutt endenden Zöpfen. Oder die, allerdings etwas längeren, Locken des Engels mit den Blumen und Josefs Bart mit in sich gedrehten Locken. Statt des Wirbels auf der Stirn, weist er hier jedoch einen an der Stirn deutlich zurückgegangen Haarwuchs auf, der ihn in Verbindung mit den gräulichen Haaren bedeutend greisenhafter

348 Kartonzeichnung, Victoria and Albert Museum, Königl. Leihgabe (No. 5).

349 s. Abschn. 2.3. In diesem Zusammenhang interessant ist, dass einige der Kartons von Raffael nach heutigem Kenntnisstand im Besitz verschiedener Künstler waren, bis 1571 waren sie höchstwahrscheinlich bei Pieter Coecke van Aelst. Da es sich hierbei um einen Schüler Bernard van Orleys handelt, ist die Verbreitung der Darstellungen in van Orleys Umfeld mehr als aussehen lässt. Die romanisierenden Architekturen sowie auch die für die altniederländische Malerei eher untypischen Gesichter der Figuren wurden bisweilen als Indiz dafür angesehen, dass Bernard van Orley bereits eine fortgeschrittene Auseinandersetzung mit dem Werk Raffaels betrieben habe, die er so möglicherweise bereits vor dessen Aufenthalt in Rom in den 1530er Jahren an seinen Schüler Michiel Coxcie vermittelt haben könnte. Eine Quelle für van Orley könnten die bereits mehrfach genannten Kartons zu der in Brüssel nach den Entwürfen Raffaels gewebten Serie von Tapisserien mit der Geschichte der Apostel Petrus und Paulus gewesen sein. ${ }^{349}$

In den Sammlungen des Prado in Madrid befindet sich das Bild einer Hl. Cäcilie von 1569, das Michiel Coxcie zunächst für einen nicht mehr genauer fassbaren niederländischen Auftraggeber geschaffen hatte und das später in den Besitz Philipps II. von Spanien gelangte [ABB. 68]. ${ }^{350}$ Dieser hatte seine Agenten in Flandern zum Ankauf von Kunstwerken für seine Sammlung. ${ }^{351}$ Möglicherweise wurden solche Werke wegen ihres explizit italienisch geprägten Stils mit den bereits sich in der Sammlung befindlichen Werken, unter an-

wahrscheinlich. Die erste (druckgraphische) Rezeption stellt möglicherweise der Stich Wunderbarer Fischfang von Cornelis Massys dar (vgl. HARNACK 2018, S. 128 f.).

350 Öl auf Leinwand, $136 \times 104 \mathrm{~cm}$, Prado, Madrid. Inv.-Nr. P001467 (vgl. Kat. Prado 1997, S. 104; JONCKHEERE 2013, S. 193, Kat.-Nr. 37 u. SUYKERBUYK 2013, S. 15).

351 Vgl. Perez des Tudela 2013, S. 110-112. 
derem solchen von Tizian und Raffael stilistisch am ehesten als kompatibel empfunden, ${ }^{352}$ worauf ich zu einem späteren Zeitpunkt noch zu sprechen kommen möchte. ${ }^{353}$

Das Bild zeigt die Heilige an einem diagonal ins Bild gestellten einmanualigem Spinett oder Virginal sitzend, zwei Instrumente die im 16. Jahrhundert populär wurden und sich durch eine rechteckige bzw. dreieckige Bauform voneinander unterscheiden, was bei dem Instrument in diesem Bild jedoch nicht eindeutig zu erkennen ist. ${ }^{354}$ Cäcilie trägt ein rosafarbenes antikisierendes Kleid, das knapp unterhalb ihres Busens gegürtet ist. Diagonal zwischen den Brüsten, die sich unter dem leichten Stoff abzeichnen, ist eine Art Schulterriemen zu sehen, der auf der linken Schulter in einem mit einem dunklen Stein besetzten Spange endet, die den roten Mantel hält, welcher über Rücken und Schoß gebreitet ist. Ihr rotblondes Haar ist zu Zöpfen geflochten und hochgesteckt, während sie ein stückweit über dem Haaransatz ein goldenes, mit Perlen sowie blauen und roten Steinen besetztes Diadem trägt. Umgeben ist sie von drei knabenhaften Engeln mit aufgeschlagenen Gesangbüchern, wie bei dem als Rückenfigur gestalteten, mit dem Gesicht zum Betrachter gewendeten, leicht beschnittenen Engel unten links zu erkennen ist. Lediglich der linke in Richtung des Betrachters gewendete Engel

352 Die sich heute im Prado befindliche Kreuztragung von Michiel Coxcie (um 1555, Öl auf Holz, $81 \times 50 \mathrm{~cm}$, Inv.-Nr. P002641) wirkt sogar so, als sei sie von vornherein stilistisch an ein sich ebenfalls in derselben Sammlung befindliches Ecce Homo-Bild Tizians von 1547 (Öl auf Leinwand, $69 \times 56 \mathrm{~cm}$, Inv.-Nr. P000437) angelehnt gemalt worden (vgl. PÉREZ DE TUDELA 2013, S. 105 f.). mit rotblondem Haar ist mit Flügeln dargestellt. Sein geöffneter Mund und der auf einen unbestimmten Punkt außerhalb des Bildes gerichtete Blick kennzeichnen den Engel als singend. Der Innenraum ist durch eine graue Wand im Hintergrund und einen rechts daran herabhängenden, die Hl. Cäcilie in der Art eines Ehrentuchs hinterfangenden, dunkelgrünen Vorhang gekennzeichnet.

Die Komposition Michiel Coxcies fußt sehr deutlich auf van Orleys Heilige Familie von $1521 .{ }^{355}$ Die feingliedrigen Hände der Cäcilie mit den gespreizten Fingern ähneln den Händen des Engels auf dem Bild von van Orley. Das krause lockige, leicht rötliche Haar des hinteren Engels weist ebenfalls eine stilistische Verwandtschaft mit dem des Engels bei van Orley auf. Auch die Gesichter sind vergleichbar, allerdings mit feinen Unterschieden in der Modellierung. Besonders deutlich wird dies in dem Gesicht der Frauengestalt, das zwar grundsätzliche Ähnlichkeiten zu dem der Maria in van Orleys Hl. Familie aufweist, allerdings bei Coxcie weicher gezeichnet ist. Im Gegensatz zu van Orley ist die Form des Kopfes definierter, das Kinn spitzer und die Augen deutlich größer, während der gesenkte Blick mit den fast geschlossenen Lidern an sich vergleichbar ist.

353 s. hierzu Abschn. 3.5.

354 Zur Bauform und Bestimmung frühneuzeitlicher Tasteninstrumente s. BEURMANN 2000, passim.

355 Auch thematisch ergibt sich indirekt eine Verwandtschaft. Die Heilige Cäcilie stellt als eine der Virgines Capitales eine inhaltliche Beziehung zur Jungfrau Maria, der Virgo inter Vigines, her, vgl. LCI III [1971], Sp. 189. 
Die Raumbildung bei van Orley ist maßgeblich durch die Brüstung im Vordergrund bestimmt, welche die untere Körperpartie der Figuren überdeckt. Dieses Mittel ist durch die Darstellung des Instrumentes von Coxcie reproduziert worden, um die großen nahsichtig angelegten Figuren in dem vertikalen Bildraum unterzubringen. Die Proportionen erscheinen stimmiger als es bei der Architektur auf van Orleys Bild der Fall ist. Die Figuren sind hier noch etwas zu groß, wie dies in der älteren niederländischen Malerei häufiger begegnet. Coxcie umgeht das Problem der Größenverhältnisse weitestgehend, indem er keine Architekturmotive zeigt, sondern den Hintergrund als eine größtenteils unbezeichnete graue Wand gestaltet, vor der rechts ein grüner Vorhang zu sehen ist. Dieser kann als Reminiszenz an den Architekturhintergrund bei van Orley, welcher die Maria hoheitlich hinterfängt, zu deuten sein. Die Art wie Architektur hier in der Funktion eines ,Ehrenvorhangs' gedacht ist, ist bei van Orley und Gossaert häufiger zu beobachten. Bei Coxcie wird dieses Motiv auf seine eigentliche Bedeutung zurückgeführt, indem an Stelle der Architektur bei Coxcies Hl. Cäcilie der Vorhang tritt, der eine gemeinsame Vertikale mit der Figur der Heiligen bildet. ${ }^{356}$ Ein kleines Feld oben links, das eine Art Mauerdurchbruch zeigt, der eine Fenster- oder Türöffnung meint, erinnert an den bedeutend größeren Ausblick in die Ferne in der Darstellung der Hl. Familie. Das am Rücken angeschnittene Engelchen unten

356 Der rechts im Hintergrund in Falten herabhängende Vorhang erinnert an die bei Tizian explizit als Ehrenvorhang gebrauchten Stoffe, etwa links, das überdies zum Betrachter gewendet ist und dadurch den Bezug zwischen Bild- und Auffstellungsraum herstellt, ist in der Figur des von links herantretenden, ebenfalls leicht angeschnittenen Engels bei van Orley vorgebildet. Auch dieser Figur kommt die Funktion zu, den durch das vertikale Format beschränkten Bildraum zu den Seiten hin aufzubrechen.

Durch stilistische Vergleiche wie diesen lassen sich für die Herkunft Michiel Coxcies aus der Werkstatt Bernard van Orleys einige Indizien gewinnen, die im folgenden Kapitel noch weiter ausgeführt werden sollen. Als Zwischenfazit kann jedoch zunächst bestätigt werden, dass sich in Coxcies nachrömischem Werk, neben der in der Literatur als maßgeblich beschriebenen Orientierung an italienischen Vorbildern, durchaus auch eine Bezugnahme auf ältere niederländische Werke geltend macht. Auch wenn der in diesem Kapitel gezeigte Vergleich allein für keine Bestätigung der bei van Mander erwähnten Ausbildung Coxcies bei Bernard van Orley ausreicht, so lassen sich daran doch immerhin gewisse Gesichtspunkte ablesen, nach denen sein Umgang mit den Werken der frühen Romanisten weiter zu untersuchen ist.

dem auf dem Portrait des Dogen Francesco Venier [Ö1 auf Leinwand, $113 \times 99 \mathrm{~cm}$, Museo Thyssen-Bornemisza, Madrid, Inv.-Nr. 405 (1930.116)]. 


\subsubsection{Das Triptychon mit Szenen aus dem Leben der heiligen Jungfrau (um 1550)}

Die stilistische Orientierung am Spätwerk Bernard van Orleys lässt sich bei Michiel Coxcie stellenweise beobachten. Grundsätzlich kann konstatiert werden, dass die Kompositionsschemata häufig von seinem Lehrer herrühren, während sich die italienische Beeinflussung vor allem bei einzelnen Figuren und der Verwendung von antikischer Architektur zeigt, wie zuvor am Beispiel der heiligen Sippe in Kremsmünster $\mathrm{zu}$ beobachten gewesen ist. Ein weiteres Werk Coxcies aus derselben Zeit, das die Auseinandersetzung mit verschiedenen motivischen und stilistischen Quellen beschreibt, ist das Triptychon mit Szenen aus dem Leben Marias [ABB. 69-71], das vor 1550 entstand und ursprünglich für St. Gudula in Brüssel bestimmt war, wo es mehrere Jahrzehnte aufgestellt gewesen ist. Philipp II. erwarb dieses Bild 1586 für eine hohe Summe, wie Karel von Mander zu berichten weiß. ${ }^{357}$ Der Ankauf scheint daher eine gewisse Öffentlichkeitswirkung gehabt zu haben. In der Kathedrale von St. Michael und St. Gudula haben sich auf den heutigen Tag noch weitere Tafelbilder des Malers erhalten; darunter ein Passionstriptychon mit Kreurigung. ${ }^{358}$ Auf dem Marienretabel sind auf dem Mittelbild der Tod Mariens, links deren Geburt und rechts die Darstellung Christi im Tempel zu sehen. ${ }^{359}$

Die Mitteltafel zeigt einen steil in die Tiefe fluchtendenden Kirchenraum mit der

357 Vgl. Fransen 2006, S. 862 f.

358 Öl auf Holz, Kathedrale von St. Michael und St. Gudula, Brüssel.

359 Der Marientod erhält ab dem Spätmittelalter die Bedeutung eines, guten Todes' und wird im 15.
Darstellung des Marientodes in der unteren Bildhälfte und ihre Aufnahme in den Himmel in der oberen [ABB. 71]. Groß im Vordergrund sieht man die soeben verstorbene, auf einem Bett liegende Maria umgeben von Aposteln und einem Engel, die teilweise mit gefalteten Händen im Gebet der toten Gottesmutter zugewandt sind. Einer von ihnen, vorne links, liest in einem Buch, während rechts vom Bett ein jüngerer Mann, vermutlich Johannes, mit einer Geste des Erschreckens sich der Toten zuwendet. Ähnlich wenden sich auch einige weitere Apostel in das Gebet vertieft oder von Trauer ergriffen der Toten zu. Am Kopfende steht eine alte Frau mit Kopftuch und gefalteten Händen. Demgegenüber sieht man einige Apostel, wie sie zur oberen Bildhälfte emporblicken. Einige erheben dabei preisend, anbetend und akklamierend die Hände. Über ihnen ist Maria in einer Wolke zu sehen, umgeben von einer Engelschar, von denen jeweils zwei sie flankieren und ehrfürchtig grüßen. Maria steigt leiblich mit gefalteten Händen gen Himmel auf, während sie unten noch tot auf dem Sterbebett liegt. Bemerkenswert ist Coxcies Abweichung von der ikonographischen Tradition, indem er nicht zeigt, wie Christus am Sterbelager seiner Mutter erscheint, um deren Seele in Gestalt eines Eidolon in Empfang zu nehmen bzw. dem Erzengel Michael zu übergeben, sondern schon die leibliche Himmelsaufnahme - die erst drei Tage nach Marias Tod folgt - vor Augen bringt. Offenbar geht es ihm 1550 um die Akzentuierung der von den

Jh. pastoraltheologisch ausgelegt, besonders in den Predigten des Geiler von Keysersberg (vgl. SCHREINER 1994 [2006], S. 466 u. SCHREINER 1993, 261-312). 
Protestanten abgelehnten assumptio corporis. ${ }^{360}$ Dieser Aspekt ist ein erster Hinweis auf gegenreformatorische Tendenzen in seinem Werk, die nicht erst nach dem Bildersturm von 1566 einsetzen, wie bisher angenommen. ${ }^{361}$ Vorbildhaft für die perspektivische Ansicht des Sterbelagers der Maria sowie für die Gestalt der Toten ist höchstwahrscheinlich die Marientod-Tafel von Hugo van der Goes von 1480 gewesen [ABB. 72]. ${ }^{362}$ Das Bett bei Coxcie ist vergleichbar schräg in den Vordergrund eingebracht, während auch die Tote im Detail Ähnlichkeiten aufweist, etwa darin wie unter der Decke die leicht angewinkelten Beine kenntlich gemacht und die Hände auf dem Bauch der Toten aufeinandergelegt sind. Auch Position und Körperhaltung einzelner um das Bett gruppierter Apostel weisen Ähnlichkeiten auf. Ein weiteres, hier sehr wahrscheinlich als Bindeglied zu deutendes Bezugswerk stellt das inschriftlich auf $1520 \mathrm{da}$ tierte Triptychon von Bernard van Orley mit dem zentralen Motiv des Marientodes dar [ABB. 73], welches sich bei der Darstellung der Toten und des Sterbebettes seinerseits an Hugo van der Goes orientiert. ${ }^{363}$

Der Bildraum in Coxcies Marientod ist aus einem großen hallenartigen Raum im Stil der italienischen Renaissance gebildet, der als Kirche zu verstehen ist - und damit auf Maria als Typus und Verkörperung der Kirche verweist. ${ }^{364}$ Das Bett befindet sich in einer Art

360 Vgl. SCHREINER 2006, S. 465 f.

361 Dieser Punkt wird in Kap. IV wiederaufgenommen.

362 Öl auf Holz, 147,8 × 122,5 cm, Groeningemuseum, Brügge, Inv.-Nr. 0000.GRO0204.I.

363 „Dit es ghemacht anno XVcxx den XI dach Augusti“" (s. RKD-Nr. 46620; vgl. auch FARMER
Langhaus, während im Mittelgrund die unteren Abschnitte von auf hohen Postamenten stehenden Säulen zu sehen sind und zu beiden Seiten hin größere Pfeilerkonstruktionen angedeutet werden. Dahinter ist mit Raumöffnungen nach links und rechts eine Art Querhaus bezeichnet, während der längsgerichtete Raum bis zu einem großen Torbogen führt. Zu seinen Seiten sind mit Halbsäulen gegliederte Wandstücke zu sehen, welche große rundbogige Fensteröffnungen aufweisen. Darüber sind die Ansätze eines Tonnengewölbes dargestellt, das jedoch größtenteils durch die Wolkenformation im Vordergrund verdeckt ist. Über dem Torbogen, der wiederum von vier Halbpfeilern mit korinthischen Kapitellen gegliedert wird, ist eine hölzerne Galerie zu sehen. Durch die Bogenöffnung hindurch ist der Blick in einen weiteren hallenartigen Raum gegebenen, welcher eine hölzerne Kassettendecke und am hinteren Ende eine kleine viereckige Türöffnung zeigt, die schließlich aus dem Bauwerk hinaus in eine Stadt führt. Im Vordergrund sieht man einem ocker-, orange- und dunkelrotfarbigen Steinen ausgelegten Boden. Darauf liegt ein bastartiger Teppich, auf welchem wiederum das Totenbett mit roter Überdecke und ein kleines Tischchen am Fußende des Bettes stehen. Darauf abgestellt sind Glasgefäße, eine Art Karaffe und ein Noppengefäß mit Deckel.

1981, S. 245-248), Öl auf Holz, $105 \times 153$ cm, Musée de l'Assistance Publique, Brüssel, Inv.Nr. 1/3.

364 Vgl. LCI III [1971], s. v. „Maria, Marienbild“, Sp. 194. 
In Bezug auf die räumliche Disposition lassen sich mehrere Aussagen treffen. Zum einen steht das Bild in der Tradition älterer Marien- und Marientoddarstellungen, welche die Gottesmutter, umgeben von den Aposteln, in einem Sakralraum zeigen. ${ }^{365}$ Zum anderen zeigen sich Übereinstimmungen mit einer 1520 von Bernard van Orley geschaffenen Tafel mit der Darstellung Christi im Tempel [AвB. 74]. ${ }^{366}$ Dem Thema entsprechend, gestalterisch aber wohl auch auf van Eyck rekurrierend, ist auch hier ein längsgerichteter Raum zu sehen, der eine Kirchenarchitektur zur Darstellung des Tempels in Jerusalem zeigt. Man sieht die Bundeslade an der rückwärtigen Wand hinter einem gerafften Vorhang, der das Heilige vom Allerheiligsten trennt. Der Vorhang verweist in aller Regel auf Maria, die dem apokryphen Protevangelium des Jakobus zufolge als junge Frau den Tempelvorhang gewebt haben soll. ${ }^{367}$ Darüber hinaus ergibt sich auch eine motivische Verknüpfung mit dem Baldachin aus dem kleinformatigen Dresdner Madonnenbild von Jan van Eyck. Das Baldachinmotiv wird bei van Orley durch eine Art Stoffkrone an der Decke der Vierung oberhalb des Altares wiederaufgegriffen. Der Raum zeigt auch die Seitenschiffe, in die man bei van Eyck durch die Pfeilerarkaden blicken kann. Statt des goti- schen Interieurs ist der Bau jedoch antikisierend bzw. im Renaissancestil gestaltet, was durch die viereckigen Pfeiler mit ornamentalen Relieffeldern und Kapitellen, die mit Grotesken verziert sind, bezeichnet ist. Beides Details, die in nahezu identischer Form auf der Mitteltafel des Hiob-Retabels zu sehen sind. ${ }^{368}$ Auch die weiter oben erwähnte Tafel mit der Darstellung Christi im Tempel von Bernard van Orley führt die von van Eyck begründete Tradition fort, bedient sich hierfür jedoch bereits eines antikisierenden Architekturstils [ABB. 74]. Coxcie übernimmt das Raumkonzept von van Orley, was in der gemeinsamen perspektivischen Ausrichtung auf jeweils einen Punkt im Hintergrund zu erkennen ist - zum einen die Bundeslade bei van Orley und zum anderen der Torbogen bei Coxcie, der in den hinteren Raum und aus dem Gebäude hinausführt. Das Bogenmotiv ist auch beim Marientod das beherrschende architektonische Detail, das sowohl die Wände der Halle als auch die zu beiden Seiten angedeuteten Durchgänge zu den Nebenräumen betrifft, die eine Art Querhaus meinen könnten. Statt der Pfeiler mit den Phantasiekapitellen bei van Orley, findet sich eine Vielzahl rotmarmorierter und graufarbiger Halbsäulen, die den Wänden und Pfeilern als Vorlagen vorgelagert sind. Die Verwendung von Säulenschäften und korinthischen
365 Jan van Eycks Triptychon mit der thronenden Maria und den Hll. Michael und Katharina von 1437 (Öl auf Holz, $33 \times 27$ cm, Gemäldegalerie Alte Meister, Dresden, Inv.-Nr. AM-799-PS01) gilt gemeinhin als eines der frühesten Werke, die Maria nicht nur vor einem Architekturfond, sondern zentral in einem longitudinalen Kirchenraum zeigen.
366 Öl auf Holz, $135 \times 118 \mathrm{~cm}$, zuletzt $2005 \mathrm{im}$ Kunsthandel bei Cesare Lampronti, Rom / London angeboten (s. RKD-Nr. 46987).

367 s. hierzu Lexikon der antiken christlichen Literatur [1998], s. v. ,Jakobus (d. J.)-Literatur“ [Röwekamp], Sp. 325. Die entsprechende Stelle aus dem Protevangelium ist bei SCHNEIDER 1995, Kap. 10.1, S. 113-115 nachzulesen.

368 s. Abschn. 2.3. 
Kapitellen verweist stärker auf van Eycks gotische Säulen mit hohen Basen und Blattkapitellen. Die von van Orley vielfach verwendeten, den Ornamentstichen entnommenen Akanthusreliefs finden sich auch bei Coxcie, jedoch hier an der Wand oberhalb des Rundbogens über der Ausgangstür und nicht wie bei seinem Lehrer an den Pfeilern.

Weitere Architekturformen, wie die in die Wand eingelassenen Nischen und die Wandvorlagen mit korinthischen Kapitellen, legen nahe, dass Michiel Coxcie vergleichbare Renaissancebauten in Rom gekannt hat, während es van Orley anzumerken ist, dass er die Idee für solche Formen vermutlich hauptsächlich aus graphischen Vorlagen und vielleicht auch den zuvor erwähnten Kartons von Raffael bezogen hat. Dies markiert im Wesentlichen auch die stilistische Beziehung zwischen Coxcie und seinem Lehrer. Statt eines engeren Anschlusses an den Lehrer geht es hier möglicherweise um die konkrete Verbesserung des Vorbilds. Das Rundbogenmotiv, welches mehrere hintereinander liegende Räume miteinander verbindet, orientiert sich in Bezug auf Anlage und Gestalt des Raumes an Raffaels Schule von Athen. Auch die in eine Nische gestellte Skulptur links im Mittelgrund von Coxcies Darstellung des Marientodes verweist auf die monumentalen Nischenfiguren in Raffaels Wandbild. Der Versuch einer überzeugenden Wiedergabe von Architektur findet sich überdies bereits bei Jan van Scorels Darstellung Christi im Tempel (um 1530-1540) vorgeprägt [ABB. 75]. ${ }^{369}$ Das im Thema geforderte Interieur ähnelt hier wiederum der Schule von Athen.

369 Öl auf Holz, $114 \times 85 \mathrm{~cm}$, Kunsthistorisches Museum, Wien, Gemäldegalerie, Inv.-Nr. 6161
Das Tonnengewölbe, das durch eine Kuppel über der Vierung unterbrochen wird, ist bei Coxcie nur angedeutet und letztlich größtenteils durch die Wolken, auf denen Maria gen Himmel auffährt, verdeckt. Eine konkrete Entsprechung zu Raffaels Fresko bilden die beiden links unten am Bett knieenden männlichen Figuren, die mit denen links im Vordergrund von Raffaels Fresko nahezu identisch sind [ABB. 76]. Lediglich das Buch ist zwischen beiden vertauscht - der Mann, der dieses hält, hat hier stattdessen seine Hände im Gebet zusammengelegt, während derjenige, den Raffael beim Schreiben dargestellt hat, ein Buch vor sich hat. Auch der Gewandstil spiegelt das Vorbild von Raffael und das Bestreben mit der Gestaltungsweise seines Lehrers van Orley zu brechen. Über die Schultern einzelner Figuren geworfene Stoffbahnen, etwa bei dem Greis, der links auf Maria blickt, oder den beiden Rückenfiguren rechts, legen nahe, dass es Coxcie darum gegangen ist, antikisch anmutende Gewänder zu evozieren - ähnlich auffällig, wie es etwa 15 Jahre zuvor bei Jan van Scorels Darbringung im Tempel zu beobachten ist.

Die beiden Seitentafeln sind auf Grund der annähernd quadratischen Mitteltafel vergleichsweise schmal - ein Format das sich bei vielen Triptychen Michiel Coxcies zeigt, etwa bei dem Kremsmünsteraner Triptychon mit der Heiligen Sippe und den beiden Darstellungen aus dem Leben des Evangelisten Johannes, bei dem die schmalen Seitenflügel vermutlich maßgeblich den Anlass dafür gegeben haben, die beiden Tafeln nach der späteren Zerteilung des Retabels zu einer einzelnen

(vgl. FRIEDLÄNDER 1967-1976, Bd. XII, Kat.Nr. 316 u. REZNICEK 1985, S. 6-13). 
zusammenzufügen. Die Geburt Marias auf dem linken Flügel folgt der ikonographischen Tradition - während die Mutter Anna im Kindbett ruht, waschen Frauen links im Vordergrund den Säugling, den sie dabei sorgsam in ein Tuch legen [ABB. 69]. Anna ist derweil oben rechts im Mittelgrund in einem Himmelbett zu sehen, dessen hölzerne Bekrönung profiliert und mit einem Fries aus geschnitzten Akanthusranken verziert ist. Über dem Kranz sind zwei gegenläufige, auf die Seite gelegte Voluten angebracht. Durch die aufgezogenen und an den säulenförmigen Bettpfosten verknoteten Vorhänge ist der Blick in den Hintergrund frei, in welchem man einen steinernen Kamin sieht, in dem ein Feuer brennt und über dem eine brennende Kerze in ihrem Wandhalter steckt. Links davon ist ein Kreuzstockfenster mit vier Sprossen und milchigem Glas zu sehen. Drei Frauen unterschiedlichen Alters sind der halbaufrecht im Bett sitzenden Anna zugewandt. Die junge Frau links scheint ihr dabei zu helfen, die Kissen hinter ihrem Rücken zurecht zu rücken, während eine etwas ältere Frau links davon, den Ellenbogen auf dem Bett und das Kinn auf der Faust abstützend, sinnend zu Anna hinüberblickt. Die dritte, ebenfalls eher mädchenhaft anmutende weibliche Gestalt tritt von links her mit einem Tablett und einer sich darauf befindlichen
Kanne heran. Vor dem Bett steht ein kleiner niedriger Rundtisch mit drei Löwenfüßen. Zwischen dem Bett und den beiden Frauen mit dem Waschgeschirr vorne links, mehr noch diesen zugeordnet, ist eine ältere Frau mit Kopftuch auf einem Schemel sitzend und in einem aufgeschlagenen Buch lesend, das sie mit beiden Händen vor ihrem Gesicht hält, dargestellt. Die Figur bezieht sich erkennbar auf die Persische Sibylle in Michelangelos Deckenfresko in der Sixtinischen Kapelle [ABB. 77]. ${ }^{370}$ Coxcie zeigt eine vielfältige Szene und einen reich ausgestalteten Innenraum mit einer ornamentierten Kassettendecke und einem opus sectile-Fußboden aus grauem und rotem Marmor. Bereits im späten 15. Jahrhundert war es üblich geworden, Szenen aus dem Marienleben in die Wohnstuben von Adeligen und des gerade erst entstandenen wohlsituierten Stadtbürgertums zu verlegen. ${ }^{371}$

Der von grauen Streifen durchbrochene rote Steinfußboden findet sich auf der rechten Tafel wieder, welche die Darstellung Christi im Tempel zeigt. ${ }^{372}$ Auch das Stufenmotiv, das in diesem Fall durch einen noch größeren Höhenunterschied gesteigert wird, findet sich wieder. Durch die dem Format geschuldete starke vertikale Ausrichtung ergibt sich eine noch weiter gesteigerte ,Höhe‘, die ihr Echo in der im Hintergrund erkennbaren
370 Vgl. García-Frías CheCA 2013, S. 39 u. Kat. Prado 1985, S. 171.

371 Vgl. LÜKEN 2000, S. 298-300. Eines der frühesten Beispiele hierfür stellt Robert Campins Verkündigung aus der Zeit um 1430 dar (Öl auf Holz, 64,5 x 27,3, The Metropolitan Museum of Art, New York, Inv.-Nr. 56.70). Vgl. auch KEMPERDICK 1997, S. 129.

372 Der Inhalt der Tafel wird in der Literatur und im Inventar des Prado (Nr. P001470) auch als
„Presentation of the Virgin at the Temple“ (Praesentatio Beatae Mariae Virginis) ausgewiesen (vgl. Kat. Prado 1985, S. 171). Da Maria jedoch erst im Alter von drei Jahren von ihren Eltern in den Tempel gegeben wird, wie das apokryphe Jakobusevangelium berichtet, kann es sich bei dem dargestellten Säugling nicht um Maria handeln. 
Monumentalarchitektur findet. Hierbei handelt es sich erneut um einen hallenartigen, mit Gurtbögen und einer Tonne überwölbten Bau im Stil der Renaissance. Viel genauer lässt sich die räumliche Disposition nicht bestimmen, da wiederum, bedingt durch das Format, sämtliche Architekturformen zu beiden Seiten stark beschnitten wiedergegeben werden. Darunter auch eine Art Ziborium, von dem zwei rote auf hohen Postamenten ruhende Porphyrsäulen sowie ein Architrav zu sehen sind. An letzterem sind vermittels Ketten Öllampen bzw. Ampeln befestigt. ${ }^{373}$ Die Wand im Hintergrund zeigt einen Pilaster mit korinthischem Kapitell, sowie ein Gebälk mit Faszienarchitrav, einem Fries und Akanthusranken und einem kräftig vorspringenden Gesims, während sich darüber ein Tonnengewölbe, seinerseits mit Reliefschmuck versehen, anschließt. Die Wahl des Bildausschnitts lässt erneut an van Scorels Darstellung Christi im Tempel denken. Auch in Bezug auf die Reliefs auf den Säulenbasen und das als figuratives Halbrelief gestaltete Feld über der Supraporte im Hintergrund bei Coxcie entsprechen einem ähnlichen Relieffeld bei van Scorels monumentaler Pfeilerbasis sowie den dort in Wandnischen aufgestellten Skulpturen. Auch ikonographisch ergeben sich Überein-stimmungen. So sind die beiden langen Kerzen, die auf den Aspekt des Festtages als Mariä Lichtmess verweisen und die von zwei Personen hinter Simeon mit dem Christuskind gehalten werden, in bei-

373 Coxcie könnte eine ähnliche Anlage über dem Grab des Apostel Petrus in der alten Peterskirche gesehen haben. Das Ziborium als sakrale Bauform nimmt in der stadtrömischen Tradition eine zentrale Rolle ein, die mit den Gräbern den Bildern zu finden. Bei van Orleys Darstellung Christi im Tempel findet sich dieses Detail indessen nicht, während dieser wiederum im Vordergrund eine knieende weibliche Frauenfigur zeigt, die vor dem Altar, über den der Christusknabe vom Priester gehalten und präsentiert wird, einen Käfig mit einer Taube darreicht. Bei Coxcie wird diese Opfergabe von Josef im Vordergrund links dargebracht.

Abschließend lässt sich sagen, dass Coxcies Bilder der 1540er und 1550er Jahre, was ihre Komposition betrifft, oftmals auf ältere Vorbilder seines Lehrers Bernard van Orley zurückgreifen. Diese erweitert er durch Architekturen, die auf seine Eindrücke in Rom verweisen, und passt die Figuren daran an, wofür er sich ebenfalls nach italienischen Vorstellungen richtet und was sich unter anderem in den antikisierenden Kostümen widerspiegelt. Es wird deutlich, dass hier neben einer zunächst als zeitgemäß zu bezeichnenden Aktualisierung des alten Bildmotivs, auch die Expertise eines gereisten und in Rom geschulten Romanisten deutlich vor Augen tritt. Der Vergleich mit Jan van Scorel, der ihm in dieser Hinsicht bereits gut zehn Jahre früher vorausgeht, bezeichnet noch zusätzlich den Unterschied zu Bernard van Orleys, frühromanistischem'Spätwerk, welchem eine authentische Einsicht in die Kunst Italiens weitestgehend fehlt.

mehrerer Märtyrer assoziiert wird (LCI IV [1968], s. v. „Baldachin, Ciborium“ [G. Bandmann], Sp. 239-241). 
3.4 Michiel Coxcie im Dienst der habsburgischen Höfe von Brüssel und Madrid

Wenige Jahre später, nämlich 1541, folgte Coxcie seinem inzwischen verschiedenen Lehrer Bernard van Orley in die Stellung als Hofmaler der habsburgischen Statthalterin Maria von Ungarn. Van Orley hatte dieses Amt bereits unter der Regentschaft der als kunstinteressiert geltenden Margarete von Österreich innegehabt. ${ }^{374} \mathrm{Als}$ besonders günstig für Michiel Coxcie erwies sich, dass auch Maria eine Kunstsammlung in ihrem Brüsseler Palast besaß. ${ }^{375}$ Die prestigeträchtige Position des Hofmalers war mit einer umfangreichen Anzahl bedeutender Aufträge verknüpft. Mit der Ausmalung a fresco des alten gotischen Palastes von Binche festigte sich sein Ruhm, da er die in Italien erlernte Technik nun als eine Art Alleinstellungsmerkmal einsetzen konnte. Seine Arbeit für Maria trug ihm in der Folge auch die Patronage Kaisers Karls V. ein. Weitere Habsburger, allen voran Phillip II. von Spanien, gehörten schon bald zu seinen prominenten Mäzenen. ${ }^{376}$ In dieser Zeit, die sich an seine nur kurze Bewährungsprobe der Jahre 1539-1540 nach seiner Rückkehr aus Italien anschloss, konnte er seine Fertigkeiten in zahlreichen Altarbildern, Buntglasfenstern, Tapisserien und

374 Zur Sammlung Margaretes s. EICHBERGER 2002, passim.

375 Vgl. JONCKHEERE - SUYKERBUYK 2013, S. 31 f.

376 Vgl. CAPREAU 2013, S. 12.

377 Vgl. JONCKHEERE 2013, S. 72 u. REINTJENS 2013, S. 140.

378 „Der erste vollständige Romanist“ (HOOGEWERFF 1912, S. 75).

379 „COEXIUS Illustris pictor mechlinia cujus / Patria, doctorum quae fuit artificum. / Hic magno pinxit. name Zeuxis creditur esse: / carus divitibus, princibúsque Viris.“ (Kupferstich
Wandgestaltungen für seine habsburgischen Mäzene sowie in Druckgraphiken zum Ausdruck bringen, von denen einzelne Beispiele hier bereits erörtert wurden. ${ }^{377}$

Womöglich ergab es sich gerade wegen seiner italienischen Ausbildung, dass Coxcie schon kurze Zeit nach seiner Rückkehr in die Niederlande bei Hofe großen Anklang finden konnte. ${ }^{378}$ Hinweise hierauf spiegelt das Künstlerlob, das ihm bereits zu Lebzeiten entgegen gebracht wurde und zumindest bis in die erste Hälfte des 17. Jahrhunderts nicht in Vergessenheit geriet. Bei Hendrick Hondius wird Coxcie in einem kurzen Lobgedicht gar mit Zeuxis von Herakleia verglichen. Weiter heißt es, Coxcie sei ein gebildeter Maler gewesen, der von den Reichen und den Fürsten was als eine Anspielung auf seine Tätigkeit für Philipp II. und Karl V. zu verstehen ist - geschätzt wurde. ${ }^{379}$ Bekannt ist auch, dass Karl V. mehrere von Coxcies Gemälden besaß und sie im Kloster der Hieronymiten von Yuste in der spanischen Extremadura verwahrte, bevor sie in den Besitz Philipps übergingen. ${ }^{380}$ Dazu gehört eine um $1560 \mathrm{zu}$ datierende Kreuztragung [ABB. 78], die in einem vergleichsweise altmodischen Stil gestaltet ist und die Karl höchstwahrscheinlich von seiner Schwester

von Simon Frisius, 20,5 × 126,6 cm (ganzes Blatt), Text von Lampsonius [?], um 1610, Rijksmuseum, Amsterdam, Inv.-Nr. RP-P-1907-357; New Hollstein (Dutch), Nr. 162-1[2]).

380, ,... [ un grandt tableau de bois, ou est contrefait JesuCrist portant la croix, mené de deux juifs, Nostre-Dame et sainct Jehan et la Véronique et Simon le suivant, faict par maistre Michaël“" (Inventareintrag aus Brüssel vom 18. August 1556, zit. nach GACHARD 1855, Bd. 2, S. 91). 
Maria von Ungarn, der Statthalterin der spanischen Niederlande, erhalten hatte. ${ }^{381}$ Eine Chronik des Klosters aus dem 17. Jahrhundert rekurriert auf dieses Präsent an den Kaiser; entsprechende Geschenke waren innerhalb der Familie üblich. ${ }^{382}$ Interessant ist, dass dieses Bild sich an altniederländischen Vorbildern und der Druckgraphik des frühen 16. Jahrhunderts orientiert, ${ }^{383}$ so etwa an Dürers entsprechendem Holzschnitt in dessen Großer Passion. ${ }^{384}$ Auch lässt sich eine stilistische Verwandtschaft zu einem ähnlichen Bild aus dem Umfeld Bernard van Orleys, welches 2014 bei Christie's veräußert wurde, konstatieren [ABB. 79]. ${ }^{385}$ Coxcies Kreustragung sticht daher aus den ansonsten vornehmlich ,tizianesken' Bildern der Sammlung heraus und liefert einen Hinweis auf Marias Vorliebe für solche Arbeiten, während die Gemälde Coxcies, die Philipp später auf eigenes Betreiben erwarb, eher als komplettierende Ergänzung zu den Werken

381 Öl auf Holz, $207 \times 143 \mathrm{~cm}$, Patrimonio Nacional, Aranjuez (vgl. JONCKHEERE 2013, S. 100 u. ebd., Kat.-Nr. 45); s. auch Online-Artikel des Patrimonio Nacional: Michiel Coxcie en la Celda Prioral Baja del Real Monasterio de San Lorenzo de El Escorial vom 26.04.2016, 〈https://www.patrimonionacional.es〉 (ab-gerufen am 19.07.2019).

382 Vgl. García-Frias Checa 2009, S. 246 f. im Hinblick auf den von Fray Luis de Santamaría erbrachten Hinweis, dass sich das Bild während der Lebenszeit Karls V. auf dem epistelseitig gelegenen Nebenaltar der Kirche befunden habe, flankiert von Tizians Gloria.

383 Öl auf Leinwand, $98 \times 116 \mathrm{~cm}$, Prado, Madrid, Inv.-Nr. P000439 (vgl. Kat. Prado 1999, S. 184).

384 Kupferstich, ca. $38,3 \times 28,3 \mathrm{~cm}$; Bartsch VII.117.10.

385 Öl auf Holz, 65,5 $\times 58 \mathrm{~cm}$, Privatbesitz (vgl. FARMER 1981, S. 252-253 u. Ebd., Kat.-Nr. 202; FRIEDLÄNDER 1967-1976, Bd. VIII, S. 112). Das Bild war zuvor an die Nachfahren des privaten Sammlers H. L. Larsen zurückgeführt des von seinem Vater bevorzugten Tizian gedacht gewesen zu sein scheinen. Philipp II. ließ die Kirche nach dem Tod seines Vaters zu dessen vorläufiger Grablege weiter ausstatten. Ein weiteres Inventar aus dieser Zeit verzeichnet mehrere Bilder, darunter Tizians Mater Dolorosa mit den gefalteten Händen [ABB. 81], ein Ecce Homo desselben [ABВ. 80] sowie eine weitere Kreuztragung von Michael Coxcie [ABB. 82] - was die Absicht einer gezielten Kombination von Bildern des flämischen Romanisten mit denen Tizians nahelegt, da dieser zweite kreuztragende Christus stilistisch mit dem Ecce Homo von Tizian übereinstimmt, was im folgenden Kapitel erörtert werden soll. ${ }^{386}$

Nur knapp zwei Jahre nach seiner Rückkehr aus Rom, hatte Coxcie die Stellung als Hofmaler bei der Statthalterin Maria von Ungarn angetreten. Denkbar ist, dass er mit der in Italien erlernten Fertigkeit der Freskomalerei einen nicht unerheblichen Vorteil bei

worden, nachdem es 1940 von den Nazis konfisziert und für das geplante Kunstmuseum in Linz bestimmt worden war.

386 Im vorherigen Abschn. bereits angedeutet. Zur Dokumentation s. im Einzelnen: Archivo General de Simancas, Contraduría Mayor de Cuentas, leg. 1145, exp. 2, S. 15, zit. nach GONZÁLES 1950, S. 237. Möglicherweise handelt es sich bei letzterem um Coxcies kreuztragenden Christus welcher heute im Prado (Inv.-Nr. P002641) zu sehen ist; s. hierzu auch Abschn. 3.5.

Es liegt nahe, dass diese Bilder, da sie als persönliche Devotionalien anlässlich des Todes von Karl V. erworben wurden, später am habsburgischen Hof in Madrid verwahrt wurden und so in die heutige Sammlung gelangten. Bei dem Ecce Homo handelt es sich möglicherweise um die Kreuqtagung (um 1555) [Inv.-Nr. P002641, Prado, Madrid], die stilistisch dem Ecce Homo von Tizian (1547) [Inv.-Nr. P000437, Prado, Madrid], ebenfalls später im Besitz Philipps II., folgt. 
seiner Bestellung zum Hofmaler hatte. ${ }^{387} \mathrm{Ei}-$ nige Jahre später, 1548/49, entwarf und malte Coxcie einen Großteil der Dekorationsmalerei in Marias Palast in Binche. ${ }^{388}$ Seine Arbeit brachte ihm den inoffiziellen Titel „Maler der Königin“ ein; ${ }^{389}$ zudem taucht er in den Quellen als Mitglied des Brüsseler Hofes in den Jahren von 1548 bis 1551 auf. In dieser Zeit entstanden zahlreiche Portraits der Statthalterin und ihrer Verwandtschaft. Zahlungen belegen solche von ihr selbst, Karl V., Kaiserin Isabella, Königin Eleanor von Frankreich, und Christina von Dänemark - dem einzigen heute noch erhaltene Werk aus dieser Reihe. Die Rechnungen erwähnen, dass diese Bilder offenbar in recht kurzer Abfolge die Werkstatt Coxcies verließen, woraufhin sie fertig gerahmt und in Holzkisten verpackt versendet wurden - vermutlich als Präsente an Angehörige des Hauses, an Günstlinge oder an die dargestellten Personen selbst. ${ }^{390}$

Der spanische Historiograph und $\mathrm{Hu}-$ manist Juan Calvete de Estrella (ca. 1520-1593) hat die einzigen auf uns gekommenen Informationen über die bei einem Brand 1554 zerstörten Arbeiten im Palast von Binche überliefert. Daraus lässt sich ableiten, dass Coxcie speziell dafür bezahlt wurde, die Ausmalungen im großen Saal schnellstmöglich, noch vor einer bevorstehenden Ankunft des kaiserlichen Gefolges, zu vollenden. Weiterhin hat er Ent-

387 Vgl. PÉREZ DE Tudela 2013, S. 100.

388 Vgl. VAN DEN BOOGEERT 1993a, S. 127-133.

389 Der Titel findet sich im Zusammenhang mit den beträchtlichen Gehaltszahlungen, die Maria ihrem Hofmaler Michiel Coxcie gewährte (vgl. VAN DEN BOOGERT 1992a, S. 123-126; VAN DEN BOOGERT 1993, S. 281 u. 289 f.

390 Vgl. Perez de Tudela 2013, S. 100. würfe für Glasfenster, eine Arbeit für die bereits sein Lehrer van Orley bekannt gewesen war, sowie für aus Marmor gearbeitete Kamine geliefert. ${ }^{391}$ Der Humanist beschreibt die Bilder, die er im großen Saal und in der sich daran anschließenden Galerie betrachten konnte, als eine Art Kuriosität. ${ }^{392}$ Diese womöglich gar nicht einmal wertend zu verstehende Bezeichnung muss mit dem schwierigen und ungewöhnlichen Programm aus Malerei, Skulptur und Tapisserien zusammenhängen. Das zentrale Thema war eine explizite Ermahnung an protestantische Fürsten, die sich gegen die habsburgische Herrschaft stellen, wie PÉrEz De TUdela resümiert hat. ${ }^{393}$ Die einzelnen Ausmalungen der Palastdecken und -wände mit Fresken, die zwischen 1548 und 1549 in Binche entstanden, sind uns heute nurmehr literarisch und auch das nur schemenhaft überliefert. Mutmaßlich hat es sich dabei um eine Vielzahl von biblischen und klassischen Mythenstoffen gehandelt, die zusammen das überlieferte Bildprogramm ergaben. So sollen über den beiden Kaminen Bilder von Apoll und Marsyas zu sehen gewesen sein, die durch ein Gemälde mit Tantalus von Coxcie und dem Sisyphus von Tizian programmatisch zu einer Gruppe von vier, Verdammten` ergänzt wurden. ${ }^{394}$ Diese Gruppe stand möglicherweise in einem inhaltlichen Kontext zu dem Freskenprogramm und sollte die Folgen der Abtrünnigkeit gegenüber dem Haus

391 Vgl. Lejeune 1878, S. 427 f.

392 Vgl. Calvete de Estrella 1552 [2001], S. 315-317; PEREZ DE TUDELA 2013, S. 100.

393 Vgl. ebd., S. 100 f.

394 Während Coxcies Tantalus nicht erhalten ist, befindet sich Tizians Sisyphus heute im Prado, Madrid, Inv.-Nr. P000426, Öl auf Leinwand, $237 \times 216$ cm (s. Kat. Prado 1985, S. 701 f.). 
Habsburg (und der römischen Kirche) untermalen.

Die weiter oben und im vorherigen Abschnitt angesprochene Kompatibilität der von Coxcie für die Habsburger ausgeführten Auftragsarbeiten mit solchen Tizians ließe sich damit noch weiter untermauern. In einem Inventar der Besitztümer Marias von Ungarn, die diese im Jahre 1556 mit sich nach Spanien führte, ist ein Bild von Coxcie mit der darauf gezeigten Gestalt des Marsyas erwähnt, bei welchem es sich womöglich um jenes von Calvete de Estrella beschriebene handelt. ${ }^{395}$ Später soll die Vierergruppe in der Casa del Tesoro aufgehangen worden sein, auch wegen ihres profanen Themas und der Nacktheit der Figuren, an der Philipp II. nach späteren Aussagen angeblich Anstoß genommen habe. ${ }^{396}$ Angesichts der damaligen Gefahr eines französischen Angriffs wurden in dieser Zeit auch die meisten anderen beweglichen Stücke aus dem Bestand in Binche ins wallonische Mons verbracht, wo sie, im Gegensatz zu den Fresken, von dem Brand des Palastes in Binche im Juli 1554 unberührt blieben. Bereits 1556 scheint man dazu übergegangen zu sein, die beschädigten bzw. teils großflächig zerstörten Wandbilder zu rekonstruieren bzw. zu ersetzen. $^{397}$

In den Zusammenhang der Ausstattung des Palastes gehört auch die Entstehung einer Kopie der Kreuzabnabme Rogier van der

395 Vgl. PINCHART 1856, S. 141, Nr. 42.

396 Vgl. hierzu Pérez de Tudela 2013, S. 102. Diese Annahme wurde vor allem in Bezug auf das verlorene und lange Zeit für nie ausgeführt gehaltene Paar der Stammeltern Adam und Eva aus Coxcies Kopie des Genter Altars geäußert, s. Abschn. 3.6.

397 Vgl. Hedicke 1911, S. 420 f., Nr. 76.
Weydens [ABB. 84]. ${ }^{398}$ Bereits 1549 beim Besuch ihres Neffen Philipp II. befand sich dieses Bild in Marias Palastkapelle. Es ist überliefert, dass Maria der Gilde der Armbrustschützen, die die Kreuzabnabme einst bei van der Weyden für ihre Kapelle Onze-Lieve-Vrouwvan-ginder-buiten bestellt hatten, mit Erfolg eine Kopie des Werkes angeboten habe, um das Original schließlich 1555 erwerben zu können. Die Kopie wurde von Vicente Álvarez, von dem wir überhaupt über deren Aufbewahrung zunächst in Binche erfahren, als dem Original äußerst ähnlich beschrieben. ${ }^{399}$ Dass es sich bei dieser Kopie um eine von möglicherweise mehreren Versionen aus der Werkstatt des Mechelner Malers Michiel Coxcie handelt, wird erst 1570 von dem Theologen Johannes Molanus berichtet sowie 1604 von Karel van Mander erneut erwähnt. ${ }^{400}$ Während des Besuches von Philipp II. in Binche muss es zu einer Begegnung mit dieser Kopie in der Sammlung seiner Tante gekommen sein. Die Qualität des Stücks sowie die Empfehlung seiner Verwandten mag ihn dazu bewogen haben, Coxcie für sich arbeiten zu lassen. Es entstanden weitere größtenteils nicht mehr erhaltene Kopien der Kreuzabnabme sowie nur wenige Jahre später die berühmte Kopie des Genter Altares von Jan van Eyck. ${ }^{401}$ Daneben führte Coxcie jene Arbeiten fort, die sein Lehrer Bernard van Orley für die

398 Öl auf Holz, $210 \times 168,5$ cm, Bode-Museum, Berlin (vgl. PUTZGER 2019, S, 76. Anm. 10).

399 Calvete de Estrella 1552 [2001], S. 646 f.

400 De Ram 1861, S, 609; van Mander 1604, fol. 207r.

401 Pérez De Tudela 2013, S. 102. s. hierzu Abschn. 3.6. 
Habsburger begonnen und nicht hatte vollenden können. Eigene Entwürfe für eine Reihe von Tapisserien mit biblischen und historischen Themen, etwa Szenen aus dem Leben des Erzvater Abraham oder Julius Caesars entstehen ebenfalls im Auftrag des Hofes. ${ }^{402}$ Nach dem Tod seines Meisters soll Coxcie laut CAMPBELL die Rolle eines Chefaufsehers und leitenden Gestalters der Brüsseler Produktion zugefallen sein, bis er in dieser Funktion ab 1563 von dem jüngeren Peter de Kempener abgelöst worden sei. ${ }^{403}$ In diese Zeit fallen weitere namentlich bekannte Aufträge seiner Mäzenin Maria von Ungarn, wie etwa die Entwürfe zu Wandbehängen mit der Schlacht bei Mühlberg, die 1550 entstanden, sowie Entwürfe für einen Baldachin, die er, wie erhaltene Dokumente nahelegen, der Statthalterin persönlich vorführte. ${ }^{404}$ Daneben vollendete er auch die von van Orley begonnenen Entwürfe für Glasmalereien in der Sakramentskapelle von St. Michael und St. Gudula in Brüssel. ${ }^{405}$ Der erste neue Auftrag in diesem $\mathrm{Zu}$ sammenhang ging 1541, nach dem Tode van Orleys, von Johann II. von Portugal aus, dem mit Katherina von Österreich verheirateten Schwager des Kaisers; worauf noch Entwürfe für vier weitere Fenster folgen sollten. ${ }^{406}$

Während seiner Anwesenheit in Brüssel im Jahr 1549, als Karl V. und seine Schwester Maria dort Hof hielten, kam Philipp II.

\footnotetext{
402 Vgl. Campbell 2002b, S. 302 u. 387 f.

403 Ebd., S. 394-402.

404 „Pour un patron dung dossel quil a faict pour nous [...]“ (Brüssel, 9. August 1556, Archivo Generale de Palacio [AGP], Casa y Sitios Reales [CSR], leg. 377, zit. nach PÉREZ DE TUdELA 2013, S. 113, Anm. 26; auf Deutsch in etwa: „Er lieferte den Entwurf in ihre Hände [...]“.

405 Vgl. ReINTJENs 2013, S. 140-147.
}

höchstwahrscheinlich zum ersten Mal in Kontakt mit den Werken Michiel Coxcies. Die Glasmalereien in der Sakramentskapelle, für die Coxcie in der Nachfolge van Orleys seine Entwürfe geliefert hatte, waren bereits vollendet, sodass Philipp sie gesehen haben mag. ${ }^{407}$ Bei seinem Aufenthalt im Palast von Binche werden dem spanischen Monarchen auch die gerade erst ausgeführten Dekorationsmalereien nicht entgangen sein. Philipp war von Augsburg angereist, wo Karl zuvor das Ziel verfolgt hatte, für seinen Sohn die deutsche Königswürde zu erlangen. Coxcie war zu diesem Zeitpunkt bereits einige Jahre in den Diensten Marias, und es ist wahrscheinlich, dass er als Angehöriger des Hofes der Generalstatthalterin von der Anwesenheit von Kaiser und König zu profitieren wusste, nachdem er mit mehreren gerade erst vollendeten Arbeiten brillieren konnte. Es ist denkbar, dass das Ereignis der Ausgangspunkt für die spätere Auftragsbeziehung zwischen Philipp II. und Coxcie war. Nach 1554 findet Coxcie, nachdem er bereits einige Jahre für Philipp gearbeitet haben muss, explizit Erwähnung in einer Quelle, die ihn als „Maler des Königs von England“ bezeichnet. Dieser Titel rührt her von der zweiten Heirat des Habsburgers mit Maria I. von England, die nach dem Bruch mit Rom unter Heinrich VIII. ihr Land zum katholischen Glauben zurückzuführen suchte. ${ }^{408}$

406 Vgl. PÉREZ De Tudela 2013, S. 102.

407 Vgl. REINTJENS 2013, 138-155.

408 Wäre aus der Ehe ein legitimer Nachfolger hervorgegangen, hätte sie damit den Thronanspruch ihrer protestantischen Schwester Elisabeth untergraben und England in den Schoß der römischen Kirche zurückführen können (vgl. EDWARDS 2005, S. 3). 
Grundsätzlich lässt sich an dieser offiziellen Bezeichnung des Malers ein gewisses Prestige ablesen, das er bis zu diesem Zeitpunkt - etwa 15 Jahre nach seiner Rückkehr aus Rom - erworben hatte.

Im Januar des Jahres 1559 verließ die vollendete Kopie des Genter Altars den Verschlag in St. Bavo, der dem Maler bis dahin als Atelier gedient hatte, um dem König zur Begutachtung vorgeführt zu werden. ${ }^{409}$ Der Wunsch, das kostbare Werk gesichert zu wissen, veranlasste Philipp II., das inzwischen im Alcázar von Madrid eingetroffene Retabel mit Metallbeschlägen zum Verschließen der Flügel $z u$ versehen sowie einen Vorhang anbringen zu lassen, der während seiner Abwesenheit das Kunstwerk schützen sollte. ${ }^{410}$ Darüber hinaus ist überliefert, dass der Bildschnitzer Giles de Boulon ein heute nicht erhaltenes Gesprenge für die Bekrönung des Retabels anfertigte und

409 „Quenta de las partidas q[ue]l mro de la camara [Francisco de España] [h]a pagado para cosas del serv[ici] o de la m[ajesta] del Rey n[uest]ro señor durante el t $\mathrm{e}] \mathrm{e}$ [[ci] o primero de 1559: En 17 de henero de 1559 a unos [h]ombres que en tres carros truxeron desde gante a brusselas el retablo de hadan y eba q[ue] $\mathrm{m}$ [aestr] e Michael coxia pintor contrahizo para que le viese su $\mathrm{m}[\mathrm{a}] \mathrm{g}[\mathrm{esta}]$ con 3 florines costo la tela en que vino envuelto." (Archivo General de Palacio (AGP), Madrid, Maestro de Cámara, legajo 6724, zit. nach PÉREZ DE TUdela 2013, S. 113, Anm. 32).

410 Dennoch wurde bereits am 17. November 1590 eine Restaurierung der Malerei von Hernando Ávila durchgeführt, die durch den beständigen Gebrauch notwendig geworden war. Der Altar war durch den Rauch von Wachskerzen mit einer dunklen Rußschicht überzogen und infolge der Wandlung hatten sich Brüche in der Malschicht gebildet (Archivo General de Palacio, Administraciones Patrimoniales (AP), El Pardo, caja 9382, exp. 8). Die Angaben folgen auch hier und im Weiteren der Quellenforschung von PÉREZ DE TUDELA. die Rahmen von dem flämischen Hofmaler Cristiano de Amberes in Gold gefasst wurden. ${ }^{411}$ In der Kapelle des Alcázar verblieb das Retabel bis zum Jahr 1661, als es während der Regentschaft Philipps IV. durch Raffaels Kreuətragung ersetzt wurde. ${ }^{412}$

Philipp II. erbte später die berühmte Kreuzabnabme von Rogier van der Weyden, welche sich im Besitz Maria von Ungarns in Binche befunden hatte - möglicherweise hatte sie es aber auch bereits auf seinen Wunsch hin erworben. ${ }^{413}$ Der König beauftragte Coxcie, nachdem zunächst das Original für den Palacio Real bzw. den Prado bestimmt gewesen war, eine weitere Kopie von dem altniederländischen Werk anzufertigen. Man weiß von der Aufhängung einer der beiden Kopien in der Palastkapelle aus einem Bericht des spanischen Historiographen Gonzalo Argote de Molina, der sie 1582 dort gesehen haben

411 Für die Arbeiten von Giles de Boloun und Cristiano de Amberes s. Briefwechsel zwischen Philipp und Pedro de Hoya: Brief von Pedro de Hoya an Philipp II. vom Juli 1563 (Archivo de General de Palacio (AGS), CSR, leg. 247-1, fol. 69, abgedr. bei GÉRARD 1984, S. 170, Nr. 16). Das Antwortschreiben von Philipp II. an Pedro de Hoyo erging am 7. Juli 1563 (Archivo del Instituto de Valencia de Don Juan, Madrid, Envío 61 (I), fol. 414v). Vgl. PÉREZ DE TUdela 2013.

412 PÉREZ DE Tudela 2013, S. 104 mit Verweis auf die Rechnung für den Ankauf von 1661 (Archivo General de Palacio [AGP], AP, El Pardo, caja 9402, exp. 9, fol. 5745-76). Das Coxcie-Retabel wurde in den Convento de Santa Isabel überbracht, in welchem sich eine Sammlung der Königsfamilie befand. Das Inventar von 1666 erwähnt, dass das Retabel 1663 Eingang in die Sammlung fand (s. PÉREZ DE TUDELA 2013, S. 114, Anm. 39).

413 Sie hatte das Original im Tausch gegen eine Kopie Coxcies erwerben können. Für die genaueren Umstände vgl. DE VOS 1999, S. 10 u. 86; MELIS 2011, S. 8. 
will. ${ }^{414}$ Darüber hinaus muss es noch eine dritte Kopie gegeben haben, die Philipp der Statthalterin Leonor de Mascareñas vermachte. Bevor auch dieses Werk im 19. Jahrhundert in den Bestand des Prado überführt wurde, befand es sich in der Kirche des Convento de los Ángeles in Madrid. ${ }^{415}$

Schließlich ist es der Versuch Philipps, Coxcie zu sich an den Hof in Madrid zu holen, der die besondere Wertschätzung des flämischen Romanisten durch den spanischen Monarchen deutlich macht. Dies wird noch dadurch untermauert, dass er auch versuchte, Cornelis Floris, dessen Bruder Jan bereits für den Königshof arbeitete, zu einem Umzug nach Madrid zu bewegen. Die Aufzeichnungen des Jean de Vandenesse zur Regierung Philipps beschreiben außerdem Verhandlungen mit Anthonis Mor van Dashorst, den man

414 Vgl. Argote de Molina: Libro de la montería que mandó escrivir el rey D. Alfonso de Castilla y de Léon, Sevilla 1582, Kap. 46, S. 21; Es handelt sich möglicherweise um das Exemplar, welches sich heute als eine Leihgabe des Prado im Museo de Pintura de San Lorenzo de El Escorial befindet. Nachweislich befand sich das Werk von 1566 bis 1939 im Escorial, bis es in den Bestand des Prado überführt wurde (vgl. Museo Nacional de Prado, Inv.-Nr. p-1893).

1563 will Kardinal Granvelle als Agent Philipps II. eine Kreuzabnahme von Coxcie in Mecheln gesehen haben, bei der es sich möglicherweise um die van der Weyden-Kopie handelt, die heute als Leihgabe des Prado im Escorial hängt. PÉREZ DE TUDELA hält diese Verknüpfung für wenig wahrscheinlich und nimmt stattdessen an, dass besagtes Gemälde eine auf Leinwand ausgeführte Version meint, welche 1569 möglicherweise zusammen mit der Hl. Cäcilie nach Madrid bzw. an den Escorial übersandt wurde. Eine Beschreibung von 1626 berichtet von einem solchen Bild im Kapitelhaus (Capítulo Vicarial), den Räumlichkeiten in welchen Philipp II. seine wertvollsten Kunstwerke aufzubewahren pflegte. Danach verliert sich die jedoch ebenso wie Floris nicht zu einem Ortswechsel nach Spanien bewegen konnte. ${ }^{416}$ PÉREZ DE TUDELA sieht darin zwar eine besondere Wertschätzung der flämischen Künstler, dennoch sei es verwunderlich, dass Philipp trotz seiner guten Erfahrung mit Coxcie bei der Anfertigung der Kopie des Genter Altares nicht diesen 1567 nach Leuven sandte, um ein nicht näher benanntes Altarbild mit der Darstellung der Heiligen Jungfrau zu kopieren, sondern einen anderen Maler. ${ }^{417}$ Immerhin belegt dieser Umstand, dass Philipp II. zumindest noch einen weiteren Künstler mit Kopien altniederländischer Tafelbilder beauftragt hat, Anthonis Mor. Dieser fertigte 1554 eine heute verlorene Kopie von Rogier van der Weydens Christus am Kreuz zwischen Maria und Johannes (um 1445) für die Kartäuserabtei in Scheut, die

Spur vorerst, vermutlich im unmittelbaren $\mathrm{Zu}-$ sammenhang mit der Neugestaltung der Räumlichkeiten durch Velázquez in der Mitte des 17. Jhs. (s. hierzu HARRIS - DE ANDRÉS 1972, S. 16). Gegen Ende des 18. Jhs. soll es in die Sala de Capas verbracht worden sein, wo es PONZ 1947 (ebd., S. 192) gesehen haben will (vgl. PÉREZ DE Tudela 2013, Anm. 51). PÉREZ DE Tudela 2013 erwähnt noch ein weiteres ähnliches Gemälde in der Kirche von St. Ginés (ebd., S. 104, mit Verweis auf MONTES - QUESADA 2009, S. 30-32).

415 Vgl. Perez des Tudela 2013, S. 98-115.

416 Jean de Vandenesse, Kontaktperson des Hofes in Flandern berichtet 1563 an den Hofsekretär Pedro de Hoyo, dass Michiel Coxcie sich bereit erklärt habe dem König bei Hofe als Maler zu dienen (Schreiben von J. Vandenesse an Pedro de Hoyo, Brüssel im September 1563; abgedr. bei PÉrez des Tudela 2013, Anm. 48).

417 Die Information, dass es sich um ein ebensolches Bild der Jungfrau handelt, wird in einem Brief an den König von J. Courteville aus Antwerpen vom 22. November 1567 angedeutet (AGS, CSR, leg. 252:4, fol. 42, s. PÉREZ DE TUDELA 2013, S. 105). 
diese Kopie im Tausch gegen das Original erhielt. ${ }^{418}$ Das Vorgehen erinnert an das der Generalstatthalterin Maria, um die Kreuzabnabme van der Weydens - möglicherweise im Auftrag Philipps - zu erwerben.

Eine Reihe von Werken schufen Michiel Coxcie und seine Werkstatt ab 1571 für die Ausstattung der Räume des neu errichteten Escorial. Unter anderem gehören dazu das 1574 von Maria ererbte Bild mit David und Goliath [ABB. 85] sowie ein Diptychon mit einer Kreuztragung und einer Schmerzensmutter. ${ }^{419}$ 1569 erwarb Philipp eine Kreuzabnabme und die zuvor besprochene Hl. Cäcilie vom Herzog von Alba, dem nach dem Bildersturm 1567 zwischenzeitlich neueingesetzten Statthalter der Niederlande. ${ }^{420}$ Weiter hinzu kommen ein Bild mit Kain und Abel - einem vergleichsweise ungewöhnliches Thema - und ein Triptychon mit der Anbetung der Könige, die nach 1584 geliefert worden sind, wie die Quellen angeben. ${ }^{421}$ Die hochformatige Tafel mit Kain und Abel zeigt letzteren ermordet und den flüchtenden Kain. Das Bild basiert auf einer früher entstandenen Druckgraphik Coxcies und soll in dieser Arbeit noch einmal vertiefte Behandlung erfahren. ${ }^{422}$ Die Mitteltafel des letzteren

418 Vgl. Wooldett 2012, S. 84. Öl auf Holz, 323 $\times 192 \mathrm{~cm}$, El Escorial, Inv.-Nr. 10014602 (Original); s. hierzu auch DE Vos 1999, S. 291-294.

419 Zum Gemälde aus dem Nachlass Marias (Prado, Madrid, Inv.-Nr. 10014584, Öl auf Holz, $140 \times$ $133 \mathrm{~cm})$ s. ZARCO 1930, S. 134 f. Für Krenztragung und Schmerzensmutter s. ebd., S. 122, Nr. 881.

420 Philipp II. erwidert das Geschenk des Herzogs und Statthalters der Niederlande mit einem Brief vom 18. November 1569: ,[...] que me han satisfecho mucho [...]“" (s. FALCÓ 1891, S. 168). Das Bild mit der Hl. Cäcilie befindet heute im Prado (s. Abschn. 3.3.3).

421 Öl auf Holz, $151 \times 125$ cm, Prado, Madrid, Inv.Nr. P001518 (Kain und Abel).
Retabels mit der Anbetung ist verloren gegangen, während sich die beiden Seitenflügel mit Verkündigung und Anbetung der Hirten auch heute noch im Escorial befinden. ${ }^{423}$ Der habsburgische Auftraggeber lässt sich durch augenfällige ikonographische Details bestimmen. So sind etwa die beiden Herkulessäulen, das Emblem und die Imprese von Philipps Vater Karl V., zu sehen. ${ }^{424}$ Bemerkenswert ist eine zeitgenössische Abänderung einer der beiden Heiligenfiguren auf der Rückseite des Triptychons mit der Anbetung, die bei der zuletzt vorgenommenen Restaurierung im Jahr 2006 zu Tage getreten ist. Der von Coxcie in römischer Soldatenkleidung dargestellte Hl. Julianus Hospitator, ein Schutzheiliger der Pilger, welcher der Legenda Aurea zu Folge unwissentlich seine Eltern getötet hatte, ${ }^{425}$ war am spanischen Hof vor dem Hintergrund der Kirchenreform möglicherweise als problematisch empfunden worden, zumal das Triptychon für den Escorial, also ein Kloster, bestimmt war. Jedenfalls wurde die Figur bereits bald nach der Vollendung des Werkes in den Evangelisten Johannes abgeändert, indem der Kelch mit der Schlange als ikonographisches Attribut er-

422 s. Kap. V.

423 Beide erhaltenen Tafeln sind heute getrennt, jeweils $263 \times 62,7 \mathrm{~cm}$. Zeigen links die Anbetung der Hirten und St. Julian (Grisaille, vormals übermalt mit Johannes dem Evangelisten), Öl auf Holz, Escorial, Inv.-Nr. 10014583; rechts die Verkündigung und Jakobus d. Ä., Escorial, Inv.-Nr. 10014582 (vgl. PÉREZ DE TUDELA 2013, S. 106 und ohne Nennung des Künstlers s. ZARCO 1930, S. 147, Kat.-Nr. 1260).

424 Vgl. PÉrez de Tudela 2013, S. 106.

425 „Sed verius dicitur esse alius Iulianus, qui scilicet utrumque parentem ignoranter occidit cuius historia infra ponetur." (s. HÄUPTLI 2014, Legenda Aurea, S. 463). 
gänzt wurde. PÉREZ DE TUDELA sieht in dieser mutmaßlich von Philipp angeordneten Abänderung des Heiligen ein Beispiel für gegenreformatorische Tendenzen im Umgang mit historisch zweifelhaften Bildthemen. ${ }^{426}$ Die überkommenen Stoffe und Motive der christlichen Bildkunst wurden in Folge des Tridentinums und der sich anschließenden Bilddebatte einer kritischen Untersuchung unterzogen und teilweise verboten, wenn es Zweifel an deren Wahrheitsgehalt bzw. Historizität gab. ${ }^{427}$ Inwieweit es sich bei diesem Beispiel tatsächlich um ein dezidiert bildreformerisches Vorgehen oder vielleicht einfach um eine persönliche Abneigung gegenüber dem Bildthema seitens des Monarchen handelt, ist nicht befriedigend zu klären.

Die regelrechten Großlieferungen von Bildern aus der Werkstatt Coxcies setzten sich weiter bis zum Jahr 1586 fort, als das sogenannte Erlöser-Diptychon von 1552 in die Sammlung gelangte. Die Tafeln sind heute getrennt; während eine Darstellung mit Christus und der Jungfrau als Interzessorin heute einen Altar im Chorumgang der Klosterkirche schmückt, ist die Rückseite der anderen Tafel mit der Vertreibung Joachims aus dem Tempel noch an ihrem ursprünglichen Ort über dem Altar in der Aula del Moral zu sehen. ${ }^{428} \mathrm{Da}$ rauf folgte das in dieser Arbeit besprochene Triptychon mit dem Leben der heiligen Jungfrau [ABB. 69-71], das ursprünglich für St. Gudula in Brüssel bestimmt gewesen war und für das der

426 Vgl. Perez de Tudela 2013, S. 106 f.

427 Zur vortridentinischen Reform in Spanien s. REDZINSKI 2017, passim.

428 Vgl. ZarCo 1930, S. 112 f.

429 Heute im Prado, Madrid, Inv.-Nr. P001468-70 (s. PÉREZ DE TUdELA 2013, S. 109 u. ZARCO 1930 ,
König van Mander zufolge eine hohe Summe bezahlte. ${ }^{429}$ Zusammen mit dem Retabel gelangte auch die weiter oben besprochene zweite Fassung der Heiligen Sippe [ABB. 63], in welcher der Maler in einem Kryptoportrait zu sehen ist, in das königliche Kloster. Als letztes größeres Werk aus Coxcies Werkstatt erreichte das Triptychon mit dem Martyrium des Hl. Philipp den Escorial [ABB. 86]. Das Retabel zeigt den Namenspatron des Königs sowie den Hl. Andreas, den Patron des Ordens vom Goldenen Vlies, dem der König als Hochmeister vorstand. ${ }^{430}$ Weiter folgten eine Reihe von Entwürfen für Tapisserien mit den antiken Themen des Perserkönigs Kyros dem Großen und die Geschichte Noahs, die Coxcie für die privaten Räumlichkeiten des Königs schuf. ${ }^{431}$

\subsection{Die Stilmodi bei Michiel Coxcie}

Nach der bisherigen Erörterung, die vor allem einer Konkretisierung der in der Literatur zwar verschiedentlich erwähnten, nur zum Teil jedoch tatsächlich untersuchten Abhängigkeit Michiel Coxcies von stilistischen Vorbildern galt, erscheint es sinnvoll, auf einzelne der im Zusammenhang mit den habsburgischen Sammlungen genannten Werke näher einzugehen. Dies betrifft zunächst Werke Coxcies, die offenbar in der Absicht erworben oder dezidiert in Auftrag gegeben wurden, um sie mit bereits vorhandenen Bildern zu kombinieren

S. 23). s. auch die Beobachtungen zu diesem Werk in Abschn. 3.3.4.

430 Vgl. PÉrez DES Tudela 2013, S. 109.

431 Für weitere Informationen zu diesen Arbeiten s. PÉreZ De TUdeLa 2013, S. 110. 
und innerhalb eines größeren gestalterischen Konzeptes zu arrangieren. Besonders deutlich wird diese Absicht in einem neugestalteten Saal in Binche. Die Fresken, Gemälde und kunsthandwerklichen Arbeiten, die als ein 1549 vollendetes Ensemble heute größtenteils nurmehr in schriftlichen Quellen fassbar sind, waren gezielt ausgesucht bzw. aufeinander abgestimmt worden. So kann nur darüber spekuliert werden, ob das Coxcies Fresko mit Marsyas und sein ebenfalls nicht erhaltendes Gemälde mit Tantalus über den rein inhaltlichen Zusammenhang hinaus auch in einer formalstilistischen Beziehung zu Tizians Sisyphus gestanden hat [ABB. 87]. ${ }^{432}$

Deutlicher wird die Beziehung bei zwei anderen Gemälden, die sich heute im Prado befinden. Coxcies Darstellung des kreustragenden Christus, die um 1555 entstanden ist [ABB. 82], zeigt ausgeprägte stilistische $\mathrm{Pa}$ rallelen zu bestimmten Werken Tizians. ${ }^{433}$ Das Bild, das in einem schmalen Ausschnitt Christus als Halbfigur mit dem ebenfalls angeschnittenen Kreuz zeigt, steht in der Tradition entsprechender close-up-Darstellungen vor allem in der venezianischen Malerei. ${ }^{434}$ Der Erlöser ist vor einem dunklen Hintergrund zu sehen, der keinerlei Aussagen über eine räumliche Disposition zulässt. Der Fokus liegt auf dem leicht geneigten Kopf und dem Gesicht Jesu im Dreiviertelprofil sowie seinem gegen den Betrachter gewendeten Oberkörper, der im Bereich der angewinkelten Ellenbogen

432 Öl auf Leinwand, $237 \times 216 \mathrm{~cm}$, Prado, Madrid, Inv.-Nr. P000426 (s. FAus 2003, S. 214 u. Kat. Prado 1985, S. 701 f.). vom unteren Bildrand überschnitten wird. Vor sich hält er mit beiden Händen den schräg nach rechts geneigten Stamm des Kreuzes. Kein festes Zupacken, wie unter der schweren Last des Holzes zu erwarten wäre, ist zu sehen; stattdessen wirken die Hände geradezu behutsam, so als würden sie den hierdurch federleicht anmutenden Kreuzesstamm nur ganz leicht festhalten. Dies steht in einem gewissen Kontrast zu dem blassen Gesicht und den von der Dornenkrone herrührenden über die Stirn laufenden Blutstropfen. Der Blick ist gesenkt, und die Augen sind nahezu geschlossen. Der Ausdruck der Figur und das Thema an sich legen eine Deutung nach rezeptionsästhetischen Gesichtspunkten nahe und regen zur Meditation über das Leiden Christi an.

Bei dem Gegenstück, auf das Coxcie sich maßgeblich zu beziehen scheint, handelt es sich um Tizians knapp zehn Jahre ältere Darstellung des Ecce-Homo von 1547 [ABB. 80], die heute ebenfalls im Prado bewahrt wird. Eine gemeinsame Geschichte haben beide Bilder insofern, als dass Coxcies Bild in der privaten Sammlung Karls V. in Yuste einige Zeit lang neben Tizians Mater Dolorosa mit den gefalteten Händen hing [ABB. 81]. Auch Philipp hatte zumindest das Bild mit der schmerzerfüllten Gottesmutter in seinen privaten Gemächern im Alcazar von Madrid hängen - hier zusammen mit Tizians oben genanntem Ecce-

433 Öl auf Holz, $81 \times 50 \mathrm{~cm}$, Prado, Madrid, Inv.Nr. P002641 (vgl. JONCKHEERE - SUYKERBUYK 2013, S. 34 u. 39 u. VAN DEN BOOGERT 1993).

434 Zur Entwicklung des Bildtypus s. BRUCHER 2015 u. RINGBOM 1984. 
Homo. ${ }^{435}$ Darnach scheint es, dass dieses Werk das Bild Coxcies gewissermaßen ersetzte. Dies könnte ein Hinweis darauf sein, dass letzteres zunächst nur als ,Platzhalter' gedient hatte, den Philipp II. schließlich gegen ein passendes Werk Tizians austauschte. Entsprechend wäre es naheliegend anzunehmen, dass Coxcies Kreu₹tragung von 1555 bereits unter der Prämisse geschaffen worden war, dem Ecce-Homo oder einem ähnlichen Bild Tizians stilistisch zu entsprechen, um ein stimmiges Pendant zur Mater Dolorosa zu bilden.

Weitere Indizien für diese Annahme lassen sich vermittels der formal-stilistischen Gegenüberstellung ermitteln. So ist auf dem Bild Tizians der gebundene Christus mit Dornenkrone und Purpurmantel ebenfalls vor einem nicht näher bezeichneten, dunkelbraunen Hintergrund als Einzelfigur dargestellt - ganz ähnlich der Darstellung auf Coxcies Kreuztragung. Christus erscheint als Halbfigur im Dreiviertelprofil, das Gesicht leicht nach rechts geneigt. Die Arme sind gebunden, die linke wie kraftlos wirkende Hand ist über die andere gelegt, während Jesu Haupt geneigt und sein Blick abwärts gesenkt ist. Von seinem von den Dornen versehrten Haupt rinnen Blutstropfen herab, jedoch stärker als im unmittelbaren Vergleich zu Coxcies Darstellung. Auch läuft das Blut bis auf die nackte und mit Striemen überzogene Brust, während Coxcies Jesus bekleidet ist. Der Unterschied liegt jedoch vor allem in der Körperlichkeit; so erscheint Christus bei Coxcie feingliedrig und

\footnotetext{
435 Tizians Mater Dolorosa mit den gefalteten Händen: Öl auf Holz, $68 \times 61 \mathrm{~cm}$, Prado, Madrid, Inv.Nr. P000443; s. auch Abschn. 3.5 dieser Arbeit.
}

schlank, während er bei Tizian ungleich kräftiger und muskulöser ist. Ähnlichkeiten zeigen sich vor allem im blassgräulichen Inkarnat, der Betonung der Augenpartie und deren dunkler Verschattung bei Tizian gegenüber den leicht stilisiert wirkenden Augenringen bei Coxcie, die eine stärkere Mitgenommenheit der Figur bezeichnen. Überhaupt wirkt Tizians Jesus viel stärker von der unmittelbar voraufgehenden Geißelung und Dornenkrönung gezeichnet als bei dem Flamen - eine ideale Auffassung, die hier vermutlich dem vergeistigten Ausdruck entgegenkommen soll, während der zwar sehr ähnlich wirkende Ausdruck im Gesicht der Figur bei Tizian ein deutlich, diesseitigeres ${ }^{6}$ Erdulden der körperlichen Pein zeigt. Beide Bilder - die als Andachtsbilder zu verstehen sind - zielen darauf ab, durch eine nahsichtige Fokussierung und Konzentration auf Christus ohne Nebenfiguren dessen Leiden zu vergegenwärtigen, auf die im Einzelnen das Blut, die Dornenkrone und die Striemen auf dem Oberkörper in Tizians Darstellung hindeuten. Auffällig sind auch Ähnlichkeiten in der Oberflächengestaltung. Neben dem bereits angesprochenen Inkarnat, macht sich dies bei beiden Bildern im feingekräuselten Bart und dem in Locken auf die Schulter fallenden Haar bemerkbar. Die Wiedergabe des Haares ist sehr stofflich und weist dadurch einen hohen Grad von Naturalismus auf. Bei Tizian ist dies tendenziell stärker ausgeprägt, während Coxcie dem aber kaum nachsteht. Auch in der Größe ähneln sich beide Bilder; Coxcies Tafel ist nur wenig höher als der auf 
Schiefer gemalte Christus von Tizian. ${ }^{436}$ Hinsichtlich der Feinheit des Auftrags und der farblich stark ausdifferenzierten Gestaltung der Hautpartien kann beiden Bildern eine malerische Auffassung bescheinigt werden. Unterschiede liegen hauptsächlich in der Komposition und den zwei unterschiedlichen Stadien, die verschiedene Aspekte der Passion Christi betonen.

Angesichts der formalen und stilistischen Beziehung zwischen beiden Bildern scheint Coxcie sich auf das Vorbild von Tizian bezogen zu haben. Wann und wo er dieses oder andere Werke von Tizian gesehen hat, lässt sich schwer sagen. Allerdings ist für das Ecce Homo-Sujet zu konstatieren, dass es relativ erfolgreich war und dass Tizian mehrere Bilder dieses Themas gemalt hat, von denen zwei datiert sind. Zum einen schenkte der Maler Papst Paul III. 1546 ein solches Bild und 1548 ein weiteres dem römischen Schriftsteller Pietro Aretino. ${ }^{437}$ Die Figur steht darüber hinaus dem deutlich späteren vielfigurigen Ecce Homo-Bild Tizians (um 1565) sehr nahe, obschon sich hier die für Tizians Spätwerk deutlich sichtbare Pinselschrift geltend macht, die in einem starken Gegensatz zu der glatteren Faktur der früheren Werke steht.

Eine andere Herleitung des Motivs ist über weitere italienische Vorbilder zu leisten. Ausgangspunkt ist neben dem Bildthema an sich auch die Tatsache, dass Tizians Ecce Homo auf Schiefer gemalt ist - ein Umstand der auf entsprechende Versuche des Sebastiano del
Piombo verweist, nach dem Sacco di Roma und der damit verbundenen Zerstörung vieler auf Holz und Leinwand gemalter Kunstwerke einen widerstandsfähigeren Bildträger zu finden. ${ }^{438}$ In diese späte Phase des Malers, die Vasari aus Parteilichkeit für Michelangelo als Niedergang beschreibt, fällt auch der sogenannte Christus als Kreuzträger von 1537 [АВB. 83]. ${ }^{439}$ Das Bild zeigt Christus als Halbfigur annähernd frontal, dabei den Kopf nach rechts im Halbprofil gewendet, wie er das Kreuz, dessen Last ihn niederdrückt, auf seinen Schultern trägt. Der Hintergrund ist auch hier unbezeichnet und in dunklen Brauntönen gehalten. Das Kreuz ist anders als bei Coxcies Kreuztragung bis auf die Spitze und den unteren Stamm in Gänze zu sehen und erscheint in Form einer leicht schräg gestellten Diagonale auf der Mittelachse des Bildes. Das Gesicht Christi offenbart ein Klagen oder Ächzen, das durch den geöffneten Mund angezeigt wird, während der Blick gesenkt ist. Anders als bei Tizian und Coxcie trägt Jesus keine Dornenkrone und zeigt keine Spuren, die auf die vorausgegangene Geißelung und Verspottung hindeuten würden. Die Figur ist somit aus dem Zusammenhang der biblischen Erzählung herausgelöst und akzentuiert Christus als Kreuzträger (oder auch ,Kreuzschlepper'), ein Motiv, das seit dem späten Mittelalter begegnet. ${ }^{440}$ Besonders hervorgehoben sind die Hände, die den Kreuzesstamm umfassen und ihn dem Eindruck nach kaum noch zu halten vermögen. Es ist denkbar, dass Michiel Coxcie

439 Szépművészeti Múzeum, Budapest, Inv.-Nr. 77.1.

440 Vgl. SCHILLER 1968, Bd. 2, S. 88-93 u. LCI II [1970], s. v. „Kreuztragung“, Sp. 640-665. 
dieses Bild oder entsprechende Werke während seiner Zeit in Rom kennengelernt hatte. Da Sebastiano del Piombo, eigentlich Sebastiano Francesco Luciani, ab 1531 das Amt des päpstlichen Siegelverwahrers („Frate del Piombo") bekleidete und zu den Malern gehörte, die nach dem Sacco bald nach Rom zurückgekehrt waren, ist es sogar recht wahrscheinlich, dass beide Maler einander kannten. ${ }^{441}$

Von Bedeutung ist in diesem Zusammenhang auch, dass sich von Michiel Coxcie mehrere nahsichtige Halbfigurenbilder erhalten haben, die vielfach kopiert wurden. Von diesen Kopien sind einige in den letzten Jahren auf dem Kunstmarkt angeboten worden. ${ }^{442}$ In der Regel handelt es sich um Darstellungen Christi mit Dornenkrone, der das Kreuz trägt. Manchmal ergänzt durch weitere Figuren. Ähnlichkeiten bestehen auch zu einem weiteren Kreuztragenden Christus, der sich ursprünglich im Besitz der Herzöge von Mantua befunden haben soll und zuletzt 2001 bei Christie's angeboten wurde [АВB. 92]. ${ }^{443} \mathrm{Hier}$

441 Interessant ist auch, dass Vasari ein recht negatives Bild zum Leben und Wirken Sebastiano del Piombos zeichnet - augenscheinlich aus Parteiergriffenheit für Michelangelo, der eine persönliche Feindschaft gegenüber dem Venezianer Sebastiano gehegt haben soll. Die Vita führte zu einer bis ins 20. Jh. hineinreichenden negativen Bewertung des Malers, was in gewisser Hinsicht an van Manders unrühmliche Werturteile über Michiel Coxcie erinnert (vgl. BERTLING-BIAGGINI 2016, S. 212 u. IRLENBUSCH 2004, passim).

Hierzu s. auch die in Abschn. 3.2.2 behandelte Überlegung zu einer möglichen Ausbildung Coxcies in der römischen Werkstatt Sebastianos.

442 Eine Geißelung Christi (Kopie nach Coxcie) wurde bei Campo \& Campo 2015 in Antwerpen angeboten. Ein sehr ähnliches, von einem ähnelt die Figur deutlich dem Bild von 1555, wird allerdings im Hintergrund szenisch durch die Darstellung von einem der Schergen, der mit gefesselten Händen von einem Soldaten im Harnisch angetrieben wird, dabei seinen Blick zur Seite auf Christus richtet, erweitert. Im Kolorit ergeben sich Unterschiede, während Christus und das Kreuz ähnlich nahsichtig und angeschnitten wiedergegeben sind. Grundsätzlich kann angenommen werden, dass es sich bei Coxcies Kreuztragendem Christus aus dem Prado um eine reduzierte Version dieser mehrfigurigen Darstellung handelt, von der überdies weitere Versionen bekannt sind so entspricht die Komposition einem Bild in der Parkabtei in Leuven [ABB. 93] sowie einem weiteren im Bonnefantenmuseum in Maastricht. ${ }^{444}$ Im Gegensatz dazu ist keine weitere Einzeldarstellung des kreuztragenden Christus bzw. des Ecce-Homo bekannt, sodass ein spezieller Wunsch des Auftraggebers möglich scheint. In diesem Fall konnte Coxcie die Figur des Christus aus den früheren Darstellungen ,isolieren‘. Vielleicht hat er Tizians Ecce

Nachahmer geschaffen, wurde 2003 bei Christies versteigert. Gegenwärtig wird das Bild Kreuztragender Christus und zpei Diebe von einem privaten Händler aus England auf der OnlinePlattform, 1stdibs' angeboten, welches aus einer Pariser Privatsammlung stammen soll. 2011 wurde vom spanischen Auktionshaus Alcalá Subastas ein ähnliches Bild verkauft, dessen Komposition wiederum identisch ist mit einem bereits 2009 bei Christies veräußerten Bild.

443 Öl auf Holz, $111 \times 94,5 \mathrm{~cm}$, Verbleib unklar, zuletzt bei Christies, Auktion vom 12. Dezember 2001 (Lot. 64). Vgl. hierzu BINION 1990, S. 134, 192, 222, 270 u. 275 u. RKD-Nr. 112749.

444 Öl auf Holz, $61,2 \times 76 \mathrm{~cm}$, Bonnefantenmuseum, Maastricht, Inv.-Nr. 76 (laut RKD ehemals als Werk Vincent Sellaer geführt, heute Coxcie zugeschrieben (RKD-Nr. 28203). 
Homo und Mater Dolorosa aus Philipps Sammlung gekannt, sodass er sich unmittelbar nach einem der Bilder (oder beiden) richten konnte. Nichtsdestotrotz liegen die Vorbilder für Coxcies mehrfigurige Darstellungen mit dem gegeißelten Christus in Norditalien, etwa bei Tizian und der venezianischen Malerei - oder aber (auch) in Florenz, wie das Werk von Jacopo Ligozzi nahelegt.

Eines dieser Bilder, das von einem Nachfolger Michiel Coxcies geschaffen worden sein soll, stellt das 2003 bei Christie's gehandelte Bild Ecce Homo mit Pontius Pilatus und zwei Schergen dar [ABB. 88]. ${ }^{445}$ Obwohl die Ursprungsfassung bislang nicht nachzuweisen ist, lassen sich doch wenigstens vier Versionen des Bildes bestimmen, die größtenteils ins späte 16. Jahrhundert und nach Flandern verortet werden können. Stilistisch gesehen steht diese Version Coxcies weiter oben behandeltem Kreuztragenden Christus von 1555 nahe. Vor allem in der Modellierung des Gesichts mit den nahezu geschlossenen Lidern und der länglichen Nase mit dem geraden Nasenrücken macht sich die Beziehung der beiden Bilder geltend. Der Kopf ist seitlich zur Schulter geneigt, allerdings in die andere Richtung. Auch die erschlafften Hände mit den langen Fingern sind hier ähnlich auffällig in den Fokus gerückt. Überdies ist das Inkarnat vergleichbar blass, allerdings gelblicher - was auch teilweise durch den schlechteren Zustand des Bildes zu erklären ist. Daneben ist die blaugraue Gewandfarbe vergleichbar mit der

445 Öl auf Holz, $94 \times 70,5$ cm, Verbleib unklar, zuletzt verkauft am 5. Februar 2003 (Lot 270) bei Christies, New York.

446 Öl auf Holz, 113,5 × 90,5 cm, Hampel, Auktion vom 12. Dezember 2016 des Umhanges auf dem Bild aus der Versteigerung. Auch dieses Bild ist nicht überzeitlich $\mathrm{zu}$ verstehen, sondern meint angesichts der Anwesenheit des römischen Statthalters und zweier seiner Knechte eine szenische Darstellung. Als mögliches Vorbild gelten kann die nicht genauer datierte Ecce Homo-Darstellung von Jacopo Ligozzi, einem aus Verona stammenden und in Florenz zur Bekanntheit gelangten Maler, die 2016 beim Auktionshaus Hampel angeboten wurde [ABB. 90]. ${ }^{446}$ Das Werk wurde von Sadeler 1596 als Kupferstich herausgegeben und verbreitet [ABB. 89], ${ }^{447}$ sodass spätere Nachahmer womöglich auf diese graphische Reproduktion zurückgriffen, während die Kopie des ,Coxcie-Nachfolgers' früher entstanden sein müsste. Möglicherweise handelt es sich aber auch um ein erst später entstandenes Werk, das neben der druckgraphischen Vorlage Sadelers auch eines der älteren Halbfigurenbilder Coxcies zum Vorbild hat. Dies wird durch die Existenz weiterer vergleichbarer Bilder, die in das Umfeld Coxcies verortet werden, untermauert. So zeigt etwa eine weitere Tafel mit dem Ecce-Homo eine noch etwas anders angelegte Komposition, die im Detail dennoch Übereinstimmungen aufweist [ABB. 91]. Von den Figuren ist hier etwas mehr zu sehen, da sie etwa bis zur Hüfte abgebildet sind. Wieder wird der an den Handgelenken gefesselte Christus neben Pontius Pilatus gezeigt. Die Positionen im Bild sind getauscht, während drei weitere Figuren dahinter zu sehen sind. Diese nehmen identische Plätze

(www.lot-tissimo.com/de/i/11137969/p/18> (aufgerufen am 25.08.2019).

447 Kupferstich, $24,80 \times 19,40 \mathrm{~cm}$, National Galleries Scotland, Inv.-Nr. P 5715. 
ein wie bei dem 2003 bei Christie's angebotenen Bild, sind hier nun allerdings in einem Innenraum mit Ausblick durch eine an der Rückwand sich befindliche Türöffnung dargestellt. Bei der Figur des Christus lassen sich Ähnlichkeiten feststellen, wie etwa die Kopfhaltung oder die Art wie die halb geschlossenen Augen ausgearbeitet sind. Der Kopf wirkt runder und das Gesicht hierdurch breiter. Insgesamt ist die Figur plastischer und durch den stärkeren Einsatz von Helldunkel feiner modelliert.

Der Einfluss italienischer Vorbilder hatte sich bereits in den 1540er und frühen 1550er Jahren in Coxcies CEuvre vor allem durch die mehr oder weniger genaue Übernahme von figürlichen Motiven, vorrangig aus verschiedenen Werken Raffaels, aber auch von anderen Malern der Hochrenaissance, darunter Michelangelo und Leonardo, geltend gemacht. Mit der um 1555 entstandenen Kreuətragung, bei der es sich angesichts der bisherigen Beobachtungen um eine Auftragsarbeit für Karl V., der Coxcie zeitlebens aufgrund dessen italianisierenden Stils schätzte, handeln könnte, beweist der Mechelner seine breite Kenntnis der italienischen Malerei. Die häufigen Zitate nach Raffael legen nahe, dass Coxcie eine ganze Reihe von Zeichnungen und druckgraphischen Reproduktionen der römischen Kunstwerke besaß. Auch die Architekturdarstellungen in seinen frühen Altarretabeln deuten auf solche Vorlagen hin. ${ }^{448}$ So mögen ihm für die einfigurige Komposition des kreuztragenden Christus Zeichnungen oder zumindest die Erinnerung an Vergleichbares, das er in Rom gesehen hatte, von Nutzen gewesen sein. Inwieweit eine spätere Beschäftigung mit der italienischen Kunstentwicklung möglich gewesen ist, kann nicht befriedigend geklärt werden. Allerdings lässt sich konstatieren, dass er in seinen Werken auch in späterer Zeit stets den gleichen Vorbildern verpflichtet blieb. Das raffaeleske Idiom und unterschiedlich stark ausgeprägte manieristische Tendenzen stellen eine Konstante bei Michiel Coxcie dar, der aber zugleich auch immer wieder an seinen Lehrer Bernard van Orley anknüpfte.

Vergleicht man den kreuztragenden Christus von 1555 [АВВ. 82], der höchstwahrscheinlich als Pendant zu Tizians Mater Dolorosa gedacht war [ABB. 81], bevor sie durch dessen Ecce Homo ersetzt wurde [ABB. 80], mit der auf 1560 datierten und ebenfalls in Karls und später Philipps Sammlung befindlichen mehrfigurigen Kreuətragung nach dem Vorbild Dürers und der niederländischen Malerei des ersten Viertels des 16. Jahrhunderts [ABB. 78], wird der Unterschied zwischen zwei sehr unterschiedlichen Bezugspunkten bzw. Vorbildern deutlich. Dies zeigt sich bei Coxcie auch jeweils in der gewählten stilistischen Form. Während das eine Bild offenkundig in der Tradition älterer Darstellungen auch stilistisch zu archaisieren versucht, ist das andere möglicherweise - obwohl einige Jahre früher entstanden - an die Vorgabe geknüpft gewesen, den Stil eines anderen Bildes, nämlich eines von Tizian, zu reproduzieren. Das Vorgehen, das

Marienleben erinnert; s. hierzu Abschn. 3.3.1 u. 3.3.2. 
ihm nachweislich die Wertschätzung fürstlicher Auftraggeber einbrachte, das heißt von Personen, die Bilder von Tizian und Raffael kannten, geht dabei über bloßen Eklektizismus hinaus, wie van Mander vor dem Hintergrund seiner Zeit noch behaupten musste. Vielmehr wird hier eine ,chamäleonartige“ Befähigung sichtbar, ${ }^{449}$ die letztlich ursächlich dafür gewesen sein mag, dass man ihn damit betraute, berühmteste Werke, wie van der Weydens Kreuzabnabme und van Eycks Genter Altar, zu kopieren.

\subsection{Die Kopien nach Jan van Eyck und Rogier van der Weyden}

Als ein Schlüsselwerk bei der Entwicklung der Malerei im ausgehenden Mittelalter hat der Genter Altar in der Kunstgeschichte seit langer Zeit einen besonderen Stellenwert, wie Stephan KEMPERDICK jüngst resümierte [ABB. 94]. ${ }^{450}$ Die von Michiel Coxcie für Philipp II. angefertigte Kopie des Genter Altars bezeugt indessen [ABB. 95] wie kaum ein anderes Werk in dieser vor allem von den Einflüssen der italienischen Hochrenaissance geprägten Phase der niederländischen Malerei, welchen Stellenwert die lokale Tradition gegenüber der primär geförderten und als progressiv verstandenen maniera italiana einnahm und mag Auskunft

449 Diesen Begriff verwendet SUYKERBUYK 2017, S. 73, um Coxcies stilistische Variationsbreite und Anpassungsfähigkeit zu beschreiben.

450 Vgl. KEMPERDICK 2017, S. 6.

451 Vgl. SUYKERBUYK 2017, S. 71.

452 Vgl. ebd., mit Verweis auf SUYKERBUYK 2013 u. 2014 sowie die Publikationen von DUverger 1954; STEPPE 1930; ROOBAERT 2005; DUBOIS- darüber geben, welche Gründe die Anfertigung solcher Kopien nach den großen Meistern des 15. Jahrhunderts, wie Jan van Eyck, Rogier van der Weyden oder auch Hieronymus Bosch, veranlasst haben können.

Die Kopie des Genter Altars ist wahrscheinlich einer der Gründe dafür, dass Michiel Coxcie in späteren Jahrhunderten positiv rezipiert wurde, bis die historische Verknüpfung seines Namens mit dem Stichwort „Kopie ${ }^{6}$ in der kunsthistorischen Forschung des 19. und 20. Jahrhunderts zu einer negativen Bewertung des Künstlers führte. Die Quellen, auf die man sich hierfür bezog, gaben nur indirekten Anlass dazu, sodass die Frage nach dem, Wert' der künstlerischen Leistungen Michiel Coxcies von der jeweiligen Lesart abhängig war. ${ }^{451}$ Faktisch handelt es sich um eines der am besten dokumentierten Werke im CEuvre Michiel Coxcies, zu dem sich eine vergleichsweise umfangreiche Dokumentation mit vertraglichen Bestimmungen und Zahlungen erhalten hat, die eine Rekonstruktion des Entstehungsprozesses ermöglichen. ${ }^{452}$ Für diesen Auftrag war Coxcie gezwungen, einige Jahre nach Gent zu übersiedeln, um in unmittelbarer Nähe des in St. Bavo aufgestellten Retabels von Jan van Eyck arbeiten zu können, während er zuvor als Mitglied des Hofes von Brüssel ein eigenes Anwesen in der Stadt bewohnt hatte. ${ }^{453}$ Die Anfertigung der Kopie des berühmten Vijd-Retabels, wie

Syfer D’Olne 2006 u. PÉrez de Tudela 2013.

453 Der König gewährte ihm hierfür eine steuerfreie Überführung seiner Werkstatt und seines Hausstandes nach Gent (s. hierzu SUYKERBUYK 2017, S. 74 f. u. Appendix III [Dokument mit ,Reiseerlaubnis' (Brüssel, 24. Januar 1557)], zuerst abgedr. bei SZMYDKÍ 2001, S. 128f.). 
es nach dem Namen der Stifterfamilie auch zuweilen bezeichnet wird, ist im Zusammenhang mit den Bemühungen Philips II., eine umfangreiche Kunstsammlung anzulegen, die neben italienischen Werken auch solche der flämischen Malerei des 15. Jahrhunderts umfasste, zu verstehen. Auch andere Habsburger, allen voran Maria von Ungarn, hatten sich zu dieser Zeit als Sammler herausstechender altniederländischer Meisterwerke betätigt. So erwarb Maria unter anderem die Kreuzabnabme Rogier van der Weydens, die sie wie erwähnt gegen eine Kopie, die von Michiel Coxcie ausgeführt worden war [ABB. 84], eintauschen konnte. ${ }^{454}$ Außerdem ist überliefert, dass sie erfolglos versuchte Jan van Eycks Madonna mit dem Kanonikus Georg van der Paele (1434-1436) $\mathrm{zu}$ erwerben. ${ }^{455}$ Eine weitere Rolle spielten Kopien im Zusammenhang mit der Errichtung des Klosters und Palastes Escorial in den 1560er Jahren. Viele Werke, die Philipp II. zunächst im Alcázar und im Palacio Real versammelt hatte, wurden in den neuen Palast transferiert und an den alten Aufstellungsorten durch Kopien ersetzt. Nach dem Tod Marias von Ungarn erbte Philipp II. die Kreuzabnabme Rogier van der Weydens, die zunächst im Palacio Real (El Pardo) aufgestellt wurde und

454 Öl auf Holz, $210 \times 168,5$ cm, Bode-Museum, Berlin (vgl. PutZGer 2019, S, 76. Anm. 10).

455 Öl auf Holz, $141 \times 176,5 \mathrm{~cm}$ (mit Rahmen), 122 $\times 157 \mathrm{~cm}$ (ohne Rahmen), Groeningemuseum, Brügge (s. hierzu SUYKERBUYK 2017, S. 71). Der Versuch Maria von Ungarns das Werk 1547 zu erwerben wurde vom Kapitel von St. Donatian in Brügge höflich abgewiesen, da dies zu „Protesten, Aufruhen und Klagen“ seitens der Bevölkerung führen würde. Während des calvinistischen Bildersturms von 1578 sei der Altar zu dessen Sicherung in ein privates Haus verbracht worden (vgl. BRINE 2015, S. 189).
1566 ebenfalls in das Kloster von El Escorial verbracht wurde. Eine von Coxcie schon im Auftrag von Maria von Ungarn gefertigte zweite Kopie wurde an Stelle des Originals im Königspalast aufgehängt. ${ }^{456}$

Die Kopie des Genter Altars hatte demgegenüber sicherlich eine andere, weitaus bedeutsamere Funktion und ist wahrscheinlich dadurch zu erklären, dass es Philipp II. bzw. dem von ihm in den Niederlanden eingesetzten Agenten unmöglich war, des Originals habhaft zu werden, da das Werk bei der lokalen Bevölkerung und dem Klerus eine besondere Wertschätzung genoss und es in den Augen der Zeitgenossen durchaus als bedeutsames Kunstwerk aus der großen Tradition des 15. Jahrhunderts verstanden wurde. ${ }^{457}$ Der Versuch, das Original zu erwerben ist nicht dokumentiert, da ein Ankauf entweder von vornherein selbst für den Monarchen als unmöglich angesehen wurde oder aber entsprechende Informationen nicht erhalten sind. ${ }^{458}$ In einer zeitgenössischen Quelle behauptet der Wahlflame Guicciardini (1521-1598) indes, dass der König tatsächlich nie versucht habe, das Retabel von seinem Aufstellungsort in St.

456 Für die Rolle von Kopien im Werkstattkontext s. WOOLLETT 2012, S. 75-94 und für die betreffende Kopie bzw. weitere Beispiele s. KEMPERDICK 2010, passim.

457 Ähnlich was es Maria von Ungarn 1547 beim versuchten Ankauf der Madonna von van der Weyden aus St. Donatian in Brügge ergangen, s. o.

458 Vgl. SuYkerbuYK 2017, S. 76 u. Duverger 1954, S. 58. Zu späteren Anfragen an das Kapitel s. ebd., S. 60-64. 
Bavo zu entfernen. ${ }^{459}$ Dass der Monarch finanzielle Mittel zur umfassenden Restaurierung des Originals zur Verfügung stellte, belegt immerhin seine Wertschätzung dieses Kunstwerks, wie es auch in Lucas de Heeres Lobgedicht zum Ausdruck gebracht wird. Die Information über eine Restaurierung im Jahr 1550 stammt von dem Genter Historiker und Rederijker van Vaernwyck; Lancelot Blondeel, der hauptsächlich in Brügge tätig gewesen ist, und Jan van Scorel haben demnach das Retabel mit großer Aufmerksamkeit gereinigt und ausgebessert. ${ }^{460}$

Anlässlich der Kapitelversammlung des Ordens vom goldenen Vlies in St. Bavo 1559 rühmte de Heere Philipp II. als Bewahrer der Kunst, der den berühmten ,Altar ' habe restaurieren sowie eine dem Vorbild würdige Kopie durch Michiel Coxcie anfertigen lassen. ${ }^{461}$ Die Beauftragung Coxcies ist in den Schatzbüchern des Königs ab dem 30. Oktober 1556 nachweisbar. Johann Lopez Gallo, der Schatzmeister Philipps II., traf an diesem

459 Guicciardini 1567, S. 97: ,[...] non osando de la torla [...]" und ähnlich bei van Mander 1604, S. 200:, ,[...] om de stadt van Ghendt van dit luweel niet te berooven $[\ldots]$ “; s. auch SUYKERBUYK 2017, S. 72.

460 Vgl. van Vaernwyck 1568, zit. nach DHANENS 1965, S. 111.

461 De Heere, Lucas: Den hof en boomgaert der poësien, Gent 1565, S. 35-38 (abgedr. bei MIEDEMA 1994[-99], Bd. I, S. 211 f.).

462 Zu López Gallo s. Huvenne 1984, S. 180-182; zu den Archivalien s. MARTíneZ MilláN FERNÁNDEZ CONTI 2005, S. 130 sowie SUYKERBUYK 2017, Appendix I (Vereinbarung über die Bezahlung Michiel Coxcies [Gent, 30. Oktober 1556]). Weiterführende Informationen zudem bei SUYKERBUYK 2017, S. 73 f. u. KEMPERDICK 2014, S. 44.
Datum in Gent Vereinbarungen mit dem Maler über eine Bezahlung in Höhe von insgesamt 2700 Gulden, von denen der Betrag von 300 Gulden bereits im Voraus bezahlt werden sollte, während der Differenzbetrag von weiteren 2400 Gulden im Verlauf der Arbeit erfolgen sollte. ${ }^{462}$ Ruben SUYKERBUYK verweist in diesem Zusammenhang darauf, dass Coxcie laut den erhaltenen Dokumenten am 16. Januar 1557 am Brüsseler Hof erschienen war, um sich weitere Zahlungen überschreiben zu lassen. ${ }^{463}$ Die notarielle Vertretung dieser Transaktionen übernahm der Hofbeamte Philips de Lens. Dieser ist nur im Stammbuch bzw. album amicorum des Chronisten Emanuel van Meteren (1535-1612) fassbar. ${ }^{464}$ Er wird hier neben weiteren Personen, darunter hauptsächlich Autoren und Maler wie etwa Abraham Ortelius, Joris Hoefnagel, Lucas de Heere, Frans Pourbus und Abraham Bloemaert, genannt. ${ }^{465}$ Coxcie, der offenbar mit de Lens zumindest in geschäftlicher Beziehung stand, mag die bei van Meteren genannten Persön-

Auch Lucas de Heere erwähnt Dauer und Bezahlung, wenn auch keine genauen Zahlen: Michiel Coxsye, hadde voor dit waerck zulc gewinaant. / Twee iaren daer met besigh zijnde in dees capelle. / Hy bewaerde sijn eere van int beghin / Totten hende toe, als een oprecht werck-gheselle (De Heere, Lucas: Den hof en boomgaert der poësien, Gent 1565, S. 32 (abgedr. bei MIEDEMA 1995, Bd. 2, S. 211 f.).

463 Vgl. SuYKerbuYK 2017, Appendix II (Die notarielle Beauftragung Philips de Lens durch Michiel Coxcie, [Brüssel, 16. Januar 1557]); zuerst abgedr. bei DUverger 1954, S. 58, Anm. 36.

464 Oxford, Bodleian Library, MS Douce 68 (s. ROGGE 1897, passim).

465 Vgl. SuYkerbuYK 2017, Anm. 16. Für Personen aus dem album amicorum s. ROGGE 1897, S. 171. 
lichkeiten gekannt haben und sich möglicherweise im selben Umfeld am Brüsseler Hof bewegt haben, dessen Angehöriger er durch seine Stellung als Hofmaler der Statthalterin Maria von Ungarn seit 1541 war. Weiterhin heißt es, dass die Wahl Coxcies für die Anfertigung der Kopie nicht überraschend gewesen sei, da er sich bereits im Dienst Marias von Ungarn befunden hatte und mit der Anfertigung einer Kopie von Rogier van der Weydens Kreuzabnabme aus Leuven hatte bewähren können. SuYKERBUYK bezeichnet Coxcie in diesem Zusammenhang als „stylistic Chameleon“ "466 und meint damit dessen Befähigung, sich unterschiedliche Stile anzueignen. Bis zum Jahr 1556 hatte er durch verschiedene Aufträge für den habsburgischen Hof sowohl in Flandern als auch in Spanien unter Beweis gestellt, dass er in der Lage war, nach unterschiedlichen stilistischen Vorbildern zu arbeiten, zugleich aber auch einen eigenen Stil zu entwickeln, der bereits in seinen frühen Arbeiten der 1540er Jahre voll ausgeprägt ist. Neben seinen Kopien nach altniederländischen Meistern war er, wie wir gesehen haben, in der Lage, auch Werke nach dem Vorbild Tizians zu schaffen, die mit dessen Bildern in der Sammlung Philipps II. stilistisch übereinstimmten. ${ }^{467}$ In St. Bavo ließ Coxcie, offenbar nach peinlich genauer Absprache mit dem örtlichen Klerus, zunächst eine hölzerne räumliche Abtrennung errichten, in welcher er selbst ungestört und ohne die liturgischen Abläufe in der Kirche zu stören, arbeiten konnte. ${ }^{468}$ Eine Quelle verweist darauf, dass zwei Tischler mit der Anfertigung dieses kastenartigen Raumes, der als „camere“ bezeichnet wird, zwölf Tage beschäftigt waren. Es ist nicht geklärt, wie diese Konstruktion genau aussah, aber vermutlich umfasste sie das Vijd-Retabel und ausreichend Platz für die Verfertigung der einzelnen Tafeln der Kopie vor Ort. ${ }^{469}$ Der Umstand, dass Coxcie direkt vor dem Original arbeiten konnte, ist auch in Lucas de Heeres Lobgedicht angesprochen, in welchem es heißt, Coxcie habe ,in des capelle“ seine Arbeit verrichtet. ${ }^{470}$ Entsprechend hat SUYKERBUYK die These aufgestellt, dass der mehrjährige Aufenthalt in Gent von 1556-1559 nicht allein der Anfertigung dieser einen, obschon im Hinblick auf Format und Anspruch herausragenden Kopie gedient habe. ${ }^{471}$ In der Forschung wurde Coxcie zuvor für den Entwurf von drei monumentalen Glasfenstern im Querschiff von St. Bavo verantwortlich angesehen, was zu einer fast hundertjährigen Fortschreibung dieser Annahme führte. ${ }^{472}$ Die Fenster waren

469 Vgl. Buchanan 1999, S. 151, Anm. 59.

470 Vgl. Dhanens 1976, S. 12 f. u. Nr. 3, S. 46-48.

$471, \ldots[. .$.$] zaken onsen diensten angaende“ heißt es$ in der königlichen Genehmigung zur Übersiedlung nach Gent, was nicht zwingend nur die Anfertigung der Kopie meint, wie SUYKERBUYK konstatiert (SUYKERBUYK 2017, S. 75 u. für das Dokument, Appendix III (Dokument mit ,Reiseerlaubnis“ 'Brüssel, 24. Januar 1557]), zuerst abgedr. bei SZMYDKí 2001, S. 128f.).

472 Vgl. ReInTJENs 2013, S. 138-155. 
1556 von Maria von Ungarn, Karl. V und Philipp II. gemeinsam gestiftet worden, das heißt im selben Jahr wie die vertragliche Vereinbarung zwischen dem Monarchen und Michiel Coxcie über die Anfertigung einer Kopie des Genter Altars. ${ }^{473}$ Die These stützt sich vor allem darauf, dass sich ein Skizzenbuch erhalten hat, das bereits im 19. Jahrhundert mehrfach Coxcie zugeschrieben worden war und Zeichnungen zu den heute nicht mehr erhaltenen Fenstern in St. Bavo enthält. Eine Quelle, die diese Annahme untermauern könnte, hat sich nicht erhalten. ${ }^{474}$ Die von SUYKERBUYK herangezogenen Rechnungen, die die Verfertigung des hölzernen Kastens betreffen, stammen aus der Buchführung des Klerus von St. Bavo. Eine Kooperation mit den Geistlichen war unumgänglich bei der Errichtung einer räumlichen Abtrennung von einem der Altäre. Möglicherweise waren die 1556 gestifteten Fenster eine Gegenleistung Philipps II. für die Kirche, die der Anfertigung der Kopie des Genter Altares zustimmen musste. Zumindest erscheint eine solche Annahme verlockend, obschon es sich dabei um reine Spekulation handelt.

Die Abrechnungen aus St. Bavo enthalten neben den üblichen Unterhaltskosten für den Gottesdienst eine Reihe von Einträgen, welche die drei Buntglasfenster direkt betreffen. ${ }^{475}$ Darin aufgeführt ist auch der Vermerk für die Anschaffung von zwei Stapeln großformatiger Bögen Papier, die eventuell für die
Anfertigung der Entwürfe zu den Fenstern gedient haben könnten. Zwar enthält die Quelle keine genaueren Aussagen über die Zuordnung dieser Kosten, das heißt den Zweck der erworbenen Materialien; dennoch ist es denkbar, dass sie die Arbeiten Coxcies betreffen. Dieser könnte sich, parallel zu seiner Beschäftigung mit der Kopie, auch mit der Anfertigung der Entwürfe für die Fenster befasst haben und mit der Überwachung der sich daran unmittelbar anknüpfenden Ausführung durch eine lokale Bleiglaserwerkstatt betraut gewesen sein. ${ }^{476}$ Indizien dafür liefert ein ähnlicher Auftrag Coxcies in den 1540er Jahren. Dabei handelt es sich um weitere Fenster, dieses Mal in St. Gudula in Brüssel, die ein bereits vollendetes Fenster des kurz zuvor verstorbenen Bernard van Orley ergänzen sollten. Beide Fenster, das des Lehrers wie auch die daran sich orientierenden Michiel Coxcies, haben sich erhalten. Auch für diesen Auftrag, der ebenfalls von seinen habsburgischen Mäzenen erteilt worden war, hatte der Maler zeitweilig umziehen müssen; von seiner Heimatstadt Mecheln nach Brüssel, um die Arbeiten unmittelbar vor Ort beaufsichtigen zu können und möglicherweise auch hier die Entwürfe an die örtlichen Gegebenheiten anzupassen. ${ }^{477}$

Die Kopie des Altaraufsatzes von Michiel Coxcie umfasst, mit Ausnahme der Stifterbildnisse, die er durch zwei weitere Grisaillen mit Darstellungen von Evangelisten ersetzte, das komplette Programm des Genter
473 SuYKERBuYK 2017, S. 75 nach VANDEN BEMDEN 1993, S. 150 f.

474 Für eine Auflistung der Literatur seit dem 19. Jh., in der diese These aufgegriffen wird s. SUYKERBUYK 2017, Anm. 22.
475 Vgl. SuYKerbuYK 2017, Appendix IV (Rechnungsführung zur hölzernen Abtrennung in St. Bavo [Gent, Februar 1557]).

476 Vgl. SUYKERBUYK 2017, S. 76.

477 Vgl. JONCKHEERE - SUYKERBUYK 2013, S. 30. 
Altares. Stilistisch ahmen die neuen Darstellungen den Stil des Jan van Eyck nach, zeigen aber durch die Verwendung des Kontrapostes bei den Figuren auf ein zeitgenössisches Stilmittel. Lange Zeit wurde angenommen, dass die heute fehlenden Tafeln mit den nackten Gestalten von Adam und Eva ausgespart worden seien. Diese Figuren seien auf den Wunsch Philipps II. nicht kopiert worden, da dieser sich aus Gründen der Pietät oder gar Prüderie daran gestoßen habe. ${ }^{478}$ SUYKERBUYK nennt mehrere Argumente, die diese Hypothese in einem neuen Licht erscheinen lassen. Die Annahme einer Prüderie des Königs, die vermutlich von einer idealisierten Vorstellung des katholischen Herrschers herrührt, sei nicht aufrechtzuerhalten, wenn man einen anderen Auftrag, nämlich die erotische Poesie-Serie, die Philipp von Tizian hatte anfertigen lassen, berücksichtigt. Die Folge ist ungefähr in derselben Zeit entstanden, in der angeblich die Darstellung von Adam und Eva aus den oben genannten Gründen durch den König abgelehnt worden sei. Dabei ist allerdings zu bedenken, dass diese Serie nicht für die fromme Kontemplation bzw. den Gottesdienst gedacht war, während die Kopie des Retabels tatsächlich im funktionellen Zusammenhang des Originals, als Aufsatz eines Altares, verwendet werden sollte. Eine Ablehnung von Nacktheit im Zusammenhang mit religiösen Darstellungen, wie sie 1570 unter anderem auch von der Mechelner Synode gefordert werden sollte, ${ }^{479}$ bedeutet nicht zwangsweise auch, dass der Monarch in einem profanen Kontext, das heißt in einem intimeren Umfeld außerhalb des Hofzeremoniells und der kirchlichen Liturgie, als ,prüde‘ gegolten haben muss. Gegen die These, die Tafeln von Adam und Eva seien im Auftrag Philipps nicht kopiert worden, führt SUYKERBUYK außerdem die durchaus plausible Erklärung an, dass die beiden Tafeln des Originals mit den nackten Stammeltern in der Mitte des 16. Jahrhunderts so populär gewesen seien, dass sie dem Retabel seinen landläufigen Namen eintrugen und selbst in den spanischen Rechnungen zu Coxcies Kopie ist die Bezeichnung „el retablo de Adam y Heva“ zu lesen ist. ${ }^{480}$ Es sei daher unwahrscheinlich, dass die beiden Bilder ausgespart wurden, da eine Übertragung dieses spezifischen Namens für das Original auf die Kopie dann schlichtweg keinen Sinn ergeben würde. Stattdessen sei anzunehmen, dass die beiden Bilder vom Rest des Altares in späterer Zeit getrennt wurden, da der Altar Mitte des 17. Jahrhunderts veräußert und, in seine Einzelteile zerlegt, im frühen 19. Jahrhundert auf dem Kunstmarkt weiterverkauft wurde. Zwei Darstellungen, die offenbar dem Vorbild Jan van Eycks folgen und die sich heute in Saragossa befinden, ${ }^{481}$ sind jedoch nicht als die fehlenden Tafeln mit Adam und Evan von Coxcie zu identifizieren, wie teilweise angenommen wurde. Problematisch an einer solchen Zuweisung ist, dass es sich um ein ganz anderes Format als bei der Kopie des Retabels handelt. Die anderen Tafeln von Coxcie Kopie

481 Im Besitz der Real Sociedad Económica Aragones de Amigos del País in Saragossa.
479 s. hierzu Abschn. 4.1.

480 Vgl. BuCHanan 1999, S. 137 u. 151, Nr. 59/60

u. PÉrez de Tudela 2013, S. 113, Anm. 32. 
entsprechen ziemlich genau den Ausmaßen des Originals. ${ }^{482}$ Möglicherweise sind die Darstellungen von Adam und Eva im Laufe der Zeit abhandengekommen; die beiden heute in Saragossa befindlichen Bilder könnten entweder eine weitere Kopie aus der Werkstatt Michiels Coxcies oder das Werk einer anderen, möglicherweise spanischen Werkstatt darstellen, die in einem kleineren Maßstab wiederum dem Vorbild der berühmten Kopie folgt.

Eine andere These, die von KEMPERDICK referiert wird, stellt die angebliche Nichtübernahme der Tafel mit den Stammeltern wegen ihrer Nacktheit in den Kontext eines angeblich veränderten Decorum infolge des Konzils von Trient, nach welchem solche Darstellungen nicht näher genannten neuen Bestimmungen widersprochen hätten und deshalb, wie oben erwähnt, auf ausdrückliche Anordnung des Königs hin gar nicht erst kopiert worden seien. ${ }^{483}$ Jan REDZINSKI weist darauf hin, dass ein Fehlen der beiden Tafeln mit den Stammeltern dazu geführt hätte, dass der Aufbau der Kopie nicht mehr dem des Genter Altars entsprach, da das Fehlen der Tafeln dazu geführt hätte, dass die beiden mittleren Bildfelder der Verkündigungsszene im geschlossenen Zustand durchbrochen gewesen wären und das dahinterliegende Bild Gottvaters, das beim Original nur im geöffneten $\mathrm{Zu}$ stand zu sehen ist, ständig sichtbar gewesen

482 Zuerst Michiel Coxcie zugewiesen von STEPPE 1990, S. 39; später der Kopie des Genter Altares für Philipp II. zugewiesen (vgl. CHECA CREMADES 1998, S. 478), was zuletzt von SUYKERBUYK 2013, S. 7-10 und KEMPERDICK 2014, S. 47 dementiert wurde.

483 Vgl. KEMPERDiCK 2014, S. 47 f.

484 Vgl. REDZINSKI 2017, S. 85 f. u. Abb. 50. wäre. Er verweist auf eine Reproduktion des 19. Jahrhunderts, eine Lithographie von 1836, die genau dieser Theorie folgt und das Retabel in diesem merkwürdigen Zustand wiedergibt. ${ }^{484}$ Die beiden Bilder, die hierdurch verloren gegangen wären, dasjenige mit dem Fensterausblick und das mit der mehrfach kopierten Waschnische, hätte es in der Kopie dann nicht geben können. ${ }^{485}$ Dem ist jedoch nicht unbedingt zuzustimmen, da eine weitere Möglichkeit darin besteht, dass diese Tafeln vorhanden, aber mit einem anderen Motiv auf der Rückseite bemalt waren. Den Beweis für eine Existenz von Tafeln, die die beiden Stammeltern zeigen, liefert das von Pantoja de la Cruz im Jahr 1600 angelegte Inventar der Kunstwerke des Alcázars von Madrid, in dem das Retabel sehr eindrücklich und ausführlich beschrieben wird. ${ }^{486}$ Eva und Adam werden hier ausdrücklich als desnudo bzw. desnuda bezeichnet, was eine frühere Überlegung, dass die beiden Figuren teilbekleidet wiedergegeben worden sein könnten, ebenfalls wiederlegt. ${ }^{487}$ Diese Information erklärt jedoch nicht, weshalb die beiden Tafeln zu einem späteren Zeitpunkt verschwunden sind. Weiterhin sei dem Inventar nach zur selben Zeit in der Sakristei ein Bild Tizians zu sehen gewesen, das ebenfalls nackte Figuren gezeigt habe. ${ }^{488}$

485 Vgl. SANDER 2008, S. 192-202, MusPer 1961, S. 50; 226 u. BALDASS 1953, S. 7-26.

486 Abgedr. u. a. bei SÁNCHEZ CANTÓN 1958, S. 29, fol. 32, Nr. 103. Vgl. auch REDZINSKI 2017, S. 86.

487 Vgl. REDZINSKI 2017, S. 88.

488 s. hierzu SÁNCHEZ CANTON 1958, S. 34, fol. 32, Nr. 125 sowie REDZINSKI 2017, S. 88 nach 
Das unter Isabella und Ferdinand entstandene Staatskirchentum habe einige der Reformen, die das Konzil von Trient erst über ein halbes Jahrhundert später aufnahm, bereits 1478 auf dem spanischen Nationalkonzil von Sevilla vorweggenommen. Interessant in diesem Zusammenhang ist, dass Philipp II. die Beschlüsse von Trient in Spanien, wo er als Monarch bedeutend größeren Einfluss auf ,seine' aus der Reconquista hervorgegangene ,Staatskirche' hatte, sehr viel zögerlicher umsetzte als in den Niederlanden. ${ }^{489}$ Da das Bilderdekret des Konzils erst in der letzten Sitzungsperiode von 1563 behandelt wurde, kann schließlich auch das Postulat eines veränderten Decorum zu der Zeit als Coxcie die Kopie des Genter Altars anfertigte, nicht aufrecht erhalten werden.

Die Kopie wurde 1558-1559 vollendet und erst 1563 auf Philipps Veranlassung nach Madrid überführt, obwohl eine andere Quelle die Ankunft im Alcázar in Madrid bereits für den 4. Oktober 1559 überliefert. ${ }^{490}$ SUYKERBUYK betont, dass diese Angabe insofern stimmig erscheint, als dass sie ungefähr mit der Rückreise Philipps aus den Niederlanden nach Spanien im August desselben Jahres

MulCAHY 2010, S. 22 f. Es sei auf letztere Monographie von MULCAHY hingewiesen, die sich dem Selbstverständnis Philipps II. als Sammler und ,Patron der Kunst' widmet.

489 Vgl. REDZINSKI 2017, S. 88 nach Weiß 2005, S. $24 \mathrm{f}$.

490 AGS, Tesoro, inv. 24, leg. 564 (veröffentl. von Pérez des Tudela 2013, S. 113, Anm. 32).

491 Für die Quellendokumentation s. Suykerbuyk 2017, Anm. 50 u. für die Maße der Kopie des Retabels s. KEMPERDICK - RÖßLER 2014b, S. 145, 150 u. CHECA CREMADES 1998, S. 478 bzw. Kat. Nr. 146.

492 Hierzu SUYKERBUYK 2017, S. 78. übereinstimmt. Allerdings ähnelt der Wortlaut in dieser Quelle, welche die Kopie nicht explizit erwähnt, einer Nachricht aus dem Jahr 1563, die ihrerseits die Ankunft eines großformatigen Retabels $(350 \times 242 \mathrm{~cm})$ im Königlichen Palast von Madrid vermeldet; laut SUYKERBUYK entsprechen dessen Maße ungefähr denen der Kopie des Genter Altars. ${ }^{491}$ Die These einer späteren Überführung nach Madrid würde auch mit den Angaben in der 1559 von de Heere verfassten Ode, nach welcher das Retabel zunächst in Valladoid aufgestellt worden sei, übereinstimmen. ${ }^{492}$ In der Kapelle des Palastes in Madrid sei das Retabel dann (erneut?) gerahmt und mit einem Gesprenge versehen worden, welches dem des Originals ähnlich gewesen sei. ${ }^{493}$ An diesem Standort sei das Retabel dann zumindest bis zur Mitte des 17. Jahrhunderts verblieben und wahrscheinlich lange Zeit von der Herrscherfamilie hochgeschätzt worden, wie eine im Maßstab verkleinerte Kopie der Maria in der privaten Sammlung nahelegt. ${ }^{494}$ Erst in den 1660 er Jahren wurde Coxcies Kopie durch Raffaels Kreuðtragung Christi (1515-1516), die die könig-

493 Vgl. PÉrez des Tudela 2013, S. 104 u. STEPPE 1990, S. 34.

494 Diese Information zur Aufstellung ist bei Vincente Cadurcho: Diálogos de la pintura (1633) und Francisco Pacheo: Arte de la pintura (1638) zu entnehmen (s. SUYKERBUYK 2017, Anm. 53). Außerdem ist das Retabel im selben Zeitraum mehrfach restauriert worden (vgl. SUYKERBUYK 2017, S. 78; PÉrEZ DE TudeLa 2013, S. 104, 114, Anm. 37 u. 38; STEPPE 1990, S. 37). Für die Kopie mit der Darstellung der Hl. Jungfrau s. PÉREZ DE TUdeLA 2013, S. 104, ähnlich STEPPE 1990, S. 37. 
liche Familie aus Sizilien erwerben konnte, ersetzt. ${ }^{495}$ Danach fehlen Nachrichten über den weiteren Verbleib des Werkes. PÉREZ DES TUDELA geht von einer allmählichen Zerteilung desselben aus. Erst während der napoleonischen Herrschaft taucht es 1808 wieder auf, wird nach Brüssel verbracht und dort auf dem Kunstmarkt, offenbar in seine Einzelteile zerlegt, angeboten. In der Folge gelangten die Tafeln in unterschiedliche Sammlungen. So erwarb König Maximilian von Bayern 1820 die beiden Tafeln mit Maria und Johannes dem Täufer; sie befinden sich heute in der Alten Pinakothek in München. ${ }^{496}$ Zur selben Zeit erwarb Friedrich-Wilhelm III. von Preußen die Tafel mit der Anbetung des Lammes und die mit Gottvater, die sich heute in der Berliner Gemäldegalerie befinden. ${ }^{497}$ Nur die Seitenflügel, die eine Zeit lang im Besitz Wilhelm II. von Oranien waren, wurden 1861 an den Belgischen Staat veräußert, nachdem die ursprünglichen Seitenflügel des Genter Altares nach Berlin verkauft worden waren, sodass man die verbliebene Mitteltafel von van Eycks Altar in Gent mit den Seitenflügeln Coxcies versah. ${ }^{498}$ Erst in Folge der Bestimmungen des Friedensvertrages von Versailles kehrten nach dem Ersten Weltkrieg die originalen Seitenflügel zurück nach Gent, während die beiden Seitenflügel Coxcies ihren Eingang in die Sammlung der Königlichen Museen für Schöne Künste in

495 Öl auf Leinwand (urspr. auf Holz), $318 \mathrm{~cm}$ $\times 229 \mathrm{~cm}$, Prado, Madrid, Inv.-Nr. P000298. Auch unter dem Titel Il Spasimo di Sicilia bekannt (erstmals erwähnt im Inventario Palacio Real de Madrid, III, Madrid, 1686, S. 12; Kat. Prado 1985, S. 526 f. u. zuletzt bei DAL BELLO 2012, S. 84 f.; s. auch REDZINSKI 2017, S. 88).

496 Alte Pinakothek, München, Inv.-Nr. 5789 u. 5790.
Brüssel fanden. ${ }^{499}$

In Bezug auf die Motive und deren Platzierung im Bildraum hält sich auch Michiel Coxcies Kopie der Anbetung des Lammes [ABB. 97], der zentralen Darstellung des Genter Altares, streng an das Original des Jan van Eyck [ABB. 96]. Das zeigt sich in der identischen Anordnung der Figuren, die das zentral dargestellte Lamm Gottes auf dem Altar umstehen. Auch der Lebensbrunnen am unteren Bildrand sowie die Vegetation - Bäume und Büsche in vollem Laub, die den Mittel- vom Hintergrund trennen - stimmen hinsichtlich Gestalt und Position im Bild überein. Entsprechend verhält es sich auch mit der Stadtarchitektur und der Landschaft des Hintergrundes, die in Blautönen gehalten ist. Hierin zeigt sich aber auch einer der wesentlichen Unterschiede zwischen dem Original und der Kopie Michiel Coxcies, welche die technische Umsetzung betrifft: Das Original zeigt einen hohen Grad von Detailgenauigkeit, die selbst bei der Darstellung entfernter Landschaftsformationen und Gebäudestrukturen erhalten bleibt und die es ermöglicht, selbst Ausschnitte des Hintergrundes von nahem gleichsam wie durch eine Lupe zu betrachten, ohne dadurch ein Nachlassen der zeichnerischen Präzision beobachten zu können. Anders verhält es sich bei der Kopie, die zwar in der Gesamtschau

497 Gemäldegalerie, Berlin, Inv.-Nr. 524 u. 525.

498 Vgl. SuYbKerbuYK 2017, S. 79 u. KemperDICK - RÖßLER 2014b, S. 84 u. 139-149.

499 Koninklijke Musea voor Schone Kunsten, Brüssel, Inv.-Nr. 6696-6701. Vgl. WAAGEN - DE BAST 1825, S. 45 f. u. HINTERDING - HORSCH 1989, S. 12 u. 74 f. 
bei einer Betrachtung aus der Distanz verblüffende Ähnlichkeit suggeriert, sich im Hinblick auf das Detail jedoch als unschärfer erweist. Die Wiedergabe der Architektur und der Landschaft im Hintergrund erscheint in den Farben blasser und auch deutlich weniger stark konturiert, was eine gewisse, Weichzeichnung' gegenüber dem Vorbild erkennbar werden lässt. Am deutlichsten wird die gegenüber dem Original zurückgenommene, feinmalerische' Detailliertheit bei der Gruppe von heiligen Jungfrauen rechts und der der heiligen $\mathrm{Bi}$ schöfe und Geistlichen links, deren zuvorderst dargestellten Figuren noch deutlich feiner akzentuierte Gesichtszüge aufweisen, während die dahinterliegenden Gesichter kaum mehr voneinander unterschieden sind.

Anders verhält es sich bei den Figuren des Vordergrundes - den Patriarchen und Propheten des Alten Testaments und den Heiden, die das Kommen Christus vorausgesehen haben, auf der linken und den Aposteln und den in deren Nachfolge stehenden Hirten der Kirche auf der rechten Seite, die sich wiederum streng an das Vorbild halten und den Versuch des Malers erkennen lassen, bei der Gestaltung von Anatomie, Gewändern und Gesichtern dem Vorbild zu entsprechen. Doch auch hier zeigt sich im Detail die technische Verschiedenheit der Kopie von dem Original. Zwar handelt es sich um eine identische Wiedergabe, die schablonenartig all das reproduziert, was auch bei van Eyck zu sehen ist, doch sind dabei sehr viel weniger Details wiedergegeben. Deutlich wird dies erneut in den weicheren Konturen, die sich zum Beispiel im weniger stark betonten Faltenwurf der Gewänder zeigen - etwa bei den Propheten auf der linken Seite [ABB. 96a-97a]. Auch ein Blick auf die aufgeschlagenen Codices, die von heidnischen und jüdischen Gelehrten in der vorderen Reihe gehalten werden, zeigt, dass bei van Eyck einzelne Zeilen erkennbar und die Initialen, die die einzelnen Absätze einleiten, sogar deutlich lesbar sind. Coxcie deutet die Schrift hingegen nur an, sodass vom distanzierten Betrachterstandpunkt aus derselbe Eindruck entsteht wie vor dem Original, bei dem die einzelnen Buchstaben auch nur aus größter Nähe entziffert werden können. Weiterhin sind es Objekte wie Gürtelschnallen, die goldbestickten Krägen und Säume der Rauchmäntel bei den Päpsten rechts sowie deren Papstkronen, Pektorale, Mantelschließen und Bischofsstäbe, das heißt alle Gegenstände, die aus Edelmetall sind, aber auch die darin eingesetzten Edelsteine, die bei Jan van Eyck in großer Stofflichkeit wiedergegeben werden, die ihre Materialität nicht nur zu illusionieren sucht, sondern durch den reichen Gebrauch von Blattgold sogar authentisch wiedergibt. Zahlreiche verzierende Punzen sowie die mit Weißhöhungen zum Funkeln gebrachten Edelsteine verleihen dem,Gepräge' eine illusionistische Wirkung [ABB. 96b]. Bei Coxcie fehlt das Blattgold und wird durch vergleichsweise matte Farben ersetzt [ABB. 97b]. Auch die mit durchscheinendem Blattgold gestaltete Aufschrift „ECCE AGNVS DEI QUI TOLLIT PEC[CAT]A MVNDI“ auf dem Antependium, das bei van Eyck einen bestickten roten Brokatstoff vor Augen bringt, fehlt bei Coxcie mutmaßlich deshalb, weil er von der hierfür verwendeten Technik bei seiner Kopie keinen Gebrauch macht. Viele Details, wie das 
metallene Wasserspiel des Lebensbrunnens oder aber die beiden Weihrauchfässer, die von den Engel unmittelbar unterhalb des Altares geschwenkt werden, verlieren gegenüber dem Vorbild ihre herausstechende Wirkung, die der Polimentvergoldung desselben geschuldet ist. ${ }^{500}$ Die technisch einfachere und kostengünstigere Methode der Ölvergoldung, derer sich Coxcie bediente, stellt damit einen weiteren Grund dafür dar, weshalb die Kopie, neben den genannten Gründen der weniger detaillierten, eher malerischen Auffassung bei der Wiedergabe der Details und der Ausrichtung auf eine Wirkung aus der Distanz, weniger ,naturalistisch“ wirkt; ja sogar die hierfür grundlegenden technischen und handwerklichen Eigenschaften ein stückweit verwirft, indem Coxcie etwa - vielleicht auch einem straffen Zeitplan geschuldet - weniger Aufwand in die Ausgestaltung von Details investierte, die immerhin einen ganz entscheidenden Reiz bei der Wirkung das Originals ausmachen, und sich unter anderem statt echtem Gold für Ölfarbe entschied.

Außer dem für heutige Augen zunächst nachteiligen Effekt, den diese gegenüber dem Original veränderte Technik für die Gesamtwirkung des Bildes erzeugt, können möglicherweise auch Aspekte wie der Zeitgeschmack oder kunsttheoretische Überlegungen eine Rolle gespielt haben, sodass der Verzicht auf den technischen Aspekt der Vergoldung von bei Zeitgenossen möglicherweise sogar positive Aufnahme fand, weil es den
Versuch beschreibt, mit ,rein malerischen' Mitteln und der Wirkung von Farbe eine Annäherung an die mit dem Blattgold erzielten Effekte des Originals zu erreichen. So empfiehlt etwa Alberti, dass der Wirkung von Farbe und der Fertigkeit, damit die Wirklichkeit illusionistisch darzustellen, der Vorzug gegenüber dem reinen Materialwert, das heißt dem Gebrauch von Blattgold, zu geben sei. ${ }^{501}$ Zugleich zeigt es aber auch die Suche des Künstlers nach einer Möglichkeit, die ihm nicht vertraute Technik der Polimentvergoldung, die überdies inzwischen als unzeitgemäß galt, zu ersetzen. ${ }^{502}$

Neben de Heeres Lobpreis auf Philipp II., den Genter Altar, dessen Schöpfer Jan van Eyck und indirekt auch den Kopisten Coxcie enthält auch Guicciardnis Discrettione di tutti $i$ Paesi Bassi von 1567 eine Erwähnung der Kopie und der Kosten, ${ }^{503}$ die unter anderem für die Verfertigung wie auch für das Material aufgewandt werden mussten. Die darin anklingende Betonung des Materialwertes steht in einem gewissen Spannungsverhältnis zu den oben gemachten Beobachtungen und dem Verzicht einer kostspieligen Polimentvergoldung nach dem Vorbild des Originals. Offenbar waren die Kosten dennoch eine Information, die für die zeitgenössische Leserschaft von Bedeutung war. Er beschreibt, dass das Werk nach seiner Vollendung einem Komitee, bestehend aus Kunstexperten, vorgeführt wurde, die festzustellen hatten, ob es sich tat-

503 Vgl. SUYKerbuYK 2017, Appendix IV (Rechnungsführung zur hölzernen Abtrennung in St. Bavo [Gent, Februar 1557]).
500 Vgl. PutzGer 2019, S. 81 f.

501 Vgl. BÄtsCHMANN - SCHÄUBlin 2000, S. 290 f.

502 Vgl. PutzGER 2019, S. 83. 
sächlich um eine gelungene Kopie des Originals von van Eyck handelte. ${ }^{504}$ Laut Guicciardini sei Coxcie im Endeffekt sogar reichlicher, als ursprünglich vereinbart worden war, durch Philipp II. entlohnt worden. ${ }^{505}$ Unabhängig davon, ob die Information der Wahrheit entspricht, kann angesichts dessen durchaus darauf geschlossen werden, dass das Werk den Erwartungen des Komitees entsprach und auch die Wünsche Philipps II. voll befriedigen konnte, aber auch ein größeres Publikum kunstinteressierter Niederländer zu beeindrucken im Stande gewesen sein muss.

Die an Michiel Coxcie ausgezahlte Summe wird tatsächlich an keiner Stelle in den Archivalien erwähnt. ${ }^{506}$ Die einzige von SUYKERBUYK angeführte Quelle stellt eine Korrespondenz zwischen dem König und seinen ,Finanzbeamten“ von 1557 dar. Coxcie wird hier als „Maestre Miguel de Coxies, pintor, para en quente del retable de Gante del Adam y Heva" bezeichnet und Zahlungen im Umfang von „166 Escudos“, „24 Placas“ (etwa 300 Gulden) sowie weiteren „1333 Escudos“, „12 placas“ (etwa 2400 Gulden) erwähnt. ${ }^{507}$ Die Endsumme entspricht also der 1556 vertraglich vereinbarten Gesamtsumme, die Coxcie für einen erfolgreichen Abschluss seines Auftrages erhalten sollte.

504 Vgl. SUYKERBUYK 2017, S. 77.

505 Vgl. Guicciardini 1567, S. 97 (abgedr. bei SUYKERBUYK 2017, Appendix VII).

506 Diese Archivalien wurden veröffentlicht von BUCHANAN 1999, S. 151, Anm. 59 u. 60; RoOBAERT 2005, S. 191 f., Anm. 97 u. 98 sowie zuletzt bei PÉREZ DE TUdela 2013, S. 113, Anm. 30.

507 „A maestre Miguel de Coxies pinto ccc florines.“ (AGS, Estado, leg. 513, fol. 32 vom 14.
Von dem starken Interesse Philipps II. an der Kopie berichtet auch Marcus van Vaernwyck 1568. Ihm zufolge war es der ausdrückliche Wunsch des Königs, dass die Krone der Jungfrau in Azurit gemalt werde, ein mineralisches Pigment, das er während des Türkenkrieges hatte in Augenschein nehmen können. Die Farbpigmente sollen von Tizian aus Venedig übersandt worden sein, da die Stadt Handelsbeziehungen mit den Türken unterhalten habe. ${ }^{508}$ Coxcies Kopie wird auch von Giorgio Vasari in der zweiten Auflage seiner Künstlerviten von 1568 berücksichtigt, ${ }^{509}$ nachdem er seine persönliche Bekanntschaft mit Coxcie, die er in den 1530er Jahren in Rom gemacht haben will, bereits in der Erstauflage erwähnt hatte. Die große Beachtung, die er in seiner Heimat mit der Kopie des berühmten Werkes des Begründers der niederländischen Malereitradition fand, führte möglicherweise dazu, dass er als einziger noch lebender Maler in die Effigies pictorum (1571) des Dominicus Lampsonius aufgenommen wurde. ${ }^{510}$ Das darin enthalte Portrait Coxcies, ein Kupferstich von Simon Frisius, wird später von Hendrick Hondius erneut herausgegeben und enthält eine Beischrift, die seine Fähigkeiten lobt und

November 1556 (abgedr. bei SUYKERBUYK 2017, Anm. 37).

508 Vgl. van Vaernwyck 1568, fol. 117v (abgedr. bei SuYKERBUYK 2017, Appendix VIII). Das Pigment wird in der Literatur häufiger als Ultramarin interpretiert, so auch bei WOOLLETT 2012, S. 83 u. PÉrez De Tudela 2013, S. 103. Vgl. auch SUYKERBUYK 2017, Anm. 42.

509 Vgl. Vasari 1568, Bd. VII, S. 585.

510 Vgl. SUYKERBUYK 2017, S. 78. 
ihn sogar mit Zeuxis von Herakleia vergleicht. ${ }^{511}$ In dieser Reihe von Autoren steht schließlich auch Karel von Mander, der in seiner Beschreibung des Lebens der Brüder van Eyck in seinem Schilder-Boeck von 1604 die Kopie von Coxcie erwähnt. Er überliefert hier auch die Anekdote über das angeblich von Tizian beschaffte Azurit, die er höchstwahrscheinlich von van Vaernwyck übernommen hat. Van Mander ist es auch, der Coxcie im Wesentlichen als Kopisten der Werke Raffaels bezeichnet. Neben der Nennung der Kopie des Genter Altares mag dies ein weiterer Grund für die spätere Bewertung von Coxcies Werk als das eines Kopisten gewesen sein. ${ }^{512}$ Die einleitenden Worte des von Lucas de Heere im Juli 1559 anlässlich der in St. Bavo stattfindenden Versammlung des Ordens vom Goldenen Vlies verfassten Lobgedichtes rühmen das Werk des Meisters van Eyck, den Genter Altar sowie Philipp II. von Spanien, der nicht nur als Souverän der Niederlande und Vorsitzender des Ordenskapitels auftrat,

511 „COEXIUS Illustris pictor mechlinia cujus / Patria, doctorum quae fuit artificum. / Hic magno pinxit. name Zeuxis creditur esse: / carus divitibus, princibúsque Viris." (Kupferstich von Simon Frisius, $20,5 \times 126,6 \mathrm{~cm}$ (ganzes Blatt), Text von Lampsonius [?], um 1610; Rijksmuseum, Amsterdam, Inv.-Nr. RP-P-1907-357; New Hollstein Dutch 162-1[2]).

512 Vgl. van Mander 1604, fol. 200v (abgedr. bei SUYKERBUYK 2017, Appendix X).

513 Vgl. JONCKHEERE 2012, S. 7.

514 Vgl. De Heere, Lucas: Den hof en boomgaert der poësien, Gent 1565, S. 35-38; MELION 1991, S. 129.

515 „Kommt herbei, ihr Kunstliebhaber aus allen Geschlechtern, / und betrachtet diesen köstlichen Schatz, dieses Pfand, / gegen das ihr des Krösus Reichtum als Nichts sollt achten: / sondern auch als Liebhaber der altniederländischen Meisterwerke bekannt war: ${ }^{513}$ Erst 1565 wurde die Ode schließlich von de Heere publiziert, nachdem sie bereits viele Jahre auf einem am Retabel befestigten Schild zu lesen gewesen war. ${ }^{514}$ Sie beginnt mit einem Appell, indem er zur Betrachtung des herausragenden Kunstwerkes auffordert: „Lest zuerst, versteht, und betrachtet dann das Werk", heißt es sinngemäß in der Ausgabe von 1565: „Comt hier ghi const beminders van alle gheslachten, / En besiet desen costelicken schat oft pant, /Waerbi ghi Croesus rijcdommen niet en zult achten: / Want tis eenen hemelschen schat in

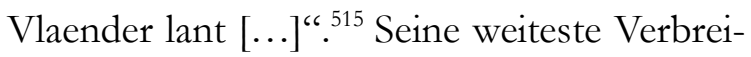
tung fand die panegyrische Ode jedoch erst durch ihren Abdruck in van Manders SchilderBoeck. ${ }^{516}$

Diese Ode an ein damals bereits über 100 Jahre altes Kunstwerk, das sich zur Zeit des 23. Kapitels des Ordens in einem tadellosen Zustand befunden haben muss und mit seinen leuchtenden Farben großen Eindruck erwecken konnte, ${ }^{517}$ ist zugleich ein indirektes

Denn dies ist ein himmlischer Schatz im Flandernland“ (Ode anlässlich des 23. Kapitel des Ordens vom Goldenen Vlies in St. Bavo von Lucas de Heere, Juli 1559, zit. nach de Heere, Lucas: Den hof en boomgaert der poësien, Gent 1565, S. 35, zit. nach der Übers. von KEMPERDICK 2014, S. 9).

516 Vgl. MiedeMA 1995, Bd. 2, S. 211. Bei van Mander wird dieser Text erwähnt (s. van Mander 1604, fol. 201r). Ursprünglich zu lesen bei Lucas de Heere: Den hof en boomgaerd der poësien, Gent 1565, S. 25-38.

517 Eine Reihe restauratorischer Maßnahmen ist belegt, die allerdings erst nach der Kapitelversammlung in St. Bavo stattgefunden haben. Lancelot Blondeel und Jan van Scorel, wurden 1550 beauftragt, das durch die vor ihm gefeierten Messen verrußte Retabel zu reinigen (s. 
Künstlerlob, mit dem de Heere, selbst Maler, den im 16. Jahrhundert als Ahnherrn der flämischen Malerei gefeierten Jan van Eyck zu ehren suchte. ${ }^{518}$ Die Malerei des 15. Jahrhunderts entsprach zwar anderen ästhetischen Vorstellungen als zur Zeit de Heeres, dennoch blieb die altniederländische Malerei für das gesamte 16. Jahrhundert vorbildhaft, wenn es um das Anknüpfen an ältere ikonographische Traditionen oder die Gestaltungsweise ging. ${ }^{519}$ Das Gedicht de Heeres mündet schließlich in ein Herrscherlob, bei welchem auch weiterhin das Retabel im Zentrum steht. So sei es Philipp II. gewesen, der Michiel Coxcie eine Kopie habe anfertigen lassen, die an ihrem Aufstellungsort mit dem Hinweis aus de Heeres Ode: „Van ons Cooninghs liefde, die ic voor ander stelle: / Ende tot Heycus, en Coxyens glorie groot“ ${ }^{520}$ versehen worden war. ${ }^{521}$ Der Monarch war als Kunstsammler bekannt, der eine besondere Vorliebe für die italienische Malerei hatte. ${ }^{522}$ Als Hofmaler der Statthalterin Maria von Ungarn hatte Michiel Coxcie seine Fähigkeiten als Romanist beweisen und seinen Ruhm in den Diensten Philipps weiter vermehren können, sodass es weniger verwundert, dass bereits zu seinen Lebzeiten vom ,flämischen Raffael' die Rede war. Zugleich hatte er sich mit der Kopie von Rogier van der Weydens Großer Kreuzabnahme (1549) für seine

hierzu BORCHERT 1998, S. 16 mit Verweis auf die Beschreibung des Genter Patriziers van Vaernwyck 1566-1568, S. 132). Vgl. auch DHANENS 1965, S. 111.

518 „Ten rechten siet men onder de zulcke verkeeren, / Den princelicken Schilder die dit werck voldé“ (De Heere, Lucas: Den hof en boomgaert der poësien, Gent 1565, S. 30).

519 Vgl. JONCKHEERE 2012, S. 8.
Mäzenin Maria einen Namen hatte machen können. Es kommen hier also gleich zwei Faktoren zusammen, die für eine Beauftragung Coxcies sprechen; zum einen sein Ruf als Vertreter des italienischen Stils und zum anderen seine technische Befähigung, originalgetreue Kopien altniederländischer Meister, sozusagen der Höhepunkte der flämischen Malereitradition, anzufertigen.

Diesen Auftrag hatte nicht zuletzt de Heeres Lobgedicht zu einem Akt der Nachfolge van Eycks stilisiert, indem es den Ahnherren, den Monarchen und den Kopisten Coxcie nennt. In der Malerei Coxcies kulminierte also bereits für seine Zeitgenossen die Verbindung zwischen der altniederländischen Tradition und der Rezeption italienischer Vorbilder. Auch wenn Lucas de Heere davon nicht unmittelbar spricht, klingt dies doch an, wenn er schreibt, dass Tizian, gewissermaßen als Repräsentant der italienischen Malerei, zur Unterstützung des Projekts kostspieliges Ultramarin beigesteuert habe. Die stark gesuchte Verbindung zwischen Jan van Eyck, Michiel Coxcie und Tiziano Vecellio ist zumindest augenfällig. ${ }^{523}$

Die Kopie Coxcies ist nachweislich die erste des berühmten Retabels. Anders als vielfach angenommen wurde, hängt dies nicht zunächst damit zusammen, dass die Kanoniker

520 Vgl. de Heere, Lucas: Den hof en boomgaert der poësien, Gent 1565, S. 35-38 (abgedr. bei MiEDEMA 1995, Bd. 2, S. 211 f.; ferner hierzu DHANENS 1965, S. 107).

521 Die Verwahrung der Kopie in Spanien erwähnt de Heere nur kurz und unbestimmt:

„Dees copie is in Spaignen (op dat ict vertelle)“, s. de Heere 1565, S. 32.

522 Vgl. SuYKERBUYK 2017, S. 72.

523 Vgl. Miedema 1994, Bd. 1, S. 63-67. 
von St. Bavo nur ausnahmsweise eine Genehmigung erteilten, Zeichnungen nach dem Werke anzufertigen. ${ }^{52}$ Die Detailstudien Gerard Davids belegen, dass durchaus die Möglichkeit bestand, Zeichnungen vor dem Kunstwerk anzufertigen. Der Hinweis von Kemperdick, dass es nicht der spätmittelalterlichen Praxis entsprach, vollständige Kopien von den Werken anderer Meister anzufertigen, sondern dass nur einzelne Motive aufgenommen wurden, trifft den Sachverhalt sehr viel eher. ${ }^{525}$ Es ist daher nicht verwunderlich, dass es keine früheren Kopien der Werke van Eycks gibt. Erst Ende des 16. Jahrhunderts tauchen diese, obschon in kleinem Format, vermehrt auf. ${ }^{526}$ Noch von Zeitgenossen des jungen Coxcie, Jan Gossaert oder van Orley, sind keine Kopien bekannt. Vielmehr folgten diese Maler ganz der Tradition, sich nur einzelner Motive zu bedienen, in dem Fall häufig aus Werken Raffaels und der italienischen Druckgrafik des frühen 16. Jahrhunderts. Das Aufkommen von vollständigen Kopien hängt wesentlich mit den im 16. Jahrhundert wachsenden Sammelinteressen zusammen, wie dies etwa am Brüsseler Hof bei Maria von Ungarn zu beobachten ist. ${ }^{527}$ Die auf Massenware für den Export ausgerichteten Werkstätten, vor allem im prosperierenden Antwerpen um die Jahrhundertwende, weisen vergleichbare Tendenzen auf. Ein Beispiel stellt das vielfach nachgeahmte Abendmahl von Dirk Bouts (14641467) aus Löwen dar. ${ }^{528}$

524 Vgl. KeMPERDICK 2014, S. 46 mit Verweis auf DUVERgER 1954, S. 55 u. MENSGER 2000, S. 45.

525 s. KEMPERDICK 2014, S. 46.

526 Vgl. ebd., Anm. 156.

527 Zur Sammlung der Statthalterin Maria von Ungarn s. VAN DEN BOOGERT 1993, passim.
Neben der 1558 vollendeten Kopie Coxcies entstand unmittelbar nach den beiden Bilderstürmen in Gent 1566 und 1578 in Folge des Anschlusses der calvinistischen Genter Republik an die Utrechter Union eine weitere Kopie des Meisterwerks, ${ }^{529}$ das nur mit großen Schutzmaßnahmen die Zerstörungen der „ikonoklastischen Esel“ ${ }^{\text {“530 }}$ hatte überstehen können. Anders als Coxcies Werk ist diese zweite Kopie, die wohl um 1590 entstanden sein könnte, auf Leinwand gemalt, hielt sich aber stärker an das Vorbild, indem sie auf die bei Coxcie gezeigten Portraits des Künstlers und der habsburgischen Regenten verzichtete. Da diese Kopie über keine Alltagsseite verfügt, vermutet Kemperdick, dass sie das Original an einer bestimmten Stelle ersetzen sollte. Nachdem der Genter Altar in die nach den bilderstürmerischen Unruhen wiederhergestellte Vijd-Kapelle 1585 aus der Kapelle des Genter Stadthauses, wo sie sicherheitshalber verwahrt wurde, zurückgebracht worden war, könnte der Auftrag für diese zweite Kopie von Seiten der Stadtregierung ausgegangen sein. ${ }^{531} \mathrm{Zu}$ gleich ist es denkbar, dass dieses gleichsam immer geöffnete Werk eine Reaktion auf die strengen Bestimmungen des Kapitels von St. Bavo hinsichtlich der Wandlungspraxis war, die nun lediglich eine viermalige Öffnung des Retabels im Kirchenjahr vorsahen. ${ }^{532}$ Urheber der möglicherweise für das Stadthaus bestimmten Kopie könnte Michiels Sohn, Raffael Coxcie sein, der als solcher in einem viel

528 Vgl. MARWEDE 2007, S. 82.

529 Vgl. PÉrEZ de Tudela 2013, S. 103.

530 Van Vaernwyck 1566-68, S. 132 u. 147.

531 Vgl. KEMPERDICK 2014, S. 94.

532 Vgl. ebd., S. 94 f. 
späteren Inventar von 1777 genannt wird. ${ }^{533}$ Eine geschäftliche Beziehung zwischen ihm und den städtischen Amtsträgern lässt sich durch ein 1588 verfertigtes Weltgericht für die Genter Schöffen sowie seine Favorisierung für eine ausstehende Restaurierung des Originals im selben Jahr nachweisen. ${ }^{534}$

\subsection{Zur Funktion und Bedeutung von Coxcies Kopien altniederländischer Werke}

Bereits im letzten Drittel des 15. Jahrhunderts galt die Genter Sint Jans-Kirche, ab $1559 \mathrm{Ka}$ thedrale und Hauptkirche des neueingerichteten Bistums von Gent, als eine der wichtigsten Stationen auf dem Besichtigungsprogramm auswärtiger Besucher. Einige der sehr frühen Berichte zeigen explizit ein Interesse am Genter Altar, für den die Stadt bereits wenige Jahre nach dessen Vollendung 1432 berühmt geworden war. ${ }^{535}$ So schrieb der Nürnberger Arzt Hieronymus Münster im März 1495 über das Werk, es sei „mit wundervollem und so kunstreichem Ingenium gemalt, daß du dort nichts Gemaltes, sondern die ganze Kunst des Malens zu sehen meinst, und alles lebendige Bilder zu sein scheinen“. ${ }^{536}$ Diese Beschreibung zeigt, wie die genaue Wirklichkeitswiedergabe der altniederländischen Malerei auf die zeitgenössischen Betrachter wirkte, auch wenn hier Topoi des Künstlerlobes mit in Rechnung ge-

533 Für Informationen zu Michiels Sohn Raffael s. VAN AUTENBOER 1992, S. 14-18.

534 Vgl. KEMPERDICK 2014, S. 50.

535 Die Assoziation des Altarretabels mit seinem ursprünglichen Stifter war höchstwahrscheinlich auch das 16. Jh. über noch bekannt (vgl. stellt werden müssen. Im Hinblick auf rezeptionsästhetische Fragestellungen angesichts einer allmählich sich verändernden Funktion und Bedeutung von sakraler Kunst nach 1500 kann eine solche Äußerung als Ergänzung zu Zeugnissen über den religiösen, das heißt den primären Gebrauch solcher Altarbilder dienen. Wenige Jahrzehnte später, nämlich 1517, schrieb der Italiener Antonio de Beatis kaum weniger rühmend, das Retabel sei ,in Öl gemalt mit solcher Vollkommenheit und Natürlichkeit, sowohl in den Proportionen der Körperteile als auch in der Karnation und der Schattengebung“". Weiter scheute er sich nicht zu behaupten, es handle sich um „das schönste Werk der Christenheit“،.${ }^{537}$ Eine solche Bewertung, ausgerechnet durch einen Italiener, lässt die später von Vasari aufgenommene Idee einer Rolle Jan van Eycks als Stammvater der niederländischen Malerei bereits anklingen. Auch deutet die Verwendung ,maltechnischer' Begriffe den kennerschaftlichen Hintergrund von Antonio de Beatis an. Der Kanoniker aus Melfi und Sekretär des Kardinals Luigi d'Aragona begleitete seinen Dienstherren 1517-1518 auf dessen Reise in die Niederlande und war dort unter anderem Gast des noch jungen Karl V. Zuvor in Italien hatte er Bekanntschaft mit aufstrebenden Künstlern seiner Zeit gemacht, die sich im Umfeld der römischen Kurie bewegten, darunter Leonardo da Vinci. ${ }^{538}$ Der wahrscheinlich populärste Bericht über die Besichtigung

Dhanens 1965, S. 85-118 u. Dhanens 1976, S. 46-48 u. 51-56).

536 HINDRIKS 2017, S. 117, zit. nach DHANENS 1965, S. 102 u. HERZNER 1995, S. 181.

537 Zit. nach DHANENS 1965, S. 102 f.

538 Vgl. BotTineau-FuCHS 2002, S. 143-162. 
der Kirche und des Genter Altares stammt allerdings aus der Feder Albrecht Dürers, welcher das Werk am 10. April 1521 besichtigt hat, wie er in dem sogenannten Tagebuch zu seiner Reise in die Niederlande dargelegt hat: ,[...] das ist ein überköstlich, hoch verständig Gemähl, und sonderlich die Eva, Maria und Gott der Vatter sind fast [sehr] gut. “5539 Aber auch niederländische Autoren des 16. Jahrhunderts widmen sich dem Werk ihres berühmten Landsmanns. So hatte Marcus van Vaernwyck neben seinem Lob für die Kopie Michiel Coxcies auch das Original der Brüder van Eyck als herausragendes Kunstwerk beschrieben. Dieser berichtet, dass neben Dürer auch Hugo van der Goes und Jan Gossaert, - Vertreter zweier unmittelbar aufeinander folgender Generationen flämischer Maler - das Werk ihres ,Ahnherren' gelobt hätten. Wichtiger erscheint jedoch die Information, dass das Werk 1550 von Lancelot Blondeel und von Jan van Scorel restauriert worden sei. ${ }^{540}$ Jüngere technische Untersuchungen haben gezeigt, dass ein Teil des heute erhaltenen Bestandes der Malerei eine Übermalung des 16. Jahrhunderts darstellt, die höchstwahrscheinlich auf diese oder eine spätere Restaurierung zurückzuführen ist, bei der bereits die Kopie Coxcies von 1558/59 als Referenz für Ausbesserungen an fehlenden und stark verschmutzen Stellen des Originals gedient haben könnte, was bisher jedoch nicht eindeutig geklärt werden konnte. ${ }^{541} \mathrm{Da}$ die Kopie Michiel Coxcies gegenüber dem Original gewisse Änderungen

539 Zit. nach UNVERFEHRT 2007, S. 158. Vgl. auch HINDRIKS 2017, S. 117, zit. nach RUPPRICH 1956, Bd. I., S. 168.

540 Vgl. DHANENS 1965, S. 111 zu den Ausführungen van Vaernwycks zu diesem Thema. bei den verwendeten Techniken aufweist etwa durch den Verzicht auf die Vergoldung, ist es denkbar, dass auch die Korrekturen, die während der verschiedenen Restaurierungsmaßnahmen durchgeführt wurden, nicht zwingend exakt dem Originalzustand entsprachen, sondern von den Vorstellungen und Fähigkeiten der jeweiligen Maler abhingen.

Eine wesentliche Frage, der man sich angesichts der Quellen aus drei Generationen nach Jan van Eycks Wirken stellen muss, ist die nach einer Entsprechung des literarischen Lobs in Bezug auf die Rezeption des Künstlers von Seiten anderer Maler. Lässt sich eine solche vermittels erhaltener Werke oder durch Quellen belegen? Die pauschale Antwort darauf fällt zunächst grundsätzlich positiv aus. Die im vorherigen Abschnitt behandelte, im Auftrag des spanischen Königs entstandene Kopie von Michiel Coxcie stellt dabei den Höhepunkt und zugleich auch den Beginn der eigentlichen Rezeption dar. Auch Sandra HiNDRIKS hat, wie schon andere Autoren zuvor, darauf hingewiesen, dass sich die Rezeption des Genter Altares zu Beginn des 16. Jahrhunderts zunächst auf einzelne Motive beschränkte. ${ }^{542}$ Grundsätzlich entspricht dies einer gängigen Praxis, wie sie allgemein für die Werkstätten des 15. und 16. Jahrhunderts angenommen und durch zahlreiche Zitate aus den Werken von Jan van Eyck oder Rogier van der Weyden oder auch Hans Memlings bestätigt wird, wenn man etwa an Werke der beiden

541 Vgl. DubOIs 2017, S. 102-105.

542 Vgl. Hindriks 2017, S. 117 f. Zu den Teilkopien s. KEMPERDICK 2014; MENSGER 2000; DUVERGER 1954 u. STEPPE 1990. 
Nachfolgegenerationen mit Namen wie Gerard David, Ambrosius Benson, Adriaen Isenbrandt oder Colijn de Coter denkt. Letztere waren im frühen 16. Jahrhundert tätig und stützen sich auf Vorbilder des 15. Jahrhunderts. So finden sich bei Isenbrandt und noch stärker bei de Coter teilweise bereits von Gerard David tradierte und weiterentwickelte Muster, die ,schablonenartig' zum Einsatz gekommen zu sein scheinen. ${ }^{543}$

Während FRIEDLÄNDER das Vorgehen dieser Generation noch als, epigonenhaft' bewertet hatte, wird heute davon ausgegangen, dass die Popularität der altniederländischen Malerei noch bis weit ins 16. Jahrhundert hinein zu einer nur langsam abflauenden Nachfrage nach Werken in diesem Stil geführt hatte. Den Gründen hierfür lässt sich nur spekulativ beikommen. Jedoch kann angenommen werden, dass das Idiom eines Jan van Eyck oder Rogier van der Weyden einerseits für eine lokale Erfolgsgeschichte stand und andererseits eine Darstellungsweise bot, die durch einen verlebendigenden Naturalismus geprägt war, der vor allem das Schauverlangen und die Frömmigkeitspraxis des späten Mittelalters befriedigte. ${ }^{544}$ Die Werke als Mittel einer Vergegenwärtigung der Heilsgeschichte, in die hinein sich der fromme Betrachter versetzen konnte und sollte, entsprachen den religiösen

543 Vgl. HiNDRIKS 2017, S. 122-126. Für de Coter und Isenbrandt s. FRIEDLÄNDER 1924-1937, Bd. XI. Für Isenbrandt im Speziellen s. auch MARTENS - HUVENNE 1998, S. 120-122. Und für Benson s. FRIEDLÄNDER 1910, S. 139-148.

544 Beispiele für Objekte aus dem privaten Gebrauch stellen die kleinformatigen Retabel, oftmals Diptychen, dar. Im frühen 16. Jh. stellte ein Großteil der in der Tradition des $15 \mathrm{Jhs}$. verhafteten Kunstproduktion Brügges [!] solche
Bedürfnissen des 15. Jahrhunderts in einer solchen Weise, dass sie für eine ganze Epoche wegweisend wurden. ${ }^{545}$ Dieser Charakter war schließlich auch mitverantwortlich für die protestantische Bildkritik, die später solche levende beelden als zur Idolatrie anstiftendes Blendwerk beschrieb, obgleich der Genter Altar selbst die großen niederländischen Bilderstürme durch den besonderen Schutz lokaler wie spanischer Kräfte gleichermaßen überstehen konnte. ${ }^{546}$

Es lassen sich jedoch auch Indizien für eine vom religiösen Zweck unabhängigere Rolle solcher Bilder ausmachen. Die besondere Wertschätzung, mit der man schon früh dem Genter Altar begegnete, wurde bisher oft auch als Begründung für die These gebraucht, dass das Kapitel von St. Bavo eine restriktive Besucherpolitik verfolgt hätte. So seien etwa strenge Regeln und ein Kopierverbot eingeführt worden, um die Exklusivität des Werkes nicht durch Vervielfältigungen preiszugeben, obschon sich diese These durch keine Quelle belegen lässt. ${ }^{547}$ Eine gewisse Bestätigung dafür könnte immerhin der hölzerne Kasten sein, der für Michiel Coxcie und seinen Auftrag, eine 1:1 Kopie des berühmten Retabels anzufertigen, errichtet wurde. Möglicherweise handelte es sich hierbei um eine Ausnahme, die nur durch die Vermittlung Philipps II. gewährt worden war. Auch ist darauf hinzuweisen,

Werke dar, die inzwischen auch auf dem Markt von Antwerpen angeboten wurden (vgl. MARTENS 1998, S. 54 f.; SCHREINER 2006, S. 256 f.).

545 Zur Rolle von religiösen Bildern für den spätmittelalterlichen Glauben s. NOLL 2006, S. 403424.

546 Für die Schutzmaßnahmen s. auch KEMPERDICK 2014, S. 44.

547 Vgl. Mensger 2000, S. 45 u. DUVERGer 1954, S. 55. 
dass erst nach dem Entstehen dieser Kopie weitere Wiederholungen, meist in kleinerem Maßstab, entstanden. Es ist allerdings möglich, dass diese Werke nach der Kopie Coxcies geschaffen wurden, die möglicherweise mehrere Jahre vor dem Transport nach Madrid im nordspanischen Valladolid zu besichtigen gewesen war. ${ }^{548}$ KEMPERDICK ist hingegen der Ansicht, dass allein die schiere Größe des originalen Werks der ausschlaggebende Grund dafür gewesen sei, dass die Maler bis dahin keine Kopie davon angefertigt hatten. Auch die komplexe, in sich geschlossene Ikonographie, die sich nicht einfach partiell in andere Werke übertragen lasse, sei dafür ein möglicher Grund. ${ }^{549}$ Angesichts der Popularität des Genter Altares erscheint diese These jedoch nicht gänzlich befriedigend. Dass es dem Klerus oder auch der bürgerlichen Vertretung der Stadt Gent darum gegangen sein könnte, die Einzigartigkeit ,ihres' Retabels zu wahren, spricht in Anbetracht der Tatsache, dass eigens zu dessen Besichtigung Personen in die Stadt reisten, meines Erachtens eher für die älteren Überlegungen. Eine geordnete Besichtigung unter der Aufsicht von Kirchenschweizern, wie sie aus dem Pilgerwesen bekannt ist, erscheint eine Überlegung wert zu sein, da hierdurch ein originalgetreues Abzeichnen

548 s. auch Abschn. 3.6.

549 Vgl. Hindriks 2017, S. 118 u. KEMPERDiCK 2014, S. 46.

550 Die bloße Tatsache, dass das Retabel während des Bildersturm geschützt wurde und die daran geknüpfte Information, dass der Stadtrat eine Leinwandkopie des Altars in Auftrag gegeben hat, unterstreichen die These eines geschützten ,Kulturguts'. Für diese weitere Kopie s. KEMPERDICK 2014, S. 66.

551 Bei Lampsonius 1572 heißt es indessen in der Biographie über die Gebrüder van Eyck: „Hoc und damit eine Reproduktion des Werkes ebenfalls ausgeschlossen wäre, was letztendlich der These einer restriktiven Besucherpolitik entspräche und ein frühes Beispiel für ein vom Eigentümer eingefordertes Recht am Bild bedeuten würde. ${ }^{550}$ Die komplexe Ikonographie, die auf eine Darstellung der überzeitlichen - katholischen - Kirche abzielt, mag hingegen ein Grund für Philipp II. gewesen sein, das berühmte Werk kopieren zu lassen und in der Palastkapelle in Madrid zur Schau zu stellen. ${ }^{551}$

Aufschlussreich ist im Vergleich damit der Fall von Jan Gossaert und Philipp von Burgund. Die Beschreibungen des Hofschreibers Geldenhouwer legen nahe, dass es Gossaerts Dienstherrn um die zeichnerische Aufnahme der römischen Antiken ging und das Interesse daran mehr bei ihm als bei dem Künstler zu suchen ist. Dessen spätere, zunehmend, romanistische‘ Werke, die eine ganze Welle der gegenseitigen Beeinflussung unter den südniederländischen Malern auslöste, wäre demnach nur eine logische Konsequenz gewesen, die aber nicht von einem emanzipierten Künstler ausgegangen war, sondern von dessen Herren und seiner möglicherweise gezielten kulturpolitischen Agenda, die in Lucas

vestrum [...] opus Gandense Philippum / Quod Regem tanto cepit amore sui / Eius ut ad patrios mittendum exemplar Iberos Coxennii fieri iusserit ille manu“. Dieser Passage zu Folge sei Philipp derart von dem Genter Altar angetan gewesen, dass er eine Kopie in Auftrag gegeben habe. Diese blumige Umschreibung fällt vermutlich, wie die ähnlich anmutenden Verse Lucas de Heeres, unter die Rubrik des Herrscherlobs und verschleiern die eigentliche Motivation hinter dem Auftrag mit dem Topos der Kunstsinnigkeit. 
de Heeres Ode feierlich umschrieben wird. ${ }^{552}$

Denn ein weiterer Punkt ist der, dass es sich bei dem Vijd-Retabel um die Stiftung eines bürgerlichen Auftraggebers handelt, die aufgrund ihrer Monumentalität sowie den Gebrauch kostbarer Materialien nicht ohne die Duldung des burgundischen Hofs denkbar gewesen wäre, dessen Vertreter deshalb und zum Zweck des Herrscherlobes bei der Darstellung berücksichtigt worden sein könnten. ${ }^{553}$ Demnach wäre die Darstellung von Philipp dem Guten unter den christlichen Streitern - die hinterste Gestalt am linken Bildrand - als Zugeständnis gegenüber dem burgundischen Herzog zu verstehen, was jedoch zweifelhaft erscheint. Möglich erscheint, dass das symbolträchtige Werk mit Hilfe der von Coxcie angefertigten und leicht abgewandelten Kopie durch einen Herrscher, vereinnahmt ${ }^{6}$ worden ist, indem sie das Aushängeschild der von Philipp II. betriebenen Politik wurde, die einerseits das Bekenntnis zur katholischen Kirche und andererseits den Anspruch, in deren Sinn auch in den Niederlanden zu herrschen, geltend machen sollte. Die dokumentierte Anbringung eines Schildes am Retabel, welches den Text der Ode Lucas de Heeres gezeigt haben soll, stützt diese Interpretation. ${ }^{554}$ Die Kopie, wie auch die Verbreitung des Textes, der die Verbindung zum König herstellt, könnte unter anderem dem Zweck gedient haben, die Stellung des Monarchen als Landesherr gegenüber den bürgerlichen Eliten der flandrischen Stadt, zum Ausdruck zu bringen, indem es von der Stiftung des Altars durch einen Vertreter letzterer Gruppe abzulenken versucht. ${ }^{555}$ Auch das erfolgreiche Betreiben Philipps II., Gent zum Bischofssitz einer neugegründeten Diözese zu machen, mag einem politischen Zweck - der Festigung seines Einflusses in Flandern - gedient haben, sodass der Auftrag einer Kopie nach Jan van Eyck und die Erhebung der Kirche 1559 zur Kathedrale keine voneinander unabhängigen Ereignisse darstellen würden.

Der Genter Altar zeigt auf einem seiner linken Tafeln in der Schar der christlichen Streiter Herzog Philipp den Guten, der damit seinerseits als christlicher bzw. katholischer Herrscher dargestellt wird [ABB. 98]. Für die Religionspolitik der Habsburger in den Niederlanden könnte dieses Detail von besonderem Interesse gewesen sein. Der 1430 von Philipp dem Guten gegründete Orden vom Goldenen Vlies hatte sich dem Ziel seines Gründers verschrieben, die Ideale des mittelalterlichen, christlichen Rittertums wiederherzustellen. Philipp II. knüpft mit seiner Anwesenheit bei der Kapitelversammlung, die 1559 in St. Bavo stattfand, an die Gründung des Ordens und dessen Verknüpfung mit dem Genter Altar an, auf dem durch die Darstellung der christlichen Streiter eine Analogie zum Orden hergestellt wird, und bekräftigt dessen Fortbestand, indem er indirekt an die Verwurzelung der niederländischen Kultur im katholischen Glauben appelliert, wie sie der Genter

553 Vgl. hierzu HiNDriks 2017, S. 118.

554 Vgl. KEMPERDICK 2014, S. 10.

555 Zum bürgerlichen Stifterkontext s. HINDRIKS 2017, S. 118. 
Altar als eine der herausragenden Schöpfungen dieser Kultur, repräsentiert. Möglicherweise ging es dem spanischen Monarchen darum, eine feudale wie religiöse Kontinuität zu betonen, die in seiner Person, dem König und Oberhaupt des Ritterordens, kulminiert. ${ }^{556}$ Dass die Kopie an Stelle des burgundischen Herzogs im Original, unter den christlichen Rittern stattdessen Philipp II. von Spanien zeigt [ABB. 99], hätte nach dieser Lesart eine tiefere Bedeutung, die über die bloße Kennzeichnung des Auftraggebers hinausgeht.

$\mathrm{Zu}$ einer politischen Verwendung des Genter Altares bzw. einzelner seiner Darstellungen war es knapp 100 Jahre zuvor bereits schon einmal gekommen, wie die Kronyk van Vlaenderen schildert. Anlässlich des Einzugs von Philipp dem Guten in Gent am 23. April 1458 sei ein tableau vivant mit den Darstellungen aus der Innenseite des Genter Altars mit Gottvater, der thronenden Maria und Johannes dem Täufer sowie der Darstellung mit der Anbetung des Lammes vom Stadtrat in Auftrag gegeben worden. Dies zeigt, wie das Altarbild, das sein Portrait enthielt, mit dem „christlichen Herrscherideal des Herzogs ${ }^{\text {“557 }}$ in der öffentlichen Wahrnehmung verknüpft wurde. In

$556 \mathrm{Zu}$ weiteren Assoziationen zwischen dem Genter Altar und der burgundisch-habsburgischen Herrschaft s. HiNDRIKS 2017, S. 118 f.

557 s. hierzu SMITH 1990, passim. Zum Einzug Philipps des Guten 1458 und den tableaux vivants nach Darstellungen des Genter Altares s. RIDDERBOS 2008, S. 46-50; HuRLBUT 1990, S. 222257 sowie ARNADE 1996, S. 130-142.

558 GEIRNAERT - VANDAMME 1998, S. 34. Vgl. auch HARNACK 2018, S. 15 u. VAN DEN BOOGERT 1998, S. 73 f.

559 De Puys, Remy: La triomphante et solennelle entrée de Charles-Quint en sa ville de Bruges diesem Zusammenhang erscheint es erwähnenswert, dass wenige Jahrzehnte später beim Einzug des noch jungen Karl V. in Brügge 1515 wiederum, lebende Bilder ${ }^{6}$ aufgestellt wurden, die ihre Motive nun jedoch aus der antiken Mythologie sowie der Geschichte des Altertums bezogen und sich des antikischen Repertoires der italienischen Hochrenaissance bedienten; das heißt sie standen stilistisch auf Höhe der aktuellen künstlerischen Entwicklungen und entsprachen mit ihrer auf die Antike und das römische Imperium bezugnehmenden Symbolik dem Herrschaftsanspruch der Habsburger. ${ }^{558}$ Der vom Hofchronisten Remy du Puys bzw. Remigius Depuis verfasste Bericht umfasst auch Nachzeichnungen der Aufbauten, die nach 1515 in einem Buch zusammengetragen und heute in der Österreichischen Nationalbibliothek verwahrt werden. ${ }^{559}$ Motive des Genter Altars waren also bereits seit dem 15. Jahrhundert in einem politischen Kontext zu sehen - wenn auch nur von ephemerem Charakter, wie im Falle der tableaux von 1485, welche die Herrschaftsansprüche des Hauses Habsburg widerspiegeln sollten. Sie wurden also mitunter unabhängig von ihrem Stiftungskontext, ausschließlich ihrer Programmatik wegen, im Zusammenhang

[...] (Der Einzug Karls V. in Brügge) von 1515. Das Original befindet sich unter der Signatur Cod. 2591 in der Österreichischen Nationalbibliothek und enthält farbig (Tempera) gefasste Nachzeichnungen des Einzuges und seiner ephemeren Bauten; darunter bspw. solche mit verschiedenen Triumphbögen (s. fol. 35v; fol. $42 \mathrm{v}$ u. fol. 46v) und dem adventus vor der Stadt (bes. fol. $7 \mathrm{v}-8 \mathrm{r}$ ). Der Text liegt auch als überarbeiteter Nachdruck von 1850 vor. Vgl. auch BlockMANS 1998, S. 27 u. MARTENS 1998, S. $48 \mathrm{f}$. 
mit den Einzügen der Herrscher gezeigt. Im Falle des Einzugs von Philipp dem Guten in die Residenzstadt Gent oder Karls V. in Brügge nutzte der Stadtrat ganze Bildergeschichten und deren Symbolgehalt dazu, sich dem Landesherrn zu empfehlen. Die milites Christi auf dem Genter Altar, zwischen denen Herzog Philipp der Gute dargestellt ist, bzw. die Gesamtschau der ecclesia militans, die in den Bildern des Altares dargeboten wird, mögen zusätzlich auch dem visuellen Eindruck nach eine Brücke zu den festlichen Einzügen geschlagen haben. ${ }^{560}$

\section{$* * *$}

Die Deësis-Darstellung von Jan Gossaert [ABB. 100], die zwischen 1525 und 1530 entstand, ${ }^{561}$ zeigt in der Dreiergruppe mit dem Weltenrichter, Maria und Johannes dem Täufer, eine Bezugnahme auf die Gruppe des Genter Altares, auf dem ebenfalls Christus zwischen Maria und Johannes dem Täufer dargestellt ist; Gossaerts Christusbild orientiert sich überdies an einer nur in Kopien überlieferten vera icon von Jan van Eyck. ${ }^{562}$ Maryanne AINswORTH hat in ihrer Arbeit zu Jan Gossaert die These aufgestellt, dass es sich bei der Deësis möglicherweise um einen Auftrag der niederländischen Generalstatthalterin Margarete von Österreich handelt und das Bild in ihrer Grablege (und der ihres verstorbenen Gemahls) im

560 Vgl. HiNDRIKS 2017, S. 119.

561 Öl auf Holz, $122 \times 133 \mathrm{~cm}$, Prado, Madrid, Inv.Nr. P001510 (vgl. BASs 2016, S. 35-38; MENSGER 2002, S. 35 u. Kat. Prado 1985, S. 380).

562 Vera icon nach Jan van Eyck (München), um 1440, Öl auf Holz, $50 \times 37 \mathrm{~cm}$, Alte Pinakothek, München, Inv.-Nr. WAF 251 (vgl. AINSWORTH 2010, S. 286) u. Vera Ikon nach Jan van Eyck
Kloster von Brou hätte aufgestellt werden sollen. ${ }^{563}$ Der Gebrauch wertvoller Materialien, darunter eine große Menge Blattgold für die im Hintergrund dargestellten Architekturmotive mit ihren gotischen Maßwerken und Zierranken, die überdies sehr gut zu der spätgotischen Architektur des Klosters passen, deuten auf einen fürstlichen Auftraggeber hin. In diesem Zusammenhang könnte es dem Maler möglich gewesen sein, ähnlich wie später Michel Coxcie, den Genter Altar für die Anfertigung von Skizzen aus der Nähe zu betrachten. Der Klerus von Sint-Jans bzw. Sint-Baafs in Gent könnte hierfür auf Geheiß der Statthalterin die Erlaubnis gegeben haben, wie bereits im vorherigen Abschnitt angeklungen ist. Diese These ist deshalb bestechend, weil es sich um eine sehr detailgenaue Kopie der drei Figuren des Genter Altars handelt, die ein eingehendes Studium des Originals voraussetzt. Vergleichbares ist für diese Zeit nicht bekannt und wird erst im Zusammenhang mit der Kopie Coxcies in den 1560er Jahren in den Quellen konkret fassbar. ${ }^{564}$

Im Zusammenhang mit Margaretes Grablege in Brou erscheint es zunächst auffällig, dass sie mit Jan Gossaert ausgerechnet einen der frühen Romanisten dazu beauftragt hat, die Kopie nach einem altniederländischen Vorbild aus der ersten Hälfte des 15. Jahrhunderts anzufertigen. Ihr Verwandter Philipp II. wird sich ebenfalls an einen Vertreter dieser

(Berlin), um 1440, Öl auf Holz, $44 \times 32 \mathrm{~cm}$, Staatliche Museen, Berlin, Gemäldegalerie, Inv.Nr. 528 (vgl. Dhanens 1980, S. S. 239 u. FRIEDLÄNDER 1967-1976, Bd. I, S. 68-69 u. Kat. Berlin 1996, S. 45 f.).

563 Vgl. AINSWORTH 2010, Kat.-Nr. 29. 564 Vgl. KEMPERDiCK 2014, passim. 
,Richtung“ wenden, den Hofmaler Marias von Ungarn, Michiel Coxcie. Beide Kopien, sofern die Deësis, wie AINSWORTH vorgeschlagen hat, tatsächlich im Auftrag Margaretes ausgeführt wurde, legen den Gedanken nahe, dass sowohl sie, als auch Philipp ein differenziertes Interesse an Kunst besaßen und womöglich mit unterschiedlichen Bildern ganz unterschiedliche Ziele verfolgten. Zum einen beauftragten sie Maler wie Tizian, der unmittelbar für die Malerei der italienischen Renaissance stand, zum anderen solche wie Bernard van Orley oder dessen Schüler Michiel Coxcie, die als niederländische Rezipienten der italienischen Hochrenaissance, der Kunst Raffaels und Michelangelos, anzusehen sind. Ihre Ausbildung erhielten die zuletzt genannten Flamen jedoch noch in der Tradition der großen Meister des 15. Jahrhunderts, die auf Jan van Eyck oder Rogier von der Weyden zurückgeht. Überhaupt ist die Grablege Margaretes [ABB. 101], entgegen ihrem Interesse an einer italienisch geprägten Malerei, ein Paradebeispiel für den fortdauernden Stellenwert spätmittelalterlicher Formen. Das Grabmal sowie die Kapelle samt ihrem skulptural ausgestalteten Altar zeigen die gesamte Bandbreite des spätgotischen Formenvokabulars, das an keiner einzigen Stelle durch die Einmischung auch nur eines einzigen Renaissanceornaments überformt wird. Das von Margarete in der Malerei favorisierte Stilelement sucht man in ihrer Grablege vergeblich. Sofern die Tafel mit der
Deësis nach Jan van Eyck ebenfalls zur Aufstellung in dieser Kapelle vorgesehen war, hätte sie stilistisch in das Gesamtensemble gepasst, obschon eine Funktion als Altarretabel auf Grund des steinernen Altaraufbaus ausgeschlossen werden muss. Die Rundbögen im Hintergrund der Figuren, die in Form eines gotischen Maßwerks auf kompliziert gebildeten Konsolen aufsetzen, reproduzieren gewissermaßen das steinerne Maßwerk auf dem Grabmal Margaretes in Brou und das in den Baldachinen des ebenfalls als monumentale Steinmetzarbeit gearbeiteten Altarschreins. Die Dornenranken, die in den hölzernen Rahmen der Deësis eingeschnitzt sind und die Form des gemalten Maßwerks zwischen den Rundbögen, finden sich in verblüffend ähnlicher Form auch auf dem Lettner von Brou sowie dem Altar in der Grabkapelle Margaretes [ABB. 100]. ${ }^{565}$

Das Tafelbild mit der Deësis, über dessen tatsächlichen Aufstellungskontext nichts überliefert ist, geriet später in den Besitz von Philipp II. ${ }^{566}$ Margarete von Österreich besaß mehrere Werke von Jan van Eyck wie die Arnolfini-Hochzeit oder die Madonna am Springbrunnen. ${ }^{567}$ In den von Dagmar EICHBERGER aufgearbeiteten Inventaren werden diese Werke als außerordentlich erlesen („fort exquis") und als sehr alt (,fort anticque“) bezeichnet, was eine differenzierte Sicht auf diese Dinge und eine Wertschätzung des Antiquarischen nahelegt. ${ }^{568}$ Der Sammlerin Mar-
565 HÖRSCH 1994, passim.

566 Vgl. HiNDRIKS 2017, S. 120.

567 Ebd., S. 119. Zur Sammlung s. EICHBERGER 2002, S. 353-367.
568 Zur Rekonstruktion und Auswertung des Sammlungsinventars s. EICHBERGER 2002, passim. 
garete war das hohe Alter dieser Werke bewusst, davon kann ausgegangen werden. Ihr Interesse daran lässt sich vermutlich, wie auch bei anderen Sammlern ihrer Zeit, als ein Bekenntnis zur kulturellen Tradition der Niederlande verstehen, zu deren Wahrung sie sich wie Philipp II., neben ihrer religiösen Sendung, berufen sah. ${ }^{569}$ In einem Zusammenhang mit dem Sammeln alter Kunstwerke steht auch die Anfertigung von Kopien solcher Werke, deren Ankauf aus verschiedenen Gründen nicht möglich war. Die Beauftragung Michiel Coxcies eine Kopie des Genter Altares anzufertigen, auf welcher statt des Herzogs Philipp der Gute nunmehr Philipp II. von Spanien und möglicherweise Kaiser Karl V. unter den christlichen Streitern dargestellt wurden, macht erneut auf die kulturpolitische Bedeutung aufmerksam. ${ }^{570}$ Dieser Zusammenhang wird noch weiter dadurch unterstrichen, dass die Kopie nur wenige Monate vor der 23. Kapitelversammlung des Ordens vom Goldenen Vlies in Gent vollendet wurde, sodass Philipp II. das fertige Werk in Flandern selbst hatte sehen können, da er an der Kapitelversammlung teilnahm, wie weiter oben bereits erwähnt. Dieser Aufenthalt des Jahres 1559 war zugleich sein letzter in Flandern. Es liegt nahe anzunehmen, dass die Kopie sogar anlässlich dieses Kapiteltreffens in Auftrag gegeben wurde bzw. dieses zeitnah nach der Restaurierung des Originals und der Anfertigung der Kopie angesetzt wurde, sodass das Lobgedicht von Lucas de Heere, die Anwesenheit Phillips II., die Erhebung der Kirche zur Kathedrale, die Kopie des Altarretabels sowie höchstwahrscheinlich auch die voraufgegangene Restaurierung des Originals durch Jan van Scorel und Lancelot Blondeel in einem engen Zusammenhang zu sehen sind: Der ,Verkündigung ${ }^{6}$ einer politischen Botschaft, für die Philipp II. die Kapitelversammlung in St. Bavo nutzte. Die sowohl religiöse als auch kulturelle Dimension dieser politischen Strategie mag bei Michiel Coxcie nachhaltigen Eindruck hinterlassen haben, sodass dieser, noch weiter bestätigt durch den Ikonoklasmus von 1566, bis zu seinem Tod ein treuer Gefolgsmann Philipp II. und bekennender Katholik blieb.

Die These, dass Jan van Eycks Werke eine idealisierte burgundische Kulturtradition $\mathrm{zu}$ visualisieren versuchen, wie von Susan Frances JONES vorgeschlagen wurde, mag die Überlegungen $\mathrm{zu}$ einer ,kulturpolitischen Funktion“ der Kopie des Genter Altares ebenfalls untermauern. Die burgundische Kultur des 15. Jahrhunderts habe sich selbst - so die Meinung von JONES - als eine rezipierende betätigt, die mit ihren Bildwelten, Formen und Modellen an eine abermals 200 Jahre ältere Tradition anknüpfte, sodass die Idee einer kulturellen Kontinuität, die sich vor allem auch in den Gebräuchen und Ausstattungsstücken des katholischen Kultes widerspiegelt, das Interesse des habsburgischen Königs geweckt haben könnte. ${ }^{571}$ Inwieweit dieser Überlegung zugestimmt werden kann, müsste an anderer Stelle untersucht werden, da es unklar ist, inwieweit Philipp II. sich dieser kulturgeschichtlichen Zusammenhänge bewusst war.
569 Vgl. EiCHBERGER 2002 u. HARNACK 2018, S. 14-16.
570 Vgl. Hindriks 2017, S. 120 f. u. DUVERGER 1954, S. 55.

571 Vgl. JONES 2017, S. 139-144. 


\section{TV Michiel Coxcie als Maler der katholischen Reform}

\subsection{Grundzüge der Bilddebatte: Johannes Molanus (1533-1585) und seine Kritiker}

Die Maler des 16. Jahrhunderts in den Niederlanden waren es gewohnt, Auftragsarbeiten unter anderem für die Bruderschaften und Gilden des städtischen Bürgertums auszuführen, was vielfach mit der Aufstellung ihrer Werke in den reich ausgestatteten Kapellen dieser Institutionen verknüpft war. Mit dem Bildersturm des Jahres 1566 drohte diese Tradition ihrem Ende entgegenzugehen. Die Verhältnisse in den südlichen Niederlanden veränderten sich jedoch spätestens 1585 mit der Rückeroberung durch den habsburgischen Feldherrn Alessandro Farnese. Von Philipp II. wurde er als neuer Statthalter der südlichen Niederlande eingesetzt, um den Unruhen ein Ende zu setzten. Für Protestanten im Machtbereich der katholischen Habsburger begann damit erneut eine Phase der Repression, ähnlich der Schreckensherrschaft des Herzogs von Alba nur knapp zehn Jahre zuvor, die viele namhafte Angehörige des protestantischen Milieus ins Exil zwang, darunter die Familie van Manders und dessen Lehrer, der Maler und Literat Lucas de Heere, der wenige Jahrzehnte zuvor noch Lobeshymnen auf Philipps
Kunstsinn und Jan van Eycks Genter Altar verfasst hatte. ${ }^{572}$ Anders als zu Beginn des Jahrhunderts und zuletzt noch während des Konzils von Trient, konnte die Kritik an der religiösen Malerei nicht länger ausgeblendet werden, da sie in dem Bildersturm von 1566 in verheerender Weise hervorgetreten war. Von der reformatorischen Lehre blieb auch die Einstellung vieler Katholiken zur Bilderfrage nicht unberührt. Die jüngere Forschung hat darauf verwiesen, dass die niederländische Bevölkerung in der ersten Hälfte des 16. Jahrhunderts mehrheitlich mit den Reformideen sympathisierte und viele folglich als Kryptoprotestanten oder aber zumindest sympathisierende Katholiken gelten müssen. ${ }^{573}$ Auf Maler trifft dies ebenso zu, wie deren Verbindungen zum protestantischen Milieu, Gerichtsprozesse oder kirchenkritische Details in den Kunstwerken nahelegen. ${ }^{574}$

Doch wo beginnt diese konkrete Erneuerung, die nicht vorbereitet worden war und die vornehmlich unter dem Eindruck des Bildersturms geschah, wenn die eigentliche Zielsetzung der sogenannten Gegenreformation letztlich die Bewahrung der katholischen Tradition bedeutete, wie etwa Christian HECHT darlegte. ${ }^{575}$ Und wie verhielten sich Künstler zu den veränderten Verhältnissen in

574 Ausführlich behandelt und an einer Vielzahl von Beispielen expliziert wurde dieser Sachverhalt zuletzt von HARNACK 2018, S. 73-79.

575 Vgl. HeCHT 2012, S. 405. Analog hierzu hat Thijs WESTSTEIjN die Begegnung von Bildersturm, Kunsttheorie und religiöser Schriften im späten 16. Jh. in den Fokus seiner Forschung gerückt. Mehr noch als bereits geschehen, sei es in Zukunft notwendig den sozialen und religiösen 
Folge des Bildersturms? Neben der polemisierenden Kritik gab es zunächst kaum konkrete Ideen, die dieses Problem hätten beseitigen können. Stattdessen bieten die meisten Schriften zur Bilderfrage, die in der Mitte des 16. Jahrhunderts entstanden, eine grundsätzliche Apologie der traditionell von der Kirche autorisierten Funktion von Bildern. Unter den Autoren finden sich Namen wie Ambrosius Catharinus, Josse van Clichthove, Simprecht Schenk oder aber der Franzose René Benoist, welcher zuletzt erste praktische, das heißt problemorientierte Vorschläge lieferte. ${ }^{576}$ Für die meisten Autoren war eine Rechtfertigung der Bilder im Hinblick auf ihre Bedeutung für die Jenseitsfürsorge, die nicht zuletzt in der Stiftung sakraler Bilder ihren Ausdruck gefunden hatte, nicht länger in gewohnter Weise aufrechtzuerhalten. Die Ausgangssituation war dennoch die, dass es von Seiten der kirchlichen Autoritäten zunächst kaum Hilfestellungen gab, derer sich die Künstler hätten bedienen können. Sie und ihre Kunstwerke gerieten über Jahre hinweg zwischen die Fronten und wurden von den verschiedenen Parteien jeweils für sich in Anspruch genommen. ${ }^{577}$

Wandel und dessen Einfluss auf die Kunst des späten 16. Jh. in den Blick zu nehmen (s. hierzu WESTSTEIJN 2012, S. 109).

576 Vgl. FreEDBERG 1988, S. 87.

577 Die Traktatliteratur des 16. Jhs., die sich mit dem Problem der sakralen Malerei beschäftigt weist einen theologisch-philosophischen Duktus auf und beschränkt sich auf einzelne Titel. $\mathrm{Zu}$ nennen ist der Traktat des Johannes Molanus über die Darstellung von Heiligen (De Picturis et Imaginibus Sacris, pro vero earum usu contra abusu), der erst 1570 vergleichsweise spät innerhalb der Debatte um das religiöse Bild erschien. Dass die Schrift auch an Maler gerichtet ist, wird exemplarisch in seiner Grundlegung der allen
Das Problem der religiösen Darstellungen bestand weniger in der Befürchtung schrifttreuer Protestanten, dass Bilder etwas zeigen könnten, was von der biblischen Erzählung abwich, als vielmehr darin, dass Bilder selbst zum Gegenstand der Verehrung würden. Die Gefahr also, dass die Verehrung sich nicht auf das Urbild, sondern auf das Abbild richtete und die Bilder gleichsam zu Verkörperungen des Heiligen und Göttlichen selbst wurden, wie es im katholischen Bilderkult vielfach zu sehen war. ${ }^{578}$ Hans BELTING weist in seiner der Bilderverehrung gewidmeten Monographie Bild und Kult von 1990 darauf hin, dass religiöse Bilder im 16. Jahrhundert viel von ihrer ursprünglichen Qualität verloren hatten. Im (späten) Mittelalter hätte deren Eigenschaft noch darin bestanden, dass in den Darstellungen der Heiligen diese selbst als anwesend gedacht wurden. WESTSTEIJN verweist auf den animistischen Charakter dieser Vorstellung. ${ }^{579} \mathrm{Im}$ Verlauf des Jahrhunderts sei dieser Animismus schließlich, so BELTING, zunehmend damit vermischt worden, dass Kunstwerke zu (Kunst-)Objekten wurden, die die schöpferische Befähigung des Menschen zeigen und verklären würden. ${ }^{580}$

Heiligen gleichermaßen eigenen Attribute deutlich: Nimbus und Märtyrerpalme. Sein Hauptanliegen ist eine ,Methode', die der theologischen Tradition folgt und bestehende Entwicklungen daran einer kritischen Untersuchung unterzieht (s. hierzu HECHT 2012, S. 493).

578 Vgl. WeSTSTEIJN 2012, S. 110; s. auch HANEGRAAFF 2007, S. 107-36.

579 Vgl. WestSTEIjN 2012, S. 11.

580 Vgl. Belting 1990, S. 457-464. In Analogie zu BELTINGs These verweist WESTSTEIJN auf Alberti. In seinem Malereitraktat von 1435 habe dieser den antiken Schriftsteller Tismegistus, 
Einer der polemischsten Kritiker dieser Vorstellung der bildlichen Präsenz des Heiligen war zweifelsohne der Calvinist Philips Marnix van Sint Aldegonde, der Heiligendar-

den die Kirche als Häretiker verworfen hatte, zitiert. Die daraus abgeleitete und nicht unproblematische Vorstellung war, dass der Mensch durch seine Fähigkeit Kunst zu produzieren, eine Art Gott sei. Zur Haltung des Kirchenvaters Augustinus zu Trismegistus s. Augustinus, De Civitas Dei, VIII. Trismegistus hatte in seiner Schrift zum Ausdruck gebracht, dass „Malerei und Skulptur zur selben Zeit, wie die Religion" entstanden seien (s. WeSTSTEIJN 2012, S. 111 mit Verweis auf Albertis De pictura (1435), hrsg. von J. R. Spencer, New Haven/London 1966, S. 63-65). Eine der Thesen in Albertis Malereitraktat, die für das humanistische Denken prägend wurde, war die Vorstellung, dass der Maler in früheren Zeiten lebende Personen sichtbar machen könne (s. hierzu WESTSTEIJN 2012, S. 111, Anm. 17). Gregor WEBER hat dieses Phänomen in der jüngeren kunstgeschichtlichen Forschung mit dem Begriff „Lebendigkeitstopos" umschrieben. Gemeint ist damit das malerische Ziel, in einem Kunstwerk einen möglichst gesteigerten Realismus zu erzeugen (vgl. WeBER 1991, passim). Der feinmalerische Detailnaturalismus in der niederländischen $\mathrm{Ma}$ lerei des 15. Jhs. bezeugt diese Tendenz. WESTSTEIJN knüpft diesen Naturalismus an den Begriff der „Transsubstantiation“ und behauptet, dass es dem Maler daran gelegen gewesen sei, mit Pigmenten echtes Fleisch zu suggerieren. Er rekurriert dabei auf die Beschreibungen der Malerei Tizians durch den Italiener Pordenone, der über ersteren ausgesagt haben soll, dass dessen Akte mit „Fleisch anstelle von Farbe“ gemalt sein müssen („,che Titiano in quel nudo habbia posto carne, e non colori“", Ludovico Dolce: Dialogo della pittura (1557), hrsg. von M. W. Roskill, New York 1968, S. 51; zit. bei WESTSTEIJN 2012, S. 111). Vgl. auch KRUSE 2000, S. 126-144).

Diese Vorstellung sei dann auch in der niederländischen Kunsttheorie des 17. Jhs. zu finden, obwohl sie im Jahrhundert zuvor der verurteilten Idolatrie Vorschub geleistet hatte. Der calvinistische Prediger und Kunsttheoretiker stellungen als „leblose Holzklötze“ und „Kinderpuppen“ bezeichnete. ${ }^{581}$ Der Prediger Jakobus Revius sprach ebenfalls von „lahmen Puppen und toten Malereien“ “. ${ }^{582}$ Ein weiterer Prediger, Dirck Camphuysen behauptete, dass

Franciscus Junius bezieht sich in der Einleitung zu seinem Werk De schilderkonst der oude von 1641 ebenfalls auf Trismegistus (F. Junius: De schilderkonst der oude, Middelburg 1641).

Karel van Mander schreibt Goltzius ähnliche ,alchemische' Befähigungen zu, indem er dessen Streben nach der Reinheit der Farben anführt („In de kenntnis der Nature, als natuerlijck Philosoph, niet onervaren“, van Mander 1604, S. 286). Ähnlich hatte bereits Vasari über Jan van Eyck und dessen Erfindung der Ölmalerei geschrieben („Giovanni da Bruggia [...] si mise $[\ldots]$ come quello che si dilettava dell'archimia, a far di molto olj pe(r) far vernici“", Vasari 1568, Bd. 1, S. 375). Und auch Rubens wurde mit der Alchemie und dem Stein der Weisen in Verbindung gebracht („Hab ich durch den Pensel und die Farben den rechten wahrhaften Lapidem Philosophicum gefunden", Rubens-Zitat bei Sandrart 1675, Bd. I, 3. Buch, S. 283; zit. bei WESTSTEIJN 2012, S. 111).

Die Lebendigkeit realistischer Darstellungen findet ihren Höhepunkt in der metaphorischen Verknüpfung von Blut und Farbe: „Die Nägel am Kreuz Christi sind des Malers Pinsel und das Blut Christi seine Farbe“ („Uwe roeden zullen mijn pincelen zyn, u bloed mijn verwen, en u kruis mijn paneel, waar op ik my geheel nieuw af-schilderen zal“, J. Puget de la Serre: Het onderboud der goede geesten op d'ydelheden van de werelt [1658], S. 166, zit. bei WESTSTEIJN 2012, S. 111). Die Rückbindung an die Idee der Inkarnation als ursächliches Ereignis, das eine religiöse Kunst mit der Darstellung des christlichen Gottes ermöglicht habe, ist auch hier erkennbar.

581 „Houte ende steene leeflose blocken ende afgodenbeelden oft kinderpoppen" (P. Marnix: Van de beelden afgheworpen in de Nederlanden in Augusto 1566, ed. von VAN TOORENENBERGHEN 1871, S. 34). Vgl. auch FREEDBERG 1988, S. 65.

582 „Het lamme poppenwerk en de dode schilderijen" (J. Revius: Over-Ysselsche zangen en dichten, hrsg. von SMIT 1930, S. 201). 
Bilder lediglich „mit Farbe beschmierte Leinwände oder Tafeln" seien. ${ }^{583}$ Er wandte sich gegen fromme Beschauer von Bildern, die ihre hoffnungsvollen Erwartungen lediglich auf „ein totes Ding“ oder einen bloßen „Schatten“ richten würden. Grundtenor dieser ÄuBerungen ist die Feststellung, dass gemalte Figuren nicht aus Fleisch und Blut seien, auch wenn ihr Erscheinungsbild anderes zu evozieren suche. Interessant ist, dass diese Argumentation hinsichtlich der Bilder als lebloser Materie auch von den katholischen Verteidigern religiöser Bilder aufgegriffen wurde, um damit zu erklären, dass diesen Bildern keine böse Kraft innewohnen könne, so zum Beispiel in Jan Verpoortens D'Net der beeltstormers (1591). ${ }^{584}$ Es gebe demnach nichts, wovor sich die Bildergegner fürchten müssten.

Der katholische Autor Renatus Benedictus präzisierte das Verständnis von Bildern und von deren Gebrauch in der Kirche in seiner Schrift Een Catholic tractaet van de beelden ende van het rechte gebruyck dier selfder (1567). ${ }^{585} \mathrm{Er}$ greift die ältere Rechtfertigung der Bilder auf und beschreibt Heiligenbilder sinngemäß als

583 ,„...] doeck of planck / met verw besmeerd“ (D. R. Camphuysen: Geestichdom der schilderkonst, in: Ebd.: Verscheyden theologische wercken, Amsterdam 1638, S. 113-115).

584 Jan Verpoorten: D'Net der beeltstormers, verclarende dat wettelijck ghebruyck der kerckelijcker beelden ende d'onrecht bestormen der selver, Antwerpen 1591. Für Veerporten s. FREEDBERG 1988, S. 76-86.

585 Benedictus, Renatus: Een Catholic tractaet van de beelden ende van het rechte gebruyck dier selfder, Antwerpen 1567 bei Van Keerberghen.

586 Vgl. ebd., S. [57] (ohne Seitenzählung). Renatus vergleicht Bilder an dieser Stelle metaphorisch mit Wolken, durch die hindurch der Betrachter Gott suchen müsse (vgl. WeSTSTEIjN 2012, Anm. 34). ein ,Medium für den kontemplativen Aufstieg des Geistes` zu den wirklichen Heiligen. ${ }^{586}$ Die Verehrung der Heiligen schließe deren Bild automatisch mit ein, so wie die Göttlichkeit Christi nicht ohne dessen Menschsein zu erkennen sei (Zwei-Naturen-Lehre) ${ }^{587}$ Die Materialien, aus denen das Bild gemacht sei, seien als das Medium zu verstehen und nicht als das Objekt selbst. Ersteres sei aber nötig, um letzteres verehren zu können. ${ }^{588}$ Das fromme Niederknien und Beugen vor einem Heiligenbild sei demnach dem im Bild repräsentierten Heiligen gewidmet und nicht etwa dem Bildmedium selbst. ${ }^{589}$

Philips van Marnix versuchte, solche Positionen von katholischen Autoren, vor allem die des Johannes Molanus, ad absurdum zu führen. ${ }^{590}$ In seiner Schrift De byencorf der $H$. Roomsche Kercke, ${ }^{591}$ die stark von der Institutio Christianae Religionis des Johannes Calvin geprägt war, wendete Marnix sich nicht allein gegen das religiöse Bild, sondern auch gegen die katholische Verehrungspraxis an sich, unabhängig davon, ob sie die Heiligen oder Gott selbst betraf. Er kommentierte die Definition

587 Ebd., S. [23 f.] (ohne Seitenzählung).

588 Vgl. WeSTSTEIjN 2012, S. 112 f. mit Verweis auf Renatus Benedictus: Eeen Catholic tractaet van de beelden ende van het rechte gebruyk dier selfjder, Antwerpen 1567, S. [23-24] (Titel ohne Seitenzählung).

589 Diese Definition wird u. a. in einer anonym verlegten späten Reminiszenz an Thomas von Aquins Summa Theologia vertreten (für Wortlaut s. JONCKHEERE 2016, S. 112 mit Verweis auf FELD 1990, S. 63-66).

590 Hierzu WeStSTEIjN 2012, S. 112 mit Verweis auf Molanus 1570 [1594], S. 219.

591 Philips van Marnix van Sint-Aldegonde: De Byencorf der H. Roomsche Kercke, Emden 1574. 
der Begriffe latria, dulia und die eigens auf den Sonderstatus der Gottesmutter Maria zugeschnittene byperdulia des Thomas von Aquin. Die drei Begriffe beziehen sich auf Augustinus und betreffen die Verehrung der Heiligen (und Marias), die dem biblischen Gebot der alleinigen Verehrung Gottes widerspricht. Während dulia den Dienst gegenüber den Heiligen meinte, bedeutete latria allein die Anbetung Gottes; zwei Formen der Verehrung, die im Hochmittelalter durch den Sonderstatus der im Himmel gekrönten Mutter Gottes ergänzt wurden (byperdulia). ${ }^{592}$ Marnix sah in dieser Unterscheidung eine Verschleierung, die es den Katholiken in Wahrheit ermöglicht habe, wie die Heiden Vielgötterei zu betreiben. Die Heiligenverehrung sei daher seiner Auffassung nach nicht nur Idolatrie, sondern auch hinsichtlich ihrer Begründung falsch, sodass die Katholiken derselben Praxis folgen würden, wie vormals die Heiden. ${ }^{593}$

Ähnlich argumentierte auch der protestantische Bildkritiker Petrus Bloccius, der wie Marnix die Bilderverehrung als eine „heidnische Anbetung von Holz, Stein, Gold und Silber" bezeichnete. ${ }^{594}$ Bei allen Versuchen, die katholische Bilderlehre und deren Apologeten

592 Thomas von Aquin, Summa II, Quaestio 84 u. Quaestio 103 (s. HeLD 1990, S. 63-66). Vgl. auch JONCKHEERE 2016, S. 111 u. JONCKHEERE 2012, S. 168-197.

593, ,... Ende derhalven en verstonden sy noch het onderscheydt niet datter is tusschen Latria, Dulia ende Hyperdulia; ende daeromme scholden sy alle de ghene die eenighe beelden aenbeden, voor afgoden-dienaers, sonder eenich onderscheydt te maken tussen Catholijcken ende heydenen" (zit. bei JONCKHEERE 2016, S. 111 nach $\mathrm{Ph}$. Marnix van Sint Aldegonde: De bijenkorf der H. Roomsche Kerke, met inleidning en varianten, hrsg. von A. Lacroix u. A. Willems, 2 Bde,, Brüssel 1858, S. 30 f.). zu wiederlegen, fällt eines mehr oder weniger stark auf: Die Gegner des religiösen Bildes glaubten selbst an eine Kraft, die diesem innewohnt oder gaben es zumindest vor. Zeitgenössische Berichte belegen, wie Bilderstürmer den Statuen und gemalten Figuren die Augen auskratzten, um nicht deren Blicken ausgesetzt zu sein. Ein solches Vorgehen wäre nicht nötig gewesen, wenn sie die Darstellungen, wie von einigen ihrer Wortführer geäußert, nur für tote Materie gehalten hätten. Maarten van Heemskercks Stichfolge Die Geschichte von Elijah und den Priestern des Baal zeigt, möglicherweise als Reaktion auf die zeitgenössischen Ereignisse, ähnliche Verstümmelungen und ,Strategien', vermittels derer die Macht der Bilder und Figuren gebannt werden sollte; etwa indem sie in die Münder der Statuen defäkieren. ${ }^{595}$ Bekannt ist, dass nicht nur Protestanten wie Marnix den Katholiken Alchemie und Hexerei zu unterstellen versuchten, sondern dass auch umgekehrt katholische Autoren unter dem Eindruck der Ereignisse von 1566 den Protestanten derartige Praktiken vorwarfen. Nicholas Sanders zum Beispiel schrieb 1569 als Befürworter religiöser Bilder, dass jene, die den Heiligenkult angreifen, „Häretiker und

594 „Ende dat de Mis-kreemers niet t'eenmael betoovert waren, sy souden bevinden ende bekennen, dat heur afgoden zyn ghelyck der Heydenen, welcke van hout, steen, gout, silver waren gamaect, also ook Antonis, Huberts Dionjis, etc.“, P. Bloccius: Meer dan twee hondert ketteryen, blasphemien en nieuwe leeringen, welck uut de misse zyn ghecommen, Wesel 1567, S. 49-51, zit. nach WESTSTEIJN 2012, S. 112.

595 Kupferstichserie, 4 Blätter, 1567 von Philips Galle gedr. (vgl. Hollstein 129 (Heemskerck). Zur Thematik vgl. FreEDBERG 1986, S. 79 f. u. SAUNDERS 1978, S. 59-83. 
Magier" seien. ${ }^{596}$

Nach 1566 verstrichen noch weitere Jahre, bis man 1570 offenbar erste Schlüsse aus den überstandenen und inzwischen weitestgehend reparierten Schäden und zahlreichen schriftlichen Anfeindungen zog. Die Synode von Mecheln, die in diesem Jahr abgehalten wurde, knüpfte an den letzten Artikel des Konzils von Trient 1563 an. ${ }^{597}$ Es hat den Anschein, dass Beschlüsse des Tridentinums, wie etwa jene Klausel, nach welcher die bischöfliche Autorität in kritischen Fällen eigenverantwortlich reagieren solle, um einen Missbrauch, sofern es ihn denn überhaupt geben würde, abzuwenden, überhaupt erst im Zusammenhang mit der sieben Jahre später abgehaltenen Synode ihre eigentliche Bedeutung entfalten sollten. Es wurden in der Folge konkret mehrere Missstände verurteilt, darunter die Darstellung von heidnischen Göttern und mythologischen Wesen (im Zusammenhang mit Altarbildern) sowie jede Laszivität, beispielsweise nackte Figuren oder sogar Heiligengestalten. Weiterhin hieß es nun bedeutend bestimmter als es noch 1563 der Fall gewesen war, dass jedes neue Kunstwerk, Malerei oder Skulptur gleichermaßen, zunächst durch den örtlichen Bischof bestätigt werden müsse. Dieser sei fortan dazu verpflichtet, Meldun-

596 „Magos et superstitiosus [...]“ (N. Sanders: De typica et honoraria imaginum adoratione, Löwen 1569, Buch I, Kap. 10, zit. nach WESTSTEIJN 2012, S. 114). Vgl. auch FREEDBERG 1988, S. 73.

597 Die Bestimmungen des Trienter Konzils finden sich bei FreEDBERG 1988, S. 264 f. (Appendix II) in englischer Übersetzung.

598 Der originale Wortlaut findet sich bei FrEEDBERG 1988, Appendix I; erstmals abgedr. bei P. gen über fragwürdige Kunstwerke zu verfolgen, um solche gegebenenfalls entfernen zu lassen. Strafen, welche auf die Missachtung der Beschlüsse zu erfolgen hätten, kennt der Text von 1570 ebenfalls. ${ }^{598}$ Die richtungsweisende Bedeutung dieser Beschlüsse wird in der Folgezeit noch weiter präzisiert und von der dritten Provinzialsynode des Jahres 1607 erneut bestätigt. Letztere bezeichnet zeitlich den Übergang in eine andere Epoche, für welche die ab 1570 einsetzenden Reformen bereits grundlegend sein sollten. ${ }^{599}$

Das eigentlich Bemerkenswerte an diesen Beschlüssen, wenn man einmal davon absieht, dass sie nur wenige Jahre zuvor vielleicht das Schlimmste verhindert hätten, besteht darin, dass sie mehr oder weniger den kritischen Forderungen des Mechelner Theologen Johannes Molanus entsprachen. ${ }^{600}$ In seiner Schrift De Picturis et Imaginibus Sacris von 1570, die unmittelbar vor der Synode erschien und eine Erweiterung seiner bereits nach dem Ende des Trienter Konzils 1563 begonnenen Arbeit zu den Konzilsbeschlüssen darstellt, greift Molanus als erster Autor Kunstwerke auf, die er aus eigener Anschauung kannte, und stellt differenziert die konkrete Problematik einzelner Motive am Beispiel von Bildern dar, die ihm aus seiner Heimat bekannt waren oder von denen ihm berichtet worden war. ${ }^{601}$

F. X. De Ram: Synodicon Belgicum, Mecheln 1828, S. 107.

599 Vgl. FreEdBERG 1988, S. 163.

600 Vgl. ebd., S. 139.

601 Posthum wird 1594 in Löwen eine noch von ihm selbst edierte und erweiterte Auflage unter dem Titel De Historia Sanctarum Imaginum et Picturarum veröffentlicht. Der Titel dieser Edition weist bereits auf die Rolle hin, die dieses Werk 
Frühere Beiträge zur Bilderfrage, die seit Jahrzehnten von Calvinisten, Lutheranern und Katholiken kontrovers diskutiert worden war, scheinen, wenn überhaupt, lediglich bei einem gelehrten Publikum Widerhall gefunden zu haben - obschon auch hier nur eingeschränkt, da das Tridentinum die Tragweite des Problems nicht in seiner Gänze erkannt hatte. Während das Konzil, wie auch frühere Autoren, dem Thema mit wenigen Argumenten, die auf Gregor den Großen und den Bilderstreit des 8. und 9. Jahrhunderts zurückgehen, beizukommen versucht hatten, stellt De Picturis die erste ernstzunehmende Antwort auf das Problem dar und zwar aus dem einfachen Grund, weil Molanus im Hinblick auf die praktische Anwendung argumentiert und dabei seine umfangreiche Kenntnis der zeitgenössischen Kunst in seiner Heimat unter Beweis stellt. $^{602}$

Als Beispiel für sein Vorgehen mag ihm die kirchliche Zensur von Schriften gedient haben, die im Jahr 1564 einen ersten Index der verbotenen Bücher veröffentlichte. Die Punkte, nach denen die päpstliche Zensur vorzugehen hatte, betrafen Angriffe auf den Papst, häretische Behauptungen, profane Durchmischung sowie das weite Feld der sittlichen Verfehlung. Diese Punkte ähneln denen, die später die Synode von Mecheln gegen den Abusus in der Malerei anführt. ${ }^{603}$ Dabei gibt Molanus selbst zu erkennen, dass er seinerseits

im Zeitalter der Konfessionalisierung spielen sollte, das schließlich sogar kanonisiert wurde. Interessant ist auch, dass Molanus stellenweise praktische Empfehlungen für die Restaurierung und Verwahrung von Kunstwerken liefert, die neben seiner bildtheologischen Absicht, auch sein eigenes Interesse an der Kunst wiederspiegeln. dem gregorianischen Konzept folgt, nach dem eine Funktion von Bildern die sei, den Illiteraten das zu sein, was den Lesekundigen das Buch war. Dem biblischen Motiv „nam qui nimium emungit elicit sanguinem" (Spr 30,33) folgend, macht Molanus die Feststellung, dass fehlerhafte Bilder in ähnlicher Weise gefährlich für unbelesene Gläubige seien wie die Schriften von Häretikern. Es gelte daher, diese zu verhindern. ${ }^{604}$ Genauer heißt es: „Quod in libris prohibetur, prohibendum etiam esse in Picturis, quae sunt idiotarum libri" ${ }^{605}$ sodass kein Zweifel daran bestehen konnte, dass Bilder ihrer lehrhaften Funktion entsprechend derselben Aufsicht bedurften, wie es für Schriften nicht erst in jüngster Vergangenheit galt. Zugleich machte er jedoch einen gewichtigen Unterschied in der Art der fehlerhaften Darstellungen. So gebe es Fehler, die keine schwerwiegenden Irrtümer nach sich ziehen, sondern Abweichungen von der biblischen Überlieferung darstellen, die größtenteils solche Dinge betreffen, die man erwarten würde, obwohl sie im Text nicht genannt sind. Als Beispiel nennt er den Esel, auf dem Maria bei der Flucht nach Ägypten reitet, der eine Erfindung der Malerei darstellt und so im Text der Evangelien nicht vorkommt. ${ }^{606}$ Dieses Beispiel zählt Molanus zu den erlaubten Abweichungen von der Schrift, da sie nachvollziehbar sind und die Schilderung der Evangelien lediglich komplettieren, nicht aber verfälschen

602 Vgl. FreEdBerg 1988, S. 134 f.

603 Vgl. Freedberg 1988, S. 137 u. WeStsteijN 2012, S. 114.

604 „Non esse statuendas imagines quae periculosi erroris ocassionem rudibus praebent" (Molanus 1570, De picturis II, Kap. 23).

605 Molanus 1570, De Picturis I, S. 31.

606 Vgl. Molanus 1594 [1771], S. 64. 
würden. Ein weiteres Beispiel, das er in diesem Kontext anführt, betrifft die Darstellung des Hl. Hieronymus in der Kleidung eines Kardinals, die es zu dessen Lebzeiten faktisch nicht gegeben hat. Er gesteht dem Maler jedoch zu, sich in diesem Fall in ähnlicher Weise wie die Heilige Schrift und deren Auslegung durch die Kirchenväter der Allegorie bzw. Metapher zu bedienen, ${ }^{607}$ um damit Eigenschaften der Figur hervorzuheben - im Fall von Hieronymus meint dies seine Funktion als Lehrer und Vorsteher der Kirche, was sich am sinnfälligsten und für den Vorstellungshorizont seiner Zeitgenossen angemessen mit der Kleidung eines Kardinals bezeichnen lasse. Für die Ikonographie früherer und zeitgenössischer Maler war zweifelsohne die Legenda Aurea von großer Bedeutung, über deren teilweise phantastischen Inhalt Molanus sich verschiedentlich negativ äußert. Dennoch gesteht er dieser wie außerbiblischen, von ihm als „apokryph“ bezeichneten Schriften eine Bedeutung bei der Erschließung biblischer Schilderungen und der Heiligenviten zu und betont ausdrücklich, dass er diese seit Jahrhunderten herangezogenen Werke nicht verboten sehen möchte. ${ }^{608}$ Weiter bekräftigt er im Hinblick auf Darstellungen wie die Sieben Freuden bzw. Sieben Schmerzen Marias, deren Berechtigung damit, dass sie als volkstümliche Formen der Verehrung, ${ }^{609}$ die zwar nicht wortwörtlich durch die Schrift belegt seien, sich aber durchaus im Be- reich des theologisch Erlaubten bewegen würden, als sinnvoll erwiesen hätten, indem sie der Andacht nützten und eine positive Annäherung an das Mysterium Christi vermittels der Betrachtung der Lebensgeschichte Marias ermöglichen würden.

Inwieweit die Bestimmungen von Malern tatsächlich umgesetzt wurden, muss im Einzelfall geprüft werden. Auch ist es nicht immer leicht zu entscheiden, ob ein Zuwiderhandeln aus einer provokativen Absicht erfolgte, auf die Unwissenheit des Malers zurückzuführen ist oder Ausdruck eines Festhaltens an der Tradition bedeutet. Letzteres wird am Beispiel der in der zweiten Hälfte des 16. Jahrhunderts mehrfach ins Bild gesetzten Auferstehung Christi deutlich, die sich in der Regel an der spätmittelalterlichen Tradition eines siegreichen Christus auf einem geöffneten Sarkophag orientiert. So auch Michiel Coxcies zentrale Darstellung auf dem um 1570 entstandenen Retabel in Onze-Lieve-Vrouw ten Zavel (Notre-Dame du Sablon) in Brüssel. Die Kirche selbst stand während der bilderstürmerischen Unruhen unter dem Schutz der städtischen Milizen und die dort verehrte Marienfigur kann als ein Zentrum der katholischen Frömmigkeit gelten. ${ }^{610} \mathrm{Zu}$ Darstellungen dieser Art schreibt Molanus, dass ,jene, die den Auferstandenen auf einem Grab mit zur Seite geschobenem Deckel darstellen, nicht an seine Auferstehung glauben“ würden, da die Schrift
607 „In imaginibus, tametsi sint idiotarum libri, multa tamen metaphorice \& allegorice recte pingi“" (Molanus 1594 [1771], S. 66.

$608,[. .$.$] nam quaedam ex apocryphis sumpta$ aliunde habent probabilitatem." (Molanus 1594 [1771], S. 89).
609, ,...] quae populari pietate universaliter receptae sunt." (Molanus 1594 [1771], S. 330).

610 Hierzu BOELENS-SINTSOFF - WALAZYC 2004, passim. 
davon spreche, dass Christus aus einem geschlossenen Grab auferstanden ist. ${ }^{611}$

$$
* * *
$$

Der Maler Michiel Coxcie ist nicht zuletzt wegen seines knapp ein Jahrhundert umspannenden Lebens und Schaffens auch ein Spiegel der historischen Ereignisse und Transformationsprozesse in der habsburgischen Exklave der südlichen Niederlande. Die Entwicklung seiner Kunst, während und vor allem nach dem Aufenthalt in Italien, verläuft gewissermaßen parallel zur wachsenden Kritik gegenüber der tradierten Funktion religiöser Malerei, wie sie unter anderem zu Beginn des Jahrhunderts von Erasmus von Rotterdam zum Ausdruck gebracht worden war. ${ }^{612}$ Zur gemäßigten Auffassung des Luthertums hinsichtlich der Bilderfrage nach dem Streit Luthers und

$611,[\ldots]$ neque credendum est Pictoribus, qui pingunt Domino amoto lapide exire de sepulcro“ (Molanus 1594 [1771], S. 460). Vgl. auch FREEDBERG 1988, S. 154.

612 Im 1509 verfassten und 1511 erstmals in Paris gedruckten Lob der Torbeit (Neuauflage 1515 von Johann Froben in Basel) führt Erasmus von Rotterdam als einer der ersten Autoren die gängige Praxis der Bilderverehrung ad absurdum. Anders als in dieser an den menschlichen Verstand appellierenden Satire, nehmen spätere Autoren die Thematik weitaus ernster und machen sie zu einem zentralen Thema ihres Ideenstreites mit der überkommenen katholischen Lehre, s. Marnix Schrift Byencorf der Roomsche Keerke von 1574 (vgl. FrEEDBERG 1988, S. 155).

Luthers Position, die Kunst hinsichtlich ihres pädagogischen Wertes in den Kirchen zu erhalten, spielt für die niederländische Reformation nur eine untergeordnete Rolle, während es hier der katholische Autor Johannes Molanus ist, der sich für eine geregelte Zensur von Bildern einsetzt, die der Buchzensur ähnelt: „Prohibet
Karlstadts kam ab den 1530er Jahren die radikale Bilderfeindlichkeit Johannes Calvins hinzu, die in den Niederlanden großen Anklang und rasche Verbreitung finden sollte. ${ }^{613}$ WESTSTEIJN hat darauf hingewiesen, dass in dieser Hochphase der Bildkritik nur selten der Heidelberger Katechismus zitiert worden sei, obwohl dieser doch die sozio-religiöse Grundlage niederländischer Protestanten darstellte und die Absage an die Darstellung des Göttlichen als prominenten Artikel einschloss. Auch waren Calvins Institutiones bereits 1560 ins Niederländische übersetzt worden, wurden jedoch erst von Samuel van Hoogstraten aufgegriffen. In seiner Inleyding tot de booge schoole der schilderkonst von 1678 übernahm er Calvins Auslegung des zweiten Gebotes. ${ }^{614}$

Es zählt zu den verwunderlichen Erscheinungen der Frühen Neuzeit, dass ausgerechnet viele Maler und Bildhauer zu Anhängern der reformatorischen Ideen wurden,

deputatio Tridentinae Synodii, omnes libros qui res lascivas seu obscoenas ex professu tractant, narant aut docent [...] quanto ergo magis prohibendae sunt huiuismodi picturae [...]" (Molanus 1594 [1771], S. 244 f.). Bereits vor dem Bilderstreit lässt sich eine Neubesetzung alter Themen beobachten, etwa bei Pieter Brueghel d. Ä. (vgl. MEADOW 1996, S. 181-205).

613 Karlstadts Schrift Von abtuhung der Bylder (1522) verbreitete sich als Flugschrift über ganz Deutschland (vgl. SCHNITZLER 1996, S. 32).

614 Samuel van Hoogstraten: Inleyding tot de hooge schoole der schilderkonst. Anders de zichtbaere werelt, Rotterdam 1678. Es hat den Anschein, dass besonders nordniederländische Autoren die Ereignisse von 1566 zu meiden gesucht haben, wie auch van Manders verhaltene Äußerung dazu andeutet. Zeitgleich entstand von der Mitte des 16. Jhs. bis darüber hinaus eine breite Literatur, die sich mit dem Vorwurf der Idolatrie und dem Problem religiöser Malerei beschäftigt (s. hierzu WeSTSTEIJN 2012, S. 109 f.). 
wie beispielsweise Coxcies Lehrer Bernard van Orley, der einer Anklage zu Folge in seinem Haus lutherische Predigten habe halten lassen. ${ }^{615}$ Wann der Maler und Dichter Lucas de Heere sich zu den Lehren Calvins bekannte, ist nicht klar. ${ }^{616} \mathrm{Im}$ Jahr 1580 veröffentlichte de Heere eine Übersetzung ins Niederländische von Philippe de Morneys Traité de l'Eglise où l'on traite des principales questions qui ont été mues sur ce point en nostre temps (1578). Die unter dem Namen Tractaet ofte Handelinge van de Kercke in Antwerpen erschienene Abhandlung enthielt eine Auflistung aller ,Anfeindungen' des Calvinismus gegenüber der katholischen Kirche, ihren Gebräuchen und Dogmen. Die Widmung an Wilhelm von Oranien betont die anti-habsburgische Ausrichtung des Textes. Der Anführer der holländischen Freiheitsbewegung wird hier als das Pendant zu Philipp II. stilisiert. Letzteren hatte de Heere zwanzig Jahre zuvor noch für seine Förderung der Künste, besonders die Bewahrung der Werke der großen Meister des 15. Jahrhunderts, in einem Lobgedicht auf diese Kunst gepriesen. ${ }^{617}$ Der Traktat von de Morney, eines französischen Calvinisten und Vertrauten von Wilhelm I. von Oranien, sucht vermeintlichen Irrtümern der römischen Kirche ,rechtgläubige ${ }^{6}$ Antworten gegenüberzustellen. ${ }^{618}$ Es ist

615 Vgl. Galand 2013, S. 69.

616 s. hierzu BECKER 1973, S. 113-127 und sehr umfassend bei WATERSCHOOT 1974, S. 16-126.

617 An dieser Stelle sei auf die Restaurierung des Genter Altares von namhaften Malern verwiesen, die Philipp 1550, d. h. noch vor der Beauftragung Coxcies eine Kopie desselben anzufertigen, veranlasst hatte (s. van Vaernwyck 1568, zit. nach DHANENS 1965, S. 111).

618 Zum Leben und Werk Philippe de Morneys s. DAUSSY 2002, passim. kaum verwunderlich, dass auch Passagen enthalten sind, die die Verwendung von Bildern im Kirchenraum, sei es nun zu pastoralen, liturgischen oder didaktischen Zwecken, ablehnen. In der niederländischen Edition, bezeichnet bereits das einleitende Sonett aus der Feder de Heeres die sinnlich reizvolle Raumgestaltung katholischer Kirchen als Blendwerk: „Oock vele zyn verblint door haeren schoonen pracht“ ${ }^{619}$ Es ist deshalb davon auszugehen, dass de Heere die Vorbehalte de Morneys nicht nur gekannt und übersetzt hat, sondern sie auch persönlich vertrat. ${ }^{620}$ Stellt man seine Übersetzertätigkeit von 1580 dem 1559 veröffentlichten Lobgedicht auf die Brüder van Eyck und den Genter Altar gegenüber, wird ein erstaunlicher Gesinnungswandel deutlich. Es mag angenommen werden, dass die Verfolgungen nach 1566 eine Hinwendung zum Calvinismus befördert haben.

\subsection{Die Rekatholisierung von Mecheln und Brüssel: Die Position Michiel Coxcies}

Im Falle Coxcies kann von einer persönlichen Abneigung gegenüber der reformatorischen Bildkritik ausgegangen werden, wie dieser gegenüber dem neuen Statthalter brieflich erklärt. ${ }^{621}$ Als Hofmaler der Habsburger wird er

619 De Heere, Lucas: Tractaet ofte Handelinge van de Kercke, Antwerpen 1580.

620 Den Widerspruch zwischen de Heeres eigener Vergangenheit als Maler, der in seinen jungen Jahren für Philipp II. gemalt und diesen in seinem Gedicht auf den Genter Altar als Kunstfreund stilisiert hat und seine Hinwendung zum Calvinismus, führt JONCKHEERE ebenfalls an, lässt die endgültige Entscheidung über die Haltung de Heeres in der Bilddebatte jedoch offen (s. JONCKHEERE 2012, S. 7).

621 s. hierzu VAN Autenboer 1992, S. 8. 
die Haltung seines wichtigsten Auftraggebers ohnehin geteilt haben müssen. Mit dem Bildersturm von 1566 veränderte sich jedoch auch das gewohnte Lebens- und Wirkungsumfeld Coxcies dramatisch. Viele Kirchenausstattungen fielen in dieser Zeit den tobenden beeldbrekers zum Opfer, die sich gegen die vermeintlichen Götzen wandten und damit eine Vielzahl großartiger Werke der Vergangenheit und der Gegenwart unwiederbringlich vernichteten. ${ }^{622}$ Bemerkenswerterweise berichtet van Mander in diesem Zusammenhang über Pieter Aertsen, dass dieser über die Zerstörung seiner Werke, die er der Nachwelt hinterlassen wollte, dermaßen verärgert gewesen sei, dass er mit Wut und ,groote woorden ${ }^{\text {“623 und }}$ auf eigene Gefahr den Feinden der Kunst entgegengetreten sei. Da heute von diesem Maler fast ausschließlich Stillleben und Genreszenen überliefert sind, muss angenommen werden, dass der Großteil seiner sakralen Werke, die er selbst für die wichtigeren hielt, während des Bildersturms 1566 zerstört wurde. ${ }^{624}$ In diesem Zusammenhang sei erwähnt, dass bibli-

622 In Antwerpen bildete sich in dieser Zeit eine Gruppe mit dem Namen Huis der Liefde bzw. Familia caritatis, zu der sich eine Reihe von Humanisten und Verlegern bekannte; darunter etwa Christoph Plantijn u. Abraham Ortelius, welche den Lehren eines gewissen Heinrich Niclaes folgten und eine friedfertige Lösung in Form einer Assimilation der Lehren anstrebten (vgl. JONCKHEERE 2013, S. 118).

623 „Pieter was dickwils onverduldigh dat zijn dinghen die hy de Weerelt tot gedachtnis meende laten soo te nieten weerden ghebracht, ghebruyckende dickwils met sulcke constvyandighe groote woorden, tot zijn eyghen ghevaer oft perijckel" (van Mander 1604, S. 244).

624 Es ist auffällig, dass van Mander sich im Zusammenhang mit der Schilderung der Ereignisse sche Themen auch für die Bedeutung der Küchenbilder von Pieter Aertsen bedeutsam waren. Jan EMMENS beschreibt dies als ein $\mathrm{Zu}$ rücktreten der vormals zentralen religiösen Thematik hinter eine vermeintlich profane Genreszene, während die religiöse Aussage bestehen blieb. Die Konzentration auf alltägliche Gegenstände, wie von protestantischen Kritikern gefordert, wird Grundlage einer neuen protestantischen religiösen Malerei in den nördlichen Niederlanden. ${ }^{625}$

Coxcie war zum Zeitpunkt dieser Ereignisse bereits um die 70 Jahre alt und geehrtes Mitglied mehrerer katholischer Bruderschaften, so etwa der Schützengilde von Mecheln und der Broederschap van Onze-LieveVrouw in Brüssel. ${ }^{626}$ Einige der zerstörten Kunstwerke hatte er selbst als gefeierter Maler nach seiner Rückkehr aus Italien für die örtlichen Gilden geschaffen. Der Vandalismus betraf ihn persönlich und bedrohte seine gesellschaftliche Stellung. Was van Mander über Aertsen zu berichten weiß, wird in ähnlicher Weise auch für Coxcie gegolten haben. Verär-

von 1566 ungeachtet der Haltung seiner eigenen Konfession gegenüber sakralen Bildnissen, auf die Seite der Künstler stellt und so etwa die Zerstörung der wichtigsten Werke von Anthonis Blocklandt als „,blinden ijver“ bezeichnet. Auch resümiert er, dass nur ,weynich [...] over gebleven" sei und meint damit den Verlust zahlreicher Kunstwerke (van Mander 1604, S. 254). An anderer Stelle wiederholt er ähnliche Äußerungen, so etwa in Bezug auf die Werke von Jan van Scorel und Dirck Barendsz, von denen ebenfalls nur Weniges erhalten blieb.

625 Vgl. Emmens 1981, Bd. 2., S. 189-221. Vgl. auch WeSTSTEIjN 2012, S. 109.

626 Vgl. GOETSCHALKx 1906, S. 411 u. VAN AUTENBOER 1992. S. 20-22. 
gert über die Ereignisse und durch seine $\mathrm{Zu}$ gehörigkeit $\mathrm{zu}$ katholischen Vereinigungen wird er womöglich sogar aktiv in die antireformatorische Agitation verwickelt gewesen sein. JONCKHEERE beschreibt es sehr anschaulich mit den Worten, dass Coxcie als königstreuer und traditionsbewusster Katholik vermutlich bereit gewesen sei, „, für Gott und König in den Kampf zu ziehen“. ${ }^{627}$ So wundert es nicht, dass Coxcie unmittelbar nach der Rückeroberung von Brabant und seiner Heimatstadt Mecheln Fühlung zum neuen habsburgischen Statthalter Alessandro Farnese aufnahm und später, wie wir aus einem erhaltenen Briefwechsel zwischen Coxcie und dem neuen Generalstatthalter rekonstruieren können, in dessen Sold stand. ${ }^{628}$ Einmal mehr wird darin die Nähe Coxcies zur politischen Elite der Exklave deutlich, die ihn maßgeblich an den beiden Phasen der Wiederherstellung der kirchlichen Ordnung, zunächst ab 1567 und dann erneut ab 1585, beteiligte, indem sie ihn mit zahlreichen Aufträgen versah. ${ }^{629}$

Mit der Eroberung von Mecheln und Antwerpen im Jahr 1585 durch den katholischen Feldherrn Alessandro Farnese, der als Statthalter von Philipp II. in die Niederlande entsandt worden war, konnten zwei wesentliche Zentren wieder unter die Kontrolle der

627, ,[...] he was evidently willing to do battle for God and King" (JONCKHEERE 2013, S. 118 mit Bezug auf die besprochene Quelle bei VAN AUTENBOER 1992, S. 8.

628 In diesem Brief betont Coxcie seine in 50 jähriger Tätigkeit geleisteten Verdienste für den habsburgischen Hof, um sich den Statthalter gewogen zu machen und um Geld von diesem zu erhalten (s. hierzu VAN DEN BOOGERT 1992a, S. 124, Nr. 9). Daran lässt sich ableiten dass Coxcie sich zu diesem Zeitpunkt in finanziellen Schwierigkeiten befand (vgl. JONCKHEERE 2013a, S.
Habsburger gebracht werden. Farnese besiegelte damit die Rekatholisierung des Landes, deren Grundstein jedoch bereits unmittelbar nach 1566 durch den Herzog von Alba gelegt worden war. Unter dem calvinistischen Regiment und den vorangegangenen Unruhen waren viele Kunstschätze den Bilderstürmern zum Opfer gefallen und selbst dort, wo der katholische Gottesdienst stillschweigend toleriert worden war, standen umfangreiche Wiederherstellungs- und Erneuerungsarbeiten an. ${ }^{630} \mathrm{Um}$ den Zustand vor der Unabhängigkeit wiederherzustellen und die Feier der Messe zu gewährleisten, bedurfte es neuer Altäre an alten Stätten, die ihres Bildschmucks beraubt worden waren. Genau in diese Zeit, etwa in die frühen 1570er Jahre, fällt die letzte Blüte Michiel Coxcies, der sich als einstiger Hofmaler der habsburgischen Statthalterin und Protegé Philipps II. und Kaiser Karls V. als durch und durch katholischer Künstler Jahrzehnte lang hatte unter Beweis stellen können. Ab 1568 übernahm er zahlreiche Aufträge und half dabei, die zerstörten Altäre mit neuen Bildern auszustatten. Seine Werkstatt in Antwerpen ließ er zeitweilig zurück, um sich der Aufgabe in seiner Heimatstadt zu widmen. ${ }^{631} 1572$ übersiedelten er und seine Frau

45). Der König gewährte schließlich seine Unterstützung: ,,[...] estant réduit à tel estat que ne luy est possible de gaigner sa vie par son art, en laquelle il a esté non peu renommé“ (s. PINCHART 1860-1861, Bd. 2, S. 320 f.).

629 Vgl. JONCKHEERE - SUYKERBUYK 2013, S. 43.

630 Vgl. JONKCHEERE - SUYKERBUYK 2013, S. 43.

631 Für das Jahr 1584/85 war Michiel Coxcie in Antwerpen gemeldet (s. RoEY 1966, S. 122) und taucht in den Listen der Lukasgilde von 1885 bis 
jedoch bereits wieder nach Antwerpen, möglicherweise auf Grund der Unbill, denen die Werkstatt trotz einer Befreiung davon spanische Soldaten aufnehmen zu müssen, weiterhin ausgesetzt war. ${ }^{632}$

In der Folgezeit entstanden eine Reihe von Altären mit der Darstellung von Heiligenmartyrien, darunter mehrere Triptychen zum Leben des Hl. Sebastian und des Hl. Georgzwei Heilige, die stark mit den lokalen Schützengilden in Mecheln und Antwerpen verbunden werden können. Von diesen Gilden gingen entsprechend auch die Aufträge für diese Werke aus. Zu nennen sind hier das Retabel für die Oude Handboog von Antwerpen mit dem Martyrium des Hl. Sebastian Mitte der 1570er [ABB. 110] sowie ein weiteres Sebastiansretabel für die Mechelner Sint-Rombouts-Kathedrale in den frühen 1580er Jahren [ABB. 116], das sich motivisch stark an dem älteren Werk orientiert. Ähnlich verhält es sich auch bei dem Mechelner Georgsretabel aus Sint Rombouts von 1588 [ABB. 120] und einem früheren, wiederum für die Antwerpener Armbrustschützengilde geschaffenen, nur fragmentarisch erhaltenen Retabel (um 1574-

1888 mehrfach auf (s. ROMBOUTS - LERIUS 1872-1876, Bd. I, S. 301). Vgl. auch WOOLLETT 2012, S. 75 f.

632 Nach den überlieferten Zeugenaussagen des Malers Daniel Snellinck, möglicherweise ein Werkstattgeselle (?), sei das Haus Coxcies kurz zuvor beschädigt worden (s. VAN AUTENBOER 1992, S. 9). Weiterhin wurden Maler aus Mecheln, die durch die Besatzung darin gehindert wurden, ihre Handwerk auszuüben, übergangsweise von der Lukasgilde in Antwerpen aufgenommen (s. ROMBOUTS - LERIUS 1872 1876, Bd. 1, S. 245-46).

633 Vgl. WOOLLETt 2012, S. 75-94; VAN DE VELDE 1992, S. 195-214.
1575). ${ }^{633}$ Diesen Werken ist eine Fokussierung auf das Martyrium, das heißt die Opferbereitschaft der Heiligen zu eigen, welches von den zeitgenössischen Betrachtern auf das Selbstverständnis der katholischen Milizen bezogen werden konnte. Die Selbstdarstellung Coxcies als Hl. Georg auf der Außenseite des Triptychons für die Antwerpener Gilde der Armbrustschützen Mitte der 1570er Jahre bezeugt diese Lesart insofern, als sie zu verstehen geben soll, dass der Maler sich mit der Rolle des Märtyrers Georg als Patron und Symbolfigur der katholischen Milizen identifiziert [ABB. 122]. Dieser zentrale inhaltliche Aspekt dieser vier herausragenden Altarretabel soll zusammen mit einem weiteren Werk, dem Triptychon für die Sakramentskapelle von St. Gudula in Brüssel, in den folgenden beiden Abschnitten erörtert werden. ${ }^{634}$

$\mathrm{Zu}$ seinen späten Werken gehört weiterhin ein am 2. Januar 1586 geliefertes Altarbild für die Kapelle der Bäcker in Mecheln, ${ }^{635}$ danach entstanden weitere Gemälde für die Gilden der der Bogenschützen sowie die beiden Zünfte der Maurer und der Bierbrauer. ${ }^{636}$ Ebenso schuf er noch das Kreuzigungstriptychon

634 Das sog. Sakramentstriptychon sowie die Retabel mit den Martyrien von Sebastian und Georg werden in Abschn. 4.2.1 u. 4.2.2 behandelt, während die Selbstdarstellung als Hl. Georg unter Abschn. 4.3 zur Sprache kommt.

635 Das Altarbild für die Bäcker zeigte die Geschichte von David und Abigail, ein recht seltenes Motiv. Van Autenboer 1986, S. 215 u. JACOBS 1993, S. 217 gehen davon aus, dass dieses Gemälde heute verloren ist.

636 Der Vertrag mit der Bogenschützengilde von Mecheln vom 3. Januar 1587 hat sich erhalten. Es handelt sich um das Triptychon mit dem Martyrium des Hl. Stephan (Sint Rombouts, Mecheln) welches am 25. Oktober desselben 
für die Brüsseler Marienbruderschaft von St. Michael und St. Gudula von 1589 und das Triptychon mit Darstellungen aus dem Leben der Hl. Gudula, das er 1592 vollendete. ${ }^{637}$ Die zuletzt genannten Altarwerke, die in Brüssel ausgeführt wurden, bilden den Abschluss der Karriere des inzwischen hochbetagten Malers, der danach erneut nach Antwerpen übersiedelte, um dort den Auftrag zur Ausmalung des Ratssaals zu übernehmen. Von dem Sturz von einem Gerüst soll er sich nicht mehr erholt haben und verstarb bald darauf, wovon van Mander zu berichten weiß: ,[...] vallende van de steygheringhe, is [hij] eenighen tijt hier nae ghestorven, in’t Iaer ons Heeren 1592“. ${ }^{638}$ Die zeitliche Nähe des Erscheinen des SchilderBoeck zum Tode Coxcies spricht für einen zutreffenden Bericht, obschon auch hier höchstwahrscheinlich eine Ausschmückung im Sinne des Künstlerlobes vorliegt, in welcher die rege Betriebsamkeit des Malers bis kurz vor seinem Tod betont wird. Der Wahrheitsgehalt dieser Behauptung lässt sich nicht exakt ermitteln,

Jahres auf dem rekonsekrierten Altar aufgestellt wurde (s. VAN AUTENBOER 1986, S. 217). Das Retabel ist überdies signiert: „MICHIEL D. COXCIEN PICTOR REG. FECIT ANNO 1587. AETAT. SUAE 88“. Ähnlich verhält es sich mit dem Triptychon mit dem Martyrium des Hl. Georg, (ebenfalls Sint Rombouts) für die Gilde der Armbrustschützen, welches am 27. April 1588 ausgeliefert wurde: „MICHAEL VAN COXCIEN PICTOR REGIUS ME FECIT. ANN. 1588 AETATIS SUSAE 89““ (s. JACOBS 1993, S. 228).

Auch das Retabel für die Maurer ist in den Quellen überliefert. Der Altar (Sint Rombouts) wurde zwar bereits am 5. September 1585 geweiht; das Altarbild folgte jedoch erst 1589. Erhalten hat sich nur das Mittelbild mit der Beschneidung sowie dessen Signatur: „MICHIEL D. COXCIEN FECIT 1589. AETATIS SUE während jedoch ihre Intention durch einige in den späten 1580er Jahren signierte und datierte Werke durchaus plausibel erscheint.

\subsubsection{Das Triptychon mit dem Letzten Abendmahl von 1567}

Für die berühmte Sakramentskapelle von St. Michael und St. Gudula, die heutige Kathedrale von Brüssel, schuf Michiel Coxcie 1567 unmittelbar nach den Unruhen des Bildersturms ein neues Altarretabel. ${ }^{639}$ Die Kapelle war erst 1534-1539 in einem spätgotischen Stil erneuert worden. Das genaue Ausmaß ist unklar, dennoch ist von einer Zerstörung der alten Ausstattung auszugehen, da Michiel Coxcie bereits im Folgejahr ein neues Hochaltarretabel mit den Darstellungen des Letzten Abendmahls, der Fußwaschung und dem Gebet am Ölberg auf der Innenseite sowie Elija in der Wüste auf der Außenseite zum Abschluss brachte [ABB. 103-105]. ${ }^{640}$ Dabei steht

90“ (vgl. VAN AUtENBOeR 1986, S. 216 u. JACOBS 1993, S. 236). Das letzte Retabel dieser Auftragsfolge wurde laut Vertrag am 27. Juli 1589 (s. INSTALLÉ 1981, S. 191, Nr. 448) von der Bierbrauerzunft in Auftrag gegeben, nach dem der Altar bereits 1585 geweiht worden war (vgl. VAN AUTENBOER 1986, S. 215).

637 Zum Kreurigungstriptychon s. ROOBAERT 2005, S. 191. Beide Altäre befinden sich noch in der Kirche. Das St. Gudula-Retabel enthält die Signatur Coxcies: „ME MICHAEL VAN COXCIE PICTOR REGIUS FECIT ANNO SALUTIS 1592. ATATIS VERSO SVAE 92“ (s. JONKCHEERE SUYKERBUYK 2013, Anm. 113).

638 Van Mander 1604, fol. 259r

639 Die Signatur ist auch hier erhalten: „MICHEL. D COXCIE / 1567“.

640 Öl auf Holz, $279 \times 250 \mathrm{~cm}$ (Mitteltafel), $278 \times$ $102 \mathrm{~cm}$ (Seitenflügel), Koninklijke Musea voor Schone Kunsten, Brüssel, Inv.-Nr. 42. 
das Retabel sowohl inhaltlich als auch stilistisch in einer engen Beziehung zu den Glasfenstern, mit denen die Kapelle seit 1541 sukzessive ausgestattet wurde. Man geht heute davon aus, dass die meisten Vorlagen von Bernard van Orley stammen. Da dieser bereits nach Vollendung des ersten Fensters durch Jan Haeck verstarb, wurde Michiel Coxcie damit betraut, die Serie fortzuführen. ${ }^{641}$ Das erste Fenster zeigt Karl V. und seine Frau Isabella von Portugal knieend vor dem ausgesetzten Altarsakrament. Eine Zeichnung des Bernard van Orley für das Fenster mit Johann III. von Portugal und Katharina von Kastilien [ABB. 106], heute in der Ermitage in St. Petersburg, ${ }^{642}$ zeigt große Ähnlichkeiten mit dem von Michiel Coxcie 1547 entworfenen Fenster mit Ludwig II. und Maria von Ungarn [ABB. 107], ${ }^{643}$ weshalb man davon ausgehen muss, dass dieser auf die Kartons seines Lehrers zurückgreifen konnte. Erkennbar ist dies an der reichen antikisierenden Renaissancearchitektur und den Figuren, die jeweils in einer monumentalen offenen Halle dargestellt sind. Die Figur Johannes des Täufers, dem Namenspatron des portugiesischen Königs, die hinter den knieenden Monarchen steht, ist in Bezug auf ihre Position im Bild, ihre Haltung und den leicht ins Profil gewendeten Kopf mit der des Königs auf Coxcies Fenster vergleichbar. Auch die Figuren von Ludwig und Maria stimmen in Position und Haltung mit denen von

641 Vgl. JONCKHEERE 2013b, S. 127 u. REINTJENS 2013, S. 140.

642 Zeichnung, Eremitage, St. Petersburg (s. REINTJENS 2013, Abb. 140).

643 Jan Haeck (nach Michiel Coxcie), Glasfenster, Sakramentskapelle, St. Michael und St. Gudula, Brüssel.
Johann III. und Katharina von Österreich auf dem Entwurf Bernard van Orleys überein. Anders ist die Wahl des Architekturmotivs, das statt eines zentralen Rundbogens oder genauer eines Quadrifrons, wie er auf van Orleys Zeichnung und dem einzigen nach seinen Entwürfen ausgeführten Fenster zu sehen ist, eine Art Portikus mit ionischen Säulen wiedergibt, während die Bogenarchitektur seines Lehrers in beiden Fällen auf Pfeilern ruht, welche die für van Orley typische Gestaltung mit Flachreliefs und ornamental verzierten Kapitellen aufweisen.

Weitere Fensterentwürfe von Coxcie für die Kapelle bringen Ferdinand von Österreich und Anna von Böhmen vor Augen (1546). ${ }^{644}$ Alle diese Fenster zeigen aufwendige Renaissancearchitekturen, die in der Tradition von Triumphbögen und den großen herrscherlichen Einzügen stehen und an vergleichbare ephemere tableaux erinnern, wie sie von Frans van de Velde anlässlich des Einzugs von Karl V. und Philipp II. in Gent im Jahr 1549 entworfen und von Jan Liefrinck (1518-1573) noch im gleichen Jahr in Kupferstichen veröffentlicht wurden. ${ }^{645}$ Diese zeigen eine gewisse Verwandtschaft mit den von Coxcie gewählten Architekturformen, wenn auch keine direkte Übereinstimmung [ABB. 108]. ${ }^{646} \mathrm{Zu}$ sehen ist etwa ein Triumphbogen, der sich mit dem unteren Geschoss an antiken römischen Vorbildern orientiert - eine Bezugnahme, die durch

644 Vgl. REINTJENS 2013, S. 145-147. Abbildungen finden sich bei ebd., Nr. 141, 142, 144 u. 145.

645 Eine Abbildung findet sich ebenfalls bei REINTJENS 2013, S. 151, Nr. 149.

646 Der Titel der Kupferstichserie lautet Arcus triumphales Quinqe a SPQG Philippo Austrie Caroli imp. Princip. [...], Antwerpen 1549. 
die Beischrift, die Karl V. als „imperator“ und „princeps“ betitelt, inhaltlich vertieft wird. ${ }^{647}$ Das Triptychon zeigt drei Szenen aus der Passion Jesu: Links die Fußwaschung, rechts das Gebet in Gethsemane und in der Mitte das Letzte Abendmahl. Die Mitteltafel und der linke Seitenflügel nehmen die Monumentalarchitektur in den Glasfenstern auf, indem sie die biblischen Ereignisse in einer imposanten Palastarchitektur zeigen. In beiden Szenen wird der gleiche Raum gezeigt, der aus unterschiedlichen Blickwinkeln wiedergegeben ist. Im Vordergrund des linken Flügels ist Christus zu sehen, wie er vor einem der Jünger in der Hocke sitzt und diesem die Füße wäscht. Die anderen Apostel sind im dahinterliegenden Raum hintereinander gestaffelt, was mit der vertikalen Ausrichtung des Bildes zusammenhängt. Die schräg in den Hintergrund fluchtenden Pfeiler gleichen das schmale Format der Tafel aus und erzeugen eine räumliche Tiefenwirkung. Coxcie hat Ähnliches auch bei seinem Marienretabel aus den 1550er Jahren eingesetzt, um das schmale Format der AuBenflügel zu kompensieren. ${ }^{648}$ Die Wahl eines entsprechenden Innenraums aus unterschiedlicher Perspektive bei zwei der drei Darstellungen führt dazu, dass die Szene der Mitteltafel als anschließendes Geschehen an dem selben Ort erkannt werden kann, ohne dass damit jedoch eine Gleichzeitigkeit des Geschehens gemeint ist. Die Mitteltafel zeigt Christus und die Apostel an einer schräg in dem Raum gestellten Tafel. Im Zentrum erscheint der Heiland, der die rechte Hand im Redegestus erhoben hat; dargestellt ist die Verratsankündigung, die den ihm gegenübersitzenden Judas betrifft. Auffällig und an prominenter Stelle ist zuvorderst ein Knabe dargestellt, der zwei metallene Kannen hält und von der einen in die andere umfüllt. Der Apostel Petrus rechts am Tischende sieht ihm dabei zu. An der zum Betrachter gewendeten Längsseite des Tisches sitzt vorne links ein weiterer Apostel, der als Rückenfigur gestaltet ist und seinen rechten Arm fragend von sich streckt. Ähnliche Gebärden finden sich bei der Figur links am Tisch sowie bei dem Apostel am hinteren Tischende, der beide Hände abwehrend erhoben hat, so als würde er die soeben von Christus ausgesprochene Verratsankündigung von sich weisen wollen. Rechts von Christus ist Johannes zu sehen, der sich mit dem Kopf an die Schulter Jesu schmiegt, während seine Hände ineinandergelegt auf dem Tisch ruhen. Sein Blick wirkt konsterniert und korrespondiert auf diese Weise mit der Betroffenheit der anderen Jünger über die soeben gehörte Ankündigung. Rechts hinter dem Tisch ist eine weitere Gruppe von drei Personen dargestellt, die sich über die Worte Jesu erregt austauschen. Alle anderen Figuren tragen antikisierende Gewänder mit togaartigen Mänteln, die Coxcie bereits in früheren Darstellungen verwendet hat. Der Boden ist mit Fliesen oder einem Steingeplätte ausgelegt. Ein offen gestalteter Gang zwischen Säulen und Pfeilern gewährt vage Einblicke in tieferliegende Räumlichkeiten und öffnet das Bild zur linken Seitentafel hin, mit der es sich die Hintergrundarchitektur gewissermaßen teilt. Hinter dem Haupt Christi erhebt sich im Mittelgrund 
eine Art Wandvorsprung, der mit toskanischen Pilastern und zwei Rundbogennischen versehen ist. Beide Nischen zeigen eine muschelförmige Kalotte mit Gebälk sowie einer farbig abgesetzten Laibung, die unten auf einer Art Sockel aufsitzt. Darauf sind Inschriften mit hebräischen Buchstaben angebracht, während die Nischen leer sind. Rechts unterhalb dieser Pfeiler und hinter den beiden zeitgenössisch gekleideten Figuren rechts erhebt sich erhöht ein zweistufiger Schautisch. Auf diesem sind verschiedene Gefäße zu sehen, bei denen es sich augenscheinlich um Silberschmiedearbeiten handelt; darunter eine große Kanne in der Mitte, um die herum eine Girlande gelegt ist, links davon ein vergoldeter und ornamentierter Deckelpokal sowie weitere mehr oder weniger wertvoll wirkende polierte Metallgefäße, die das von links einfallende Licht reflektieren.

Neben der bloßen Tatsache, dass es sich um das Retabel für die Sakramentskapelle von St. Gudula handelt, liefert das gewählte Thema mit der zentralen Darstellung des Letzten Abendmahls auch gestalterisch eine Reihe von Hinweisen, die im Zusammenhang mit dem umgebenden Raum und der Funktion der Kapelle stehen. Obwohl das Abendmahl hier augenscheinlich mit dem Fokus auf die Verratsankündigung zu verstehen ist und nicht etwa als Einsetzung des Altarsakramentes (etwa in Form einer Apostelkommunion), lassen sich gewisse Details, wie die arrangierten Gegenstände auf dem Tisch, indirekt mit der Messfeier in Verbindung bringen. Bedenkt man die Aufstellung in der Sakramentskapelle, ist stark von einer entsprechenden Bezugnahme auszugehen. So deutet der Knabe im Vordergrund, der offenbar gerade damit beschäftigt ist, den Wein mit Wasser zu mischen, auf die Vermengung von Wein und Wasser hin, die der Priester unmittelbar vor dem Messkanon bei der Opferbereitung bzw. dem Offertorium durchführt, was symbolisch für die Zwei-Naturen-Lehre Christi steht. ${ }^{649}$ Weiterhin ist der Pokal vor Christus das einzige dargestellte Trinkgefäß auf dem Tisch und noch dazu kelchförmig gestaltet, während davor eine flache Schale mit Brotkrumen steht - was wiederum auf die Patene verweist, auf welcher der Priester die Hostie darbringt und von der er sie während des Messkanons aufhebt und nach der Wandlung emporhebt, damit die Gemeinde den Leib Christi ansehen und anbeten kann. ${ }^{650}$ Die Repräsentation von GefäBen auf dem höhergelegenen Schautisch weckt zudem gewisse Assoziationen mit einem Hochaltar, auf dem eine Vielzahl von Reliquiengefäßen aufgestellt ist. Die Gegen-

Völker Wasser genannt werden, so wird die Vereinigung des gläubigen Volkes mit Christus dem Haupt dargestellt.“" (22. Sitzung [1562]: Sacrosancta oecumenica. 7. Kap. Über das Opfer der Hl. Messe, s. DenZINGER 1973).

650 Damit ergibt sich ein „Vorgeschmack auf die Gottesschau“, die den Frommen im Himmel erwarte, die sogenannte, visio beatifica' (s. DENZINGER - HÜNERMANN 2005, Nr. 1000-1002). 
stände verweisen einerseits auf solche Reliquiare und Vasa Sacra und andererseits auf exklusive weltliche Luxusgüter, um die es sich der Darstellung nach tatsächlich handelt. So gehörte die Ausstellung kostbarer Silberschmiedearbeiten im Zusammenhang mit Hoftagen und festlichen Banketten im 16. Jahrhundert zum höfischen Zeremoniell, wie denn eine vormals Frans Floris zugeschriebene Zeichnung (?), welche die 1565 stattgefundene Hochzeit von Alexander Farnese mit Maria von Portugal zeigt [ABB. 109], einen vergleichbaren dreistufigen Tisch mit Schaugefäßen wiedergibt. ${ }^{651}$ Coxcies Bild verknüpft den weltlichen Prunk, wie er ihn möglicherweise von den habsburgischen Höfen kannte, mit der Darstellung des Letzten Abendmahls. Auch wird eine inhaltliche Verknüpfung zwischen dem Abendmahl und dem unblutigen Opfer der Eucharistie hergestellt, indem Christus und seine Jünger unmittelbar vor dem einen Altar andeutenden Schautisch versammelt sind - dem Ort also, wo die Kommunion stattfindet.

Ihre kritische Note erhält die Darstellung, wenn man sie im Kontext der gerade einmal ein Jahr zurückliegenden Zerstörungen betrachtet. So waren wertvolle Vasa Sacra und Messgewänder schon lange zuvor der Kritik seitens der Calvinisten ausgesetzt gewesen und oft mit dem Bibelwort kommentiert wor- den, nach dem irdische Reichtümer den $\mathrm{Zu}$ gang ins Himmelreich verstellen (Mt 19,23). In Folge dessen ist es wenig verwunderlich, dass neben Kunstwerken auch ebensolche sakralen Gegenstände, und diese meint Coxcie hier, daran ist kein Zweifel, von den Bilderstürmern zerstört wurden. ${ }^{652}$ Ein zentraler Aspekt der Darstellung sind die beiden leeren Nischen hinter Christus, die keine Skulpturen enthalten, für die sie üblicherweise gedacht sind. So ist auf der Mitteltafel von Coxcies Retabel mit der Heiligen Sippe aus Kremsmünster im Hintergrund eine sehr ähnliche rundbogige Nische mit der Skulptur eines Jünglings zu sehen [ABB. 61]; Ähnliches auch auf dem Kupferstich von Hieronymus Cock, der den Innenhof und die Antikensammlung des Palazzo Valle-Capranica in Rom zeigt [ABB. 64].

Die beiden Inschriften unter den $\mathrm{Ni}$ schen im Hintergrund der Abendmahlsdarstellung zitieren das zweite und dritte Gebot (Ex 20, 3-4). Dort heißt es: „Du sollst neben mir keine anderen Götter haben“, und: „Du sollst dir kein Kultbild machen und keine Gestalt von irgendetwas am Himmel droben, auf der Erde unten oder im Wasser unter der Erde“. ${ }^{653}$ Beide Gebote gehören gewissermaBen zum Standardrepertoire der calvinistischen Gegner der Bilderverehrung. ${ }^{654}$ Die Provokation könnte kaum größer und zugleich subtiler sein. Unmittelbar unterhalb des

652 Vgl. JONCKHEERE 2013b, S. 128 f. u. JONCKHEERE 2012, S. 245-248.

653 Zit. nach der Einheitsübersetzung (1980). Die Übersetzung des Hebräischen stammt von JONCKHEERE 2013b, S. 127.

654 Vgl. WeStSTEIjN 2012, S. 109-130. 
analog zu Moses Gesetzestafeln in Stein gemeißelten biblischen Bilderverbots ist Christus, der Sohn Gottes im Kreis seiner Jünger zu sehen. Es ist klar, was der Maler damit auszudrücken beabsichtigt: Christus allein gebühren Anbetung und Ver-herrlichung.

Zugleich verdeutlicht das Bild auch zentrale Kritikpunkte von Molanus, indem es zu verstehen gibt, dass mythologische Darstellungen und Aktfiguren in keiner Weise mit der Darstellung Christi und der Heiligen zu vermischen sind. ${ }^{655}$ Damit ist die Bildaussage nicht nur als provokativ zu werten, sondern letztlich auch von den jüngsten Ereignissen berührt, auch wenn sie diese von der Warte einer eindeutigen Gegenposition aus kommentiert. Interessant ist auch, dass sich in dem Bild jene Punkte visualisiert finden, die Anna Bijns in ihrer Gedichtsammlung Refereinen von 1565 anspricht, etwa die Zerstörung von „Kelchen“ und „Ziborien“ zusammen mit den Bildern „der Heiligen“ und solcher, die an „Christi Tod erinnern“ ${ }^{656}$ Es kann davon ausgegangen werden, dass das Retabel, ähnlich wie der moralisierende Text von Bijns die Argumentationsweise der gegenreformatori- schen Partei innerhalb der südniederländischen Bevölkerung thematisiert. Die eigentliche Provokation hingegen, die zugleich als neuartig zu bezeichnen ist, liegt in der subtilen Weise mit der auf die Bilderfrage Bezug genommen wird. Da das Retabel erst 1567 fertiggestellt wurde, besteht die große Wahrscheinlichkeit, dass Konzeption und Beauftragung bereits vor den Ereignissen des Jahres 1566 stattgefunden haben. Dementsprechend sind Thematik und Umsetzung der Darstellungen vergleichsweise bedachtsam gewählt und versuchen, die Standpunkte der Protestanten im Bild zu untergraben, indem die Behauptung, der katholische Bildergebrauch hätte zur Abgötterei geführt, mit demselben Verweis auf die Bibel entkräftet wird, mit dem die calvinistische Seite ihre Angriffe begründete. Bereits zwei Jahrzehnte zuvor ging es Coxcie bei seinem Marienretabel von 1550 um die vergleichsweise subtile Akzentuierung der von den Protestanten abgelehnten assumptio corporis. Dezidiert gegenreformatorische Ideen im Werk Coxcies sind somit nicht erst seit dem Bildersturm von 1566 nachweisbar. ${ }^{657}$

solche Bilder von nackten mythologischen Gestalten in ihren Häusern dulden (vgl. FREEDBERG 1988, S. 94).

656 „Tes nieu datmen kelcken breeckt / en ciborien; De sancten die met Christo sijn in glorien; Veracht / en haer beelden wijst te viere; Ja cruys Christi / dat syn doodt bringt in memorien; Doetmen wech / in stede vreemde historien [...]“ (Anna Bijns: Tweede Boeck Vol Schoone Ende Constighe Refereynen, Antwerpen 1565, S. 56 f.).

657 Dies wurde zuvor bereits in Abschn. 3.3.4 thematisiert. 
4.2.2 Die Heiligendarstellungen von Michiel Coxcie in den 1570er und 1580er Jahren

Nimmt man solche Altarbilder in den Blick, die Coxcie in den 1570er und 1580er Jahren für die Schützengilden von Antwerpen und Mecheln schuf, gewahrt man eine Reihe von affektvollen Darstellungen, die das Martyrium der Gildenpatrone Georg und Sebastian zum Thema haben. Die legendarisch überlieferten Geschehnisse gehören zu den problematischen Stoffen im Zeitalter der Konfessionalisierung, wie weiter oben erörtert. Bei aller Kritik an der Historizität des Hl. Georg, sah Johannes Molanus in diesem ein Vorbild für katholische Christen. ${ }^{658}$ Dem Anschein nach ist Coxcie dieser Problematik auf eine für ihn in dieser Zeit eigentümlich provokative Art begegnet. ${ }^{659}$ Die katholische Gesinnung, die man ihm nicht allein wegen der Aufträge, die er von

658 Auf protestantischer Seite übte u. a. Philips van Marnix Kritik an den Heiligenlegenden. Auch Molanus zeigte gegenüber den Erzählungen der Legenda Aurea Vorbehalte, wollte dieses jedoch nicht verboten sehen (Molanus 1594 [1771], S. 89: ,,[... nam quaedam ex apocryphis sumpta aliunde habent probabilitatem"), da sie wie andere nichtbiblische Stoffe als allegorische Hilfestellungen dienen würden (vgl. FREEDBERG 1988, S. 142). Molanus beließ es nicht nur bei der Kritik, sondern entwarf selbst Korrekturen für bestimmte Darstellungen (vgl. BLUNT 1940 [1978], S. 127).

659 Überhaupt erwecken einige seiner Werke den Eindruck, dass die neugeschaffenen Richtlinien für die Zensur von Bildern vielfach keine Anwendung fanden. Es ist äußerst spekulativ sich hierbei auf mögliche Erklärungsansätze einzulassen: Zum einen könnte die aufgeheizte Situation unmittelbar nach dem Bildersturm von 1566 gewisse Freiräume zugelassen haben, wenn es darum ging die Heiligen als starke Heldengestalten zu inszenieren, um den Gegnern der katholischen Partei an bestimmten Stellen nicht den Eindruck von Schwäche zu vermitteln. den katholischen Bruderschaften erhielt, zusprechen kann, sondern die sich auch anhand der überlieferten Selbstzeugnisse ausmachen lässt, ${ }^{660}$ findet in den Altarbildern nach 1566 ihren Niederschlag, indem er die Heiligen in seinen Bildern neu definiert und den Fokus besonders auf das freiwillige Erdulden von körperlichem und seelischem Leid richtet. ${ }^{661}$ Für die Oude Handboog von Antwerpen etwa galt es 1575, ein Triptychon mit dem Martyrium des Hl. Sebastian zu gestalten [ABB. 110], nachdem der ursprüngliche Altar der Gildenkapelle mutmaßlich 1566 zerstört worden war. ${ }^{662}$ Die Seitenflügel des neuen Retabels wurden ihrerseits während der erneuten ikonoklastischen Übergriffe des Jahres 1581 zerstört oder bereits zuvor unter der calvinistischen Herrschaft der sogenannten Antwerpse Republiek (1577-1585) veräußert. ${ }^{663}$ Erst

Gleichzeitig verweisen deutlich spätere Visitationsberichte, dass die Richtlinien offenbar in Teilen Anwendung fanden. Für 1604 etwa ist überliefert, dass ein heute nicht erhaltenes Werk Coxcies mit der Darstellung von David und Abigail auf dem Altar der Bäcker in Sint-Rombouts in Mecheln die Aufmerksamkeit der Zensoren erweckt habe (Mecheln, St. Romuald: Acta Capitularia, Visit. Eccl. Reg. I, 1604, veröffentlicht bei LAENEN 1920, S. 215, Anm. 10; ebenfalls abgedruckt bei FREEDBERG 1988, Apendix I.). Ein weiterer Bericht aus selbigem Kirchenregister erwähnt die erfolgreiche Übermalung nackter Körperpartien in Coxcies Anbetung der Könige auf dem Marienaltar von SintRombouts (s. LAENEN 1920, S. 234, nach Acta Capitularia, Visit. Eccl. 1624 und 1632).

660 Vgl. Van Autenboer 1992, S. 8.

661 Vgl. WoOLLETt 2012, S. 86.

662 Öl auf Holz, $267.2 \times 235 \mathrm{~cm}$, Koninklijk Museum voor Schone Kunsten, Antwerpen. Vgl. FREEDBERG 1976, S. 128.

663 Vgl. WoOlLEtt 2012, S. 86; VAN DE Velde 1992, S. 210. 
zehn Jahre später wurden sie durch zwei stilistisch der Mitteltafel verwandte Szenen aus der Werkstatt des Ambrosius Francken ersetzt, ein Maler der neben Coxcie ab den frühen 1580er Jahren von der Wiederherstellung der katholischen Altäre profitierte. ${ }^{664}$ Entsprechende Darstellungen waren vormals ganz der Meditation über das Martyrium bzw. die ChristusNachfolge des Heiligen gewidmet und zielten folglich darauf, dem Beschauer eine dem Vorbild des Heilands nacheifernde Bereitwilligkeit des Leidens, zugleich aber auch die Verdienste des Heiligen vor Augen zu führen. ${ }^{665}$ So zeigt Hans Memlings Martyrium des Hl. Sebastian von ca. 1475 noch eine anders geartete, schlank proportionierte Körperlichkeit, die für diese Zeit typisch ist und den Heiligen in seinem christusähnlichen Leiden akzentuiert [ABB. 111].

Über die ursprüngliche Aufstellung haben sich keinerlei Informationen erhalten; denkbar ist jedoch, dass es sich auch hierbei um das Altarbild der Kapelle einer der Brügger Schützengilden handelt, sodass sich ein vergleichbarer Auftraggeberkontext wie bei Coxcies Antwerpener Sebastiansretabel von

664 Die neuen Szenen von Ambrosius Francken zeigen den Hl. Sebastian vor Diokletian, die Marter Sebastians mit dem Eisen, den Hl. Sebastian im Kerker sowie die Wundersame Heilung der Zö̈ (heute Koninklijk Museum voor Schone Kunsten, Antwerpen, Inv.-Nr. 151-154, s. VAN DE VELDE 1992, S. 210 f. u. PeETERs 2000, S. 200, Kat. A7. Für Franckens Altäre der frühen Gegenreformation vgl. FREEDBERG 1976, S. 128-138.

665 Vgl. WOOLLETT 2012, S. 86.

666 Vgl. STROO-SYFER - D’OLNE 1999, S. 196; B. G. LANE gibt weiterhin an, dass der Sebastian von Memling in einer Spitalskapelle gestanden haben könnte, weil der Hl. Sebastian traditionell
1575 ergibt. ${ }^{666}$ Coxcies Sebastian steht in derselben ikonographischen Tradition wie der von Memling. Zahlreiche vergleichbare Darstellungen, wie etwa die auf dem sog. Sebastiansaltar von Hans Holbein, d. Ä. von 1516 zeigen den Heiligen auf eine sehr ähnliche Weise - an einen Baumstamm gebunden und von mordlüsternen Schergen mit gespannten Bögen und Armbrüsten umringt [ABB. 112]. ${ }^{667}$

Auch bei Coxcies früher Antwerpener Darstellung - insgesamt gibt es von Coxcie drei erhaltene Bilder, die das Martyrium des Hl. Sebastian zeigen - wird dieser nunmehr stärker nach antiken Vorbildern betont muskulös dargestellt, während er der ikonographischen Tradition folgend mit den Armen an einen Baum gebunden und von Bogenschützen umringt zu sehen ist. Die Häscher tragen antikische Kleidungsstücke oder sind mit nacktem Oberkörper dargestellt. Die Idealität der durchgebildeten Leiber stellt eine ästhetische Parallele zu mythologischen Figuren her, wie sie die nach Entwürfen Coxcies geschaffene Kupferstichserie mit den Liebschaften Jupiters zeigt. ${ }^{668}$ Das Blatt mit der Beschriftung „Invida" [ABB. 113], von dem sich heute zwei Abzüge im British Museum befinden, zeigt die

um Hilfe gegen die Pest angerufen wurde (vgl. LANE 2008, S. 259).

667 Öl auf Holz, $153 \times 107 \mathrm{~cm}$, Alte Pinakothek München, Inv.-Nr. 5352. Die Darstellung folgt hier den Schilderungen der Legenda Aurea, s. Häuptli 2014, S. 388: ,Tunc Diocletianus iussit eum in medium campum ligari et a militibus sagittari“".

668 Hier ließe sich die Kritik von Anna Bijns anführen, die in den Darstellung nackter Helden eine heidnische Tendenz sah, die sich durch die Vermischung mit der Geschichte der Heiligen auf diese übertragen würde (vgl. FREEDBERG 1988, S. 94). 
Figur des Gottes Merkur, die in Haltung und Statur mit diesem und einem weiteren von Coxcie gemalten Hl. Sebastian aus Mecheln große Ähnlichkeit hat [ABB. 116]. ${ }^{609}$ Auf der Grundlage des Studiums der antiken und italienischen Kunst eröffneten sich für Coxcie neue Gestaltungsmöglichkeiten, - namentlich bei der Körperlichkeit und der Bewegung - die von ihm dazu genutzt wurden in seinen späten Heiligendarstellungen eine bis dahin ungekannte ,Heroisierung' zu erreichen. So zeigt sich in Coxcies CEuvre eine Konstante, die bis in die 1530er Jahre zurückreicht. ${ }^{670}$ Die Tendenz zu einer idealen Körperauffassung ist in der Entwicklung der niederländischen Malerei des 16. Jahrhunderts nicht selten anzutreffen. Die Werke des Haarlemer Manieristen Marten van Heemskerck etwa, der in der Werkstatt von Jan van Scorel tätig war, zeigen den Versuch den menschlichen Körper nicht nur nach dem Vorbild der antiken Skulptur zu gestalten, sondern ihn sogar zu überhöhen. ${ }^{671}$ Neben der bereits früher erörterten Hinwendung zur antiken Körperauffassung lassen sich bei

669 Kupferstich, $272 \times 385 \mathrm{~mm}$ [1] u. $278 \times 366$ $\mathrm{mm}$ [2], British Museum, London, Inv.-Nr. 1951,0407.126 [1] u. Ii,5.26 [2] (s. HolLsTEIN 1949, Nr. 67 u. SCHÉLE 1965, Nr. 58). Diese zweite Sebastiantafel, welche der von 1575 aus Antwerpen stark ähnelt, entstand gut zehn Jahre Später für Sint-Rombout in Mecheln und befindet sich noch heute dort.

670 Ähnliche Typen finden sich bereits auf dem Fresko mit dem Martyrium der Hl. Barbara aus Santa Maria dell'Anima in Rom, das Coxcie für die Kapelle des Kardinals Enckenvoirt schuf, s. Abschn. 3.2.2.

671 Als Beispiel ist hier der Hl. Sebastian von Jan van Scorel aus dem Jahr $1542 \mathrm{zu}$ nennen (Öl auf Holz, 155,6 × 113,2 cm, Museum Boijmans Van Beuningen, Rotterdam, Inv.-Nr. 2342), sowie Marten van Heemskercks Ecce Homo-Triptychon von 1560, Öl auf Holz, $150 \times 218,5$ cm, Frans
Coxcie, in ganz ähnlicher Weise wie bei Heemskerck, Elemente des italienischen Manierismus beobachten. ${ }^{672}$ Eine zweite Version des Antwerpener Sebastian [ABB. 114], die in der Literatur gelegentlich mit dem oben erwähnten Bild für die Oude Handboog vertauscht wurde und über die sich keine näheren Informationen erhalten haben, zeigt den Heiligen in einer vergleichbaren Komposition, er ist ebenfalls an einen Baum in einer freien Landschaft angebunden, während er von seinen Verfolgern mit Pfeilen beschossen wird mit einem etwas anders akzentuierten Körper. Er erscheint massiger und gedrungener, während durch die Helldunkel-Modellierung mehr Muskeln hervortreten. Stärker noch fällt diese Gestaltungsweise bei dem in Rückenansicht gezeigten und ins Profil gewendeten Schützen am rechten Bildrand ins Gewicht. Die durch das Spannen des Bogens hervortretenden Sehnen in der Schulter- und Rückenpartie sind überzeichnet wiedergegeben, was das Bild manieristisch erscheinen lässt. Auch die Entwürfe zur Kupferstichfolge Kain und Abel, die 1576,

Hals Museum, Haarlem (vgl. HARNACK 2018, S. 330, Taf. VII; HoOGEWERFF 1955, passim). Auf die Apelles-Identifikation beruft sich van Mander in seiner Vorrede zu den Malern der Antike (vgl. Van Mander 1604, fol. 77r).

672 Einige der Studien, die Heemskerck in seiner Zeit in Rom in den 1530ern anfertigte, belegen früh sein Interesse an diesem Körperideal, wie etwa die Studie nach dem Torso Belvedere (15321536/37) zeigt (Federzeichnung, Staatliche Museen zu Berlin, Kupferstichkabinett, Heemskerck-Album 1, fol. 73 r., Abb. bei RoEMER 2013, S. 47, Nr. 12). Ebenso die zur selben Zeit entstandene Studie Bronzeherkules und Fragmente konstantinischer Kolossalstatuen im Hof des Konservatorenpalastes auf dem Kapitol (Federzeichnung, Staatliche Museen Berlin, Kupferstichkabinett, Heemskerck-Album 1, fol. 53 r., Abb. bei ROEMER 2013, S. 52, Nr. 15). 
also etwa zur selben Zeit entstanden sind, zeigen Vergleichbares [ABB. 117]. ${ }^{673}$ Vorbildhaft dafür war aber ebenso der Rücken des antiken Torso vom Belvedere. ${ }^{674}$

Vor dem Hintergrund des Ikonoklasmus sind beide Antwerpener Darstellungen mit dem Hl. Sebastian als Reaktionen auf die Krise des Heiligenbildes zu deuten. ${ }^{675}$ Die Akzentverschiebung, die im Folgenden erörtert werden soll, ist höchstwahrscheinlich maßgeblich von Bilderfrage und Bildersturm beeinflusst. Deutlich wird diese Veränderung in dem schmerzerfüllten, gen Himmel gewendeten Blick des Heiligen, der so wirkt, als habe er das irdische Leiden bereits überwunden. Während die Schützen den Vordergrund bis fast in den Mittelgrund hinein halbkreisförmig wie eine Wand dominieren und allesamt mit dem Pfeil im Anschlag gezeigt werden, erscheint der Heilige davon kaum mehr berührt. Darin spiegelt sich die Bereitwilligkeit, mit der Sebastian der Legenda Aurea nach sein Martyrium erlitten haben soll, nachdem er wie seine Peiniger Soldat in römischen Diensten gewe-

673 Radierung, $203 \times 279 \mathrm{~mm}$, British Museum, Inv.-Nr. 1968,1018.1.11 (einzeln), 1910,0208.15 (Serie), Beschriftung unten: „M. Coxcij in.“ u. „JSadelaer fecit“. Druckgraphische Serie von Sadelaer unter dem Titel: Thesaurus sacrarum bistoriarum veteris testamenti, elegantissimis imaginabus expressum excellentissimorum in hac arte virorum opera: nunc primum in lucem editus herausgegeben.

674 Vatikanische Museen, Rom, Museo Pio-Clementino, Inv.-Nr. 1192.

675 Zur Situation des Antwerpener Kunstmarktes s. VERMEYLEN 2012, S. 95-108. Vgl. auch WOOLLETT 2012, S. 76; 84-89.

676 s. hierzu HäUPTLI 2014, Legenda Aurea, S. 380 f. Zuvor hatte er Zwillinge dazu ermutigt die über sie verhängte Todesstrafe als Christusnachfolge aufzufassen und sich bereitwillig zu opfern, sen war. ${ }^{676}$ WOOLLETT bezeichnete diese neuartige Ambivalenz, die in Coxcies Figur des Sebastian zum Ausdruck kommt und für eine ganze Schaffensphase Gültigkeit haben wird, lakonisch als den ,spirituellen Sieg über physische Folter ${ }^{\text {‘ }}{ }^{677}$ Die Wirkung, die von diesem und anderen späten Bildern Coxcies für den zeitgenössischen Betrachter ausging, wird von dem Jesuiten Carolus Scribanius 1610 nach seiner Begegnung mit Coxcies Hl. Sebastian für die Oude Handboog in Antwerpen zum Ausdruck gebracht: „In Antwerpen befindet sich ein Hl. Sebastian von Coxcie, durchbohrt von einem Pfeil. Darin kannst du seine (= Sebastians) Seele leiden sehen, [...] während seine Eingeweide die Pfeile (in sich) aufnehmen. Den Schmerz der Wunde vermag der Betrachter dabei zu fühlen. ${ }^{6678}$ Weiter schreibt er, dass ,,jene, die auf des Märtyrers Wunden blicken, diese an sich selbst erleiden“ würden. ${ }^{679}$ Er folgt darin dem älteren Konzept der compassio, für das auch der Bildkritiker Johannes Molanus warb und es moralisch erweiterte, indem er Heiligenbildern die Funktion zu-

während er die Eltern mit dem Verweis auf das ewige Leben und ein Widersehen im Himmelreich tröstet. („O fortissimi milites Christi, nolite per misera blandimenta coronam deponere sempiternam. [...] Nolite timere, non separabuntur a vobis, sed vadunt parare vobis sidereas mansiones", s. ebd., S. 383).

677 WOOLLETT 2012, S. 86.

678 Frei übersetzt nach: „Coxij est Antuerpiae Sebastianus iaculo transfixus: in qou videas sentire animam, sinistri pedis femorisque retractu, cum intima, sagitta depiscatur: quin \& spectators vulneris dolorem sentien" (zit. nach HELD 1996, S. 200; 204; s. auch WOOLLETT 2012, S. 86).

679 Carolus Scribanius: Antverpia (1610), S. 39: „Et spectatores vulneris dolorem sentiunt" (zit. nach WestSTEIJN 2012, S. 114. 
schrieb, ihre Betrachter dazu anstiften zu können, den Heiligen mit demselben Gottvertrauen nachzueifern. ${ }^{60}$ Das Konzil von Trient hatte diese Funktion der Bilder bestätigt und per Dekret definiert, dass nicht nur Christus allein den Gnadenschatz der Kirche erworben habe, sondern dass nach ihm auch die Heiligen, je nach Ausmaß ihrer Verdienste, hieran Anteil hätten und somit nicht nur als exempla für die christliche Lebensführung und die fromme Standhaftigkeit dienen könnten, sondern auch als potenzielle Fürsprecher bei der Jenseitsvorsorge in Frage kamen. ${ }^{681}$ Den geltenden $\mathrm{Zu}$ sammenhang von Heiligenverehrung und ihrer künstlerischen Darstellung beschrieben in Folge des Konzils indessen weitere Autoren, wie der Genter Theologe und Augustinermönch Johannes Garetius, der das Thema der Verehrung zum zentralen Gegenstand seiner befürwortenden Abhandlung zur Funktion und Bedeutung von Heiligenbildern machte. Seiner Auffassung nach sei es Aufgabe des Malers, die ,glorreichen Taten des Heiligen“ sowie seine „Torturen“, die erlittene „Gewalt" sowie die „brennenden Feueröfen“ darzustellen. ${ }^{682}$ Zur gleichen Zeit gab

680 Vgl. Molanus 1570 [1594], S. 278.

681, ,...] tum vero ex omnibus sacris imaginibus magnum fructum percipi, non solum quia admonetur populus beneficorum et munerum quae Christos ibi collata sunt, sed etiam, quia Dei per sanctos miracula et salutaria exempla oculis fidelium subiiciuntur ut pro iis Deo gratias agant, ad sanctorum imitationem vitam mores que suos componant ex citenturque ad adorandum ac diligendum Deum, et ad pietatem colendam" (Conciliorum Oecumenicorem Decreta, Instituto per le Scienze Religiose (Hrsg.), Bologna / Freiburg 1962, S. 751 f.).
Johannes Molanus eine Neuauflage des Martyrologium Usuardi (1573) heraus und verfasste neben seinem bildtheologischen Hauptwerk den Indiculus Sanctorum Belgii (1573/1583). Beide Bücher beschreiben das Leben und Sterben der Heiligen von einem zeitgemäßen, das heißt kritischen Standpunkt und richten sich an trostsuchende Katholiken, die in der Zeit der Bilderstürme zu leiden hatten. ${ }^{63}$ Diese und andere Schriften können maßgeblichen Einfluss auf Maler wie Coxcie und seine Zeitgenossen gehabt haben, während die vormals geschätzte Legenda Aurea, zuweilen als „Legenda Plumbea“ verhöhnt, ${ }^{684}$ als alleinige Quelle nicht mehr den Bedürfnissen der Zeit entsprach. Das Zeigen des gewaltsamen und qualvollen Todes der Märtyrer war, wie Garetius zu erkennen gibt, also höchstwahrscheinlich keine Erfindung der Maler, sondern war seit dem Konzil und vor dem Hintergrund der Auseinandersetzung mit den Bilderstürmern aus der von katholischen Theologen entwickelten Neubewertung des Heiligenbildes erwachsen. Interessant ist, dass ab den späten 1570 er Jahren, bis etwa um die Jahrhundertwende, eine große Anzahl von Altarbildern mit zuweilen grausamen Martyrien entstanden.

682 „Et pictor, artis suae flores in imaginibus, exprimes res Martyris preclare gestas, labores cruciatus imagines tyrannorum aspectus, impetus, ardentum illam \& flammas evomentem fornacem. [...] Haec, inquam, nobis tamquam in libro loquente artificio describens Martyris certamina, sapienter exposuit. [...] Novit enim etiam pictura tacens in pariete loqui, \& utilitatis plurimum afferre" (Johannes Garetius: De Sanctorum invocatione Liber [...], Gent 1570, fol. 21v).

683 Vgl. hierzu FreEdBERG 2014, S. 206.

684 Johannes Molanus wählte diesen Begriff in siner kritischen Bewertung der Legendensammlung (s. Molanus 1594, S. 89). 
Die meisten Maler dieser Zeit beteiligten sich daran, vor allem in Antwerpen, wo neben Michiel Coxcie unter anderem auch Frans Pourbus, Marten des Vos und Ambrosius Francken tätig waren. ${ }^{685}$

Grundlegend für Coxcies Heiligendarstellungen in dieser ersten Phase der Wiederherstellung nach dem Bildersturm von 1566 waren höchstwahrscheinlich die Wünsche seiner Auftraggeber, die Themen der lokalen, höchstwahrscheinlich der gildeneigenen Tradition, zu bedienen und gegebenenfalls auf die Erfahrungen der Gegenwart und jüngeren Vergangenheit hin anzupassen. ${ }^{686}$ Neben dem Hl. Sebastian war der Hl. Georg als Patron der Schützengilden ebenfalls ein Exempel soldatischer Tugenden wie Tapferkeit und Loyalität. ${ }^{687}$ Die Aufträge der Schützengilden von Antwerpen und Mecheln betonen durch Anzahl und Art der neuen Aufträge die fortgesetzte Bedeutung von Altarbildern mit Schutz-

685 Einige Werke dieser Maler aus diesem Zeitraum und deren Beziehung zu den Arbeiten Coxcies behandle ich in Kap. V.

686 Vgl. WoOLLETT 2012, S. 87; im konkreten Fall der Antwerpener Oude Handboog, für die Coxcie das Altarbild mit dem Martyrium des $\mathrm{Hl}$. Sebastian malte, haben Restaurierungsarbeiten Informationen über das mögliche Aussehen der Gildenkapelle im späten 15. Jh. geliefert. In der vormals von der Gilde genutzten Kapelle an der Südseite des Chores der Kirche von OnzeLieve-Vrouwe konnte ein Wandbild mit einer Kreuzigung und dem Martyrium des Hl. Sebastian sichtbar gemacht werden (vgl. WOOLLETT' 2004, S. 86 u. GRIETEN - BUNGENEERS 1996, S. 22931). Der Heilige sei in dieser Szene an einen Baum gebunden dargestellt gewesen, während links Schützen mit gespannten Bögen zu sehen gewesen seien, d. h. solche in der Art der Darstellungen von Memling und Coxcie (vgl. WOOLLETT 2012, S. 86; WOOLLETT 2004, S. 86). 687 Vgl. LCI VII [1974], s. v. „Georg“, Sp. 385 f. heiligen für das Selbstverständnis der katholischen Milizen, ${ }^{688}$ die sich ihrerseits als bedingungslos auf Gott vertrauende Verteidiger des alten Glaubens sahen und $\mathrm{zu}$ denen Coxcie sich selbst zugehörig fühlte, wie seine Mitgliedschaft bei den Mechelner Colveniers von 1564 bis 1567 nahelegt. ${ }^{689}$

Vergleichbare frühe Auswirkungen der Gegenreformation auf die Kunst lassen sich im Grunde nur in Rom finden, wo Papst Gregor XIII. 1583 Niccolò Circignani damit beauftragte, die Wände von Santo Stefano Rotondo mit 32 Heiligenmartyrien zu bemalen. ${ }^{690}$ Die Darstellungen zeigen äußerst drastisch und detailliert das Leiden und Sterben der Heiligen. Eine graphische Adaption unter dem Titel Ecclesiae militantis triumphi wurde 1585 in Buchform von Bartolomeo Grassi herausgegeben und war daher zumindest in den späten 1580er und 1590er Jahren theoretisch einem größeren Publikum zugänglich. ${ }^{691}$

688 Vgl. WOOLLETT 2012, S. 85

689 s. WOLLETT 2012, Anm. 61. Zahlungen Coxcies sind für diese Jahre überliefert: „Ick Machiel van Coxyen maecke de gulde van de Calvieneres de some vaan een jieljaer van VII (?) ghilden nae mayn doeet ende by al dat ale dede [...]" (vgl. NeEFs 1876, Bd. 1, S. 152). Die Angehörigkeit zu den städtischen Milizen war unter Malern des 16. u. 17. Jhs. nicht ungewöhnlich. Frans Francken und Peter Paul Rubens waren ebenfalls Angehörige von Schützengilden. Die Zugehörigkeit zu den Mechelner Colveniers wird im Zusammenhang mit Coxcies Stellung als Hofmaler als Hinweis auf seine loyale und fromme Haltung gewertet (s. hierzu VAN AUTENBOER 1992, S. 8 u. ROEY 1966, S. 107-132; 122).

690 Vgl. CARratù 2013, S. 28-54.

691 Ecclesiae militantis triumphi sive Deo amabilium martyrum gloriosa pro Christi fide certamina: prout opera RR patrum Soc. Jesu, Collegii German. \& Hungarici 
Da sie gut zehn Jahre nach Coxcies ersten groBen Martyrien in Antwerpen entstanden, kann hierin nur eine weitere Spiegelung der in dieser Zeit verbreiteten Vorliebe für solche Darstellungen gesehen werden. Anzunehmen ist jedoch, dass hier wie bei Coxcies Bildern sehr ähnliche, dezidiert gegenreformatorische Überlegungen eine Rolle gespielt haben.

WoOLLETT hat in ihrem Aufsatz Michiel Coxcie and the Revitalization of Religious Painting in the Southern Netherlands after 1566 auf die in van Manders Schilder-Boeck beschriebene Anwesenheit von Federico Zuccari, einen der wichtigsten Vertreter der nachtridentinischen römischen Malerei, verwiesen, der sich 1574/1575 in Antwerpen aufhielt. ${ }^{692}$ Van Mander beschreibt den würdevollen Empfang, der ihm von lokalen Künstlergrößen bereitet worden war. ${ }^{693}$ Es sei laut WOOLLETT nicht auszuschließen, dass Coxcie durch die Begegnung mit Zuccari wesentliche Anregungen für eine Aktualisierung seines an die erste Generation der römischen Malerei des 16. Jahrhunderts angelehnten Stils bekommen haben könnte. Zwar erwähnt van Mander die Anwesenheit Coxcies nicht explizit, jedoch kann eine Begegnung mit dem römischen Maler als sehr wahrscheinlich gelten. Angesicht seiner eigenen einflussreichen Stellung unter den Antwerpener Malern und nicht zuletzt wegen seiner Zeit in Rom könne man annehmen, dass der Romanist Coxcie sich den Austausch mit einem italienischen Maler, dem er sich als stilistisch verwandt angesehen haben wird,

moderatorum, impensa S. D. N. Gregorii PP. XIII in ecclesia S. Stephani Rotundi Romae (gestochen von Giovanni Battista Cavalieri u. hrsg. von Bartolomeo Grassi, Rom 1585).

692 Vgl. WOOLLETT 2012, S. 86. nicht entgehen ließ. Der betont italienisch anmutende Figurenstil auf den beiden Antwerpener Sebastianstafeln, sowohl des Heiligen als auch der Schützen, sei ein Indiz, das auf den Stil des Federico Zuccari und der römischen Accademia verweisen würde, so WOOLLETT. ${ }^{694} \mathrm{Zu}$ dieser Einschätzung mögen sie gewisse Ähnlichkeiten der Hauptfigur auf der zweiten Sebastianstafel bewogen haben [ABB. 114], die vielleicht vage an Zuccaris Fresko mit der Geißelung Christi aus dem Oratorio del Gonfalone in Rom erinnern. Die breitschultrige, kräftige und nur mit einem Lendenschurz bekleidete Figur des Christus ähnelt dem Sebastian bei Coxcie und auch die Rückenfigur rechts, deren entblößter Oberkörper stark muskulös gezeichnet ist, ließe sich mit dem ebenfalls mit dem Rücken zum Betrachter gewendeten Schützen rechts auf der Sebastianstafel vergleichen. Insgesamt wirkt diese Verknüpfung jedoch eher spekulativ, da die stilistischen Übereinstimmungen eher marginal zu nennen sind und nicht geklärt ist, woher Coxcie das Fresko oder andere lange nach seiner Zeit in Rom entstandenen Werke Zuccaris (1540-1609) gekannt haben soll. Folgerichtiger erscheint es anzunehmen, dass Coxcie für seinen Sebastian auf das Fresko mit der Geißelung Christi von Sebastiano del Piombo in der Borgherini-Kapelle von San Pietro in Montorio in Rom zurückgegriffen hat [ABB. 118]. Dieses bereits 1524 vollendete Bild wird er gekannt haben, da er in den

693 „Hy [...] in Nederland en t'Antwerpen daer hem de Schilders goet onthael ende groote eere aen deden" (zit. nach WOOLLETT 2012, Anm. 71; vgl. auch NOË 1954, S. 250).

694 Vgl. WoOLLETT 2012, S. 86. 
1530er Jahren bei der Ausgestaltung der Barbarakapelle in Santa Maria dell'Anima, auf Sebastianos Bild in der Apsiskalotte der Borgherini-Kapelle bereits schon einmal zurückgegriffen hatte ${ }^{695}$ Ein in dieser Zeit entstandener Kupferstich mit demselben Thema und dem Monogramm Michiel Coxcies belegt die Beschäftigung mit dem Motiv und bezeugt stilistische Übereinstimmungen bei der Figur des Christus, der an die Geißelsäule gebunden in weiter Beinstellung und in sich zusammengesunken mit geneigtem Oberkörper dargestellt ist [ABB. 119]. ${ }^{696}$ Auch die Darstellung des Martyriums der Hl. Barbara in Coxcies römischem Freskenprogramm nimmt Eigenschaften dieses Vorbilds auf, etwa die Art, wie die Heilige mit ihren erhobenen Armen an einen Galgen gebunden ist und von den Folterknechten umringt wird [ABB. 26].

Ein Jahrzehnt später, in den frühen 1580er Jahren, ${ }^{697}$ erneut vor dem Hintergrund der eben erst geendigten bilderstürmerischen Unruhen, entstand eine weitere Tafel mit dem
Martyrium des Hl. Sebastian für die Sint-Rombouts-Kathedrale in Coxcies Heimatstadt Mecheln [ABB. 116] ${ }^{698}$ Die Darstellung zeigt gegenüber dem Antwerpener Bild für die Oude Handboog frappierende Ähnlichkeiten, unterscheidet sich aber ebenfalls im Hinblick auf die Körperauffassung von dem zweiten Antwerpener Bild, dessen Sebastian insgesamt massiger wirkt. Der Heilige hat ein feiner gezeichnetes Gesicht und weist einen schlankeren Wuchs auf. Die manieristische Tendenz bei der Gestaltung des Leibes auf dem zweiten Antwerpener Bild [ABB. 114] ist hier zurückgenommen, die Haltung des Körpers natürlicher und weniger stark in sich gedreht. Gegenüber den beiden Antwerpener Darstellungen, ist der an einen Baum gefesselte Sebastian in die Bildmitte gerückt und statt mit dem linken, ist er mit dem erhobenen rechten Arm an einen Ast gefesselt. Auch die Häscher mit ihren teilweise gespannten Bögen wirken beim Mechelner Bild realistischer als etwa beim zweiten Antwerpener Bild, bei welchem

$235 \mathrm{~cm}$ ) als die Autoren vor ihm [ABB. 110]. Die Inschrift dieses Bildes laute „Michel d. coxscyin aetatis suae 76 fecit", und es sei ursprünglich in der Antwerpener Kathedrale Onze-LieveVrouwe bzw. dort in der Kapelle der Gilde aufgestellt gewesen (vgl. WESTSTEIJN 2016, passim). Bei dem bei WoOLletT 2012, Abb. 1 gezeigten Bild handelt es sich um das Mittelbild eines weiteren, jedoch nicht komplett erhaltenen Triptychons [ABB. 114]. Auch WeststeijN 2012. S. 115, Abb. 2 zeigt dieses Bild, hier noch im Zusammenhang mit der Oude Handboog und dem Bericht des Humanisten Scribanius (Carolus Scribanius 1610, S. 39), während er in dem neueren Aufsatz von 2016 das andere, korrekte Bild mit selbigem Autor verknüpft [ABB. 110]. Ein weiteres Retabel, von dem sich mehr erhalten hat, schuf Coxcie für eine Gildenkapelle in Sint-Rumbouts in Mecheln [ABB. 116] (vgl. WOOLLETT 2012, S. 87). 
die stark stilisierte Zeichnung der Muskeln auf dem Rücken des rechten Schützen auffällt und eine stärker manieristische Körperauffassung evoziert. ${ }^{699}$ Die Pfeilspitzen kreisen den Heiligen gewissermaßen ein, was die Zentrierung des Körpers betont. Auch dieser Sebastian wirkt dem Leiden enthoben, was durch den himmelwärts gewandten Blick ins Pathetische gesteigert wird. Grundsätzlich kann konstatiert werden, dass diese Darstellung der des Triptychons für die Antwerpener Oude Handboog äußerst nahesteht [ABB. 110]. Es handelt sich offenbar um eine Wiederholung des Motivs, bei der lediglich einige Details abgeändert wurden, die hauptsächlich die Haltung Sebastians und die Positionen der ihn umringenden Schergen betrifft.

Wenn auch nicht als direktes Vorbild, wie es von WOOLLETT vorgeschlagen wurde, kann die Tafel Memlings doch zumindest die Herkunft Coxcies aus der altniederländischen Malerei untermauen. Die offene Landschaft des Hintergrundes und der vereinzelte Baum, an den der Heilige gebunden ist, entsprechen der Prägung des Themas durch Memling und seine Zeitgenossen. Die Armhaltung Sebastians ist stattdessen der Tradition geschuldet und findet sich vergleichbar auch bei dem weiter oben genannten Sebastian von Holbein. Auch Coxcie zeigt eine vergleichbare Streckung und lässt Sebastian in seinem Bild den rechten Arm ebenfalls auf Höhe des Kopfes halten. Ein Ast ist diesem vorgeblendet, so-

699 Vergleichbar etwa mit der massig-muskulösen Rückenpartie des Vulkan auf Marten van Heemskercks Vulkan zeigt den Göttern die in seinem Netrgefangenen Venus und Mars von 1540 (Öl auf dass sich eine Fixierung des Arms nur bei genauerem Hinsehen ausmachen lässt. Insgesamt mündet das Angebundensein des Leibes bei Memling in einer flächigeren Präsentation des Leibes, der den Pfeilen der Schützen ausgeliefert ist, ${ }^{700}$ während Coxcie seinen Heiligen in größerer Bewegung darstellt. Eine gewisse Ähnlichkeit zu den Figuren aus der Stichfolge mit den Liebschaften des Jupiter ist auch hierin erkennbar. Der Versuch, mit dem angehobenen linken Bein und dem aufwärts gerichteten Blick ein besonders affektvolles Körpermotiv, wahrscheinlich von der Laokoon-Skulptur beeinflusst, zu gestalten, findet sich auch bei van Scorels Hl. Sebastian von 1542 [ABB. 115]. Dieses einfigurige Bild, das den Heiligen in Nahsicht zeigt, lenkt das Hauptaugenmerk auf den von Pfeilen durchbohrten Körper, der ganz ähnlich wie bei Coxcies Variationen des Martyriums in einem Spannungsverhältnis zu dem von der Welt und seinen Peinigern abgewandten, himmelwärts gerichteten Blick des Heiligen steht. Demnach gab es frühere Vorbilder, durch die Coxcie maßgebliche Anregungen für seine post-ikonoklastischen Martyrien bekommen konnte.

Ebenfalls für Sint-Rombouts entstand 1588 ein Retabel mit Szenen aus dem Leben des Hl. Georg [ABB. 120]. ${ }^{701}$ Diesen Heiligen hatte Coxcie bereits Mitte der 1570er auf den äußeren Flügeln des nur fragmentarisch erhaltenen Altares für die Antwerpener Jonge Voetboog vor Augen gebracht. ${ }^{702}$ Die zugehörige Mitteltafel hat sich nicht erhalten, könnte aber eine

Holz, $96 \times 99 \mathrm{~cm}$, Kunsthistorisches Museum, Wien, Gemäldegalerie, Inv.-Nr. 6395). 700 Vgl. STROO - SYFER-D’OLNE 1999, S. 196.

701 Öl auf Holz, St. Rumbouts, Mecheln.

702 Vgl. Abschn. 4.3. 
ähnliche Darstellung mit dem Martyrium Georgs enthalten haben wie das spätere Mechelner Georgsretabel von 1588, da sich, wie weiter oben erwähnt, die Hauptmotive bei den Altarbildern aus dieser Phase stark ähneln. Andererseits scheinen ältere Darstellungen, die den Tod Georgs ins Zentrum rücken, vergleichsweise rar zu sein, da in der Regel andere Stationen der Vita, wie der Kampf mit dem Drachen, ${ }^{703}$ der die ,Heldenhaftigkeit ${ }^{`}$ des Heiligen im Sinne eines christlichen Ritters betont, von Auftraggebern und Malern aufgegriffen wurden. Zwei wiederum ohne die zugehörige Mitteltafel erhaltene Außenseiten eines Georgsretabels von Frans Pourbus aus dem Jahr 1577 zeigen einen Heiligen [ABB. 121], der dem auf Coxcies 1588er Tafel ähnelt. Unklar ist, bei wem dieses bei beiden Heiligen Georg und Sebastian - verwendete Motiv des stark gestreckten und über dem Kopf an den gekreuzten Handgelenken gebundenen Märtyrers zuerst in Erscheinung getreten ist. ${ }^{704}$

Fest steht allerdings, dass Coxcies

703 Hierzu s. HÄUPTLI 2014, Legenda Aurea, S. 815 f. 704 Vgl. HARNACK 2018, S. 151-153, Abb. 68. Zur Erörterung der möglichen Beziehung beider Werke und ihrer Maler s. Kap. V.

705 Einen Altar mit ähnlicher Darstellung erwähnt Carolus Scribanius in seiner Antwerpener Reisebeschreibung. Er beschreibt eine Szene, in welcher Georg auf ein mit Klingen besetztes Rad gebunden wird: „Georgius ab eadum manu trunco affixus; rotaque crudeli circumactu Martyris mebra perpetuis nouaculis dilaniatura [...]“ (s. WOOLLETT 2012, Anm. 76, zuerst abgedr. u. ins Engl. übers. bei HELD 1996, S. 194 u. 204 nach Carolus Scribanius: Antverpia. Antwerpen 1610, sinngemäß: „Der Heilige Georg von derselben Hand (= Coxcie) gemalt, an einen Baum gefesselt, während das grausame Rad die Glieder des Märtyrers durch kontinuierlich sich bewegende Messer aufspießt". Möglicherweise handelt es sich bei dieser Szene um das heute
Mechelner Georgsretabel von 1588 demselben Aufbau folgt, der bei den drei Beispielen mit der Marter des Hl. Sebastian zu beobachten war. Auch hier wird die Folter des Heiligen präzise geschildert, so etwa durch die zentrale Darstellung des regelrechten Zerreißens der Gliedmaßen durch Nägel, an denen der Gebundene vermittels eines Rades entlanggezogen wird. ${ }^{705}$ Diese Marter wird in der Legenda Aurea genannt. ${ }^{706}$ Die linke Tafel setzt mit der Schilderung ein, dass Georg vor Kaiser Diokletian bzw. dessen Richter Dacianus tritt. Statt den Götterbildern zu opfern, richtete er sein Gebet an Gott, dass dieser den heidnischen Tempel zerstören möge. Das nun folgende Geschehen beschreibt die Legende: „Und sogleich kam ein Feuer vom Himmel und verbrannte den Tempel mitsamt den Göttern und Priestern, die Erde öffnete sich und verschlang alles, was davon noch übrig war. “707 Coxcie zeigt diesen Moment, indem er den Himmel auf der Mitteltafel oberhalb der Marterstätte wie eine Feuerwalze darstellt, die aus

verlorene Mittelbild des Georg-Triptychons für die Jonge Voetboog. Diese Spekulation lässt sich zumindest damit untermauern, dass sich ein vergleichbares Werk Michiel Coxcies erhalten hat, das er 1588 für die Kapelle der Mechelner Georgsbruderschaft (?) in Sint-Rombouts geschaffen hat (vgl. WOOLLETT 2012, S. 87 u. JACOBS 1993, S. 228-236) und das hier im Textabschnitt behandelt wird.

706 „Cum autem eum praeses ad se inclinare non posset, iussit eum in eculaeum levari et membratim corpus eius ungulis laniari, appostis insuper ad latera facibus, patentibus ad viscera rimis sale plagas eius fricari iussit.“ (s. HÄUPTLI 2014, Legenda Aurea, S. 816).

707 „Statimque ignis de caelo descendans templum cum diis et sacerdotibus concremavit terraque se aperiens omnes eorum reliquias deglutitivit.“"(s. ebd., S. 818). 
dunklen Wolken hervorbricht. Über Georg erscheint ein Engel mit Palmzweig und auf der rechten Tafel ist zu sehen, wie der Hl. Georg schließlich enthauptet wird. ${ }^{708}$ Die Legenda $A u$ rea erwähnt die Brutalität des Geschehens und das monströse Rad, auf das man Georg bindet. $^{709}$ Eine Passage aus dem zeitgenössischen Martyrologium Romanum von Cesare Baronius erwähnt derlei „(Folter-)Instrumente und Maschinen " ebenfalls. ${ }^{710}$ Kirchlicherseits scheint die Darstellung extremer Grausamkeit also toleriert worden zu sein, da wie die extremen Darstellungen in den Ausmalungen in Santo Stefano Rotondo auch dieses Buch von Papst Gregor VIII. in Auftrag gegeben worden war. Weil das Martyrologium im selben Jahr erschien, als Coxcie sein Mechelner Georgsretabel schuf, besteht zumindest theoretisch die Möglichkeit, dass der Text die maßgebliche Anregung für die Darstellung des Rades lieferte.

Im Aufbau ähnelt das Triptychon grundsätzlich dem Sebastiansretabel aus Mecheln. In beiden Fällen beginnt die Erzählung bei geöffnetem Zustand links mit dem Heiligen vor einem Gericht. Daran schließt sich unmittelbar die Darstellung des Martyriums an. In beiden Fällen wird auf dem rechten Flügel der Tod des Heiligen gezeigt. Zieht man in Betracht, dass es sich bei den beiden Mechelner Triptychen aus den 1580er Jahren um mehr oder weniger konkrete Wiederho-

708 „Sequenti vero die Georgius talem accepit sententiam, ut per totam civitatem traheretur, postmodum capite puniretur.“ (s. ebd., S. 820).

709 „Sequenti die iussit Georgium poni in rota gladiis bis acutis indique circumsaepta, sed statim frangitur et Georgius illaesus penitus invenitur.“" (s. ebd., S. 819). lungen mindestens zweier (?) nur fragmentarisch erhaltener Retabel aus Antwerpen handelt, erkennt man das Prinzip des Kopierens im Sinne einer Vervielfältigung von erfolgreichen Werken, wie es für die Werkstätten mehrerer Künstler, etwa der von Pieter Coecke van Aelst, Joos van Cleve sowie Frans Floris und Willem Key in der zweiten Hälfte des 16. Jahrhunderts, erforscht ist. ${ }^{711}$ Entsprechend besteht die Möglichkeit, dass es auch zum Georgsretabel ein früheres in Antwerpen entstandenes Gegenstück aus den 1570er Jahren gab, wofür unter anderem die beiden erhaltenen Außenflügel des Altares für die Antwerpener Jonge Voetboog sprechen. Inwieweit die Mitteltafel dieses Retabels dem späteren aus Mecheln entsprach, kann jedoch nur vermutet werden. Sollte es sich ebenfalls um die Darstellung des Heiligen auf dem Rad handeln, so müssten hierfür ältere Vorbilder oder andere Quellen ausschlaggebend gewesen sein als das Martyrologium des Baronius. Möglicherweise gingen von Coxcie aber auch maßgebliche Impulse für die erste Phase der post-ikonoklastischen Wiederherstellung in den 1570er Jahren aus, dessen ausdrucksstarke Heiligenbilder jedoch erst nach dem erneuten Bildersturm von 1581 und mit Anbruch der Statthalterschaft Alessandro Farneses ihren Niederschlag auch in den Erzeugnissen anderer Werkstätten fanden. Möglicherweise wurde dies sogar durch den Statthalter gefördert, wie früher bereits von

710 „Tum etiam plurimarum dictionum sane obscuram notionem ac vim declaravi, earum praesertim, quae ea instrumenta ac machinas designant, quibus reterrimi fidei oppugnatores fortissimos Martyres miris modis cruciarunt divexaruntque" (s. Cesare Baronius: Martyrologium Romanum, Antwerpen 1588, S. VII).

711 Zuvor behandelt in Absch. 2.1. 
FREEDBERG in Betracht gezogen wurde und worauf unter anderem dessen Förderung katholischer Orden, vor allem dem der Jesuiten, hindeutet. $^{712}$

\subsection{Der geharnischte Maler - Michiel Coxcies Selbstverständnis}

Eng dem Haus Habsburg als Auftraggeber verbunden, verspricht besonders das in den Bildern hervortretende Selbstverständnis Coxcies eine Auskunft über seine Stellung als Hofmaler zu geben. Auf dem Retabel aus Kremsmünster mit der Heiligen Sippe etwa ist Coxcie im Hintergrund der Mitteltafel als einer der vom Engel herbeigerufenen Hirten, den Zeugen der Geburt Christi, zu sehen. Auf einer weiteren Einzeltafel mit der Darstellung dieses Themas, die zusammen mit anderen Werken, die Philipp II. 1568 in Brüssel für die Ausstattung des Klosters von Escorial erwarb, hat sich Coxcie als ein lesender Greis ins Bild eingebracht [ABB. 63]. ${ }^{713}$ Die Figur zeigt ihn mit für sein tatsächliches Alter angemessen ergrauten Haaren. Die Art und Weise, wie die weiblichen Figuren in diesem Bild gemalt sind, erinnert an die altniederländischen Meister, deren Werke Coxcie für Philipp kopiert hatte. Darin könnte ein weiterer Hinweis auf diese Art von Aufträgen zu sehen sein, die ein Interesse des Monarchen an deren Stil nahelegt,

712 Vgl. hierzu Freedberg 2014, S. 210 u. MOREAU 1952, S. 372 f. Zur Erörterung einer gegenseitigen Beeinflussung einzelner Antwerpener Maler gegen Ende des 16. Jhs. s. Kap. V.

713 Vgl. PÉreZ DE Tudela 2013, S. 109 u. ZARCO 1930, S. 124. Für das Werk s. Abschn. 3.3.2

714 s. hierzu Abschn. 3.5.

715 Vgl. WOOLLETT 2012, S. 78. während er gleichzeitig Werke von Tizian sammelte und Coxcie weitere in dessen Manier anfertigen ließ. ${ }^{714}$ Ein geschäftliches Verhältnis zwischen königlichem Auftraggeber und Maler, das konkrete Inhalte des zu malenden Bildes beinhaltet, bezeugt auch die Kopie des Genter Altares von 1558/59, auf welchem Coxcie Philipp II. und sich selbst als Randfigur unter den christlichen Streitern platziert hat. ${ }^{715}$ In der Dichtung Lucas de Heeres über den Genter Altar, die Herrscherlob und Ekphrasis zugleich ist, wird der Name Coxcie unmittelbar nach dem des Monarchen genannt. ${ }^{716}$ Nachweislich nannte Coxcie sich seit dieser Zeit „pictor regius“, wie einzelne Werksignaturen zeigen. ${ }^{717}$

Das bemerkenswerteste und zugleich sonderbarste Werk Coxcies in der ersten Phase nach dem Ikonoklasmus von 1566 ist das Triptychon, welches er in der Mitte der 1570er Jahre, also nur wenige Jahre nach den Unruhen, für die Antwerpener Gilde der Armbrustschützen (Jonge Voetboog) schuf. Genauer ist es der linke Außenflügel, der die lebensvolle Figur des Hl. Georg vor einem dunklen, nicht näher bezeichneten Hintergrund, zeigt [ABB.

716 Es heißt dort: „Dees copie is in Spaignen (op dat ict vertelle) / Te Vendedoly, t'eender memorie bloot,aant. / Van ons Coninghs liefde, die ic voor ander stelle: / Ende tot Heycus, en Coxyens glorie groot" (s. De Heere 1565, S. 32).

717 Vgl. PÉrez de Tudela 2013, S. 109 f.; den Titel des Malers betreffend s. FERNÁNDEZ-SORIANO 2008, S. 194. 
122]. ${ }^{718} \mathrm{Ihm}$ gegenüber auf der anderen Seite ist die Hl. Margarete dargestellt. Über den Verbleib der Mitteltafel haben sich keine Nachrichten erhalten, so dass heute davon ausgegangen werden muss, dass sie entweder nach einer späteren Trennung von den Tafeln zum Zweck eines Verkaufs oder im Bildersturm von 1581, welcher die Liebfrauenkathedrale erneut schwer traf, verloren gegangen ist bzw. zerstört wurde. ${ }^{719}$ Die lebendige Darstellung des legendarischen Drachentöters beruht nicht zuletzt auf dem Kryptoportrait von Coxcie und der zeitgenössischen Uniformierung, die auf das nur wenig früher entstandene Portrait des Herzogs von Alba von Anthonis Mor van Dashorst verweist [ABB. 123]. ${ }^{720}$ Der ähnlich ernste Gesichtsausdruck

718 Öl auf Holz, $258 \times 90 \mathrm{~cm}$, Koninklijke Museum voor Schone Kunsten, Antwerpen, Inv.-Nr. 373 (Kat. KMSKA 1988, S. 97 f.).

719 Neben den Darstellungen der Heiligen Georg und Margarete auf den Außenseiten, haben sich die Bilder auf den Innenseiten dieser beiden Flügel erhalten: Die Folter Georgs mit Salz und die Enthauptung des Hl. Georg. Das Retabel entstand vermutlich 1574. Es war vormals in der Kathedrale von Antwerpen aufgestellt - heute befindet es sich im Koninkliijk Museum voor Schone Kunsten, Antwerpen (Inv. 372 bis 374, Öl auf Holz, jeweils $295 \times 90 \mathrm{~cm}$ ), s. hierzu auch WoOLLETT 2012, S. 77. Es handelt sich um das Retabel, auf welchem Coxcie dem Hl. Georg sein eigenes Portrait, ähnlich dem Antlitz des Soldaten unter den christlichen Rittern auf der Kopie des Genter Altares, sowie die Kleidung des Herzogs von Alba gegeben hat.

Ein erhaltenes Dokument vom 4. März 1586 enthält eine Beschwerde der Gilde bezüglich des Schicksals ihres Triptychons im Jahr des stillen Bildersturms 1581 und gibt Auskunft über die ursprüngliche Beschaffenheit des Retabels: Es wird gesagt, dass es darauf ein kunstvolles Gemälde des Hl. Georg gegeben habe sowie zwei weitere Flügel (,een seker constich tafereel van St. Joris vs met twee doren"), die von dem Meister Michiel aus Mecheln gemalt des Hl. Georg verrät, dass es sich hierbei um eine Mahnung handelt. Die Tatsache, dass sogenannte Rollenportraits (portrait historié) sowie heute davon unterschiedene Kryptoportraits nach dem Konzil von Trient und der Synode von Mecheln im Jahre 1570 in religiösen Bildern eigentlich verboten waren, ${ }^{721}$ scheint in diesem Fall noch nicht oder bewusst nicht zum Tragen gekommen zu sein. Die Figur des Ritterheiligen Georg stellt in diesem Zusammenhang zwar einen Affront gegenüber der kirchlichen Zensur dar, ließe sich aber möglicherweise auch als Ausnahme erklären, die den radikalisierten Stimmungen in der Bevölkerung und bei den Vasallen der Habsburger zur Zeit der Bilderstürme geschuldet war.

worden seien („Meester Michiel Schilder tot Mechelen"). Weiter heißt es, das Triptychon sei mit einer Predella, die Szenen aus dem Leben Georgs beinhaltet habe und mit zwei Pfeilern und einem Architrav, was wahrscheinlich den Altarschrein meint, ausgestattet gewesen (s. hierzu WoOLLETT 2012, Appendix, Nr. 1 sowie WOOLLETT 2004, S. 90 u. 286).

720 Öl auf Holz, $108 \times 83,5 \mathrm{~cm}$, Hispanic Society of America, New York. Besagte Lebensechtheit markiert einen Unterschied zur gängigen Darstellung von Heiligen. Die Komposition der beiden Seitenflügel, die den Hl. Georg bzw. die Hl. Margarete zeigen, entspricht dem üblichen Schema. Allerdings wäre zu erwarten gewesen, dass diese beiden Figuren statischer und in Grisaille gearbeitet sind, wie es bei altniederländischen Triptychen dieser Art der Fall ist. Eine vergleichbar ungewöhnliche Verlebendigung ist bei Joos van Cleve zu beobachten - der allerdings anders als Coxcie keine lebensechten Figuren, sondern polychrome Skulpturen gemalt hat (s. hierzu HAND 2004, S. 32 f., Abb. 8).

721 Für den originalen Wortlaut des Beschlusses sDE RAM 1861, S. 319 u. für eine Übersetzung FreEDBERG 1988, S. 163, Anm. 87. Einen Forschungsüberblick zum ,Kryptoportrait' bzw. ,Identifikationsportrait', findet sich bei POLLEROß 1988, S. 1-9 u. HECHT 2012, S. 354-375. 
Zweifellos handelt es sich hier nicht um eine Kritik am Tridentinum oder der Provinzialsynode von Mecheln, sondern um den Ausdruck des Selbstverständnisses des Künstlers. Denn obschon man sich im 16. Jahrhundert darüber bewusst war, dass es sich bei der Georgslegende um eine anachronistische Adaption des antiken Mythos von Perseus und Andromeda handelt, erfährt die Figur im Zusammenhang mit den religiösen Unruhen der Epoche neue Bedeutung. Als Patron der Schützengilden liegt die Betonung auf den kämpferischen Attributen, der die Gestalt des Ritters und Drachentöters kennzeichnet. Sein Heldenmut an sich hatte bereits das Potenzial, Georg zu einer Symbolfigur werden zu lassen, dessen bedingungslose Bereitschaft sein eigenes Leben der guten Sache zu verschreiben, im Verlauf des Jahrhunderts von beiden widerstreitenden Parteien für sich aufgegriffen wurde. Wilhelm von Oranien wurde während der holländischen Befreiungskämpfe gegen die spanische Vorherrschaft ebenfalls mit dem Hl. Georg verglichen. ${ }^{722}$ Darin wird deutlich, dass der aus der altkirchlichen Tradition herstammende Heilige als Symbol des Gottesstreiters auch für die protestantische Seite von Bedeutung war. Etwa zur selben Zeit wurde er

722 Allgemein gehört der Hl. Georg zur mittelalterlichen Ritterikonographie, seit dem späten 15. Jh. wurde er aber auch vermehrt als politische Sinnfigur gedeutet, als ,Soldat Christi' (LCI VII [1974], s. v. „Georg“", Sp. 385 f.).

723 „Nam qui nimium emungit elicit sanguinem“ (Molanus 1594 [1771], S. 14), sinngemäß meint dies, dass jene Dinge, die jemand als geschriebenes Wort akzeptiert, auch als Bild toleriert werden müssten. Molanus stützt sich dabei auf Eramus: „Lingua loquitur oculis: multaque loquacior est pictura, quam oratio, \& frequenter altius descendit in pectus hominis" (Erasmus, auch von katholischen Theologen wiederentdeckt und seine ikonographische Tradition fruchtbar gemacht, so etwa durch Johannes Molanus, der ihn als Vorbild für jeden Katholiken pries, obschon das Bewusstsein von der womöglich nur legendarischen Existenz des heldenhaften Heiligen seinen bildtheologischen Grundsätzen widersprach. ${ }^{723}$ Nichtsdestotrotz konnte die Gestalt im Sinne einer Allegorie eines streitbaren christlichen Ritters gelten, was Molanus grundsätzlich bewahrt sehen wollte. ${ }^{724}$ Zur genaueren Klärung des Widerspruchs zwischen der Anfechtung der Historizität des Heiligen und seiner fortwährenden frömmigkeits- und allgemein kirchengeschichtlichen Bedeutung heißt es im 14. Kapitel des 3. Buches seiner Abhandlung, dass es sich bei vielen Geschichten um Allegorien, folglich literarisch geformte Bilder handle; um solche, die sich letztlich des alten Prinzip der Allegorese bedienen und vermittels einer Gegenüberstellung von Typus und Antitypus auf moralische und auf heilsgeschichtliche Aspekte verweisen. So wie der Drache das Böse darstelle, würde Georg im Sinne eines ,Bildes Christi‘ für den Triumph über den Tod bzw.

Desiderius: Christiani Matrimonii Institutio, in: Desiderii Erasmi Opera Omnia, hrsg. von J. CleriCus 1703-1706, S. 719, zit. bei Molanus 1594 [1771], S. 212). Zwischen dem geschriebenen Wort und dem gemalten Bild bestehe eine Gemeinsamkeit, so Molanus. Letzterem müssten sogar gewisse qualitative Zugeständnisse gemacht werden: „Interim sicut in loquendo aliquid toleratur, sic etiam in picturis istiusmodi est tolerandum“ (ebd., S. 173).

724 ,In imaginibus, tametsi sint idiotarum libri, multa tamen metaphorice \& allegorice recte pingi“" (Molanus 1594 [1771], S. 66). 
die Befreiung von dem Bösen stehen. ${ }^{725}$ Wie kaum eine andere Gestalt, mit Ausnahme des Erzengels Michael und der streitbaren Könige und Helden des Alten Testaments, steht Georg für den Typus des christlichen Kämpfers, wie Johannes Molanus die zwar höchstwahrscheinlich fiktive, aber eben symbolträchtige Figur beschreibt. ${ }^{726}$ In Zeiten der wechselnden reformatorischen und gegenreformatorischen geistigen sowie territorialen Landnahme avancierte der Heilige zum Bannerträger beider Seiten. Die Gründung einer Antwerpener Georgsbruderschaft etwa diente einzig und allein dem Zweck, die Interessen Philipps II. in den spanischen Niederlanden durchzusetzen, sodass die Assoziation mit der katholischen Seite wohl als die stärkere gelten muss.

In diesem Zusammenhang ist es sinnvoll, zu dem von Anthonis Mor ausgeführten und vielfach kopierten Portrait des Herzogs von Alba, ${ }^{727}$ des ,Henkers der Niederlande‘, und dem Selbstportrait Michiel Coxcies auf dem Retabel für die Jonge Voetboog zurückzukehren. Coxcie inszeniert sich hier offenkundig als standhafter und ehrfurchtgebietender Soldat im Harnisch und mit der roten Schärpe des habsburgischen Feldherrn. Eine

725 „Sed nos prius de picturae historia agamus, quae allegoriae est anteponenda. Cur cum dracone pingatur, de quo triumphum ducit, explicate potest ex encomijs martyris, quae in menologio Simeonis metaphrastis exstant. In quibus legitur, Georgium plurimos ex draconis faucibus extraxisse, qui parem cum eo cursum transfigentes, proprium sanguinem Deo libarunt [...]" (Molanus 1570, Lib. III, hrsg. von BOESPFLUG CHRISTIN 1996, S. 277).

726 „Haec cura militis Georgij fuit: eandem que esse oportet omnium qui inscripti sunt in militarem sive equestrem ordinem. Nam \& regulae suae
Analogie zum Portrait des Herzogs liegt nahe. Eine Kenntnis des Portraits von Philipp II. von Anthonis Mor (1560) ist ebenfalls denkbar, da beide Bilder Ähnlichkeiten bei der Haltung der sportartig beleuchteten menschlichen Figur und dem dunklen Hintergrund zeigen. ${ }^{728}$ Zur Entstehungszeit des Retabels wäre eigentlich mit einer Darstellung des Heiligen in einem antikisierenden Soldatenkostüm zu rechnen, während er in der älteren niederländischen Kunst um die Jahrhundertwende und davor in einer zeitgenössischen Rüstung dargestellt wurde. Ganz anders ist es jedoch in diesem Fall, in dem es augenscheinlich weniger um die Legende des Heiligen geht als um dessen Bedeutung für Coxcies Zeitgenossen. Der Herzog von Alba als derjenige, der sich entschieden für die Interessen der katholischen Partei eingesetzt hatte, wird hier mit der Figur des Hl. Georg in Verbindung gebracht. Es ist von einer psychologischen Wirkung auf den zeitgenössischen Beschauer auszugehen, der sich je nach Konfession vor dem Bild zu seiner Altgläubigkeit bekennen oder aber darin eine Drohung erkennen konnte, die sich mit der realen Verfolgung von Protestanten unter der Herrschaft des Herzogs und später der

statutis, \& oris sui iureiurando, constringuntur, pro fide Catholica corpus audacter exponere: sanctamque Ecclesiam eiusque, ministros, a quibuscumque grassatoribus liberare." (Ebd., Lib. III, S. 277).

727 Öl auf Holz, $108 \times 83,5 \mathrm{~cm}$, Hispanic Society of America, New York City (s. VAN WAMEL 2014, S. 49-60; MARLIER 1934, S. 95 u. FRIEDLÄNDER 1967-1976, Bd. XIII, Kat.-Nr. 343).

728 Öl auf Leinwand, $103 \times 200 \mathrm{~cm}$, Patrimonia Nacional, El Escorial, Inv.-Nr. 1653. 
von Alessandro Farnese deckt. ${ }^{729}$ Dass Coxcie sein eigenes Gesicht gewählt hat, statt das Portrait des habsburgischen Statthalters zu verwenden, erweitert die oben beschriebene Deutung um ein persönliches Bekenntnis des $\mathrm{Ma}$ lers, das in seiner Doppelrolle von Hl. Georg und Herzog von Alba seinen Ausdruck findet. Hinzu kommt, dass es verbrieft ist, dass er mit seinem spanischen Herrscher ideologisch übereinstimmte, beide trafen hinsichtlich ihrer Loyalität gegenüber der römischen Kirche und dem Haus Habsburg zusammen, jeder verfolgte auf seine Weise die Ziele der Gegenreformation. ${ }^{730}$

Umso bemerkenswerter erscheint es, dass Coxcie den Richtlinien des Tridentinum und der Synode von Mecheln missachtete, indem er sich in Form eines Kryptoportraits man könnte sogar von einem Rollenportrait sprechen - mit dem Hl. Georg identifizierte. ${ }^{731}$ Ursächlich für die Beschlüsse der Synode mag die protestantische Kritik an der Einbettung von historischen Personen, wie etwa Stiftern,

729 Bildprogramme, die eine theologische Argumentation zu Gunsten des Katholizismus liefern, sind in Coxcies Werk nicht völlig neu. Aus den Beschreibungen von Calvete de Estrella ist ein komplexes Programm aus Wandbildern im Palast von Binche überliefert, das die protestantische Lehren zu dekonstruieren versuchte (s. Abschn. 3.4).

730 In einem Schreiben an den neuen Statthalter, den Herzog von Alba, bietet Michiel Coxcie seine Dienste bei der Wiederherstellung der zerstörten Altäre an (zu der Quelle s. VAN AUTENBOER 1992, S. 8).

731 JONCKHEERE 2013, S. 132.

732 s. hierzu ,Tit. VII' der Synode von Mecheln 1570 (s. DE RAM 1861, S. 319 u. für eine englische Übersetzung vgl. FrEEDBERG 1988, S. 162). in das Geschehen der Heilsgeschichte gewesen sein, da es diese Personen in eine sakrale Sphäre rückte. ${ }^{732}$ Auch die offizielle katholische Position richtete sich inzwischen gegen diese lang gepflegte Praxis, befürchtete sie doch, dass die Heiligkeit des dargestellten Personals durch die visuelle Präsenz eines Sünders befleckt werden könnte. ${ }^{733}$ Molanus behandelte die Problematik des ,Identifikationsportraits', wie HECHT es nach Friedrich Polleroß nennt, im Zusammenhang mit der lascivitas. ${ }^{734}$ Das alte Konzept eines Prototyps sei nicht mehr aufrecht zu erhalten gewesen, wenn Maler bestimmte Heilige mit dem Gesicht lebender Persönlichkeiten verknüpften, da ein Sünder nicht auf das Ideal eines Heiligen, das in seinem künstlerischen Abbild gezeigt werden sollte, zurückverweisen konnte. ${ }^{735}$

Selbst Angehöriger einer pro-habsburgischen Miliz, den Mechelner Colveniers, wurde Coxcie als Künstler in katholischen Kreisen geschätzt, wie die große Zahl entsprechender Aufträge bezeugt. ${ }^{736}$ Es verwundert

733 Als Reaktion auf die protestantische Bildkritik wurde während des Trienter Konzils, am 3. Dezember 1563 (sess. XXV.) definiert, wie Bilder zu gestalten seien, es heißt dort u. a.: ,[...] nichts Profanes, nichts Unanständiges dürfe an ihnen in Erscheinung treten, da dem Hause Gottes Heiligkeit gezieme [...]“ (zit. nach Denzinger 1973, S. 986-988, Mansi, Concil. XXXIII, $171 \mathrm{~A})$.

734 Hingewiesen sei auf die umfassende Studie zur Bildtheologie des 15. und 16. Jhs. von Christian HECHT aus dem Jahr 2012. Zur Prägung des Begriffs durch Friedrich Polleroß s. ebd., „Das sakrale Identifikationsporträt. Ein höfischer Bildtypus vom 13. Bis zum 20. Jahrhundert", zwei Bde., Worms 1988.

735 Vgl. HeCHT 2012, S. 354.

736 Vgl. WOOLLETT 2012, S. 85. 
nicht, dass er, der selbst dem katholischen Glauben treu blieb, zu einer der ersten Anlaufstellen für die Wiederherstellung oder Erneuerung der während des Ikonoklasmus beschädigten und zerstörten Retabel wurde. Obschon er in den 1570er Jahren auf Grund seiner wirtschaftlichen Lage durchaus im Stande war, sich zur Ruhe zu setzen, kann bereits unmittelbar nach den Ereignissen des Jahres 1566 von einem energischen Einsatz seinerseits für die Wiederherstellung der Altarbilder die Rede sein. ${ }^{737}$ Er sicherte dem Herzog von Alba bei dessen Ankunft in Mecheln $\mathrm{zu}$, dass man auf seine Unterstützung bei der Verteidigung des katholischen Glauben setzen könne. Im Gegenzug befreite er ihn von der Pflicht, Soldaten bei sich einzuquartieren. ${ }^{738}$ Das Portrait als Hl. Georg im Feldherrenkostüm, das auf das bekannte Portrait des Herzogs von Alba von Anthonis Mor Bezug nimmt, ist sicherlich als deutlicher Ausdruck der künstlerischen Selbstdarstellung Coxcies zu werten, der jedoch nur vor dem Hintergrund des Bildersturms zu verstehen ist. ${ }^{739}$

737 Vgl. Ebd., S. 76.

738 s. hierzu Van Autenboer 1992, S. 8. Coxcie konnte als loyaler Untertan angesehen werden. Sein Kontakt zum Herzog von Alba und Alexander Farnese sowie das versicherte Bemühen sich tatkräftig für die Wiederherstellung der zerstörten Altarbilder einzusetzen, führte zu einer Fülle von Aufträgen.

739 Als der Habsburger überträgt er seine loyale Haltung gegenüber Kirche und Monarchen in das Bild des christlichen Streiters. Man gewinnt den Eindruck, Coxcie identifiziert sich darin mit den katholisch gedeuteten ,milites Christic. Die in den Quellen überlieferte Korrespondenz mit Farnese bestätigt Coxcies Haltung (vgl. hierzu WOOLLETT 2012, S. 75-94; WESTSTEIJN 2012, S. 109-124; JONCKHEERE 2012, S. 12 f. u. JONCKHEERE 2007, passim. 

von Michiel Coxcie

Rund siebzig Jahre nach dem Ableben Michiel Coxcies 1592, der zu seinen Lebzeiten als ,flämischer Raffael ${ }^{‘}$ galt, ${ }^{740}$ konnte der Lierer Rederijker Cornelis de Bie in seinem Gulden Cabinet vande Edel Vry Schilderconst von 1662 resümieren, dass der Ruhm Coxcies neben anderen heute ungleich berühmteren Namen, wie Adam Elsheimer, Otto van Veen oder Frans Floris, inzwischen „wie Rauch verflogen" sei. $^{741}$ Die Ode ist dem Topos nach der melancholische Abgesang mehrerer einstmals bedeutender Künstler des 16. Jahrhunderts: „Michiel Coxi, van Oort, Vadder en Lenaert Bramer / De Backer Pauwels Bril, van Aken, Elsenhamer / Frans Floris en Verbeeck, Octavo Venus oock / Sijn met den snellen tijdt te saem vergaen als roock [...]. ${ }^{6742}$ Die darin angesprochene „schnelle Zeit“, die vergangen ist, und die Nennung einiger der Künstler, die damals bekannt und geschätzt waren, bringt einen Aspekt der Kunsttheorie des 17. Jahrhunderts zum Ausdruck, nämlich den des Fortschritts bzw. der Kunstentwicklung. Wie zu Beginn dieser Arbeit erwähnt, wurden die Leistungen eines Künstlers in diesem Jahrhundert anders bewertet als noch in der ersten Hälfte des 16. Jahrhunderts, in der die Entwicklung mehr oder weniger von einer Synthese zwischen altniederländischer Tradition und italienischer Innovation geprägt war. Für
Karel van Mander setzten die Leistungen Raffaels und Michelangelos bereits verbindliche Maßstäbe. Daher mag auch seine Einschätzung Michiel Coxcies herrühren, den er zwar als fähigen Maler, aber dennoch lediglich als Nachahmer Raffaels bezeichnete. ${ }^{743}$ Michiel Coxcie erkannte in Raffael die Zukunft der Malerei und nahm sich ihn zum Vorbild, während er die römische Kunst der 1530er Jahre in ihrer Gesamtheit studierte und parallel zur Entwicklung der Raffaelschüler, wie etwa Giulio Romano, die Neuerungen des Manierismus aufnahm. Vergleichbar damit ist die Entwicklung von Marten van Heemskerck, der zunächst bei dem Romanisten Jan van Scorel in Haarlem seine Ausbildung fortsetzte, ${ }^{744}$ bevor er 1532 wie Coxcie nach Rom ging. ${ }^{745}$

Die nach Coxcies Rückkehr in die Niederlande entstandenen Werke, wie die beiden Flügel für Gossaerts Lukas, der die Madonna malt und das Triptychon mit der Heiligen Familie von 1540, konnten zunächst als nahezu konkurrenzlose Neuerungen in der niederländischen Kunst dieser Zeit gelten. ${ }^{746}$ Der Streit mit Hieronymus Cock wegen dessen druckgraphischer Adaption von Raffaels Schule von Athen, welche Coxcies Motivübernahmen von Raffael zu erkennen gibt, bezeugt vielmehr den erfolgreichen Aneignungsprozess, den Coxcie durchlaufen hatte - unabhängig davon ob van Mander diesem Geschehen mehr Gewicht beimisst, als vor dem Hintergrund der

744 Vgl. Bartsch 2019, S. 19-37 u. Grosshans 1980, S. 20.

745 s. hierzu auch Abschn. 3.2.

746 Vgl. hierzu MUNDELL 2013: „Leuven exhibition proves artistic merit of Michiel Coxcie" vom 07. Nov. 2013, 〈http://www.flanderstoday.eu〉 (13.06.2019). 
gängigen Praxis der Zeit nötig wäre. ${ }^{747}$

Während Jan Gossaert von Guicciardini als der erste benannt wird, der sich mit den nackten Figuren Italiens befasste und diese für die niederländische Malerei gewonnen habe, steht Coxcie, als Zeitgenosse Heemskercks in Rom doch zumindest für die konsequente Fortführung dieser Tradition, die er durch seine in Italien erworbenen Erkenntnisse zu übertreffen im Stande war. ${ }^{748}$ Immerhin hielt Vasari es für nötig, Coxcie in seinen Lebensbeschreibungen italienischer Maler als einen der ausländischen Künstler, der die italienische Malerei vollauf beherrschen würde, zu loben. ${ }^{749}$ Vergleichbar ist diese Würdigung einzig mit Jan van Scorel, der nach seiner Anstellung als Aufseher der Antikensammlung im päpstlichen Belvedere und seiner Rückkehr nach Flandern 1525 im Stande gewesen war, Bilder mit authentischen Ruinen- und Renaissancearchitekturen sowie anatomisch korrekt gebildeten Figuren im antikisierenden Kostüm zu schaffen, während Zeitgenossen wie Bernard van Orley sich zeitlebens schwerer damit taten, den noch stark auf die ,Antwerpener Manieristen' des frühen 16. Jahrhunderts verweisenden experimentellen Romanismus zu überwinden. Möglicherweise war das innovative Schaffen des zurückgekehrten van Scorel einer der Gründe und das eindeutige Signal für Bernard van Orley gewesen, um sei-

747 Vgl. van Mander 1604, fol. 258v. Vgl. MiedemA 1997, Bd. 4, S. 185.

748 Vgl. Abschn. 2.1.

749, ,...] conobbi nel 1532 in Roma un Michele Coxie, il quale attese assai alla maniera italiana, e condusse in quella città molte opere a fresco [...]“(Vasari 1568, ed. Milanesi, VII, S. 585). nen Schüler Michiel Coxcie nach Rom zu entsenden, um den zeitgenössischen Ansprüchen an die Kunst, der in van Orleys Leitspruch „elx syne tijd“ (sinngemäß: jedem seine Zeit) zum Ausdruck kommt, gerecht zu werden. ${ }^{750}$ Die in dieser Untersuchung aufgezeigte Nähe Coxcies zu den Kompositionen seines Lehrers und die augenfälligen Verbesserungsversuche, etwa durch den authentischeren Gebrauch von Renaissancearchitektur und einen Figurenstil nach dem Vorbild der Antike und der italienischen Meister, durch Darstellungen, die insgesamt malerischer, aber auch bewegter und abwechslungsreicher als die des Lehrers ausfallen, beschreiben den künstlerischen Weg, den Michiel Coxcie einschlug, indem er die Vorbilder aus dem späten Werk Bernard van Orleys aufnahm, um diese mit Hilfe der in Italien gewonnenen Eindrücke weiterzuentwickeln - hierin ist er erneut mit Heemskerck vergleichbar, dessen vorrömisches Werk ähnlich schwer von dem seines Haarlemer Lehrers $\mathrm{zu}$ unterscheiden ist, wie das frühe Idiom Michiel Coxcies von dem des Bernard van Orley. ${ }^{751}$

Mit den Kopien altniederländischer Werke ist eine andere Facette von Coxcie zu fassen. Neben der Rolle eines Erneuerers erscheint er hier in der Nachfolge Jan van Eycks und Rogier van der Weydens, die als Fixsterne zu Beginn der niederländischen Malereitradition stehen. Zugleich aber wurde er selbst Teil

750 Zum Leitspruch und der Interpretation dieses künstlerischen Mottos s. DACOS 1987, S. 17-28 u. Abschn. 2.3 dieser Arbeit.

751 s. Abschn. 3.1. Vgl. hierzu auch Grosshans 1980, S. 40-46. 
einer epochalen von den Habsburgern betriebenen Religions- und Kulturpolitik, die sich in den Sammlungen von Philipp II. und Maria von Ungarn ausdrückt, welche neben Werken der italienischen Kunst, auch solche der altniederländische Malerei umfasste und damit das burgundische Erbe des Hauses einbezog. ${ }^{752}$ Die positive Aufnahme der Kopie des Genter Altares in verschiedenen Werken der humanistischen Literatur zeigt, dass Coxcie in diesen Kreisen geschätzt wurde. So schreibt Lucas de Heere in seiner Ode an den Genter Altar von 1559, dass das Werk, das heißt das Original sowie die Kopie, „dem König und Coxcie zu großer Ehre gereicht“ habe. ${ }^{753}$ Wenige Jahre später schreibt Ludovico Guicciardini im Zusammenhang mit der in relativ kurzer Zeit verfertigten Kopie, dass Michiel Coxcie ein „exzellenter Meister“ sei. ${ }^{754}$ Dies zeigt, dass Coxcies Wirken von Zeitgenossen nicht kritisch beurteilt wurde, wie in der späteren kunsthistorischen Literatur, sondern im Sinne einer künstlerischen Leistung gewürdigt wurde, die dem Prinzip der aemulatio folgt und für den Manierismus des späten 16. Jahrhunderts sowie die Malerei des flämischen Frühbarock von grundlegender Bedeutung sein

752 s. Abschn. 3.4 u. 3.5.

753 „Ende tot Heycus (Philipp) en Coxyens glorie groot." (s. De Heere 1565, S. 38, Verse 81-92).

$754,,[. .$.$] dall' eccelente maestro Michele Cockisien,$ il quale statoui sopra circa due anni, havendo servito per eccelenza [...]" (s. Guicciardini 1567, S. 97).

755 Verwiesen sei hier exemplarisch auf Karel van Manders Kunsttheorie (vgl. MÜLLER 1993, S. 40-45) u. die von Samuel van Hoogstraten (vgl. hierzu WestSTEIJN 2013, S. 35-52).

756 „Coxcie did not simply imitate the van Eyck brothers; he tried to surpass them" (SUYKERBUYK 2015, S. 78). sollte. ${ }^{755}$ Entsprechend konnte SUYKERBUYK resümieren, dass Coxcie das Werk von van Eyck nicht bloß sklavisch kopierte, sondern versucht habe, gegenüber dem Genius des großen Vorgängers „,zu bestehen“. 756

Eine konkrete Bezugnahme auf das Werk Coxcies lässt sich verschiedentlich ausmachen, so etwa bei dem calvinistischen Maler Adriaen Thomasz. Key, der mehrere Kompositionen des habsburgischen Hofmalers kopiert hat. ${ }^{757}$ Darunter Coxcies Darstellung von Kain und Abel aus den 1550er-1560er Jahren [ABB. 124]. Sowohl das Original als auch die Kopie [ABB. 125] zeigen Kain und Abel nackt. ${ }^{758}$ Während Abel bereits vorne rechts erschlagen auf dem Boden liegt - die Kinnlade eines Tiers, das Tatwerkzeug, verdeckt seine Scham - ist Kain links daneben etwas weiter in den Mittelgrund gerückt zu sehen, wie er sich das Haupt beschirmend von der Stätte abwendet. Im Hintergrund sieht man eine aus Steinen aufgerichtete brennende Feuerstelle, die man dem Opfer Kains zuordnen kann, während eine weitere identische Feuerstelle im Vordergrund das wohlgefällige Opfer Abels zeigt. Der athletisch durchgeformte Leib des Toten wirkt wie soeben rücklings zu

757 Eine weitere Kopie nach dem Vorbild Coxcies stellt die sog. Heilige Maagschap van Maria dar, welche Key zugewiesen wird und in der zweiten Hälfte des 16. Jhs. entstanden sein soll (Öl auf Holz, $114 \times 143 \mathrm{~cm}$, Privatbesitz, RKD-Nr. 109972). Motivisch handelt es sich um einen Ausschnitt aus Coxcies Mitteltafel des Triptychons mit der Hl. Sippe von 1540, das sich heute in Kremsmünster befindet.

758 Coxcie: Öl auf Holz, $151 \times 125 \mathrm{~cm}$, Prado, Madrid, Inv.-Nr. P001518 (vgl. ATKINs 2015, S. 12-39; PÉREZ DE TUDELA 2013, S. 106, JONCKHEERE 2013b, 134-135. Key: Öl auf Holz, 180 $\times 130 \mathrm{~cm}$, Zanchi Collection, Belmont (Schweiz). 
Boden gestürzt; der Oberkörper samt Kopf und Armen liegen auf dem Boden, während seine beiden Füße auf den Steinen aufliegen, so als sei er von der Feuerstelle herabgefallen. Angesichts des brennenden Feuers darauf wirkt dieses Arrangement etwas unlogisch, wird aber von Key keineswegs korrigiert. Tatsächlich sind die beiden Figuren und ihre Opferfeuer identisch wiedergegeben. Auch im Detail erscheint der Vordergrund ähnlich in beiden Bildern; so liegt der Tote jeweils auf einem sandig gelben Boden. Der sich hinter den beiden Feuern anschließende Hintergrund ist jedoch jeweils unterschiedlich gestaltet: Während bei Coxcie eine Waldung und links ein kleiner Bach zu sehen sind, zeigt Keys Bild an den entsprechenden Stellen Felsformationen, zwischen denen sich ein Ausblick in die nicht näher definierte Ferne ergibt. Das Original zeigt an der entsprechenden Stelle zwischen dem Wasserlauf und dem Waldrand links einen vergleichbaren Spalt. Der wesentliche Unterschied zwischen beiden Bildern betrifft die dritte Figur, die nur auf dem Original dargestellt ist: Gottvater, der als Greis in wallende Gewänder gehüllt und in Begleitung zweier Engel vom Himmel herniederfährt, um Kain für seine Missetat zur Rechenschaft zu ziehen und mit dem Kainsmal zu belegen. Analog hierzu ist der entsetzte Ausdruck des Mörders und die beschirmende Haltung, bei der er seiner Arme über dem Haupt hält, zu erklären. Der große Ausfallschritt bei gleichzeitiger

759 Vgl. JonCKHEERE 2013, S. 12 f. Jonckheere nennt in diesem Zusammenhang eine weitere (Teil-)Kopie nach Coxcies Hl. Lukas auf dem Seitenflügel für Gossaerts Lukasaltar in Prag
Wendung des Kopfes nach hinten unterstreicht seine erschrockene Fluchtreaktion, unmittelbar nachdem er nur einen kurzen Moment zuvor das Herannahen Gottes gewahrt hat. Die Figur ist auf Keys Version des Bildes nicht dargestellt, während die rückwärtsgewandte Blickrichtung des nach links aus dem Bildfeld hinausstrebenden Kain beibehalten ist. Gerade dieses Detail zeigt, dass es sich bei dem fehlenden Gottvater um eine ganz bewusste Veränderung handelt. Das, was Coxcie wortwörtlich dem Bibeltext nach zu illustrieren versucht, ist bei Key nur in Form einer Andeutung umgesetzt, die sich in dem Zurückblicken Kains zeigt. Die Darstellung gibt klar zu erkennen, dass es sich um den Brudermord handelt, sodass die in der Erzählung folgende Konsequenz der Bestrafung des Missetäters durch Gott vom Betrachter eigenständig erschlossen werden kann. Die Tatsache, dass Key dem calvinistischen Umfeld zugerechnet wird, gibt Anlass zu der Annahme, dass die Weglassung Gottvaters möglicherweise mit der bilderfeindlichen Auslegung des zweiten Gebots zusammenhängt. ${ }^{759}$ Coxcie selbst hatte das Vorbild, das er für den toten Abel gebrauchte, aus Rom mitgebracht. Auch von der Skulptur des Laokoon könnten wesentliche Impulse für die Gestaltung des Abel ausgegangen sein, wie Natasja PEETERs aufgezeigt hat. ${ }^{760}$ Das Vorbild ist jedoch vor allem der stehende Christus im Jüngsten Gericht an der Altarwand der Sixtinischen Kapelle [ABB. 126]. Coxcie hat die Figur gewissermaßen um 180

(JONCKHEERE 2012, S. 14-16). Zur Biographie und zum Gesamtwerk Keys s. JONCKHEERE 2007, passim.

760 Vgl. PEETERS 2012, passim. 
Grad gedreht und dabei die gebeugten Unterschenkel des Vorbildes so interpretiert, dass sie bei der Liegefigur an der Feuerstelle emporragen. ${ }^{761}$ Die Haltung des linken Armes entspricht der des rechten bei Michelangelo; auch der auffällig gespreizte Daumen ist übernommen sowie die seitliche Neigung des Kopfes. Es ist denkbar, dass ihm eine Zeichnung aus seiner Zeit in Rom vorgelegen hat, die er tatsächlich nur noch zu drehen brauchte, um danach seinen liegenden Abel zu zeichnen. Die daraus hervorgegangene Vorzeichnung, die Abel als Einzelfigur zeigt, gelangte später in den Besitz von Peter Paul Rubens [ABB. 127]. ${ }^{762}$ Die Studie regte diesen maßgeblich dazu an, eine eigene Zeichnung eines fallenden Mannes anzufertigen [ABB. 128], ${ }^{763}$ offenbar mit der Absicht, die auffälligen Probleme beim Maßstab der Füße sowie die insgesamt sonderbar anmutende Haltung der geradezu gymnastisch gespreizten und dabei erhobenen Beine zu korrigieren. Die Beine sind bei Rubens stattdessen angewinkelt wiedergegeben und der Oberkörper weist eine stärkere Biegung auf, die sich an der gespannten Brustund Bauchmuskulatur und dem weiter bis über den Kopf gezogenen linken Arm deutlich abzeichnet. ${ }^{764}$ Diese Figur weist wiederum große Ähnlichkeiten mit dem Gebundenen Prometheus von 1611/12 auf [ABB. 129]. Zu sehen ist eine mit der Zeichnung fast identische

761 Vgl. ATKINS 2017, S. 111-122.

762 Zeichnung, $214 \times 210$ mm Fitzwilliam Museum, Cambridge.

763 Zeichnung um 1610/11, $550 \times 426$ mm, Musée du Louvre, Paris (Abb. in Kat. Städel 2017, Kat.Nr. 96. männliche Liegefigur, die hier jedoch an einer von rechts unten nach links oben verlaufenden Diagonale ausgerichtet ist, während die Zeichnung sich in diesem Punkt stärker an dem Vorbild von Coxcie orientiert - was den Zusammenhang beider Blätter nahelegt. Als Ergebnis dieser Herleitung lässt sich konstatieren, dass das Endresultat bei Rubens eine Figur von größerem Naturalismus ist, welche anatomisch wirklichkeitsgetreuer modelliert ist und die fehlerhaften Proportionen der zu großen Füße und die sonderbare Steifheit der gestreckten Beine von Coxcies Abel hinter sich gelassen hat. Man kann von einer Weiterentwicklung des Ausgangsmotivs sprechen, obschon eingeräumt werden muss, dass es sich bei der Figur des Prometheus um die Darstellung eines lebenden Körpers handelt, dessen schmerzerfüllte Reaktion auf den seine Leber fressenden Adler allein deshalb schon mehr Körperspannung suggeriert als es bei dem toten Abel von Coxcie der Fall sein kann.

Für seine Zeitgenossen scheinen vor allem die späten Kompositionen mit den Heiligenmartyrien für rezeptionswürdig befunden worden zu sein; stehen sie doch stilistisch auf der Höhe der Zeit, in der die Romanisten um Coxcie mehrheitlich dem Manierismus zuge$\tan$ waren, wie die Werke von Frans Floris, Ambrosius Francken, Otto van Veen und anderer zeigen. ${ }^{765}$ Vielleicht bediente sich Coxcie

764 Vgl. Weppelmann 2017, S. 228. Vgl. Kat. Städel 2017, S. 242, Kat.-Nr. $94-96$ u. 99. Zur Methode des Kopierens bei Rubens allgemein vgl. BÜTTNER 2017, S. 127-158.

765 Zum niederländischen Manierismus s. FRIEDLÄNDER 1921; BOUSQUET 1985; HOCKE 1991. Für eine Erörterung von Marterbildnissen des späten 16. Jhs. im Umfeld der Francken-Werkstatt s. FREEDBERG 2014, S. 181-212. 
in dieser letzten Schaffensphase aber auch lediglich der bevorzugten Ausdrucksformen im letzten Drittel des 16. Jahrhunderts in Flandern, vor deren Hintergrund, neben den persönlichen Erfahrungen der Reformationszeit, auch die emotionale und spirituelle Zuspitzung seiner Marterbilder zu deuten ist.

Das Verhältnis von Vorbild und Nachahmung bzw. der gegenseitige Austausch zwischen den (süd-)niederländischen Malern dieser Zeit lässt sich im Vergleich bestimmter Werke erörtern. Coxcies Darstellung des geräderten Georg auf der Mitteltafel des Mechelner Georgsretabels von 1588 etwa [ABB. 120] scheint für die Komposition von Otto van Veens Martyrium des Hl. Andreas von nicht geringer Bedeutung gewesen zu sein [ABB. 130]. ${ }^{760}$ Beide Bilder zeigen zentral den jeweiligen Heiligen umringt von Folterknechten und Schaulustigen, der bereits auf sein Marterinstrument gebunden ist. Während van Veens Tafel nachweislich über keine Seitenflügel verfügte, ${ }^{767}$ zeigen solche bei Coxcie frühere Stationen aus der Vita des H1. Georg. Auch van Veen orientiert sich in seiner Darstellung an der Legenda Aurea, wie das Detail des von Sonnenstrahlen illuminierten Andreaskreuzes, das dem Text nach den Tod des Heiligen markiert, bezeugt. ${ }^{768}$ Die Verteilung und Gewichtung der Bildbestandteile sowie die zentrale Dreieckskomposition sind Coxcies Georgs-Martyrium entnommen. Letztere ergibt sich aus der in der Bildmitte dargestellten Figur des Heiligen, dessen Angebundensein auf dem Rad eine diagonale Ausrichtung des Körpers im Bild ergibt, die sich nach rechts in der Figur eines sich abwendenden Soldaten fortsetzt. Eine weitere, sich mit der anderen im Bereich des Gesichtes von Georg schneidende von links unten her geführte Diagonale setzt sich in den Schultern der beiden Folterknechte links und in dem schräggestellten Nagelbrett über dem Haupt Georgs fort. Van Veen greift diese beiden einander kreuzenden Diagonalen sehr deutlich in der Form des Andreaskreuzes auf und verlängert diese in der Brust und dem rechten Vorderbein des von rechts herantretenden Pferdes, während der linke Schenkel des Dreieckes, ausgehend von dem Kreuzbalken links unten, in der Schulter- und Armpartie einer frontal zum Betrachter gewendeten sitzenden Frau fortgesetzt wird. Auch das Moment des sich öffnenden Himmels, was durch den gelben Schein einer Gloriole hinter Andreas angezeigt wird, findet sich in nur leicht abweichender Form rechts oben bei Coxcies Georgsmartyrium. In beiden Bildern erscheinen Engel mit Palmzweig und Siegerkranz am Himmel. Statt der antikisierenden Engelsgestalt bei Coxcie wählt van Veen eine Mehrzahl kleiner Putti mit übergroßen Kinderköpfen. Auch im Hinblick auf die Verteilung der Bildgegenstände lassen sich große Übereinstimmungen ausmachen: So zeigen in beiden Bildern alle vier Ecken flächenfüllende Landschafts- und Architekturmotive. Dieser horror vacui fällt bei van Veen sogar etwas stärker aus, da er die Menschenmenge visualisiert, die laut Überlieferung zur der Marterstätte gekommen sein soll, um den noch lebenden Andreas von
766 Öl auf Holz, $437 \times 287$ cm, Sint-Andries-Kerk, Antwerpen, Inv.-Nr. 0140019000.

767 Vgl. FreEDBERG 1976, S. 135.
768 „His dictis splendor nimius de caelo veniens dimidia hora eum circumdedit, ita ut nullus“" (s. HäUPTLI 2014, Legenda Aurea, S. 116). 
seinem Kreuz herab predigen zu hören. ${ }^{769}$ Auch der Prokonsul ist als Reiter dargestellt, welcher, dem Wunsch der Masse folgend, versucht haben soll das über Andreas gefällte Urteil zurückzunehmen und ihn vom Kreuz abnehmen zu lassen. ${ }^{70}$ Dies lehnte Andreas aber ab, da er sein Urteil - den Tod am Kreuz bereits im Sinne der Christusnachfolge angenommen hatte. ${ }^{771}$ Links im Hintergrund ist ein Stadttor zu sehen, durch das weitere Menschen herandrängen, während rechts oben ein Rundtempel mit Götterstandbild gezeigt wird und im Vordergrund Figuren dargestellt sind, die vom unteren Bildrand überschnitten werden. Ähnlich auch bei Coxcie, bei dem zwei Soldaten unten links erst vom Rumpf an dargestellt sind. Rechts im Hintergrund ist der sich öffnende Himmel mit einem Engel zu sehen und dem gegenüber eine Art Stadtsilhouette mit Tor und einem nebenstehenden Baum, der die rechte Diagonale der Dreieckskomposition verlängert. Auch die Gestaltung der Figuren ist vergleichbar - die Figur des Prokonsuls trägt eine Art Wams mit kurzen Ärmeln, das den Lederharnischen der Soldaten bei Coxcie ähnelt. Der blassrötliche Farbton des Umhangs wiederum ist derselbe wie bei dem Soldaten unten rechts auf Coxcies Tafel.

Für sein Martyrium des Hl. Andreas greift Rubens 1638 die Komposition seines Lehrers Otto van Veen auf und extrahiert diese bereits bei Coxcie erkennbare Dreieckskomposition, um sie mit einer reduzierten Anzahl von Figuren und in stärkerer Untersicht

769 s. HÄUPTLI 2014, Legenda Aurea, S. 115.

770 s. ebd., S. 155 f.

771 Er bekennt zuvor feierlich: „Antequam te ascenderet dominus, timorem terrenum habuisti, modo vero amorem caelestam obtinens; pro vor einem grauen, bedrohlich wirkenden Himmel darzustellen [ABB. 131]. ${ }^{772}$ Für den Zusammenhang von Michiel Coxcies und Otto van Veens Gemälde spricht weiter, dass die Gestalten der beiden Heiligen gewisse Eigenschaften teilen. Beiden gemein ist der gen Himmel gewandte Blick. Auch die unnatürliche Körperhaltung beider Figuren, die an Armen und Beinen gebunden und fast vollständig entblößt dargestellt sind, verfolgt das gleiche Ziel - den jeweiligen Heiligen als wehrloses, der tobenden Masse ausgeliefertes Opfer zu zeigen. Diese Charakteristika sind es auch, die bei dem HI. Andreas von Rubens eine weitere Steigerung durch gezieltere Lichtführung und eine stärker vom Malerischen bestimmte Auffassung erfährt, während Coxcie und van Veen noch stärker von den von der Linie her entwickelten Vorbildern aus der italienischen Hochrenaissance und dem Manierismus beeinflusst sind.

Manieristische Elemente finden sich im Übrigen etwa in der antikisierenden und die Anatomie betonenden Kleidung sowie in der unproportionalen Bildung der Figuren, was vor allem bei Otto van Veen zum Tragen kommt. Der Reiter am rechten und die am unteren Bildrand sitzende Frauenfigur sind im Verhältnis zu dem weiter hinten gezeigten Andreas und den beiden Knechten mit herkulischer Statur, die das Kreuz aufrichten, zu klein dargestellt. Auch nimmt der Größenmaßstab zum Hintergrund zu schnell ab. Die Hände und Arme des Andreas sind im Verhältnis

voto susciperis“" (s. HÄUPTLI 2014, Legenda Aurea, S. 144).

772 Öl auf Holz, $305 \times 216$ cm, Fundación Carlos de Amberes, Madrid. 
zum restlichen Körper überdimensioniert. Bei Coxcies Hl. Georg ist Vergleichbares hinsichtlich der zu langen Beine des Heiligen zu beobachten.

Neben der Tafel von Otto van Veen steht auch die Darstellung auf der rechten Außenseite eines fragmentarisch erhaltenen Triptychons von Frans Pourbus mit dem Georgsmartyrium aus dem Jahr 1577 [ABB. 121] in einem engeren Zusammenhang mit Coxcies Mechelner Retabel von $1588 .^{773} \mathrm{Zu}$ sehen ist der Hl. Georg, der auch hier mit den Armen und Beinen - dieses Mal an einen Pfahl statt des Rades - gebunden ist. Die Streckung des Leibes und der zum Himmel gerichtete Blick des ebenfalls nur mit einem Lendenschurz bekleideten Heiligen erinnern an den Georg auf Coxcies späterer Tafel. Ein Zusammenhang beider Bilder besteht darüber hinaus auch bei der von dem plötzlich hereinbrechenden Chaos bestimmten Atmosphäre. Während einer der Peiniger angesichts der am Himmel sich abzeichnenden Ereignisse panisch die Marterstätte zu verlassen versucht, liegt ein weiterer bereits, seinen Kopf mit den Händen beschirmend, am Boden - eine Figur übrigens, die auf Coxcies Laokoon-Rezeption verweist und gegen Ende des 16. Jahrhunderts in Antwerpen vielfach aufgegriffen wurde. ${ }^{774}$ Der graue Wolkenhimmel und das diffuse Geschehen im Hintergrund - man sieht einen Reiter, der sein Pferd im Galopp zum rechten Bildrand treibt - zeigen weitere Übereinstimmungen. Bei Coxcie sieht man deutlicher, was sich

773 Öl auf Holz, $320 \times 121 \mathrm{~cm}$, Musée des BeauxArts, Dünkirchen.

774 Vgl. hierzu die Studie von PeETERs 2012, passim. Sie nennt das Triptychon mit der zentralen Darstellung der Anbetung der ehernen Schlange im Hintergrund ereignet: Auch hier sind Reiter und flüchtende Soldaten zu sehen. Da das Werk von Pourbus früher entstand, muss hier zunächst davon ausgegangen werden, dass es Einfluss auf Coxcie ausgeübt haben könnte. Die Alternative wäre ein Zusammenhang mit einem noch früheren Bild mit einer ähnlichen Darstellung aus Coxcies Antwerpener Schaffenszeit in den 1570er Jahren, dessen Existenz jedoch lediglich hypothetischer Natur ist. Zumindest aber kann konstatiert werden, dass beide Antwerpener Maler einander in die eine oder andere Richtung beeinflusst haben müssen. Die diagonal auf dem Boden im Vordergrund liegende und dadurch perspektivisch leicht verkürzt wiedergegebene Figur auf dem Seitenflügel von Frans Pourbus stellt indessen mit großer Wahrscheinlichkeit ein zuerst bei Coxcie in Erscheinung tretendes Motiv dar. ${ }^{775}$ In den späten 1580er Jahren entstanden die beiden Seitenflügel [ABB. 132-133], die Ambrosius Francken im Auftrag der Antwerpener Oude Handboog als Ersatz für die unter der Herrschaft des calvinistischen Stadtrates in den Jahren von 1581 bis 1585 zerstörten oder veräußerten Seitentafeln des erst 1575 von Coxcie angefertigten Sebastiansretabels schuf [ABB. 110]. Als Folge des calvinistischen Bilderverbots mussten die Gilden ihre Altarbilder und andere Ausstattungsstücke entfernen; teilweise wurden sie auch veräußert, um die während des Bildersturms und unter der Schreckensherrschaft des Herzogs von Alba

von 1555 als eines der ersten Werke Coxcies, in denen er das Motiv verarbeitet (Abb. bei ebd., S. 30; heute im Maagdenhuis Museum, Antwerpen, RKD-Nr. 232762).

775 Vgl. PeETERs 2012, passim. 
verarmten Mitglieder finanziell zu unterstützen. ${ }^{776}$ In jedem Fall blieb die Mitteltafel mit dem Martyrium des Hl. Sebastian davon unberührt. Coxcie war zu diesem Zeitpunkt bereits deutlich über 80 Jahre alt und hatte Geschäft und Wohnort in seine Heimatstadt Mecheln zurückverlegt, wo er die hier zuvor bereits besprochenen Motive der beiden Antwerpener Retabel aus den 1570er Jahren mit den Martyrien der Heiligen Sebastian und Georg als einander recht ähnliche Variationen wiederholte. Denkbar ist, dass er einer neuen Generation von Malern in Antwerpen das Feld überlies, zu der unter anderen Ambrosius Francken und Marten de Vos zu zählen sind, obschon er im Stande gewesen wäre, die verlorenen Tafeln zu rekonstruieren, wie seine Mechelner Altarbilder der 1580er Jahre bestätigen können. ${ }^{777}$

Die Flügel, die Francken als Ergänzung zu Coxcies Sebastiansmartyrium schuf, zeigen auf den Innenseiten den Hl. Sebastian im Kerker, wie er die Brüder Marcellus und Marcellinus dazu auffordert, mit ihm zusammen das Martyrium zu erleiden, ${ }^{778}$ und auf der anderen Seite die Wunderheilung der Zoë. Auf den Außenseiten sieht man auf der einen Seite, wie Sebastian an seinem Richter - es soll sich wohl um Diokletian selbst handeln - vorübergeführt wird und auf der anderen [ABB. 132], wie der Heilige von Folterknechten mit Stangen oder Stöcken geschlagen wird [ABB. 133]. Das Erscheinungsbild des Sebastian ist

776 Für die aufgearbeiteten Archivalien s. PRIMS 1939, S. 357-363 u. 183-188.

777 Anzumerken ist hier, dass die Antwerpener Lukasgilde Coxcie in den Jahren 1585-1586 als ihr Mitglied aufführt (ROMBOUTS - LERIUS 18721876, Bd. 1, S. 301). Vgl. FreedBerG 2014, S. 199; FREEDBERG 1976, S. 132. an den auf der von Coxcie geschaffenen Mitteltafel angepasst und zeigt den Heiligen ebenfalls mit idealschön gebildetem Körper. Auch hier ist der Fokus auf die Ambivalenz zwischen der körperhaften Figur und ihrem Ringen mit den erlittenen Schmerzen gerichtet. Die krampfartig verrenkten Arme und Beine, vor allem aber die Streckung und Drehung des muskulösen Oberkörpers versucht die Figur Coxcies zu imitieren, was besonders an dem erhobenen rechten Arm und dem unsicheren Stand der bewegten, von Pein erfüllten Figur deutlich wird. Das linke Bein ist dem Anschein nach soeben erst von einem harten Schlag getroffen und daraufhin krampfartig nach hinten eingeknickt. Die unter den Schlägen schmerzerfüllt verrenkten Gliedmaßen sind in alle Richtungen verdreht, was die Momenthaftigkeit der Darstellung des auf einem Bein sich windenden und brutal geschlagenen Heiligen betont. Eine Repoussoir-Figur unten links, bei dem es sich um einen der Peiniger handelt, wendet seinen Blick zum Betrachter, während er mit einem Stück Holz in der Hand auf den gefolterten Heiligen weist - ganz so als wolle er die Drangsal, der dieser ausgesetzt ist, dem Betrachter vorführen. Solche Figuren, oftmals mit höhnischen oder bösartig verzerrten Grimassen versehen, stellen eine Besonderheit der Bilder Franckens dar, während aber auch bei Coxcies zweiter Antwerpener Tafel mit

778 Den Ausruf überliefert Jacobus de Voragine: „O fortissimi milites Christi, nolite per misera blandimenta coronam deponere sempiternam“ (HÄUPTLI 2014, Legenda Aurea, S. 810). 
dem Sebastiansmartyrium unten links eine Figur zu sehen ist, die - größtenteils von einer weiteren bedeckt - mit der Hand auf den am Baum angebundenen Sebastian weist, während er sich mit dem Blick über die rechte Schulter zum Betrachter wendet [ABB. 114]. Die manieristische Streckung und Krümmung des Leibes, mit der Ambrosius Francken seinen Sebastian zeigt, greift ganz eindeutig die Darstellung von der Mitteltafel auf. Bemerkenswert ist dies vor allem auch deshalb, weil eine weitere Tafel, die ihrerseits zu den erhaltenen Flügeln eines Altares von Ambrosius Francken aus der Antwerpener Georgskirche gehört, die auf 1595-1598 datiert werden, eine sehr ähnliche Figur zeigt. Dieses Mal handelt es sich jedoch um die Darstellung des an einen Pfahl gebundenen Hl. Georg [ABB. 134], dem Coxcies Sebastian als Vorbild vorgelegen haben muss. ${ }^{779}$ Details wie die frontale Darstellung des mit den Armen hinter dem Rücken und über dem Kopf angebundenen Heiligen greifen erneut die Figur auf der Mitteltafel des Retabels für die Oude Handboog auf, während die Streckung des angespannten Oberkörpers zugleich auch auf die zuvor beschriebene, von Francken selbst geschaffene Tafel mit dem Hl. Sebastian, der von seinen Folterknechten geschlagen wird, zurückzuführen ist [ABB. 133]. Weiterhin könnte auch die zweite Tafel des fragmentarischen Georgsretabels von Ambrosius Francken, welches die

$779 \mathrm{Zu}$ beachten gilt es jedoch, dass sich Ähnlichkeiten in Bezug auf die Darstellung des Heiligen auch bei dem weiter oben erwähnten Dünkirchener Triptychon von Frans Pourbus feststellen lassen.

780 Öl auf Holz, 236,4 × 90,2 cm, Koninklijk Museum voor Schone Kunsten, Antwerpen. Zur
Enthauptung des Heiligen zeigt [ABB.135], motivisch von der rechten Innenseite von Coxcies Mechelner Georgsretabel von 1588 oder einem vergleichbaren, nicht erhaltenen früheren Werk aus Antwerpen abgeleitet worden sein [ABB. 120]. In beiden Fällen ist der Heilige zusammen mit dem Henker im Bildvordergrund dargestellt. Der Heilige kniet, während sein Schlächter zunächst noch das Haupt seines Opfers in die richtige Position dreht - bei Coxcie holt er bereits zum Streich aus. Noch deutlicher ist die Bezugnahme auf Coxcie in Franckens Tafel mit dem Martyrium der Heiligen Cosmas und Damian [ABB. 136], die in dieselbe Zeit datiert werden kann. ${ }^{780}$ Allen drei Beispielen ist die Monumentalität gemein, mit welcher die Brutalität der Henker und das Leiden der Heiligen vor Augen geführt wird.

Vorbildhaft war Coxcie auch für Josse van der Baren aus Löwen, dessen auf 1597 datiertes Martyrium des Hl. Sebastian, der einzigen erhaltenen Tafel eines Triptychons [ABB. 137], in Bezug auf Stil und Motivik stark auf Coxcies Malerei verweist. ${ }^{781}$ Einige der Schützen, die den Heiligen umringen, sind in Rückenansicht gezeigt. Hier verweist die Figur des Sebastian möglicherweise auf Coxcies zweites Antwerpener Bild mit dem Martyrium des Hl. Sebastian, indem der breite Oberkörper und die Muskeln des Heiligen sowie die seiner Peiniger ähnlich stark betont werden [ABB. 114]. Zugleich wiederholt van der Baren

Klärung der in der Literatur gelegentlich widersprüchlichen Datierungsvorschläge bei den Marterbildern des Ambrosius Francken s. FreEdBerg 2014, S. 194-196 u. PeETERS 2003, S. 68-91.

781 Öl auf Holz, $143 \mathrm{~cm} \times 124 \mathrm{~cm}$, M-Museum, Leuven. 
aber auch das weiter oben bei Ambrosius Francken erörterte Repoussoir-Motiv, indem auch er unten links eine Figur zeigt, die den Betrachter anblickt.

Grundsätzlich ist zu beobachten, dass die hier exemplarisch besprochenen Werke in einem engen Zeitraum entstanden sind und eine Erscheinung in der flämischen Malereigeschichte widerspiegeln, die eng an die religiös und politisch motivierten Ereignisse von Bilderfrage, Bildersturm und spanischer Rückeroberung geknüpft sind. Auch im Hinblick auf das Format können Übereinstimmungen festgestellt werden, da es sich in der Regel um vergleichsweise schmale Mitteltafeln und entsprechend noch schmälere Seitenflügel handelt, deren Szenerien einem grundsätzlich ähnlichen Aufbau folgen. Die in leichter Aufsicht gezeigten Tafeln weisen eine hohe Dichte an bewegten Figuren auf, die meist Vorder- und Mittelgrund dominieren, während sich zum Hintergrund Ausblicke in eine Landschaft öffnen oder Renaissancearchitekturen zu sehen sind. Der Vordergrund indessen bleibt den Hauptfiguren reserviert - den Märtyrern und ihren Peinigern. Angesichts der Tatsache, dass vor 1580 bis auf wenige Ausnahmen, wie das Georgsmartyrium von Frans Pourbus aus dem Jahre 1577, welches sich motivisch, wie wir gesehen haben, ebenfalls in die Reihe der behandelten Beispiele einfügen lässt, lediglich die Antwerpener Martyrien von Michiel Coxcie als unmittelbare Vorgänger der brutalen Marterbilder der 1580er- und 1590er Jahre benannt werden können, ist eine Vorbildfunktion seiner Bilder sehr wahrscheinlich. Obwohl sich als Referenz nur die zwei Versionen des Sebastiansmartyriums aus Antwerpen erhalten haben, von denen eines, wie oben besprochen, bei Scribanius erwähnt wird, kann doch immerhin bei den Beispielen von Ambrosius Francken und Otto van Veen aus den 1590er Jahren auf eine unmittelbare Bezugnahme auf Coxcie geschlossen werden. Es besteht die Möglichkeit, dass Coxcie die gegen Ende des Jahrhunderts populären und mit dem Beginn der Statthalterschaft Alessandro Farneses 1585 größere Verbreitung findenden Heiligenmartyrien mit ihren exzessiven Gewaltdarstellungen in den 1570er Jahren, das heißt während der ersten Phase der Wiederherstellung der im Bildersturm 1566 zerstörten Altarbilder, vorbereitet hatte. Die immerhin in einem Briefwechsel angedeutete Verbindung Michiel Coxcies zum Herzog von Alba in dieser ersten postikonoklastischen Phase kann zwar nicht allein als ausschlaggebendes Indiz gelten, widerspricht aber auch nicht der Annahme, dass Coxcie in seiner prominenten Stellung als spanischer Hofmaler bei der Einführung dieser drastischen Motive zunächst eine führende Rolle spielte, bevor sie dann nach dem Ende der calvinistischen Herrschaft in Antwerpen von weiteren Auftraggebern angenommen und von findigen Malern umgesetzt wurden. Unabhängig davon ist anzunehmen, dass diese Bilder eine relativ kurze Phase der südniederländischen Malerei beschreiben, die wie kaum eine andere zuvor die religiösen und kulturgeschichtlichen Ereignisse innerhalb der gespaltenen niederländischen Gesellschaft des späteren 16. Jahrhunderts spiegelt. 


\section{Anhang}

\section{Literatur- und Quellenverzeichnis}

A

\section{Ainsworth 1982}

Ainsworth, Maryan W.: Bernart van Orley as a Designer of Tapestry. (Dissertationsschrift, Yale University), 2 Bde, New Haven 1982.

\section{Ainsworth 1990}

Ainsworth, Maryan W.: „Bernart van Orley, Peintre-inventeur", in: Studies in the History of Art 24 (1990), S. $41-64$.

\section{Ainsworth 1998}

Ainsworth, Maryan W.: Gerard David. Purity of Vision in an Age of Transition, New York 1998.

\section{Ainsworth 2006}

Ainsworth, Maryan W.: „Romanism as a Catalyst for Change in Bernard van Orley's Workshop Practices“, in M. Faries (Hrsg.), Making and Marketing: Studies of the Painting Process in Fifteenth- and Sixteenth-Century Netherlandish Workshops, Turnhout 2006, S. 99-118.

\section{Ainsworth 2010}

Ainsworth, Maryan W.: Man, Myth, and Sensual Pleasures: Jan Gossart's Renaissance, New York 2010.

\section{Ainsworth 2019}

Ainsworth, Maryan W.: „Van Orley als tekenaar“, in: Kat. Brüssel 2019, S. 39-48.

\section{Argote de Molina 1582}

Gonzalo Argote de Molina: Libro de la montería que mandó escrivir el rey D. Alfonso de Castilla y de Léon, Sevilla 1582

\section{Arnade 1996}

Arnade, Peter: Realms of Ritual. Burgundian Ceremony and Civic Life in Late Medieval Ghent, London 1996.

\section{Atkins 2015}

Atkins, Christopher D.M.: The Wrath of the Gods: Masterpieces by Rubens, Michelangelo and Titian, Philadelphia 2015.
Atkins 2017

Atkins, Christopher D. M.: „Michiel Coxcie's Artistic Quotations in The Death of Abel“", in: Cashion, Debra; Luttikhuizen, Henry u. West, Ashley (Hrsg.): The Primacy of the Image in Northern European Art, 1400 1700, Leiden 2017, S. 111-122.

\section{B}

\section{Baldass 1937}

Baldass, Ludwig: „Die niederländischen Maler des spätgotischen Stiles“, in: Wiener Jahrbuch für Kunstgeschichte, Ausg. 11, Wien 1937, S. 117-138.

\section{Baldass 1944}

Baldass Ludwig: „Die Entwicklung des Bernart van Orley“, in: Jahrbuch der Kunsthistorischen Sammlungen in Wien, N. F. 13 (1944), S. 141-191.

\section{Baldass 1953}

Baldass, Ludwig: „Malerei und Plastik um 1440 in Wien“, in: Wiener Jahrbuch für Kunstgeschichte, Ausg. 15 (1953), S. 7-26.

\section{Bartsch 2013}

Bartsch, Tatjana: „Von Gossaert bis Goltzius - Zur Reproduktion antiker Plastik auf den Zeichnungen niederländischer Künstler der Renaissance“, in: Luchterhandt, Manfred; Roemer, Lisa et. al. (Hrsg.): Abgekupfert. Roms Antiken in den Reproduktionsmedien der Frühen Neuzeit, Petersberg 2013, S. 13-26.

\section{Bartsch 2019}

Bartsch, Tatjana: Maarten van Heemskerck. Römische Studien zwischen Sachlichkeit und Imagination (Römische Studien der Bibliotheca Hertziana, Bd. 44), München 2019.

\section{Bass 2016}

Bass, Marisa: Jan Gossart and the invention of Netherlandish antiquity, Princeton 2016.

\section{Bätschmann - Schäublin 2000}

Bätschmann, Oskar; Schäublin, Christoph: Leon Battista Alberti. Das Standbild. Die Malkunst. Grundlagen der Malerei, Darmstadt 2000.

\section{Bauch 1967}

Bauch, Kurt: „Ikonographischer Stil“ - Zur Frage der Inhalte in Rembrandts Kunst (1966), in: Ders., Studien zur Kunstgeschichte, Berlin 1967. 


\section{Baxandall 1977}

Baxandall, Michael: Die Wirklichkeit der Bilder. Malerei und Erfahrung im Italien des 15. Jahrhunderts, Frankfurt a. M. 1977.

\section{Becker 1973}

Becker, Jochen: „Zur niederländischen Kunstlisteratur des 16. Jhs.: Lucas de Heere“, in: Simiolus 6 (1972-73), S. 113-127.

\section{Behling - van Puyvelde 2000}

Behling, A.; van Puyvelde, A.: „Passieretabel van Oplinter. Een groot authentiek retabel in Antwerpse manieristische stijl met oorspronkelijke polychromie“, in: C. Périer-D'Ieteren u. N. Gesché-Koning (Hrsg.), Brusselse gids van retabels uit de Zuiderlijke Nederlanden (15de-16de eeuwen). Omgeving Brussel, Brüssel 2000, S. $72-79$.

\section{Belting 1990}

Belting, Hans: Bild und Kult. Eine Geschichte des Bildes vor dem Zeitalter der Kunst, München 1990.

\section{Benedictus 1567}

Benedictus, Renatus: Eeen Catholic tractaet van de beelden ende van het rechte gebruyk dier selfjder, Antwerpen 1567.

\section{Bertling Biaggini 2016}

Bertling Biaggini, Claudia: Sebastiano del Piombo - Felix Pictor. Raum, Zeit und Klang in Bildern der Memoria, Hildesheim/Zürich 2016.

\section{Beurmann 2000}

Beurmann, Andreas: Historische Tasteninstrumente Cembali, Spinette, Virginale, Clavichorde. Die Sammlung Andreas und Heikedine Beurmann im Museum für Kunst und Gewerbe Hamburg, München 2000.

\section{Białostocki 1968}

Białostocki, Jan: „Le gothicque tardif. Désaccords sur le concept", in: Information d'Histoire d'Art, Ausg. 13, Paris 1968, S. 106-128.

\section{Biermann 1997}

Biermann, Veronica: Ornamentum. Studien zum Traktat De re aedifactoria« des Leon Battista Alberti, Hildesheim 1997.

\section{Bijns 1565}

Anna Bijns: Tweede Boeck Vol Schoone Ende Constighe Refereynen, Antwerpen 1565 (bei Jan van Ghelen).

\section{Binion 1990}

Binion, A.: La Galleria scomparsa del maresciallo von der Schulenburg. Un mecenate nella Venezia del Settecento, Mailand 1990.

\section{Bloccius - Pieters 1567}

Bloccius, Petrus u. Pieters, Jacob: „Meer Dan Tvvee Hondert Ketteryen, Blasphemien Ende Nieuwe Leeringen, Vvelck Vvt De Misse Zyn Ghecomen / Eerst Van Petro Bloccio School-Mester Te Leyden in Latyn Ghemaeckt, Daer Nae in Duytsch Voor Slechte Menschen Overghesett, Wesel (Augustijn van Hasselt) 1567.

\section{Bloccius 1567}

Bloccius, P.: Meer dan twee hondert ketteryen, blasphemien en nieuwe leeringen, welck uut de misse zyn ghecommen, Wesel 1567

\section{Blockmans 1998}

Blockmans, Wim: Hingegeben der Melancholie der Armut. Leben und Arbeiten in Brügge 1482-1584, in: Memling und seine Zeit. Brügge und die Renaissance, Stuttgart 1998, S. 26-32.

\section{Bloemacher 2016}

Bloemacher, Anne: Raffael und Raimondi. Produktion und Intention der frühen Druckgraphik nach Raffael, Berlin 2016.

\section{Blunt 1940 [1978]}

Blunt, Anthony: Artistic theory in Italy. 1450-1600, Oxford 1940 (Nachdr. 1978).

\section{Bober - Rubinstein - Woodford 1986}

Bober, Phylis P. - Rubinstein, Ruth u. Woodford, Susan: Renaissance Artists and Antique Sculpture. A Handbook of Sources, London 1986.

\section{Boelens - Sintsoff - Walazyc 2004}

Boelens-Sintsoff, F. u. Walazyc A.-S. (Hrsg.), De OnzeLieve-Vrouw ten Zavelkerk, Brüssel 2004.

\section{Boespflug - Christin 1996}

Molanus, Johannes: De Historia SS imaginum et picturarum, 1570[1594] (Ed. Boespflug, François u. Christin, Olivier et. Al.: Traité des saintes images, Zwei Bände, Paris 1996. 


\section{Bonenfant - Frankignouelle 1935}

Bonenfant, P.; Frankignouelle, E.: „Notes pour servir à l'histoire de l'art en Brabant", in: Annales de la Société Royale d'Archéologie de Bruxelles 39 (1935).

\section{Bonneure 1984}

Bonneure, Fernand: Brugge Beschreven. Hoe een stad in teksten verschijnt, Brüssel 1984.

\section{Boon 1965}

Boon, K. G.: „Gossaert en de Renaissance in de Nederlanden“, in: Pauwels, H. - Hoetink, H. R. u. Herzog, S. (Hrsg.): Jan Gossaert genaamd Mabuse Mabuse (Gemeinamer Katalog von Groenigemuseum und Museum Boymans - van Breuningen), Brügge/Rotterdam 1965, S. $15-31$.

\section{Borchert 1997}

Borchert, Till-Holger: „Rogier's St. Luke: the case for corporate identification“, in: Purtle, Carol (Hrsg.): Rogier van der Weyden, 'St. Luke Drawing the Virgin'. Selected Essays in Context, S. 61-87.

\section{Borchert 1998}

Borchert, Till-Holger: Die Entdeckung der Brügger Malerei, in: Memling und seine Zeit. Brügge und die Renaissance, Stuttgart 1998, S. 15-21.

\section{Born 2005}

Born, Annick: „Antwerp Mannerism - a fashionable style?", in: Van den Brink, Peter et. al. (Hrsg.): ExtravagAnt. A forgotten chapter of Antwerp Painting. 1500 1530 [Katalog zur Ausstellung], Antwerpen 2005, S. 10-19.

\section{Born 2008}

Born, Annick: „Pieter Coecke van Aelst and the Roads Leading to Rome“, in: De Floriana, A. u. Glassi, Maria Clelia: Culture figurative a confronto tra Fiandre e Italia dal XV al XVII secolo, Mailand 2008, S. 94-105.

\section{Born 2010}

Born, Annick: „Essai d'analyse critique du maniérisme anversois de Max Jacob Friedländer suivi d'une révision du groupe des oeuvres du Maitre de 1518“ (Dissertationsschrift von 2010, Universität Gent).

\section{Bottineau-Fuchs 2002}

Bonttineau-Fuchs, Yves: „Georges Ier d'Amboise et les artistes italiens“, in: Cahier des Annales de Normandie 29. Les Italiens en Normandie, de l'étranger à l'immigré.
Actes du colloque de Cerisy-la-Salle (8-11 octobre 1998), 2000, S. 143-162.

\section{Bousquet 1985}

Bousquet, Jacques: Malerei des Manierismus. Die Kunst Europas von 1520 bis 1620 (3. Aufl.), München 1985.

\section{Brine 2015}

Brine, Douglas. Pious Memories. The Wall-Mounted Memorial in the Burgundian Netherlands, Brill 2015.

\section{Buchanan 1999}

Buchanan, Iain: „The Tapestries Acquired by King Philip II. In the Netherlands in 1549-50 and 15551559“, in: Gazette des Beaux-Arts 141 (1999), S. 13152.

\section{Bücken 2019}

Bücken, Véronique: „Bernard van Orley. De kunstenaar en zijn artistieke milieu in Brussel", in: Paleis voor Schone Kunsten (BOZAR): Bernard van Orley (Kat. zur Ausstellung „Bernard van Orley. Brussels and the Renaissance“), Brüssel 2019, S. 29-38.

\section{Buijnsters-Smets 1995}

Buijnsters-Smets, Leontine: Jan Massys. Eeen Antwerps Schilder uit de Zestiende Eeuw, Zwolle 1995.

\section{Büttner 2017}

Büttner, Nils: „Die Grundlagen. Kopieren und Interpretieren“, in: Rubens. Kraft der Verwandlung (Kat. Städel 2017), S. 127-158.

\section{Calvete de Estrella 1552 [2001]}

Calvete de Estrella, Juan Cristóbal: El felicíssimo viaje del muy alto y muy poderoso Príncipe Don Phelippe (1552), herausgegeben von Sociedad Estatal para la Conmemoración de los Centenarios de Felipe II y Carlos V, Madrid 2001.

\section{Campbell 1981}

Campbell, Lorne: „The Early Netherlandish Painters and Their Workshops", in: Hollanders-Favart, Dominique u. Van Shouten, Roger (Hrsg.): Le dessing sous-jacent dans la peinture, Colloq. III 1979. Le problème Maître de Flémalle - van der Weyden, NeuLöwen 1981, S. 43-61. 


\section{Campbell 1997}

Campbell. Lorne: „Gossaert's Adoration of the Kings“, National Gallery, in: Technical Bulletin 18 (1997), S. 87 97.

\section{Campbell 1998}

Campbell, Lorne: The Fifteenth Century Netherlandish Schools (Kat. National Gallery), London 1998.

\section{Campbell 2002}

Campbell, Thomas (Hrsg.): Tapestry in the Renaissance. Art and Magnificence (Kat. Metropolitan Museum of Art, New York), New Haven/London 2002.

\section{Campbell 2015}

Campbell, Lorne: Rogier van der Weyden and the Kingdoms of the Iberian Peninsula, Madrid 2015.

\section{Camphuysen 1638}

Camphuysen. D. R.: „Geestichdom der schilderkonst“, in: Ders.: Verscheyden theologische wercken, Amsterdam 1638 bei Colom.

\section{Capreau 2013}

Capreau, Peter: „Vanished like Smoke along with Fleeting Time. Michiel Coxcies Lost Reputation“, in: Jonckheere, Koenraad (Ed.): Michiel Coxcie 1499-1592 and the Giants of his Age, London/Turnhout 2013, S. 10 21.

\section{Carratù 2013}

Carratù, Tullia: „Santo Stefano Rotondo“, in: Elio de Rosa editore: Roma Sacra. Santo Stefano Rotondo, Itinerarium 34, Rom 2013, S. 28-54.

\section{Chastel 1996}

Chastel, André: Marsile Ficin et l'art, Genève 1996.

\section{Checa Cremades 1998}

Checa Cremades, Fernando (Hrsg.): Felipe II, un monarca su época. Un príncipe del Renacimento (Ausst.Kat. des Museo Nacional del Prado, Madrid), Madrid 1998.

\section{Clericus 1703-1706 (Erasmus)}

Erasmus, Desiderius: „Christiani Matrimonii Institutio“, in: Desiderii Erasmi Opera Omnia, hrsg. von J. Clericus, Leiden 1703-06.

\section{Copper 2005}

Copper, Elizabeth: The Domenichino Affair. Novelty, Imitation and Theft in Seventeenth-Century Rome, New Haven 2005.

\section{Curschmann 1992}

Curschmann, Michael: „Pictura laicorum litteratura? Überlegungen zum Verhältnis von Bild und volkssprachlicher Schriftlichkeit im Hoch- und Spätmittelalter", in: Keller, Hagen - Grubmüller, Klaus u. Staubach, Nikolaus (Hrsg.): Pragmatische Schriftlichkeit im Mittelalter. Erscheinungsformen und Entwicklungsstufen, München 1992, S. 211-229.

\section{$\mathrm{D}$}

\section{Dacos 1964}

Dacos, Nicole: Les peintres belges à Rome au XVI siècle, Brüssel 1964, S. 22-30.

\section{Dacos 1993 a}

Dacos, Nicole: „Michiel Coxcie dans l'atelier de Bernard van Orley“, in: De Smedt, Raphaël: Michiel Coxcie, pictor regius (1499-1592), Mecheln 1993, S. 41-54.

\section{Dacos 1993 b}

Dacos, Nicole: „Michiel Coxcie et les romanistes - à propos de quelques inédit“ in: De Smedt, Raphaël: Michiel Coxcie, pictor regius (1499-1592), Mecheln 1993, S. 55-92.

\section{Dacos 1993 c}

Dacos, Nicole: „Entre Bruxelles et Séville. Peter de Kempener en Italié“, in: Nederlands kunsthistorisch Jaarboek 44 (1993), S. 143-163.

\section{Dal Bello 2012}

Dal Bello, M.: Raffaels Madonnenbilder, Regensburg 2012, S. 84-85.

\section{Daussy 2002}

Daussy, Hugues: Les Hugenots et le Roi. Le combat politique de Philippe Duplessis-Morney (1572-1600), Genf 2002.

\section{De Bie 1662}

De Bie, Cornelis: Het gulden cabinet van de edel vry schilderconst, Antwerpen 1662 


\section{De Jongh 1968}

De Jongh, E.: „Speculaties over Jan Gossaerts Lucasmadonna in Praag", in: Bulletin Museum Boymans-van Beuningen 19 (1968), S. 42-61.

\section{De Meûter 2019}

De Meûter, Ingrid: „Bernard van Orley en de wandtapijten“, in: Paleis voor Schone Kunsten (BOZAR): Bernard van Orley (Kat. zur Ausstellung „Bernard van Orley. Brussels and the Renaissance“), Brüssel 2019, S. 4958.

\section{De Ram 1861}

De Ram, Pierre François Xavier: „Les quatorze livres sur l'histoire de la ville louvain du docteur et professeur en théologie Jean Molanus“, in: Commission royale d'histoire (Hrsg.), Collection de chroniques inédites I, Brüssel 1861.

\section{De Ram I-IV}

De Ram, Pierre François Xavier: Synodicon Belgicum, sive acta omnium ecclesiarum Belgii a celebrato concilio Tridentino usque ad concordatum anni 1801, 4 Bde, Mecheln 1928 (1929, 1939).

\section{De Smedt 1993}

De Smedt, Raphaël: Michiel Coxcie, pictor regis (14991592), Mecheln 1993.

\section{De Smedt 2011}

De Smedt, Raphaël: „Autopsie de Michel Coxcie. Nouveaux horizons bibliographiques 1565-2010“, in: Revue belge d'archéologie et d'histoire de l'art (2011).

\section{De Vos 1979 (Kat. Groenigemuseum)}

De Vos, Dirk (Hrsg.): Stedelijke Musea Brugge - Catalogus schilderijen 15de en 16de eeuw (Kat. (Groeningemuseum), Brügge 1979.

\section{De Vos 1999}

De Vos, Dirk: Rogier van der Weyden, het volledige oeuvre, Antwerpen 1999.

\section{Delmarcel 1992}

Delmarcel, Guy: „De Passietapijten van Margareta van Oostenrijk (ca.1518-1524). Nieuwe gegevens en documenten", in: Revue belge d'archéologie et d'histoire de l'art 61 (1992), S. 127-160.

\section{Den Hartog - Veerman 2011}

Den Hartog, Elizabeth u. Veerman, John (Hrsg.): De Pieterskerk in Leiden. Bouwgeschiedenis, inrichting en gedenktekens, Zwolle 2011.

\section{Denzinger - Hünermann 2005}

Denzinger, Heinrich; Hünermann, Peter (Hrsg.): Enchiridion Symbolorum. Kompendium der Glaubensbekenntnisse und kirchlichen Lehrentscheidungen (40. Auflage), Freiburg im Breisgau 2005.

\section{Denzinger 1973}

Denzinger, Heirich u. Schönmetzer, Adolf (Hrsg.): Enchiridion symbolorum definitionum et declarationum de rebus fidei et morum. Kompendium der Glaubensbekenntnisse und kirchlichen Lehrentscheidungen. Lateinisch-Deutsch, 35. Auflage, Freiburg i. Br. 1973.

\section{Dhanens 1965}

Dhanens, Elisabeth: „Het retabel van het Lam Gods in de Sint-Baafskathedraal te Gent“, in: Inventaris van het kunstpatrimonium van Ostvlaanderen 6, Gent 1965.

\section{Dhanens 1975}

Dhanens, Elisabeth: „Bijdrage tot de studie van de repentirs en oude overschilderingen op het Lam-Godsretabel van Hubert en Jan van Eyck", in: Miscellanea in Memoriam Paul Coremans, Bulletin de l'Institut royal du Patrimoine artistique, 15, 1975, S. 110-118.

\section{Dhanens 1976}

Dhanens, Elisabeth: „De Vijd-Borlut fundatie en het Lam Godsretabel 1432-1797“, in: Mededelingen van de Koninklijke Academie voor Wetenschappen. Letteren en Schone Kunsten van België, 38, 2 (1976).

\section{Dhanens 1980}

Dhanens, Elisabeth: Hubert en Jan van Eyck, Antwerpen 1980 .

\section{DiFuria 2019}

DiFuria, Arthur: Maarten van Heemskerck's Rome. Anitquity, Memory, and the Cult of the Ruins, Leiden 2019.

\section{Dubois 2017}

Dubois, Hélène: „Michiel Coxcie’s Copy As a Formal Reference of the Material Condition of the Ghent Altar-Piece in 1557“, in: Kemperdick, Stephan et. al. (Hrsg): Der Genter Altar. Reproduktionen, Deutungen, Forschungskontroversen, Berlin/Petersberg 2017, S. 92-107. 


\section{Duverger 1954}

Duverger, Joseph, „Kopieën van het Lam Godsretabel van Hubrecht en Jan van Eyck", in: Bulletin van de Koninklijke Musea voor Schone Kunsten Brussel, Bd. 3, Brüssel 1954, S. 55-67.

\section{Duverger 1980}

Duverger, Jozef: „Margaretha van Oostenrijk (1480$1530)$ en de Italiaanse renaissance“, in: Relations artistiques entre le Pays-Bas et l'Italie à la Renaissances ; etudes dédiés à Suzanne Sulzberger, Brüssel-Rome 1980, S. 127-142.

\section{Duverger 1993}

Duverger, Erik: „De Brusselse stadtspatroonschilder voor de tapijtkunst Michiel van Cocxyen (ca. 19471592. Een inleidende studie“, in: De Smedt, Raphaël: Michiel Coxcie, pictor regius (1499-1592), Mecheln 1993, 161-92.

\section{Duverger - Roobaert 1960}

Duverger, Jozef; Roobaert, E.: „Lancelot Blondeel (1498-1561). Zijn rol en betekenis“, in: Gentse bijdragen tot de kunstgeschiedenis en de oudheidkunde 18 (1959-1960), S. 95-105.

\section{E}

\section{Edwards 2005}

Edwards, John: „Introduction - Carranza in England“, in: Edwards, John u. Truman. Ronald (Hrsg.): Reforming Catholicism in the England of Mary Tudor. The achievement of Friar Bartolomé Carranza. Ashgate/Aldershot 2005, S. 1-20.

\section{Eichberger 2002}

Eichberger, Dagmar: Leben mit Kunst - Wirken durch Kunst. Sammelwesen und Hofkunst unter Margarethe von Österreich, Regentin der Niederlande, Turnhout 2002.

\section{Elliott 1968}

Elliott, John Huxtable: Europe Divided 1559-1598, London 1968.

\section{Emmens 1981}

Emmens, J. A.: „'Eins aber ist nötig' - zu Inhalt und Bedeutung von Markt- und Küchenstücken des 16. Jahrhunderts“, in: Ders.: Kunsthistorische opstellen, 2 Bde., Amsterdam 1981, Bd. 2, S. 189-221.

\section{F}

\section{Faries 1975}

Faries, Molly: „A Drawing of the Brazen Serpent by Michiel Coxie“, in: Revue Belge d'Archeologie et d'Histoire de l'Art 44 (1975), S. 131-141.

\section{Farmer 1981}

Farmer, John David: Bernard van Orley of Brussels, Princeton University (Dissertationsschrift) 1981.

\section{Farmer 1994}

Farmer, John David: „How one workshop worked. Bernard van Orley's Atelier in early sixteenth-century Brussels“, in: A tribute to Robert A. Koch. Studies in the Northern Renaissance, Princeton 1994, S. 21-52.

Faus 2003

Falomir Faus, Miguel: Tiziano, Museo Nacional del Prado, Madrid, 2003.

\section{Feld 1990}

Feld, Helmut: Der Ikonoklasmus des Westens, Leiden / Köln 1990.

\section{Fernández Soriano 2008}

Fernández Soriano, Victor: „Michiel Coxcie. Pintor grato a la casa de Habsburgo“, in: Archive de español de Arte 81 (2008), S. 191-196.

\section{Filedt-Kok 1986}

Filedt-Kok, J. P. et. al. (Hrsg.): Kunst voor beeldenstorm: Noordnederlandse kunst 1525-1580 (Ausstellungskatalog, Rijksmuseum), Zwei Bände, Amsterdam 1986.

\section{Fischer 2009}

Fischer, Stefan: Hieronymus Bosch. Malerei als Vision, Lehrbild und Kunstwerk, Köln 2009.

\section{Freedberg 1971}

Freedberg, David: ,Johannes Molanus on Provocative Paintings. De Historia Sanctarum Imaginum et Pictuarum, Book II, Chapter 42", in: Journal of the Warburg and Courtauld Institutes 34 (1971), S. 229-45.

\section{Freedberg 1976}

Freedberg, David: „The Representation of Martyrdoms during the Early Counter-Reformation in Antwerp“, in: Burlington Magazine 118 (1976), 128-13. 


\section{Freedberg 1982}

Freedberg, David: „The Hidden God. Image and Interdiction in the Netherlands in the Sixteenth Century “, in: Art History 5, 2 (1982), S. 133-53.

\section{Freedberg 1986}

Freedberg, David: „Art and Iconoclasm, 1525-1580: The Case of the Northern Netherlands“, in: Filedt Kok, J. P. et. al. (Ed.): Kunst voor beeldenstorm: Noordnederlandse kunst 1525-1580 (Ausstellungskatalog, Rijksmuseum), Zwei Bände, Amsterdam 1986, S. 69-84.

\section{Freedberg 1988}

Freedberg, David: Iconoclasm and painting in the revolt of the Netherlands, New York 1988.

\section{Freedberg 2014}

Freedberg, David: „Zu den Martyrerbildern Anrwerpens im spaten 16. Jahrhundert", in: Behrmann, C. u. Priedl, E. (Hrsg.), Autopsia. Blut-und Augenzeugen. Extreme Bilder des christlichen Martyriums, München 2014, S. 181-212.

\section{Friedländer 1910}

Friedländer, M. J.: „Ambrosius Benson als Bildnismaler“, in: Jahrbuch der Königlich Preussischen Kunstsammlungen 31 (1910), S. 139-148.

\section{Friedländer 1915}

Friedländer, M. J.: „Die Antwerpener Manieristen von 1520“, in: Jahrbuch der königlich preußischen Kunstsammlungen 36 (1915).

\section{Friedländer 1918}

Friedländer, M. J.: ,Jan Wellens de Cock“, in: Zeitschrift für bildende Kunst, Ausg. 29, Leipzig 1918, S. 67-74.

\section{Friedländer 1921}

Friedländer, M. J.: Die niederländischen Manieristen, Leipzig 1921.

\section{Friedländer 1924-1937}

Friedländer, Max J.: Die altniederländische Malerei, 14 Bde, Leiden 1924-1937.

\section{Friedländer 1929}

Friedländer M. J: „Über Willem Key“, in: Pantheon, Nr. 6 (1929), S 254-256.

\section{Friedländer 1944}

Friedländer, M. J.: On Art and Connoisseurship, Oxford 1944 (Erste Auflg. 1942).

\section{Friedländer 1972}

Friedländer, M. J., Early netherlandish painting, LeydenBrüssel, 1972.

\section{Friedländer 1974}

Friedländer, M. J.: The Antwerp Mannerists; Adriaen Ysenbrant, Leiden/Brüssel 1974.

\section{G}

\section{Gachard 1855}

Gachard, Louis-Prosper: Retraite et mort de CharlesQuint au monastère de Yuste. Lettres inédites pub. d'apres les originaux conservés dans le archives royales de Simancas, Bd. 1, Brüssel 1855.

\section{Galand 2013}

Galand, Alexandre: The Bernard van Orley Group (The Flemish primitives 6), Turnhout 2013.

\section{Galand 2019}

Galand, Alexandre: „Biographie“, in: Paleis voor Schone Kunsten (BOZAR): Bernard van Orley (Kat. zur Ausstellung „Bernard van Orley. Brussels and the Renaissance"), Brüssel 2019, S. 16-19.

\section{Gampp 1995}

Gampp, Axel C.: „Varietas. Ein Beitrag zum Verhältnis von Auftraggeber, Stil und Anspruchsniveau“, in: Meier, Hans-Rudolf (Hrsg.): Für irdischen Ruhm und himmlischen Lohn. Stifter und Auftraggeber in der mittelalterlichen Kunst, Berlin 1995. S. 287-208.

\section{García-Frías Checa 2013}

García-Frías Checa, Carmen: „De la grandeza t.Kay variedad de la pintura que hay en esta casa“, in: La colección pictórica de Felipe II en El Monasterio de El Escorialo, De El Bosco a Tiziano. Arte y maravilla en El Escorial, Madrid 2013, S. 35-51.

\section{Geirnaert - Vandamme 1998}

Geirnaert, Noël; Vandamme, Ludo: „Kultur und Mentalität“, in: Martens, Maximiliaan P. J. (Hrsg.): Memling und seine Zeit. Brügge und die Renaissance, Stuttgart 1998, S. 33-42.

\section{Geldenhouwer 1516}

Geldenhouwer, Gerard: Pompa exequiarum catholici Hispaniarum regis Ferdonandi, Brüssel 1516. 


\section{Geldenhouwer 1529 (Prinsen 1901)}

Prinsen, Jacob (Hrsg.): Collectanea van Gerardus Geldenhouwer Noviomagus, gevolgd door den herdruk van eeniger zijner werken, Amsterdam 1901 (= Werken uitgeven door het historisch genootshap, Nr. 16).

\section{Gérard 1984}

Gérard, Veronique: De castillo a palacio. El Alcázar de Madrid en el siglo VXI, Bilbao 1984.

\section{Goethe 1789}

Goethe, J.W. von: „Einfache Nachahmung der Natur, Manier, Stil“, in: Der Teutsche Merkur (Feb. 1789), A. G. XIIII, S. 66-71

\section{Goetschalkx 1906}

Goetschalkx, Pieter Jozef: „Eeenige inlichtingen over de schilders Michiel en Raphaël van Coxyen“, in: Bijdragen tot de geschiedenes bijzonderslijk van het aloude Hertogdom Brababant 5 (1906), S. 409-422.

\section{Gramaccini - Meier 2003}

Gramaccini, Noberto; Meier, Hans Jakob: Die Kunst der Interpretation. Italienische Reproduktionsgraphik 1485-1600, München 2013.

\section{Grasman 2011}

Grasman, E.: „Het Laatste Oordeel van Lucas van Leyden“, in: De Pieterskerk in Leiden, Zwolle 2011, S. 218 234.

\section{Grieten - Bungeneers 1996}

Grieten, S.; Bungeneers, J. (Hrsg.): De Onze-LieveVrouwekathedraal van Antwerpen. Kunstpatrimonium van het Ancien Régime (Inventaris van het Kunstpatrimonium van de provincie Antwerpen 3, Turnhout 1996, S. 364-65.

\section{Grosshans 1980}

Grosshans, Rainald: Maerten van Heemskerck. Die Gemälde, Berlin 1980.

\section{Grosshans 2002}

Grosshans, R.; Asmus, G.: Gemäldegalerie Berlin. 200 Meisterwerke, Berlin 2002.

\section{Guicciardini 1567}

Guicciardini, Ludovico: De idyllische Nederlanden: Antwerpen en de Nederlanden in de 16e eeuw, Antwerpen 1567.

\section{Guicciardini 1567 (1612)}

Guicciardini, Ludovico: Beschryvinghe van alle de Nederlanden (Übersetzung ins Niederländische von Cornelius Kilianus), Amsterdam 1612.

\section{Guldan 1966}

Guldan, Ernst: Eva und Maria. Eine Antithese als Bildmotiv, Graz 1966.

\section{$\mathrm{H}$}

\section{De Heere 1565}

De Heere, Lucas; Den hof en boomgaerd der poësien, Gent 1565.

\section{Hand 2004}

Hand, John Oliver: Joos van Cleve. The Complete Paintings, New Haven/London 2004.

\section{Hanegraaff 2007}

Hanegraaff, W. J.: ,'The Trouble with Images: Anti-Image Polemics and Western Esotericism“, in: Hammer, O.; von Stuckrad, K. (Ed.): Polemical Encounters, Leiden 2007, S. 107-36.

\section{Harnack 2018}

Harnack, Maria: „Niederländische Maler in Italien. Künstlerreisen und Kunstrezeotion im 16. Jahrhundert" (Dissertationsschrift [2018] an der Westfälischen Wilhelms-Universität, Münster), in der Reihe: Seng, Eva-Maria u. Göttmann, Frank (Hrsg): Reflexe der immateriellen Kultur 6 (2018).

\section{Harris - de Andrés 1972}

Harris, E. u. de Andrés, G.: „Descripción del Escorial por Cassiano del Pozzo (1626)“, in: Archivo Español de Arte 45 (Madrid 1972).

\section{Häuptli 2014}

Häuptli, Bruno W. (Hrsg.): Legenda aurea. Einleitung, Edition, Übersetzung und Kommentar von Bruno W. Häuptli, zwei Bde., Freiburg im Breisgau / Basel / Wien 2014.

\section{Hecht 2012}

Hecht, Christian: Katholische Bildertheologie der Frühen Neuzeit - Studien zu Traktaten von Johannes Molanus, Gabriele Paleotti und anderen Autoren, Berlin 2012. 


\section{Hedicke 1911[-12]}

Hedricke, Robert: Jacques Dubroecq de Mons, 2 Bde., Brüssel 1911-1912.

\section{Heikamp 1961}

Heikamp, Detlef: Scritti d'arte di Federico Zuccaro, Bd. 2, Florenz 1961,

\section{Held 1931}

Held, Julius: Dürers Wirkung auf die niederländische Kunst seiner Zeit, Den Haag 1931.

\section{Held 1954}

Held, Julius Samuel: „A Drawing by Michiel Coxcie after the Ghent Altarpiece“, in: The Art Quaterly XVII, 1 (New York 1954), S. 58-62.

\section{Held 1996}

Held, Julius: „Carolus Scribanus. Observations on Art in Antwerp", in: Journal of the Warbug and Courtauld Institutes, 59 (1996).

\section{Henne 1855}

Henne, Alexandre: „Les arts en Belgique sous Charlesquint, Bd. II: peinture“, in: Revue universelle des arts I (1855), S. 86-104.

\section{Heriguez 2013}

Heriguez, Samantha: La Madone de Louvain de Bernard van Orley: les dessous d'une attribution longtemps controversée, Ars longa, Aug. 22 (2013).

\section{Herzner 1995}

Herzner, Volker: Jan van Eyck und der Genter Altar, Worms 1995.

\section{Herzog 1968}

Herzog, Sadja: „Tradition und Innovation in Gossaerts Neptun und Amphitrite und Danä̈“, in: Bulletin Museum Boymans - Van Beunigen 19, Rotterdam 1968, S. 25-41.

\section{Hessler 2006}

Christiane J. Hessler: „The Man on Slate: Sebastiano del Piombo's Portrait of Baccio Valori and Valori the Younger's Speech in Borghini's Il Riposo“, in: Source. Notes in the History of Art, Bd. 25 (2006), Heft 2, S. $18-22$.

\section{Hindriks 2017}

Hindriks, Sandra: „Mit kunstreichem Ingenium gemalt“? Zur Bedeutung des Kunstwerts in der Rezeption Jan van Eycks“, in: Kemperdick, Stephan, Rößler et. Al. (Hrsg.): Der Genter Altar. Reproduktionen, Deutungen, Forschungskontroversen, Petersberg / Berlin 2017, S. 116-127.

\section{Hindriks 2019}

Hindriks, Sandra: Der „vlaemsche Apelles“. Jan van Eycks früher Ruhm und die niederländische „Renaissance“, Petersberg 2019.

\section{Hinterding - Horsch 1989}

Hinterding, Erik; Horsch, Femy: „A small but choice collection: The art gallery of King Willem II of the Netherlands (1792-1849)“, in: Simiolus, 19/20 (1989), S. 5-122.

\section{Hocke 1991}

Hocke, Gustav René: Die Welt als Labyrinth. Manierismus in der europäischen Kunst. Rowohlt, Reinbek b. Hamburg 1991.

\section{Hoffmann 1998}

Hoffmann, Godehard: „Der Annenaltar des Adrian van Overbeck in der Propsteikirche zu Kempen - Werk und Werkstatt eines Antwerpener Manieristen“, in: Hansmann, Wilfried u. Hoffmann, Godehard (Hrsg.): Spätgotik am Niederrhein. Rheinische und flämische Flügelaltäre im Lichte neuer Forschung, Köln 1998, S. 117 291.

\section{Hoogewerff 1912}

Hoogewerff, G. J.: Nederlandsche Schilders in Italië in de XVIe eeuw. De geschiedenis vaan het Romanisme, Utrecht 1912.

\section{Hoogewerff 1923}

Hoogewerff, G.J.: „Bescheiden in Italië ometrent Nederlandsche kunstenaars en geleerden II“, in: Rijks Geschiedenkundige Publicatiën, minor series 12 (Den Haag 1923).

\section{Hoogewerff 1928}

Hoogewerff, G. J. u. van Regteren Altena, J. Q. (Hrsg.): „Arnoldus Buchelius 'Res pictorae'. Aanteekeningen over kunstenaars en kunstwerken voorkomende in zijn Diarium, Res pictorae, Nota quotidianae en Descriptio urbus Ultrajectinae (1583-1639)“, in: Quellenstudien zur holländischen Kunstgeschichte 15 (Den Haag 1928).

\section{Hoogewerff 1954}

Hoogewerff, G. J.: Het Landschap van Bosch tot Rubens, Antwerpen 1954. 


\section{Hörsch 1994}

Hörsch, Markus: Architektur unter Margarethe von Österreich, Regentin der Niederlande (1507-1530). Eine bau- und architekturgeschichtliche Studie zum Grabkloster St.-Nicolas-de-Tolentin in Brou bei Bourg-enBresse, Brüssel 1994.

\section{Hübner 1912}

Hübner, P. G.: Le Statue di Roma. Grundlage für eine Geschichte der antiken Monumente in der Renaissance, Bd. I., Leipzig 1912.

\section{Hurlbut 1991}

Hurlbot, Jesse D.: Ceremonial Entries in Burgundy. Philip the Good and Charles the Bold (1419-1477), Ann Arbor 1991.

\section{Huvenne - Grevenstein 2005}

Huvenne, Paul; Grevenstein, Alexander van: „Vorwort“ zu Van den Brink, Peter (Ed.) et. al.: ExtravagAnt. A forgotten chapter of Antwerp Painting. 1500-1530 [Katalog zur Ausstellung], Antwerpen 2005.

\section{Huvenne 1984}

Huvenne, Paul: Pieter Pourbus, meester-schilder 1524 1584 (Ausstellungskatalog Memlingmuseum, Brügge), Brügge 1984.

\section{I}

\section{Installé 1981}

Installé, Henri: „Inventaris van het Fonds Brouwersambacht op het Stadsarchief te Mechelen“, in: Handelingen van de Koninklijke Kring voor Oudheidkunde, Letteren en Knust van Mechelen, Nr. 85 (1981).

\section{Irlenbusch 2004}

Irlenbusch, Christina (Hrsg.): Das Leben des Sebastiano del Piombo (von Giorgio Vasari u. neu übers. von Victoria Lorini. Kommentiert von Christina Irlenbusch), Berlin 2004.

\section{Irmscher 1984}

Irmscher Günter: Kleine Kunstgeschichte des europäischen Ornaments seit der Frühen Neuzeit (1400-1900), Darmstadt 1984.
J

\section{Jacobs 1993}

Jacobs, A.: „Michiel Coxcie à Saint-Rombout“, in: De Smedt, Raphaël: Michiel Coxcie, pictor regis (14991592), Mecheln 1993, S. 215-246.

\section{Jansen 2003}

Jansen, Linda: „,The Last Supper as a Starting Point for the Study of the Workshop Practivces in the Group Pieter Coecke van Aelst", in: Verougstraete, Helène; Van Shouten, Roger (Ed.): Jérome Bosche et son Entourage et Autres Études, Löwen u. Paris 2003, S. 165174.

\section{Jonckheere - Suykerbuyk 2012}

Jonckheere, Koenraad u. Suykerbuyk, Ruben (Hrsg.): Art after iconoclasm: Painting in the Netherlands between 1566 and 1585, Turnhout 2012.

\section{Jonckheere - Suykerbuyk 2013}

Jonckheere, Koenraad u. Suykerbuyk, Ruben: „The life and times of Michiel Coxcie. 1499-1529“, in: Jonckheere, Koenraad (Hrsg.): Michiel Coxcie and the giants of his age: 1499-1592, London 2013.

\section{Jonckheere 2007}

Jonckheere, Koenraad: „Adriaen Thomasz. Key (Ca. 1545-1589). Portrait of a Calvinist Painter", in: Vlieghe, Hans; Van der Stighelen, Katlijine (Hrsg.): Pictura Nova, Studies in the 16th- and 17th-Century Flemish Painting and Drawing 14 (Turnhout 2007).

\section{Jonckheere 2012}

Jonckheere, Koenraad: „Repetition and the genesis of meaning. In introductory note", in: Jonckheere, Koenraad u. Suykerbuyk, Ruben (Hrsg.): Art after iconoclasm: Painting in the Netherlands between 1566 and 1585, Turnhout 2012, S. 7-20.

\section{Jonckheere 2013}

Jonckheere, Koenraad (ed.): Michiel Coxcie and the giants of his age: 1499-1592, London 2013.

\section{Jonckheere 2013 a}

Jonckheere, Koenraad: Michiel Coxcie and the Reception of Classical Antiquity in the Low Countries, in: Jonckheere, Koenraad (Hrsg.): Michiel Coxcie and the giants of his age: 1499-1592, London 2013, S. 64-97. 


\section{Jonckheere 2013 b}

Jonckheere, Koenraad: „First Painter of the CounterReformation“, in: Jonckheere, Koenraad (Hrsg.): Michiel Coxcie and the giants of his age: 1499-1592, London 2013, S. 116-137.

\section{Jonckheere 2016}

Jonckheere, Koenraad: „Levende beelden Gods‘. A note on the depiction of saints in Netherlandish art after 1585“, in: Leuschner, Eckhard (Hrsg.): Rekonstruktion der Gesellschaft aus Kunst. Antwerpener Malerei und Graphik in und nach den Katastrophen des späten 16. Jahrhunderts, Petersberg 2016, S. 111-116.

\section{Jones 2017}

Jones, Susan France: „Reconsidering Jan van Eyck. Text, Objects and a Regional Revial“, in: Kemperdick et. al. (Hrsg.): Der Genter Altar. Reproduktionen, Deutungen, Forschungskontroversen, Berlin 2017, S. 128-148.

\section{Junius 1641}

Junius, Franciscus: De schilderkonst der oude, Middelburg 1641 bei Zacharias Roman.

\section{Jürgen 1999}

Paul, Jürgen: „Umbrüche in der Kunst des späten Mittelalters. Synchronismus und Asynchronismus unter stil-, inhalts- und funktionsgeschichtlicher Betrachtung“, in: Haug, Walter (Hrsg.): Mittelalter und frühe Neuzeit: Übergänge, Umbrüche und Neuansätze, Tübingen 1999, S. 471-453.

\section{K}

\section{Kat. Antwerpen 1973-1975}

Antwerp's Golden Age: The Metropolis of the West in the 16th and 17th Centuries. An exhibition organizes by the City of Antwerp in collaboration with the Belgian Ministry of Flemish Culture. Sponsored bei the Belgian Embassy, Antwerpen 1973-1975.

\section{Kat. Basel 2000}

Öffentliche Kunstsammlung Basel: Die Sammlung Max Geldner im Kunstmuseum Basel, Basel 2000.

\section{Kat. Berlin 1996}

Gemäldegalerie Berlin (Staaliche Museen zu Berlin): Gesamtverzeichnis, Berlin 1996.

\section{Kat. Brüssel 2002}

Stroo, C.: Catalogue of Early Netherlandish Painting. Royal Museums of Fine Arts of Belgium, Bd. 3, Turnhout 2002.

\section{Kat. Brüssel 2019}

Paleis voor Schone Kunsten (BOZAR): Bernard van Orley (Kat. zur Ausstellung „Bernard van Orley. Brussels and the Renaissance"), Brüssel 2019.

\section{Kat. KHM 1991}

Ferino-Pagden, Sylvia u. Prohaska, Wolfgang et al. (Verf.): Die Gemäldegalerie des Kunsthistorischen $\mathrm{Mu}-$ seums in Wien. Verzeichnis der Gemälde, Wien 1991.

\section{Kat. KMSKA 1988}

Catalogus schilderkunst oude meesters, Antwerpen (Katalog des Koninklijk Museum voor Schone Kunsten), Antwerpen 1988.

\section{Kat. KMSKB 1984}

Pauwels, Henri (Hrsg.): Inventariscatalogus van de oude schilderkunst, Brussel (Koninklijke Musea voor Schone Kunsten van België, Departement Oude Kunst) 1984.

\section{Kat. Prado 1985}

Museo del Prado: Catálogo de las pinturas, Madrid 1985.

\section{Kat. Prado 1989}

Museo Nacional del Prado: La pintura flamenca en el Prado, Amberes 1989.

\section{Kat. Prado 1997}

Museo Nacional del Prado: Los cinco sentidos y el arte, Madrid, 1997.

\section{Kat. Prado 1999}

Museo Nacional del Prado: Pintura italiana del Renacimiento, Madrid, 1999.

\section{Kat. Prado 2001}

Museo Nacional del Prado: Pintura flamenca de los siglos XV y XVI, Madrid, 2001.

\section{Kat. Städel 2017 (Rubens)}

Gruber, Gerline u. Haag, Sabine; Weppelmann, Stefan; Sander, Jochen (Hrsg.): Rubens. Kraft der Verwandlung (Ausstellungskatalog zur gleichnamigen Ausstellung in Wien und Frankfurt 2018), München 2017. 


\section{Kavaler 2000}

Kavaler, Ethan Matt: „Renaissance Gothic in the Netherlands: the Uses of Ornaments", in: The Art Bulletin, 81 (2000), S. 226-151.

\section{Kemperdick - Rößler 2014 a}

Kemperdick, Stephan; Rößler, Johannes (Hrsg.): Der Gentar Altar der Brüder van Eyck. Geschichte und Würdigung (Ausst.-Kat. Gemäldegalerie, Berlin), Berlin 2014.

\section{Kemperdick - Rößler 2014 b}

Kemperdick, Stephan u. Rößler, Johannes: „Der Genter Altar in Berlin 1820-1920. Geschichte einer Wiederentdeckung“, in: Kemperdick, Stephan; Rößler, Johannes (Hrsg.): Der Gentar Altar der Brüder van Eyck. Geschichte und Würdigung (Ausst.-Kat. Gemäldegalerie, Berlin), Berlin 2014, S. 71-99.

\section{Kemperdick - Sander 2008}

Kemperdick, Stephan; Sander, Jochen (Hrsg.): Der Meister von Flémalle und Rogier van der Weyden, Ostfildern 2008

\section{Kemperdick 2014}

Kemperdick, Stephan: „Die Geschichte des Genter Altars“, in: Kemperdick, Stephan u. Rößler, Johannes (Hrsg.): Der Gentar Altar der Brüder van Eyck. Geschichte und Würdigung (Ausst.-Kat. Gemäldegalerie, Berlin), Berlin 2014, S. 8-69.

\section{Klauner 1977}

Klauner, Friederike: „Renaissance/Raum V/2“, in: Wutzel, Otto (Hrsg.): 1200 Jahre Kremsmünster. Stiftsführer, Geschichte, Kunstsammlungen, Sternwarte, Linz 1977, S. 132-139.

\section{Kotkova - Pokorny 2008}

Kotkova, O.; Pokorny, A.: „Technological research into the painting 'St Luke drawing the Virgin' by Jan Gossaert, called Mabuse“, in: Bulletin of the National Gallery in Prague 18-19 (2008-2009), S. 31-41

\section{Krohm 2001}

Krohm, Hartmus: Alter Daedalus. „Zum Begriff künstlerischer Tätigkeit in Dürers Marienleben“, in: Brinkmann, Bodo; Krohm, Hartmut et. Al. (Hrsg.): Aus Dürers Welt. Festschrift für Fedja Anzelewsky, 2001, S. 77-90.

\section{Krönig 1936}

Krönig, Wolfang: Der italienische Einfluss in der flämischen Malerei im ersten Drittel des 16. Jahrhunderts. Beiträge zum Beginn der Renaissance in der Malerei der Niederlande, Würzburg 1936.

\section{Krönig 1957}

Krönig, Wolfang: „Das Abendmahlsbild des Pieter Coecke“, in: De Keyser, Paul (Hrsg.): Miscellanea Prof. Dr. D. Roggen, Antwerpen 1957, S. 161-177.

\section{Kruse 2000}

Kruse, C.: „Fleisch werden - Fleisch malen: Malerei als ,incarnazione‘. Mediale Verfahren des Bildwerdens im Libro dell'arte von Cennino Cennini“", in: Zeitschrift für Kunstgeschichte 63 (2000), S. 126-44.

\section{Kuhn-Forte 2013}

Kuhn-Forte, Brigitte: „Römische Antikensammlungen in Stichen und Druckausgaben des 16. und 17. Jahrhunderts“, in: Luchterhandt, Manfred; Roemer, Lisa et. al. (Hrsg.): Abgekupfert. Roms Antiken in den Reproduktionsmedien der Frühen Neuzeit, Petersberg 2013, S. 75-100.

\section{L}

\section{Laenen 1920}

Laenen, J: Histoire de l'Eglise Métropolitaine de St. Rombout à Malines, 2 Bde., Mecheln 1920.

\section{Lahme 2007}

Lahme, Heribert: Das Ziel menschlichen Bildschaffens im Gottesbild (Diss.), Köln 2007.

\section{Landau 1996}

Landau, David, in: David Landau \& Peter Parshall, The Renaissance Print, Yale, 1996.

\section{Lane 2008}

Lane, B. G.: Hans Memling. Master Painter in FifteenthCentury Bruges, London 2008.

\section{Lavallaye 1943}

Lavallaye, J.: „Le style du peintre Bernard van Orley“, in: Societé royale d'archeologie de Bruxelles. Bernard van Orley, 1488-1541, Brüssel 1943. 


\section{Lecocq 2019}

Lecocq, Isabelle: „Bernard van Orley en de glasschilderkunst“, in: Paleis voor Schone Kunsten (BOZAR): Bernard van Orley (Kat. zur Ausstellung „Bernard van Orley. Brussels and the Renaissance"), Brüssel 2019, S. 67 78.

\section{Leeflang 2007}

Leeflang, Micha: Uytnemende Schilder van Antwerpen. Joos van Cleve: Atelier, Productie en Werkmethoden, Groningen 2007.

\section{Leeflang 2011}

Leeflang, Micha: „Was ihr wollt“, in: Van den Brink, Peter (Ed.): Joos van Cleve. Leonardo des Nordens (Ausstellungskatalog des Surmondt-Ludwig-Museum), Aachen 2011, S. 132-155.

\section{Leeflang 2011}

Leeflang, Huigen: „De prentmaker Lucas van Leyden. Zijn werkwijzen, voorbelden en genie“, in: Vogelaar, Christian (Hrsg.): Lucas van Leyden en de Renaissance, Antwerpen 2011, S. 121-150.

\section{Lefèvre 1945}

Lefèvre, P.: „Documents relatifs aux vitraux de SainteGudule, à Bruxelles, du VXIe et du XVIIe siècle“, in: Revue belge d'archéologi et d'histoire de l'art 15 (1945), S. $117-162$.

\section{Lejeune 1878}

Lejeune, Th.: „Le palais de Marie des Hongarie, à Binche, 1545-1554“, in: Documents et rapports de la Société paléontologique et achéologique de Charleroi 9 (1878).

\section{Leuschner 2013}

Leuschner, Eckhard: „The Young Talent in Italy“, in: Jonckheere, Koenraad (ed.): Michiel Coxcie and the giants of his age: 1499-1592, London 2013, S. 50-63.

\section{Leuschner 2016}

Leuschner, Eckhard (Hrsg.): Rekonstruktion der Gesellschaft aus Kunst. Antwerpener Malerei und Graphik in und nach den Katastrophen des späten 16. Jahrhunderts, Petersberg 2016.

\section{Loining 1995}

Loining, Hans: „Zu Michal Coxcies Sippen- und Johannestafel von 1540: Frühe Paradigmen des Romanismus in den Niederlanden“, in: Wiener Jahrbuch für Kunstgeschichte 48 (Wien 1995).

\section{Lootsma 2017}

Lootsma H.: „A re-assembled allltarpiece by Bernard van Orley“, in: The Burlington Magazine 159 (2017), S. 88-98.

\section{Luchterhandt 2013}

Luchterhandt, Manfred; Roemer, Lisa et. al. (Hrsg.): Abgekupfert. Roms Antiken in den Reproduktionsmedien der Frühen Neuzeit, Petersberg 2013.

\section{Lüken 2000}

Lüken, Sven: Die Verkündigung an Maria im 15. und fruhen 16. Jahrhundert. Historische und kunsthistorische Untersuchungen, Göttingen 2000.

\section{M}

\section{Marlier 1934}

Marlier, Georges: Anthonis Mor van Dashorst (Antonio Moro), Brussel 1934.

\section{Marlier 1957}

Marlier, Georges: Ambrosius Benson et la peinture a Bruges au temps de Charles-Quint, Brüssel 1957.

\section{Marlier 1966}

Marlier, Georges: Pierre Coeck d'Alost, Brüssel 1966.

\section{Marnix 1574}

Philips van Marnix van Sint-Aldegonde: De Byencorf der H. Roomsche Kercke, Emden 1574 (bei Goosen Goebens).

\section{Marrow - Strauss 1981}

Marrow, James u. Strauss, Walter L. (Hrsg.): Hans Baldung Grien, Hans Springklee, Lucas van Leyden. Engravings and etchings. Woodcuts (The illustrated Bartsch 12), New York 1981.

\section{Martens - Huvenne 1998}

Martens, Maximiliaan P. J. - Huvenne, Paul u. Ainsworth, Maryan (Hrsg.): Brugge en de Renaissance. Van Memling tot Pourbus, Brugge (Ausstellungskat. Memlingmuseum - Oud-Sint-Janshospitaal) 1998. 


\section{Martens 1998}

Martens, Maximiliaan P. J.: „Der Dialog zwischen künstlerischer Tradition und Erneuerung", in: Martens, Maximiliaan P. J. (Hrsg.): Memling und seine Zeit. Brügge und die Renaissance, Stuttgart 1998, S. 43-57.

\section{Martens 2003}

Martens, Didier: „Les frères Van Eyck, Memling, Metsys et alii ou le répertoire d'un faussaire éclectique “, in: Wallraf-Richartz-Jahrbuch 64 (2003), S. 253-284.

\section{Martens 2004 / 2005}

Martens, Maximiliaan P. J.: „Antwerp Painters. Their Markets and Networks“, in: Jaarboek Koninklijk Museum voor Schoone Kunsten, Antwerpen 2004, S. $47-$ 73.

\section{Martens 2010}

Martens, Didier: Peinture flamande et goût ibérique aux XVème et XVIème siècles, Brüssel 2010.

\section{Martens-Kat. 1998}

Martens, Maximiliaan P. J. (Hrsg.): Memling und seine Zeit. Brügge und die Renaissance, Stuttgart 1998.

\section{Martínez Millán - Fernández Conti 2005}

Martínez Millán, José u. Fernández Conti, Santiago (Hrsg.): La monarquía de Felipe II. La casa del Rey, 2 Bde., Madrid 2005.

\section{Marwede 2007}

Marwede, Herbert: Vorreformatorische Altäre in OstFriesland [Dissertationsschrift], Hamburg 2007.

\section{Mc Grath 2009}

Mc Grath, Elizabeth: „Platonic myth in Renaissance iconography“, in: Partenie, Catalin (Ed.): Platos's Myths, Cambridge 2009.

\section{Meadow 1996}

Meadow, M. A.: „Bruegel's Procession to Calvary, Æmulatio and the Space of Vernacular Style“, in: Nederlands Kunsthistorisch Jaarboek, Nr. 47 (1996), S. 181-205.

\section{Melion 1991}

Melion, Walter S.: Shaping the Netherlandish Canon Karel Van Mander's Schilder-Boeck, Chicago 1991.

\section{Melis 2011}

Melis, Annemarie: „De Kruisafneming van Rogier van der Weyden, Een onderzoek naar de waardering en de navolging“, in: Scriptie in de opleiding van Master Kunstgeschiedenis, 2011.

\section{Mensaert 1763}

Mensaert, Guillaume Pierre: Le Peintre amateur et curieux, ou Description générale des Tableaux des plus habiles Maitres, qui font l'ornement des Eglises, Couvents, Abbayes, Prieurés \& Cabinets particuliers dans l'étendue des Pays-Bas Austrichiens, Brüssel 1763.

\section{Mensger 2000}

Mensger, Ariane: „Jan van Eyck, ,Belgarum Splendor‘, und der Anfang einer niederländischen Geschichte der Kunst", in: Pantheon, 58, 2000, S. 44-53.

\section{Mensger 2002}

Mensger, Ariane: Jan Gossaert. Die Niederländische Kunst zu Beginn der Neuzeit, Berlin 2002.

\section{Meuwissen 2014}

Meuwissen, Daantje (Hrsg.): Jacob Cornelisz. van Oostsanen (ca. 1475-1533). De Renaissance in Amsterdam en Alkmaar, Zwolle 2014.

\section{Meyer zur Capellen 2001}

Meyer zur Capellen, Jürg: Raphael. A critical catalogue of his paintings, drei Bde. Landshut 2001.

\section{Meyer-Wenschel 1933}

Meyer-Wenschel, A.: Renaissance und Antike. Beobachtungen über das Aufkommen der antikisierenden Gewandgebung in der ital. Renaissance, Reutlingen 1933.

\section{Michalsky 2012}

Michalsky, Tanja: Projektion und Imagination. Die niederländische Landschaft der Frühen Neuzeit im Diskurs von Geographie und Malerei, Leiden 2012.

\section{Miedema 1973 a}

Miedema, Hessel: Grondt der Edel vry Schilder-const, Utrecht 1973.

\section{Miedema 1973 b}

Miedema, Hessel: „Karel Van Mander's Grondt Der Edel Vry Schilder-Const (Foundations of the Noble and Free Art of Painting)", in: Journal of the History of Ideas 34, No. 4 (1973), S. 653-668.

\section{Miedema 1994[-99]}

Miedema, Hessel: Karel van Mander. The Lives of the Illustrious Netherlandish and German Painters, Bd. 16, Doornspijk 1994-99. 


\section{Molanus 1570 [1594]}

Molanus, Johannes: De Picturis et Imaginibus Sacris, pro vero earum usu contra abusus (1570) / De Historia SS imaginum et picturarum, (1594), Boespflug, François; Christin, Olivier et. al. (Hrsg.): Traité des saintes images, Zwei Bände, Paris 1996.

\section{Molanus 1594 [1771]}

Molanus, Johannes: De Historia SS. Imaginum et Pictuarium, ed. J.N. Pacquot, Löwen 1771.

\section{Monbeig-Goguel 1998}

Monbeig-Goguel, Catherine (Hrsg.): Francesco Salviati ou la Bella Maniera (Kat. Der Villa Medici, Rom und dem Musée du Louvre, Paris), Mailand 1998.

\section{Moreau 1952}

De Moreau, Édouard: Histoire de l'eglise en Belgique, Brüssel 1952.

\section{Mulcahy 2010}

Mulcahy, Rosemarie: Philip II of Spain. Patron of the Arts, Dublin 2010.

\section{Müller 1993}

Müller, Jürgen: Concordia Pragensis. Karel van Manders Kunsttheorie im Schilder-Boeck. Ein Beitrag zur Rhetorisierung von Kunst und Leben am Beispiel der rudolfinischen Hofkünstler, München 1993.

\section{Müller 2015}

Müller, Jürgen: Der sokratische Künstler. Studien zu Rembrandts Nachtwache, Leiden 2015.

\section{Musper 1961}

Musper, Heinrich Theodor: Gotische Malerei nördlich der Alpen, Köln 1961.

\section{Van Mander 1604 [1994-99]}

Van Mander, Karel: The Lives of the Illustrious Netherlandish and German Painters, from the First Edition of the Schilder-boeck (1603-1604), Precedes by the Lineage, Circumstances and Place of Birth, Life and Works of Karel van Mander, Painter and Poet, and Likewise His Death and Burial, from the Second Edition of the Schlder-boeck (1616-1618), Ed. von Hessel Miedema, Bd. 1-6, Doornspijk 1994-99.

\section{Neefs 1876}

Neefs, E.: Histoire de la Peinture et de la Sculpture à Malines, 2 Bde., Gent 1876.

\section{Nikulin 1989}

Nikulin, N. N.: Netherlandish painting. Fifteenth and sixteenth centuries (The Hermitage catalogue of western European painting, Bd. V), Sankt Petersburg 1989.

\section{Noë 1954}

Noë, H.: Carel van Mander in Italië. Beschouwingen en notities naar aanleiding van zijn, Leven der deestitjsche doorluchtige Italiaensche Schilders', Den Haag 1954.

\section{Noll 2006}

Noll, Thomas: „Religiöse Verehrung und ästhetischer Genuß. Zur Wahrnehmung von Bildern im späten Mittelalter", in: Arend, Sabine u.a. (Hrsg.): Vielfalt und Aktualität des Mittelalters. Festschrift für Wolfgang Petke zum 65. Geburtstag, Bielefeld 2006, S. 403-424.

\section{North 1997}

North, Michael: Geschichte der Niederlande, München 1997.

\section{$\mathrm{O}$}

\section{Oehlig 1992}

Oehlig, Ute: Die philosophische Begründung der Kunst bei Ficino, Stuttgart 1992.

\section{$\mathrm{P}$}

\section{Panofsky 1930}

Panofsky, Erwin: Das erste Blatt aus dem Libro Giorgio Vasaris, in: Städel- Jahrbuch 6, Frankfurt a. M. 1930, S. 25-72.

\section{Panofsky 1933}

Panofsky, Erwin: „Der gefesselte Eros (zur Genealogie von Rembrandts Danaë)“, in: Oud Holland, Ausg. Nr. 50, Leiden 1933, S. 203-17.

\section{Panofsky 1938}

Panofsky, Erwin: Studies in Icolonology: Humanistic Themes in the Art of the Renaissance, Oxford/New York 1938. 


\section{Panofsky 1977}

Panofsky, Erwin: Das Leben und die Kunst Albrecht Dürers, Princeton 1943 (Nachdr. München 1977).

\section{Paredes - Demeter 2019}

Paredes, Cecilia; Demeter, Stéphane: „Een schilder in zijn stadt. Bernard van Orley en Brussel“, in: Kat Brüssel 2019, S. 19-28.

\section{Partenie 2009}

Partenie, Catalin (Ed.): Platos's Myths, Cambridge 2009.

\section{Pauwels et al. 1965}

Pauwels, H. Hoetink, H. R., Herzog, S. (Hrsg.): Jan Gossaert genaamd Mabuse Mabuse (Gemeisamer Katalog von Groenigemuseum und Museum Boymans van Breuningen), Brügge / Rotterdam 1965.

\section{Pedrocco 2007}

Pedrocco, Filippo: „Titian's ,Ecce Homo“ Reconsidered“, in: Artibus et Historiae, Bd. 28, No. 56, 2. Teil (2007), S. 187-196.

\section{Peeters 2000}

Peeters, N.: Tussen continuïteit en vernieuwing. De bijdrage van Frans en Ambrosius Francken I., en de jonge generaties Francken, tot de historieschilderkunst te Antwerpen, ca. 1570-1620 (Diss. Freie Universität Brüssel 2002).

\section{Peeters 2003}

Peeters, N.: „Frans Francken I and Ambroius I Francken, painters of the metropolis Antwerp, and their altarpieces in the years just after the fall of Antwerp (1585-1589)“, in: Jarboek Koninklijk Museum voor Schone Kunsten, Antwerpen 2003, S. 68-91.

\section{Peeters 2012}

Peeters, N.: „Michiel Coxcie (1499-1592), the Laocoon, and the introduction of raccourci in the Southern Netherlands", in: Relations artistiques entre Italie et anciens Pays-Bas (16e et 18e siècles), Brussel 2012, S. 27 39.

\section{Pérez de Tedula 2013}

Pérez de Tudela, Almudena: „Michiel Coxcie, Court Painter", in: Jonckheere, Koenraad (ed.): Michiel Coxcie and the giants of his age: 1499-1592, London 2013, S. 98-115.

\section{Périer-d'Ieteren 1985}

Périer-d'Ieteren, Catheline: Colyn de Coter et la technique picturale des peintres flamands du XVe siecle, Brüssel 1985.

\section{Pfisterer 2002}

Pfisterer, Ulrich: Donatello. Die Entdeckung der Stile 1430-1445, München 2002.

\section{Philippot 1994}

Philippot, Paul: La Peinture dans les anciens Pays-Bas. XV'eme-XVI'eme siècles, Paris 1994.

\section{Pinchart 1856}

Pinchart, Alexandre: „Tableaux et sculptures de Marie d'Austriche, reine douairière de Hongrie (1558)“, in: Revue elge d'archéologie et d'histoire de l'art 17 (194748), S. 133-147.

\section{Pochat 2004}

Pochat, Götz: Bild - Zeit. Zeitgestalt und Erzählstruktur in der bildenden Kunst des 14. und 15. Jahrhunderts, Wien 2004.

\section{Polleross 1988}

Polleross, Friedrich B.: Das sakrale Identifikationsporträt: ein höfischer Bildtypus vom 13. bis zum 20. Jahrhundert, Bd. 1-2, Worms 1988.

\section{Ponz 1947}

Ponz, Antonio: Viaje por España, Madrid 1772-1794, (Nachdr. 1947).

\section{Putzger 2019}

Putzger, Antonia: „Rückgriff oder Simulation? Zu frühneuzeitlichen Kopierverfahren am Beispiel Michiel Coxcies", in: Magdalena Bushart, Henrike Haug, Stefanie Stallschus (Hrsg.): Unzeitgemäße Techniken. Historische Narrative künstlerischer Verfahren, Köln 2019.

\section{$\mathrm{R}$}

\section{Reintjens 2013}

Reintjens, Melina: „The Habsburg Windows in Brussels Cathedral“", in: Jonckheere, Koenraad (ed.): Michiel Coxcie and the giants of his age: 1499-1592, London 2013, S. 138-155. 


\section{Reznicek 1985}

Reznicek, E. K. J.: „A survey of recent discoveries and of bibliography concerning Dutch art 1500-1600“, in: Cavalli-Björkman, G. (Hrsg.): Netherlandish Mannerism. Papers given at a symposium in Nationalmuseum Stockholm, 21.-22. September 1984, Stockholm 1985, S. 6-13.

\section{Ridderbos 2008}

Ridderbos, Bernhard: „Creating Frameworks. The social function of the Ghent Altarpiece“, in: Hoen, Herman W.: Kemperink, Mary G. (Hrsg.): Vision in text and image. The cultural turn in the study of arts, Löwen 2008, S. 33-52.

\section{Ridderbos 2014}

Ridderbos, Bernhard: Schilderkunst in de Bourgondische Nederlanden, Löwen 2014.

\section{Ringbom 1984}

Ringbom, Sixten: Icon to narrative. The rise of the dramatic close-up in fiftienth-century devotional painting, Doornspijk 1984.

\section{Roemer 2013}

Roemer, Lisa: „Antike Bildwerke in der Romliteratur des Mittelalters und der Frühen Neuzeit“, in: Luchterhandt, Manfred; Roemer, Lisa et. al. (Hrsg.): Abgekupfert. Roms Antiken in den Reproduktionsmedien der Frühen Neuzeit, Petersberg 2013, S. 43-60.

\section{Roey 1966}

Roey, J. van: „De Antwerpse Schilders in 1584-1585. Poging tot sociaal-religeus onderzoek“, in: Jaarboek van het Koninklijk museum voor schone kunsten Antwerpen, Antwerpen 1966, S. 107-132.

\section{Rogge 1897}

Rogge, H. C.: „Het album van Emanuel van Meteren“, in: Oud Holland, 15/1 (1897), S. 159-192.

\section{Rombouts - Lerius 1872-1876}

Rombouts, Ph. u. van Lerius, Th. (Ed.): De liggeren en andere historische archieven der Antwerpsche sint Lucasgilde, onder zinspreuk 'Wt ionsten versamet', 3 Bde. Antwerpen 1872-1876 (Nachdr. Amsterdam 1961).

\section{Romein 1935}

Romein, Jan: „De dialectiek van de vooruitgang“, in: Forum - Maandschrift voor Letteren en Kunst (1935), S. $752-777$.

\section{Roobaert 2005}

Roobaert, Edmond: Meester Jan Vande Perre (1559), goudsmid van de keizer, en meestergeneraal van de keizerlijke munt van de Nederlanden, Brüssel 2005.

\section{Rubach 2013}

Rubach, Birte: „Rom als Kategorie in der italienischen Druckgraphik des 16. Jahrhunderts“, in: Luchterhandt, Manfred; Roemer, Lisa et. al. (Hrsg.): Abgekupfert. Roms Antiken in den Reproduktionsmedien der Frühen Neuzeit, Petersberg 2013, S. 61-74.

\section{Rudziñska 2005}

Rudziñska, Wanda M.: „The Brussels Album from the Print Room of Warsaw University Library“, in: Biblioteka Narodowa (Hrsg.): Polish Libraries today 6. Forein Collections in Polish Libraries, Warschau 2005, S. $42-51$.

\section{S}

\section{De la Serre 1685}

J. Puget de la Serre: Het onderhoud der goede geesten op d'ydelheden van de werelt, Rotterdam 1658 bei Bentingh.

\section{De Smedt 1993}

De Smedt, Raphaël (Hrsg.): „Michel Coxcie, pictor regis (1499-1592). Internationaal Colloquium, Mechelen, 5. / 6. Juni 1992“, in: Handelingen van de Koninklijke Kring voor Oudheidkunde, Letteren en Kunst van Mechelen, Bd. 96, Mechelen, 1993.

\section{De Smedt 2011}

De Smedt, Raphaël: Autopsie de Michel Coxcie. Noveaux horizons bibliographiques 1565-2010, Brüssel 2011.

\section{Sander 2008}

Sander, Jochen: „Meister von Flémalle. Mérode-Triptychon“, in: Kemperdick, Stephan; Sander, Jochen (Hrsg.): Der Meister von Flémalle und Rogier van der Weyden, Ostfildern 2008, S. 192-201.

\section{Sanders 1569}

N. Sanders: De typica et honoraria imaginum adoratione, Löwen 1569 [bei Foulerus]. 


\section{Saunders 1978}

Saunders, E. A.: „A Commentary of Iconoclasm in Several Print Series by Maarten van Heemskerck", in: Simiolus 10 (1978-79), S. 59-83.

\section{Schéle 1965}

Schéle, Sune: Cornelis Bos. A study of the origins of the Netherland grotesque, Stockholm 1965.

\section{Schiller 1968, Bd. 2}

Schiller, Gertrud: Ikonographie der christlichen Kunst, Band 2: Die Passion Jesu Christi, Gütersloh 1968 (zweite Auflage 1988).

\section{Schlegelmilch 2011}

Schlegelmilch, Anna M.: Die Jugendjahre Karls V. Lebenswelt und Erziehung des burgundischen Prinzen, Köln 2011.

\section{Schmidlin 1906}

Schmidlin, Joseph: Geschichte der deutschen Nationalkirche in Rom S. Maria dell'Anima, Wien u. Freiburg im Breisgaug 1906.

\section{Schmidt 1876}

Schmidt, Wilhelm Adolf: „Coxcyen, Michael van“, in: Allgemeine Deutsche Biographie (ADB). Bd. 4, Leipzig 1876, S. 537-539.

\section{Schmidt 2000}

Schmidt, Margarethe: Warum ein Apfel, Eva? Die Bildsprache von Baum, Frucht und Blume, Regensburg 2000.

\section{Schneebalg-Perelman 1973}

Schneebalg-Perelman, Sophie: „Les Neuf Preux et les Sept Vertus. Tapisseries brodées d'après les cartons de Michel Coxcie et de Vredeman de Vriese“, in : Bulletin de Musées royaux d'Art et d'Histoire 45 (1973), S. 201 227.

\section{Schneider 1995}

Schneider, Gerhard: Apokryphe Kindheitsevangelien (Originaltext in Griechisch mit deutscher Übersetzung), Fontes Christiani 18 (Freiburg im Breisgau 1995).

\section{Schneider 2015}

Schneider, Norbert: Von Bosch zu Bruegel. Niederländische Malerei im Zeitalter von Humanismus und Reformation, Berlin 2015.

\section{Schnitzler 1996}

Schnitzler, Norbert: Ikonoklasmus - Bildersturm. Theologischer Bilderstreit und ikonoklastisches Handeln während des 15. und 16. Jahrhunderts, München 1996.

\section{Schrader 2010}

Schrader, Stephanie: „Drawing for Diplomacy: Gossaert's Sojourn in Rome“, in: Ainsworth, Maryan: Man, Myth, and Sensual Pleasures: Jan Gossart's Renaissance, New York 2010, S. 45-55.

\section{Schreiner 1993}

Schreiner, Klaus: „Der Tod Marias als Inbegriff christlichen Sterbens. Sterbekunst im Spiegel mittelalterlicher Legendenbildung“", in: Borst, Arno (Hrsg.): Tod im Mittelalter, Konstanz 1993, S. 261-312.

\section{Schreiner 1994 [2006]}

Schreiner, Klaus: Maria. Jungfrau, Mutter, Herrscherin, München Wien 1994 (Neuaufl. Von 2006).

\section{Shearman 1972}

Shearman, John K. G.: Raphael's cartoons in the collection of Her Majesty the Queen and the tapestries for the Sistine Chapel, London 1972.

\section{Silver 1984}

Silver, Larry: The Pantings of Quinten Massys. With Catalogue Raisonné, Oxford 1984.

\section{Silver 1986}

Silver, Larry: „Figure nude, historie e poesie. Jan Gossaert and the renaissance nude in the Netherlands", in: Nederlands Kunsthistorisch Jaarboek 37 (1986), S. 140.

\section{Smeyers 1991}

Smeyers, Mauritz: „Demut und Protz. Frömmigkeit und Umgang mit Bildern im 15.-16. Jahrhundert“, in: Van den Stock, Jan et. al. (Hrsg.): Stadtbilder in Flandern. Spuren bürgerlicher Kultur. 1477-1787, Brüssel 1991, S. 219-236.

\section{Smit 1930}

Smit, W. A. P.: Jacobus Revius. Over-Ysselsche sangen en dichten, 2 Bde., Amsterdam 1930.

\section{Smith 1990}

Smith, Jeffrey Chips: „The Practical Logistics of Art. Thoughts on the Comissioning, and Storing of Art at the Burgundian Court", in: Laurinda S. Dicxon (Hg.): 
Detail. New Studies of Northern Renaissance Art in Honor of Walter S. Gibson, Turnhout 1998, S. 27-48.

\section{Snyder 1985}

Snyder, James: Northern Renaissance Art. painting, sculpture, the graphic arts from 1350 to 1575, New York 1985

\section{Snyder 1985}

Snyder, James: Northern Renaissance Art: Painting, sculpture, the graphic arts from 1350 to 1575, New York 1985

\section{Sohm 2000}

Sohm, Philip: „Ordering history with style. Giorgio Vasari on the art of history“, in: Antiquity (2000), S. 4054.

\section{Steppe 1968}

Steppe, Jan Karel: „Vlaams tapijtwerk van de 16de eeuw in Spaans koninklijk bezit“, in: Miscellanea Jozef Duverger. Bijdragen tot de kunstgeschiedenis der Nederlanden, Bd. II, Gent 1968, S. 719-765.

\section{Stroo - Syfer-d'Olne 1999}

Stroo, C. u. Syfer-d'Olne, P.: The Flemish Primitives. II. The Dirk Bouts Petrus Christus, Hans Memling and Hugo van der Goes Groups, Brüssel 1999.

\section{Stroo 2001}

Stroo, Cyriel (Hrsg.): The Flemish Primitives III: The Hieronymus Bosch, Albrecht Bouts, Gerart David, Colijn De Coter and Goossen Van der Weyden, Brüssel 2001.

\section{Suykerbuyk 2013}

Suykerbuyk, Ruben: „Coxcie's copies of old masters. An addition and an analysis“, in: Simiolus 37 (2013), S. 5-24.

\section{Suykerbuyk 2017}

Suykerbuyk, Ruben: „A royal reproduction. Michiel Coxcie's Copy of the Ghent Altarpiece (1557-1558), its documentary evidence and early reception“, in: Kemperdick, S.; Rößler, J.; Heyder, J. C. (Hrsg.): The Ghent Altarpiece. Reproductions, interpretations, scholarly debates, Petersberg 2017, S. 70-83.

\section{Tischer 1994}

Tischer, Sabine: Tizian und Maria von Ungarn, Der Zyklus der „pene infernali“ auf Schloss Binche (1549), Frankfurt a. M. 1994.

\section{Unsinn 2018}

Unsinn, Christina: „Eine exakte Teilkopie von Joos van Cleve. Zur Funktion von Kopien im frühen 16. Jahrhundert (2018)“, veröffentlicht in: E-Journal für Kunstund Bildgeschichte (kunsttexte.de), Ausgabe 01/2018.

\section{Unverfehrt 2007}

Unverfehrt, Gerd: Da sah ich viel köstliche Dinge. Albrecht Dürers Reise in die Niederlande, Göttingen 2007.

\section{V}

\section{Van Autenboer 1986}

Van Autenboer, Eugeen: „Mechelen in de 16 de eeuw. Schaade wordt toegebracht en hersteld“, in: Handelingen van de Koninklijke Kring voor Oudheidkunde, Letteren en Kunst van Mechelen 89 (1986), S. 197-242.

\section{Van Autenboer 1992}

Van Autenboer, Eugeen: „De Familie Coxcie“, in: Handelingen van de Koninklijke Kring voor Oudheidkunde, Letteren en Kunst van Mecheln 96, 2 (1992), S. 5-29.

\section{Van de Velde 1992}

Van de Velde, C.: „De Coxcies uit de Onze-Liebe-Vrouwekerk van Antwerpen“, in: De Smedt, Raphaël: Michiel Coxcie, pictor regius (1499-1592), Mecheln 1993, S. 195-214.

\section{Van den Boogert 1992 a}

Van den Boogert, Bob C., „Michiel Coxcie, hofschilder in dienst van het Habsburgse huis", in: Handelingen van de Koninklijke Kring voor Oudheidkunde, Letteren en Kunst van Mechelen, in: De Smedt, Raphaël (Hrsg): Michel Coxcie, pictor regis (1499-1592) Internationaal colloquium, Mechelen, 5 en 6 juni 1992, 2, Mechelen 1993, S. 118-140. 


\section{Van den Boogert 1992 b}

Van den Boogert, Bob C. „Habsburgs imperialisme en de verspreiding van renaissancevormen in de Nederlanden: De vensters van Michiel Coxcie in de Sint-Goedele te Brussel“", in: Oud Holland, CVI, 2, Mechelen 1992, S. $57-80$.

\section{Van den Boogert 1993}

Van den Boogert, Bob. C.: Maria Van Hongarije 15051558. Koningin Tussen Keizers en Ku, Zwolle 1993.

\section{Van den Boogert 1998}

Van den Boogert, Bob C.: Habsburgs hofmecenaat en de introducie van de Italiaanse Hoogrenaissance in de Lage Landen, Amsterdam 1998.

\section{Van den Brink - Martens 2005}

Van den Brink, Peter (Hrsg.) u. Martens, Maxiiliaan P. J [et al.]: ExtravagAnt. A forgotten chapter of Antwerp Painting. 1500-1530 [Katalog zur Ausstellung], Antwerpen 2005.

\section{Van den Brink 1995}

Van den Brink, Peter: „Underdrawing in the workshop production of Bernart van Orley. A first impression“, in: Le dessin sous-jacent dans la peinture, Colloque $\mathrm{X}$ (1993), Louvain-la-Neuve 1995, S. 177-184.

\section{Van den Brink 2011}

Van den Brink, Peter (Hrsg.): Joos van Cleve. Leonardo des Nordens, Katalogbuch, Suermondt-Ludwig-Museum, Aachen 2011.

\section{Van Grieken 2013}

Van Grieken, Joris: „Publish or Perish. Michiel Coxcie in Print", in: Jonckheere, Koenraad (Hrsg.): Michiel Coxcie and the giants of his age: 1499-1592, London 2013, S. 156-179.

\section{Van Puyvelde 1960}

Van Puyvelde, Leo: „Considerations sur les maniéristes flamands“, in: RBAHA/BTOK 29 (1960), S. 63-101.

\section{Van Puyvelde 1962}

Van Puyvelde, Leo, La peinture flamande au siècle de Bosch et Breughel, Brussel 1962, S. 410-417.

\section{Van Toorenenbergen 1871}

Van Toorenenbergen, J. J. (Hrsg.): Philips van Marnix. Godsdienstige en kerkelijke geschriften, Den Haag 1871, S. $1-34$

\section{Van Vaernwyck 1566 / 1568}

Van Vaernwyck, Marcus: Van de beroerlicke Tijden in de Nederlanden en voornamelijk in Ghendt 1566-1568 (Handschrift der Universitätsbibliothek Gent [Hs. G 2469], Ausgabe F, Vanderhaeghen, Gent 1872.

\section{Van Vaernwyck 1568}

Van Vaernwyck, Marcus: Den Spieghel der Nederlandscher audtheyt, Gent 1568, (2. Ausg: De Historie van Belgis [...], Gent 1574).

\section{Vanden Bemden 1993}

Vanden Bemden, Yvette: „Michel Coxcie, créateur de vitraux“, in: De Smedt 1993, S. 141-159.

\section{Vandenbroeck 2005}

Vandenbroeck: „Late Gothic Mannerism in Antwerp. On the Significance of a ,Contrived' Style“, in: Jaarboek Koninklijk Museum voor Schoone Kunsten Antwerpen (2004-2005), S. 301-329.

\section{Vasari 1568}

Le vite de' più eccellenti Pittori, Scultori, e Architettori. Scritte da M. Giorgio Vasari Pittore et Architetto Aretino. Di Nuovo dal Medesimo Riviste Et Ampliate Con i Ritratti loro Et con l'aggiunta delle Vite de' vivi, \& de' morti Dall' anno 1550 infino al 1567, 3 Bde., Florenz 1568.

\section{Vasari 1568, Ed. Gronau}

Vasari, Giorgio: Die Lebensbeschreibungen der berühmten Architekten, Bildhauer und Maler (Über. Gronau, Georg), Straßburg 1908, Bd. V.

\section{Vasari 1568, Ed. Milanesi}

Milanesi, Gaetano: Le vite de'più eccellenti pittori, scultori ed architettori seritte da Giorgio Vasari. 9 Bände, Florenz: G. C. Sansoni, 1878-1885., Bd. 1-9.

\section{Veratelli 2011}

Veratelli, Federica: ,Jacopo de' Barbari alla corte di Margherita d'Austria (ca. 1510-1516). Il milieu italiano, qualche aggiustamento e una notizia inedita", in: Venezia Cinquecento. Studi di storia dell'arte e della cultura, Bd. 21, Rom 2011, S. 61-73.

\section{Vermeylen 2012}

Vermeylen, Filip: „Between hope and despair. The state of the Antwerp art market, 1566-1585“, in: Jonckheere, Koenraad; Suykerbuyk, Ruben: Art after Iconoclasm. Painting in the Netherlands between 1566 and 1585, S. 95-108. 


\section{Von der Osten - Vey 1969}

Von der Osten, G.; Vey, H.: Painting and sculpture in Germany and the Netherlands: 1500 to 1600 , Baltimore 1969.

\section{Von der Osten 1961}

Von der Osten, G.: „Studien zu Jan Gossaert“, in: Meiss, M. (Hrsg.): Essays in honor of Erwin Panofsky, New York 1961, S. 454-475.

Vos 1978

Vos, Rik: Lucas van Leyden, Maarsen, 1978.

\section{W}

\section{Waagen-De Bast 1825}

Waagen, Gustav Friedrich: Notice sur le Chef-d'œuvre des Frères van Eyck, traduit de l'allemand par L. de Bast, Gent 1825.

\section{Walsh 1991}

Walsh, Michael (Ed.): Butler's Lives of the Saints. New York 1991.

\section{Wamel 2014}

Van Wamel, M.: „Zóó goed Roomsch en zóó goed spaansch. Anthonis Mor and the problematic position of sixteenth-century artists with Spanish patrons in Dutch art history“, in: Oud Holland 127 (2014), S. 4960.

\section{Waterschoot 1974}

Waterschoot, Werner: „Leven en Betekenis van Lucas d'Heere“, in: Verslagen en Medelingen van de Koninklijke Academie voor Nederlandse Taal- en Letterkunde (1974), S. 16-126.

\section{Watershoot 1995}

Watershoot, Werner: „16th Century Antwerp, a Cultural Capital", in: The Tyndale Society Journal, Nr. 3, S. 15-21.

\section{Wauters 1893}

Wauters, Alphonse Guillaume Ghislain: Bernard van Orley, in der Reihe Librairie de l'Art, Paris 1893.

\section{Weber 1991}

Weber, G. J. M.: Der Lobtopos des ,lebenden` Bildes. Jan Vos und sein ,Zeege der Schilderkunst ${ }^{\star}$ von 1654, Hildesheim 1991.

\section{Weidema - Koopstra 2012}

Weidema, Sytske; Koopstra, Anna: Jan Gossaert. The Documentary Evidence (with a foreword by Maryan W. Ainsworth), London/Turnhout 2012.

\section{Weiland-Pollerberg 2004}

Weiland-Pollerberg, Florian: Amor und Psyche in der Renaissance. Medienspezifisches Erzählen im Bild, Petersberg 2004.

\section{Weiß 2005}

Weiß, Dieter J.: Katholische Reform und Gegenreformation, Darmstadt 2005.

\section{Wenzel 1993}

Wenzel, Horst: „Die Verkündigung an Maria. Zur Visualisierung des Wortes in der Szene oder: Schriftgeschichte im Bild“, in: Opitz, Claudia, Röckelein, Hedwig (Hrsg.), et. al.: Maria in der Welt. Marienverehrung im Kontext der Sozialgeschichte. 10.-18. Jahrhundert, Zürich 1993, S. 23-52.

\section{Weppelmann 2017}

Weppelmann, Stefan: „Körper sehen und Körper malen“, in: Rubens. Kraft der Verwandlung (Kat. Städel 2017), S. 227-248.

\section{Weststeijn 2012}

Weststeijn, Thijs: „Idols and ideals in the rise of Netherlandish Art Theorie“, in: Jonckheere, Koenraad u. Suykerbuyk, Ruben (Hrsg.): Art after iconoclasm: Painting in the Netherlands between 1566 and 1585, Turnhout 2012, S. 109-130.

\section{Weststeijn 2013}

Weststeijn, Thijs: The universal art of Samuel van Hoogstraten (1627-1678). Painter, Writer, and Courtier, Amsterdam 2013.

\section{Weststeijn 2016}

Weststeijn, Thijs: „The Sublime and the 'Beholder's Share'. Junius, Rubens, Rembrandt", in: Journal of Historians of Netherlandish Art 8:2 (2016).

\section{Wethey 1969-1975}

Wethey, Harold E.: The paintings of Titian, 3 Bde., London 1969-1975.

\section{Woollett 2004}

Woollett, A. T.: The Altarpiece in Antwerp, 1554-1615: Painting and the Militia Guilds (Diss. PhD., Columbia University 2004). 


\section{Woollett 2012}

Woollett, Anne T.: „Michiel Coxcie and the revitalization of religious paintings in the Southern Nethrlands after 1566“, in: Jonckheere, Koenraad (Hrsg.): Art after Iconoclasm. Painting in the Netherlands between 1566-1585, London 2012, S. 75-94.

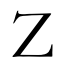

\section{Zarco 1930}

Zarco Cuevas (Hrsg.): Inventario de las alhajas, relicarios, estatuas, pinturas, tapices y otros objetos de valor y curiosidad donados por el rey dom Felipe II al Monasterio de El Escorial. Años de 1571 a 1598, Madrid 1930.

\section{Zentai 1983}

Zentai, L.: „Drei Kupferstiche des „Meisters mit dem Würfel: Überlegungen zu Bildtehemen von Baldassare Peruzzi“, in: Sitzungsberichte / Kunstgeschichtliche Gesellschaft zu Berlin. Neue Folge, Band 33 (1984/85), 1983, S. 16-18.

\section{Zerling 2007}

Zerling, Clemens: Lexikon der Pflanzensymbolik, München 2007.

\section{Zöllner 1990}

Zöllner, Franz: Leonardo da Vinci. 1452-1519. Sämtliche Gemälde u. Zeichnungen, Köln 2003.

\section{Nachschlagewerke}

\author{
ADB \\ Allgemeine Deutsche Biographie (ADB), Leipzig \\ 1875-1912 (Nachdruck 1967-1971).
}

\section{Höfe und Residenzen (2007)}

Paravicini, Werner (Hrsg.); Hirschbiegel, Jan; Wettlaufer, Jörg: Handbuch der Höfe und Residenzen im spätmittelalterlichen Reich, Zwei Bände, Ostfildern 2007.

\section{LThK}

Lexikon für Theologie und Kirche (Neubearbeitete Auflage des Kirchlichen Handlexikons). Hrsg. von M. Buchberger, 10 Bände, Freiburg i. Br. 1930-1938; 2.
Auflage, hrsg. von J. Höfer und K. Rahner, 11 Bde., Freiburg i. Br. 1957-1967.

\section{LCI}

Lexikon der christlichen Ikonographie. Hrsg. von Engelbert Kirschbaum (Bände 1-4) und Wolfgang Braunfels (Bände 5-8). 8 Bände, Freiburg im Breisgau u. a. 1968-1976.

Lexikon der antiken christlichen Literatur, Freiburg im Breisgau 1998.

\section{Internetartikel und Digitalisate}

\section{De Puys 1515 (ÖNB Cod. 2591)}

Remy de Puys: Solemnelle entrée faicte sur l'advenement de Charles Archidux d'Autriche en Bruge 1515, Digitalisat der Österreichischen Nationalbibliothek, 〈http://data.onb.ac.at/rec/AC13947423〉 (abgerufen am 04.03.2019).

\section{Index Lib. Prohib. 1559}

Digitalisat, Bayerische Staatsbibliothek, Sign. Rar. 1630, eingestellt am 05.09.2005, http://daten.digitale-sammlungen.de/ db/bsb00001444/images/index.html> (abgerufen am 05.06.2019).

Index Avctorvm, Et Libroru[m], Romae 1559.

\section{Mundell 2013}

Mundell, Ian: „Leuven exhibition proves artistic merit of Michiel Coxcie“ vom 07. Nov. 2013 auf http://www.flanderstoday.eu/art/leuven-exhibitionproves-artistic-merit-michiel-coxcie) (abgerufen am 13.06.2019).

Patrimonio Nacional 2016 Blog-Artikel „Michiel Coxcie en la Celda Prioral Baja del Real Monasterio de San Lorenzo de El Escorial“" vom 26.04.2016, 〈https://www.patrimonionacional.es〉 (abgerufen am 19.07.2019).

\section{Sandrart 1675, TA}

Joachim von Sandrart: Teutsche Academie (TA) der Bau- Bild- und Mahlerey-Künste, 1675, ed. und hrsg. von Thomas Kirchner et al., http://www.sandrart.net/de> (abgerufen am 15.09.2019). 


\section{Abbildungen}

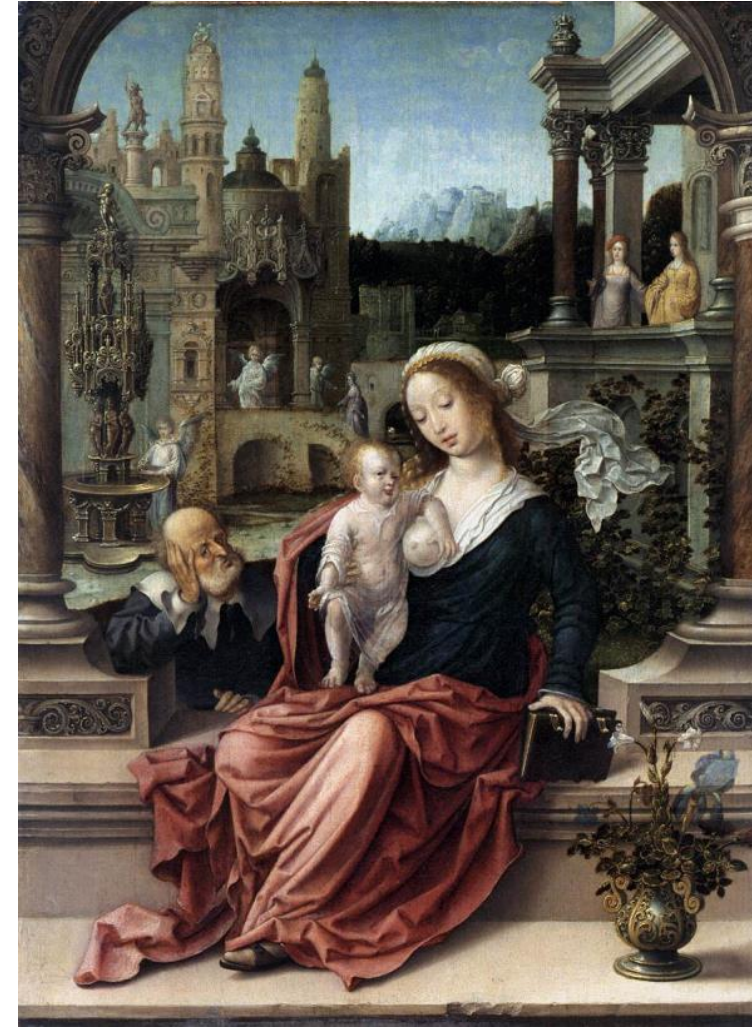

Abb. 1: Jan Gossaert - Hl. Familie (1510)

Öl auf Holz, J. Paul Getty Museum, Los Angeles

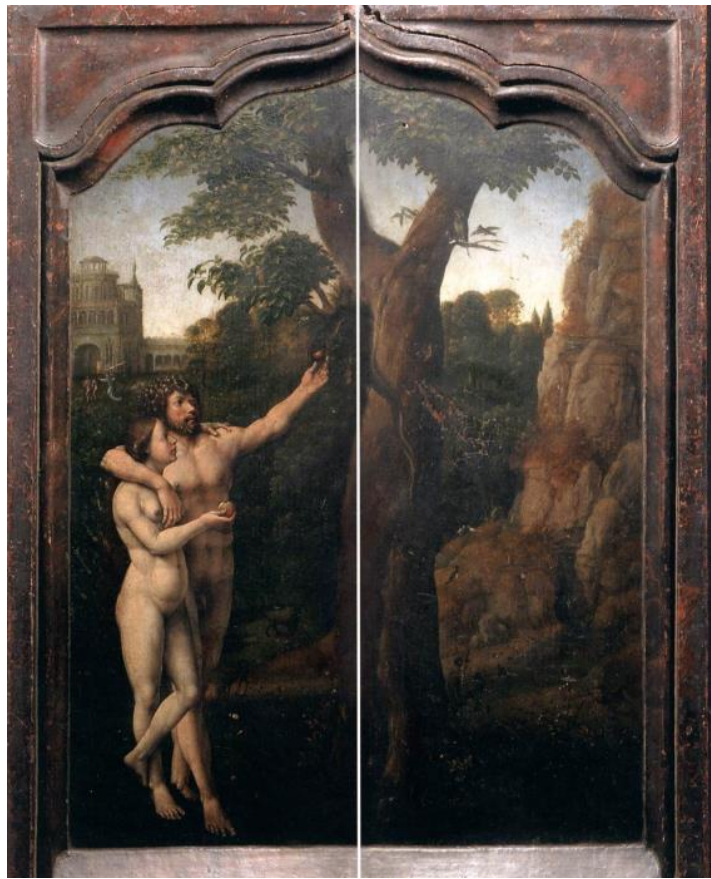

Abb. 3: Malvagna-Triptychon (Außenseite)

Öl auf Holz, Galleria Regionale della Sicilia, Palermo

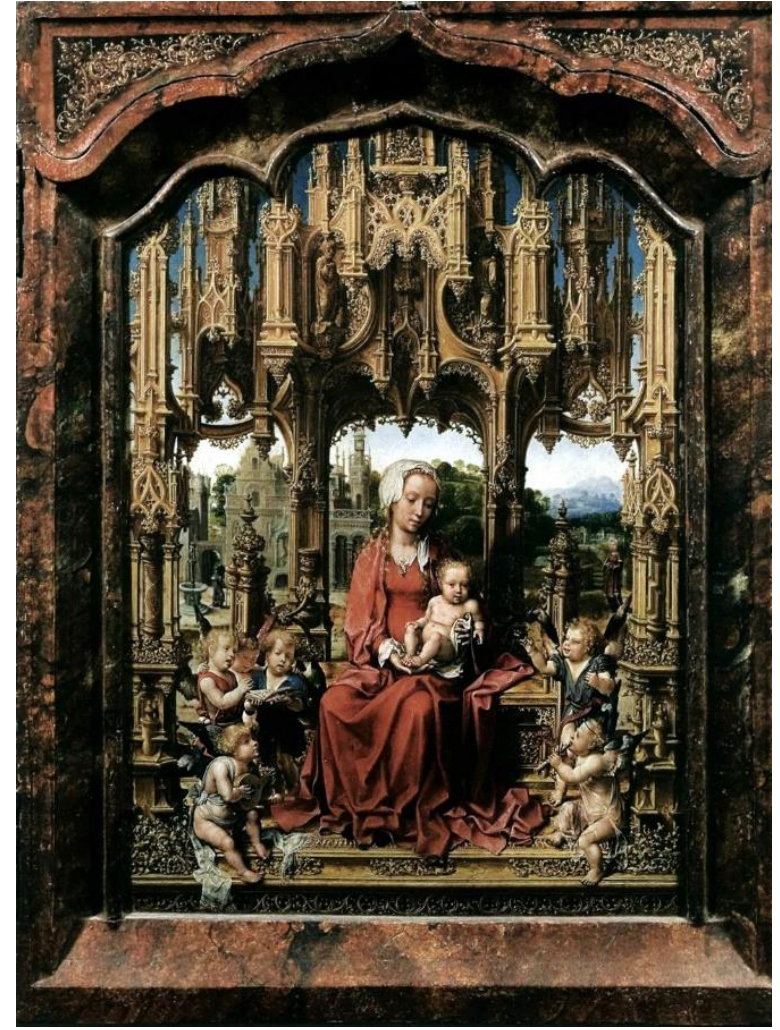

Abb. 2: Jan Gossaert - Malvagna-Triptychon (Mitteltafel, um 1515), Öl auf Holz, Galleria Regionale della Sicilia, Palermo

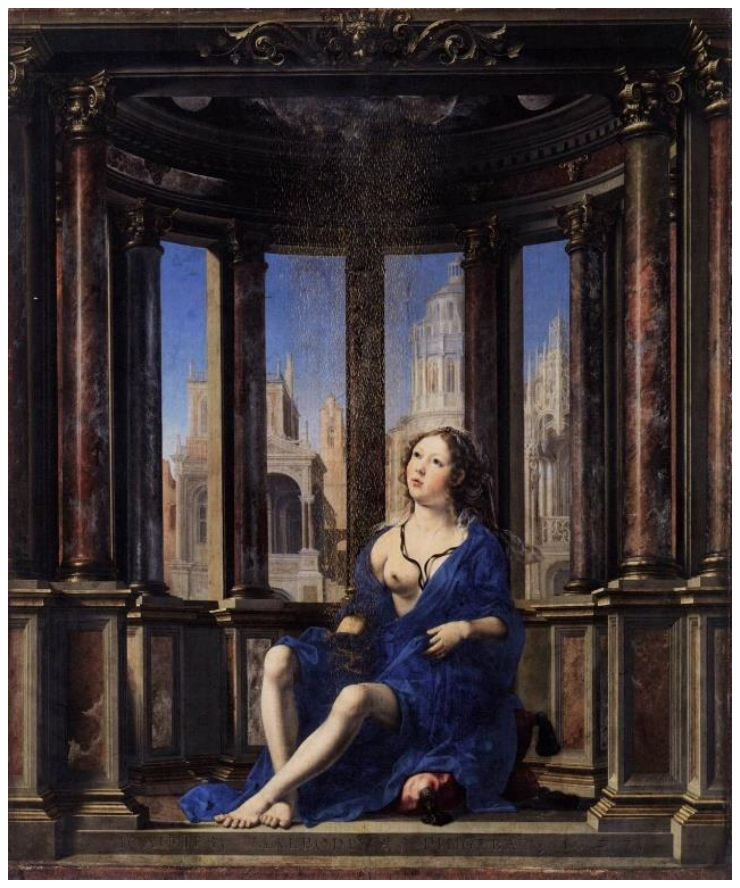

Abb. 4: Jan Gossaert - Danaë (1527)

Öl auf Holz, Alte Pinakothek, München 


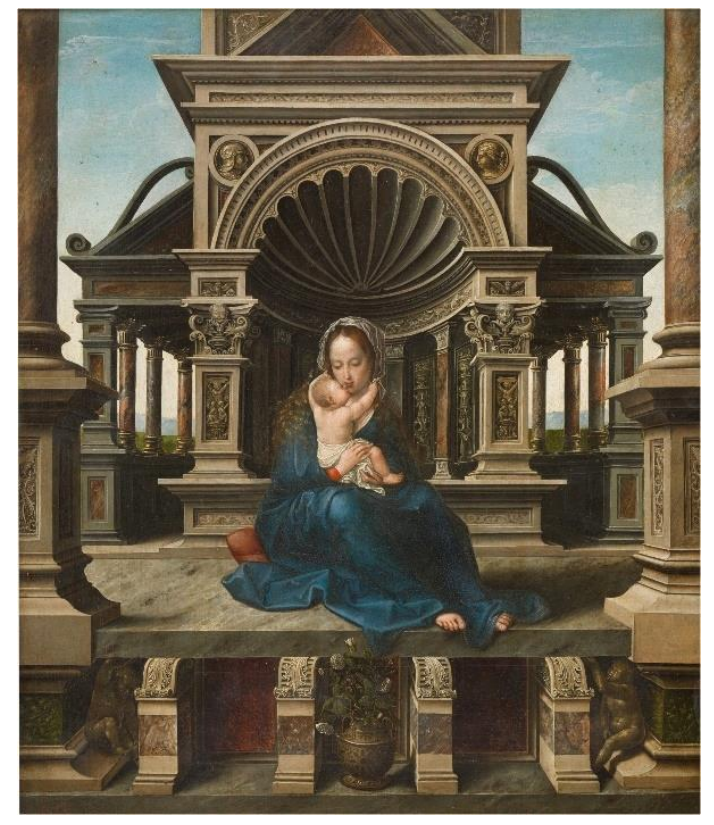

Abb. 5: Bernard van Orley - Löwener Madonna (um 1520) Öl auf Holz, Prado, Madrid

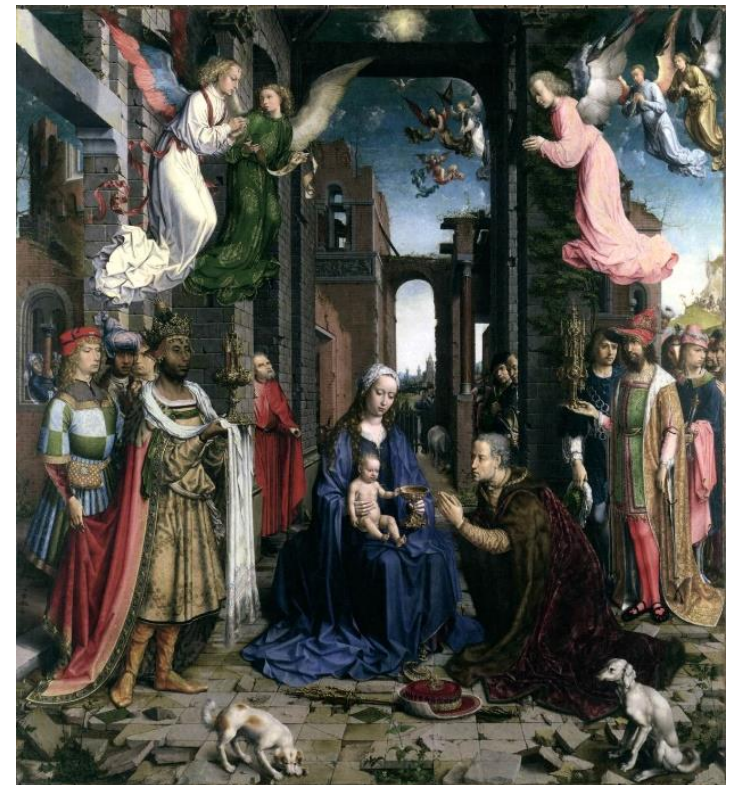

Abb. 6: Jan Gossaert - Anbetung der Könige (um 1510) Öl auf Holz, National Gallery, London

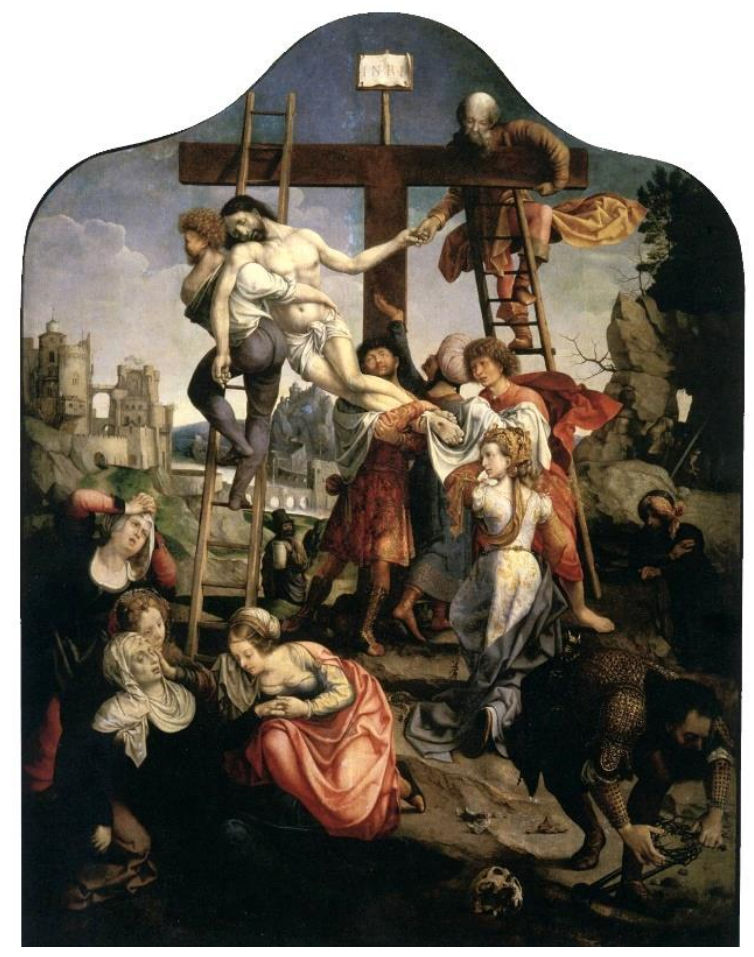

Abb. 7: Jan Gossaert - Kreuzabnahme (1521)

Öl auf Holz, Ermitage, St. Petersburg 


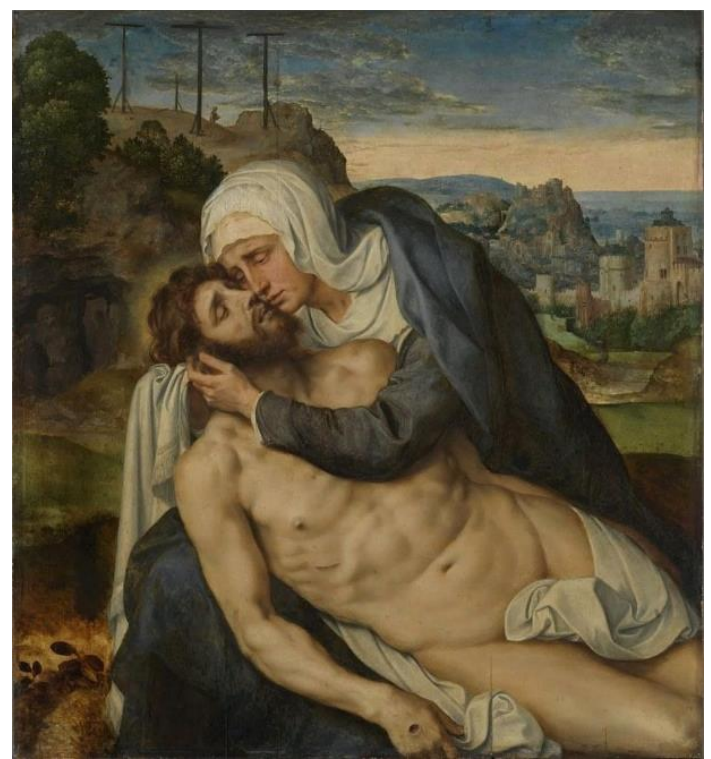

Abb. 8: Willem Key - Beweinung Christi (um 1550) Öl auf Holz, Alte Pinakothek, München

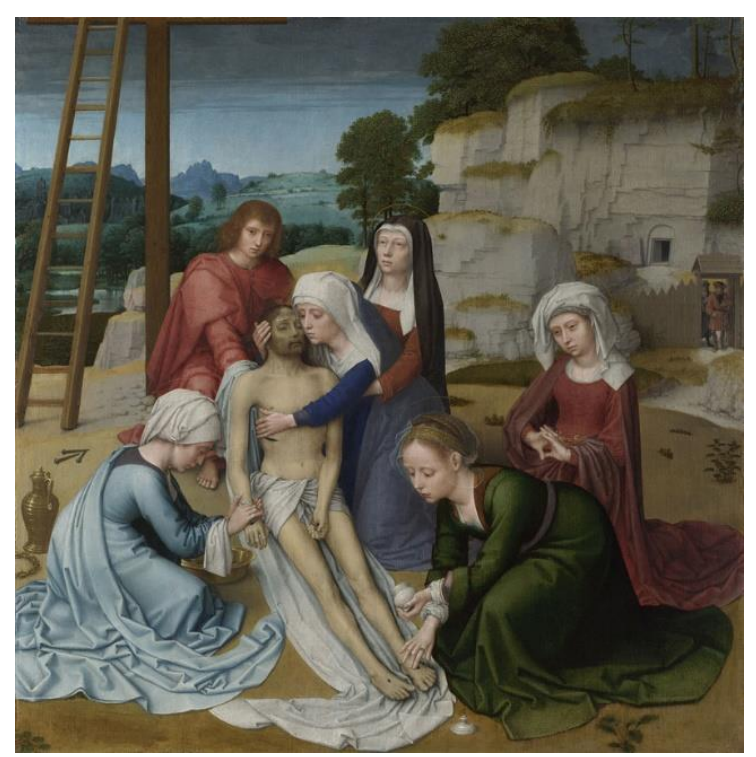

Abb. 10: Gerard David - Beweinung Christi (um 1515) Öl auf Holz, National Gallery, London

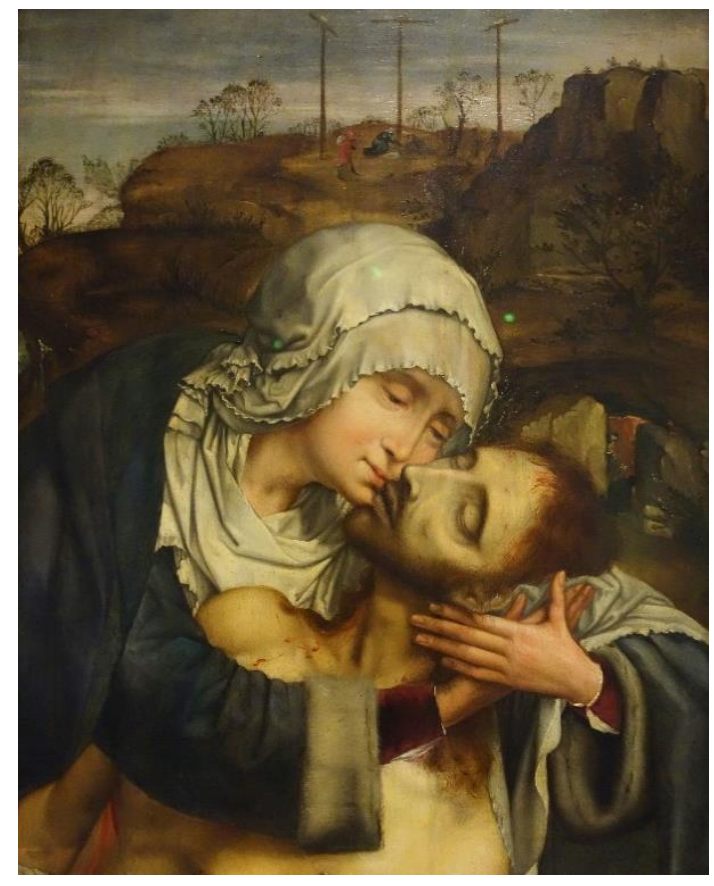

Abb. 9: Quentin Massys (Umkreis?)

Öl auf Holz, KMSKA, Antwerpen

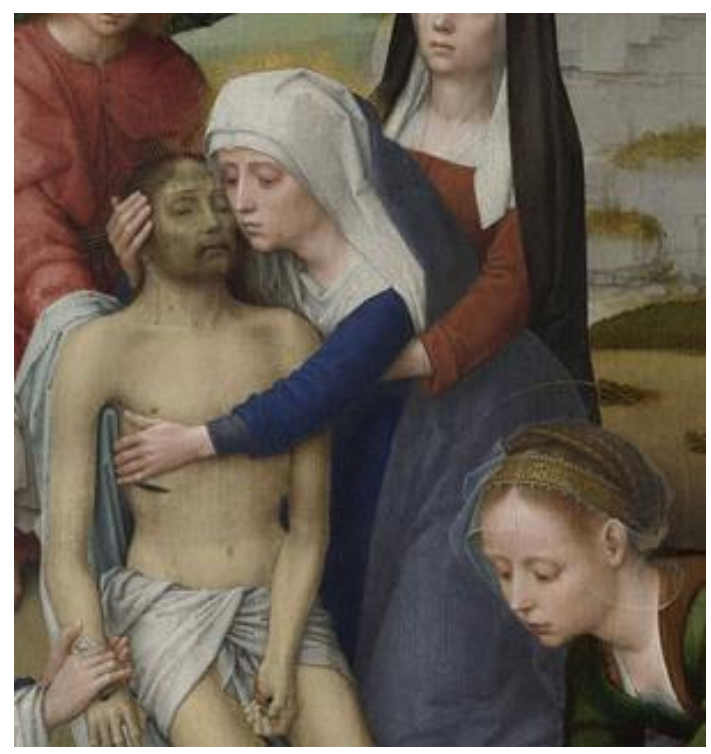

Abb. 10 (Detail) 

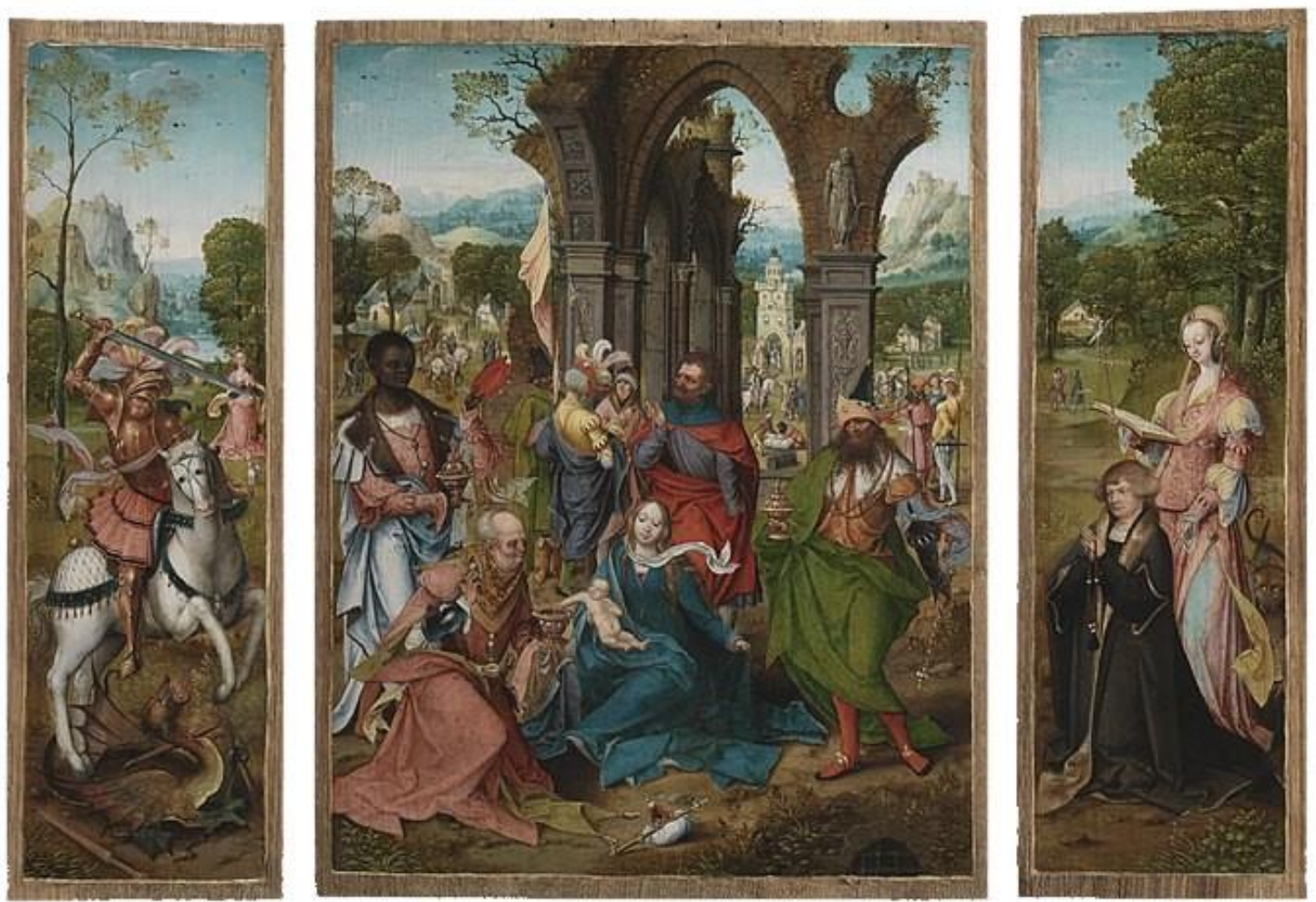

Abb. 11: Meister der Antwerpener Anbetung - Anbetung der Könige (um 1520)

Öl auf Holz, Koninklijk Museum voor Schone Kunsten, Antwerpen

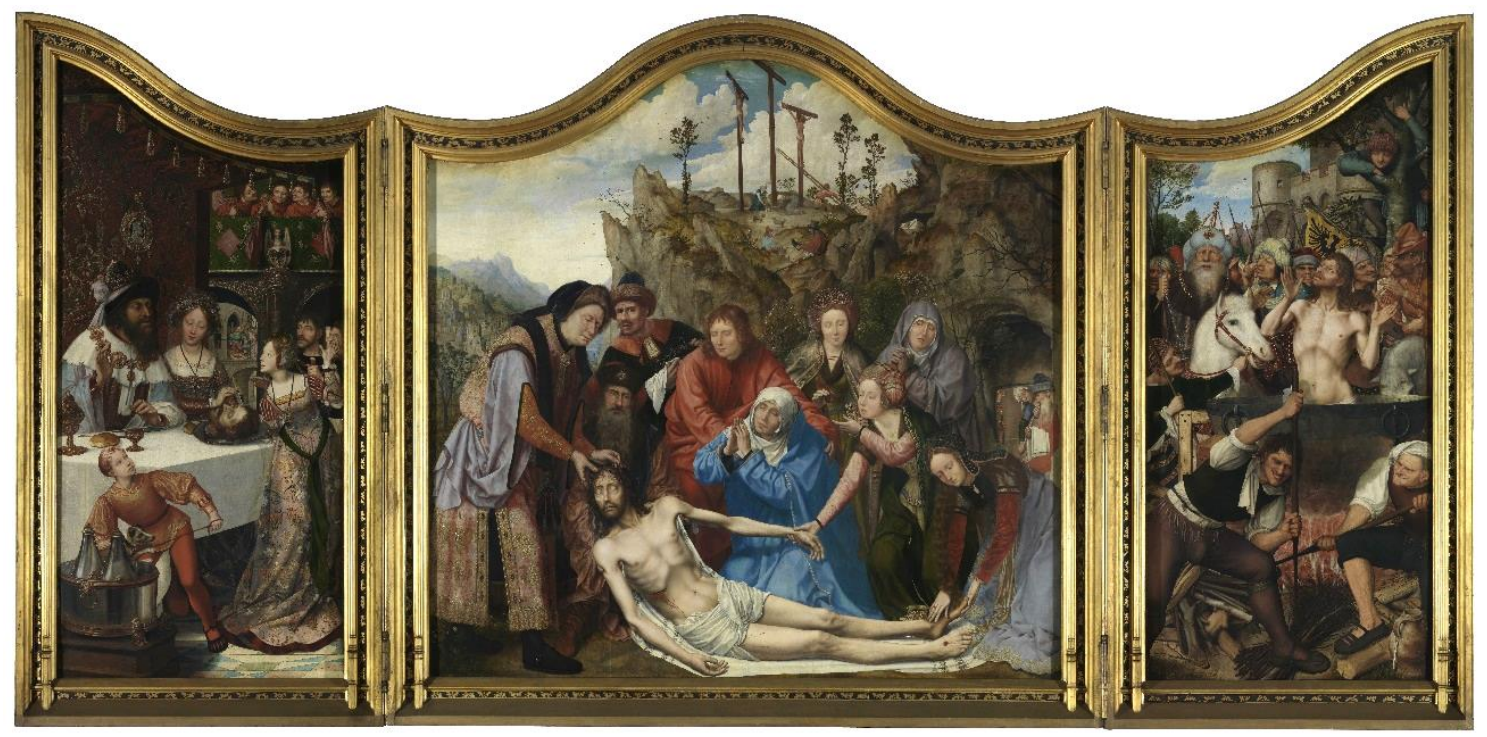

Abb. 12: Quentin Massys - Triptychon der Zimmerleute (1511)

Öl auf Holz, Koninklijk Museum voor Schone Kunsten, Antwerpen 


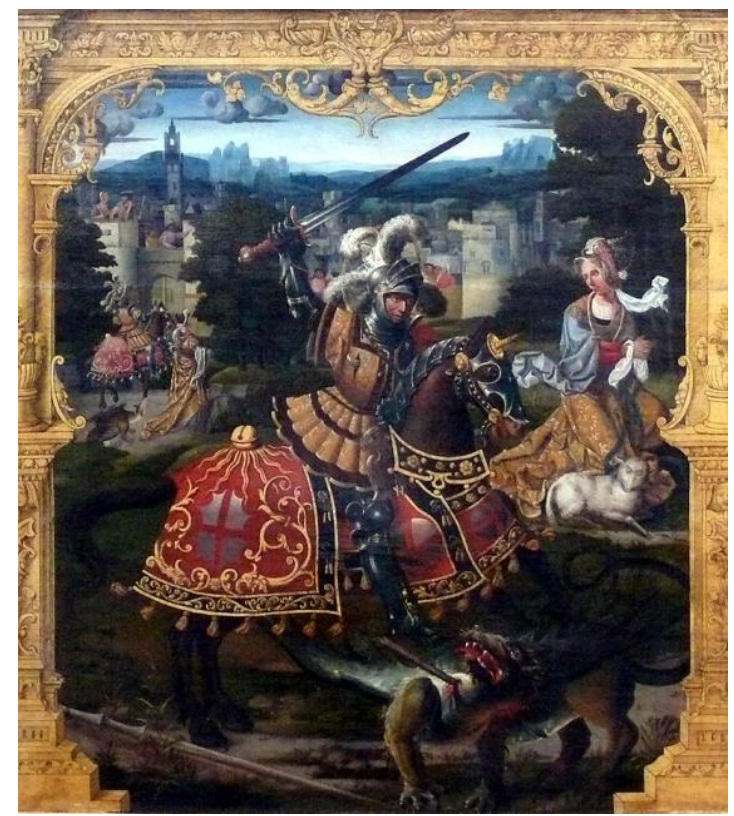

Abb. 13: Lancelot Blondeel - Hl. Georg (um 1535)

Öl auf Holz, Groeningemuseum, Brügge

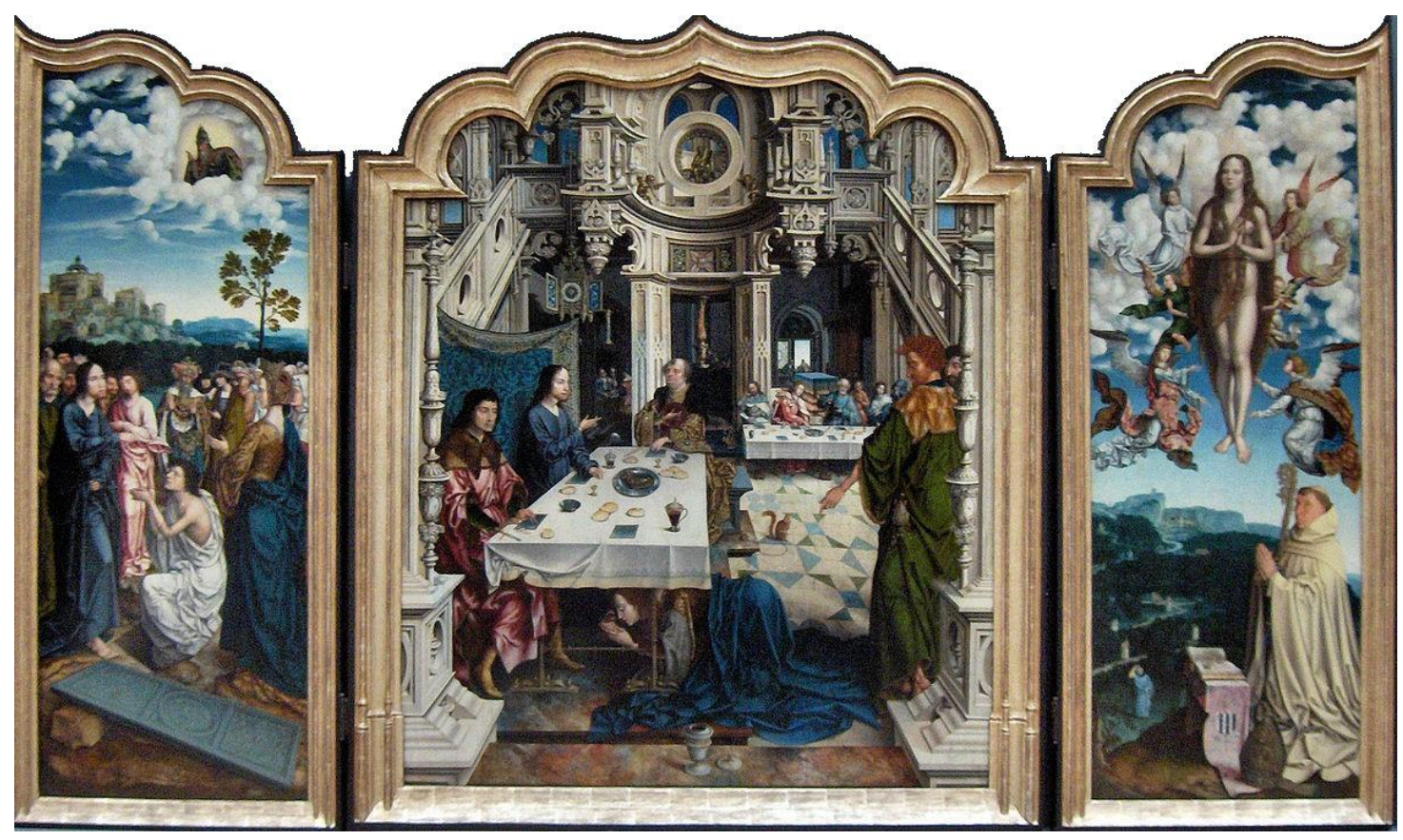

Abb. 14: Sog. Meister von 1518 - Christus im Haus Simons (um 1520)

Öl auf Holz, Koninklijke Musea voor Schone Kunsten, Brüssel 


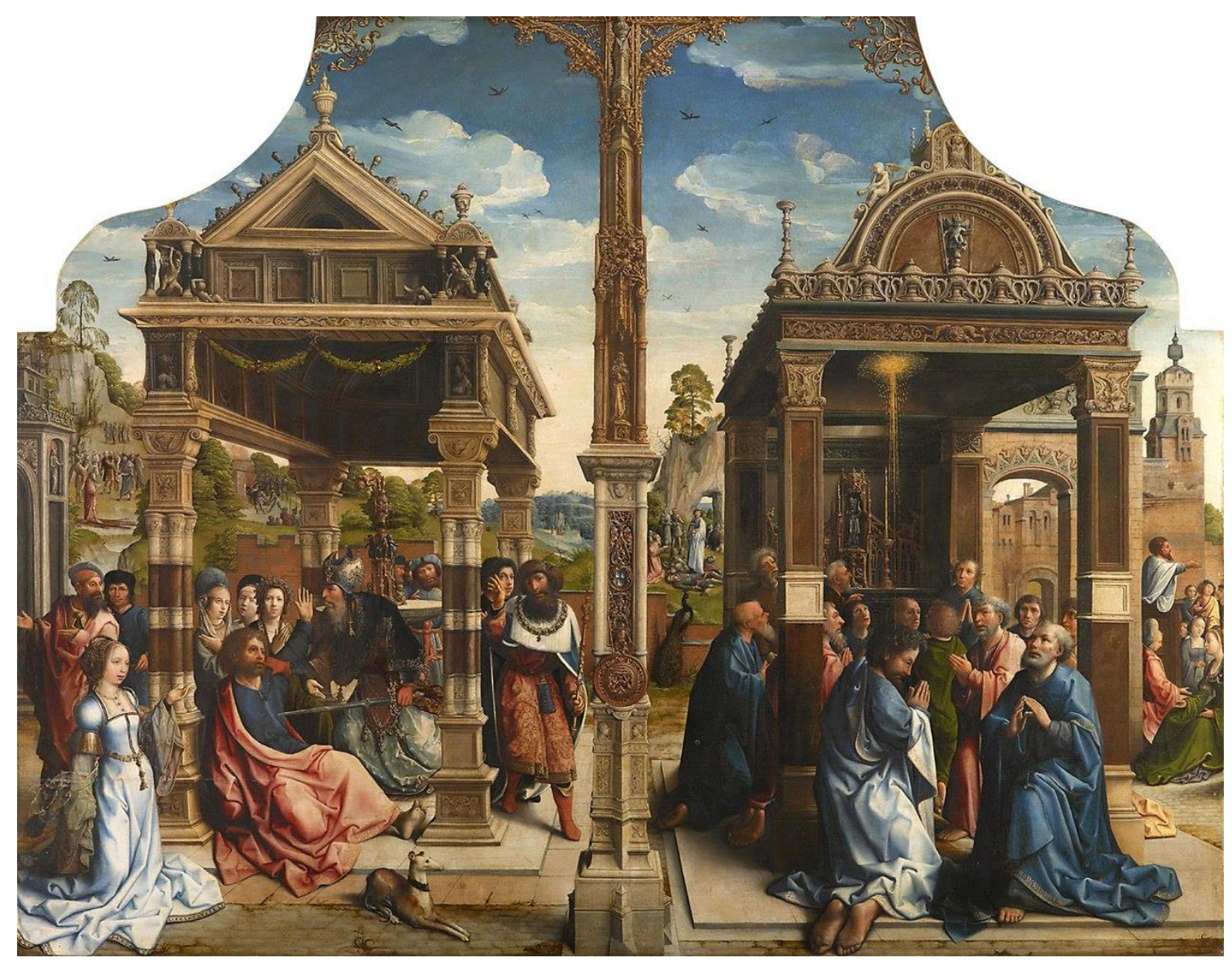

Abb. 15: Bernard van Orley - Thomas- und Matthiastafel (um 1510) Öl auf Holz, Kunsthistorisches Museum, Wien

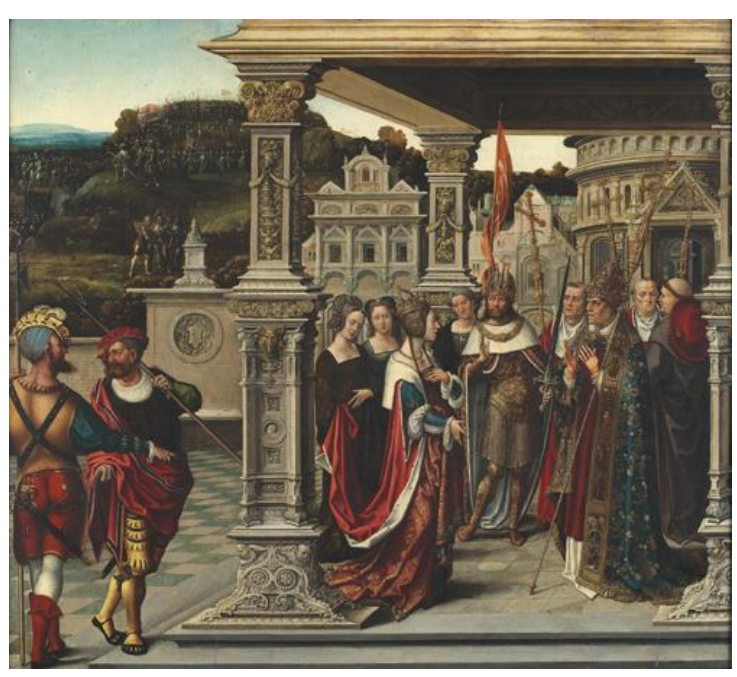

Abb. 16: Bernard van Orley - Die Hl. Helena vor dem Papst Öl auf Holz, KMSKB, Brüssel

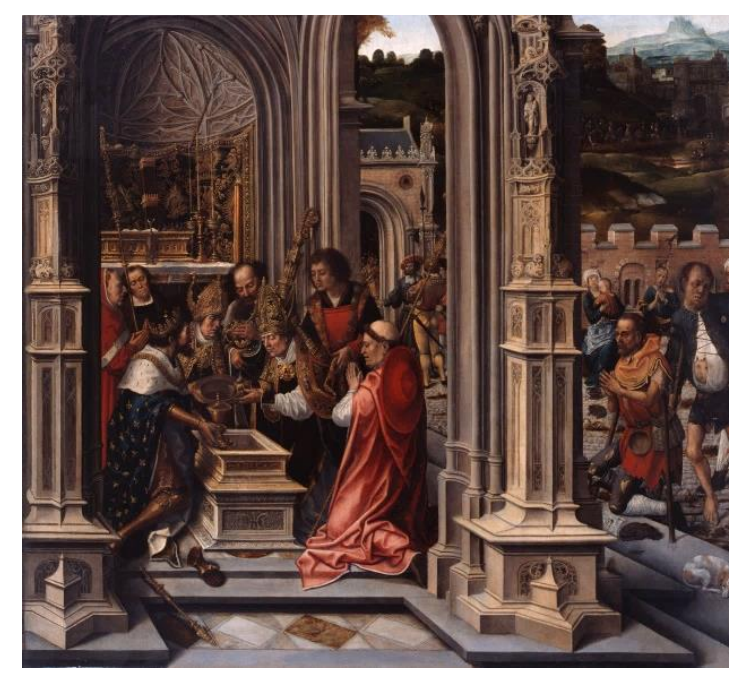

Abb. 17: Bernard van Orley - Karl der Große birgt die Passionsreliquien in Aachen, Öl auf Holz, Galleria Sabauda, Turin 


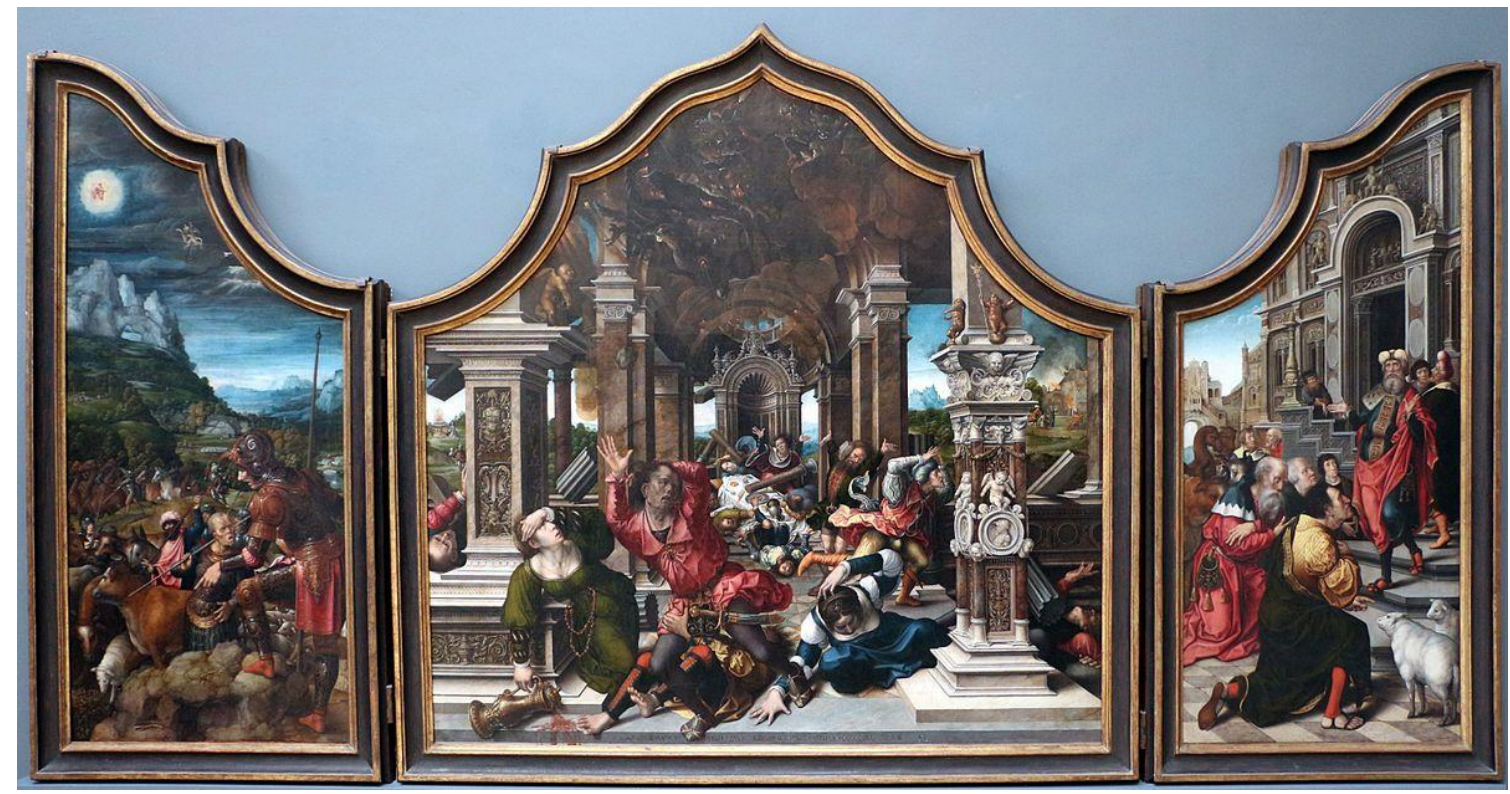

Abb. 18: Bernard van Orley - Hiob-Retabel

Öl auf Holz, Koninklijke Musea voor Schone Kunsten, Brüssel

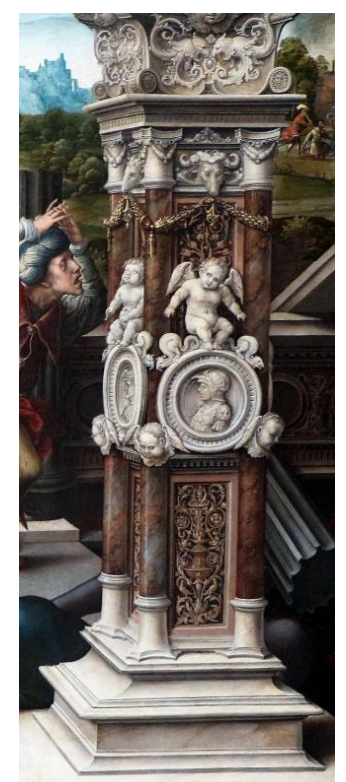

Abb. 18 (Detail)

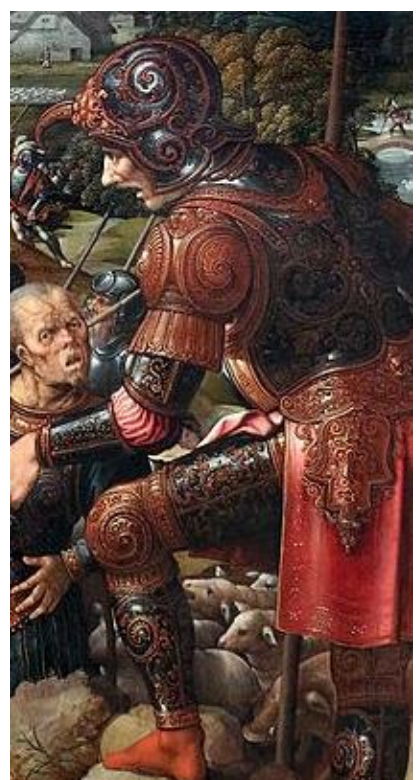

Abb. 18 (Detail) 


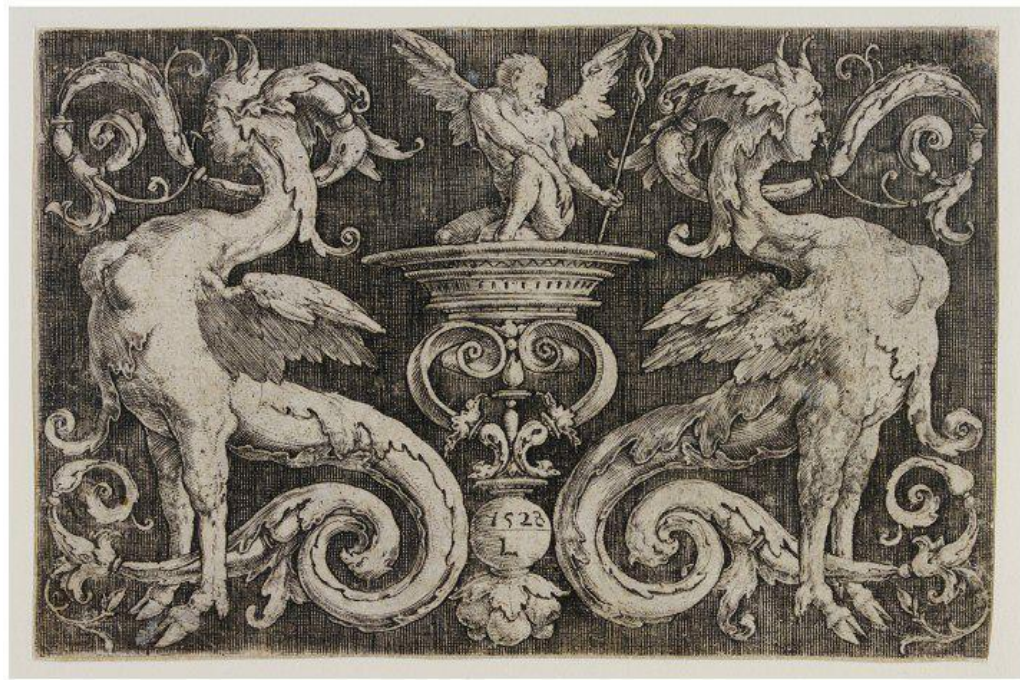

Abb. 19: Lucas van Leycen - Groteske mit zwei Chimären (1528) Kupferstich, Victoria and Albert Museum

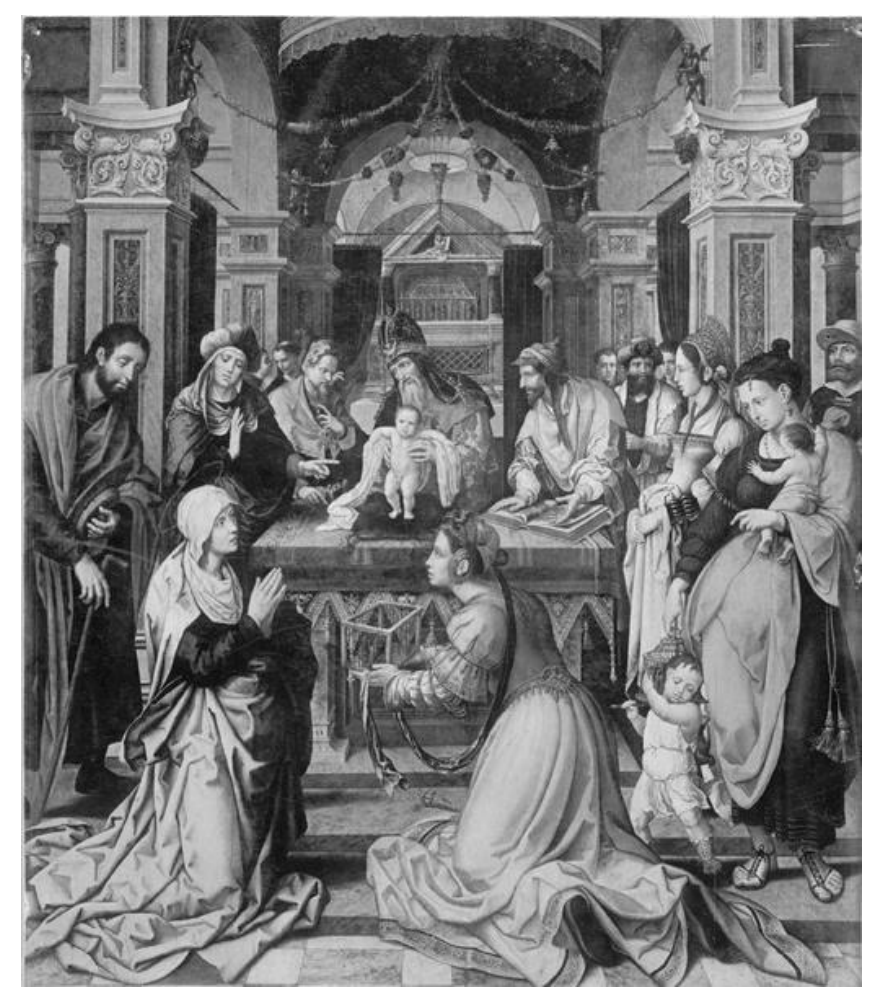

Abb. 20: Bernard van Orley - Darstellung Christi im Tempel Verbleib unbekannt 


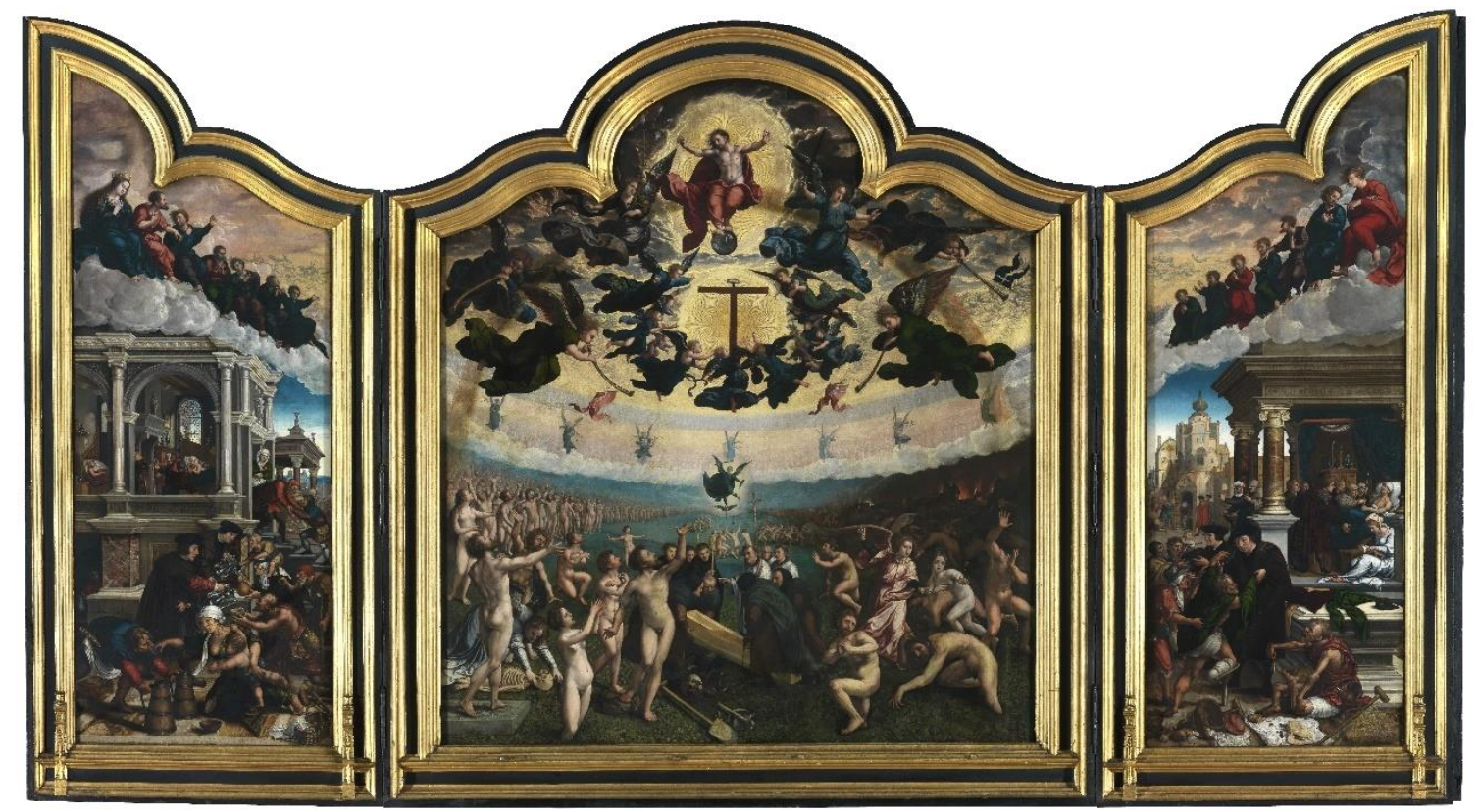

Abb. 21: Bernard van Orley - Triptychon mit dem Jüngsten Gericht (um 1525)

Öl auf Holz, Koninklijk Museum voor Schone Kunsten, Antwerpen

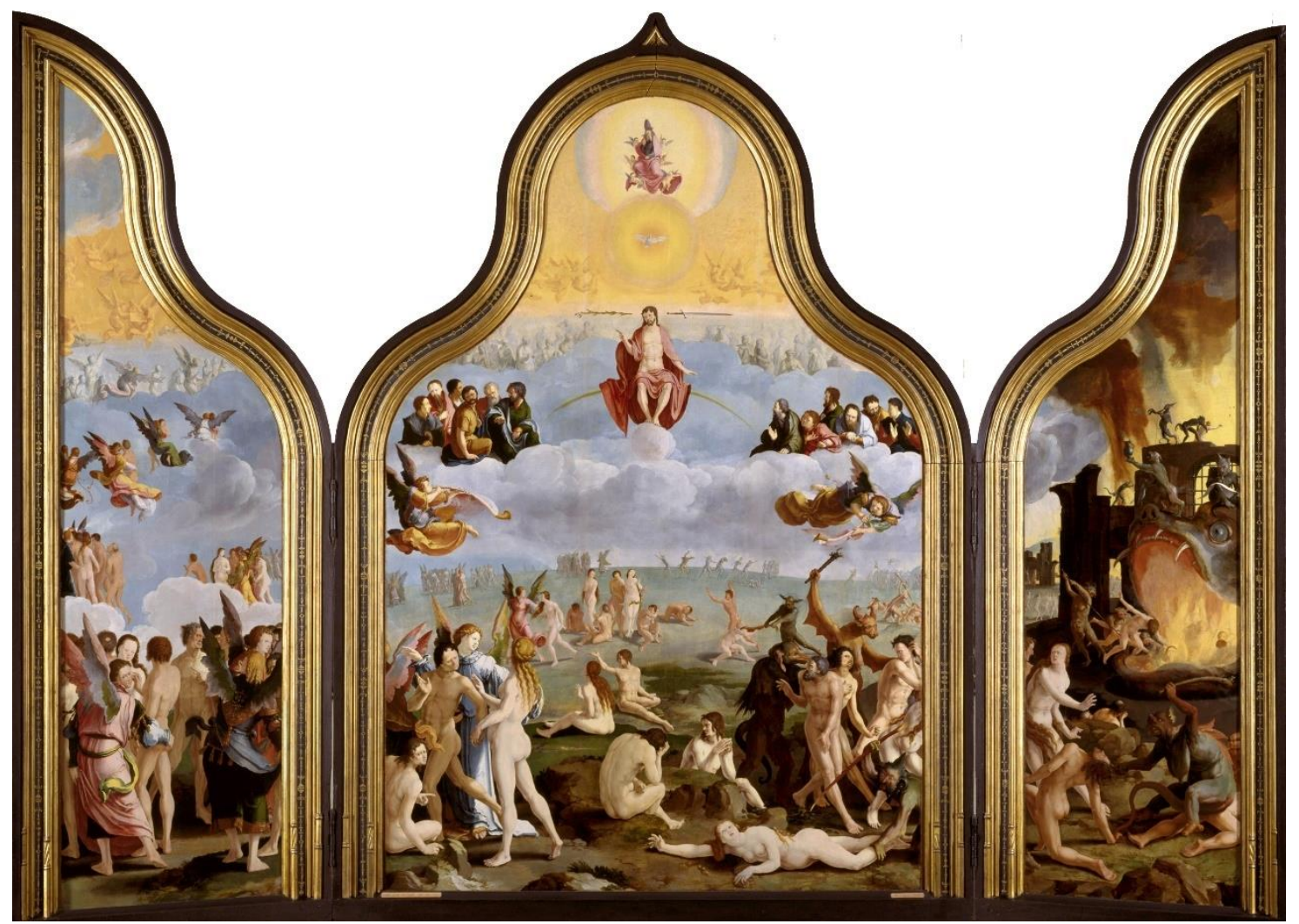

Abb. 22: Lucas van Leyden - Jüngstes Gericht

Öl auf Holz, Museum De Lakenhal, Leiden 


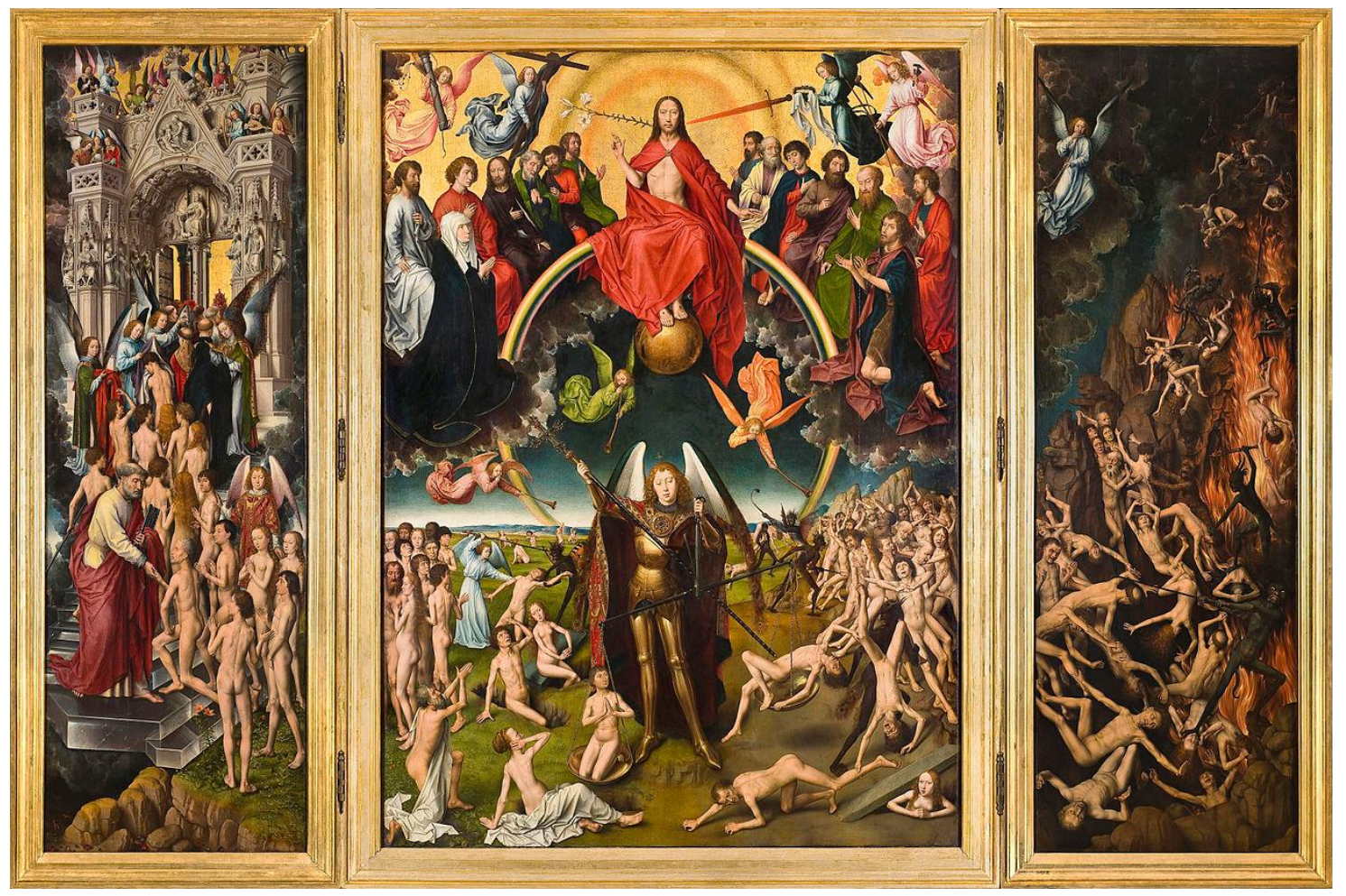

Abb. 23: Hans Memling - Triptychon mit Jüngstem Gericht Öl auf Holz, Muzeum Narodowe, Danzig

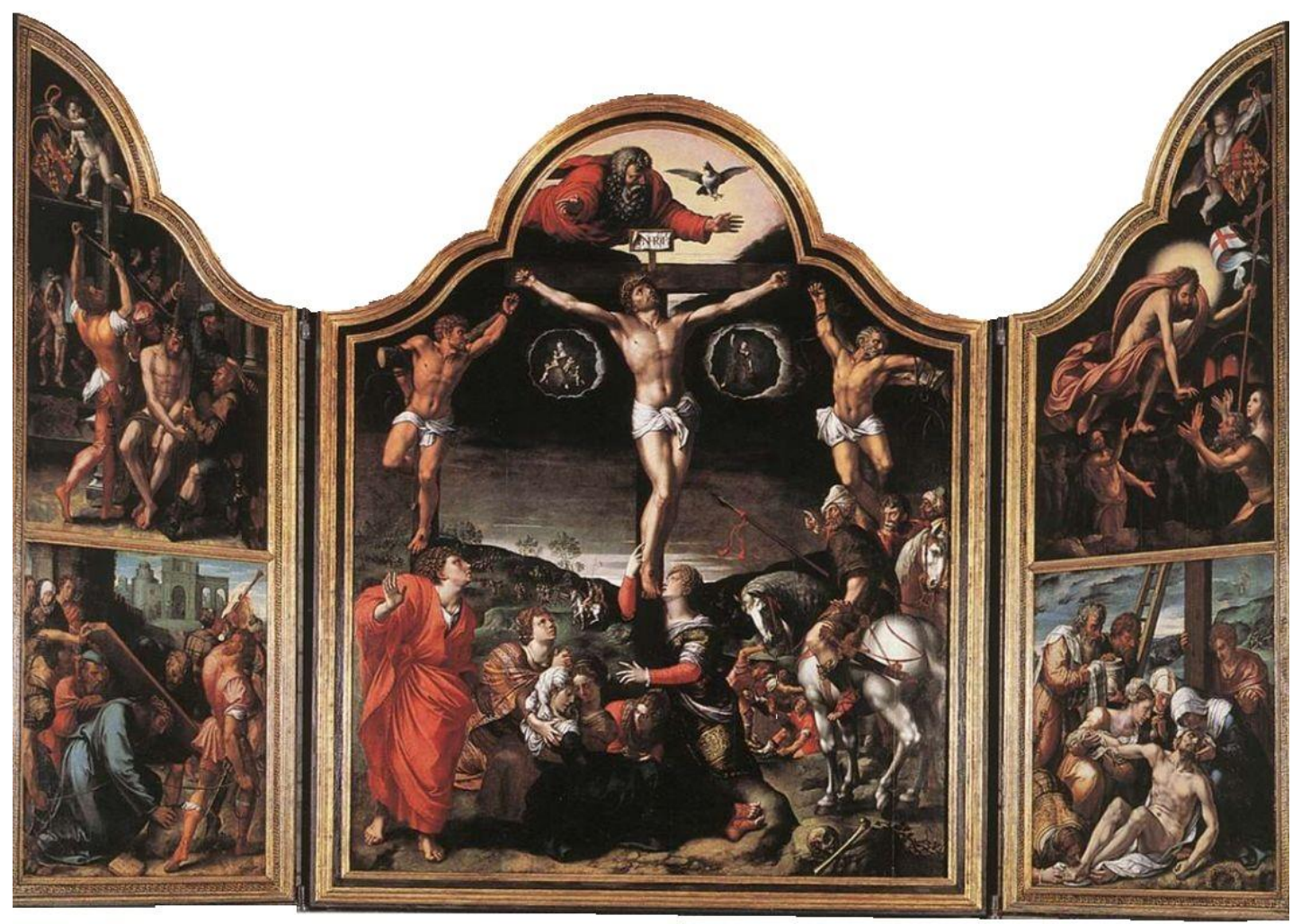

Abb. 24: Bernard van Orley - Passionstriptychon (1534) Onze-Lieve-Vrouwekerk, Brügge 


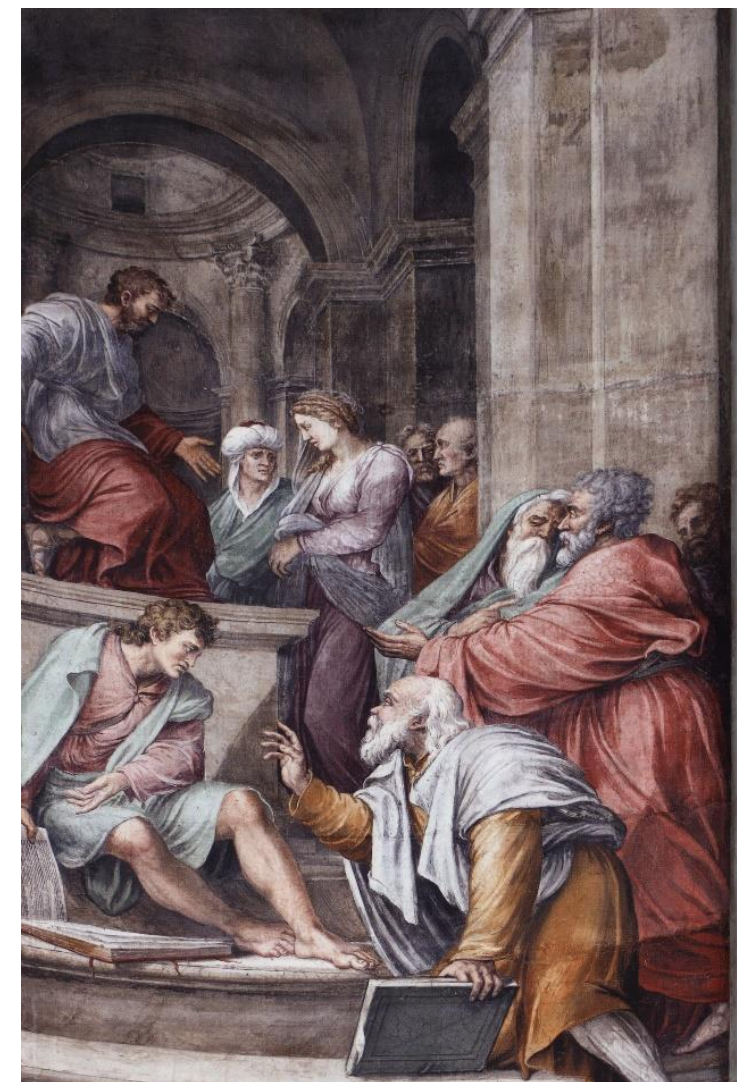

Abb. 25: Michiel Coxcie - Hl. Barbara vor den Richtern (1530er), Barbarakapelle, Santa Maria dell'Anima, Rom

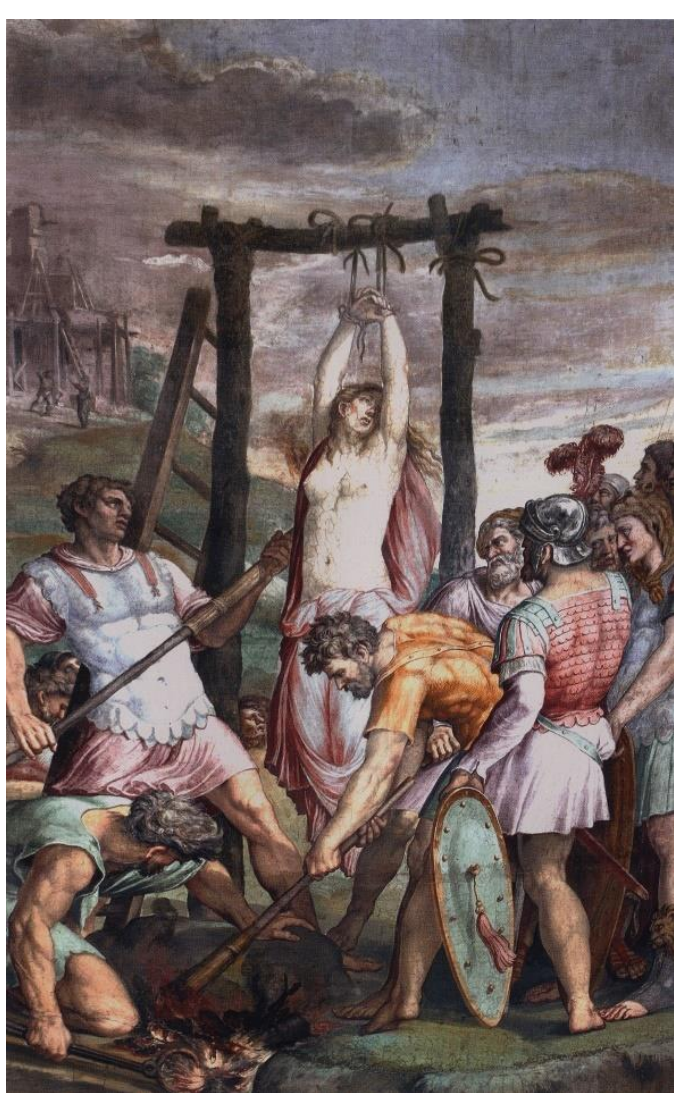

Abb. 26: Michiel Coxcie - Martyrium der Hl. Barbara (1530er), Barbarakapelle, Santa Maria dell'Anima, Rom

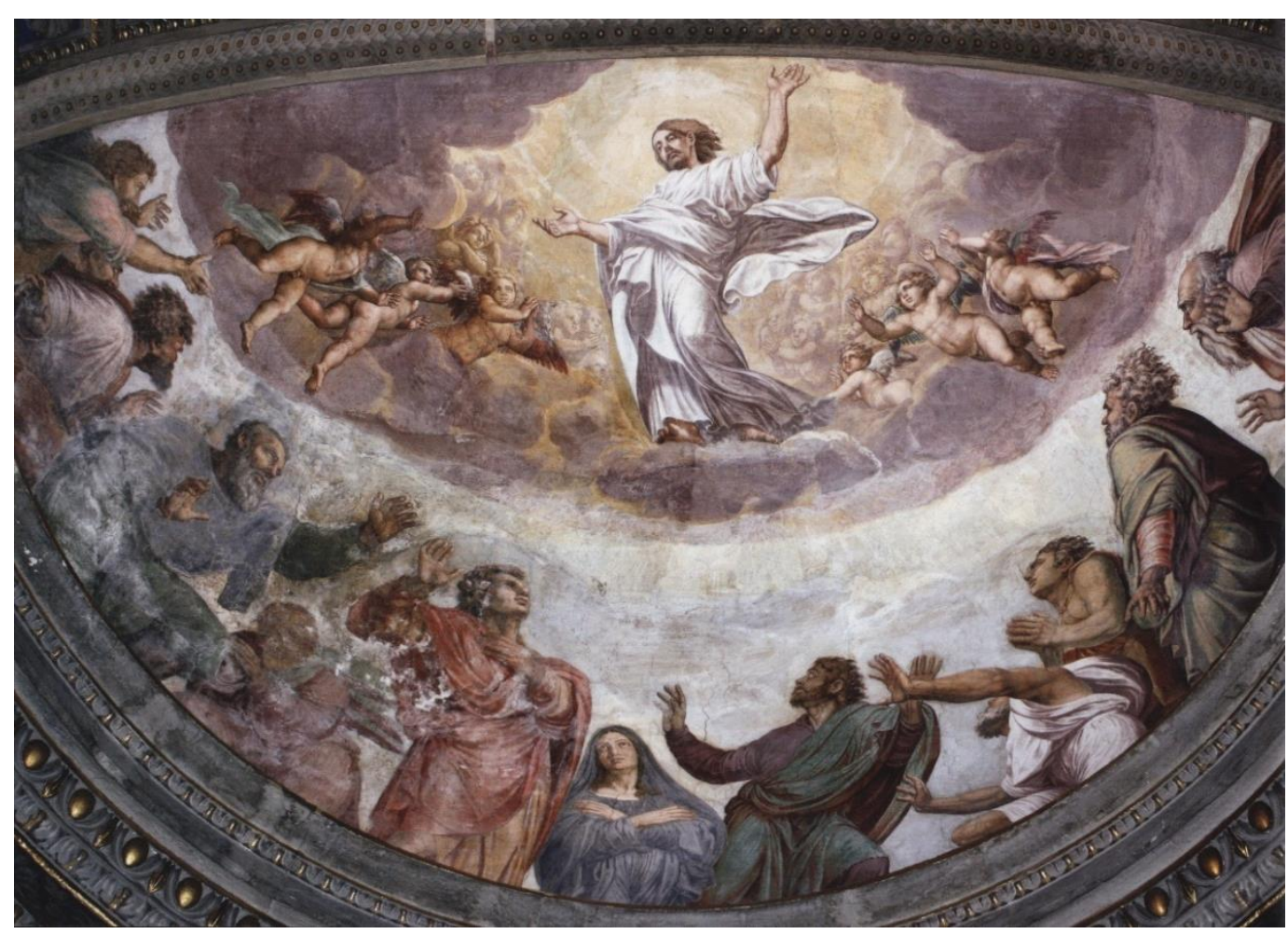

Abb. 27: Michiel Coxcie - Himmelfahrt Christi (frühe 1530er Jahre)

Barbarakapelle, Santa Maria dell'Anima, Rom 


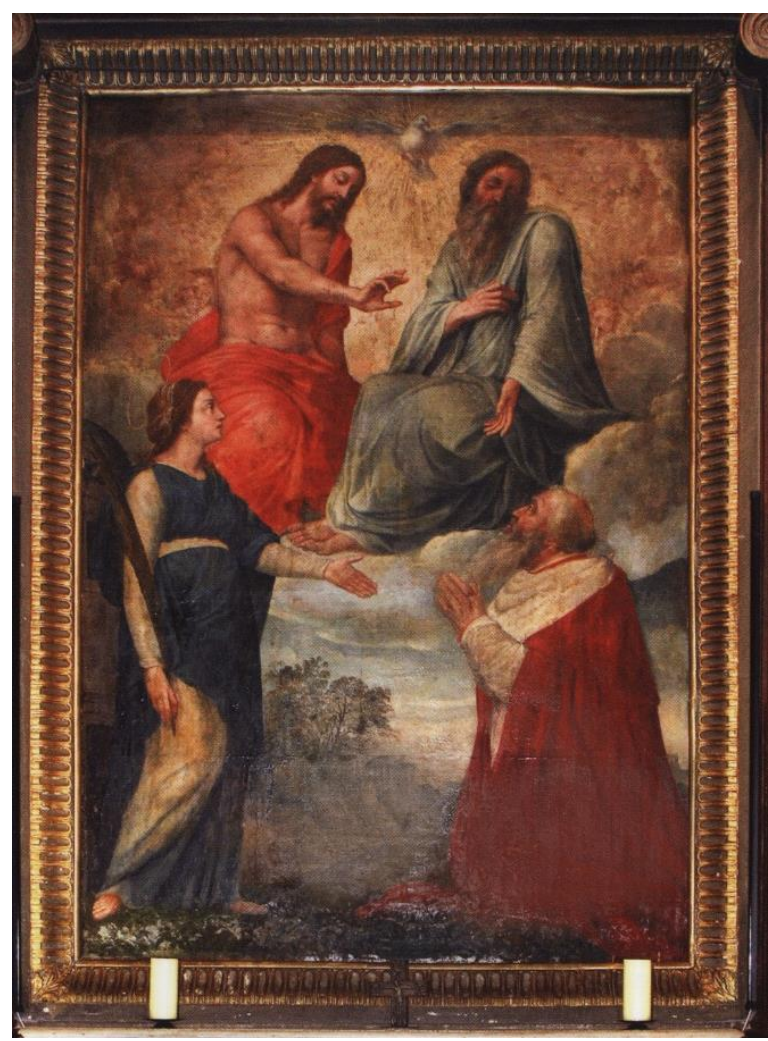

Abb. 28: Michiel Coxcie - Die Hl. Barbara empfiehlt Kardinal Enckenvoirt der Hl. Dreifaltigkeit (1530er)

Öl auf Holz, Santa Maria dell'Anima, Rom

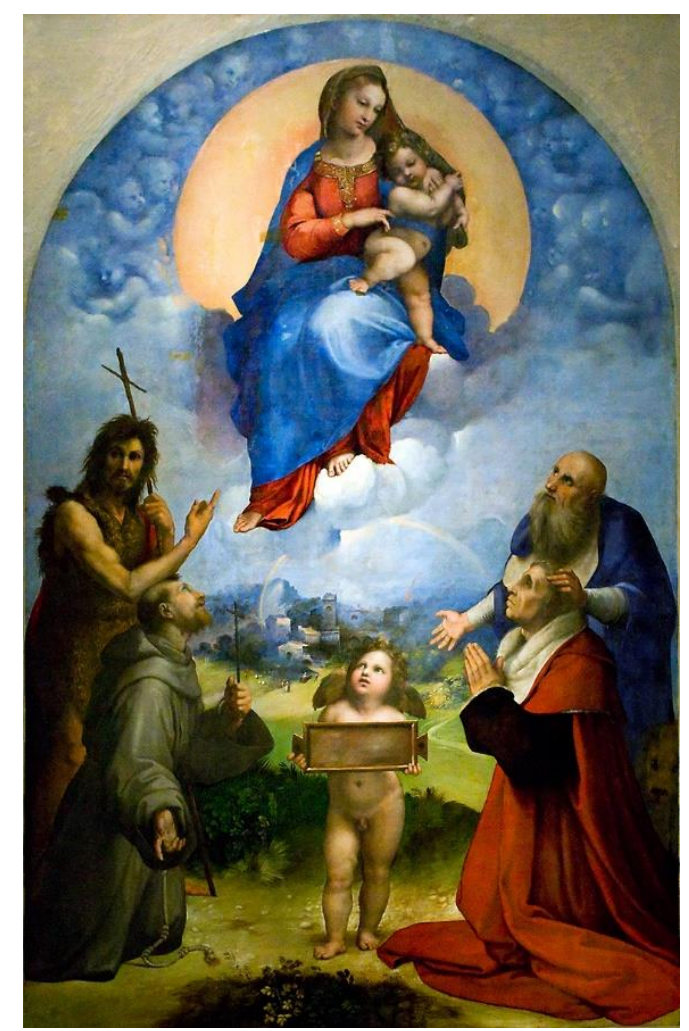

Abb. 30: Raffael - Madonna di Foligno

Tempera auf Holz, Pinacoteca Vaticana, Rom

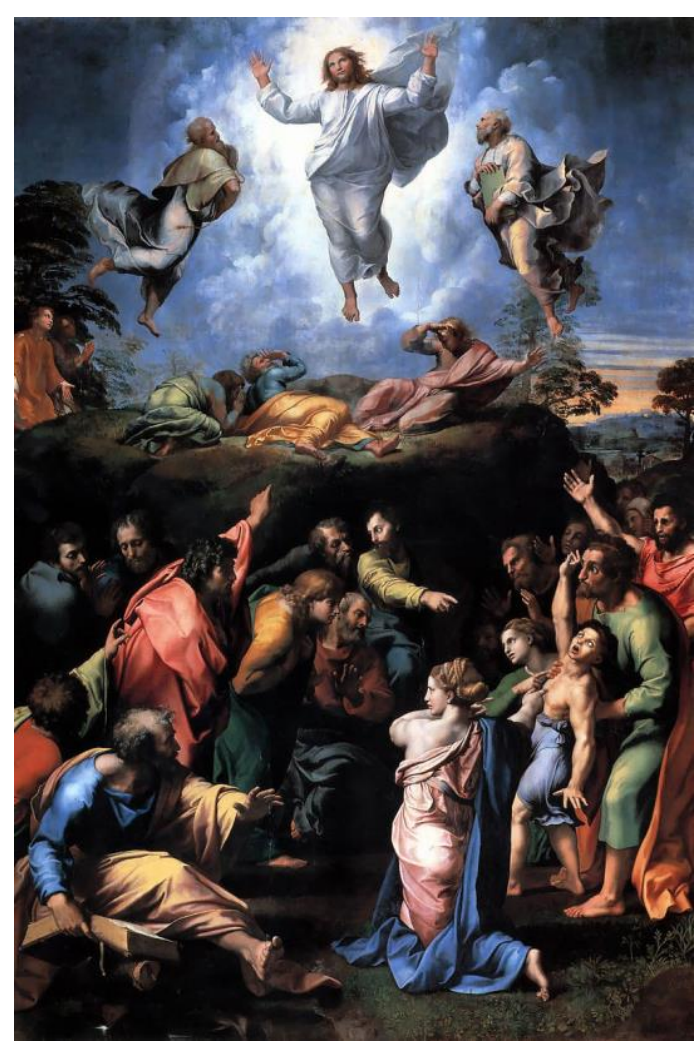

Abb. 29: Raffael - Transfiguration Christi

Öltempera auf Holz, Vatikanische Museen 


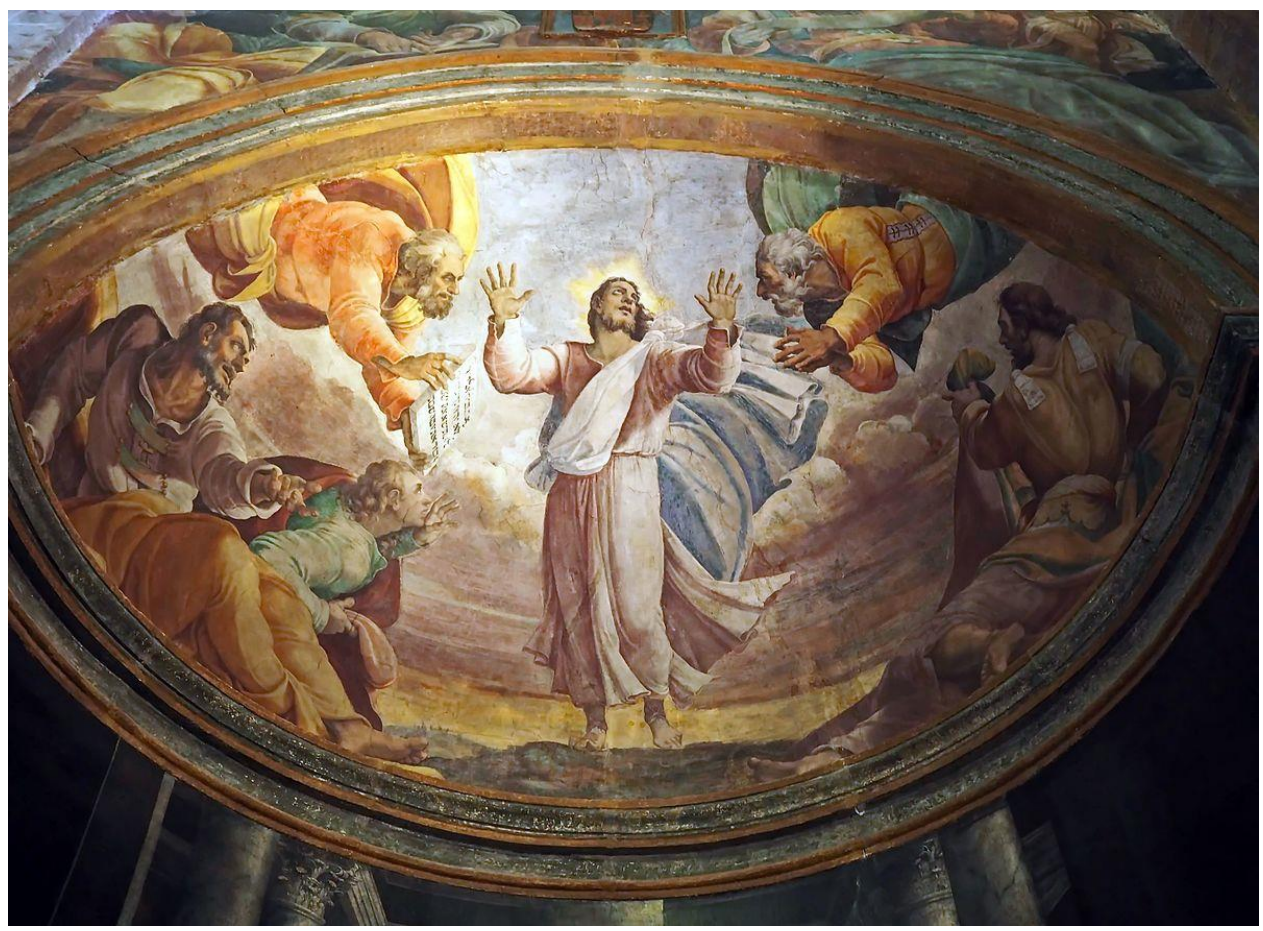

Abb. 31: Sebastiano del Piombo - Verklärung Christ

Apsiskalotte der Cappella Borgherini, San Pietro in Montorio, Rom

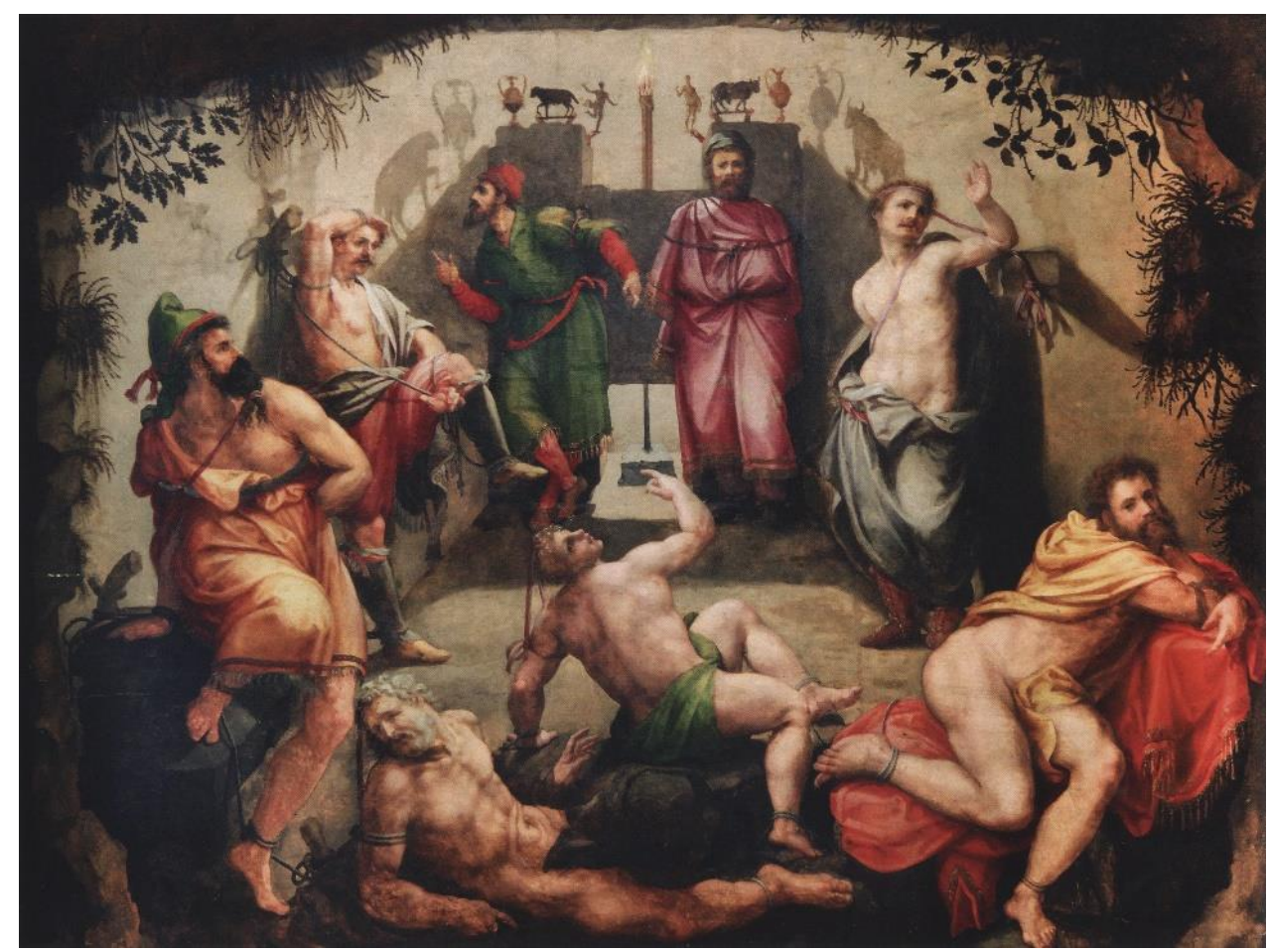

Abb. 32: Michiel Coxcie - Platons Höhlengleichnis

Musée de la Chartreuse, Douai 


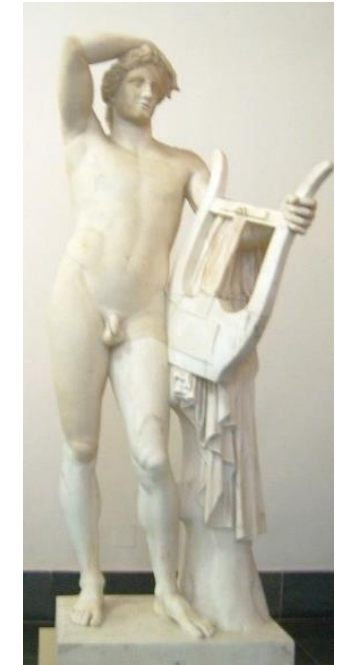

Abb. 33: Apoll Kitharoidos

Pergamonmuseum, Berlin

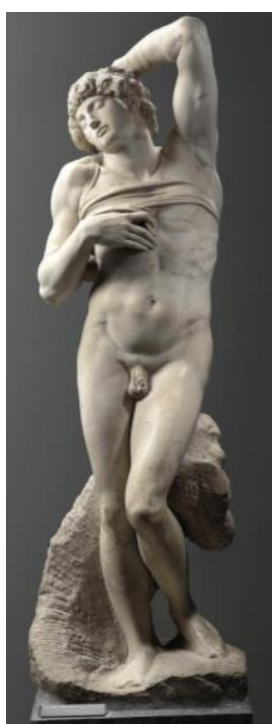

Abb. 35: Michelangelo: Sterbender Sklave Musée de Louvre, Paris

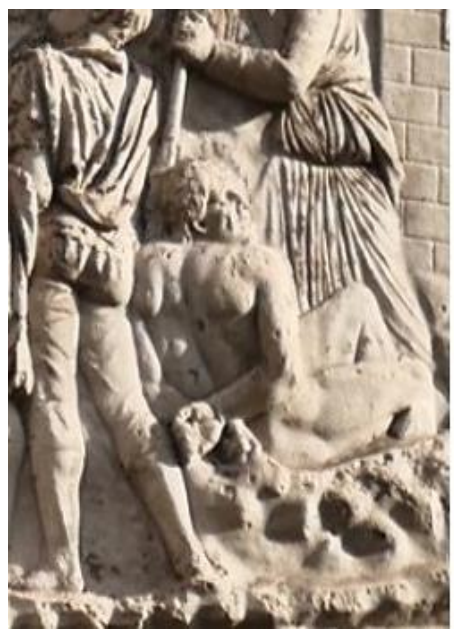

Abb. 37: Gefangener (Relief), Trajanssäule, Rom

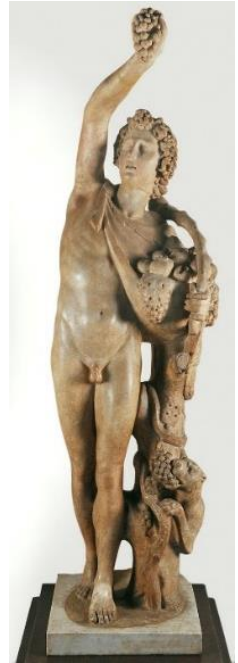

Abb. 34: Satyr mit dem Fruchtbouquet Galleria degli Uffizi, Florenz

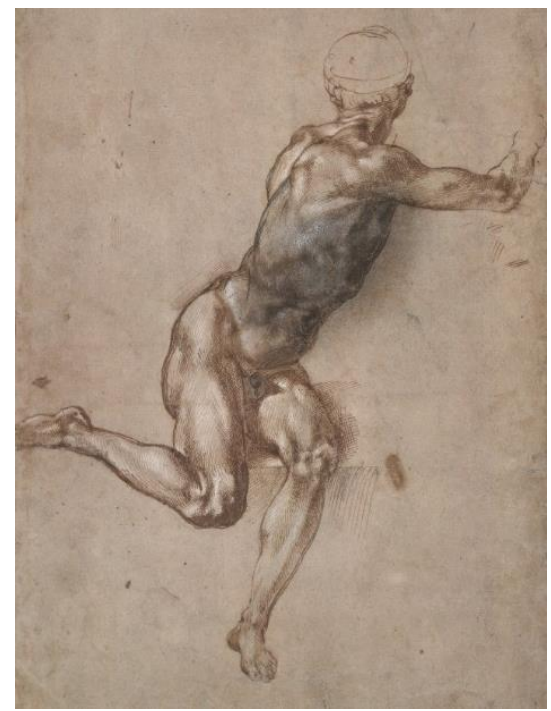

Abb. 36: Michelangelo - Studie eines Soldaten für die Schlacht von Cascina British Museum, London 


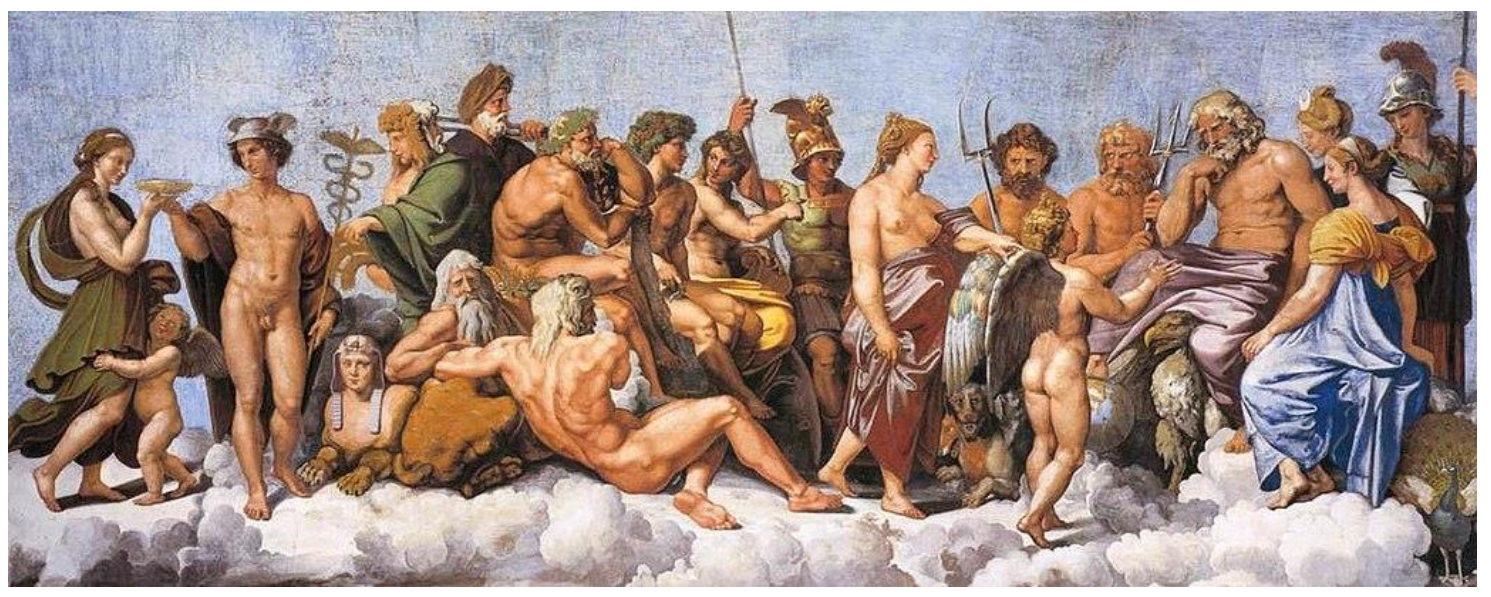

Abb. 38: Raffael - Versammlung der Götter

Deckenfresko der Villa Farnesina, Rom

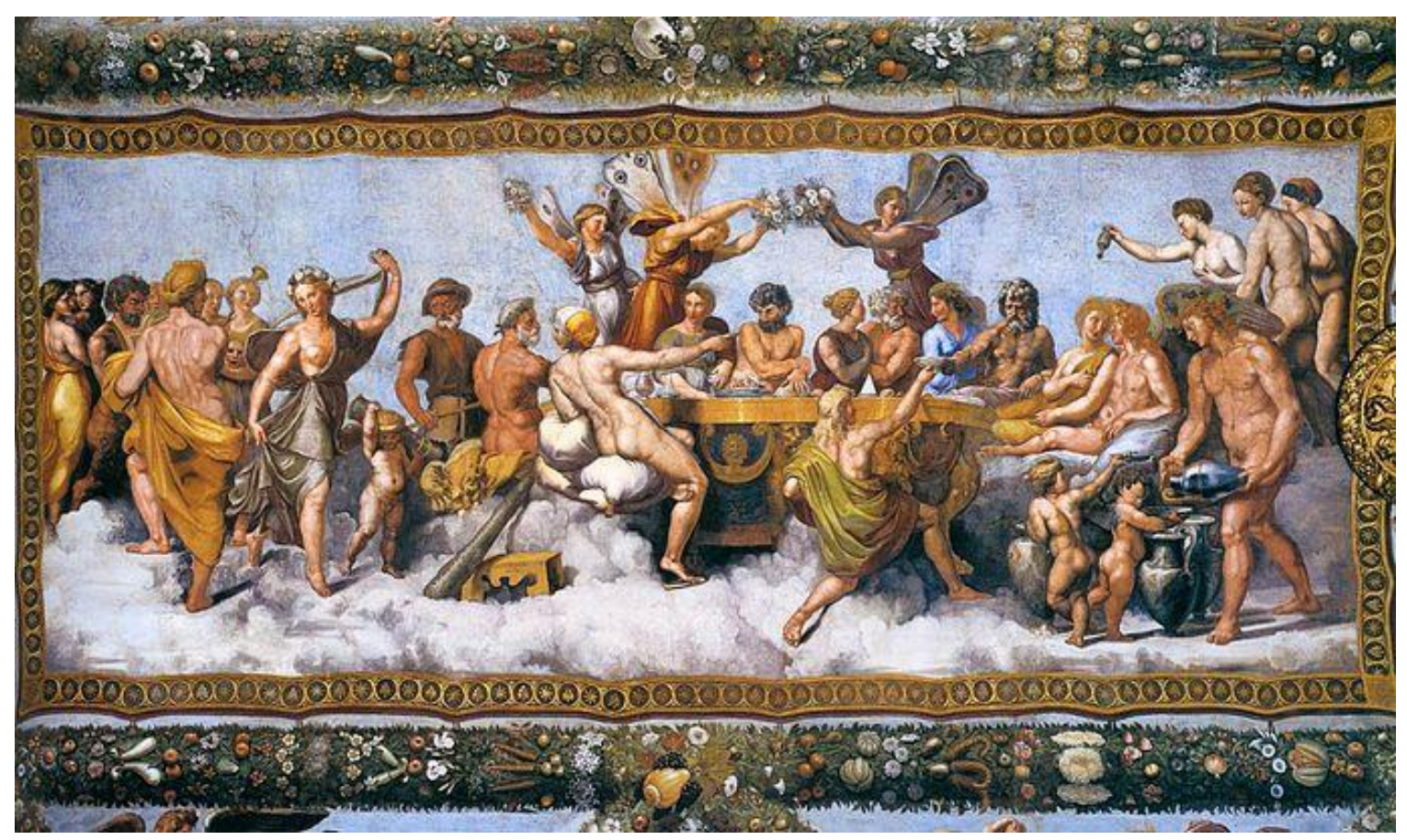

Abb. 39: Raffael - Hochzeitsmahl

Deckenfresko der Villa Farnesina, Rom 


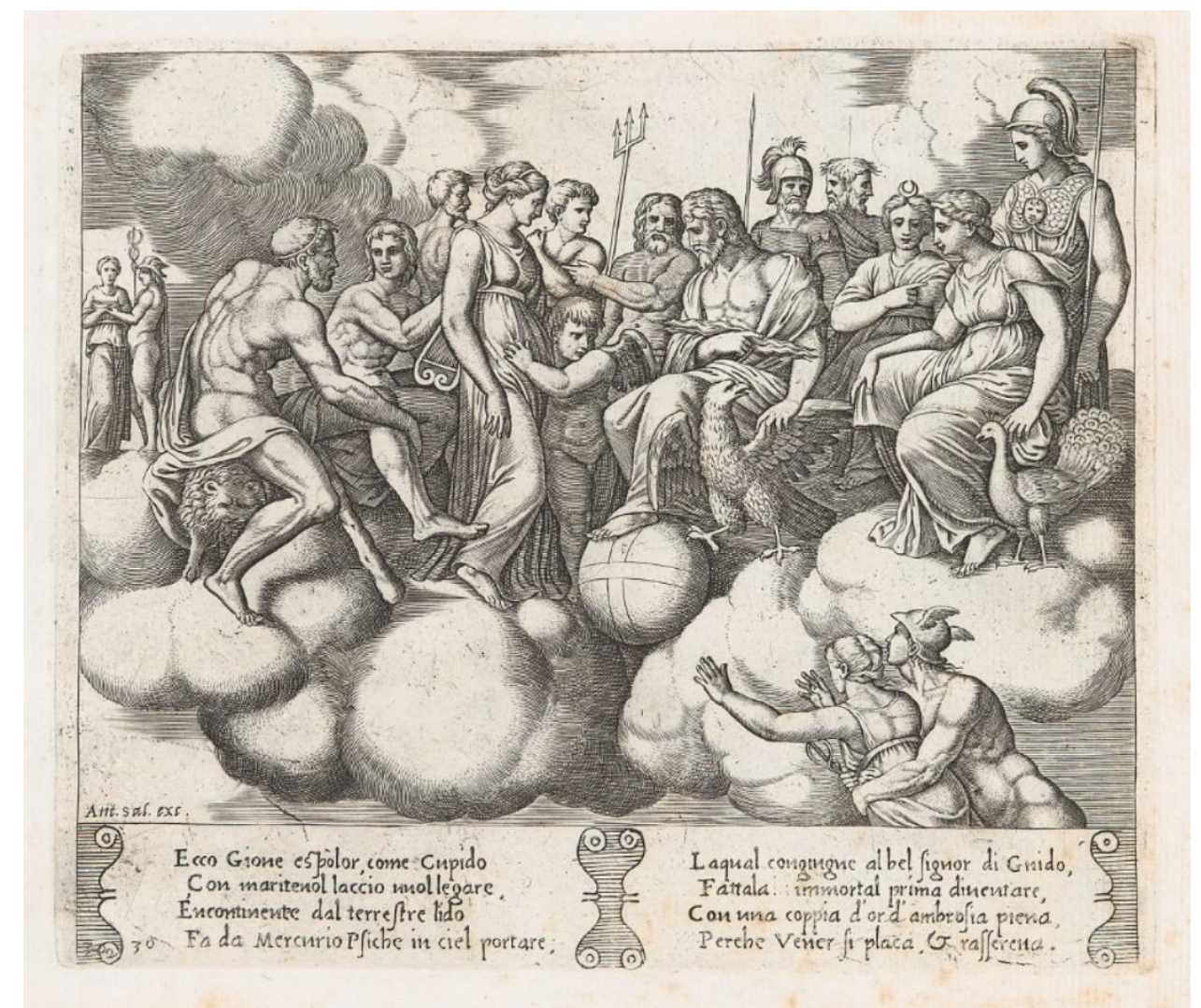

Abb. 40: Michiel Coxcie - Cupido und Psyche vor den Göttern (Blatt 30), Metropolitan Museum of Art, New York

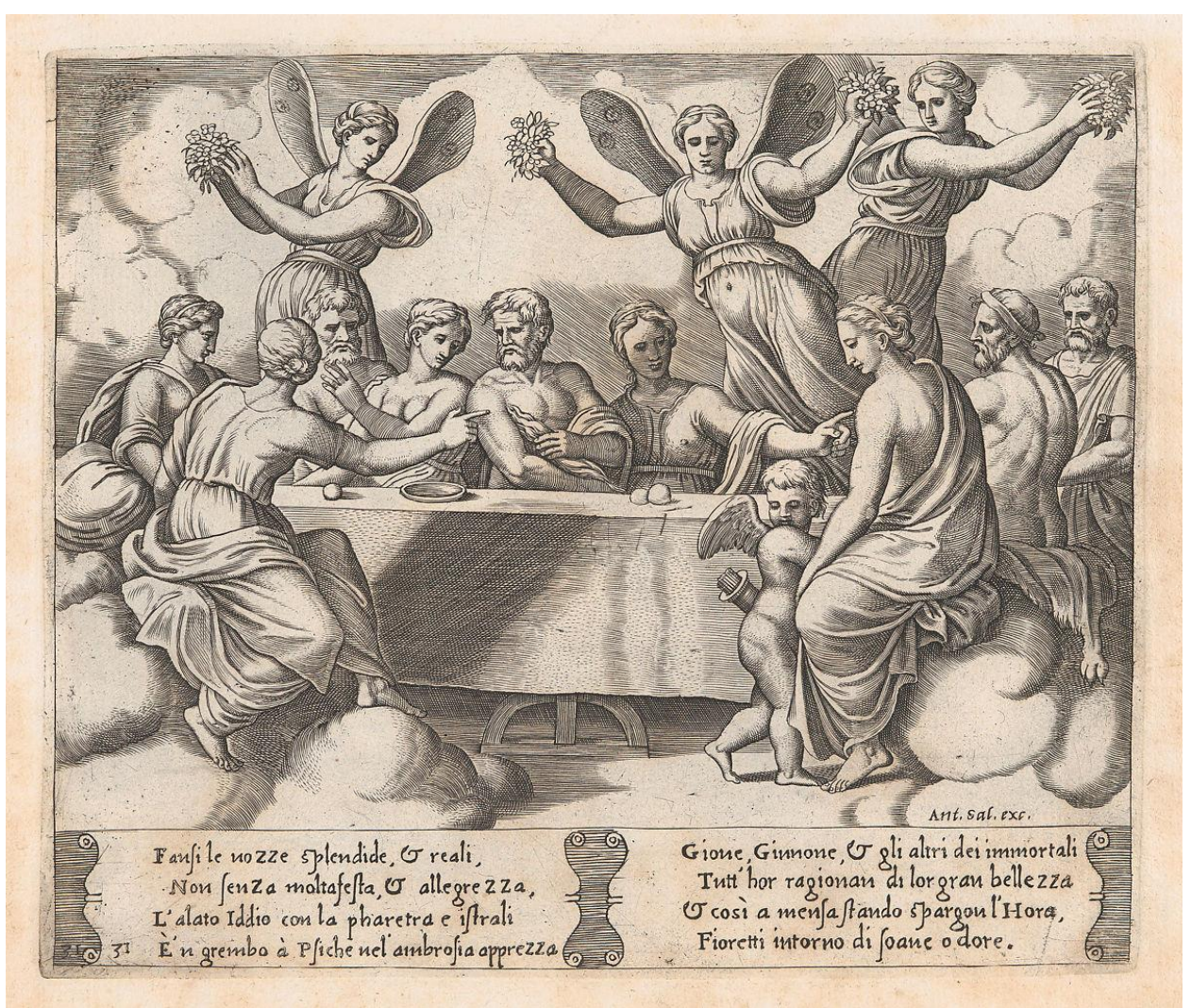

Abb. 41: Michiel Coxcie - Cupido und Psyche vor den Göttern (Blatt 31), Metropolitan Museum of Art, New York 


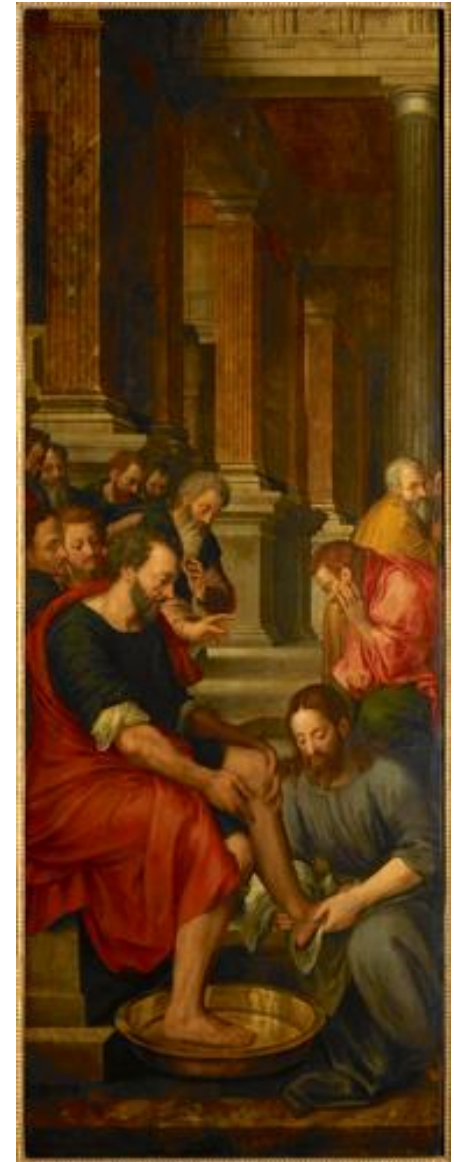

Abb. 42: Michiel Coxcie - Letztes Abendmahl (linker Flügel, innen), KMSKB, Brüssel

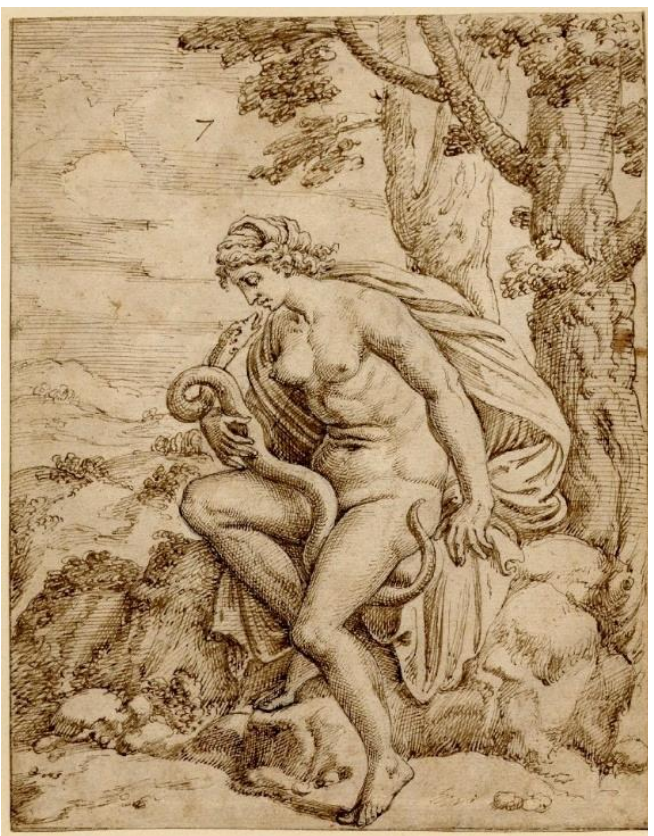

Abb. 44: Michiel Coxcie - Proserpina und Jupiter in Schlangengestalt, Die Liebschaften Jupiters (7),

Zeichnung, British Museum, London

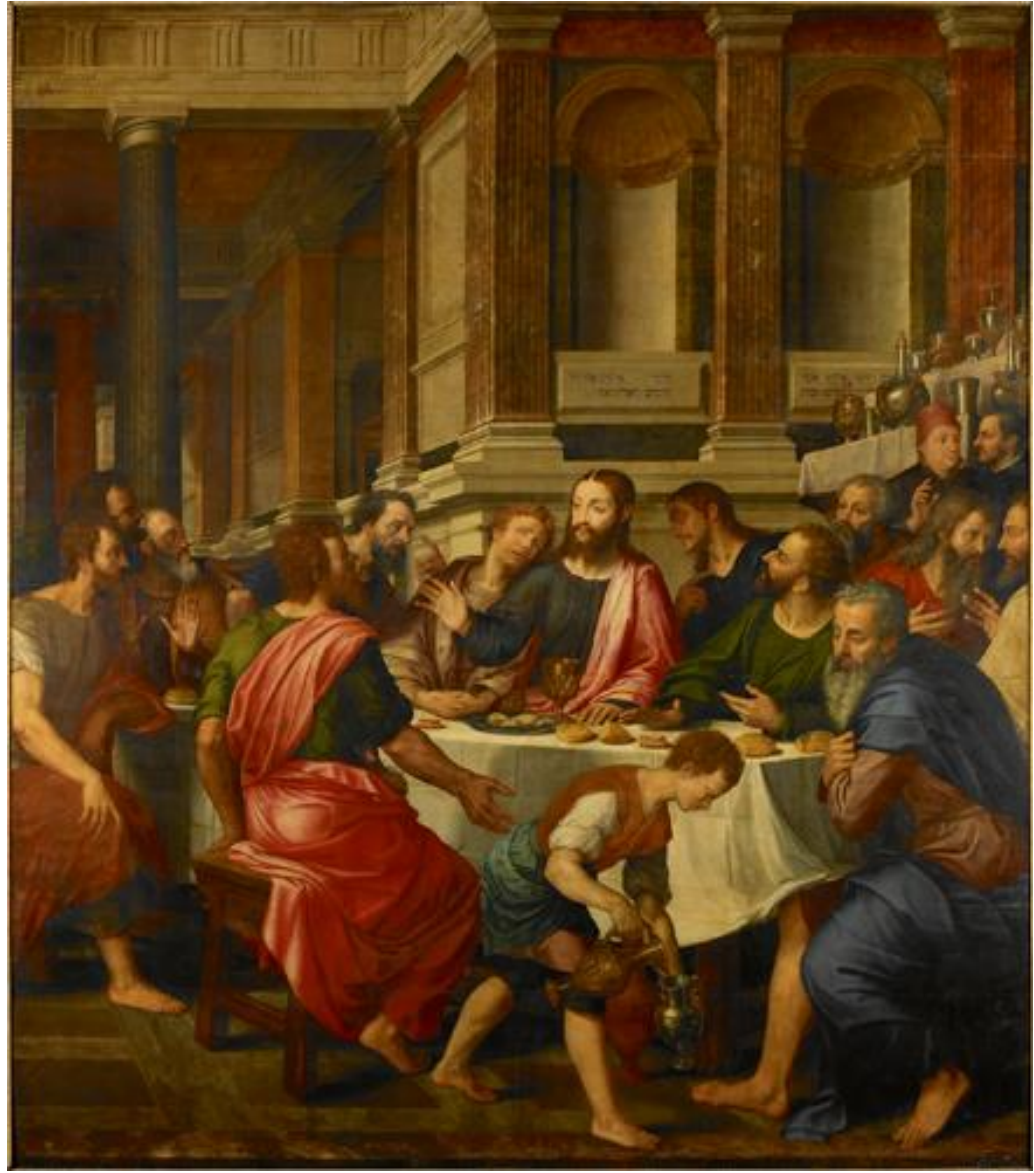

Abb. 43: Michiel Coxcie - Letztes Abendmahl (Mitteltafel) Koninklijke Musea voor Schone Kunsten, Brüssel

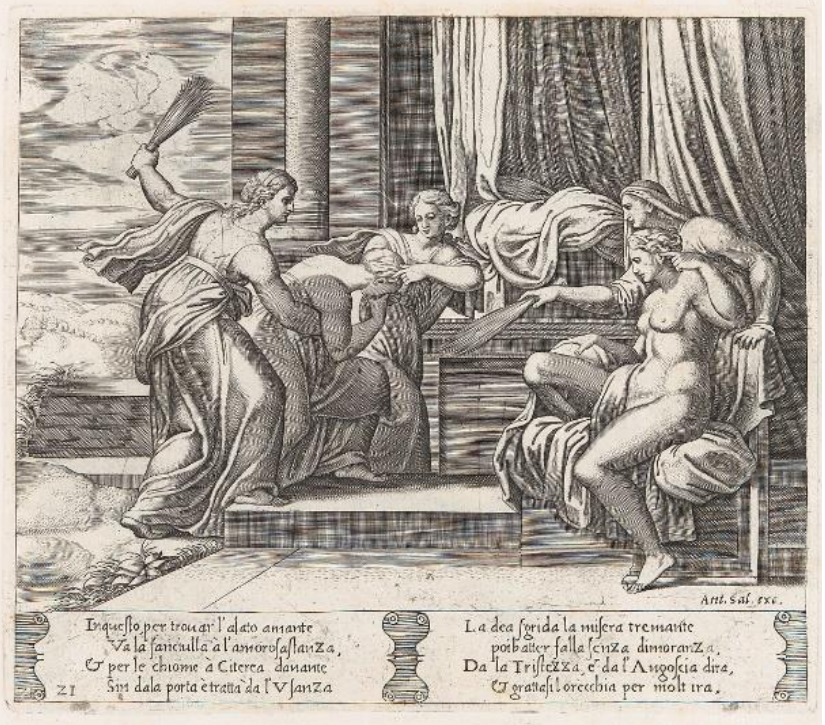

Abb. 45: Michiel Coxcie - Psyche begegnet den Personifikationen von Sorge und Schmerz, Serie: Cupido und Psyche (21), Metropoli$\tan$ Museum of Art, New York 


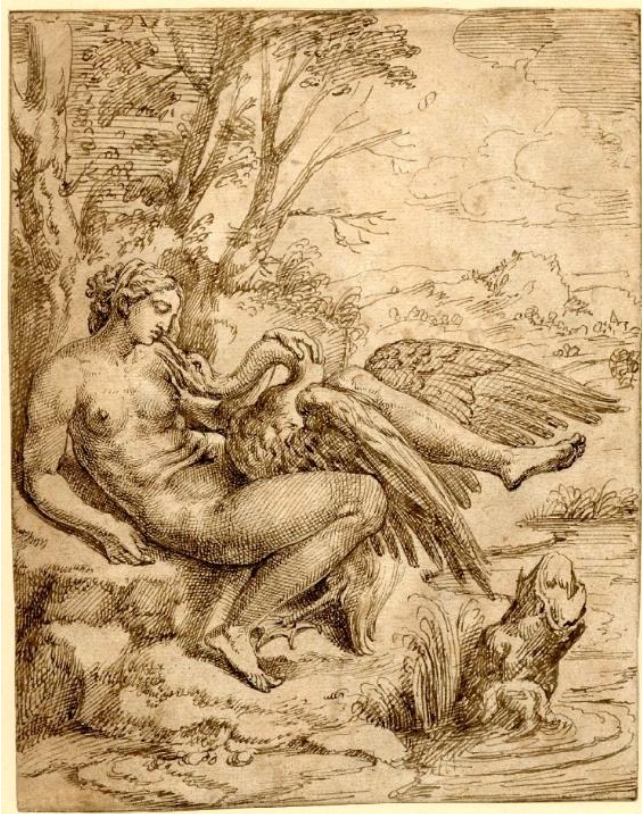

Abb. 46: Michiel Coxcie - Leda und der Schwan, Die Liebschaften Jupiters (8),

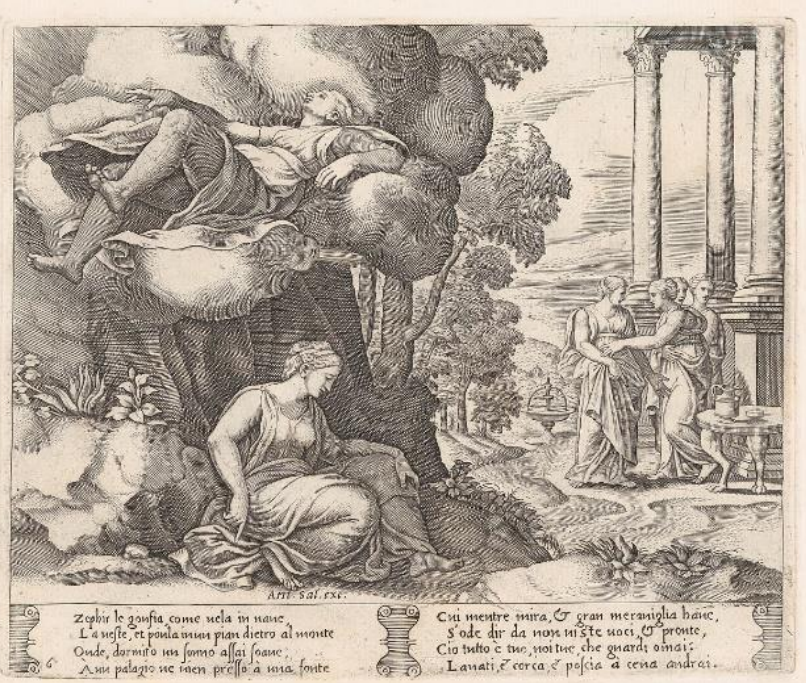

Abb. 47: Michiel Coxcie - Psyche wird von Zephyr fortgetragen, Cupido und Psyche (6), Kupferstich,

Metropolitan Museum of Art, New York

Zeichnung, British Museum, London

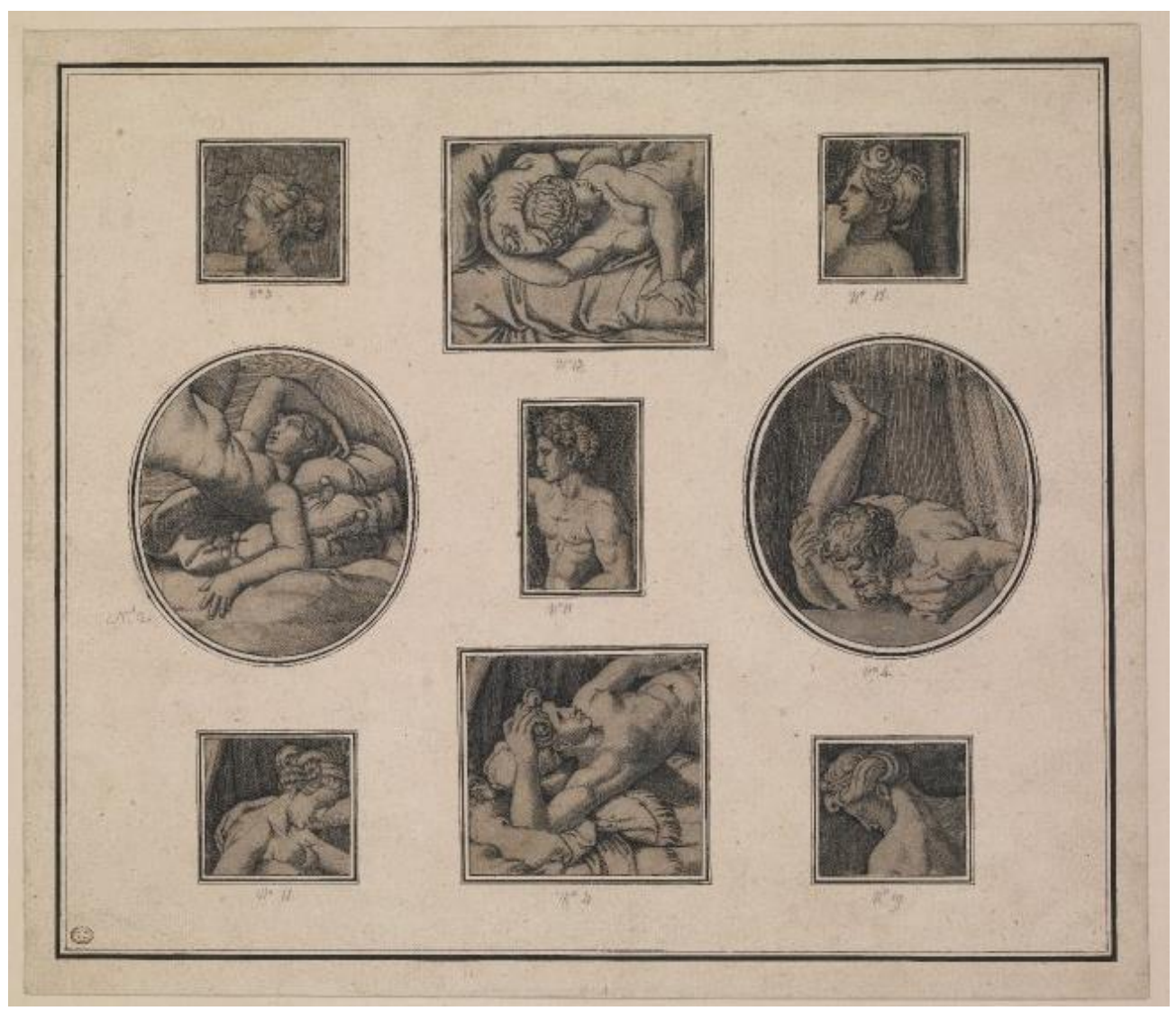

Abb. 48: Giulio Romano - I Modi (Fragmente), British Museum, London 


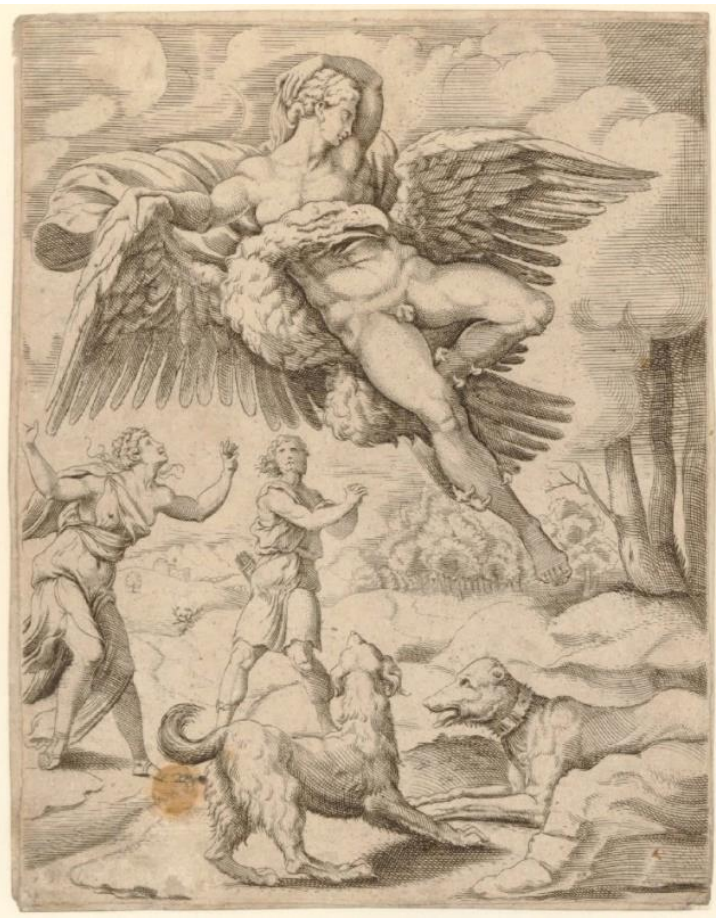

Abb. 49: Michiel Coxcie - Raub des Ganymed Die Liebschaften Jupiters (1)

Zeichnung, British Museum, London

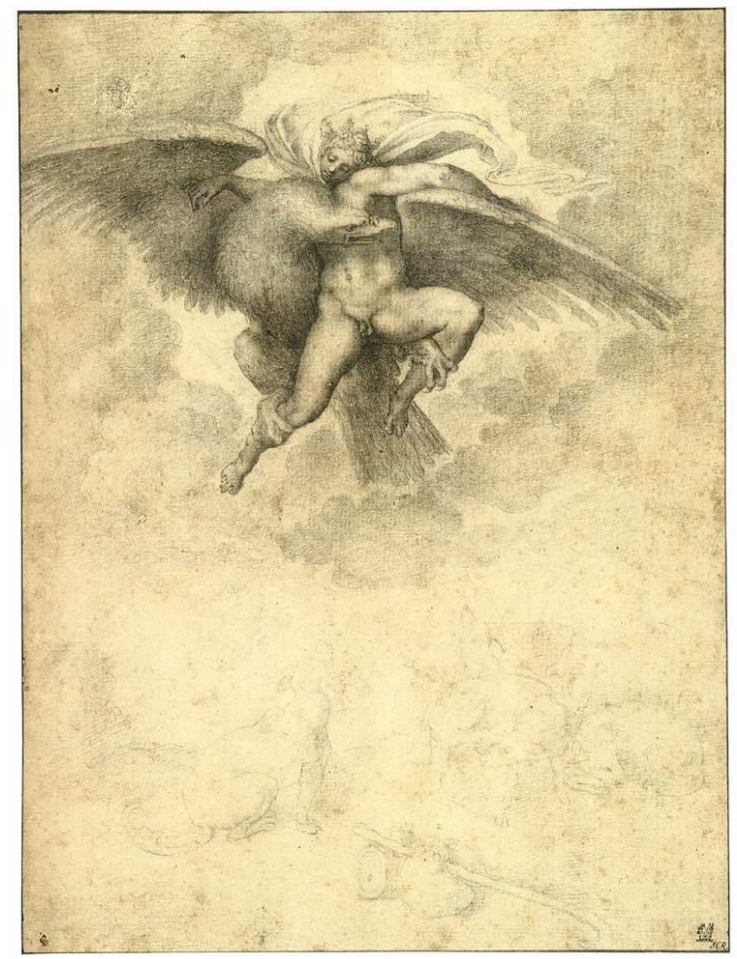

Abb. 50: Michelangelo - Raub des Ganymed Zeichnung, Fogg Art Museum, Cambridge 


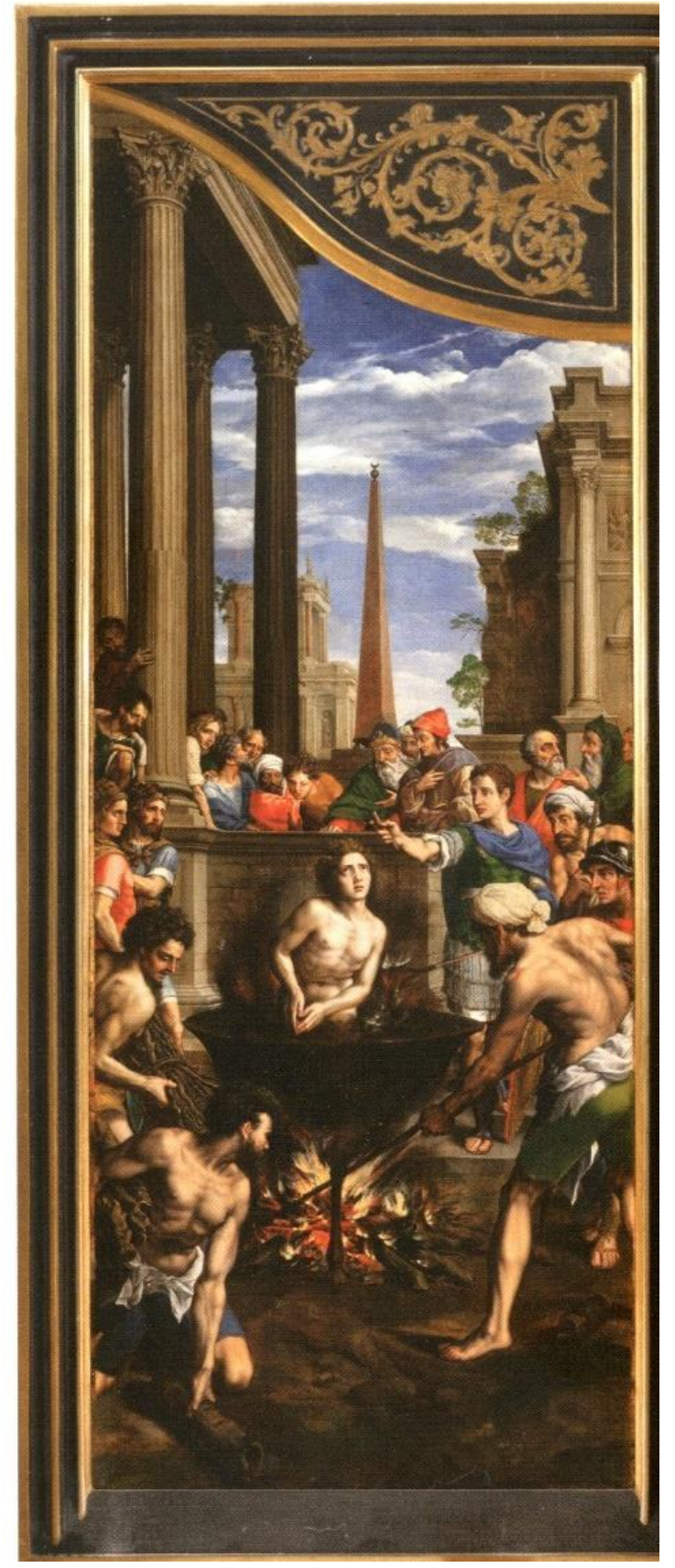

Abn. 51: Michiel Coxcie - Martyrium des Hl. Lukas (Inennseite, Seitenflügel für Gossaerts Lukasaltar) Öl auf Holz, Národni Galerie, Prag

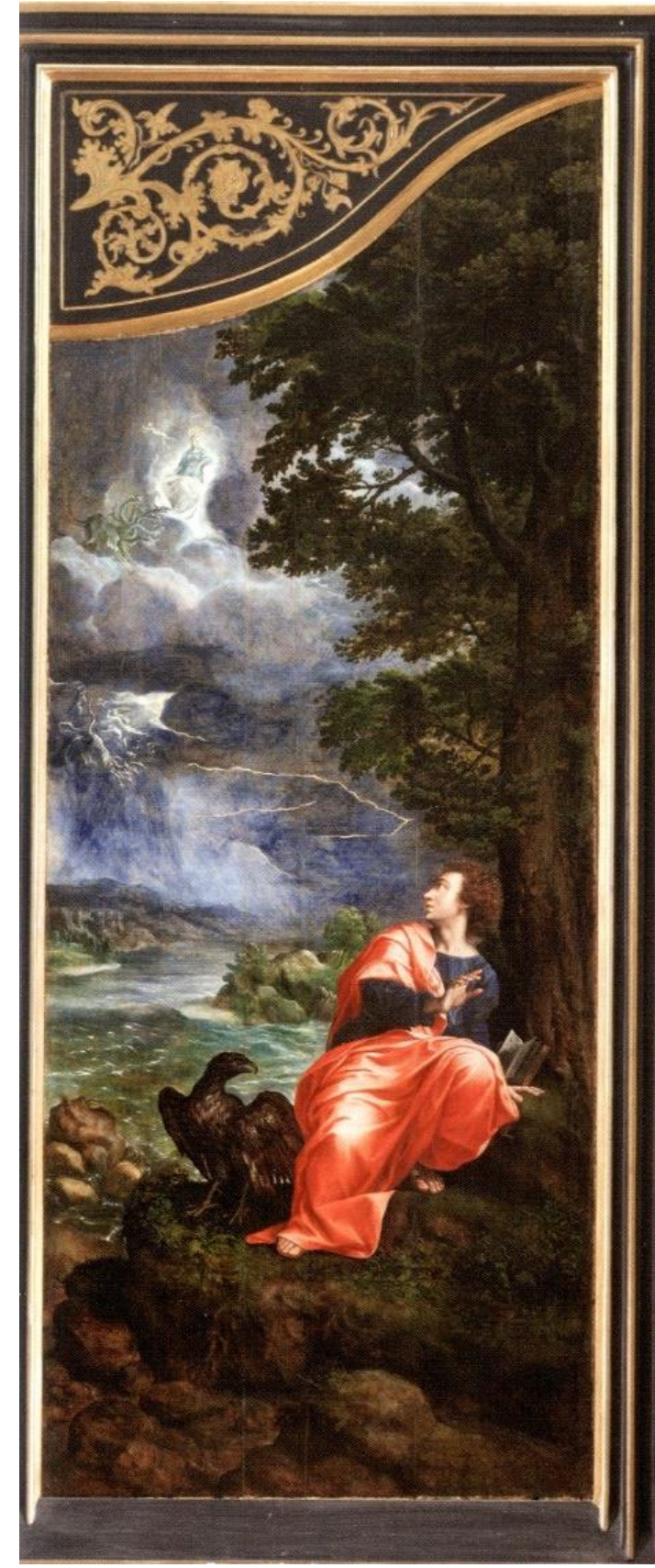

Abb. 52: Michiel Coxcie - Johannes auf Patmos (Innenseite, Seitenflügel für Gossaerts Lukasaltar) Öl auf Holz, Národni Galerie, Prag 


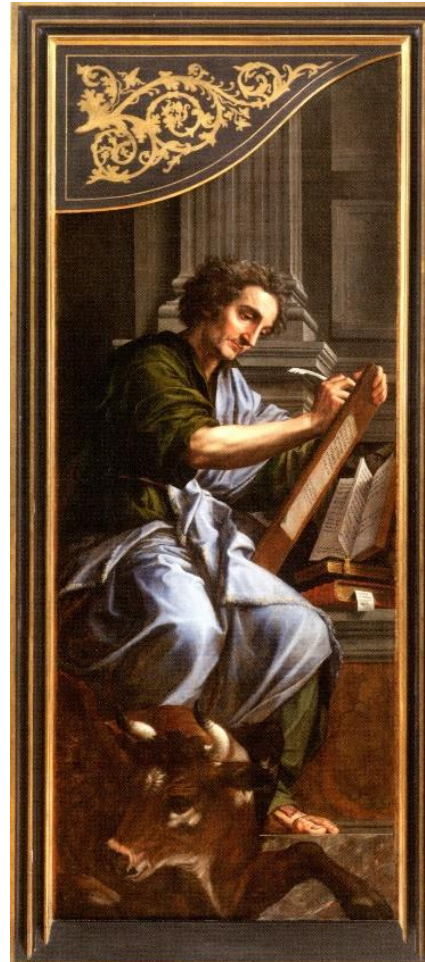

Abb. 53: Michiel Coxcie - Hl. Lukas

(Außen, Seitenflügel für Gossaerts Lukasaltar)

Öl auf Holz, Národni Galerie, Prag

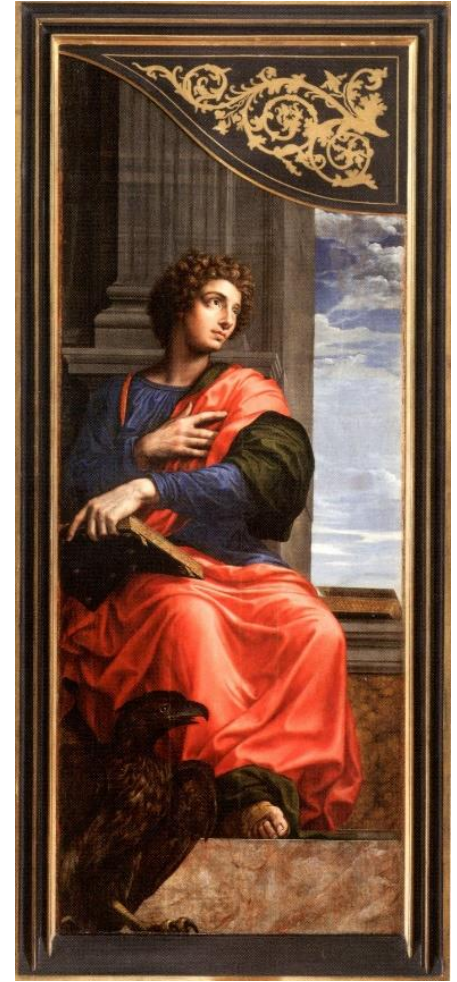

Abb. 54: Michiel Coxcie - Johannes Evangelist (Außen, Seitenflügel für Gossaerts Lukasaltar) Öl auf Holz, Národni Galerie, Prag

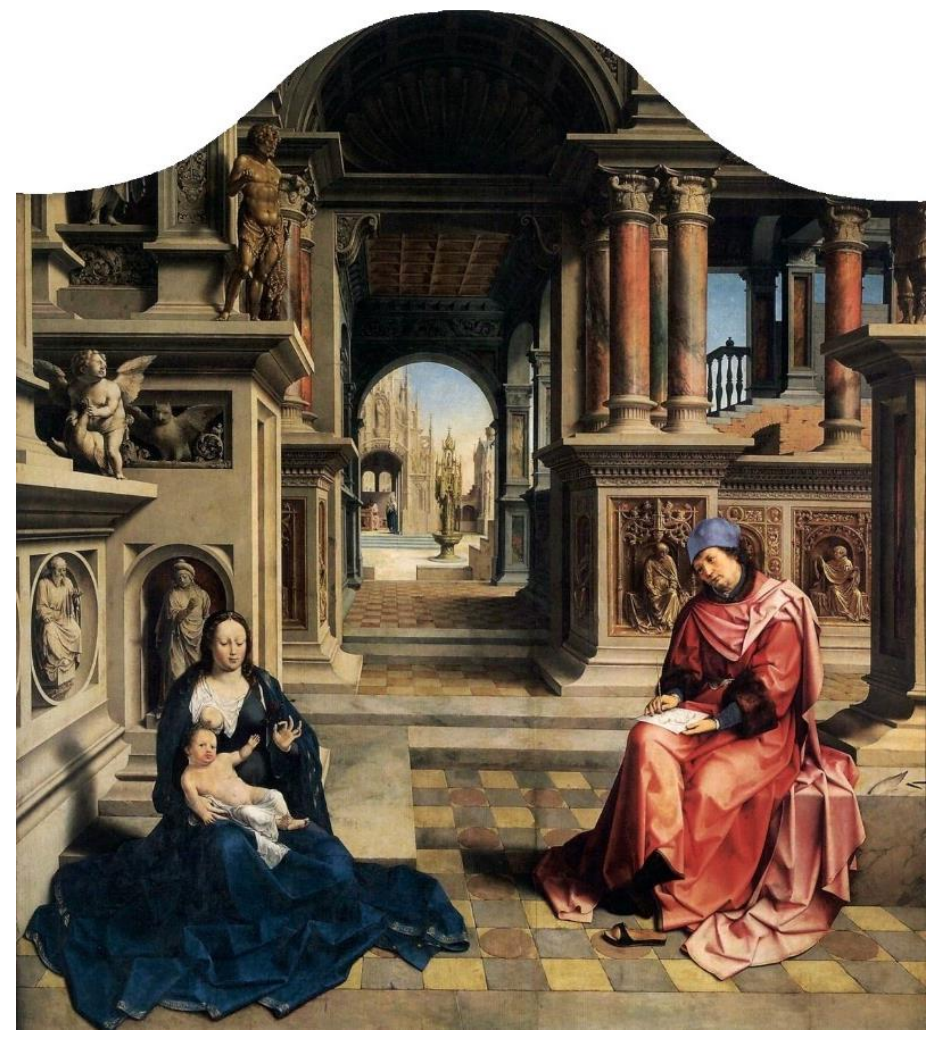

Abb. 55: Jan Gossaert - Lukas, der die Madonna malt Národni Galerie, Prag 


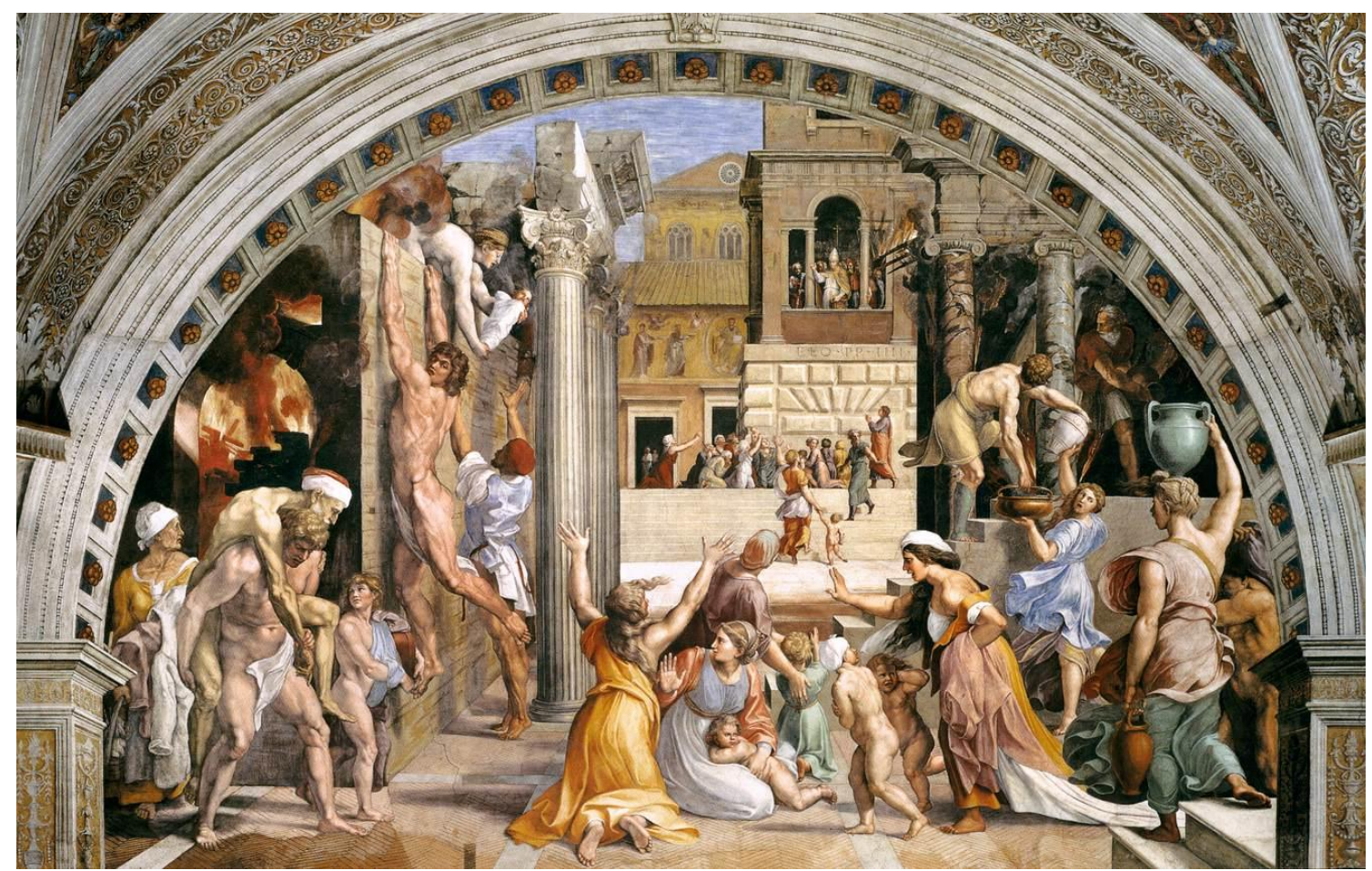

Abb. 56: Raffael - Incendio del Borgo

Apostolischer Palast, Rom

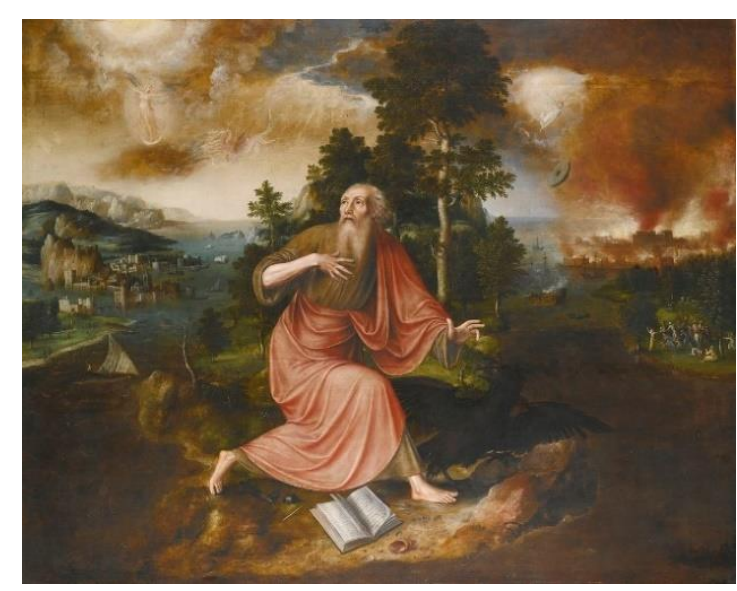

Abb. 57: Jan Massys - Johannes auf Patmos Verbleib unbekannt

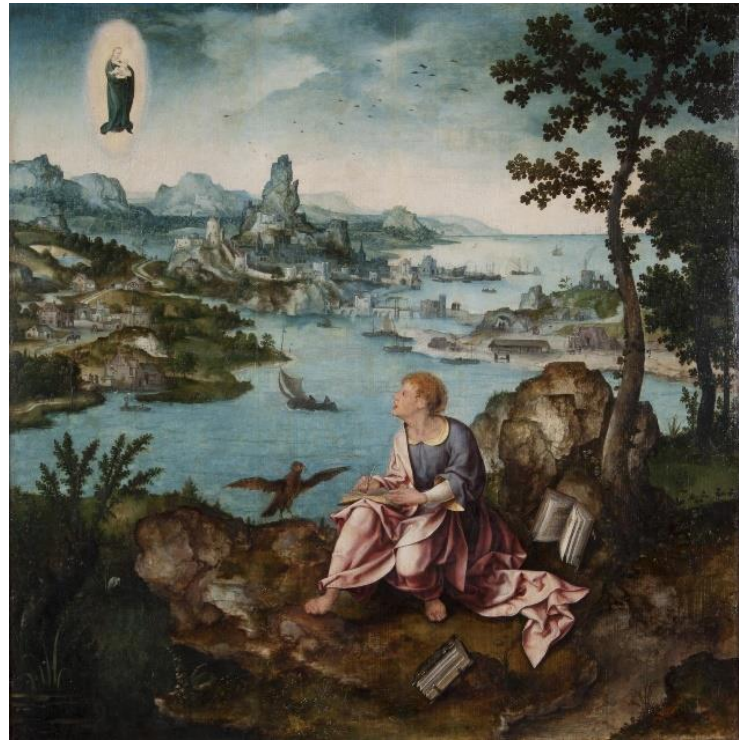

Abb. 58: Joos van Cleve - Johannes auf Patmos University of Michigan Museum of Art, Michigan 


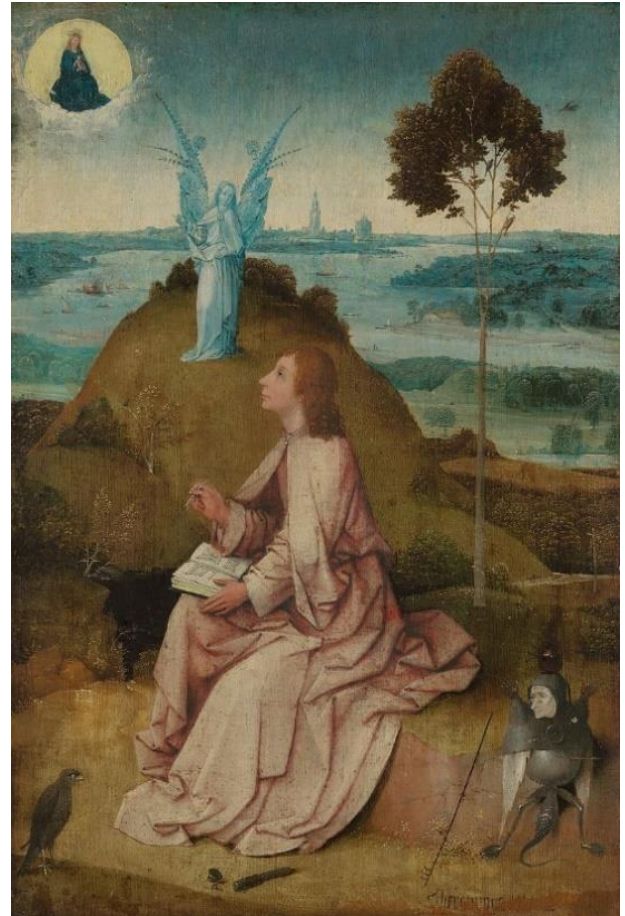

Abb. 59: Hieronymus Bosch - Johannes auf Patmos

Öl auf Holz, Gemäldegalerie, Staatliche Museen, Berlin

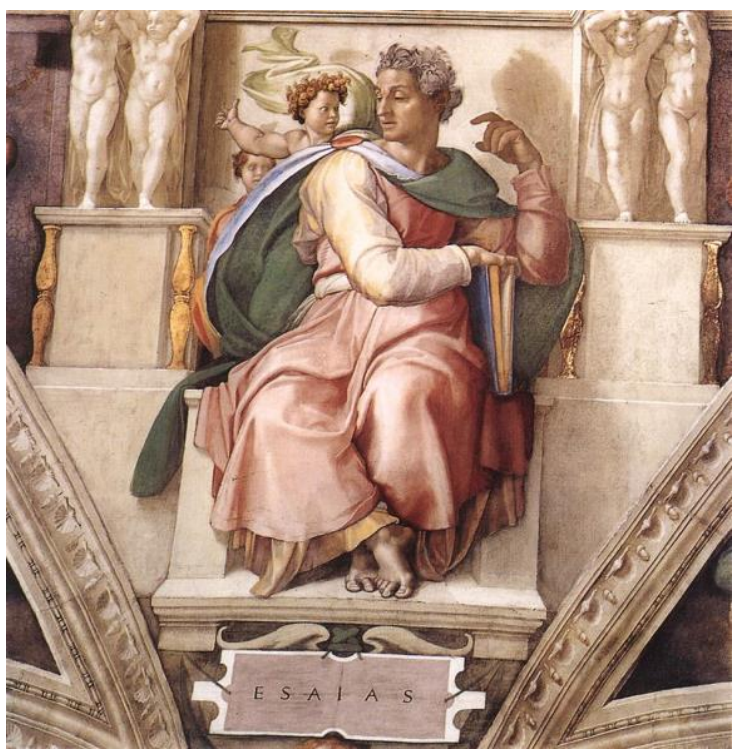

Abb. 60: Michelangelo - Jesaja

Deckenfresko, Sixtinische Kapelle, Rom
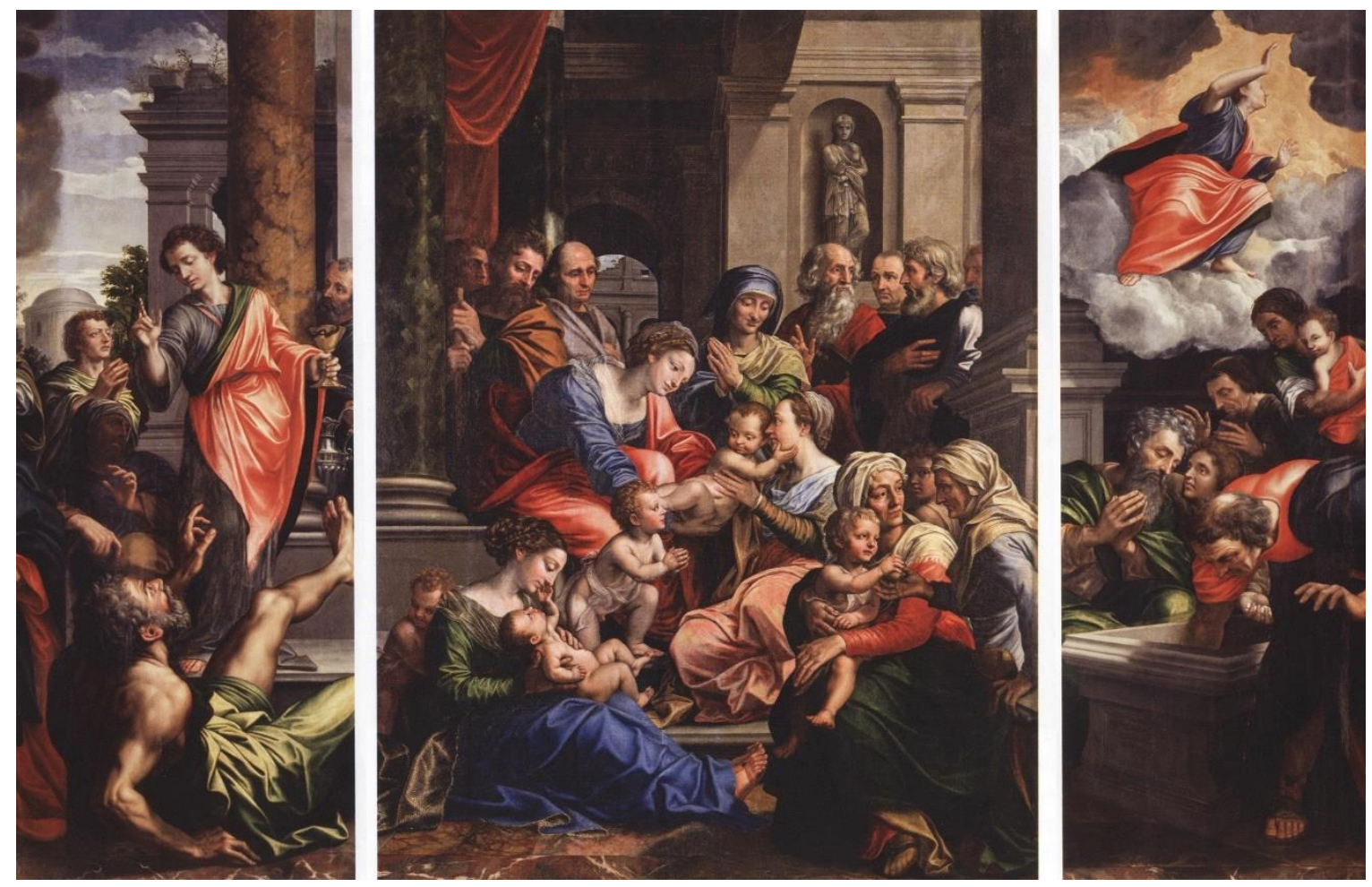

Abb. 61: Michiel Coxcie - Triptychon mit der Hl. Sippe

(Rekonstruktion der einzelnen Seitenflügel nach JONCKHEERE 2013) Stiftssammlung, Benediktinerstift Kremsmünster 


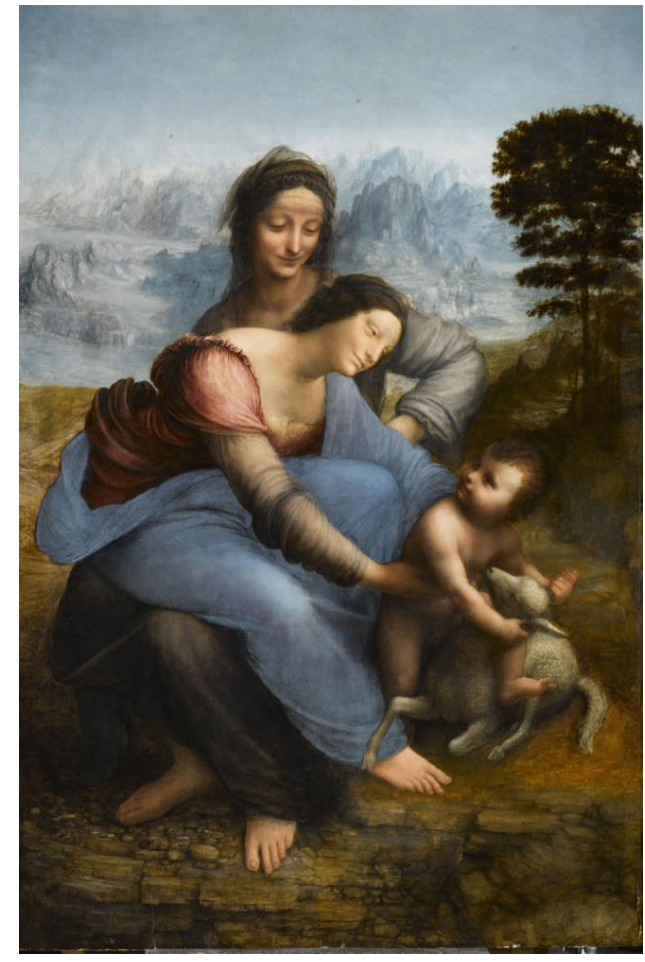

Abb. 62: Leonardo da Vinci - Anna Selbdritt Musée de Louvre, Paris

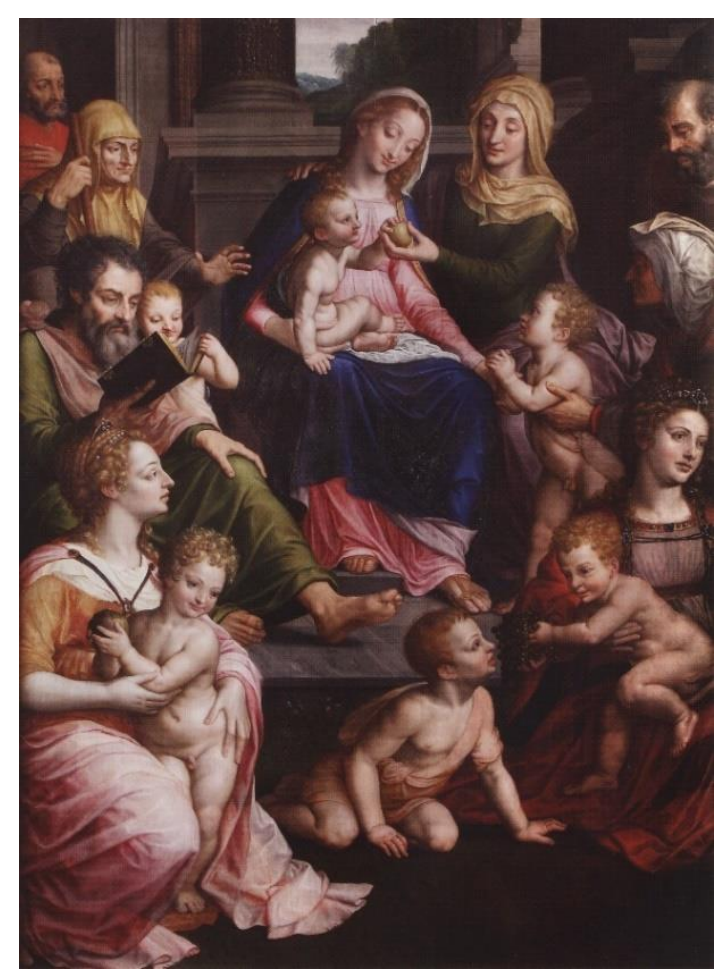

Abb. 63: Michiel Coxcie - Hl. Sippe Patrimonio Nacional, Escorial

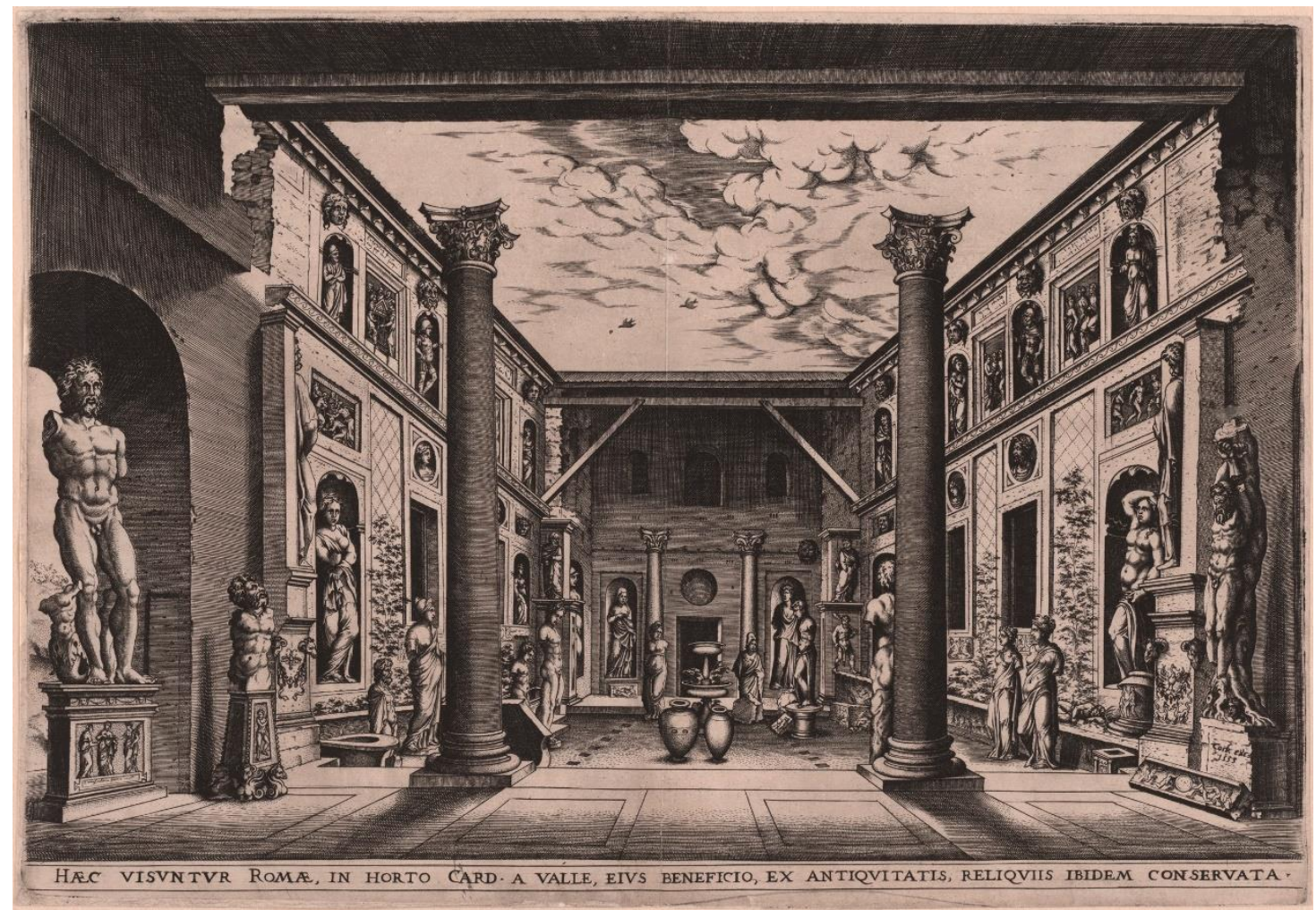

Abb. 64: Hieronymus Cock - Skulpturenhof im Palazzo Valle-Capranica (1553)

Kupferstich (nach Marten van Heemskerck), Rijksmuseum, Amsterdam 


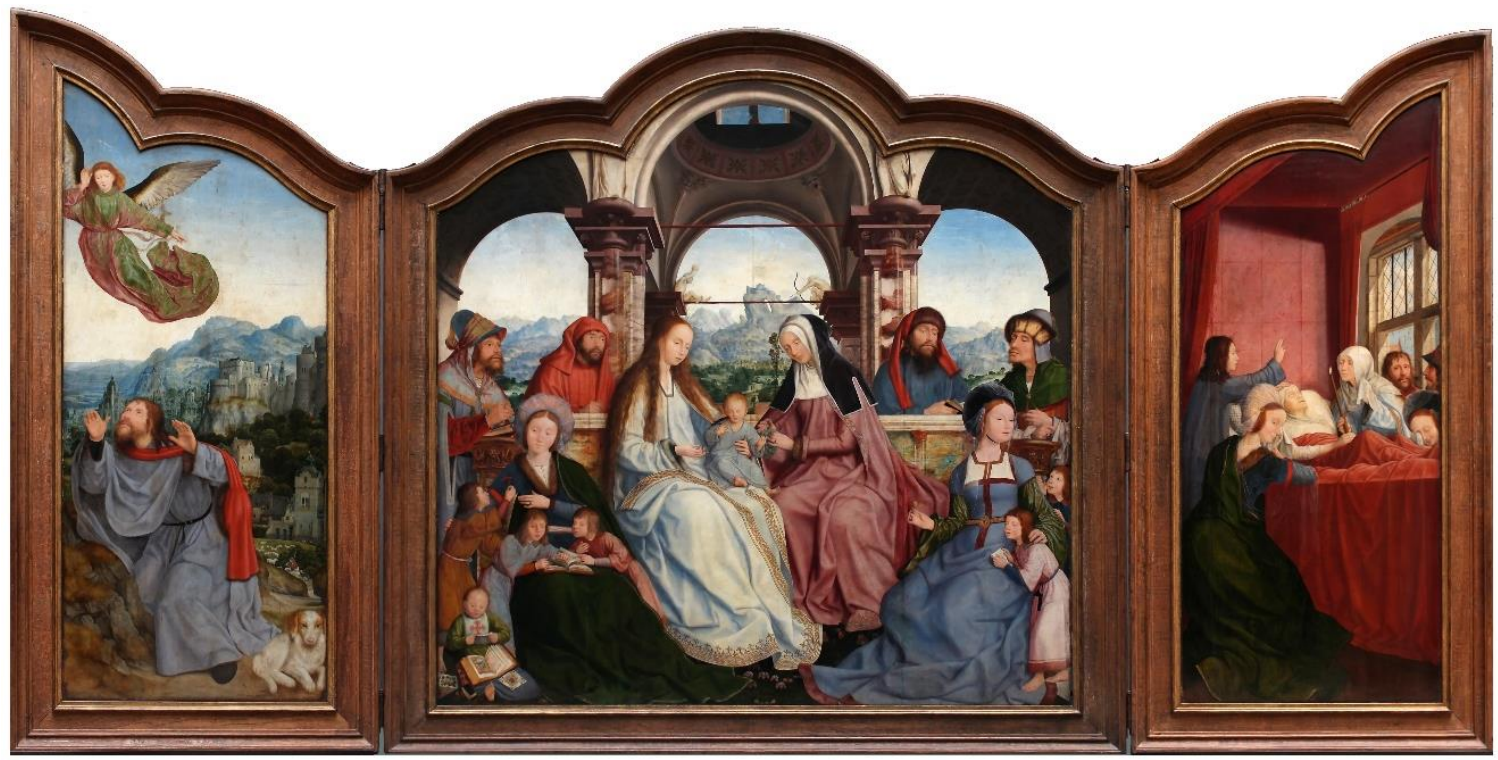

Abb. 65: Quentin Massys - Annenaltar (1509)

Koninklijke Musea voor Schone Kunsten, Brüssel

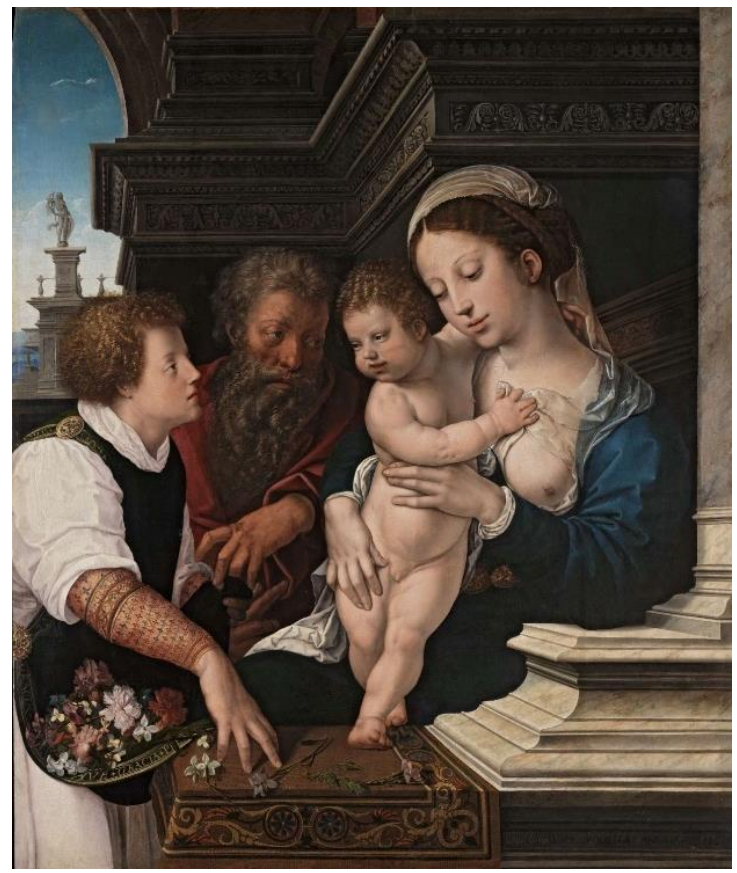

Abb. 66: Bernard van Orley - Hl. Familie

Öl auf Holz, Louvre, Paris

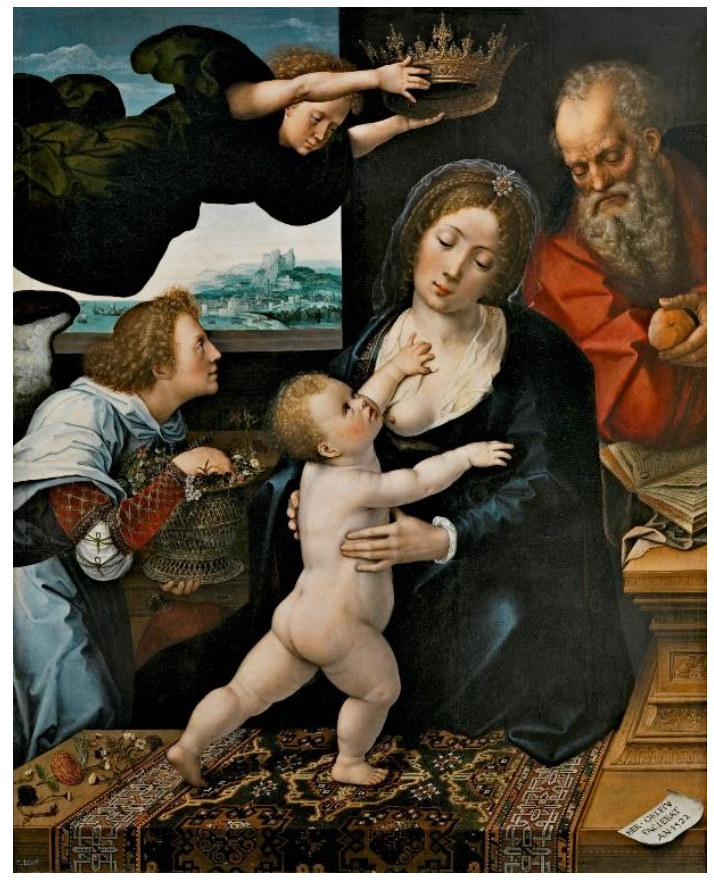

Abb. 67: Bernard van Orley - Hl. Familie Öl auf Holz, Prado, Madrid 


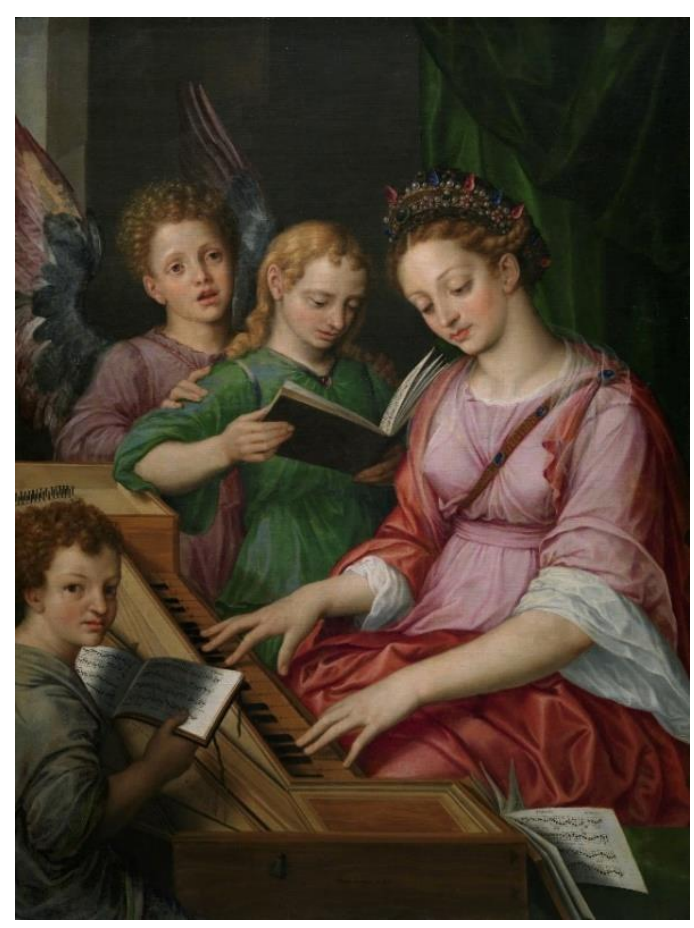

Abb. 68: Michiel Coxcie - Hl. Cäcilie Öl auf Leinwand, Prado, Madrid 


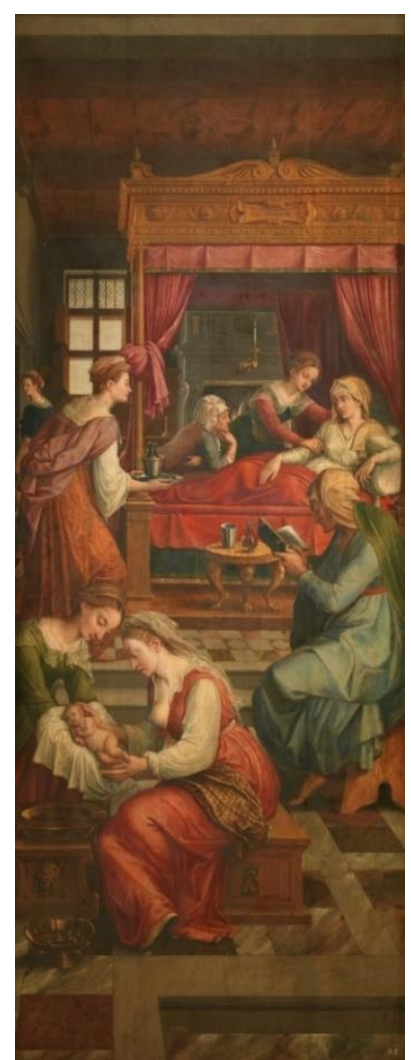

Abb. 69: Michiel Coxcie - Die Geburt der Jungfrau (innen, links), Triptychon mit Marienleben, Prado, Madrid

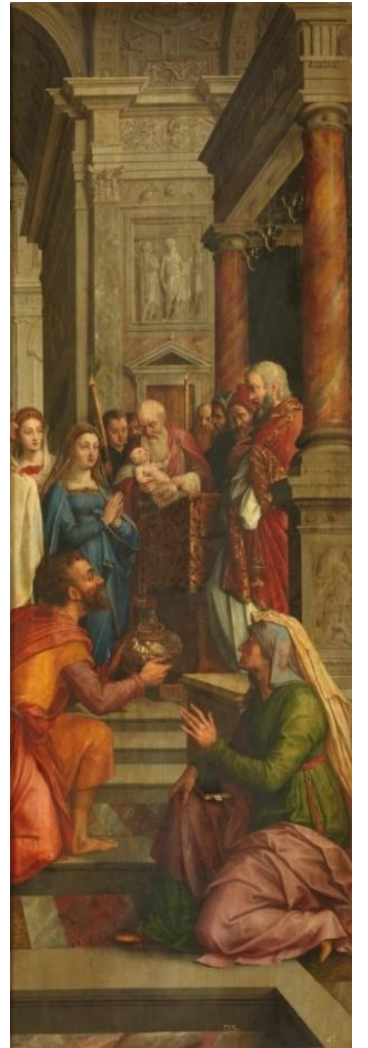

Abb. 70: Michiel Coxcie - Die Darstellung Christi (innen, rechts), Triptychon mit Marienleben, Prado, Madrid 


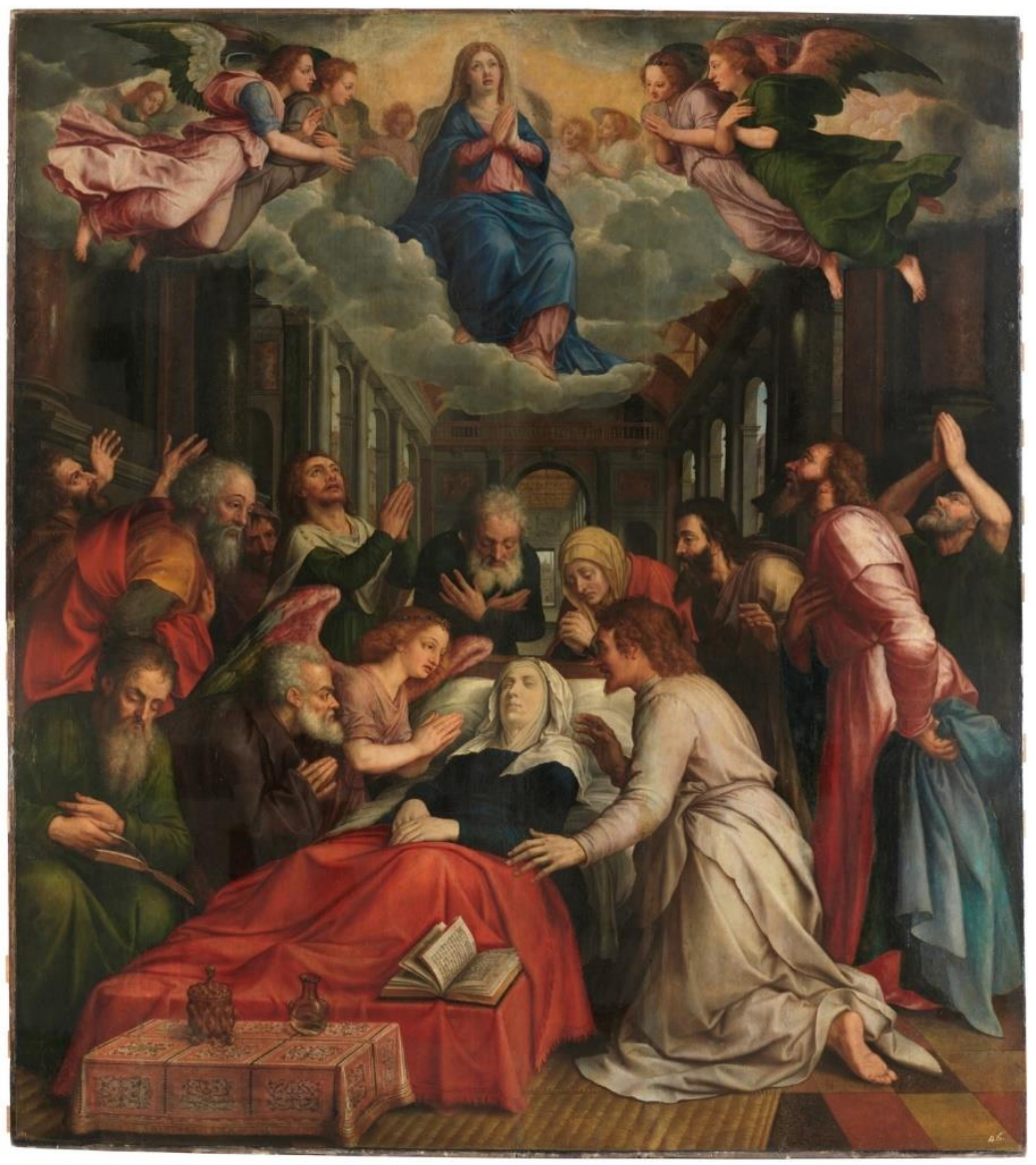

Abb. 71: Michiel Coxcie - Marientod (Mitteltafel), Triptychon mit Marienleben, Prado, Madrid

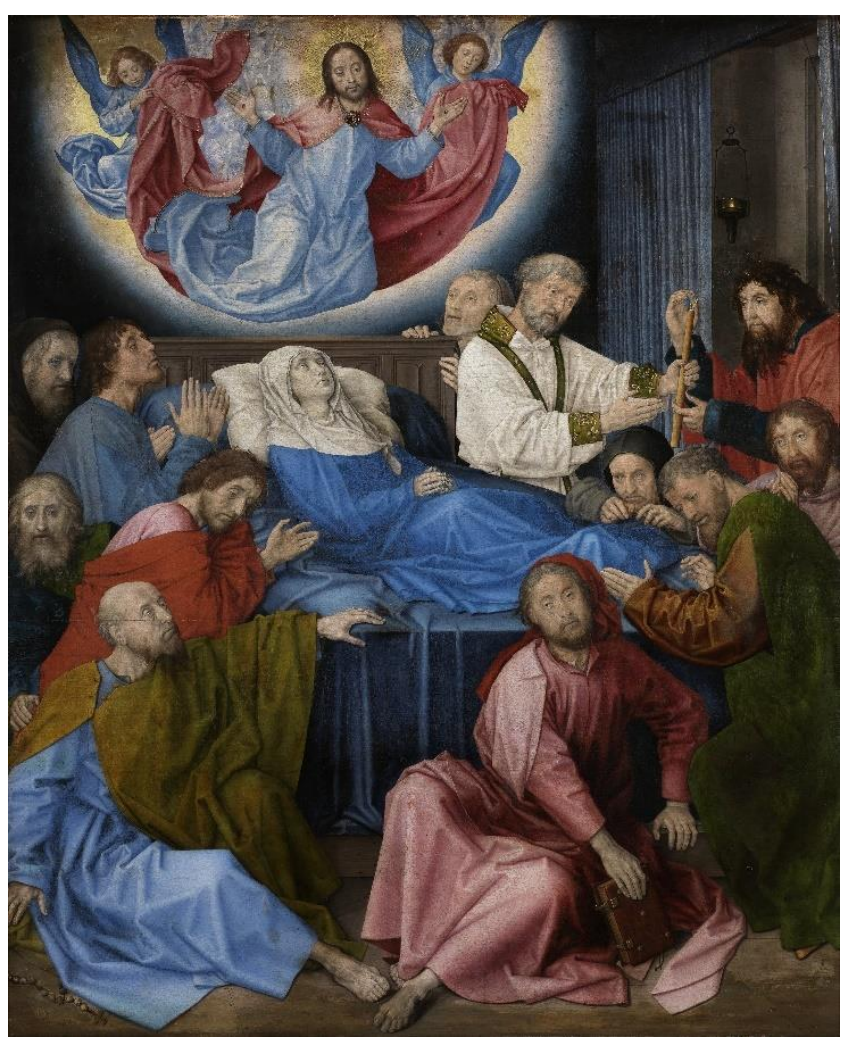

Abb. 72: Hugo van der Goes - Marientod

Öl auf Holz, Groeningemuseum, Brügge 


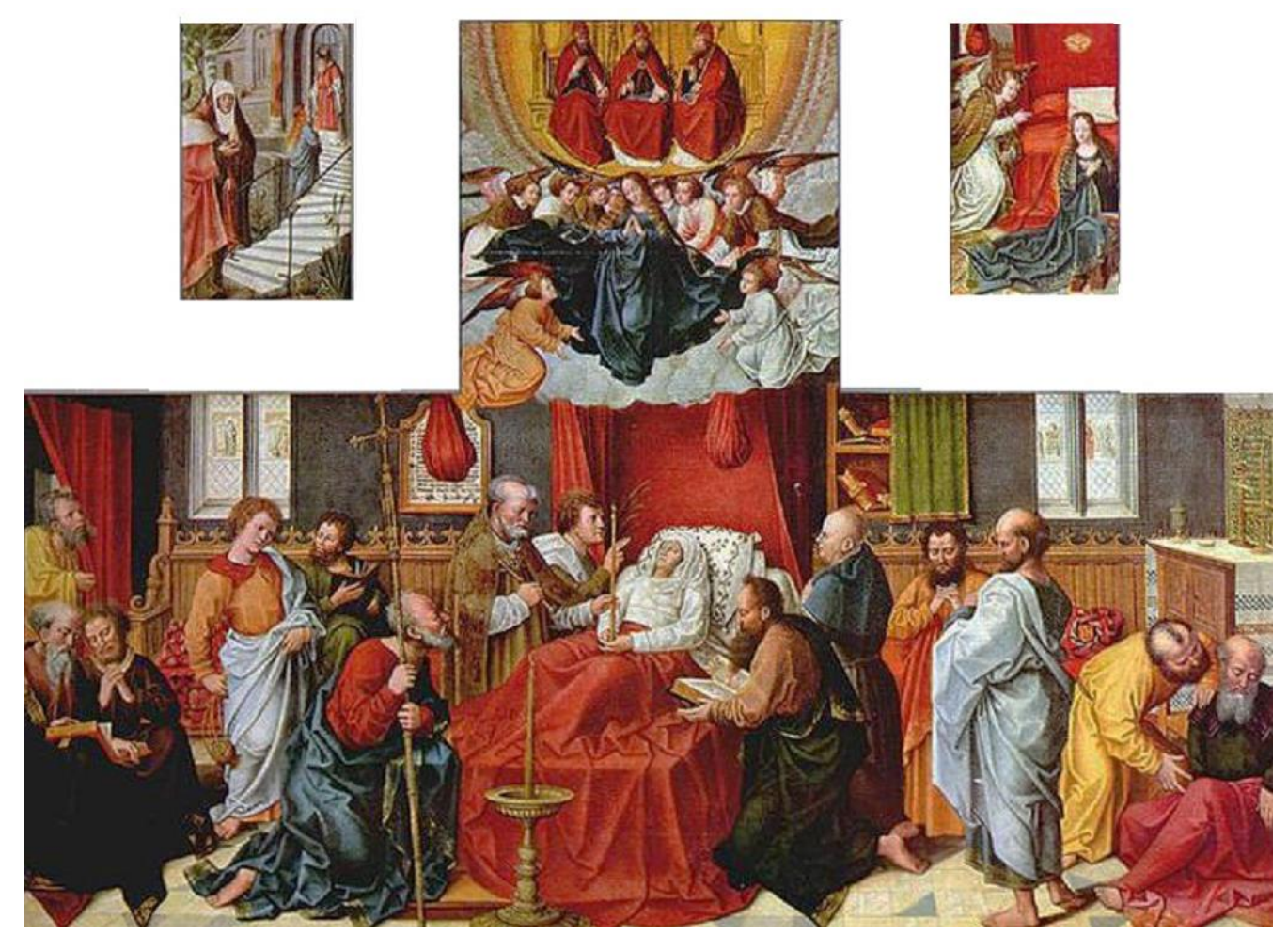

Abb. 73: Bernard van Orley - Triptychon mit Marientod

Öl auf Holz, Musée de l'Assistance Publique, Brüssel

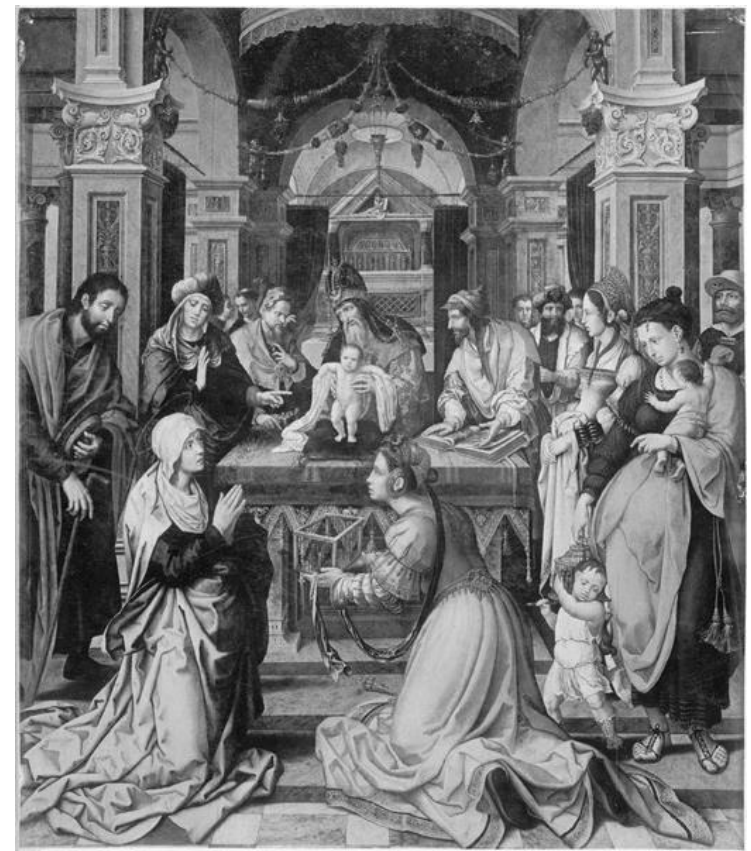

Abb. 74: Bernard van Orley - Darstellung Christi im Tempel

Verbleib unbekannt

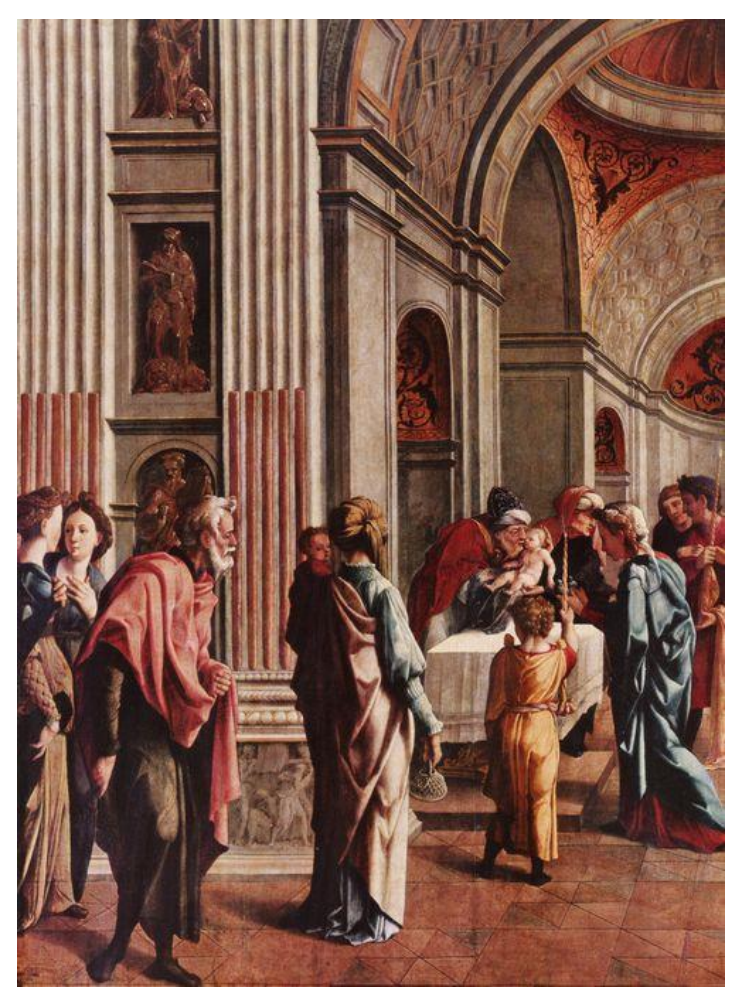

Abb. 75: Jan van Scorel - Darstellung Christi im Tempel Öl auf Holz, Kunsthistorisches Museum, Wien 


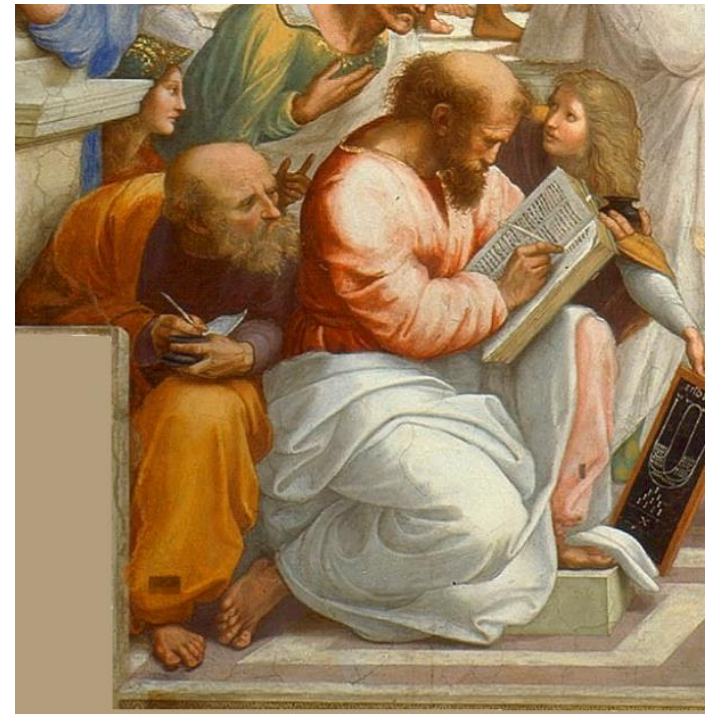

Abb. 76: Raffael - Schule von Athen (Detail) Vatikanischer Palast, Rom

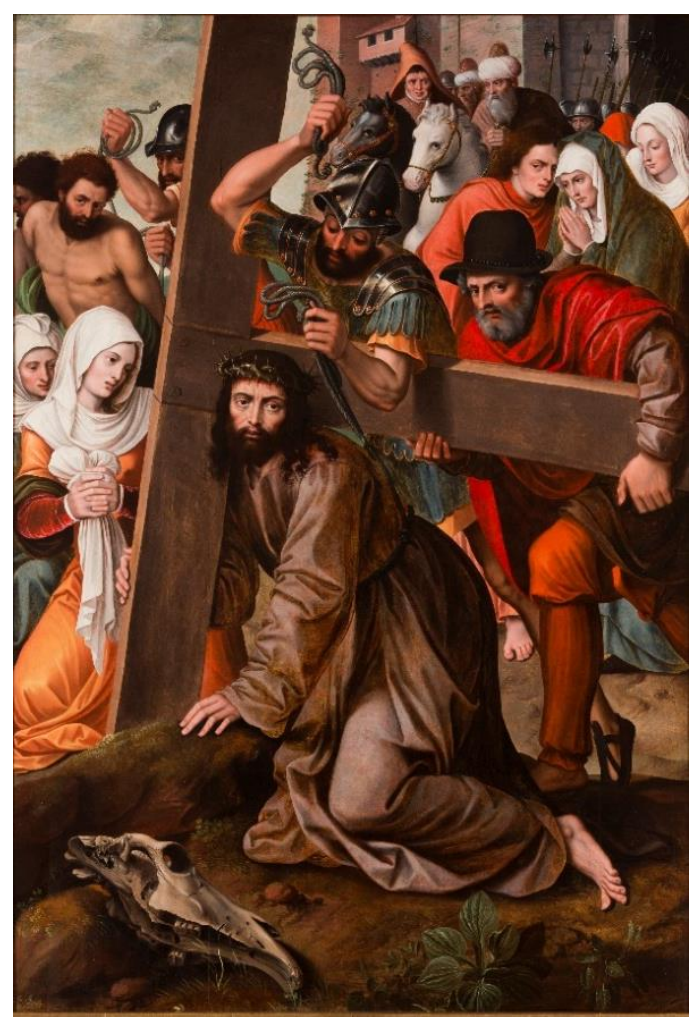

Abb. 78: Michiel Coxcie - Kreuztragung Öl auf Holz, Patrimonio Nacional, Escorial

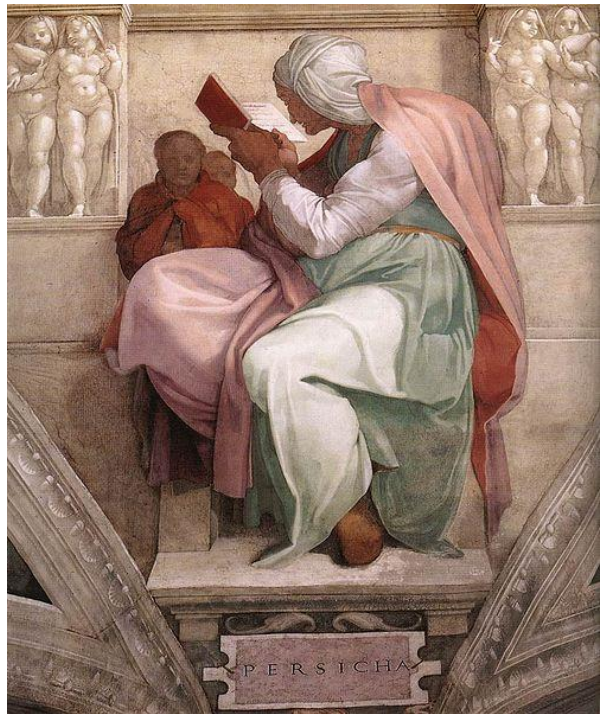

Abb. 77: Michelangelo - Persische Sybille Sixtinische Kapelle, Rom

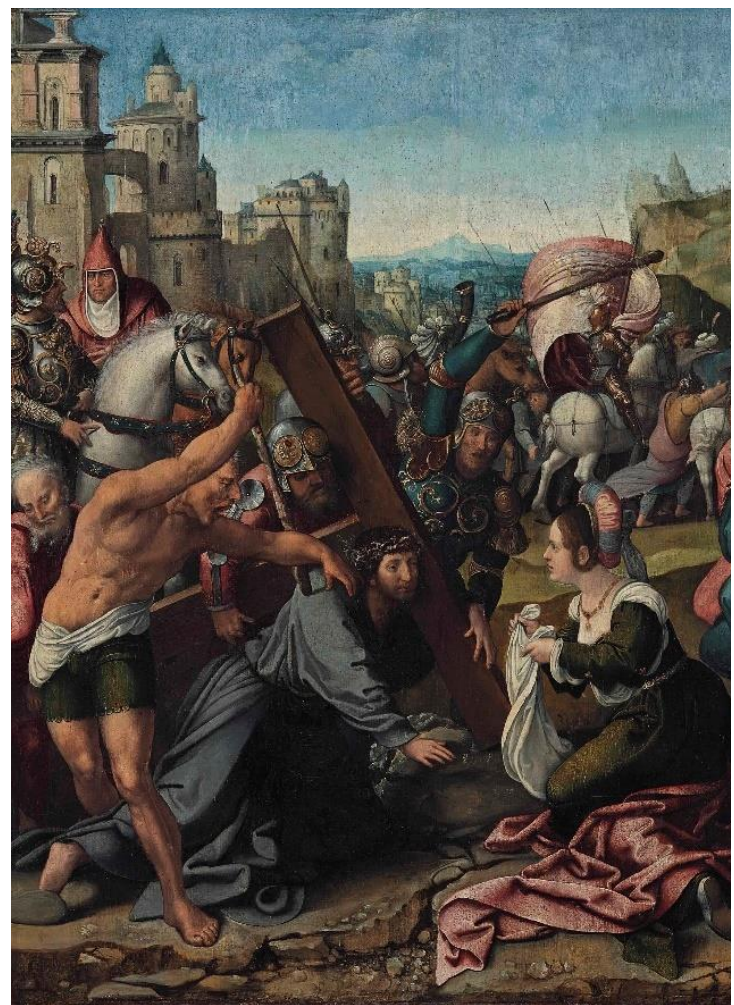

Abb. 79: Bernard van Orley (Umkreis) - Kreuztragung ,Verbleib unbekannt, Privatbesitz (?) 


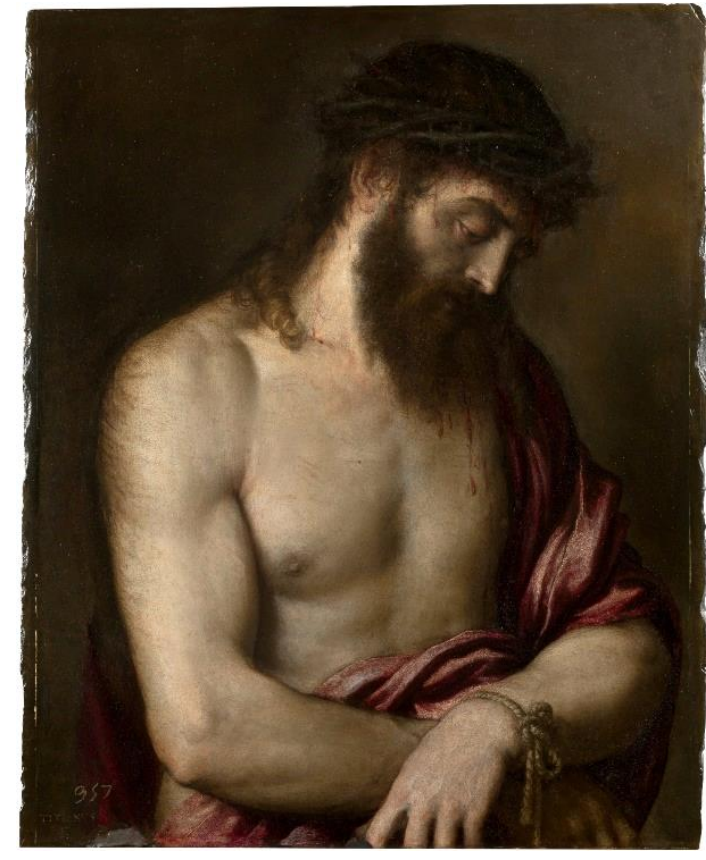

Abb. 80: Tizian - Ecce Homo (1547)

Öl auf Schiefer, Prado, Madrid

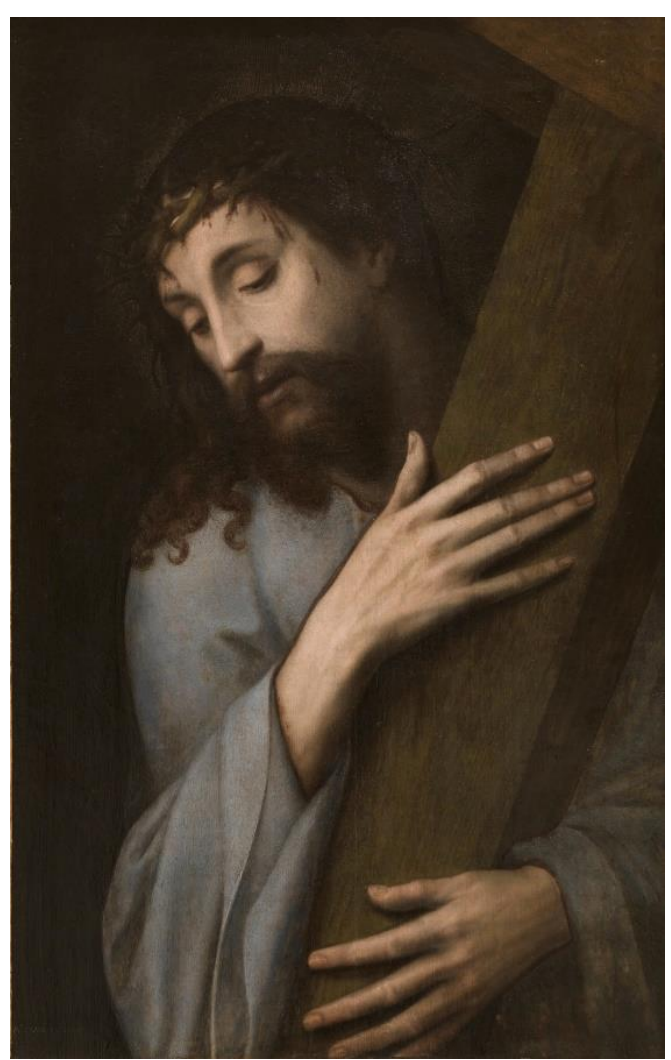

Abb. 82: Michiel Coxcie: Kreuztragung (um 1555) Öl auf Leinwand, Prado, Madrid

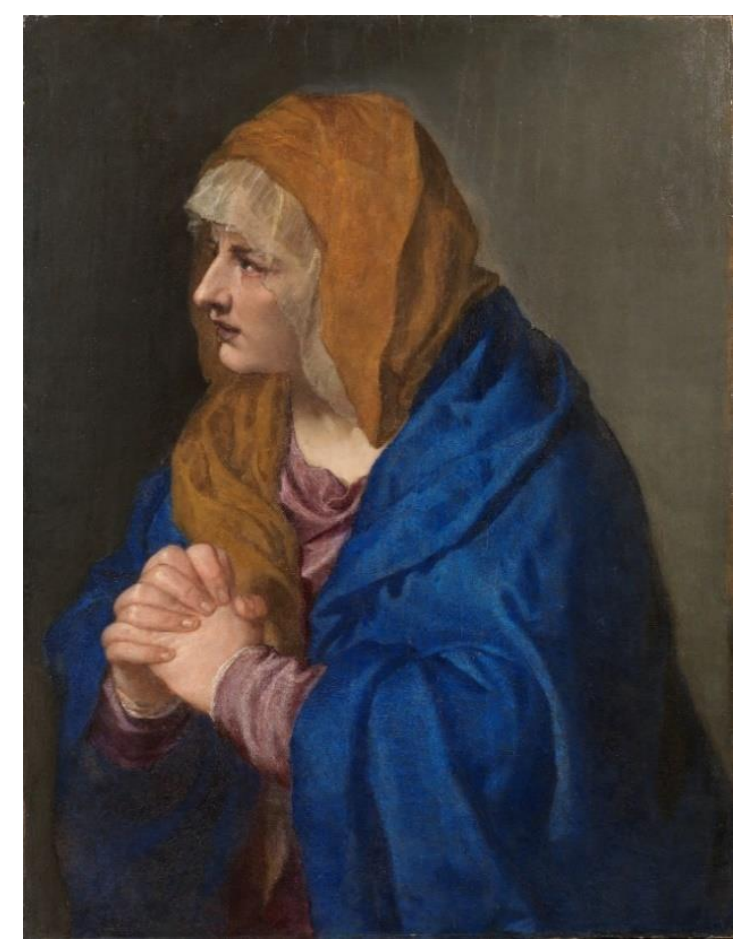

Abb. 81: Tizian - Mater Dolorosa mit den gefalteten Händen (1554), Öl auf Holz, Prado, Madrid

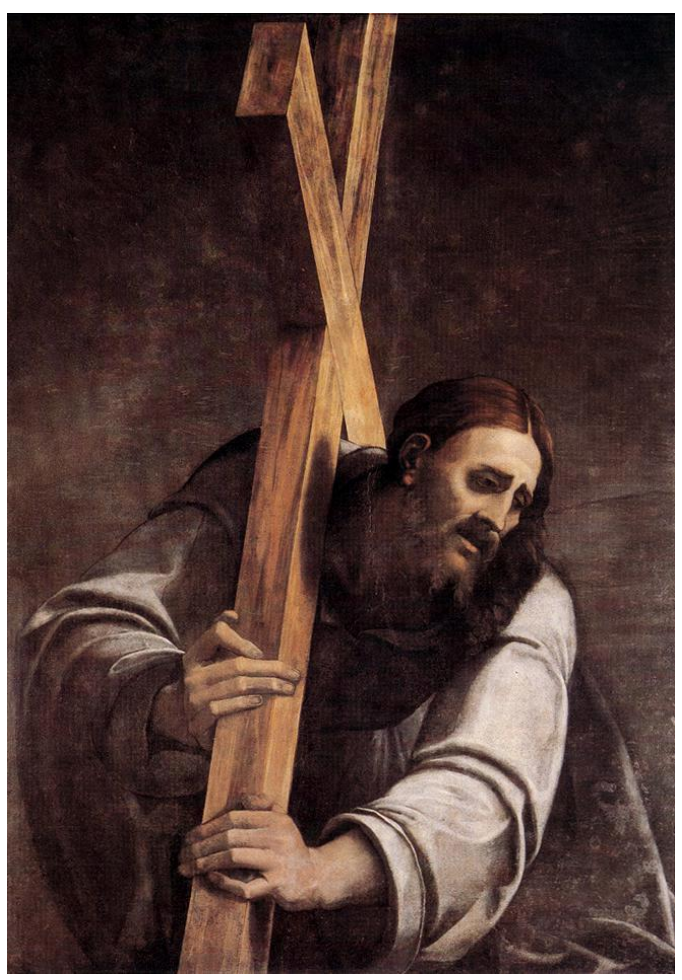

Abb. 83: Sebastiano del Piombo - Christus Kreuzträger (1537), Szépművészeti Múzeum, Budapest 


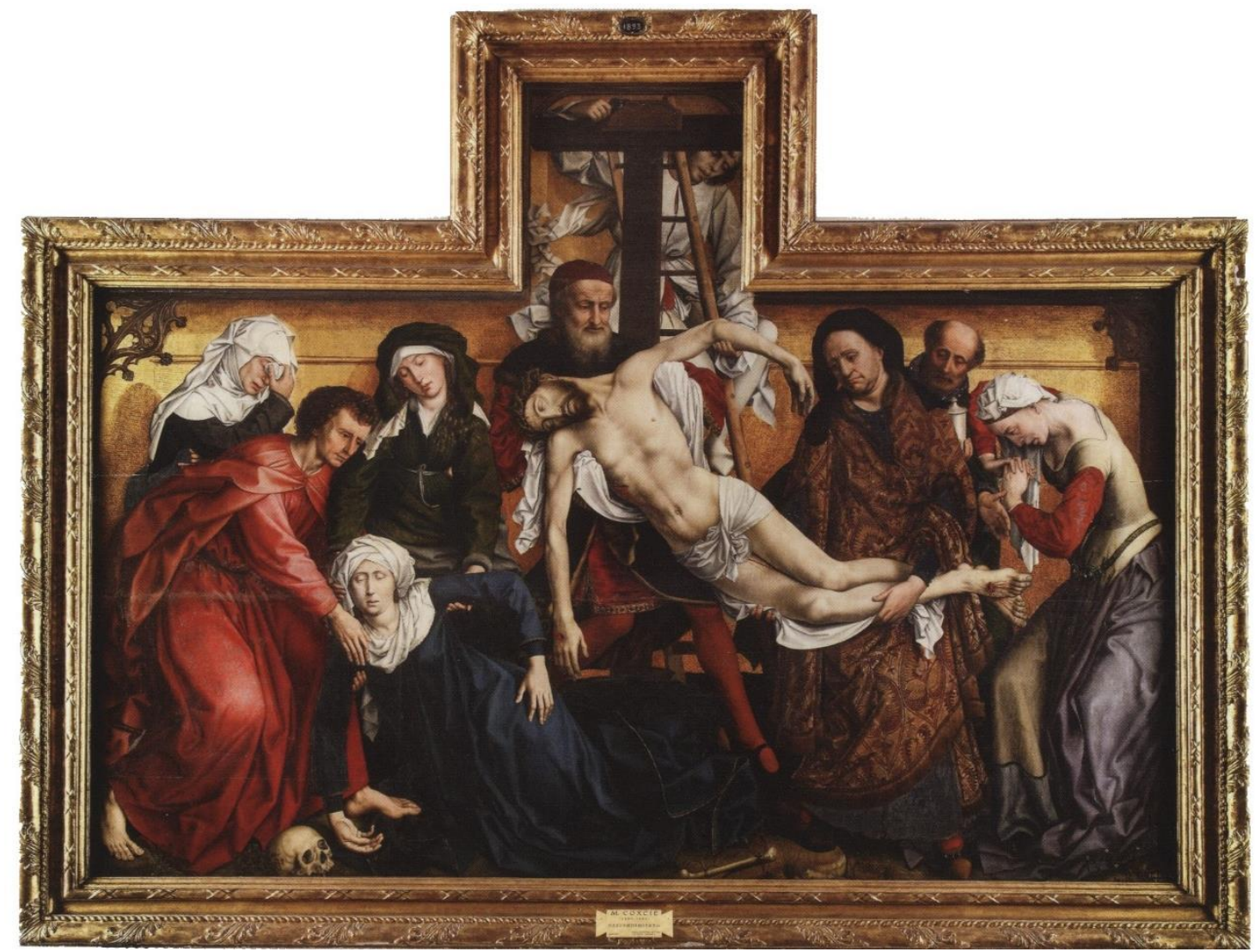

Abb. 84: Michiel Coxcie - Kreuzabnahme Christi (nach Rogier van der Weyden)

Öl auf Holz, Bode-Museum, Berlin

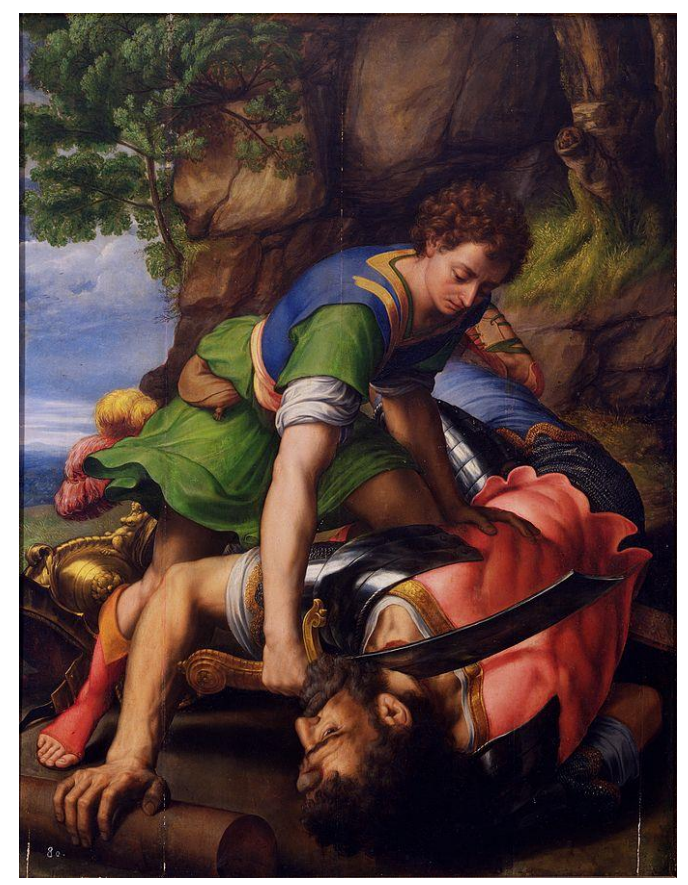

Abb. 85: Michiel Coxcie - David und Goliath Patrimonio Nacional, Escorial 


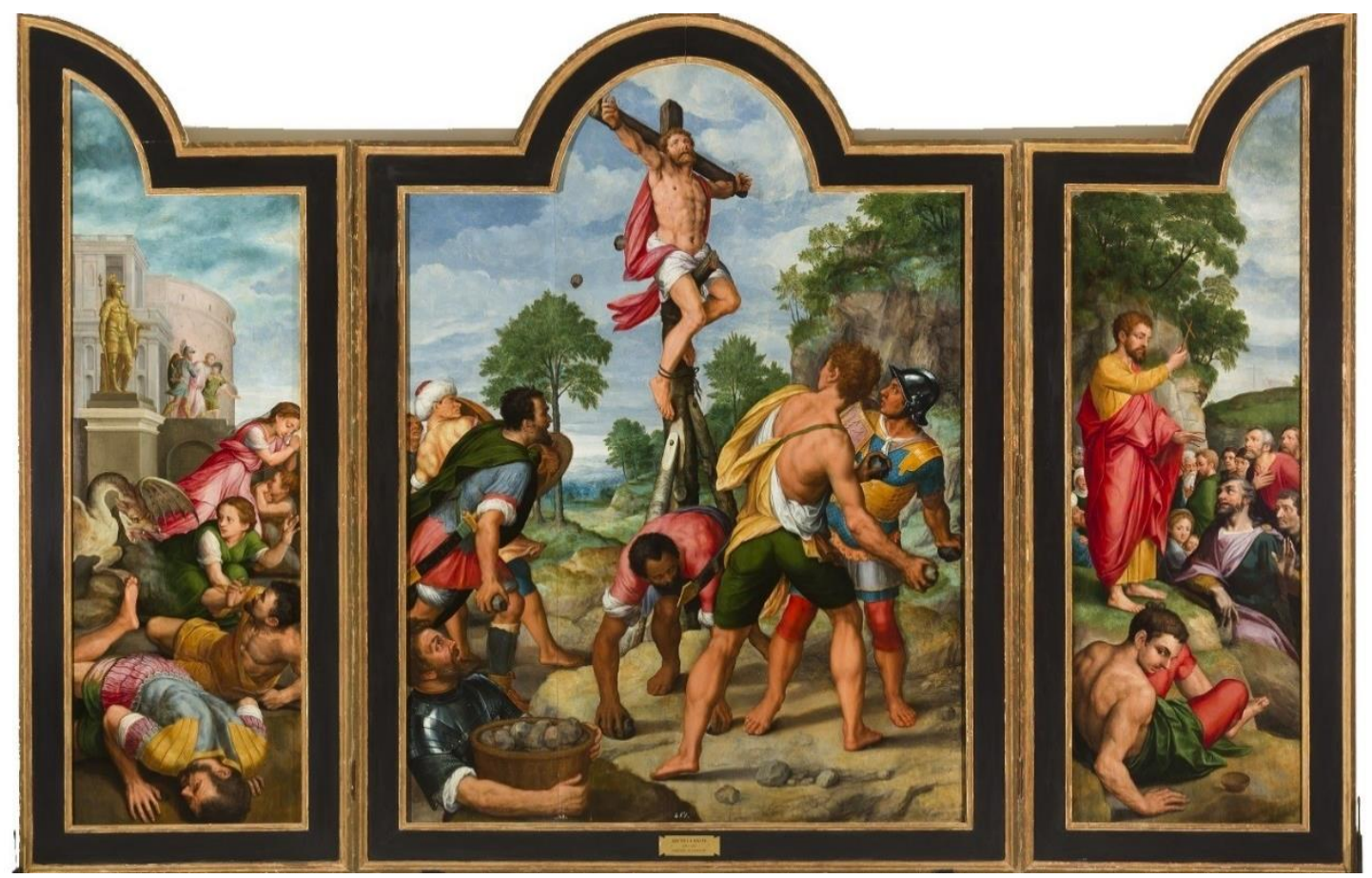

Abb. 86: Michiel Coxcie - Triptychon mit dem Martyrium des Hl. Philipp, Prado, Madrid

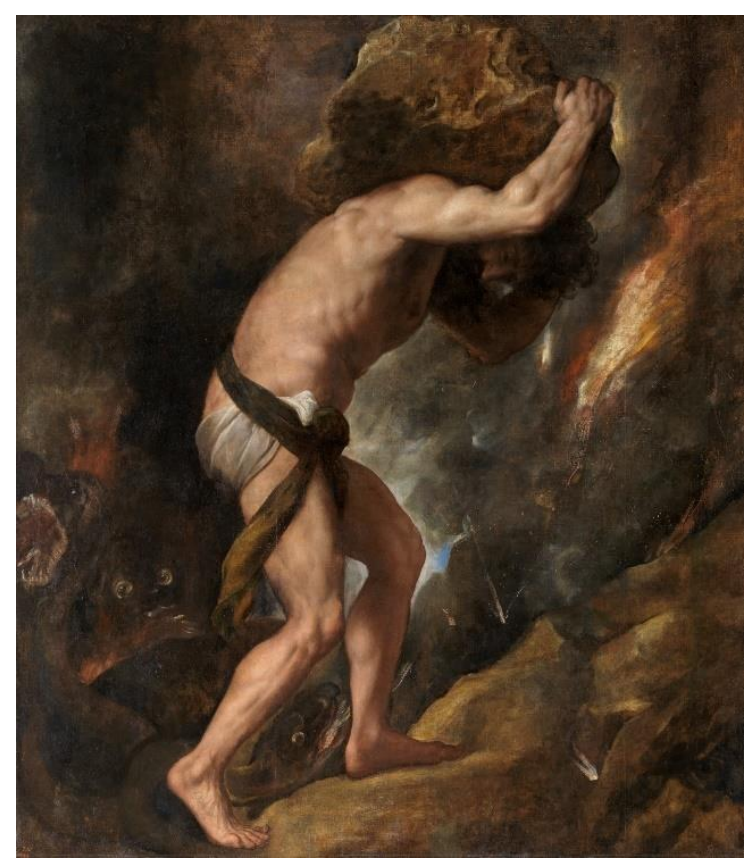

Abb. 87: Tizian - Sisyphus (1548-1549) Öl auf Leinwand, Prado, Madrid

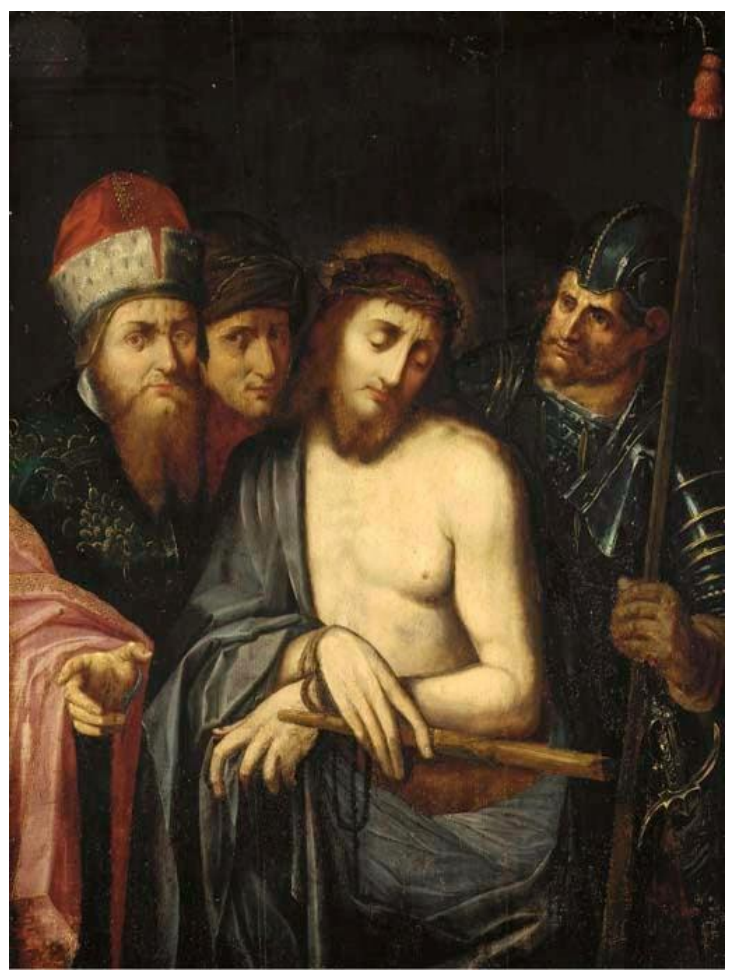

Abb. 88: Umkreis von Michiel Coxcie - Ecce Homo Privatbesitz (?) 


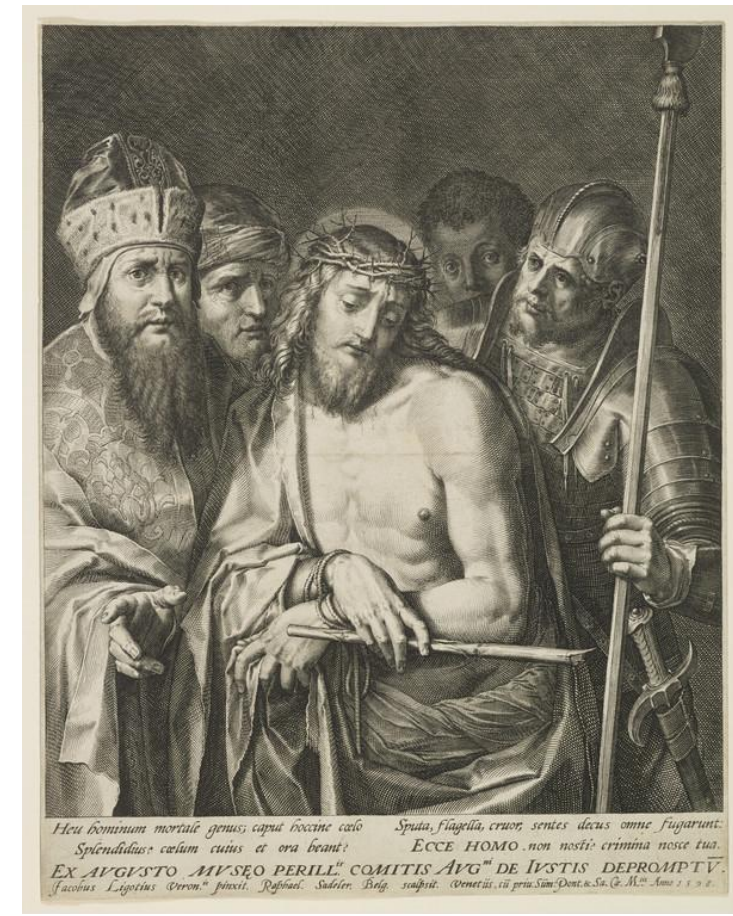

Abb. 89: Jan Sadeler - Ecce Homo (1596)

Kupferstich, Scottish National Gallery, Edinburgh

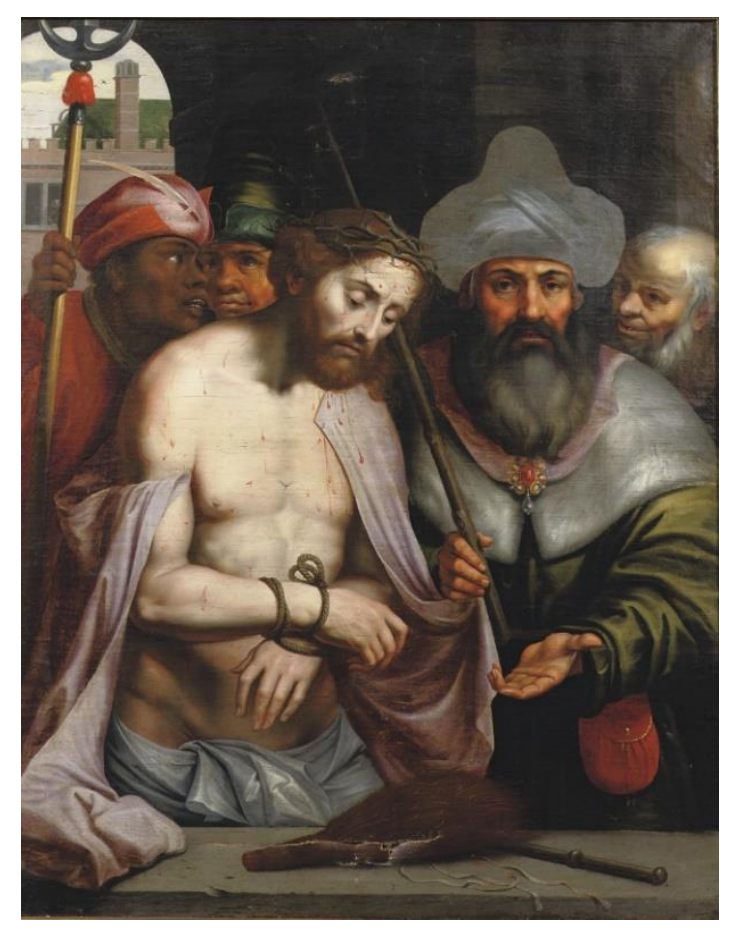

Abb. 91: Michiel Coxcie (?) - Ecce Homo Privatbesitz (?)

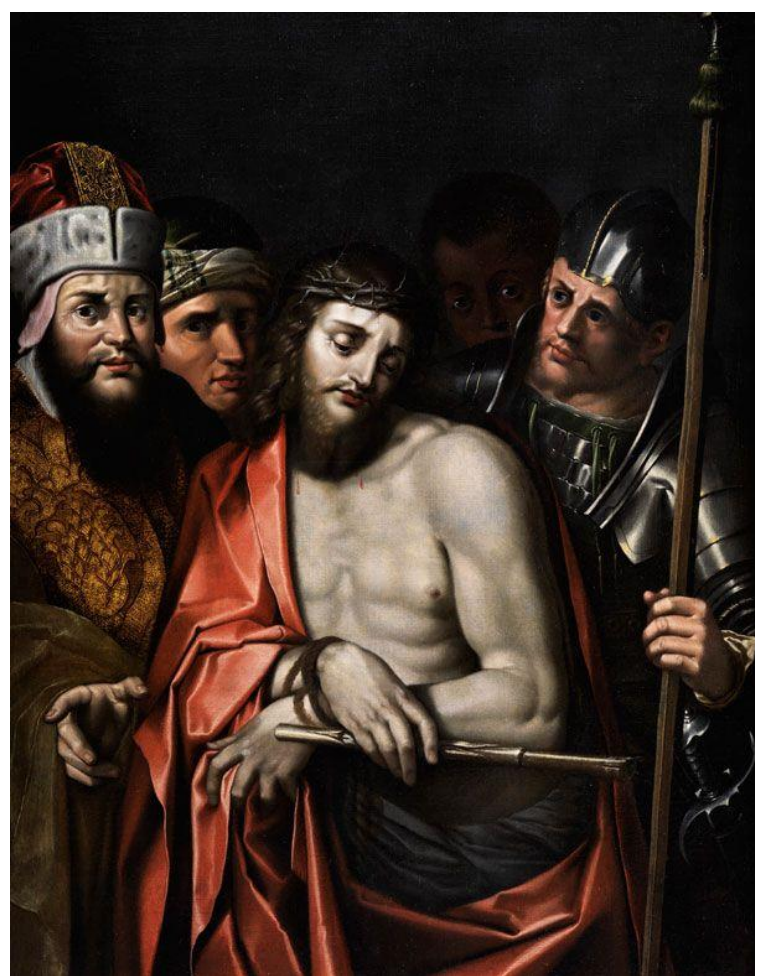

Abb. 90: Jacopo Ligozzi - Ecce Homo

Privatbesitz (?)

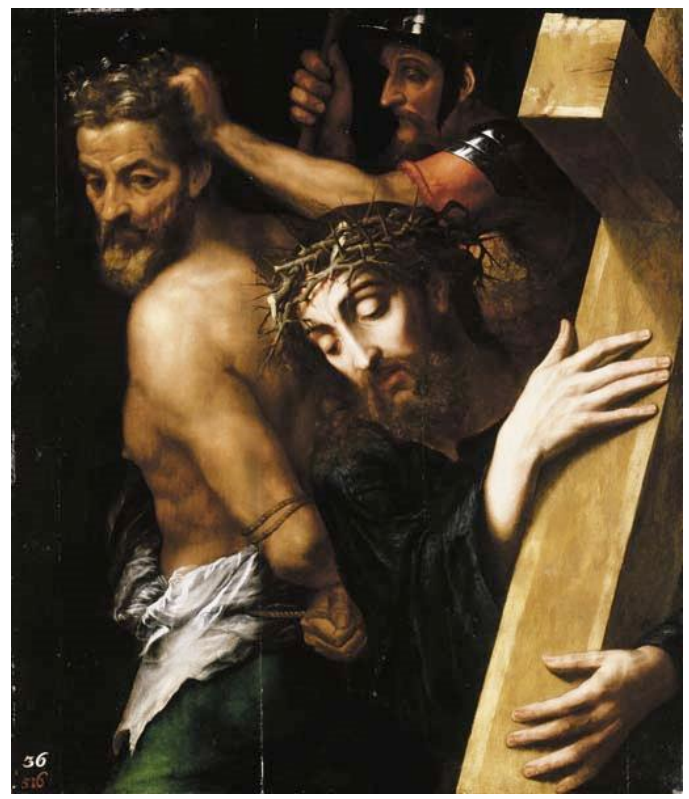

Abb. 92: Michiel Coxcie - Kreuztragender Christus Privatbesitz (?) 


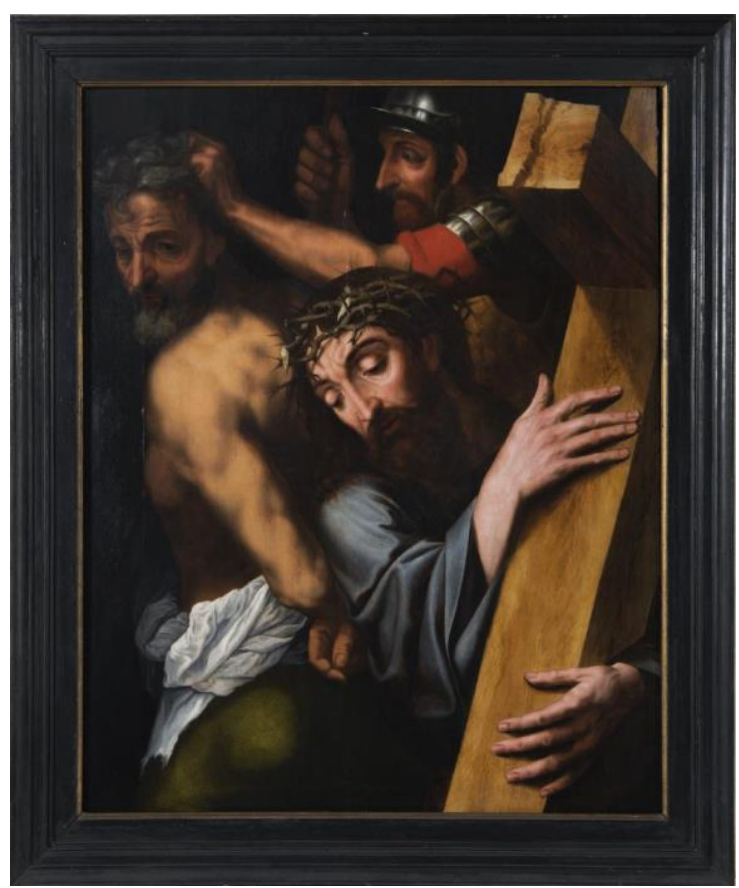

Abb. 93: Michiel Coxcie - Kreuztragender Christus Parcum-Museum (Parkabtei), Leuven 

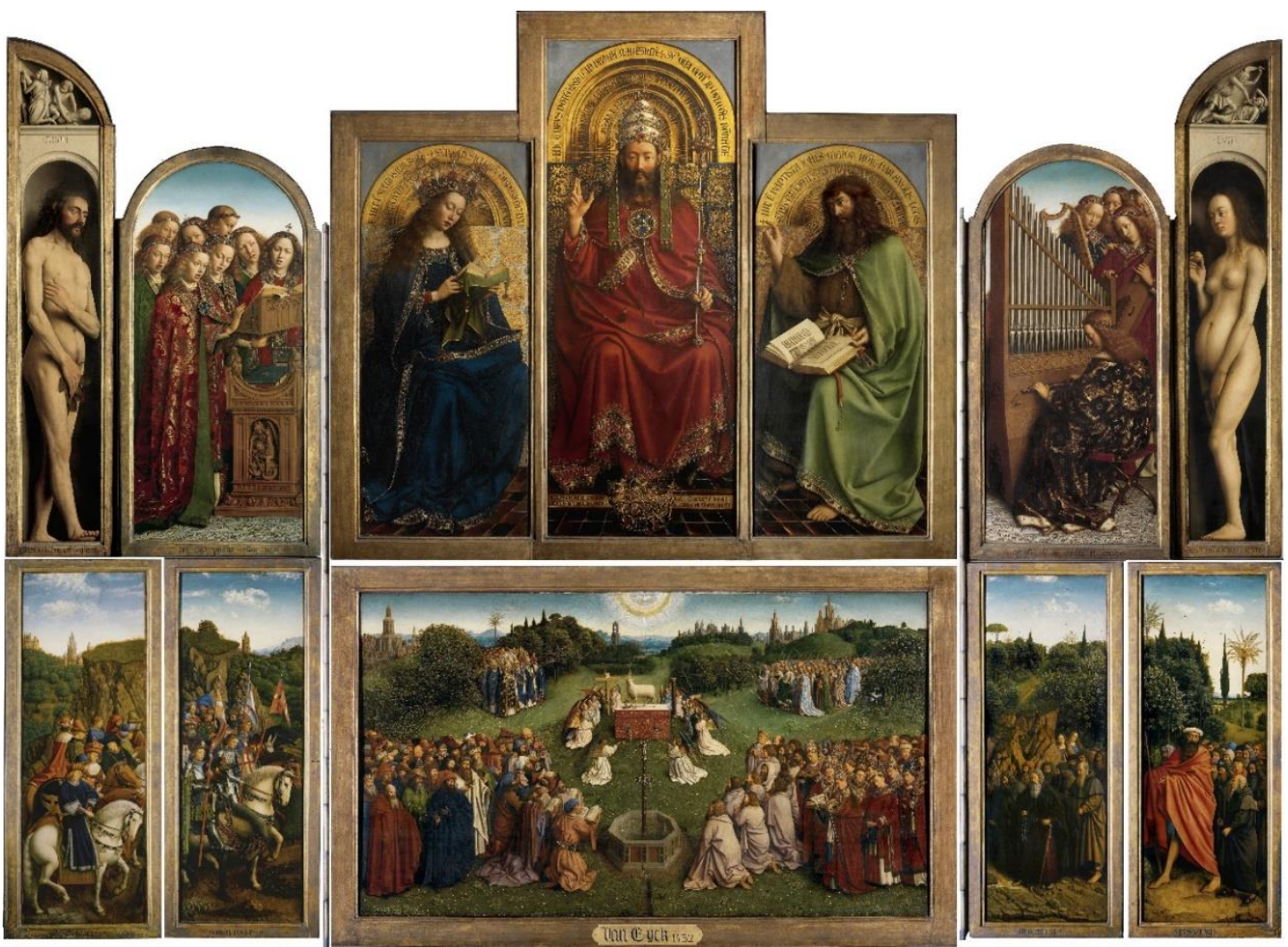

Abb. 94: Jan van Eyck - Genter Altar, Öl auf Holz, Sint-Baafskathedraal, Gent

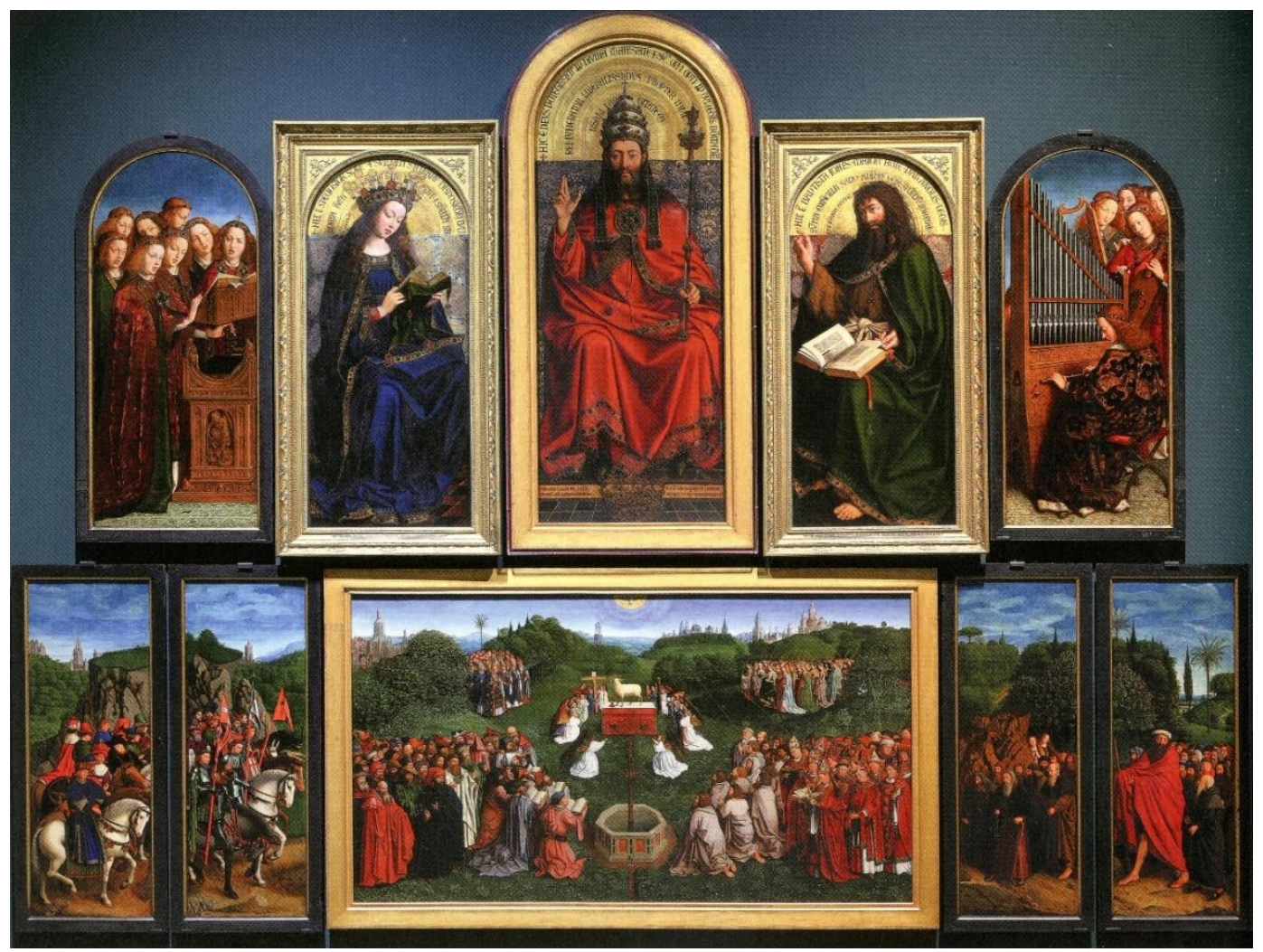

Abb. 95: Michiel Coxcie - Kopie des Genter Altars (1558), Öl auf Holz,

verschiedene Standorte: Gemäldegalerie, Berlin; Alte Pinakothek, München; KMSKB, Brüssel 


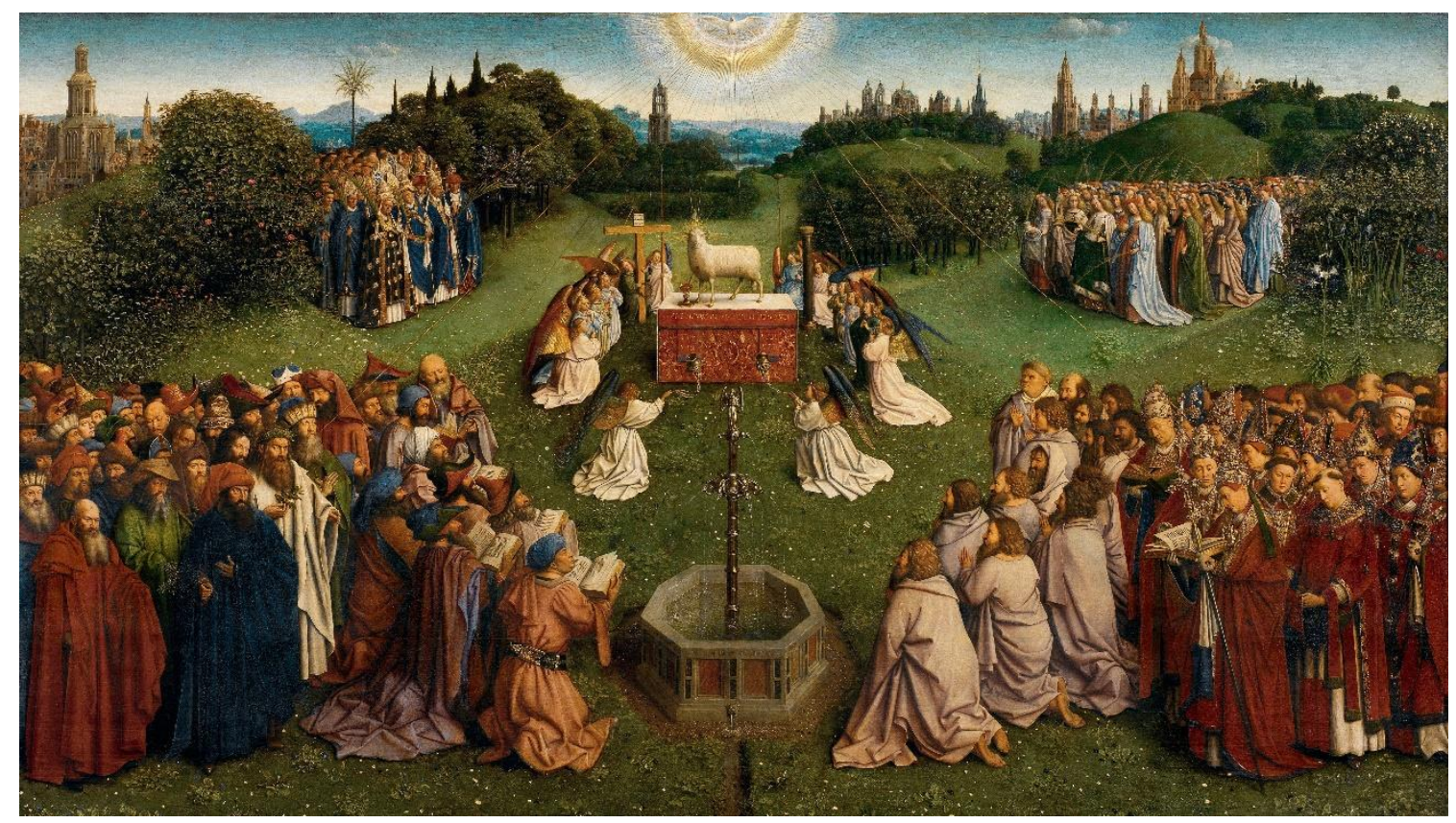

Abb. 96: Jan van Eyck - Anbetung des Lammes, Sint Baafskathedraal, Gent

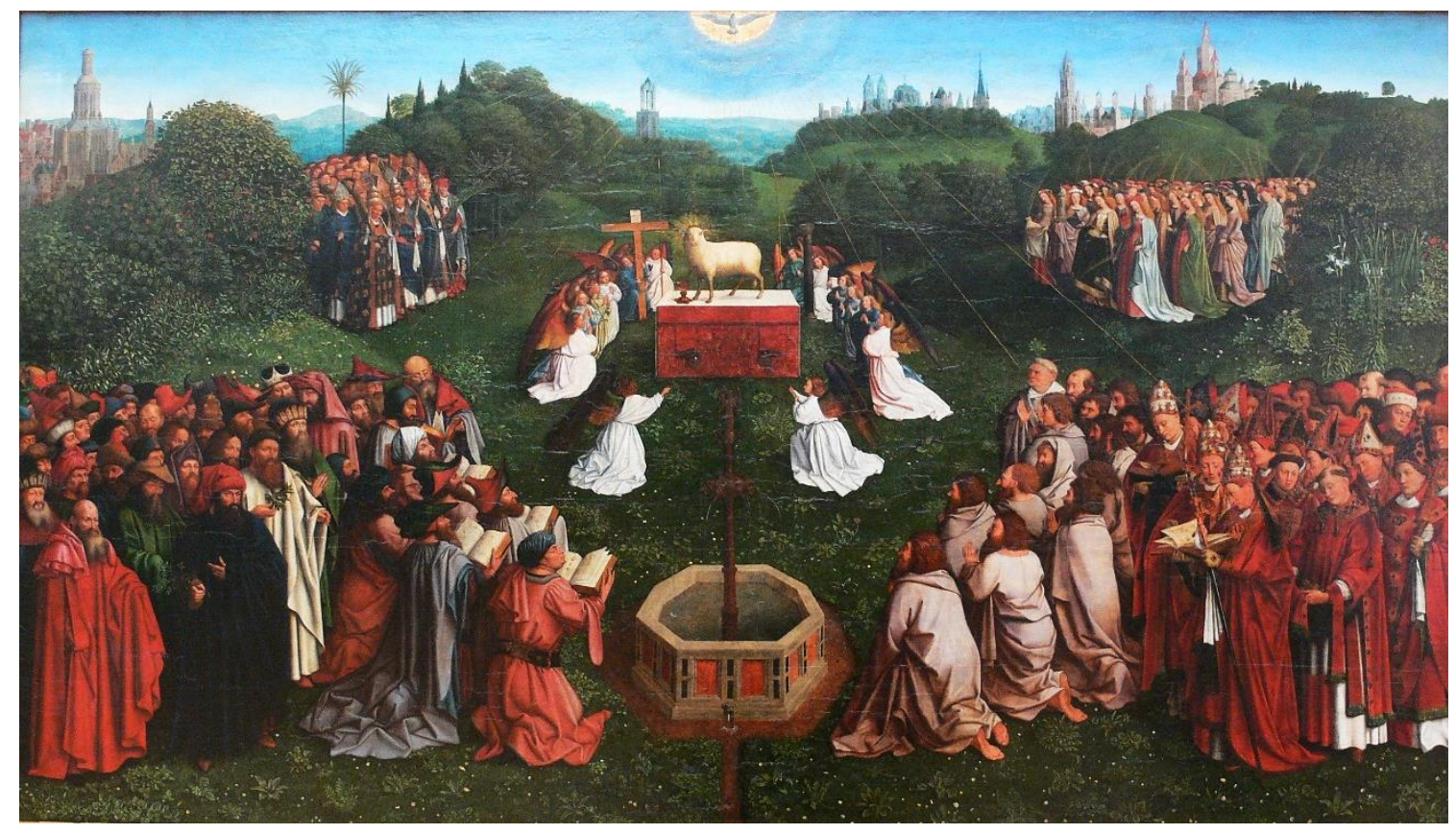

Abb. 97: Michiel Coxcie - Anbetung des Lammes (1558)

Gemäldegalerie, Staatliche Museen, Berlin 


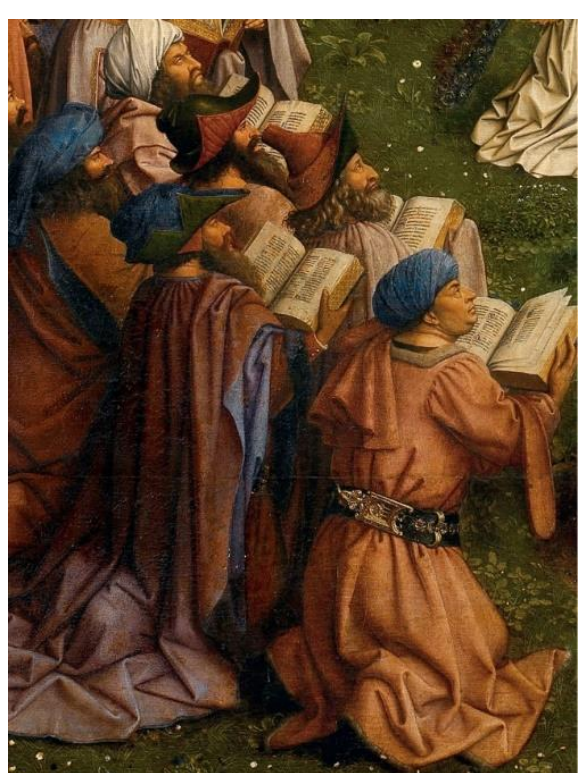

Abb. 96a: Jan van Eyck - Anbetung des Lammes (Detail)

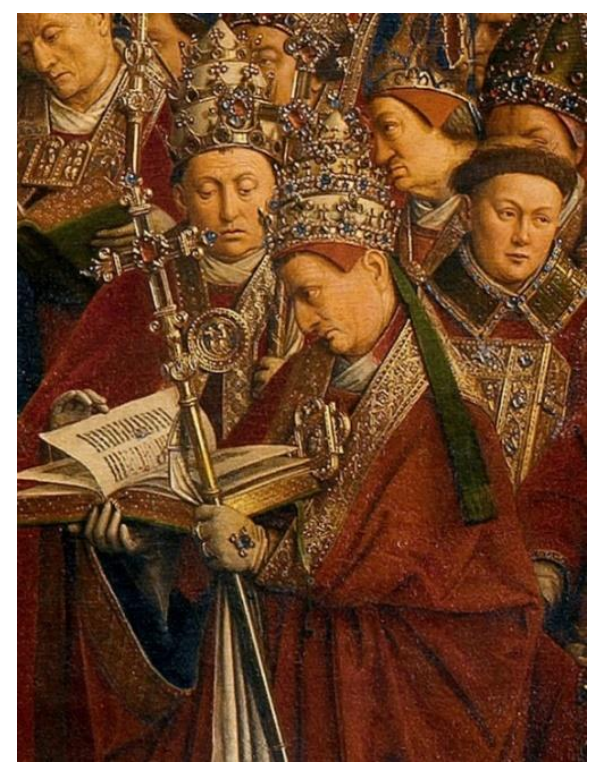

Abb. 96b: Jan van Eyck - Anbetung des Lammes (Detail)

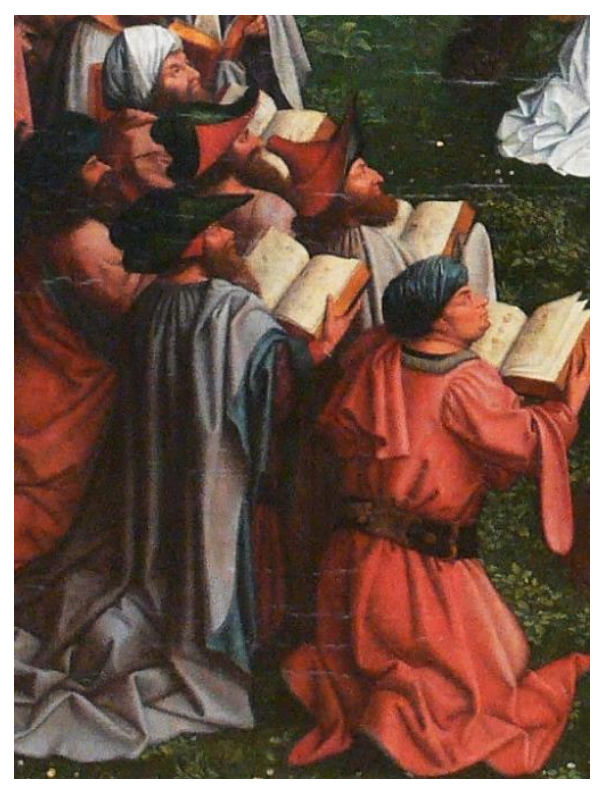

Abb. 97a: Michiel Coxcie - Anbetung des Lammes (Detail)

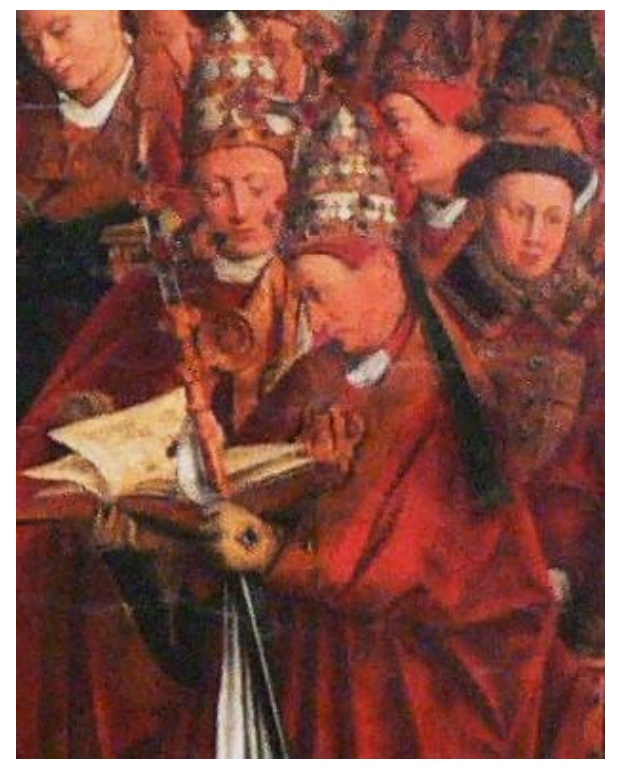

Abb. 97b: Michiel Coxcie - Anbetung des Lammes (Detail) 


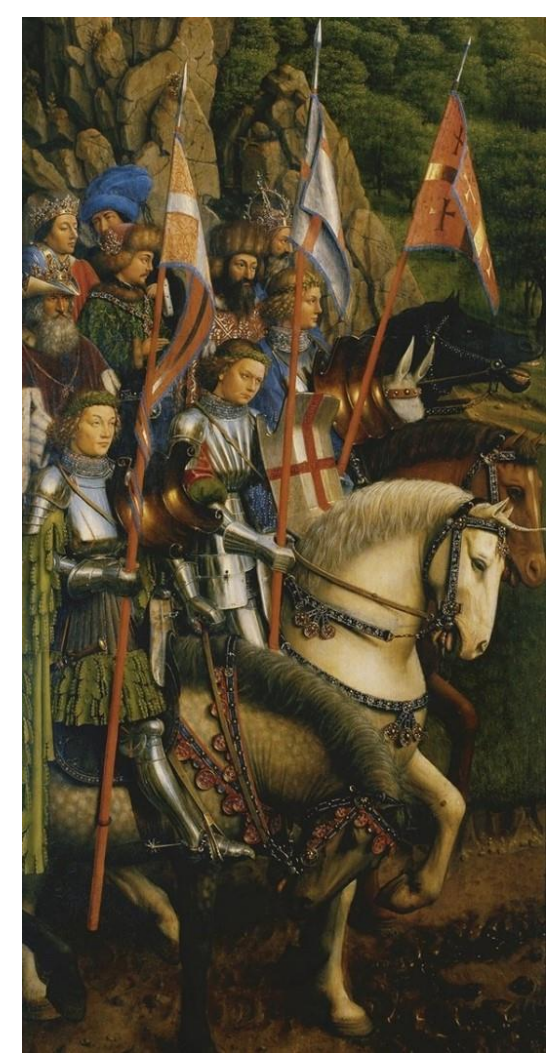

Abb. 98: Jan Eyck - Christliche Ritter (Detail)

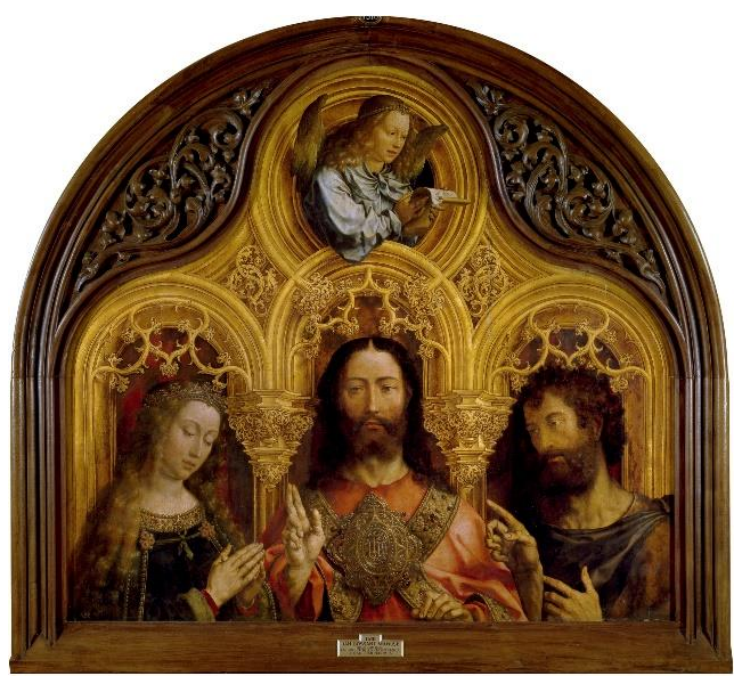

Abb. 100: Jan Gossaert - Deësis Öl auf Holz, Prado, Madrid

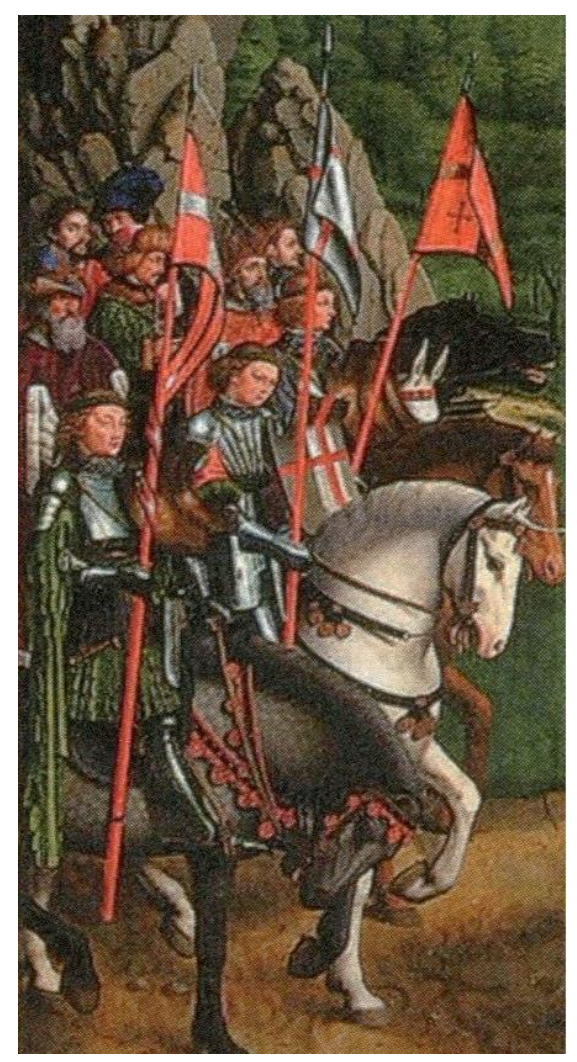

Abb. 99: Michiel Coxcie - Christliche Ritter (Detail)

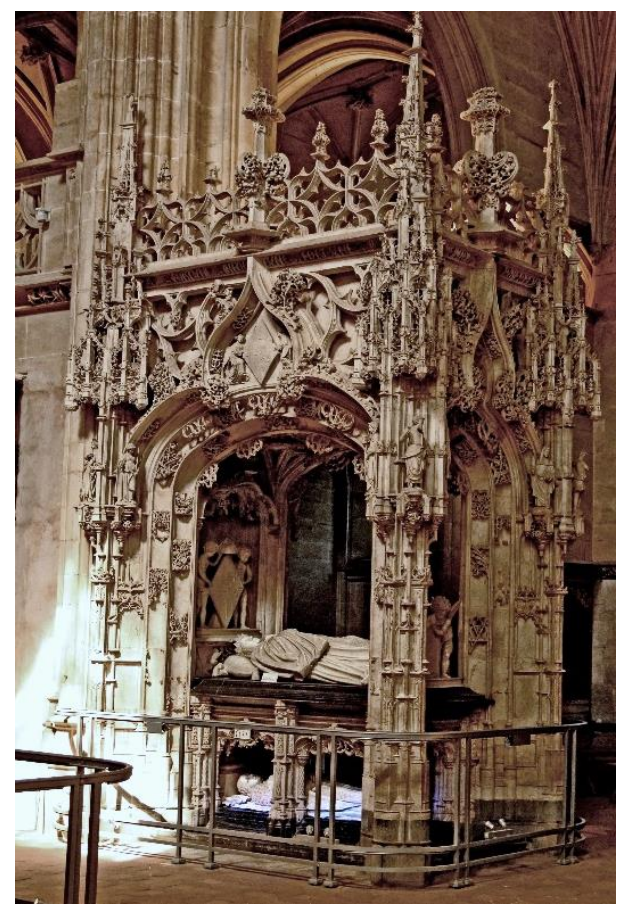

Abb. 101: Grablege Margarete von Österreichs Monastère royal de Brou, Bourg-en-Bresse 


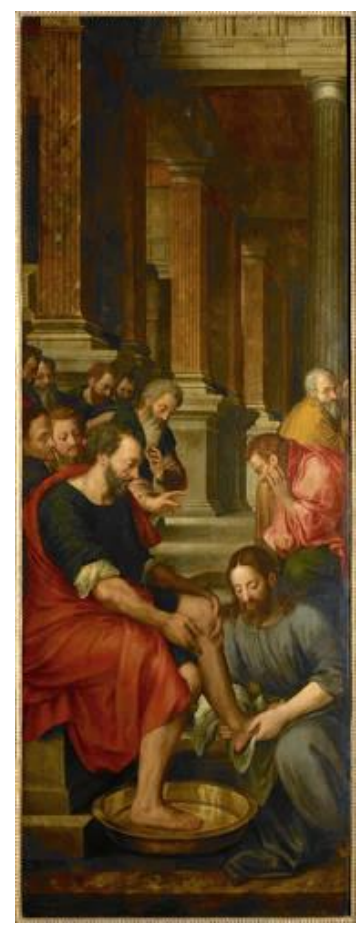

Abb. 104: Michiel Coxcie Fußwaschung (linker Flügel), KMSKB, Brüssel

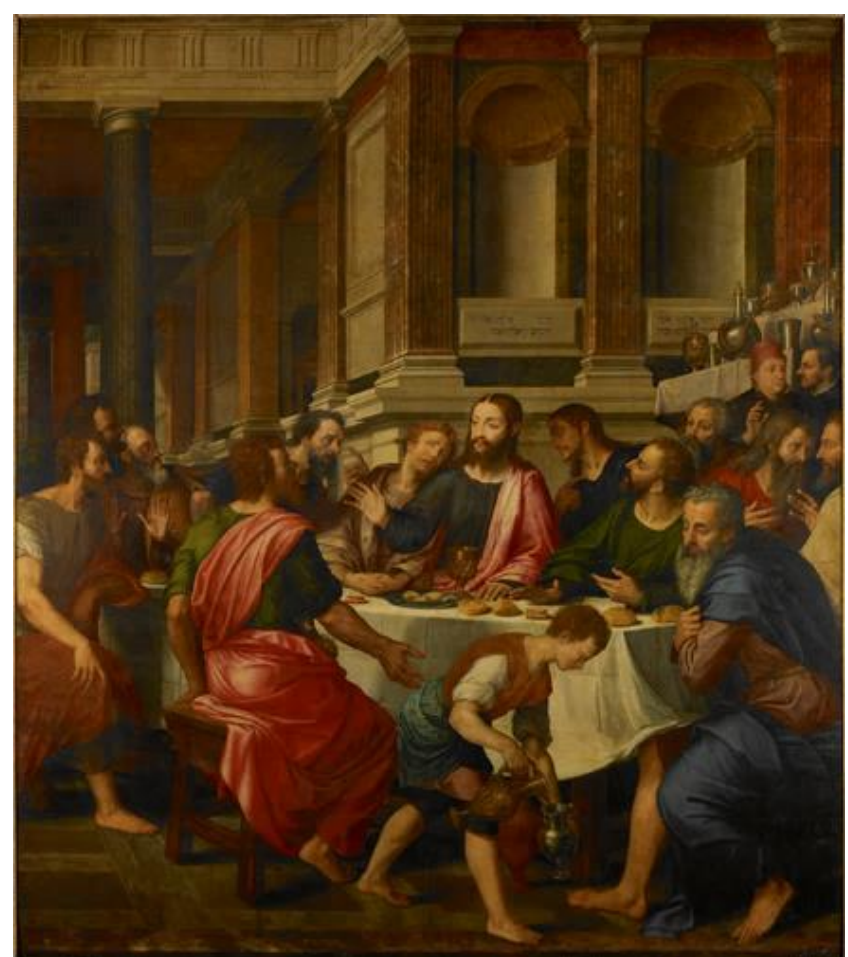

Abb. 103: Michiel Coxcie - Triptychon mit Hl. Abendmahl Öl auf Holz, Mitteltafel, Koninklijke Musea voor Schone Kunsten, Brüssel

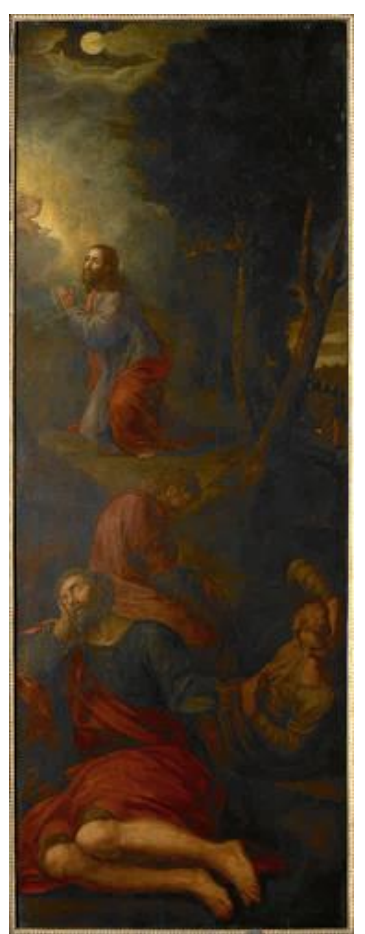

Abb. 105: Michiel Coxcie Gebet am Ölberg (rechter Flügel), KMSKB, Brüssel 


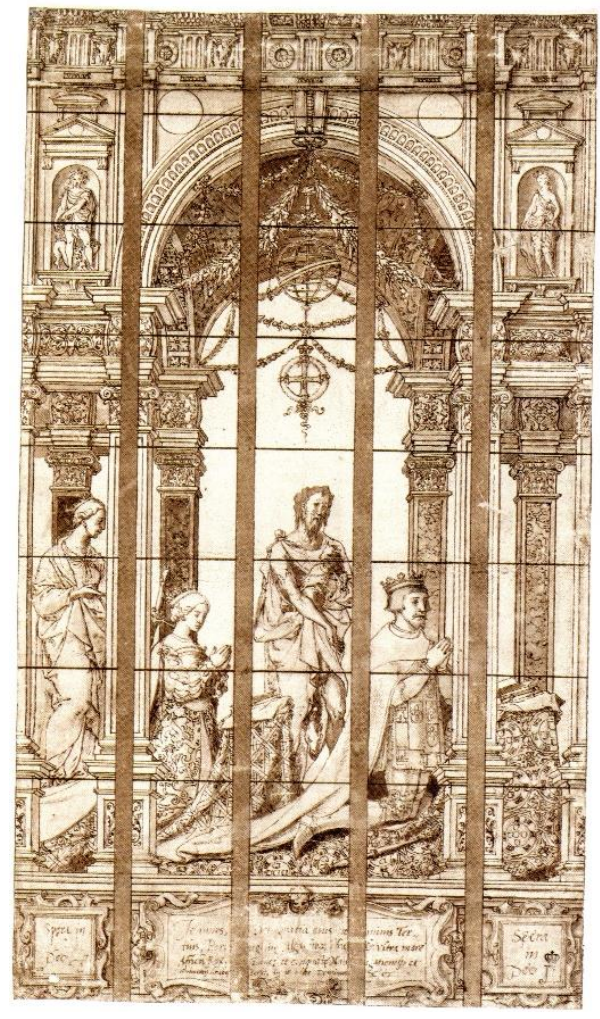

Abb. 106: Bernard van Orley - Entwurf für das Fenster mit Johann III. von Portugal und Katharina von Kastilien, Zeichnung, Ermitage, St. Petersburg

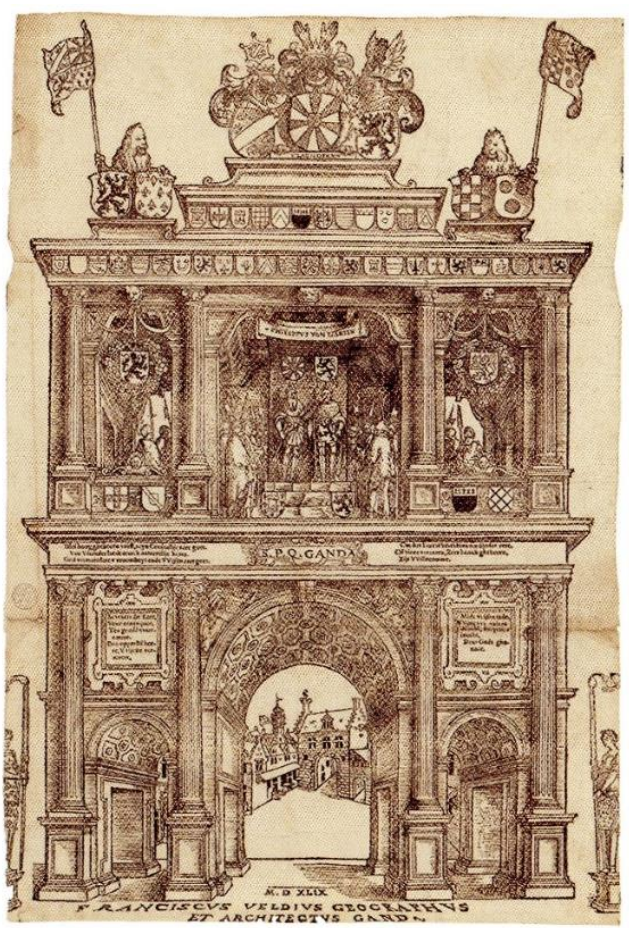

Abb. 108: Jan Liefrinck (nach Frans van de Velde) - Triumphbogen für den Einzug von Karl. V. und Philipp. II in Gent 1549, Holzschnitt

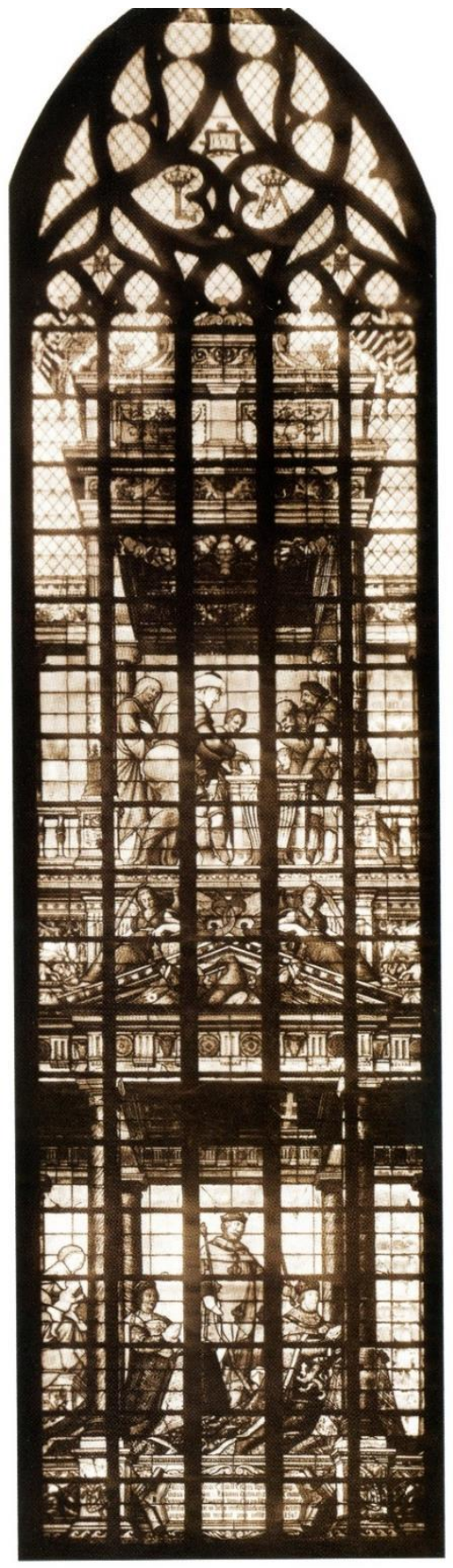

Abb. 107: Jan Haeck (nach Michiel Coxcie) Buntglasfenster mit Ludwig II. und Maria von Ungarn, 1547, Sint-Michiels en Sint-Goedelekathedraal, Brüssel 


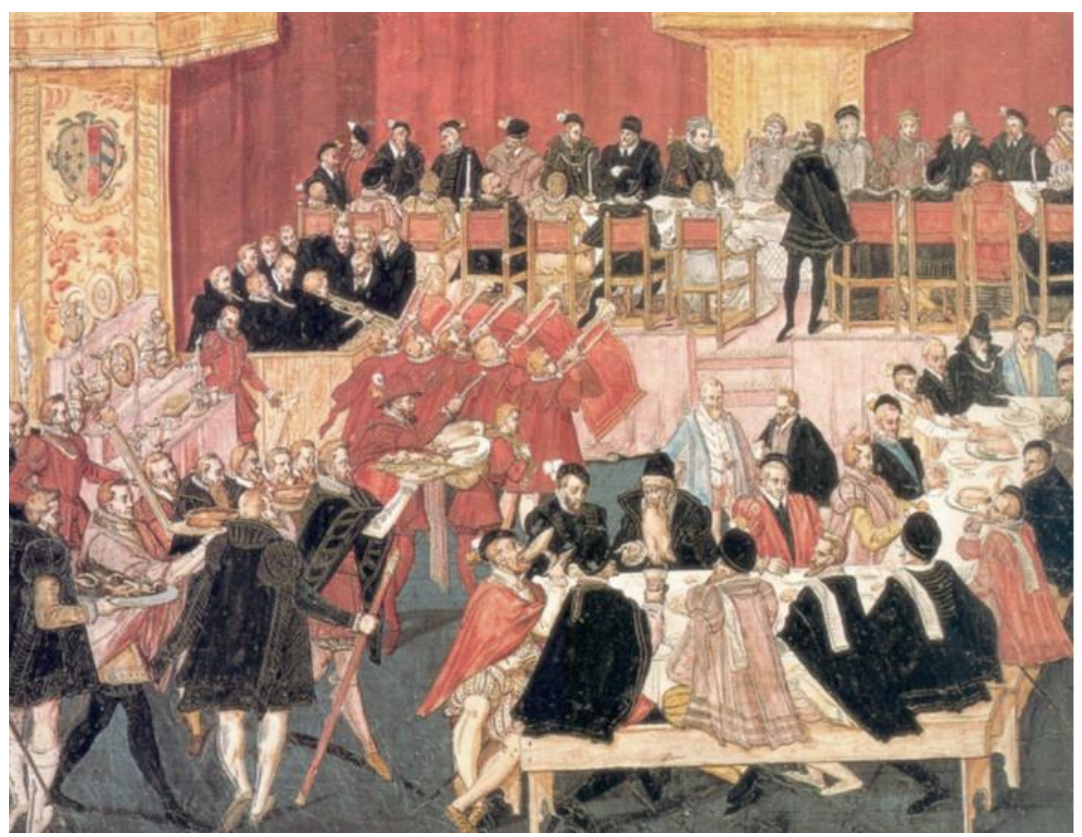

Abb. 109: Frans Floris (?) - Pourtraicts au vif des Entrees Festins Joustes \& Combatz matrimoniaux celebrees en la Ville de Bruxelles [...], Gouache auf Pergament,

Universitätsbibliothek Warschau, sog. Brüsseler Album, Nr. 7

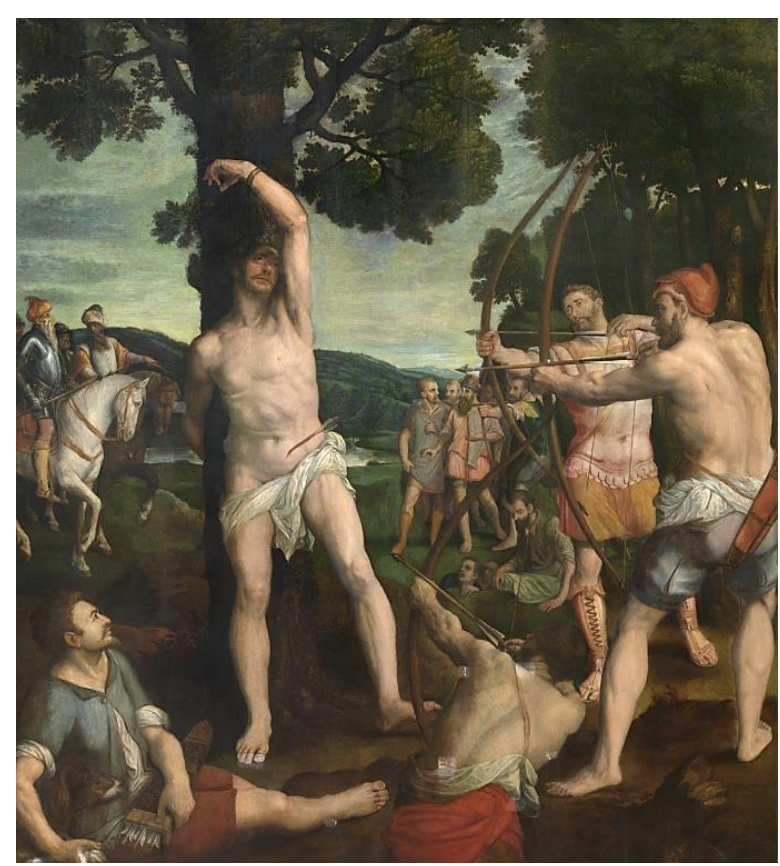

Abb. 110: Michiel Coxcie - Martyrium des Hl. Sebastian (1575, für die Oude Handboog in Antwerpen)

Koninklijk Museum voor Schone Kunsten, Antwerpen

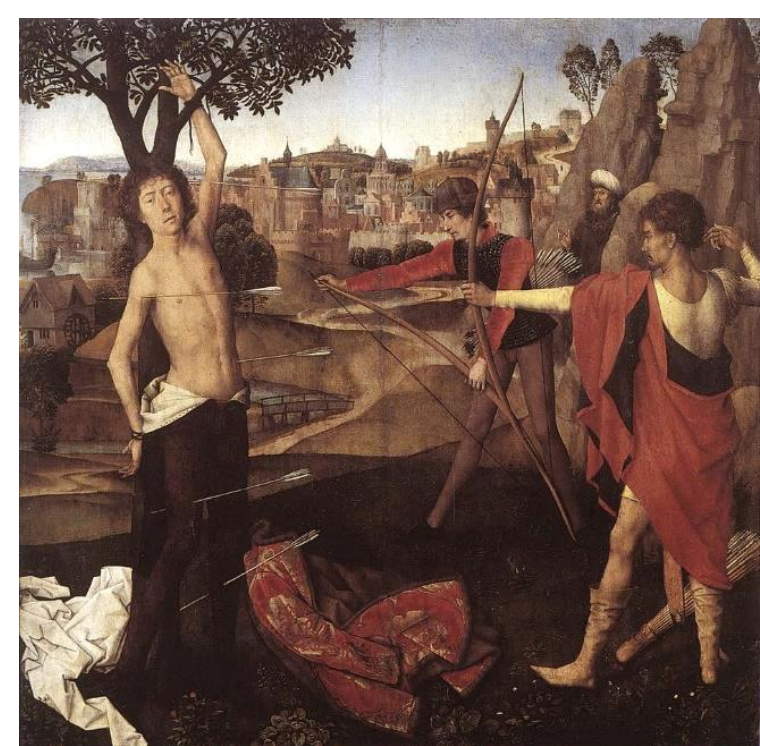

Abb. 111: Hans Memling - Martyrium des Hl. Sebastian Öl auf Holz, Koninklijke Musea voor Schone Kunsten, Brüssel 


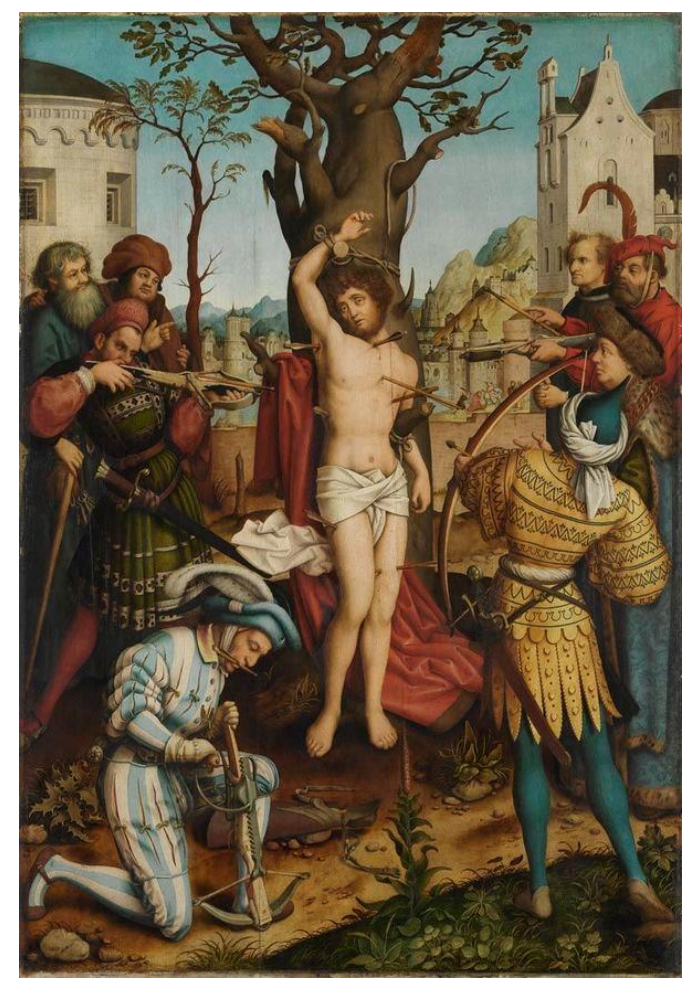

Abb. 112: Hans Holbein, d. Ä. - Sebastiansaltar Öl auf Holz, Alte Pinakothek, München

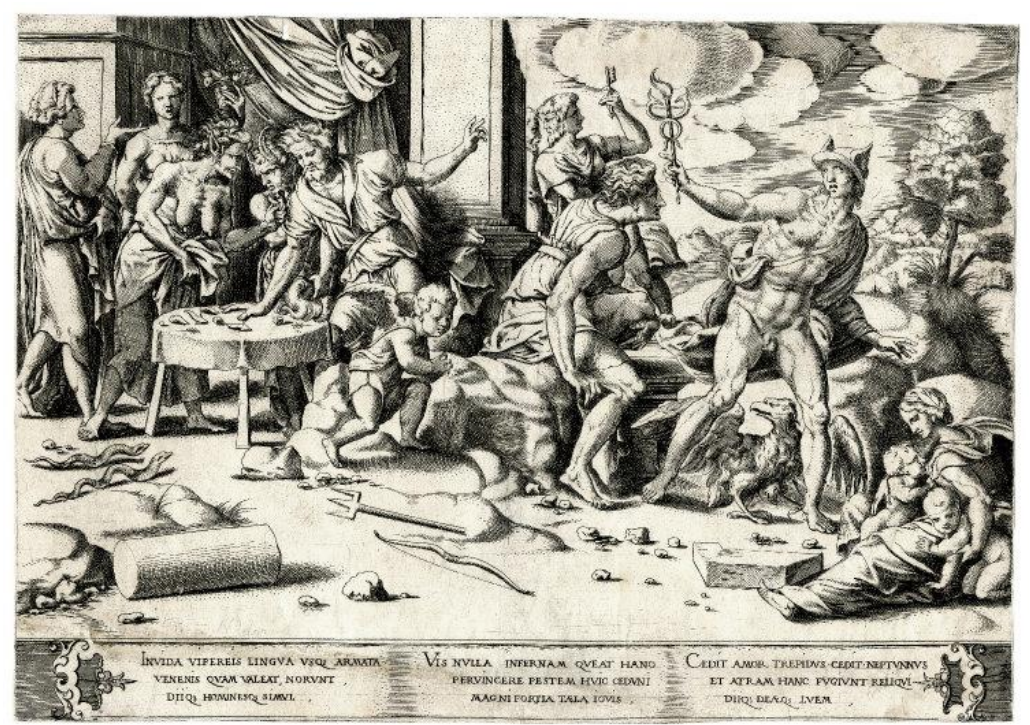

Abb. 113: Invida-Blatt, Liebschaften des Jupiters

British Museum, London 


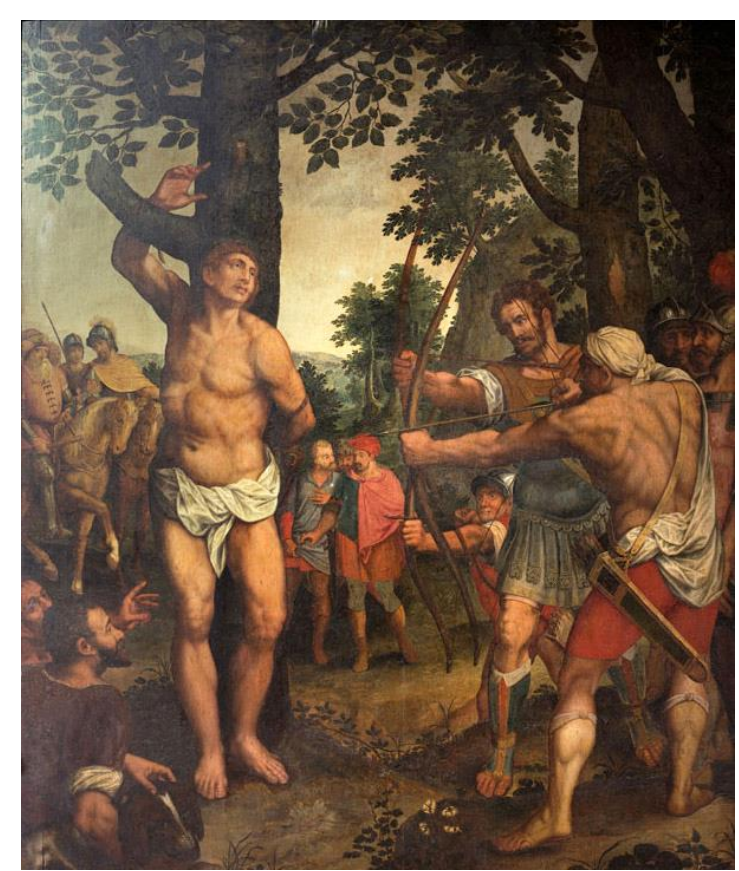

Abb. 114: Michiel Coxcie - Martyrium des Hl. Sebastian KMSKA, Antwerpen

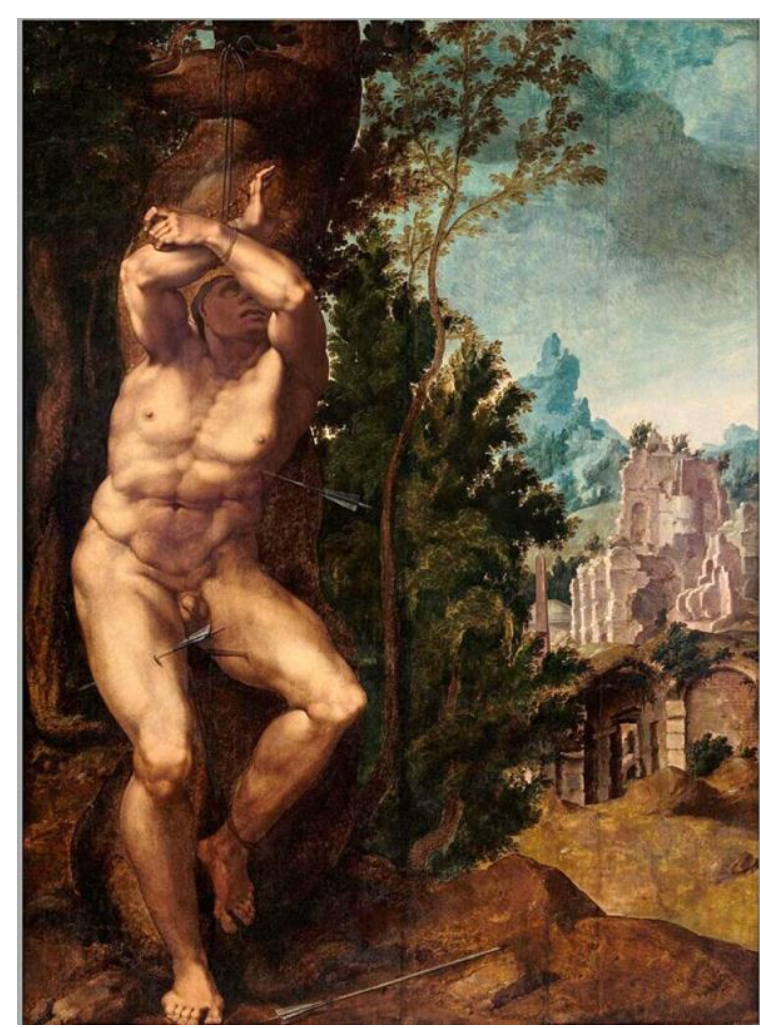

Abb. 115: Jan van Scorel - Hl. Sebastian (1542)

Museum Boijmans-Van Beuningen, Rotterdam
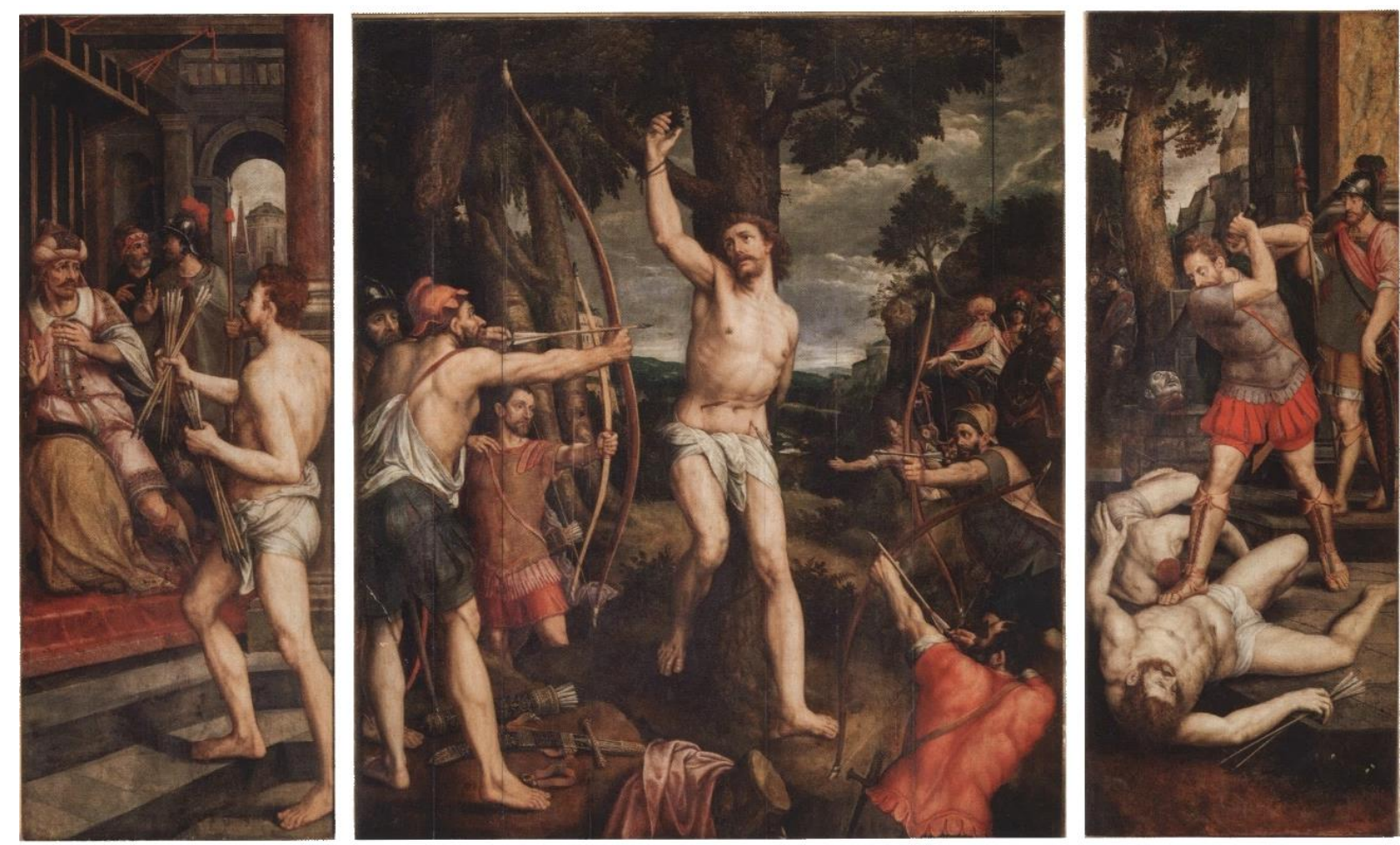

Abb. 116: Michiel Coxcie - Triptychon mit Martyrium des Hl. Sebastian (1580er), Sint-Rombouts, Mecheln 


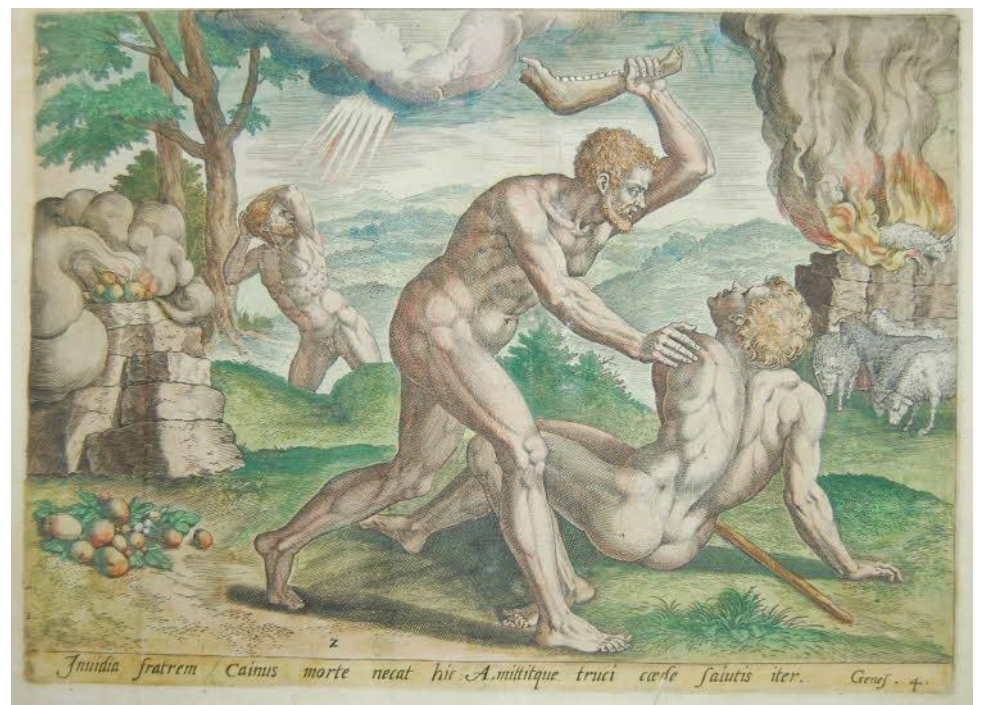

Abb. 117: Michiel Coxcie - Kain erschlägt Abel Radierung, British Museum

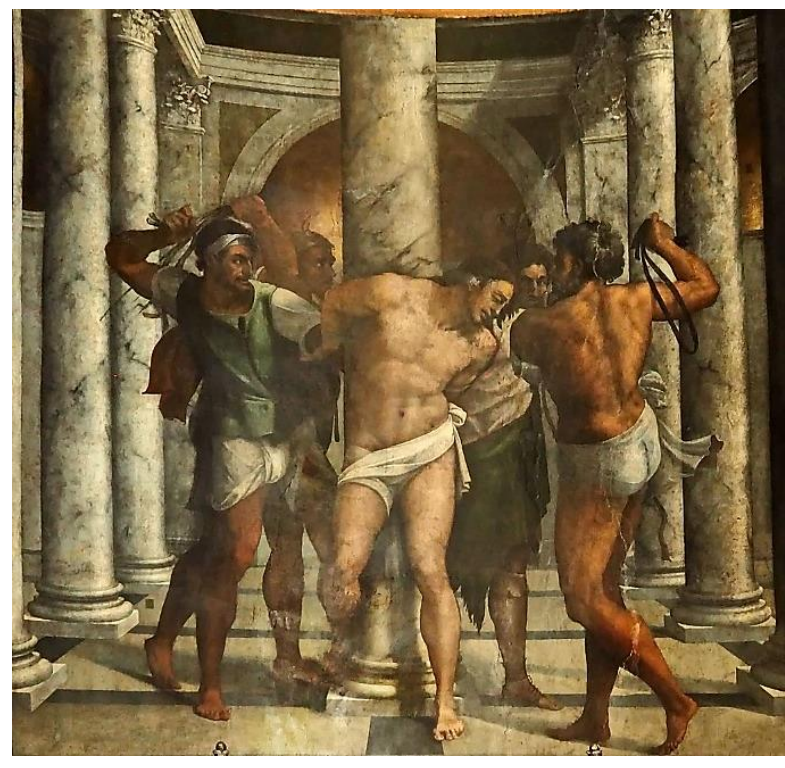

Abb. 118: Sebastiano del Piombo - Geißelung Christi Borgherini-Kapelle, San Pietro in Montorio, Rom

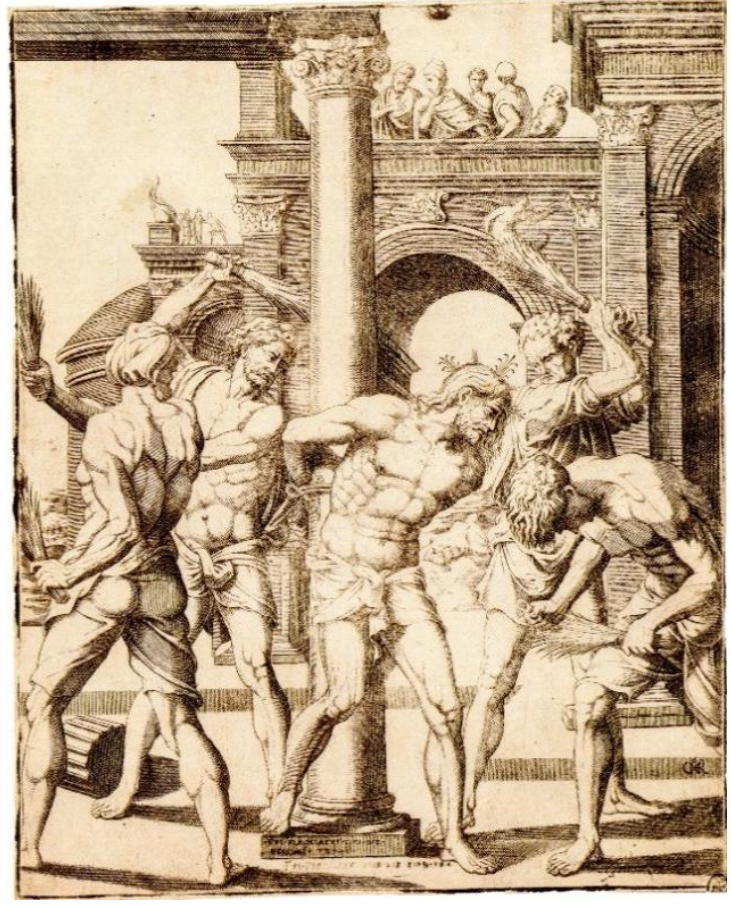

Abb. 119: Michiel Coxcie - Geißelung Christi

Kupferstich, Museum Boijmans-Van Beunigen, Rotterdam 


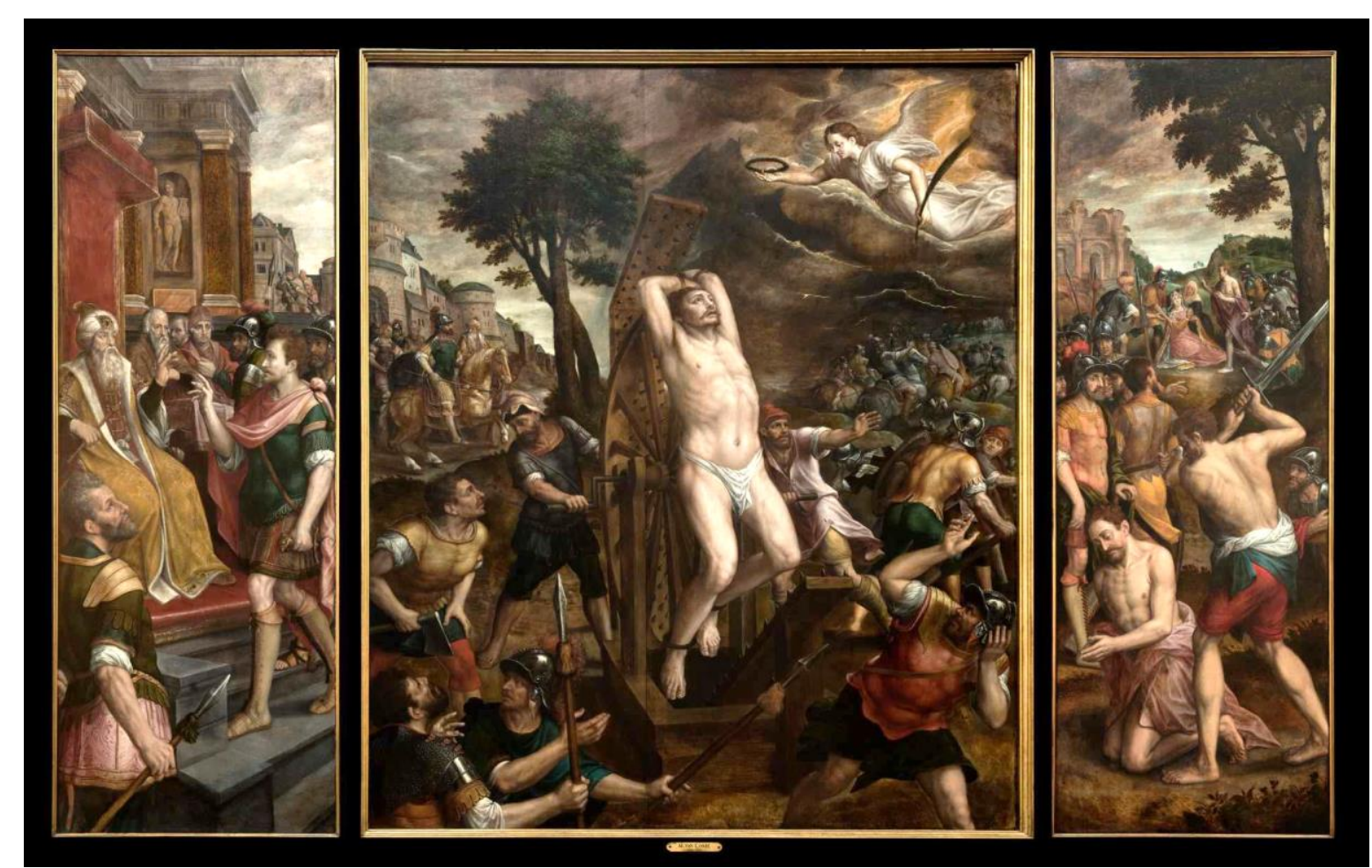

Abb. 120: Michiel Coxcie - Triptychon mit dem Martyrium des Hl. Georg (1588), Öl auf Holz, Sint-Rombouts, Mecheln

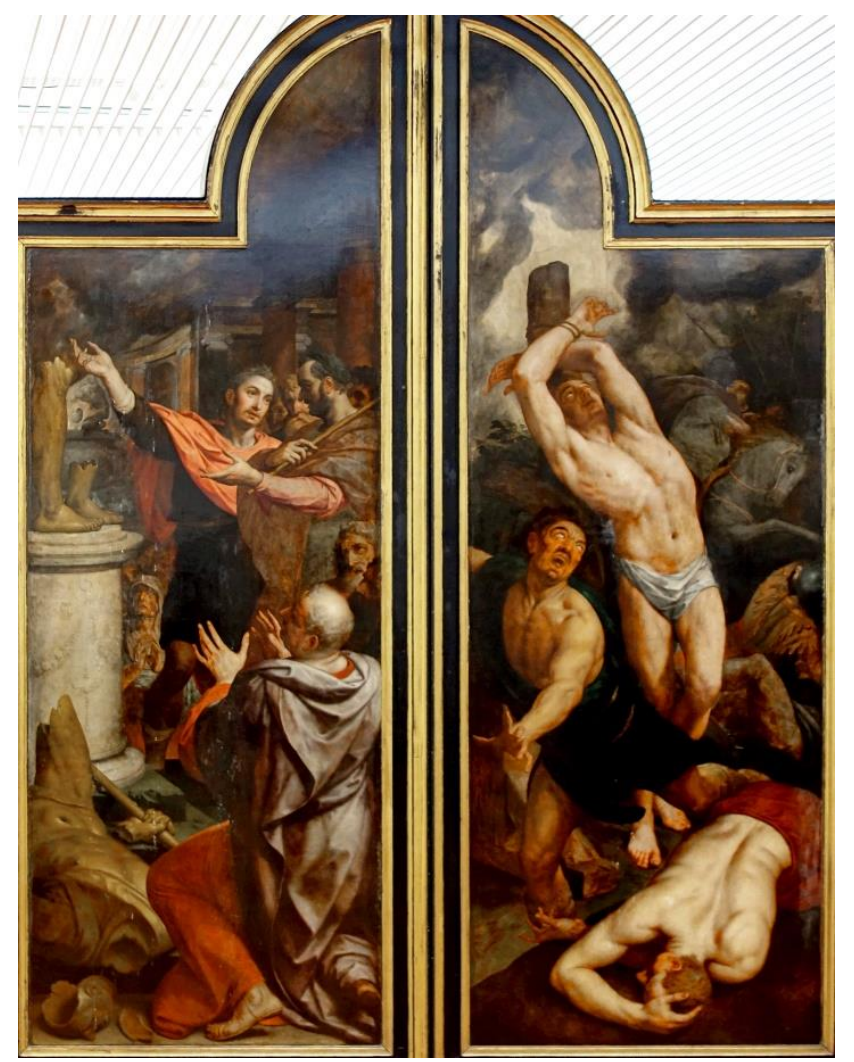

Abb. 121: Frans Pourbus - Triptychon mit dem Martyrium des Hl. Georg Öl auf Holz, Musée des Beaux-Arts, Dünkirchen 


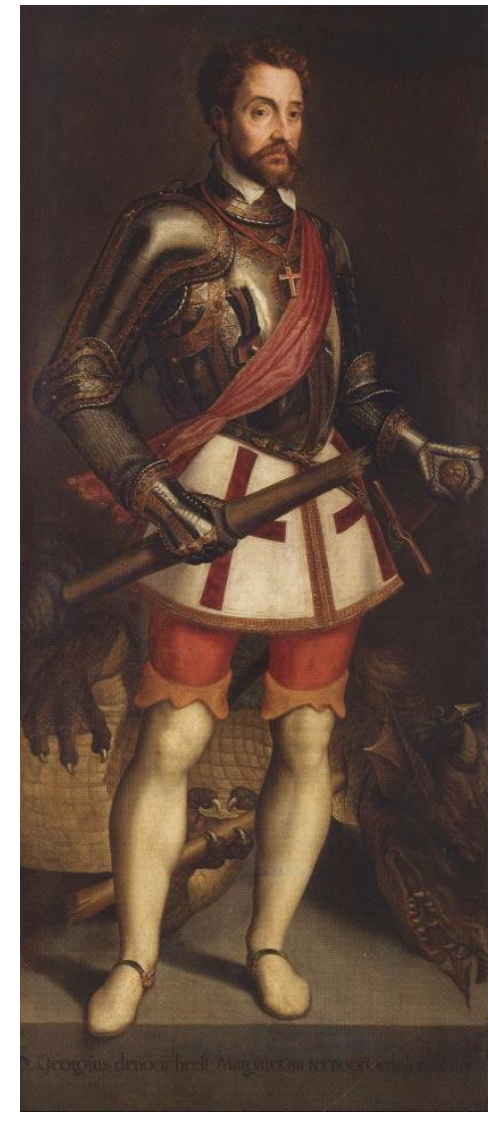

Abb. 122: Michiel Coxcie - Hl. Georg, KMSKA, Antwerpen

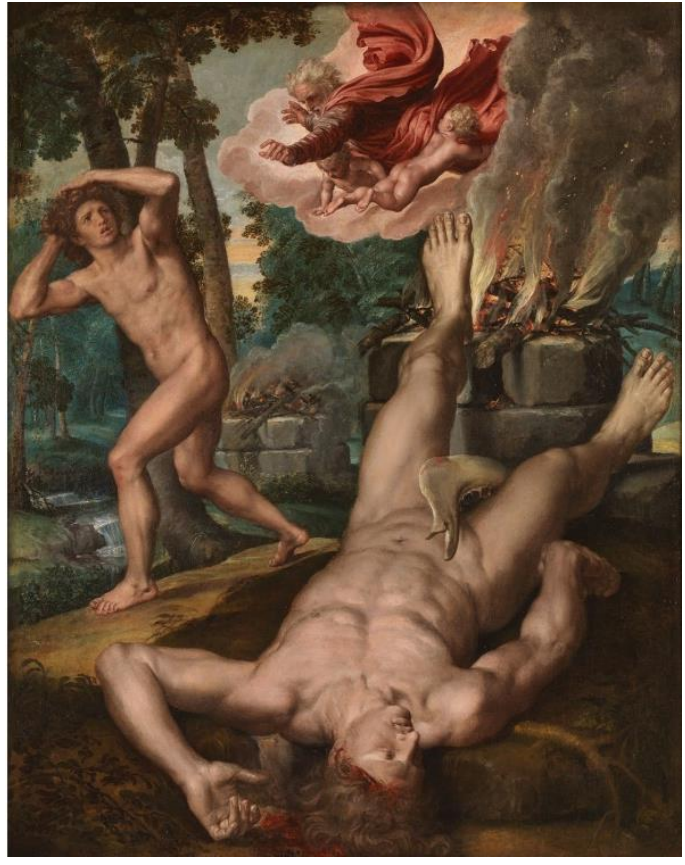

Abb. 124: Michiel Coxcie - Kain und Abel Prado, Madrid

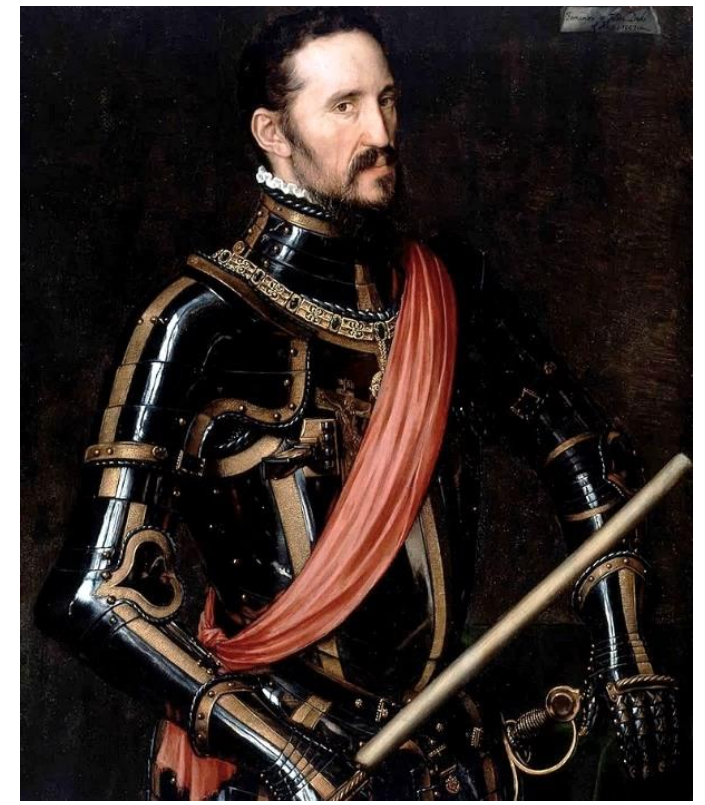

Abb. 123: Anthonis Mor - Portrait des Herzogs von Alba, Hispanic Society of America, New York

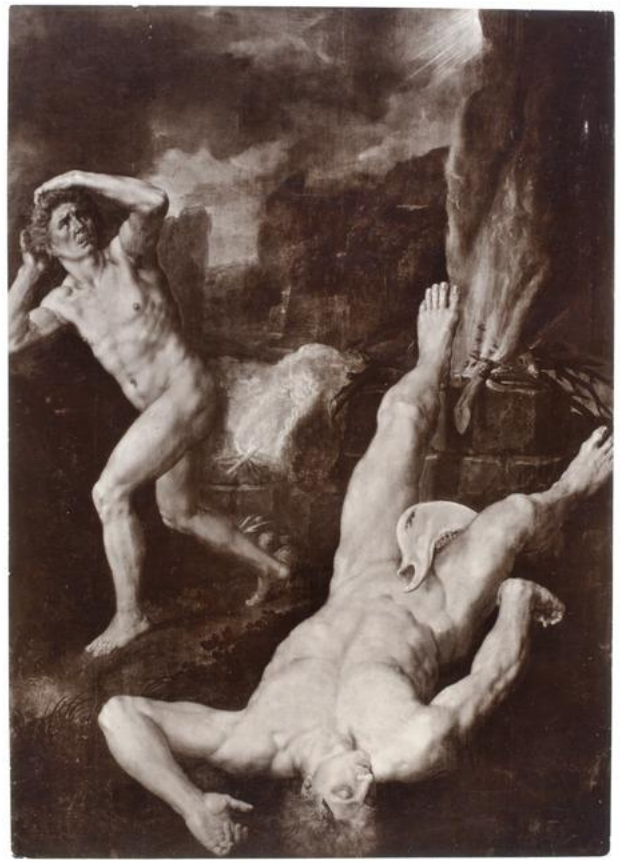

Abb. 125: Adriaen Thomasz. Key - Kain und Abel Privatbesitz (?) 


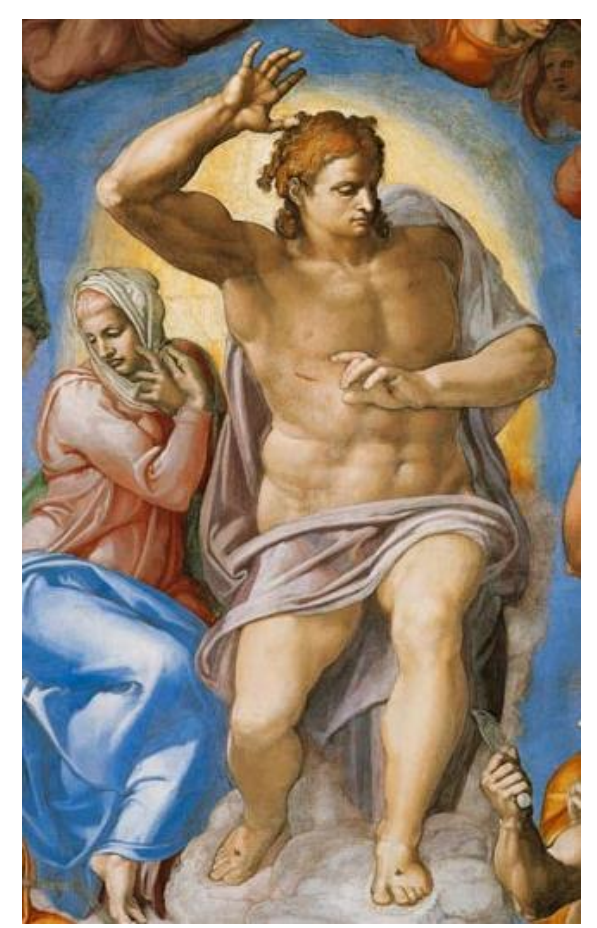

Abb. 126: Michelangelo - Christus (Jüngstes Gericht) Sixtinische Kapelle, Rom

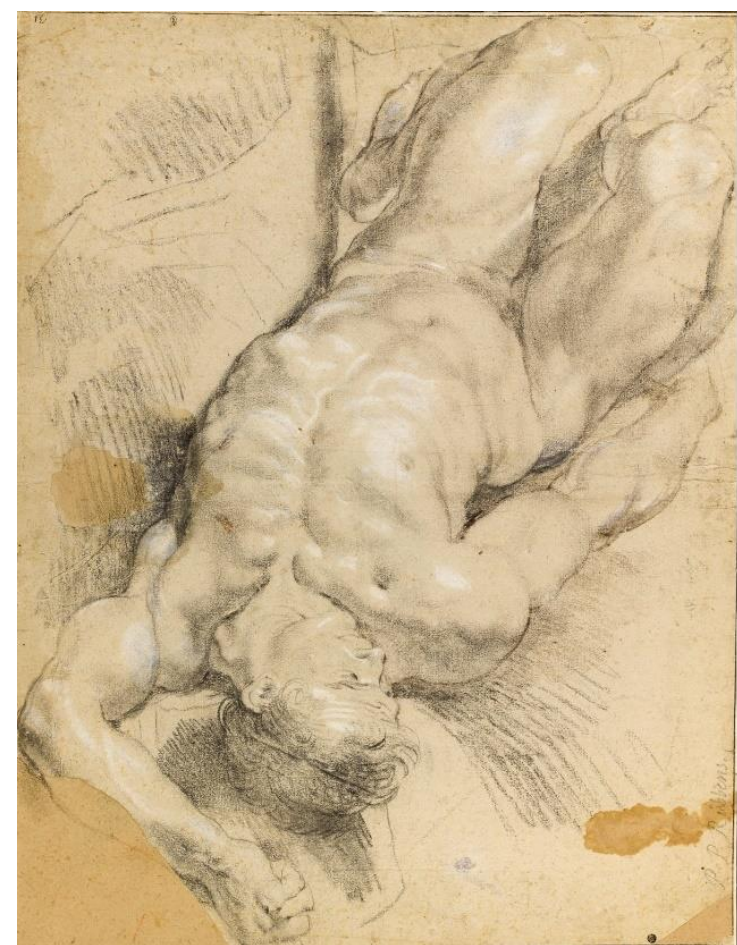

Abb. 128: Peter Paul Rubens - Studie eines fallenden Mannes, Zeichnung, Musée du Louvre, Paris

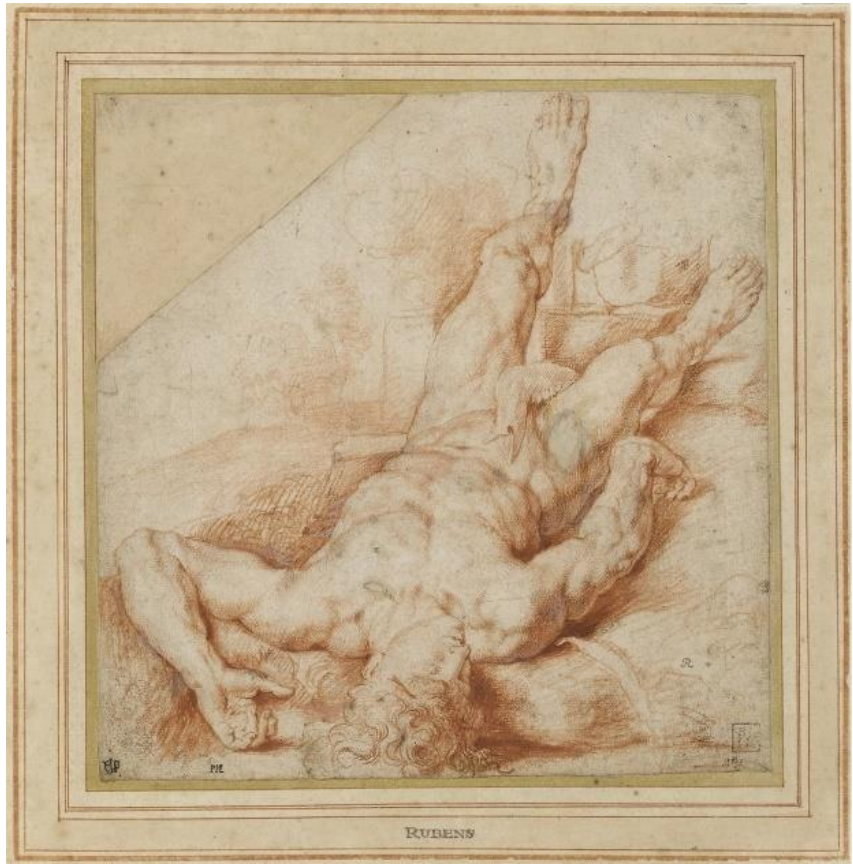

Abb. 127: Michiel Coxcie - Kain und Abel

(Vorzeichnung, von Rubens bearbeitet), Fitzwilliam Museum, Cambridge

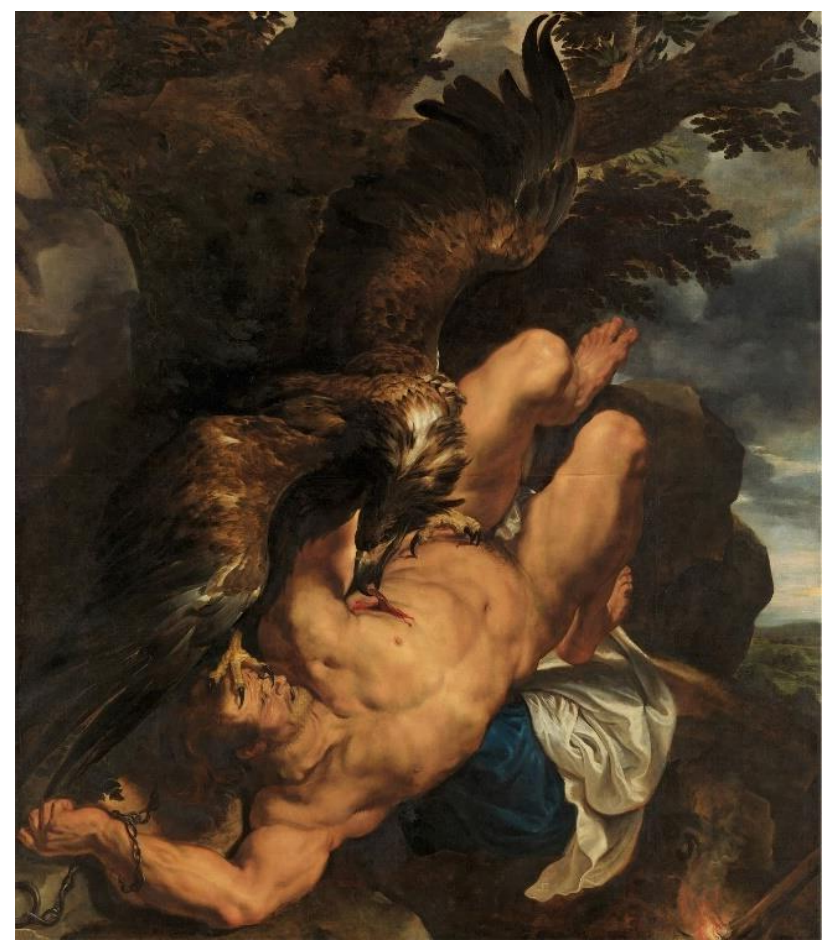

Abb. 129: Peter Paul Rubens - Prometheus (1611/12-1618), Philadelphia Museum of Art, Philadelphia 


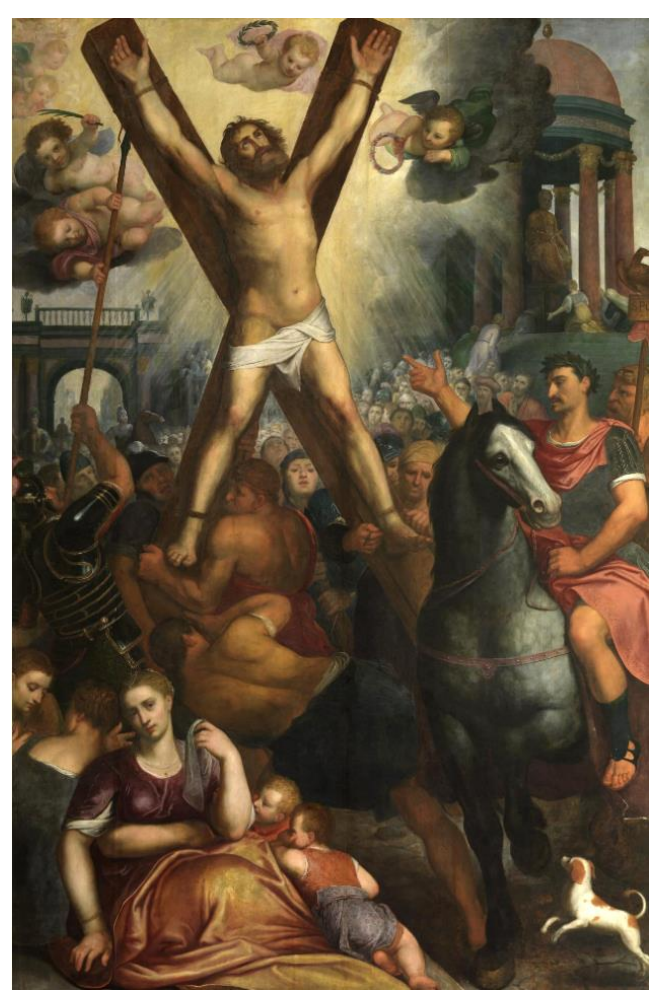

Abb. 130: Otto van Veen - Martyrium des Hl. Andreas, Öl auf Holz, Sint-Andries-Kerk, Antwerpen

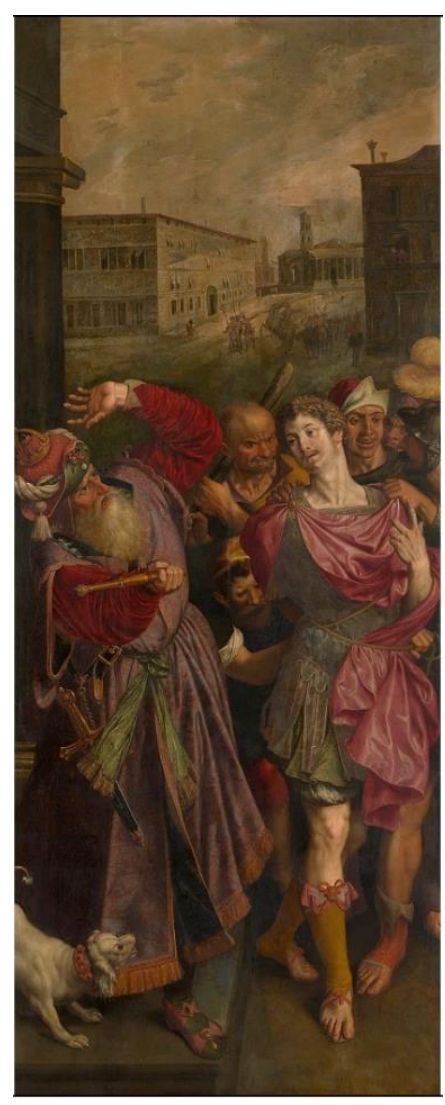

Abb. 132: Ambrosius Francken - Diokletian verurteilt den Hl. Sebastian, Öl auf Holz, KMSKA, Antwerpen

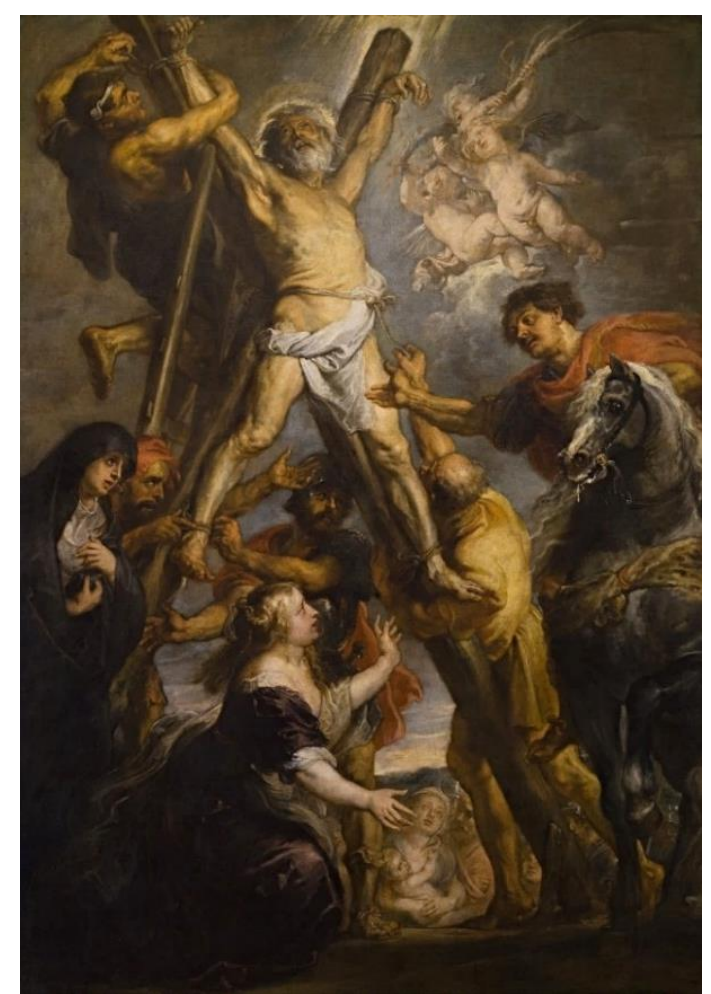

Abb. 131: Peter Paul Rubens - Hl. Andreas, Öl auf Leinwand, Fundación Carlos de Amberes, Madrid

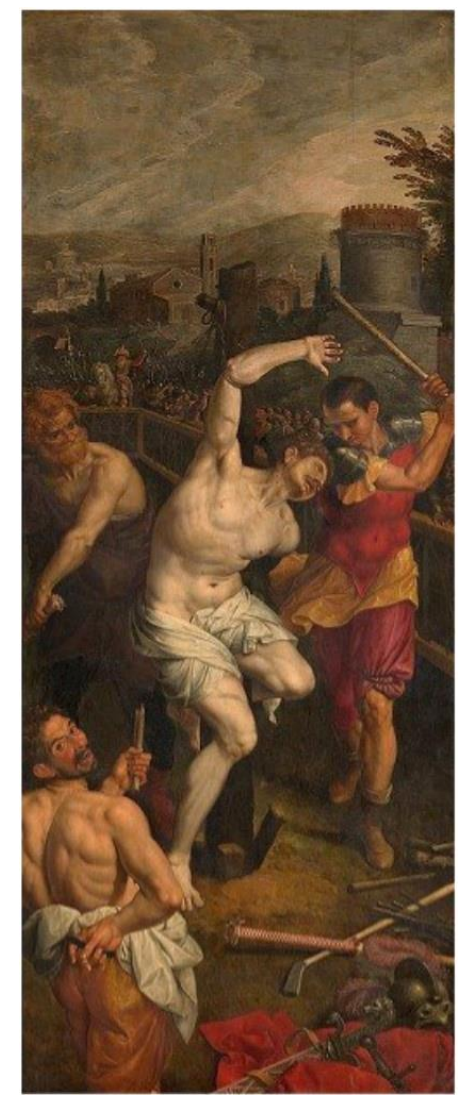

Abb. 133: Ambrosius Francken - Sebastian wird mit Stöcken geschlagen, Öl auf Holz, KMSKA, Antwerpen 


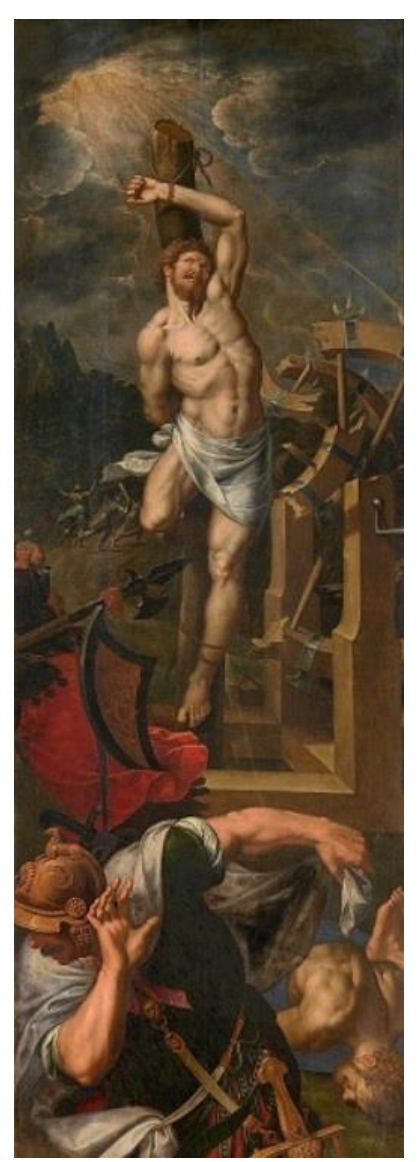

Abb. 134: Ambrosius Francken - Szene aus dem Martyrium des Hl. Georg, Öl auf Holz, KMSKA, Antwerpen

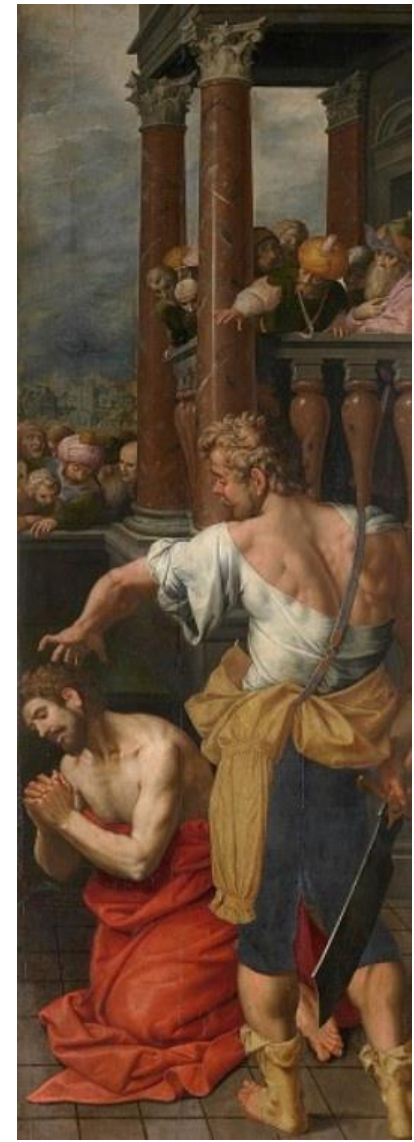

Abb. 135: Ambrosius Francken - Szene aus dem Martyrium des Hl. Georg, Öl auf Holz, KMSKA, Antwerpen 


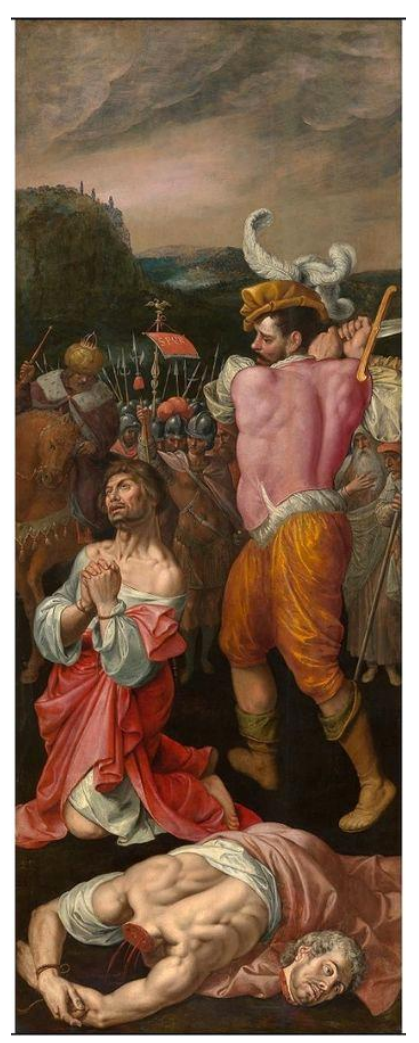

Abb. 136: Ambrosius Francken - Martyrium der Hl. Coasmas und Damian, Öl auf Holz, KMSKA, Antwerpen

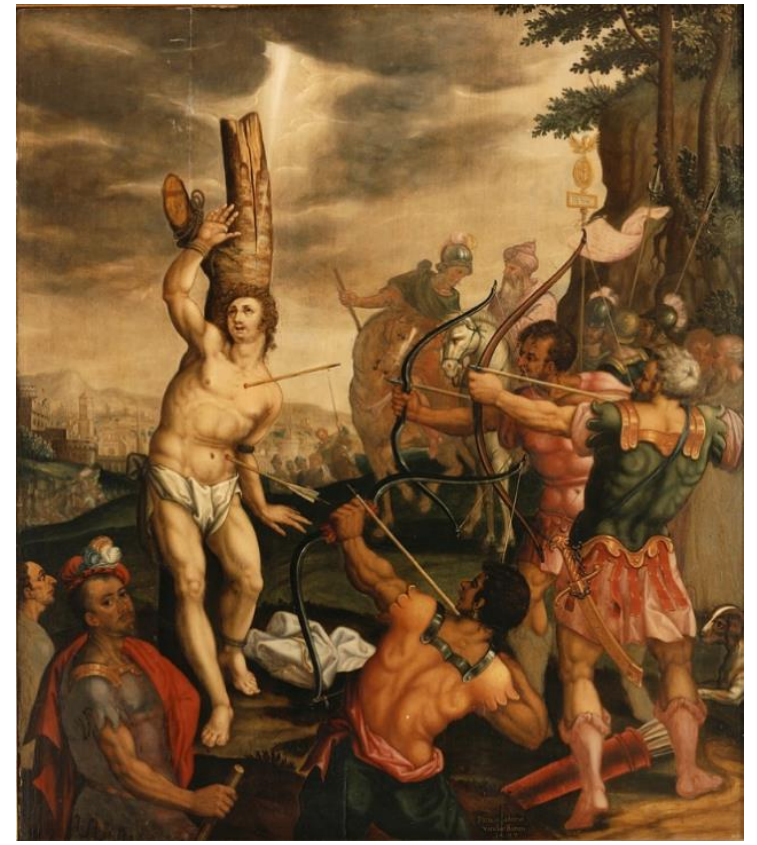

Abb. 137: Josse van der Baren - Martyrium des Hl. Sebastian, Öl auf Holz, M-Museum, Leuven 


\section{Bildnachweise}

Alte Pinakothek, München «ttps://www.sammlung.pinakothek.des: 8, 112; Biblioteka Narodowa: Polish Libraries today 6. Forein Collections in Polish Libraries, Warschau 2005: 109; British Museum 〈https://www.britishmuseum.org: 44, 46, 48, 49, 113, 117; Bücken, Véronique; De Meûter, Ingrid (Hrsg.): Bernard van Orley (Ausstellungs-Kat. 2019, Brüssel): 16, 17, 21, 24; Christies «https://www.christies.com/lotfinder): 79; Gruber, Gerlinde et. al. (Hrsg.): Rubens. Kraft der Verwandlung (AusstellungsKat. Städel 2017): 127, 128, 129; Jonckheere, Koenraad (Hrsg.): Michiel Coxcie 1499-1592 and the Giants of his Age (Ausstellungs-Kat. 2013): 25, 26, 27, 28, 32, 36, 42, 43, 50, 51, 52, 53, 54, 61, 62, 63, 84, 103, 104, 105, 106, 107, 108, 116, 119, 120, 122, 124; Kemperdick, Stephan et. al. (Hrsg.): Der Genter Altar. Reproduktionen, Deutungen, Forschungskontroversen, Berlin 2017: 95, 100; Koninklijk Museum voor Schone Kunsten, Antwerpen 〈https://www.kmska.bes: 9, 110, 114, 132, 133, 134, 135, 136; KHM Wien / Google Arts Project https:/ /artsandculture.google.com: 15, 75; Luchterhandt, Manfred et. al. (Hrsg.): Abgekupfert - Roms Antiken in den Reproduktionsmedien der frühen Neuzeit (Ausstellungs-Kat. 2013): 64; Metropolitan Museum of Art, New York https://www.metmuseum.org/art/collection: 40, 41, 45, 47; Museo del Prado, Madrid https://www.museodelprado.es): 67, 68, 69, 70, 71, 80, 81, 82, 87; Museum Boijmans Van Beuningen «ttps://www.boijmans.nl: 115; National Gallery, London «ttps://www.nationalgallery.org.uk:: 10; Parcum-Museum, Leuven «ttps://www.parcum.bes: 93; Patrimonia Nacional 〈https://www.patrimonionacional.es: 78, 85, 86; RKD «https://rkd.nl/nll: 74, 125; Victoria and Albert Museum https://collections.vam.ac.uks: 19; 〈http://vlaamsekunstcollectie.bes: 130; Web Gallery of Art 〈https://www.wga.hus: 1, 2, 3, 4, 5, 6, 7, 55; Wikimedia 〈https://commons.wikimedia.org: 11, 12, 13, 14, $18,22,23,29,30,31,33,34,35,37,38,39,56,57,58,59,60,65,66,72,73,76,77,83,88,89,90,91$, $92,94,96,97,101,111,118,121,123,126,131,137$. 


\section{Selbstständigkeitserklärung}

Hiermit versichere ich, dass ich diese Dissertation mit dem Titel „Michiel Coxcie. Studien zur flämischen Malerei im Zeitalter der Konfessionalisierung" selbstständig verfasst habe und keine anderen als die angegebenen Quellen und Hilfsmittel benutzt wurden, sowie Zitate kenntlich gemacht habe. Ich versichere außerdem, dass ich die beigefügte Dissertation nur in diesem und keinem an-deren Promotionsverfahren eingereicht habe und, dass diesem Promotionsverfahren keine endgültig gescheiterten Promotionsverfahren vorausgegangen sind.

Weiterhin bestätige ich, dass die digitale Version der Arbeit mit der eingereichten schriftlichen Version übereinstimmt.

Hanke E. Tammen

Göttingen, im Oktober 2019 